\title{
LA FUNCIÓN DEL ARTE EN PROCESOS DE TRANSICIÓN A LA SOSTENIBILIDAD: CASOS ANGLOSAJONES Y ESPAÑOLES
}

Nuria Sánchez León Programa de Doctorado en Arte: Producción e Investigación.

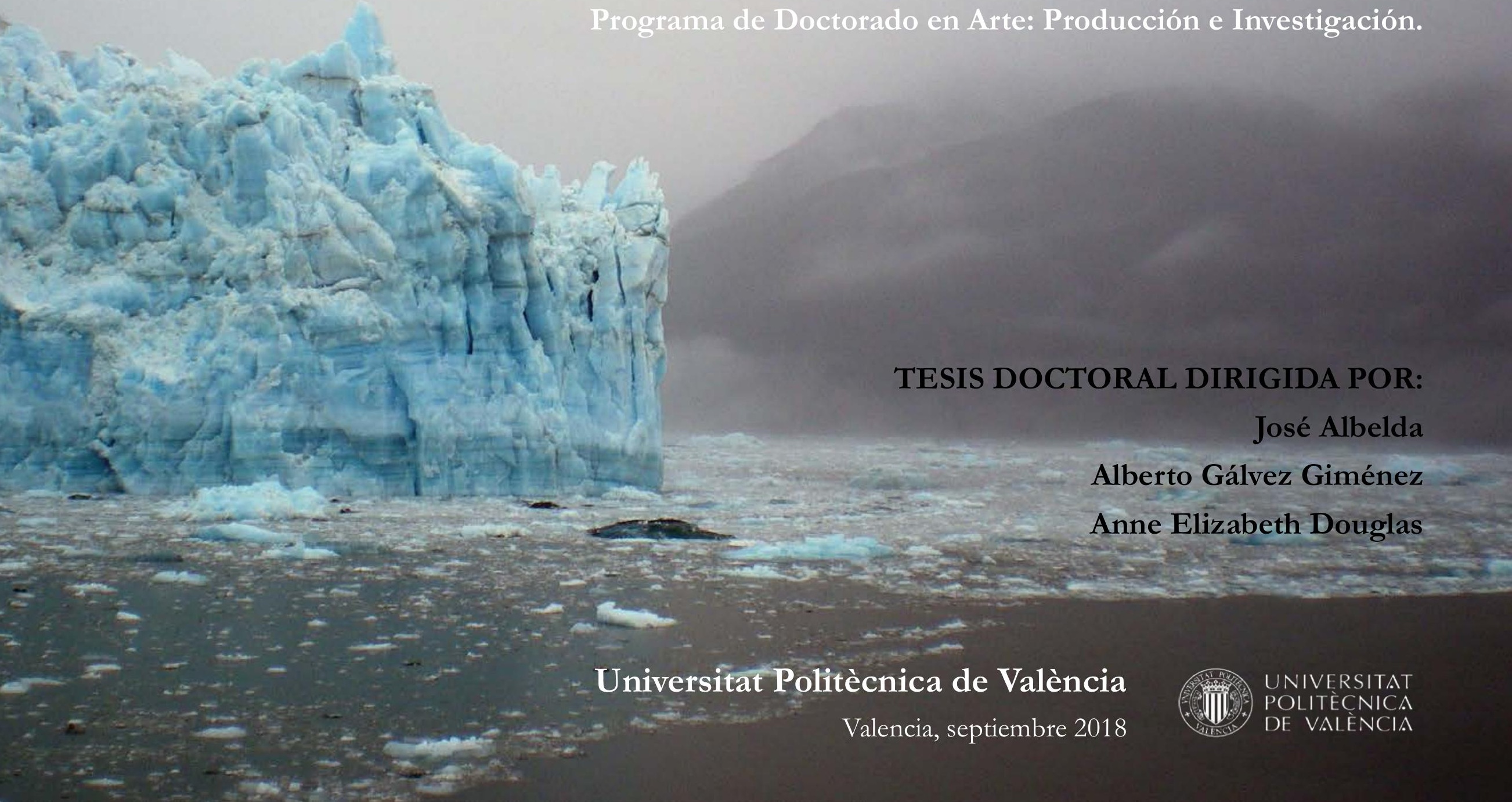




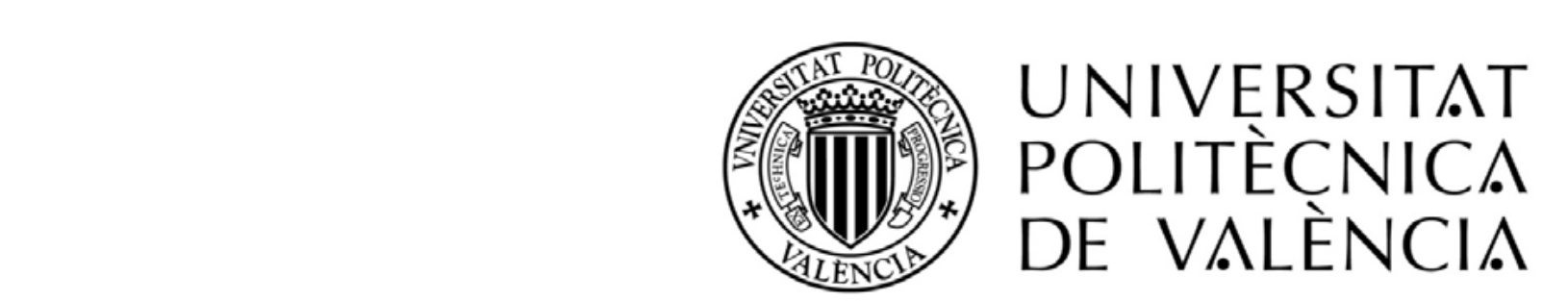

LA FUNCIÓN DEL ARTE EN PROCESOS DE TRANSICIÓN A LA SOSTENIBILIDAD: CASOS ANGLOSAJONES Y ESPAÑOLES

\author{
Nuria Sánchez León \\ Programa de Doctorado en Arte: Producción e Investigación. \\ Departamento de Pintura. Facultad de Bellas Artes \\ TESIS DOCTORAL DIRIGIDA POR: \\ José Albelda \\ Alberto Gálvez Giménez \\ Anne Elizabeth Douglas
Universitat Politècnica de València \\ Valencia, septiembre 2018
}


THE ROLE OF ART IN TRANSITION TO

SUSTAINABILITY PROCESSES:

\section{ANGLO-SAXON AND SPANISH CASE STUDIES}

\section{Nuria Sánchez León}

Doctoral Program in Art: Production and Research

$$
\text { Faculty of Fine Arts }
$$

DOCTORAL THESIS DIRECTED BY

$$
\text { José Albelda }
$$

Alberto Gálvez Giménez

Universitat Politècnica de València

Valencia, September 2018 
All the past decisions and the time invested take me right to this moment in which I thank all the people who have paved my way. It has been a challenging learning process that has made me grow both, at work and emotionally. For this reason, I want to especially thank Pablo Guillén, my inseparable and admired life partner, for listening to me so many times with patience, for making me laugh every day, for the doctoral "uniform", for the pranks in my shoes, for letting me in in your life and in your family. Also to my parents and my sister, who have always believed in me even if I pull along the "long" way; even when I was so many moments in front of the computer and increadibly they keep inviting me at Christmas.

Of course thanks to my thesis directors: José Albelda, who has supported me in many ways as director, a boss and even a friend since that afternoon in June 2013 when we decided to throw ourselves into this vortex It was not just by chance but causality and I will keep in

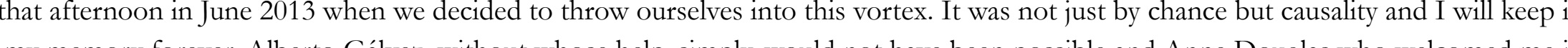
my mer

her research team as one of then, and has always linotr. raschini, Raquel Moreno, Ana Sevilla and Julia Haba, for listening to me so much and sharing their time and knowledge.

I am also very grateful for the welcome at the Art and Environment Research Center, which is already a second home for me, and Silvia Molinero, Constancio Collado, Paula Santiago, Toni Simarro and Miriam del Saz for making my day-to-day easier. Likewise, I would like to thank the girls from the research group On The Edge Research for hosting me, Hilal Bugali, Nil Gulari, Nicola Chambury, Maja Zeco and especially Caroline Gausden who opened the doors of her house and her family (together with Lance Manak and Guyatri).

We want to express our deep gratitude to the people of Carrícola and other friends who participated in the construction of the oven for their time and energy: Thomas Decker, Juan Martí, Pedro Torres, Felicia Samper, Susana Chafer, Pedro Altabert, Bruno Sperzagni, Juán Chafer , Josefa Nácher, Juana Altabert, Esteban Chafer, Lluís Blasco, Adrián Llorens and the rest of the people who gave us their compan Finally, to all the friends and artists who have helped me to give content to this thesis and to all the people who have shared their images with me for their attention and generosity.
Todas las decisiones pasadas y el tiempo invertido me llevan justo a este momento en el que doy las gracias a todas las personas que me han facilitado el camino. Ha sido un proceso de aprendizaje desafiante que me ha hecho crecer tanto a nivel laboral como emocional. Por ello, quiero agradecer en especial a Pablo Guillén, mi inseparable y admirado compañero de vida, por escucharme tantas veces con paciencia, por
quation quiero agradecer en especial a Pablo Guillén, mi inseparable y admirado compañero de vida, por escucharme tantas veces con paciencia, por
hacerme reir cada día, por el “uniforme" de doctoranda, por los borlones en los zapatos, por dejarme entrar en su vida y en su familia. Tam-
bién a mis padres y mi hermana, que no han dejado de creer en mí aunque tire por el camino "largo"; que con resignación me han visto pasar bién a mis padres y mi hermana, que no han dejado de creer en mí aunque tire por el camino "largo"; que con resignación me han visto pasar
tantos ratos frente al ordenador y aún así, me siguen invitando en Navidad.

Por supuesto a mis directores de tesis: José Albelda, que me ha apovado en muchos sentidos como director, jefe e incluso amigo desde aquella tarde de junio de 2013 en que nos propusimos lanzarnos a toda esta vorágine. No fue solo por casualidad sino causalidad y grabado queda en mi memoria. Alberto Gálvez, sin cuya ayuda, sencillamente, no habría sido posible y Anne Douglas que me acooió en su equipo investigador como una más, y siempre ha sabido transmitirme su sabiduría con la calma de una amiga (jahora a por la poesía!).

Gracias también a todas las personas que me han brindado su amistad y apoyo en este tiempo, en especial gracias a Celia Puerto, Ilaria Moraschini., Raquel Moreno, Ana Sevilla y Julia Haba, por escucharme tanto y compartir su tiempo y conocimientos.

Agradezco también muchísimo la acogida en el Centro de Investigación Arte y Entorno, que ya es una segunda casa para mí, y a Silvia Molinero, Constancio Collado, Paula Santiago, Toni Simarro y Miriam del Saz por hacerme el día a día más fácil. Del mismo modo agradecer a las chicas del grupo de investigacion On The Edge Research por acogerme, Hilal Bugali, Nil Gulari, Nicola Chambury, Maja Zeco y en especial a Caroline Gausden que me abrió las puertas de su casa y su familia (junto a Lance Manak. y Guvatri).

Queremos expresar nuestro profundo agradecimiento al pueblo de Carrícola y demás amigos y amigas que participaron en la construcción del horno por su tiempo y energía: Thomas Decker, Juan Martí, Pedro Torres, Felicia Samper, Susana Cháfer, Pedro Altabert, Bruno Sperzagni, Juán Cháfer, Josefa Nácher, Juana Altabert, Esteban Cháfer, Lluís Blasco, Adrián Llorens y el resto del pueblo que nos brindó su compañía y cariño durante nuestra estancia.

Por último, a todos los y las amigas y artistas que me han ayudado a dotar de contenido esta tesis y a todas las personas que han compartido sus imágenes conmigo por su atención y generosidad. 


\section{ÍNDICE}

RESUMEN.

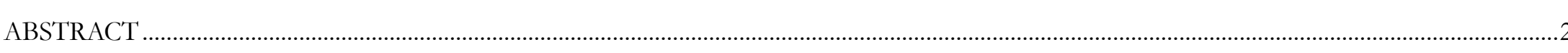

CAPÍTULO 1. EL LUGAR DEL ARTE EN EL CONTEXTO DE LA CRISIS ECOLÓGICA

1. INTRODUCCIÓN

1.1 LAS RAÍCES ECONÓMICO-SOCIALES DE LA CRISIS ECOLÓGICA

1.2 RETOS Y OBSTÁCULOS PARA LA TRANSICIÓN A LA SOSTENIBILIDAD

2 ESTADO DE LA CUESTIÓN

2.1 EL PAPEL DEL ARTE EN EL DESARROLLO DE LA CONCIENCIA AMBIENTAL: EMOCIÓN, EMPATÍA Y

LENGUAJES ARTÍSTICOS

2.2 ARTE Y ECOLOGÍA

2.3 EL VALOR DEL ARTE PÚBLICO COLABORATIVO EN LA TRANSICIÓN

2.3.1 Arte público y transición..

2.3.2 La participación y el proceso dialógico

2.3.3 Intención ....

2.3.4 Efectividad

2.3.5 Estética, ética e invisibilidad.

2.4 LA INTERSECCIÓN ENTRE ARTE COLABORATIVO, ARTE ECOLÓGICO Y ENFOQUE TRANSICIONAL ... 3. HIPÓTESIS DE PARTIDA Y PLANTEAMIENTO DE LA INVESTIGACIÓN. CUESTIONES A EXPLORAR ..

4. OBJETIVOS

5. METODOLOGÍ́ Y MEDIOS
CAPÍTULO 2. PROYECTOS DE ARTE HACIA LA TRANSICIÓN A LA SOSTENIBILIDAD.

\section{ESTUDIOS DE CASO}

1. ÁREA DE ESTUDIO Y CRITERIOS DE SELECCIÓN APLICADOS. .

2. FUNCIONES DEL ARTE y ARTISTAS EN PROYECTOS DE TRANSICIÓN A LA SOSTENIBILIDAD ..................................................8

2.1 ILUSTRAR, REPRESENTAR, COMUNICAR...

2.2 CONCIENCIAR

2.3 DESARROLLAR EMPATÍA

2.4 IMAGINAR, CREAR VISIÓN

2.5 OFRECER SOLUCIONES ALTERNATIVAS O PROYECTOS PILOTO

2.6 CONECTAR, CREAR COMUNIDAD, REDES Y ESPACIOS DE REL ACIÓN ENTRE PFRSONAS

2.7 RESTAURAR, RECUPERAR EL ENTORNO

2.8 CREAR SÍMBOLOS E IDENTIDAD.

FOMENTAR LA CIUDADANIA CRITICA, AGITAR, DENUNCIAR ...

2.10 EMPODERAR

2.11 CREAR RELATOS POSITIVOS DE CAMBIO

2.12 CONOCIMIENTO ÉTICO APLICADO

213 CONECTAR ÁREAS ALEJADAS DE CONOCIMIENTO

\section{CAPITULO 3. ACTIVIDAD ARTISTICA EN EL MOVIMIENTO DE CIUDADES Y PUEBLOS}

\section{EN TRANSICIÓN}

1. REACTIVAR LA COOPERACIÓN DESDE EL ARTE Y EL MCT.

2. PRESENCIA Y FUNCIÓN DEL ARTE EN LA RED DE TRANSICIÓN ESPAÑOL

2.1 METODOLOGÍA

2.2 PARTICIPANTES.

2.3 PROCEDIMIENTO

2.4 RESULTADOS... 
5.4.6 Papel y funciones del arte en Tooting Traschcatchers Carnival.

3.3 ORÍGENES, OBJETIVOS Y DESCRIPCIÓN DEL PROYECTO

5.5 RESULTADOS Y CONCLUSIONES PARCIALES.

\section{CAPÍTULO 4 EL PAPEL DEL ARTE EN LA TRANSICIÓN EN SENTIDO AMPLIO}

3.3.2. Arrool de la misisic

3.3.3 Festival La Noche de los Candiles ...........................................................139

3.3 .4 Almouseum, arte en la calle y Voces con historia .....................................................................................................................140

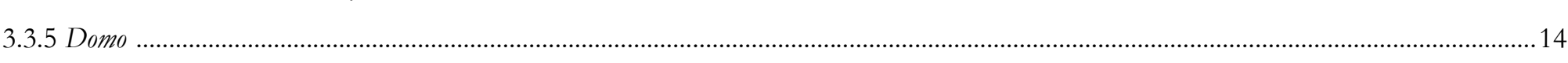

3.4 ANÁLISIS ..

3.4.1 Participación ....

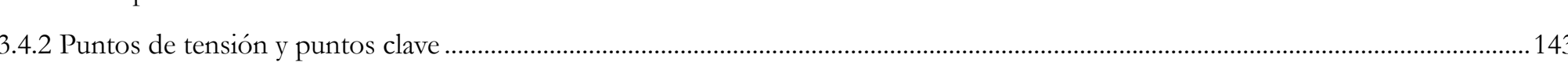

3.4.3 Intención....

3.4.4 Efectividad ..

3.4.5 Estética y ética.

3.4.6 Papel de los artistas y funciones del arte en Almócita .............................................................................................................149

3.5 LA IGNICIÓN Y OTROS PRINCIPIOS DEL ARTE TRANSICIONAL EN ALMÓCITA. CONCLUSIONES PARCIALES...............151 4. EL PAPEL DEL ARTE EN EL MOVIMIENTO DE CIUDADES Y PUEBLOS EN TRANSICIÓN (MCT) EN REINO UNIDO ..................155 5. ESTUDIO DE CASO: TOOTING TRASHCATCHERS' CARNIVAL

5.1 EL ARTE EN LA FUNCIÓN DE CELEBRACIÓN EN LOS GRUPOS DE TRANSICIÓN ………................................................158

5.2 ADECUACIÓN A LOS CRITERIOS DE SELECCIÓN DE LA INVESTIGACIÓN ………………………………….............................159

5.3 ORÍGENES, OBJETIVOS Y DESCRIPCIÓN DEL PROYECTO ...............................................................................................16

5.4 ANÁLISIS ....

5.4.3 Intención..

INTRODUCLON..........

3. ESTUDIO DE CASO: THE STOVE

3.1 EL ARTE Y SU FUNCIÓN DE CONEXIÓN DE ESPACIOS Y PERSONAS

3.2 ADECUACIÓN A LOS CRITERIOS DE SELECCIÓN DE LA INVESTIGACIÓN

3.3 ORÍGENES, OBJETIVOS Y DESCRIPCIÓN DE LOS PROYECTOS

3.3.1 We Live With Water

3.3.2 The Nittraid

3.4 ANÁLISIS

3.4.1 Participación .....

3.4.2 Puntos de tensión y puntos clave

3.4.3 Intención .

3.4.4 Efectividad

3.4.5 Estética y ética....

3.4.6 Funciones del arte

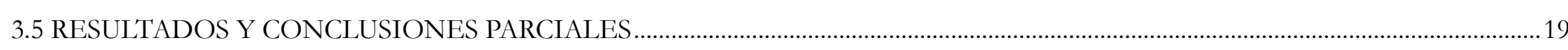

4. ESTUDIO DE CASO: DUNDEE URBAN ORCHARD

4.1 EL ARTE EN LA CONSTRUCCIÓN DE RESIIIENCIA Y FUTUROS ALTERNITIVOS ...

4.2 ADECUACIÓN A LOS CRITERIOS DE SELECCIÓN DE LA INVESTIGACIÓN …….......................................................................... 202

4.3 ORÍGENES, OBJETIVOS Y DESCRIPCIÓN DEL PROYECTO. LA CIUDAD HUERTO 
4.4 ANÁLISIS ..

4.2.1 Participación

4.2.2 Puntos de tensión y puntos clave

4.2.3 Intención ..

4.2.4 Efectividad..

4.2.5 Estética y ética.

4.2.6 Funciones del arte .

4.5 RESULTADOS Y CONCLUSIONES PARCIALFS

5. ESTUDIO DE CASO: CARRÍCOLA

5.2 ADECUACIÓN A LOS CRITERIOS DE SELECCIÓN DE LE INVESTIGACIÓN ...........................................................................222

5.3 ORÍGENES, OBJETIVOS Y DESCRIPCIÓN DEL PROYECTO ..........................................................................................22

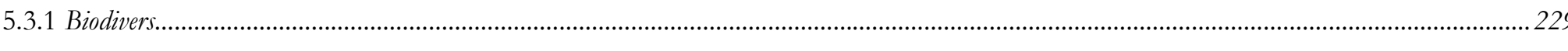

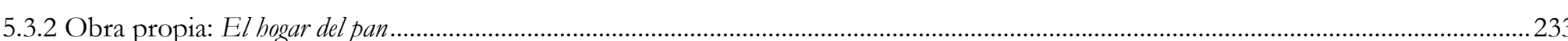

5.4. ANÁLISIS

5.4.1 Participación .....

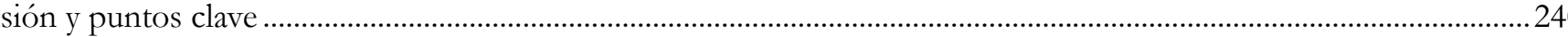

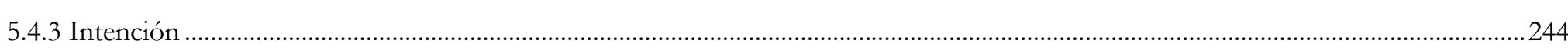

5.4.5 Estética y ética 6. ESTUDIO DE CASO: EL CUBO VERDE

6.1 OTRAS MANERAS DE APORTAR DESDE EL ARTE A LA TRANSICIÓN.................................................................................259

6.2 ADECUACIÓN A LOS CRITERIOS DE SELECCIÓN DE LA INVESTIGACIÓN ...............................................................................263

6.3 ORÍGENES, OBJETIVOS Y DESCRIPCIÓN DEL PROYECTO.
6.4 ANÁLISIS

6.4.1 Participación .................................... Puntos de tensión y puntos clave

6.4.3 Intención

6.4.4 Efectividad..........

6.4.5 Estética y ética....

6.4.6 Funciones del arte

6.5 RESULTADOS Y CONCLUSIONFS PARCIALES

7. OTROS PROYECTOS: AULA-R.

71 LA SOSTENIBILIDAD EN LA PRÁCTICA ARTÍSTICA Y LA GESTIÓN CULTURAL

7.2 ADECUACIÓN A LOS CRITERIOS DE SELECCIÓN DE LA INVESTIGACIÓN …………………………………….....28

7.3 ORÍGENES, OBJETIVOS Y DESCRIPCIÓN DEL PROYECTO AULA-R ........................................................................................28

7.4 ANÁLISIS.

7.4.1 Participación...

7.4.2 Puntos de tensión y puntos clave

7.4.3 Intención...

7.4.4 Efectividad....

7.4.5 Estética y ética......

7.4.6 Funciones del arte

7.5 RESULTADOS Y CONCLUSIONES PARCIALES.

CAPÍTULO 5. DISCUSIÓN DE RESULTADOS

1. ANÁLISIS Y DISCUSIÓN DE RESULTADOS.

1.1 PARTICIPACIÓN

1.2 PUNTOS DE TENSIÓN Y PUNTOS CLAVE

1.3 INTENCIÓN $\ldots 270$

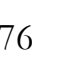
, 


\section{NOTA:}

Se ha intentado utilizar un lenguaje inclusivo a lo largo del texto, no obstante, entiéndase que cuando se usa el masculino sin aludir a una persona en concreto estamos incluyendo ambos géneros.

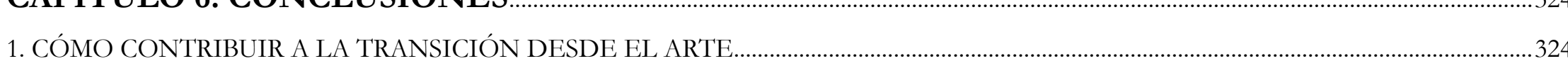

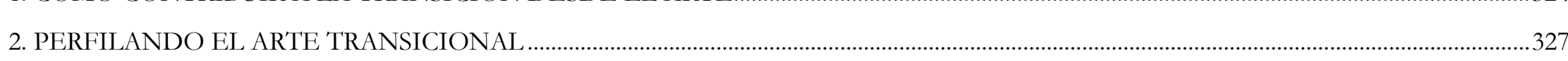

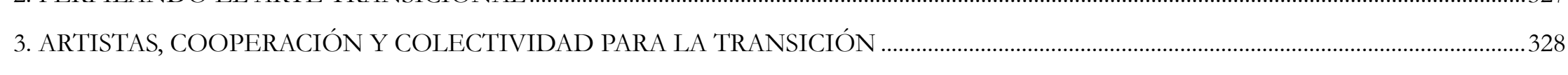

4. LIMITACIONES, CRÍTICAS, OPORTUNIDADES ..................................................................................................................................330

CHAPTER 6. CONCLUSIONS

1. HOW TO CONTRIBUTE TO THE TRANSITION THROUGH ART .... ……….....

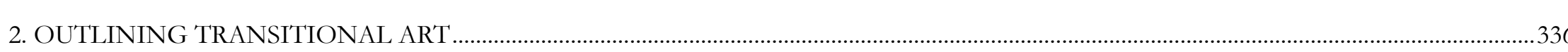

3. ARTISTS, COOPERATION AND COLLECTIVE WORK FOR THE TRANSITION ……………...............................................................33

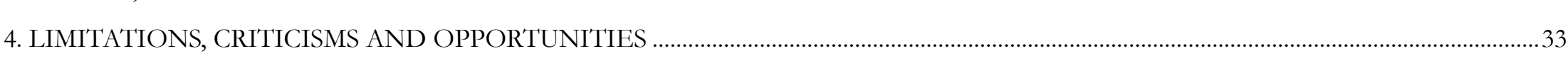

BIBLIOGRAFÍA

ÍNDICE DE FIGURAS E IMÁGENES

CAPÍTULO 1

CAPÍTULO 2..

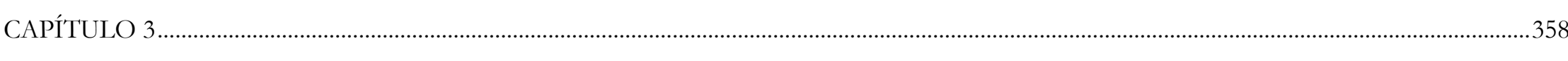

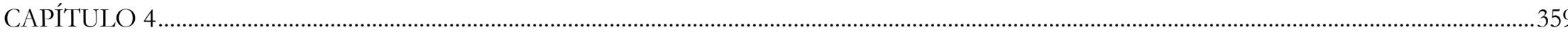

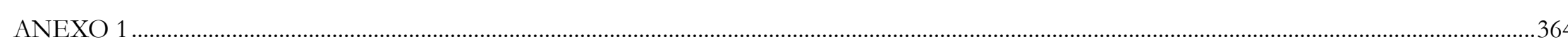

(1) 


\section{RESUMEN}

La tesis defiende la necesaria aportación de las humanidades en procesos de transformación cultural hacia la sostenibilidad y, más en concreto, profundiza en los proyectos que desde el art se están llevando a la práctica. Nos basamos en la capacidad de la creación artística para potenciar la concienciación ambiental y la transformación social, entre otras funciones, haciendo énfasis en herramientas como la empatía y la colaboración. Para mostrar este nuevo rol de los creadores en la sociedad, nos situaremos en contextos de transición a la sostenibilidad entendida en sentido amplio, así como en el Movimiento de Ciudades y Pueblos en pás pión (MCT), surgido Moving Re Unido en 2005. Siendo dicho enidos en la publicacion Playing for time. Making art as if the Wald mattered (Neal, 2015) y perfor the

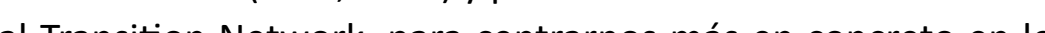

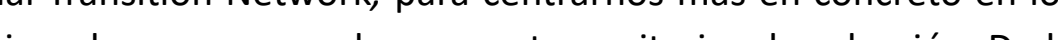

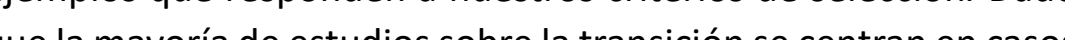
que la mayoria de estudios sobre la transicion se centran en casos 2012; Not, 2013), 2012, Neal, 2013), estableceremos un paralelismo con las iniciativas actuales de la Red de Transición en España, destacando caso de Almócita (Almería). Por otra parte, también se analizaràn propuestas artísticas al margen del MCT como Nithraid y Dundee Urban Orchard en Reino Unido y, en España, Biodivers, El Cubo Verde y Aula-R entre otras.

La metodología de investigación se basa en técnicas cualitivas como encuestas y entrevistas, así como en la Investigación Acción Participativa implicándonos en algunos de los proyectos estudiados, asi como en la práctica artistica personal en los casos de Biodivers y Aula-R. Siguiendo a la experta en arte público Su- zanne Lacy, se analizarán estas propuestas en base a la participapuntos de tensión y puntos clave, la influencia de la financiación y las funciones que desempeñan. Además comprobaremos como responden estos casos a los principios del transitional art definidos por la autora Lucy Neal (2015).

Como resultado mostraremos la función del arte en el focelán colectiva, en la construcción de identidad, en la revitalización del ertorito, en el aumento de resiliencia, en la conexión de las per sonas con su entorno y como desencadenante de dinámicas de cultades para has funciones. Pero también se subrantroducir las preocupaciones de la huella ecológica en la práctica artística y los requisitos de sostenibilidad en el campo cultural, especialmente en España. El texto contribuye así al conocimiento del MCT más allá del contexto anglosajón y a la valoración del arte como importante herramienta para el cambio cultural hacia la sostenibilidad que necesitamos.

\section{PALABRAS CLAVE}

Arte transicional, arte y ecologia, arte público, transición a la sostenibilidad, Movimiento de Ciudades y Pueblos en Transición, práctica dialógica, Red de Transición. 


\section{ABSTRACT}

This thesis defends the significant contribution of the hucosses of cultural transformation towards sustanability and, more specifically, delves into how emerging practces in art are specifically contributing to it. We rely on the ability of artistic creation to enhance environmental awareness and social transformation, among other functions, emphasizing tools such as empathy and collaboration. To show this new role of creators in society, the research is situated in contexts of transition to sustainability understood in a broad sense, as well as in the Transition Town Movement (TTM), which emerged in the United Kingdom in 2005. Being UK a pioneer in TTM, the study will review a collection of Angl-Saxon cases contained in the publication $P(a-$ (ung for time. Making art as if the world mattered (Neal, 2015)

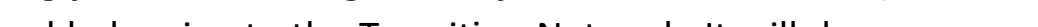
and belonging to the Transition Network. II wil draw on specific cases that meet our selection criteria. Given the fact that a great part of the studies, (Haxeltine and Seyfang 2009; Bailey et al., 2010; Aiken 2012, Neal, 2013), the research will develop a comparative study with the current initiatives of the Transition Network in Spain highlighting the case of Almócita (Almería). On the other hand artistic proposals will also be analyzed outside the TTM such as Nithraid and Dundee Urban Orchard in the United Kingdom and, in Spain, Biodivers, El Cubo Verde and Aula- $R$ among others.

The research methodology is based on qualitative techniques such as surveys and interviews, as well as on Participatory Action Research, involving myself as a researcher in some of the projects studied, as well as in personal artistic practice in the caby the expert in public art Suzanne Lacy in her practice-led PhD

\section{RESUM}

(2013), these proposals will be analyzed based on the participapoints of tension and key points, the influence of funding and the functions they perform. How these cases respond to the principles of transitional art defined by the author Lucy Neal (2015) will also be checked out.

As a result the case studies will show how art is expandin eld of sustainability plaing a function in promoting cooperation in the local community, in the collective celebration, in the construction of identity, in the revitalization of the territory, in the increase of resilience, in the connection of people with their environment and as a trigger for dynamics of change, among others. But it also underlines the difficulties to make visible its role, the necessity to introduce ecological footprint concerns in the artistic practice and sustainability requirements in the cultural field, specially in Spain. The text thus contributes to the knowledge of the TTM beyond the Anglo-Sacontor the tor challenge of the 21st century: the environmental crisis.

\section{KEY WORDS}

Transitional art, collaboration, Art and Ecology, Public Art, ansition to sustainability, Transition Town Movement, Dialogica Practice, Transition Network.
La tesi defén la necessària aportació de les humanitats en en concret, aprofundeix en els projectes que des de l'art s'estan portant a la pràctica. Ens basem en la capacitat de la creació artística per tal de potenciar la conscienciació ambiental i la transformació social, entre altres funcions, fent èmfasi en ferramentes com l'empatia i la col-laboració. Per a mostrar aquest nou rol dels creadors amb la societat, ens situarem en contextos de transició a la sostenibilitat entesa en sentit ampli, així com en el Movimen de Ciutats i Pobles en Transició (MCT), sorgit en Regne Unit l'any 2005. Sent el dit país pioner en MCT revisarem una recopilacio de casos continguts en la publicació Ploying for time. Making art as if the world mattered (Neat, 2015) i pertanyents a la xara inas if the world ten que lajora d'estudis sobre la transció se centren casos anque la majo glosaxons (Haxeltine i Seyfang 2009; Balley tal. 2010; Aiken 2012; Neal, 2013), establirem un paral lelisme ambles iniciatives actuals de la Xarxa de Transició a Espanya, destacant el cas dÁlmócita (A meria). D'altra banda, també s'analitzaran propostes artístiques a marge del MCT com Nithraid i Dundee Urban Orchard en Regne Unit i, a Espanya, Biodivers, El Cubo Verde i Aula-R entre altres.

La metodologia d'investigació es basa tant en tècniques quaItatives com enquestes i entrevistes, com en la Investigació Acció Participativa implicant-nos en alguns dels projectes estudiats, aix com en la pràctica artística personal en els casos de Biodivers Aula-R. Seguint l'experta en art públic Suzanne Lacy, s'analitzaran aquestes propostes basant-se en la participació, la intenció del creadors, els resultats, l'estètica, els punts de tensió i punts clau, la influència del finançament $i$ les funcions que exerceixen. A més incipis del transitional art, definits per l'autora Lucy Neal (2015).

Com a resultat mostrarem la funció de l'art en el foment de la cooperació en la comunitat local, en la celebració collectiva, en la construcció d'identitat, en la revitalització del territori, en

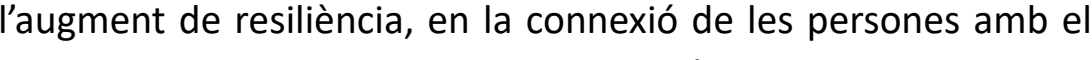
seu entorn i com a desencadenant de dinàmiques de canvi, entre altres funcions. Pero tambe se subratlen les dificultats per a fer visible el seu paper, la necesstat dintroduir les preocupacions de lempremta ecologica en la practica artistica i els requisits de sostenibilitat en el camp cultural, especialment a Espanya. El text contribueix així al coneixement del MCT més enllà del context anglosaxó i a la valoració de l'art com a important ferramenta per al canvi cultural cap a la sostenibilitat que necessitem.

PARAULES CLAU

Art transicional, art i ecologia, ar tenibilitat, Moviment de Ciutats i Pobles en Transició, pràctica dialògica, Xarxa de Transició. 
CAPÍTULO 1. EL LUGAR DEL ARTE EN EL

2 Estos proyectos artísticos colaborativos

en los que participamos como miembs

puede consultar en la tesis de Antonio CoIlados Alcaide (2012) Laboratorios artititicos
colaborativos: Espacios transfronterizos de producción cultural. El caso de Aulabierta en
la Universidad de Granada. Universidad de Granada. Disponible en: digibug.ugr.es/
tream/10481/35152/1/21168763.pdf. Ta tream/10481/35152/1/21168763.pdf. Tam.
bién se pueden consultar algunos videos de los provectos en: https
com/video/ $/ 5989 f$

\section{CONTEXTO DE LA CRISIS ECOLÓGICA}

\section{INTRODUCCIÓN}

Este trabajo de investigación se inserta dentro de la línea de investigación Arte, Entorno y (CIAE) de la Universitat Politècnica Consellería de Educación Cultura y Deporte de la Grama de becas predoctorales VALitd de la Consellería de Educación Cultura y Deporte de la Generalitat Valenciana (ACIF/2014/002). Du rante su desarrollo también ha sido beneficiado con una beca de estancia de investigación de seis meses de la misma Consellería, dentro del subprograma: Becas para estancias de contraados predoctorales centros de investigación fuera de la Comunitat Valenciana (BEPFI-2016) en la Gray's School of Arts de la Universidad Robert Gordon de Escocia, bajo la supervisión de la Profesora Anne Douglas, investigadora principal del grupo On the Edge Research ${ }^{1}$ (OTE).

Se trata de una investigación transdisciplinar que explora la aportación del arte y el papel de los artistas en los procesos de transición hacia la sostenibilidad. Varias motivaciones nos empujan en esta dirección de estudio: por un lado superar la cosmovisión cartesiana, disciplinar segmentada de las aproximaciones más frecuentes a la complejidad de la crisis ambiental, la cua demanda nuevas perspectivas transdisciplinares que incluyan el diálogo de saberes cientificos no científicos, agrupados en un nuevo paradigma civilizatorio vertebrado por la sostenibilidad. Por otro, la escasa valoración por parte de las disciplinas cientificas, el publico, las instituciones los movimientos de base, entre otros, de la aportación del arte y los artistas a la transición hacia una sociedad sostenible, más allá de su papel estético o ilustrador. En el origen de esta tesis se halla nuestra trayectoria personal iniciada con la licenciatura en Ciencias Ambientales (19982002) por la Universidad de Granada (UGR). Se continúa con la licenciatura en Bellas Artes, (UGR) (2007-2012) durante la cual colaboramos en acciones artísticas colectivas (varias con un enfoque ecológico) donde la participación era el eje de los proyectos ${ }^{2}$. Se prolonga con la formación adquirida en el desarrollo del Proyecto Final del Máster Oficial de Producción e Investiga- ción Artística de la UPV titulado: Arte público de enfoque ecológico. Análisis de resultados según Suzanne Lacy. Producción propia como artista experimentador, informador, analista y activista, 2013, en el que se realizó una aproximación al estudio de la utilización del arte público colaborativo como herramienta para tratar cuestiones de carácter ecológico con un objetivo de concienciación y transformación social. Finalmente la tesis se centra en su desarrollo en el estudio de herramientas artísticas para el fomento de la empatía y la participación, dotando al arte de nuevas funciones en proyectos que abordan la transición hacia la sostenibilidad. Hemos estudiado la relación entre creación, emoción y empatía a través de autores como Kathinka Evers, Tonia Raquejo y Reiko Goto. En concreto, hemos abordado el estudio del arte público colaborativo cotado al enfoque artístico ecol Nina Felshin, Paloma Blanco, Anne Douglas y Wallace Heim, basándonos en el marco teórico de ensayistas como Edgar Morin, Jorge Riechmann, Carlos Taibo, José Albelda, Fernando Arribas, Richard Sennet, David Haley, Chris Fremantle y artistas como Lucy Neal, Newton y Helen Mayer Harrison, Lucía Loren, Reiko Goto y Tim Collins. La aproximación a estos autores nos confirma la importancia de trabajar desde un punto de vista transdisciplinar, estando abiertos durante la investigación y creación artística a la colaboración con expertos de otras disciplinas, pero también con los no expertos, para abordar la multifacética crisis ambiental desde las ciencias y las humanidades, desde el conocimiento académico y los saberes colectivos. Investigadores como Antonio Turiel, Ferran Puig. Ernest García o Rob Hopkins nos introducen en la urgente cuestió del pico del petróleo, el cambio climático, el acotamiento de los recursos, la resiliencia y la

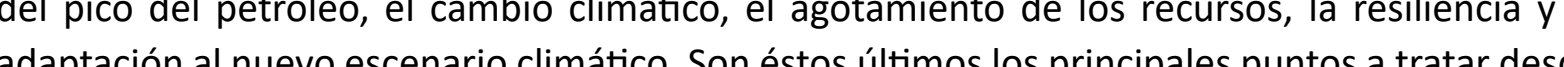
la transición a la sostenibilidad y serán parte de los criterios de selección de casos de estudio.

Nuestra hipótesis inicial se basa en demostrar la capacidad del arte para potenciar la concienciación ambiental y la transformación social, entre otras funciones, mediante el fomento de la empatía y la participación en proyectos multidisciplinares relacionados con la transición. Partimos de la asunción de la crisis del sistema político, económico y de pensamiento actual, y del conocimiento de los límites de la naturaleza en relación a los actuales modelos de desarrollo. Como consecuencia, se hace necesario un cambio profundo del paradigma del progreso en la vía de la sostenibilida se la gravedad de este conflicto eco-social exige la participacín desde todas las disciplinas para lorar un cambio cultural sistémico y duradero la colaboración transdisciplinar au preconiza Morin en su teoría de la complejidad, supone un necesario desan-

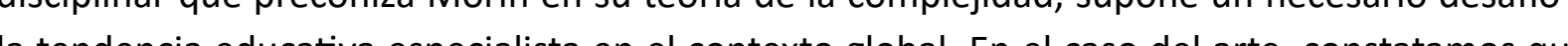


3 Estas ideas fueron además comentadas comienza a ser mejor reconocida su capacidad para implicarse en la acción cotidiana y de hibri-

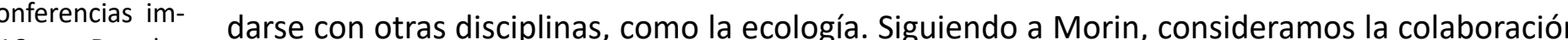
en la Acción de internacionalización en entre artistas, humanistas y científicos un paso evolutivo cultural necesario para que la humadel que formamos parte del equipo investi作 transición, frente al escenario de colapso socioambiental que se avecina. En este nuevo contexto, la investigación artística se enfrenta al desafío de consolidar sus propios modelos alternativos al marco investigador dominante neopositivista, el cual no se articula satisfactoriamente con la investigación en arte (Douglas et al., 2016). Los paradigmas de investigación crítico y participativo, junto a la investigación artística basada en la práctica, son los modelos que hemos usado a to largo de este estudio. La estancia de investigación en el grupo OTE nos ha aportado una perspectiva de autoanálisis de la propia acción investigadora, otorgando valor a técnicas cualitativas como la narración o la inducción, además de la cuantificación o la deducción como criterios de la investigación.

Entre la gran diversidad de experiencias actuales para fomentar el cambio cultural, destacamos la trayectora del Movimiento de Cludades y Pueblos en Transición (MCT) y las Redes de Transición. Su advenimiento supone un campo de exploración nuevo para los artistas, permitiendo fomentar la cooperación y crear nexos emocionales vinculados a la concienciación ambiental como medio de transformación de la sociedad. La principal aportación de estas iniciativas para nuestro trabajo es el hecho de que nos señalan ejemplos reales y contemporáneos de nuevas formas de actuación democrática alternativas a la organización política actual, que parten de la acción comunitaria y que recogen objetivos de reducción de la huella de carbono, aumento de la resiliencia y visión «glo-cal» entre otros. Algunos artistas han comenzado a trabajar junto a estos grupos generando nuevos modos de colaboración artista-público. Como veremos en el apartado 21 necesitamos relatos positivos de cambio, como los que se aglutina bajo el paraguas de los movimientos de transición (Totnes, Brixton, etc.), que añadan a la actual ucultura de las expectavas dominte, una ucultura de la espra "cultura de las ester en el dou hacia la transición, recopilando historias inspiradas desde o desarrolladas a través del arte en autoorganizada.

Para ilustrar nuestra hipótesis realizamos una compilación, análisis y estudio crítico de casos en España y en Reino Unido en los que se emplea el arte como estrategia de fomento de la empatía hacia la biosfera - entre otras funciones que veremos en los capítulos tres $y$ cuatroen municipios o iniciativas de transición a la sostenibilidad en sentido amplio, estén adheridos en mo MCT o a lod de Transión. El objetivo es estudiar las distintas fo, estén adheridos

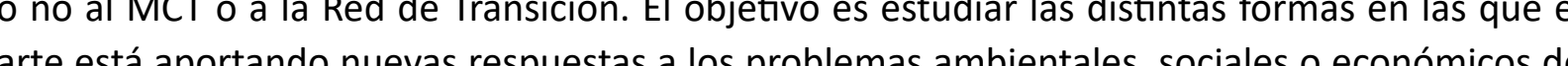
arte está aportando nuevas respuestas a los problemas ambientales, sociales o económicos de

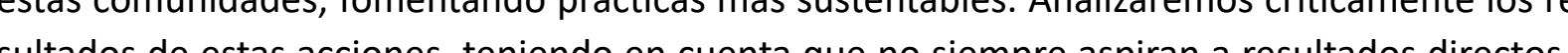
sultados de estas acciones, te lendo n cuenta que no simpre aspiran aresula dos diresto medibles, tal y como explican los Harrison al respecto de sus obras:

No puedes cambiar a las personas cuando les das información. La información se introduce en la cabeza y queda alli. Freud decia que solo se puede cambiar el comportamiento cuando se tiene la sensación de iajá! de algo que te ha impactado emocionalmente. Un aspecto básico respecto a nuestro arte es que alcanza a las personas a un nivel más profundo que las palabras o las imágenes pasando a través ison palabras e imágenes que resonarán en la mente ${ }^{55}$ (Helen M. Harrison, 2008, citado en Goto Collins, 2012, p. 138).

En esta tesis se trabaja desde un concepto amplio la idea de arte, en la línea de la escultura social iniciada por Joseph Beuys. Asimismo, se sobrepasa la idea del artista protagonista,
en favor de la coparticipación creativa y la coautoría con el público. El carácter colaborativo en favor de la coparticipación creativa y la coautoría con el público. El carácter colaborativo
sumado al enfoque ecológico, constituyen características artísticas relativamente innovadoras que acotan la bibliografía relacionada, pero que son fundamentales en este estudio. Nuestra experiencia en proyectos anteriores (Aulabierta, proyecto final de master: Aula-R, entre otros) nos empuja a sostener la hipótesis de que la colaboración en la obra facilita la empatía y concienciación de los participantes y, por tanto, un mayor asentamiento de los cambios perceptivos y comportamentales por lo que, indirectamente, educa a través de la implicación y el entorno.
5 Traducción de la autora del original:
«you cannot change people when you give them information. Information goes in the only change behaviour when you have the really struck you emotionally. The basic thing about our art is that it reaches people
ta a level deeper than just words passin are images and
the mind!). 

casos van conformando progresivamente el conjunto de la tesis doctoral. La concesión de la beca de estancia de investigación nos ha permitido tomar contacto con otros grupos de investigación a nivel internacional, en especial en el contexto anglosajón. La estancia ha facilitado el contacto directo con las fuentes de referencia, realizando entrevistas a varios especialistas, filósofos, teóricos, académicos y artistas como Anne Douglas, Chris Fremantle, Dave Pritchard, David Haley, Matt Baker, Robbie Coleman, Jan Hogarth, Reiko Goto, Tim Collins, Jonathan Baxter, Open Jar Collective y Mike Bonaventura, entre otros. También ha hecho posible la visita y exploración de diversos proyectos como Soil Fictions (Suelos ficticios), Nithraid (Carrera del Nith), Dundee Urban Orchard (Huertas urbanas de Dundee) y Grizedale. Nos ha ayudado a clarificar los límites de la acción artística entendiendo que los artistas no solo pueden enfocarse hacia la búsqueda de soluciones, sino también plantear nuevas cuestiones o imaginar alternativas. Además nos ha impulsado a ampliar los horizontes de estudio, abierto nuevas vías y preguntas y, por tanto, consideramos que ha sido determinante para el desarrollo de esta tesis.

Así mismo, han resultado cruciales las experiencias llevadas a cabo en colaboración con el CIAE a lo largo de la beca de investigación: desde la coordinación y asistencia a cursos, jornadas y seminarios, redacción de articulos, comunicaciones y posters, hasta la participación en convocatorias artisticas y exposiciones. En concreto destacamos tres actividades por orden cronológico: la coordinación del Diploma de Especialización en Sostenibilidad, Ética Ecológica y Educación Am biental desde su puesta en marcha en 2015 hasta la actualidad; la participación en la organización de las jornadas Ecoframes sobre documentales de transición en el Instituto Valenciano de Arte Moderno (IVAM) en 2015; y la participación en el equipo de trabajo del I+D+i Humanidades ambientales: estrategias para la empatía ecológica y la transición hacia sociedades sostenibles. En el contexto de este último proyecto hemos participado en el seminario Tiempos de transición. El lugar de las humanidades antes la crisis socio-ecológica global, Valencia 2016; hemos asistido a Congreso Imaginar la transición hacia sociedades sostenibles. Madrid 2017 y participado en el I Congreso Internacional de humanidades ambientales. Relatos, mitos y artes para el cambio en el Cor de Henares, 2018. Por último, mencionar también nuestra participación en las jornadas: Crear para cambiar. Encuentro sobre prácticas artisticas y sociedades en transición dentro del contexto Pe la exposición HYBRIS en el Museo de Arte Cons y socied des en 2017.

La tesis se estructura en seis capítulos. En el primero presentamos nuestra hipótesis de estudio, objetivos y metodola de la crisis ecológica. Presentaremos el concepto de transición, el MCT y su relación con el arte antes de profundizar en la relación de la emoción la empatí y la concienciación ambiental Sera

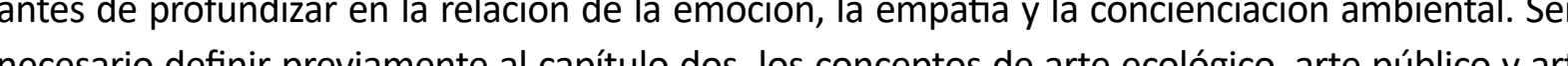
transiciona para poder estudiar sus puntos en común y posicionarnos. En el segundo capitub pretransicion di pros sentares hemos desticos de de la recticticos dentro de la Red de Transición espanola y anglosajona. Para ello nos basaremos en las recomendaciones de Lacy al respecto del análisis de obras de arte público tomando en cuenta la participación, los puntos de tensión y puntos clave, la intención de los artistas, la efectividad, la estética y la ética para concluir las funciones que estos proyectos están realizando en sus contextos sus efectos en el entorno social y físico. Profundizaremos en la importancia de la cooperación para la transición ecosocial y cómo activarla desde el arte y comprobaremos si los principios del arte transicional se están cumpliendo en estos casos y en los del siguiente capítulo. En la cuarta sección entraremos a analizar del mismo modo que en el titulo anterior los casos de estudio seleccionados fuera de la Red de Transición tanto en España como en Reino Unido, para obtener unas conclusiones parciales sobre las consecuencias de estos proyectos artisticos en sus entornos y su adecuación al arte transicional. Para el quinto capitulo realizaremos una comparativa de resultados de todos los casos seleccionados entre síy de los casos dentro de la Red de Transición con los que no pertenecen a la misma. Las observaciones parciales obtenidas nos servirán para preparar las conclusiones finaes que se presentan en el capítulo seis, y que demuestran que el arte colaborativo de enfoque ecológico tiene mucho que aportar y varias funciones que cumplir en la transición a la sostenibilidad.

\subsection{LAS RAÍCES ECONÓMICO-SOCIALES DE LA CRISIS ECOLÓGICA}

Para comenzar con este estudio primero debemos enmarcarlo dentro del contexto de crisis ecológico-social actual, para después describir el concepto de transición a la sostenibilidad y 
las prácticas culturales y estudios científicos sobre los que basaremos nuestra investigación. La crisis ecológica es probablemente el problema más global al que se ha enfrentado la humanidad en su historia. Afecta en mayor o menor medida a toda la geografía, todos los sectores y todas las facetas de la vida desde la alimentación a la reproducción, desde el trabajo a la libertad, desde el embarazo al fallecimiento, desde la educación al ocio. En un planeta de recursos finitos, hemos topado con los limites del crecimiento que ya preveia el Informe Meadows en 1972. No hay otras tierras que explotar, otros recursos, otras poblaciones. Como «viajeros de la misma nave Tierra» (Boulding, 1966), no tenemos otro puerto al que dirigirnos y no hay salida tecnológica que nos salve ni milagro al que recurrir. La imposibilidad de revertir el calentamiento globa y el pico del petróleo, dibujan un escenario futuro de colapso energético según investigadores como Riechmann, Turiel o Ferran Puig. La extracción de hidrocarburos ha alcanzado su máximo (Turiel, 2017) y aunque se paralizara ahora mismo la producción de $\mathrm{CO}_{2}$, la inercia del cambio climático es imparable con este historial de emisiones (Puig, 2016). Para los autores estudiados, ha finalizado ya el período de reacción en el que un decrecimiento global ordenado podría devolver el equilibrio a los ecosistemas y evitar el calentamiento global (Riechmann, 2015). La realidad actual sin precedentes históricos no nos deja otra opción que aprender a adaptarnos para perdurar ante el colapso como preconizan, además de los anteriores, Sèrge Latouche o Carlos Taibo (2011) o en otras palabras, «fracasar mejor» según Riechmann (2013).

Pero esta no es solo una crisis de los ecosistemas naturales, sino una crisis sistémica mu-

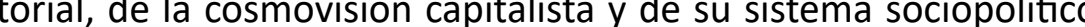
como sostienen Albelda (2017a) y Riechmann: «Los problemas medioambientales son en real dad problemas socioecológicos» (2005a, p. 25). «¿̇odavía podemos salvar el mundo? (...) Técnicamente aún sería posible sí, pero política y socialmente todo indica que no....) (Riechmann 2015, 0:49:55). Además es una crisis de la propia identidad del ser humano, que se ha vuelto en palabras de Morin «extranjero del mundo», desde que el sistema cartesiano de conocimiento impusiera su cosmovisión antropocéntrica de la naturaleza como objeto a dominar, parcelar, simplificar y ordenar. Esta reducción de sistemas completos a sus unidades constituyentes, asi como la división disciplinar a que dio lusar, representaron un avance metodológico importante importante

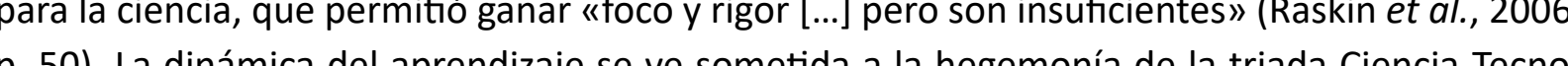
p.

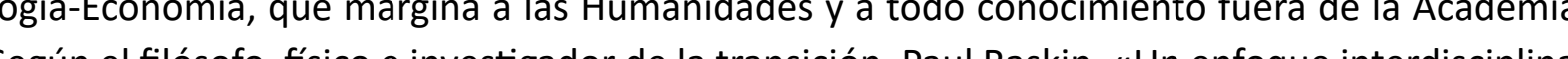

rio en torno a modelos holísticos debe complementar ahora el programa reduccionista» (2006, p. 50). Es, por tanto, un fenómeno tanto físico como cultural que debe ser abordado desde to das las disciplinas del conocimiento y desde todos los saberes, con litya pumerosos agentes se cuestionan la importancia de la cultura con la soste papel de la sostenibilidad en la misma. El investigador en cultura y desarrollo y director de cátedra Unesco Alfons Martinell destaca, sin embargo, la ausencia explicita (solo transversal) de o cultural dentro de los diecisiete Objetivos de Desarrollo Sostenible (ODS) de la Agenda 2030 (2018). Él mismo, señala la necesidad de reconocer desde los ODS la capacidad de la cultura en general, y del arte en concreto, para promover una transformación ecosocial. En esta tesis trataremos de visibilizar la aportación del arte a la sostenibilidad, lo cual refuerza la propuesta de incluir la cultura abiertamente en los ODS:

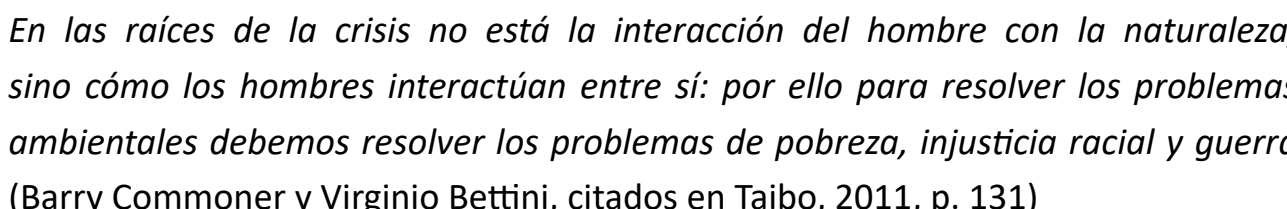

No es objetivo de esta tesis relatar los numerosos y conocidos problemas ambientales que ortunidades que tienen los artistas de contribuir a la sostenibilidad, en medio de una sociedad que se niega a aceptar lo inevitable se empeña en equiparar progreso y bienestar a crecimiento económico. La situación es insalvable mientras el eje central alrededor del cual se tomen las decisiones políticas, económicas, sociales e incluso éticas sea el mercado y no el respeto a la vida, el reequilibrio y la sostenibilidad. "Si se quiere cambiar un modelo de desarrollo se tiene que cambiar el poder que lo sustenta» (Casanova, 2004, p. 26). Y el poder imperante actualmente es el de la cosmovisión capitalista instituida en el crecimiento económico exponencial continuo basado en la supuesta infinitud de los recursos del planeta. Por el contrario, aceptar los límites de los recursos, consecuencia de vivir en un «mundo lleno» (Goodland et al, 1997), es una postura más realista, según indicaron hace décadas los economistas ecológicos Herman E. Daly (1997) y Kenneth Boulding (1966). Como Ernest Garcí explica, hemos llegado al punto de la translimitación, es decir, que el consumo de 
7 Un esclavo energético es una manera de los recursos y de la energía supera la capacidad de carga del planeta (García, 2006). En realimida por cada persona. «En los años noven- da che ta del siglo XX, el habitante promedio de la paste de la Tierra tenía a su disposición " 20 esclavos trabajary (es decir: ese habitante promedio
empleaba la energí equivalente a 20 hu-
manos a que trabajasasen 24 horas al día, 365 manos que trabajasen 24 horas al día,
días al año) (Riechmann, 2005b, p. 217). mente Pe con lómico, independiente de lómites de los recursos y representado por el Producto Interior Bruto (PIB), nos reportará la felicidad deseada, mejorará la cohesión social, creará empleo y distribuirá los recursos de la mano del mercado y del Estado. Cuando, en realidad no es una medida completa ni justa: ignora las desigualdades de género, el grado de libertad de sus ciudadanos, el trabajo invisible no remunerado (como el trabajo doméstico) y tampoco contabiliza los beneficios que nos otorga el capital natural o inmaterial (Taibo, 2011). Los que reconizaban la libertad a través del mercado, ahora nos someten a sus implacables leyes que no contemplan la variable ambiental en la ecuación, no internalizan los costes ambientales, ignoran las enormes desigualdades, las injusticias, el desigual reparto de riquezas y el horizonte de colapso hacia el que la humanidad creciente se avecina. Agobiados por el crédito, tentados por la publicidad y condenados por la obsolescencia programada, la tecnologización de nuestras vidas y el hiperconsumo parecen la salvación (y a la vez condena) de la humanidad. Nada más lejos de la realidad, la brecha de desigualdad de ingresos, poder y género ha aumentado, según el informe de 2011 del Índice de Desarrollo Humano (IDH) del Programa las Naciones Unidas para el Desarrollo (PNUD). Además, numerosos estudios empíricos en las sociedades occidentales demuestran que, superado cierto nivel de bienestar, un aumento de los ingresos ho tiene correspondencia directa con a unto de la felicidad (Ingle p. 171) produciéndose la lam los Y Semper, 2007b). Invacion rechman y Sempere, 2007). lesarrollade en paises ya desarrollados el crecimiento será lineal y bajo, y desde luego no el suficiente para resolver los problemas de desempleo. Algunos autores como Ricardo Almenar (2016) piensan que habrá que poner en práctica otras medidas como el sueldo minimo universal, el reparto del trabajo o la disminución de la jornada laboral. Otros como Jorge Riechmann, justo lo contrario, que a medio plazo, la minimización de fuentes de energía baratas con altas tasas de retorno energético (TRE), reducirá el numero de "esclavos energeticos»" (Riechmann, 2015) y, por tanto, aumentara la necesidad de trabajadores reales que suplan el trabajo que la disminución de potencia energética no pueda satisfacer. En cualquier caso, las empresas deberán adaptarse al decrecimiento buscando «beneficios óptimos y no beneficios máximos» (Linz, Riechmann y e, 2007b, pp. 15-17).

Economistas como Boulding, Nicholas Georgescu-Roegen y Daly desde los años 60 y Latouche y Naredo en la actualidad, vienen advirtiendo de estos hechos. La (eco)eficiencia (mejor aprovechamiento de los recursos) y la coherencia (uso de tecnologías compatibles con la naturaleza como la solar, eólica, etc.) no serán suficientes para cubrir los pronósticos de consumo de un modo completamente sostenible y para una población creciente (Linz, Riechmann y Sempere 2007a, pp. 7-10). Los escenarios futuros posibles se gradúan, según el Global Scenario Group (GSG), desde ignorar la situación y continuar creciendo al mismo ritmo (mundo convencional), (GS), desde ignorar la sich

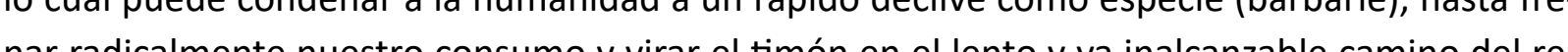

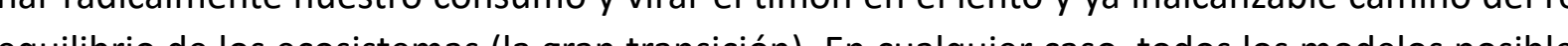
equilibrio de los ecosistemas (la gran transición). En cualquier caso, todos los modelos posibles entre estas dos opciones tienen dos puntos en común inevitables a estas alturas. El primero es
aceptar y asumir que se ha sobrepasado de forma irreversible el punto de equilibrio. El segundo, aceptar y asumir que se ha sobrepasado de forma irreversible el punto de equilibrio. El segundo, es consecuencia del anterior: la única forma de continuar en el planeta es decrecer. Así numerosos autores Riechmann (2004), Latouche (2009), Taibo (2011), Linz (2007a) proponen la ide del decrecimiento y la suficiencia (menor consumo de recursos y energia disminuyendo la demanda de bienes), Como una matriz de alternativas al crecimiento continuo. «El decrecimiento es el único debate que tiene sentido» dice Turiel (2017). La cuestión ahora es cómo decrecer, si rápidamente como en la primera opción, por agotamiento de los recursos, o lentamente, por adaptación a los nuevos escenarios, aunque no logremos de nuevo el reequilibrio y el colapso de nuestro actual sistema sea ya inevitable (Riechmann, 2014). Vamos a centrarnos en la segunda y menos probable, alternativa. Pero dicho camino nos exige un cambio drástico y urgente de cosmovisión, es decir, una auténtica revolución cultural, como anunciaba Guattari en Las tres ecologías (1996). Revolución que terminaría con la actual separación ciencia-humanidades y que colocaría a las artes y demás disciplinas humanistas entre los promotores de esa revolución. Esta cultura, en opinión de Guattari, no puede ser otra más que una cultura ecológica, que supere el papel de modelo y asimilada (1996). Sin embargo, estos cambios drásticos de inercia sociocultural son dif́ciles activar sin un detonante potente, especialmente en el caso de la crisis ambiental cuyos efectos son a veces minimizados por ser lejanos, invisiblizados o influidos por una visión nos efectos como muestra el docus por ser le the Flood (Fisher, 2016). El decrecimion
8 Para más información sobre los escena-
rios de futuro véase el trabajo de la red The Great Transition Initiative (GTI) en http:// rios originada en 2003 a partir del Global Scenario Group (1995) en http:///www.ggs. ca estos escenarios en tres tipos: Mundo con dos subtipos cada uno véase trambién

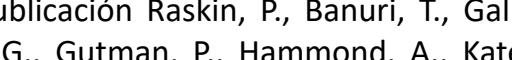
R. y Swart, R. (2006) La gran transición: La go de Chile: Naciones Unidas. Disponible Great_TransitionsSPANISH.pdf (Accedido: 20 de enero de 2018). 
tilo de vida que contesta al capitalismo (Taibo, 2011): apostar por lo local, lo pequeño, lo lento, Un Un desafío poco tentador para países emergentes seducidos por la publicidad del mundo occidental. Taibo alerta del cuidado que debemos prestar para no espantar a esos nuevos sectores de población en crecimiento (Taibo, 2011). Linz coincide en la preocupación y propone que ciertos sectores se verán atraidos por «un bienestar más equilibrado en curan y a benes, tiempoy relaciones; más autodeterminación, concordancia entre las convicciones y la propia vida» pero para el resto que no sea suficiente, propone afrontar este cambio de vida desde la perspectiva de recibir una «recompensa negativa: evitar pérdidas, alejar males» (Linz, Riechmann y Sempere, 2007, p. 14). Según afirma Linz, un gran número de importantes experiencias muestran que un estilo de vida autolimitado, lejos de considerarse una vida pobre, contiene facetas de gran atractivo.

La teoría del decrecimiento, el pico del petróleo y el colapso energético son ejes centrales de los proyectos de transición que están comenzando a aparecer en todo el planeta, como vere mos en el siguiente apartado. Pero el problema es que la crisis ecologica sigue siendo un tem marginal en las agendas políticas, incluso en periodos electorales como el vivido en España en 2016. Según Jorge Riechmann no parece realista pensar que el decrecimiento o el colapso vayan a formar parte de os programas politicos de ningun partido de peso actualmente, son muchas as inercias que habría que vencer previamente (2015). Como dijo un ministro francés de medio ambiente: «La crisis ecológica suscita una comprensión difusa, cognitivamente poco influyente, políticamente marginal, electoralmente insignificante» (Latouche, 2006, citado en Taibo, 2011, p. 139)

\subsection{RETOS Y OBSTÁCULOS PARA LA TRANSICIÓN A LA SOSTENIBILIDAD}

Hoy en día la transición es motivo de investigación desde distintos campos de estudio, sobre todo desde la gestión de sistemas, la innovación (social o tecnológica) y la gobernanza, entre otros. Es por ello que consideramos necesario aclarar a qué aspectos y contextos nos vamos a referir en este estudio. El origen del concepto de transición a la sostenibilidad se encuentra en el término The Great Transition (La gran transición), aparecido por primera vez en el libro de
Boulding El significado del siglo veinte-La gran transición ${ }^{9}$ (1964). La idea fue posteriormente arrollada por el $\mathrm{GSG}^{10}$ a lo largo de numerosos informes que cristalizan en el foro internacional Great Transition Initiative. Towards a Transformative Vision and Praxis ${ }^{11}$ (GTI). Actualmente es motivo de estudio para otras múltiples redes como Sustainability Transitions Research Network ${ }^{12}$, Transition Research Network ${ }^{13}$, centros de investigación como Leading Institute for Sustainability Transitions-DRIF en Holanda u organismos internacionales como la Unión Internacional de Conservación de la Naturaleza (UICN). En conjunto contribuyen a un creciente diálogo en torno a su teorización, modelización y puesta en práctica. El instituto DRIFT la define como «un proceso de cambio fundamental e irreversible en la cultura, las estructuras y las prácticas (institucionales) de una sociedad ${ }^{1 \text { t5 }}$. Por otra parte, la UICN en su informe de 2008 Transición a Sostenibilidad: hacia un mundo humanitario y diverso, hace un profundo análisis de la situación que hemos considerado central en este estudio y nos ayudara a conformar nuestra selección de casos. Este informe señala la necesidad de una revisión del concepto "desarrollo sostenible» así como de «sostenibilidad» e incluso del movimiento ambientalista, para superar los retos de esta era del Antropoceno definida por Paul Crutzen (Steffen et al., 2011). Desde la aparición del concepto «desarrollo sostenible» en la Estrategia Mundial de Conservación publicada por la UICN, World Wide Fund (WWF) y el Programa de Naciones Unidas para el Medio Ambiente (PNUMA) en 1980, el término «sostenibilidad» ha sido redefinido en diversas ocasiones (UICN et al., 2012) incorporando preocupaciones de distintos sectores. Des graciadamente, se comenta en este texto, en la actualidad, el desarrollo sostenible hace más hincapié en la ecoeficiencia, la tecnociencia 0 en políticas de regulación, que en incitar los verdaderos cambios en 1 orden glecos aue necesitas (Adams y Jeanrenaud, 2008; Riechmann, 2005a). Así, 38 años después,

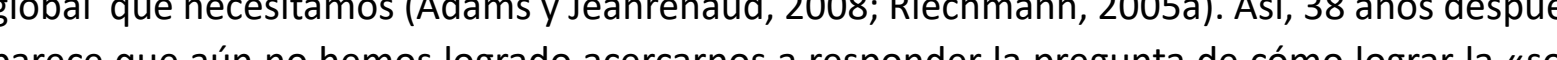
parece que aún no hom (Adams $y$

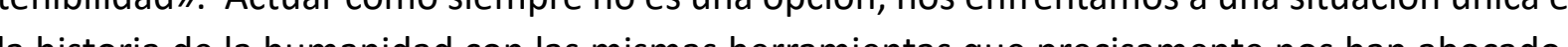

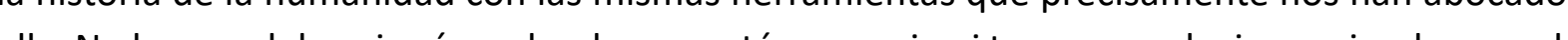
ella. No hay modelos nigulas sobre lo que está porvenir, ni tampoco soluciones simples o exclusivamente tecnológicas. «Los retos son muy grandes para un solo sector, pais o estrategia unica que los resuelvan (Adams y Jeannenaud, 2008, p. 2). Por ello, necesitamos actuar colectivamente, a todas las escalas desde individuos, comunidades $y$ gobiernos, $y$ desde todas las disciplinas, incluido el arte, para redefinir nuestros sistemas económicos, sociales y políticos ajustándonos a la urgencia y los límites reales del planeta.
9 Originalmente titulado: The Meaning
the 20 th Century - The Great Transition.

10 El Global Scenario Group (GSG) es un ficicos convocado en 1995 por el Institut para examinar las condiciones requeridas ra la transición hacia una sociedad glob sostenible. Ha evolucionado en el actual The
Great Transition Initiative GTII desde 2003
yen 2014 se ha reconvertido en un foro de discusión y debate y una revista de estudios .

11 Para más información véase http://www. 12 Véase en: https://transitionsnetwork. 13 Véase en: http $/ /$
chnetwork.org/

14 Véase en: https://drift.eur.n//about/ 15 Traducción de la autora del original: «A

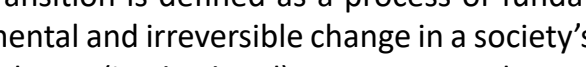
culture, (institutional) structures and prac-

16 El GSG coincide en esta necesidad (Raskin tal., 2006, p. 10). Para consultar anteriores el inform ADAMS WM 2006 The Future of Sustainability. Re-thinking Environment and Development in the Twenty-first Cen-
tury [en lineal. Gland, suiza: [Consulta: 21
enero 2018]. Disponible en: www. 1 .unc.org 
que dio lugar a un debate mundial disponi-
ble en_http:///cmsdata.iucn.org/downloads/ iucn__have_your_ary_pdf

17 Según Sennet comenta citando a Erik viduación: la cooperación es el fundamento
del desarrollo humano, en el que aprendemos antes cómo estar juntos que cómo estar separados" Esta afirmación ha sido
muy discutida en el último medio siglo pero "en el aislaindividuos» (Sennet, 2012, p. 29.

18 Aunque existe la versión en castellano
de 2006 que hemos utilizado, el original en tion The Promise and Lure of the Times

19 «Los evolucionistas son optimistas en
cuanto a que los rasgos dominantes que observamos hoy pueden traer prosperi-
dad, estabilidad y salud ecológica. Los cadad, estabilidad $y$ salud ecológica. Los ca-
tastrofistas temen que no se resuelvan las tales cada vez más profundas, con terri consecuencias para el futuro del mundo. miedos, pero creen que la transicición gstob puede ser enfrentada como una oportunidad para crear una mejor civilización. En
cierto sentido, representan tres mundos cierto sentido, representan tres mundos
diferentes: un mundo de ajuste paulationo, un mundo de cataclismo discontinuo $y$ un mundo de cambio y renovación
rall) (Raskin et al., 2006, p. 17). escrariamente una condena: podemos y debemos transformarla en una ocasión Deso eso nos exige pensar de otra manera sobre los valores de indual y lo colectivo, y en cierta forma nos convoca a reinventar lo colectivo. Riechmann, 2005a, pp. 8-9).

Pese a estar genéticamente dotados ${ }^{17}$ de habilidades cooperativas para el vínculo social Jo referido en la cita anterior ha de luchar contra la inercia global de la sociedad, puesto que tanto económica, como institucional y culturalmente, se tiende cada vez más al individualismo, a a traimiento, la indiferencia, la desafección y la homogeneización, lo cual debilita la disposición cooperación (Sennet, 2012).

Si aceptamos el reto colectivo de cambiar nuestros estilos de vida, la relación entre nosoperto de la UICN, el movimiento ambientalsta nec

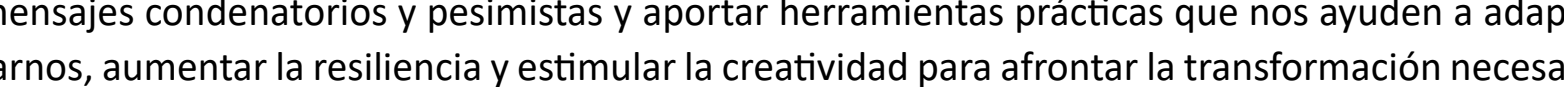
ría. Pero, ¿cuál es esa transformación?, ¿hacia qué debemos cambiar? Es muy importante tener clara una visión de hacía dónde queremos dirigirnos para comenzar la acción. «La visión más la intencionalidad son la libertad que nos lleva hacia adelante, tal como el pasado nos empuja para avanzar» (Raskin et al., 2006, p. 31).

Las investigaciones del GSG sobre los posibles escenarios futuros de transición han dado se analizan principalmente cuatro escenarios: «Fuerzas del Mercado, Reforma Política, Muno-Fortaleza y Gran Transicionn; que responden a tres corrientes principales de visión de nuestro futuro: evolucionista, catastrofista y transformacionista ${ }^{19}$. No entraremos a describir cada uno, pero baste decir que en esta investigación tendemos hacia el tercer escenario, el enfoque "Gran transición». Éste se construye sobre los rasgos generadores de riqueza del escenario «Fuerzas del Mercado» y sobre el cambio tecnológico propio de «Reforma Política» pero transciende a ambas $y$ añade un tercer ingrediente crucial para nosotros: un cambio de valores hacia de vida y mayor solidaridad social» (Raskin et al, 2006, p. 43). Esa transformación de valores

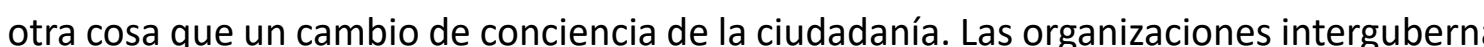
mentales, las corporaciones transnacionales, la sociedad civil y los ciudadanos comprometidos dispuestos en organizaciones no gubernamentales, pasan a ser fuentes de cambio claves para los nuevos valores que vislumbra el escenario «Grandes Transiciones» (Raskin et al., 2006, p. 47). Desde este estudio nos interesa especialmente este rasgo, pues es donde entrevemos un campo de acción y un papel de influencia para el arte y la cultura. Pero Raskin advierte de la falta de cohesión y visión positiva en el movimiento ciudadano espontáneo. Nos introduce la incertidumbre al respecto de la capacidad de esta fuerza de organizarse coherentemente y dirigir cambio desde la base hacia arriba. De ahí la importancia de redes como el MCT, que veremos en el capítulo tres y que tratan de autoorganizar esas voluntades.

Como hemos dicho, no hay respuestas únicas y definitivas que nos guien, pero ante los retos del cambio climático y el colapso energético, organismos como la UICN han perfilado un hoja de ruta de la transición que tomamos como guía de este estudio. Asimismo, veremos cómo surgen en la sociedad civil respuestas espontáneas en la línea de la transición a la sostenibilidad. Todo ello nos servirá para perfilar nuestros criterios de selección de casos de estudio posteriormente. En el informe Transición a la Sostenibilidad: hacia un mundo humanitario y diverso de 2008 la UICN perfila y justifica las transformaciones necesarias:

QUÉ: Los tres retos esenciales de la transición son:

1. El desafío de descarbonizar la economía mundial:

- Reorganización de los patrones actuales de consumo mundial a formas menos destructivas, mediante la reducción del uso de recursos naturales y especialmente los combustibles fósiles;

- Reducir el consumo de energía a niveles que puedan ser sostenibles;

- Redistribuir la riqueza hacia los menos favorecidos.

2. El desafío de comprometer el movimiento ambiental con la justicia y la equidad global.

3. El desafío de la conservación, de defender la vida y la biosfera: 
PORQUÉ: Ya hemos visto en el apartado 1.1 algunos de los problemas a los que nos enfrentamos. La UICN añade a estos retos anteriores, una larga serie de situaciones e inercias superar, entre las que destacamos (Adams y Jeanrenaud, 2008, pp. 34-52):

1. No hemos desligado el uso de energía de la emisión de carbono, ni el crecimiento económico del aumento del consumo de combustibles fosiles. Los avances en energias renovables no pueden satisfacer el nivel de consumo desenfrenado actual ni futuro. En general, los avances en tecnología han demostrado producir un efecto rebote aumentando el consumo de recursos y energía.

2. El reto de proveer de medios de vida sostenibles a todos los habitantes del planeta, implica aprender a desarrollarnos equilibradamente sin desfavorecer a terceros ni daña a las generaciones futuras. Las desigualdades en el reparto del poder dificultan el diálogo con todas las partes y la diversidad en el desarrollo de soluciones alternativas. La visión ecológica no puede implantarse desde arriba a abajo únicamente -al estilo de determinada izquierda política ${ }^{20}-$, y debe incluir las voces de los menos favorecidos que no están apenas representadas en los organismos de poder ni en las decisiones empresariales. Lamentablemente ni la desigualdad ni la sostenibilidad son los temas más importantes en las agendas políticas del primer mundo, sino la economía. Por todo ello se requiere que el ambientalismo aborde seriamente su compromiso con la justicia, la equidad y la lucha contra la pobreza. Pero no olvidemos que el crecimiento económico tampoco equivale a disminución de la desiguadad: cla inequidad ha crecido durante la un da. Durante lum

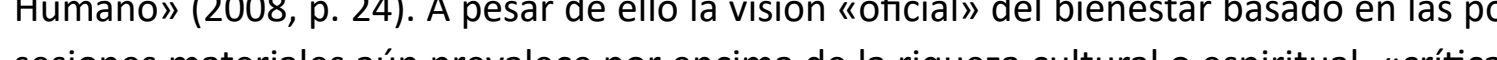
sesiones materias aun prevalece por encima de la riqueza culcural o espiritual, «criticas para el bienestar he hacia bostenibilidad $(2008, p, 49)$ hacia la sostenibilidad» (2008, p. 49)

3. Se hace indispensable superar la desconexión con la realidad biofísica para asumir nuestra «ecodependencia e interdependencia» y romper esta «burbuja cultural» en la que vivimos gran parte de la población (Riechmann, 2014, p. 94). A la par, se requieren nuevas (a) de especies (amenazadas o no), aplicadas a los distintos contextos de desarrollo y al clim cambiante, que se combinen y no comprometan las posibilidades de mejora del bienestar de países en desarrollo. La conservación no debe implicar expulsión de poblaciones, aislamiento o desigualdad sino todo lo contrario, trabajar con todo tipo de gente del lugar para vincular las necesidades humanas y las del ecosistema, una vision que hasta ahora no se ha practicado tanto como se deblera segun el texto de la UICN. A pesar de los cuantiosos estudios que señalan el paralelismo de la diversidad cultural y lingüistica con la biodiversdad, sigue siendo necesario remarcarlo para crear estrategias conjuntas de conservación.

Cómo: La gran pregunta reside en cómo conseguir estos desafíos salvando los obstáculos anteriores y con la información y herramientas de que disponemos. Cambiar nuestros esquemas de vida y aprender a vivir bien con menos, no es algo deseable ni atractivo para la población general y exige además un enorme esfuerzo de creatividad:

Plantearse el problema de una nueva sociedad equivale a plantearse el problema de una creación cultural extraordinaria. La pregunta que yo os hago es si tenemos
ante nosotros algún signo precursor y premonitorio de esa creación cultural. Castoriadis, citado en Fernández Casadevante, 2015, p. 1)

¿Cómo construir una nueva economía mundial, una nueva arquitectura del sistema, cómo ejuvenecer el movimiento ambiental global e inspirar las transiciones hacia la sostenibilidad? La UICN en el citado informe de 2008 aporta varias claves, entre las que destacamos (Adams Jeanrenaud, 2008, pp. 58-96)

1. Utilizando métodos de medición que incluyan las externalidades de los procesos industriales, económicos y sociales como la «huella ecológica» concebido inicialmente por William Rees y Mathis Wackernagel en $1990^{21}$.

2. Actuando tanto global como localmente: apoyando los movimientos sociales de base 
22 La idea de mantener la economía global
y solamente reducir las emisiones resulta atractiva para las grandes corporaciones,
es decir, intenta ser absorbida por el mercado, y por eso las medidas hacia la dism patrón Top-Down (desde mientras que las medidas contra el Peak $O$ tienden a seguir un patrón claramente Bot-
tom-Up (desde la población) (del Rio, 2009,
p. 18).

23 Aunque el término resiliencia en origen procede del campo de la fisica, (capacidad
de un material de recobrar su forma original después de someterse a una presión deformadora) fue incorporado a las ciencias sociales hace más de 50 años (Becoña, de que no hay un complete acuerdo sobre su definición desde el campo de la psicologia (Becoña, 2006) citamos aquí un par de la más aceptada es la de Garmezy slác copacidad para recuperarse y mantener un conducta adaptativa después del abandono estresante» (1991, p. 459). Y otra definición ntos adversos, y ser capaz de tener un desarrollo exitoso a pesar de circunstancia muy adversasm) (2006, p. 125 . La resiliencia
tiene que ver con la flexibilidad, la creatividad, el optimismo, la improvisación, la
habilidad, la adaptabilidad, la resistencia y la capacidad. Se diferencia de la recuperamantener un equilibrio estable en el tieara pese al trauma (Bonanno, 2004). En cuanto turación, un aprendizaje, un crecimtento y local, autofinanciados, autoorganizados, innovadores, prácticos, sensibles y resilientes como los grupos de consumo, las monedas locales, el MCT o las Redes de Acción Globa (RAM) que sin ser agentes de la política institucional, logran éxitos locales allá donde las políticas públicas y los gobiernos no llegan ${ }^{22}$. Esta cooperación comunitaria responde a modelo que plantea Sennet de izquierda social, un modelo dialógico qué busca la diversidad y la integración más que la homogeneidad y la igualdad (Sennet, 2012). Señala Riechmann la importancia de no arrinconar la ética al ámbito individual sino que «la política se concibe como la ética de lo colectivo» (Riechmann, 2014, p. 14). Actuar colectivamente es actuar políticamente.

3. Aceptando que la diversidad cultural es parte integral de la conservación ya que la mezcla de diversos elementos genera nueva creatividad y energía, así como nuevas ideas prácticas.

4. Aumentando la resiliencia ${ }^{23}$, es decir la capacidad de los sistemas de absorber perturbaciones, experimentar cambios y reorganizarse reteniendo sus funciones principales y su abjo (empresas y gobierno en todas as escalas, desde lo local en la ciudad, a lo nacio y supano

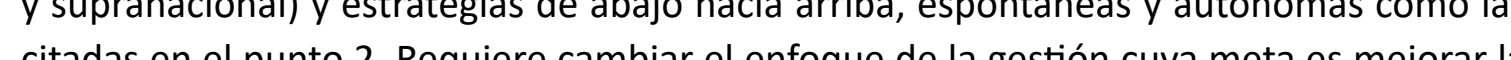
cladas en el pu to 2. Requere cambiar el enfoque de la gestion cuya meta es mejorar la eficiencia, por una gestion más desa faste y abienta al mpredecible futuro, que asuma la naturaleza dinámica del mundo y valore el papel de la diversidad biológica y cultural.

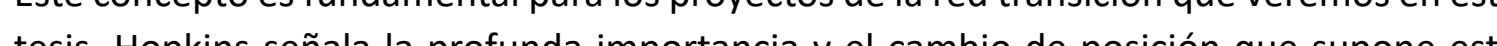
tesis. Hopkins señala la profunda importancia y el cambio de posición que supone este punto. No solo basta con que la comunidad sea menos dependiente, sino que necesita aumentar su capacidad de responder creativamente a los cambios ${ }^{24}$.

A lo largo de este estudio se pretende contestar a la cuestión del cómo mediante ejemplos Araxis reales de transición a la sostenibilidad, profundizando en los puntos dos, tres y cuatro $y$ concenta Como decíamos en la introduccín necesitamos mostrar ejemplos reales de nuevos modelos de vida, así como nuevos relatos, para ampliar el imaginario de nuestros tiempos. En otras

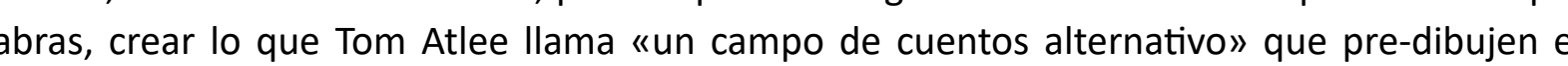
desea riodistas (Hopkins, 2008a). A nivel de práctica local, como señala Hopkins, fundador del MCT, los Transition Tales (Cuentos de Transición) tienen un papel señalado: crean representaciones para que la comunidad visualice sus objetivos, «cómo llegar hasta ellos y qué podría ocurrirles en el camino» (Brangwyn et al., 2010, p. 29). Esa visión ayuda al grupo a focalizar sus energías, entusiasmarse, aclarar sus objetivos e inspirar a otros grupos y personas ${ }^{25}$. Para ejemplificar con proyectos prácticos este nuevo modo de habitar el planeta, nos ha sido de utildad estudiar Movimiento de Ciudades y Pueblos en Transición (MCT). Dentro de esta corriente se desarrolla algunos de nuestros casos de estudio, y por ello pasamos a introducirlo en el siguiente apartado.

\subsection{EL MOVIMIENTO DE CIUDADES Y PUEBLOS EN TRANSICIÓN: PRINCIPIOS, DESCRIPCION}

Según confirma Juan del Río, cofundador y coordinador de la Red de Transición española dentro del amplio concepto de transición se sitúa el Movimiento de Transición, que ha tenido dentro del a lo conico ción personal 13 de diciembre de 2017). Uno de los motivos por los que esta investigación se ción personal, 13 de diciembre de 2017). Uno de los motivos por los que esta investigación se

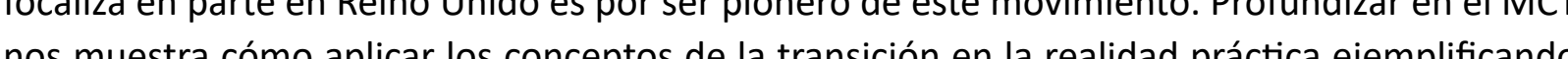
nos muestra cómo aplicar los conceptos de la transición en la realidad práctica ejemplificando el principio de "pensar globalmente actuando localmente» (Brangwyn et al., 2010, p. 8). Se trata de un movimiento positivo y de enfoque holistico que se cimenta sobre la idea de colabo rar colectivamente para disminuir el consumo de energía y recursos de la comunidad, apostar por la producción local para ser más resilientes y asi afrontar con mayor éxito dos problemas fundamentales: el colapso energético y el cambio climático. Surge en Iralanda en 2005 durante las actividades del master de permacultura de la Universidad de Kinsale, impartido por Ro Hopkins. Este profesor propone aplicar los principios de la permacultura a la comunidad loca elaborando colectivamente un plan de descenso energético para Kinsale 2021. A continuación pone en marcha la iniciativa de Totnes, (Inglaterra) en el año 2006 (Brangwyn et al., 2010, p. 11). Según sus ideólogos, el MCT se diferencia de otras corrientes ambientalistas en las ideas que se exponen en la tabla 1 elaborada por el propio Hopkins. Él mismo admite la generalidad con que describe en esta tabla el ambientalismo convencional $-\gamma$ que no compartimos en esta tesis-

cia es un rasgo intrinseco (Garcí-Vesga y
Dominguez-De La Ossa, 2013). Se diferencia en que ésta se refiere a verimplicasions perando el potencial propio que se tenía en el momento del percance estresante (Gar-
cía-Vesga y Dominguez-De La Ossa, 2013, p.
Go) 24 Por ejemplo, explica Hopkins, la comu-
nidad puede reducir su dependencia de los
envases plásticos además de reciclar los que usen. Sin embargo el reciclado y encomunidad. Sería más provechososo que los pocos residuos plásticos generados se utili-
cen para algo útil en esa comunidad (como aislante, en construcción), aumentando su de árboles: es beneficioso para el entorno aumentar las zonas verdes en número $y$ dicación especies comestibles que den frutos a la vez (Hopkins, 2008a).

25 Desde la Red de Transición se señala tables. Incluso puede haber visiones conque nos depara el futuro es incierto. Resulta, pues, más ventajoso jugar con varias
visiones eir adaptándolas al ritmo de los
acontecimientos.

26 Véase: http://www.reddetransicion.org/ El lugar del arte en el contexto de la crisis ecológica. Nuria Sánchez León 
27 Traducido por Doly García de Hopkins, pero nos resulta útil citarla para distinguir la propuesta particular del MCT de otros movimientos y mostrar sus puntos en común y especificidades. A destacar la mención al arte, la cultura y la linea]. s.l.: s.n. [Consulta: 2 julio 2017 ] Disponible en: http://www.ecohabitar.org/ wp-content/upload $/ 2$
DeTransicion.pdf.

28 Véase: https://transitionnetwork.org/ transition-near-me/initiatives/ creatividad cómo herramientas de transición.

\begin{tabular}{|l|l|}
\hline \multicolumn{2}{|c|}{$\begin{array}{c}\text { Diferencias entre la propuesta de las iniciativas en transición y otras } \\
\text { propuestas ambientales }\end{array}$} \\
\hline \multicolumn{1}{|c|}{ Ambientalismo convencional } & \multicolumn{1}{c|}{ Enfoque iniciativas en transición } \\
\hline Comportamiento individual & Comportamiento colectivo \\
\hline Un solo tema & Holística \\
\hline $\begin{array}{l}\text { Herramientas: grupos de presión, } \\
\text { campañas y protestas }\end{array}$ & $\begin{array}{l}\text { Herramientas: participación pública, eco-psi- } \\
\text { cologia, arte, cultura y educación creativa }\end{array}$ \\
\hline Desarrollo sostenible & Resiliencia - relocalización \\
\hline $\begin{array}{l}\text { Miedo, culpa, y choque como motores de } \\
\text { acción }\end{array}$ & $\begin{array}{l}\text { Esperanza, optimismo y proactividad como } \\
\text { motores del cambio }\end{array}$ \\
\hline $\begin{array}{l}\text { Cambiar política nacional e internacional } \\
\text { mediante grupos de presión }\end{array}$ & $\begin{array}{l}\text { Cambiar la política nacional e internacional } \\
\text { haciéndolas elegibles }\end{array}$ \\
\hline El hombre de la calle es el problema & El hombre de la calle es la solución \\
\hline Campañas generales & Intervenciones específicas \\
\hline Un solo nivel de compromiso & Compromiso a una variedad de niveles \\
\hline $\begin{array}{l}\text { Prescriptivos - proponen sus propias res- } \\
\text { puestas }\end{array}$ & $\begin{array}{l}\text { Actúa como catalizador-no hay respuestas } \\
\text { fijas }\end{array}$ \\
\hline $\begin{array}{l}\text { Cálculo del impacto del dióxido de } \\
\text { carbono }\end{array}$ & $\begin{array}{l}\text { Cálculo del impacto del dióxido de carbono e } \\
\text { indicadores de resilienciaa }\end{array}$ \\
\hline $\begin{array}{l}\text { Creencia de que el crecimiento económico es } \\
\text { todavía posible, aunque un crecimiento más } \\
\text { verde }\end{array}$ & $\begin{array}{l}\text { Diseño de un renacimiento económico aun- } \\
\text { que local }\end{array}$ \\
\hline
\end{tabular}

1. Fuente: The Transition Handbook by Rob Hopkins (Hopkins, 2008b) 27.

En la Guía esencial para hacer la transición de 2016 se afirma que está formado por más de 1.400 iniciativas en más de 50 países (Hopkins y Thomas, 2016, p. 5), aunque no todas están registradas en el censo que lleva a cabo la Red de Transición transition network $k^{28}$, por lo que no es posible actualmente dar una cifra exacta del número de iniciativas. En España, según un estudio de Lorenzo Chelleri (Urban Resilience Research Network (URNet) Universitat Internacional de Catalunya) y del Río (Red de Transición), llamado: «La transición en España: una primera evaluación de las dimensiones, retos y oportunidades para las iniciativas de ciudades en transición ${ }^{29}$, resulta complicado hacer un recuento del número total de proyectos debido a varios factore $^{30}(2017$, p. 33)

29 Traducción de la autora del original: Tor Transition Town Initiatives.

30 Entre ellos mencionamos: informalidad proyecto dentro de otro proyecto mayor

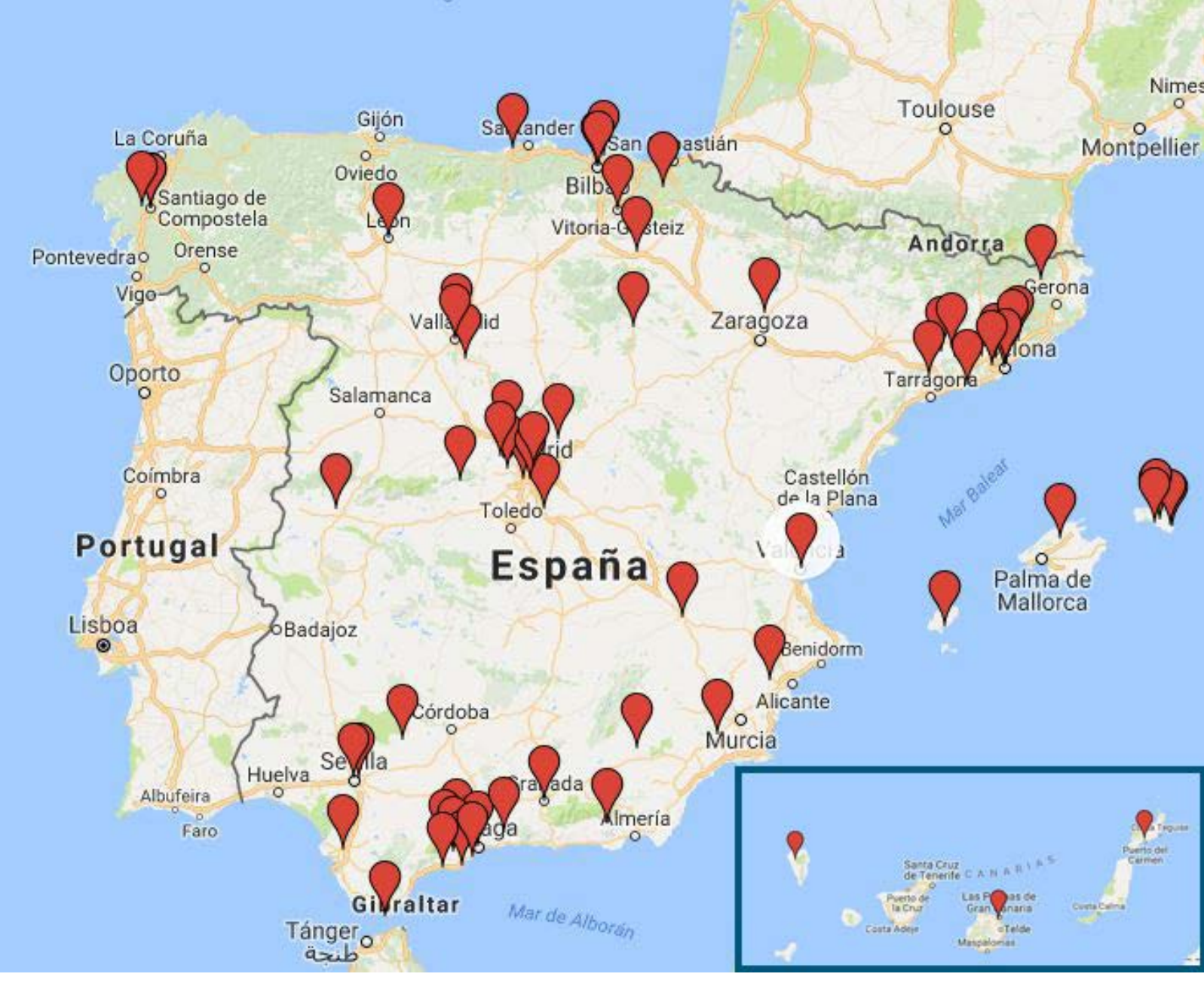

Imagen 1. Mapa de las iniciativas locales de transición en España de 2008 a 2014. Fuente: Red de Transición espa-

Debemos señalar en este punto que no hay actualmente un organismo que conceda un es- 

y 2014 (2017, p. 36). De estas, dieciocho inclativas han sido estudadas ms profun 2010 velias

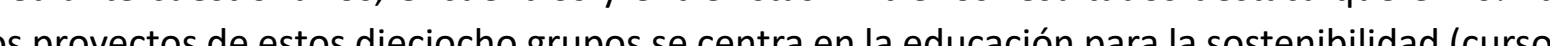
los provectos de estos deciocho grupos se centra en la educacion para la sosten billad (cursos, meriendas, video forums, charlas,...), siendo la actividad más común tanto en Lspana como en Reino Unido (Haxeltine y Seyfang 2009, p. 11). Por otra parte el $30 \%$ se relacionan con la producción de local/ecologica de alimentos (ya sean huertos, grupos de consumo, gallineros comunes, mercados locales,...), algo frecuente según Rob Hopkins señala en el documental In transition 2.o. Sin embargo, los planes de descenso energético, monedas locales, bancos de tiempo y otras propuestas son menos frecuentes (Chelleri y del Río 2017, p. 38-39).

Otras ideologías de base como ésta rechazan establecer alianzas con los organismos públicos, sin embargo, este movimiento se caracteriza por su tendencia hacia conectar con las instituciones, entendiéndolas como facilitadoras del proceso, aunque debemos admitir que en spaña solo un tercio de los proyectos estudiados han recibido algún tipo de soporte institucional (Chelleri y del Río, 2017). Otra de las barreras mas comunes que llama nuestra atención es la (Chelleri y del Río, 2017, p. 42) en comparación con las tendencias observadas en Reino Unido, donde el organismo público Arts Council England $d^{32}$ ha financiado proyectos artísticos de iniciativas de transición como The Trashcatchers Carnival que veremos en el capitulo tercero.

Entre las críticas a las iniciativas de transición desde otros grupos y activistas, como el coectivo Trapese de Reino Unido, destacan: la falta de posicionamiento político, la escasa crítica a poder, no ataque a la raíz del problema de los combustibles fósiles ni apoyo a los movimientos que luchan contra las grandes compañías, y la alianza con las instituciones en lugar de enfrenta al statu quo, entre otras (del Río, 2009, pp. 34-39). Para Hopkins, sin embargo, la estrategia de la confrontación y la separación no es la opción apropiada. Es más partidario de fomentar el empoderamiento de la comunidad que explore su propio cambio, y lo proponga a las instituciones en lugar de enfrentarse al poder. No pierden de vista los problemas globales ni las incoherencias de capitalismo, pero deciden confrontarlo de un modo práctico, cotidiano y local como la moned de Totnes, los huertos comunitarios, o las plantaciones de árboles frutales en la ciudad, entre . The con Hopkins como con del Río, que comenta al respecto:

[...] yo creo que la critica es desde la transformación que promueve, y eso, me parece que es muy complementario a otro tipo de critica, más discursiva, más política, etcétera. Para mi, el Movimiento de Transición es muy político, pero es otro tipo de politica. Desde el momento que tú estás proponiendo que quieres cambiar la manera en la que produces, en la que consumes, en la que te organizas, estamos hablando de transformar, eso es muy político. [...] cuando hay algo nuevo pues cuesta un poco, hay ciertas reticencias por parte de algunos colectivos y algunas personas yeso puede ocurrir por ambas partes. Pero yo creo que cada vez hay más colaboración más sinergia, entre estas dos propuestas (decrecimientol y otras como la permacultura las ecoaldeas y todo se empieza a entender, cada vez más como partes de algo más grande (J. del Río, comunicación personal, 13 de diciembre de 2017).

In definitiva, pensamos que el reto de la sostenibilidad puede y debe enfrentarse desde una gran diversidad de posiciones, siendo unos movimientos y otros complementarios. Las Inciativas de transición parten de cuatro supuestos básicos:

1) Asumir que es imposible un crecimiento infinito dentro de un sistema cerrado y que el descenso energético parece inevitable, por lo que debemos aprender a vivir reduciendo nuestro consumo y planificar nuestra adaptación.

2) Aumentar la resiliencia ${ }^{33}$ de nuestras comunidades ante los efectos del pico del petróleo y el cambio climático.

3) Necesidad urgente de actuar localmente en todas las estructuras sociales.

4) Importancia de actuar colectivamente para construir formas de sociedad más conecadas, más enriquecedoras y que reconozcan los límites biológicos del planeta (Hopkins, 2008a, p. 120; Scotti, 2008, p. 41). 
36 Por ejemplo: In transition 1.o; In transicoperativas de todo tipo, entre otros proyectos. Constituyen un uconjunto disperso de préticas y principios de muldo real, que se ha ido constuye la observación y mundo real, que se han ido construyendo a lo largo del tiempo a través de tion 2.0; Stop rodando el cambio; Voices of
transition entre tantos otros. . han con han comenzado a recopilar estas experiencias. Destacan los libros de Hopkins en los que explica cómo la acción local puede cambiar el mundo, como: The power of just doing stuff(2013), The Transition Companion. Making your Community More Resilient in Uncertain Times (2011) exitoso Hand Book Transition Towns, from Oil Dependency to Local Resilience (2008), traducido como Compendio de iniciativas de transición (2010) y escrito por Ben Brangwyn y el mismo Rob Hopkins. En las publicaciones mencionadas también se analizan las fases de la transición e incluso se organizan cursos preparatorios en base a la experiencia de grupos anteriores que previenen tropiezos frecuentes.

La transición es una actividad sumamente creativa y abierta, que depende de la imagi-

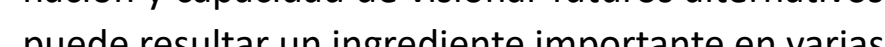
puede resultar un ingrediente importante en varias de sus fases, ya sea porque nos inspira para imaginar una vision atractiva que impulse al grupo, o bien para materializarla, para crear espacios de relación, o por su capacidad de emocionar y generar empatía. Muchas iniciativas de transición incluso llegan a formar su propio grupo artístico, como Transition Town Totnes Arts Groups (TTTAG) o el grupo de Transition Town Romsey. La actividad artística relacionada con la transición en Reino Unido ha sido estudiada por la creadora británica Lucy Neal en colaboración con otros autores ${ }^{38}$, y recogida en el libro Playing for time. Making Art as if the World Mattered (2015). En el mismo se recopilan hasta 69 proyectos que responden a los principios de lo que ha venido a denominar de modo pionero transitional art y que se explicarán más a fondo en er capítulo dos. En España, previo a nuestra selección de casos de estudio, hemos sondeado diversas iniciativas en activo para detectar aquellas en las que el arte ha tenido cierto papel. Resulta significativo estudiar el escaso número y las funciones atribuidas al arte ch cada una desulta ciativas resistradas en la Red de Transición españos. Por tanto, en nuestra selección y a ásisis de casos no nos es útil Red de Tran

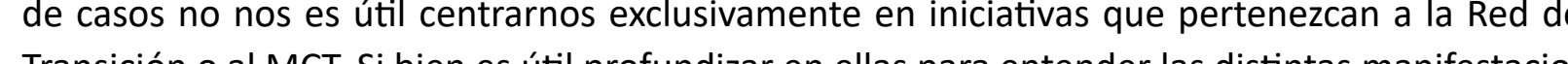

nes que están ocurriendo, entendemos su idiosincrasia como una categoría dentro del amplio a banico de la transición. Aunque este fenómeno se ha propagado por numerosos países en muy poco tiempo gracias a tecnologías como internet o documentales como In transition 1.0 y 2.0 debemos ser conscientes de su relativa importancia dentro del extenso margen de opciones de transición existentes. En nuestro análisis, por tanto, optaremos por iniciativas dentro y fuera de MCT que trabajen en elobjetivo de acercanos a los rets de la transicion (en sentido amplio) ya señalados, además de otros criterios que detallaremos en el apartado «Área de estudio y criterios de selección» del capítulo dos.

\section{ESTADO DE LA CUESTIÓN}

2.1 EL PAPEL DEL ARTE EN EL DESARROLLO DE LA CONCIENCIA AMBIENTAL: EMOCIÓN, EMPATÍA Y LENGUAJES ARTíSTICOS

Arte y emoción son conceptos tradicionalmente asociados para el público, pero la educiencia ecológica. Sin embargo, el nacimiento del arte ecológico ha corrido paralelo al del pensamiento ecologista desde los años 60. Artistas como Helen Mayer y Newton Harrison, Agnes Denes, Hans Haacke o Alan Sonfist supieron ver el valor de la apreciación estética como activador del campo simbólico y emocional, lo cual supone una importante vía para la sensibilización ambiental. Pero, ces cierto que el arte, la imagen o la experiencia estética pueden activar otras zonas del cerebro? ¿Hasta qué punto la creación artística puede modificar nuestras conciencias $y$ traducirse en transformaciones comportamentales duraderas?

En este apartado mencionaremos, muy brevemente, el origen de la consciencia en el ser humano guiados por Tonia Raquejo investigadora e historiadora del arte de la Universidad Conplutense de Madrid y a la luz de las investigaciones de psicólogos como Julian Jaynes o antropologos como Roger Bartra, entre otros. Revisaremos cómo se imbrican y retroalimentan cultura y lenguaje gracias a la plasticidad de nuestro cerebro, para crear nuestra consciencia. Pasaremos a destacar la función de la emoción y la empatía en el despertar de la conciencia ecológica, y el 
39 Asi, a pesar de que la Ecología, como papel de los distintos lenguajes artísticos para la necesaria revolución cultural que el paradigma
rama de la Biologia primero, ya se habia empezado a estudiar por Lamarck y otros, no fue hasta 1869 cuando Ernst Haeckel puso nombre al complejo sistema de relaciones una nueva disciplina que se considerará en como disciplina en sí misma, por su espelos organismos con el entorno y viceversa. Pero fueron necesarios dos pasos previos primero, que la teoría de la evolución de
Darwin pusiera de manifiesto la influencia del ambiente en los seres vivos $y$, segundo,
que Lamarck definiera la Biologia, para que la ciencia reconociera la importancia del es
tudio de las relaciones con el entorno, y se tudio de las relaciones con el entorno, y se
nombrara la Ecología como disciplina en si misma.

El corazón de la crisis ecológica actual se encuentra una terrible falta de

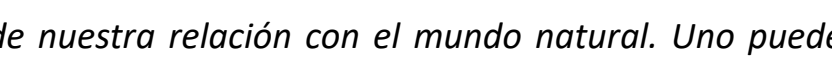
por supuesto afrontar el fracaso de forma racional y empiricamente; pero las artes (en particular las artes visuales) ofrecen diferentes perspectivas sobre esa relación y tocan a las personas de manera que la educación convencional y la defensa rara vez pueden hacer (Jonathon Porritt, citado en The Chartered Institution of Water and environmental management, 2012, p. 34)

Para comenzar conviene aclarar, según explica Tonia Raquejo, que «la consciencia no se aberga, pues, en ningún espacio anatómico, es un espacio mental que funciona como un operador que procesa funciones analógicas» (Raquejo, 2015, p. 61). La consciencia integra las distintas áreas cognitivas y nos permite procesar la información antes de tomar una decisión o reaccionar a un impulso. En la creación de la conciencia ambiental queremos llamar la atención sobre dos procesos de ran la creación de la conciencia ambiental queremos llamar la at enciona ción y la emoción . El primero consiste en identificar las causas, consecuencias, agentes y faccolon y la emocion. El primero consiste en identificar las causas, consecuencias, agentes y factores que conforman la crisis ecológica y designarlos de modo reconocible. La importancia de identificarlos y nombrarlos es crucial para que entren en el imaginario popular y se introduzcan en la cultura. Según el psicólogo Julian Jaynes, autor de El origen de la conciencia en la ruptura de la mente bicameral (1976), la conciencia y el lenguaje se desarrollan conjuntamente. A cada nueva percepción, corresponde un nuevo término, y cada nuevo término habilita nuevas percepciones e intenciones, de modo que cultura y lenguaje se traban entre $s^{39}$ (Jaynes 2000; citado en Raquejo, 2015, p. 63). De esta manera se construye la cultura, a través de las observaciones del mundo y la identificación de conceptos y su designación, que facilitan la asimilación por nuestros cerebros. Además, el cerebro humano tiene la gran cualidad de ser plástico y no una estructura fija, como se pensaba hasta mediados del siglo XX, modelándose en función de huevos planos de conciencia. Ahondando más en la cuestión, resalta Roger Bar «hay estructuras cerebrales que requieren de los sistemas culturales para desarrollarse, de ahi a capacidad plástica del cerebro» (Bartra 2006; citado en Raquejo, 2015, p. 62). De modo que un cambio cultural produce cambios en el cerebro y viceversa. Según Kathinka Evers, investgadora principal en el Centro de Ética y Bioética de la Universidad de Uppsala, el cerebro es un órgano plástico, variable, dinámico, que ha evolucionado en simbiosis con la sociedad y la cultura (Evers, 2010). No hay dos cerebros iguales, ni siquiera en gemelos monocigóticos, y no está predeterminado su desarrollo sino que depende de las experiencias vividas (Fajardo, 2005; Gloria y Vega, 2003). Nos basamos, por tanto, en estos estudios para sustentar la hipótesis de que el arte, como acto cultural, puede producir cambios en los circuitos cerebrales y por ende en la conciencia ambiental.

Pero no es la única vía, el segundo proceso importante en la creación de la conciencia ecológica es la emoción. Son muchos los centros de investigación que se han percatado de la importancia de la emoción en los procesos de aprendizaje y asimilación, como el Centro de Neurociencia para la Educación de la Universidad de Cambridge (2005). Tambien numerosos investigadores como Francisco Mora, doctor en Neurociencia por la Universidad de Oxford y caedrático de Fisiología de la Universidad Complutense de Madid, a firma que: «sin emoción no hay curiosidad, no hay atención, no hay aprendizaje, no hay memoria. [...] La atención, ventan del conocimiento, despierta cuando hay algo nuevo en el entorno [...], algo que puede significar recompensa (placer) o castigo (peligro) y que por tanto tiene que ver con nuestra propia vida (Mora, 2013, citado en López, 2013). Evers también señala «la emoción como la actividad capaz de despertar a la consciencia» (Evers, 2010; citado en Raquejo, 2015, p. 62) y añade que, «no hay consciencia si no hay emoción y ésta se genera con la experiencia» (Evers, 2010, citado en Raquejo, 2015, p. 68). La experiencia estética y la emoción son ingredientes clave de toda obra artística. ¿Puede entonces la obra artística despertar la curiosidad hacia un nuevo conocimiento a través de la estética y la emoción? La investigadora y profesora en medio ambiente y filosofia de la Universidad de Edimburgo Emily Brady incorpora la teoría kantiana $a^{40}$ (contemploción

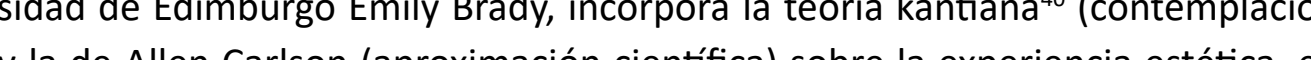
un (

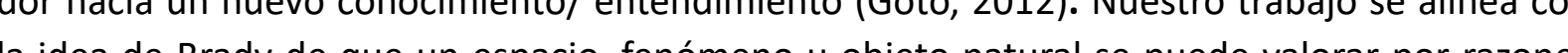
la idea de Brady de que un espacio, fenómeno u objeto natural se puede valorar por razones na información, realista y veraz es imprescindible para tomar las medidas adecuadas (González
40 En la teoría Kantiana el valor estético del del ambiente natural. 

41 Traducción de la autora del original: Reyes, 2018) pero no está separada de la emoción, como señala el neurólogo Antonio Damasio, sino
«"Knowing what you know" becomes a
que se piensa sintiendo y se siente pensando (Damasio, 1994).

conscious processes rather than one of
conscious logical fact-driven analysis, as as sumed in the rational decision making pro-
cesses that underlie the scientific method».

42 Traducción de la autora: Plein Air: el impulso estético-ético.

De modo que, la combinación de nuevos conocimientos y emoción estimula el aprendizaje el desarrollo de la conciencia. La razón, por sí sola, no bastaría para promover el cambio como confirman el investigador Roger Boyd ${ }^{41}$ "Saber lo que sabes" se convierte en un proceso mediado por a I métodis (2015, 0.14). Esto nos Ieva a cai) (2015, p. 14). Esto nos lleva a senalar que una de las herramientas que el ecologismo y el arte pueden emplear para nostima con algunos animales como los primates, que nos permite percibir las emociones, sentimientos $\mathrm{e}$ ideas de los demás y compartirlas. La empatía (del griego $\varepsilon \mu \pi \dot{\theta} \theta \varepsilon \varepsilon$, cualidad de sentirse dentro) es un constructo amplio para el cual existen dos enfoques contrapuestos, el cognitivo y el afectivo, es decir: si la empatía consiste en «ponerse en el lugar del otro» siendo uno mismo o, por el contrario, hace referencia a sentir las emociones con la adopción de la perspectiva del prójimo, imaginando construyendo el estado mental del otro (Fernández-Pinto, López-Pérez y Márquez, 2008, pp. 284 285). En cualquier caso, actualmente se acepta que comporta un componente cognitivo y otro afectivo, según el marco teórico de Mark H. Davis (1996), siendo procesos disociados tanto funciona como neurobiológicamente (Filippetti, López y Richaud, 2012). Los investigadores interesados en la empatía han encontrado relaciones positivas entre «empatía e intensidad emocional, [...] sociabilidad, autoestima, eficiencia intelectual, flexibilidad, [...] disposición a mostrar conducta de ayuda y tendencia a la afiliación» (Fernández-Pinto, López-Pérez y Márquez, 2008, p. 290).

La empatía es una habilidad que para desarrollarse ha de ser aprendida desde la infancia mediante procesos sociales. Es dependiente de la cultura y de la experiencia. Siguiendo a Raquejo, transportarnos a otras realidades o ficcions que la capacidad del arte de imagn na lia piel de otros desarrolla la empatía y. por tanto, el aprendizaje y la conciencia. De hecho, algunos autores señalan que «la identificació emocional es mucho más sólida que la comprensión racional») (Albelda y Sgaramella, 2015, p. 14) y que las personas muestran mayor empatía hacia los relatos e imágenes que hacia las cifras y estadísticas (Slovic y Slovic, 2005). Un ejemplo de proyecto basado en la vivencia multisensorial para fomentar la empatía es Plein Air: the ethical aesthetic impulse $e^{42}$ (2010), de Reiko Goto y Tim Collins. En esta obra cobra particular importancia la empatía (hacía los árboles) colno estudio critico de obras de arte ecológico, y constituye el núcleo central de la tesis doctoral de Relko Goto titulada: Ecologia y arte ambiental en el espacio público: ¿no te tomarás un minuto para escuchar situación de la naturaleza? (2012). Goto parte de las ideas de Paulo Freire al respecto de la importancia del diálogo en la comunicación y de ésta en la educación. Por otro lado, se basa en la teoría al respecto de la empatía de 1917 de la fenomenóloga Edith Stein. A pesar de ser una teoría anterior a las modernas definiciones de empatía, Goto encuentra este texto crucial para el entendimiento de la empatía y su distinción de la simpatia ${ }^{44}$. Además le permite la introducción de la metáfora como medio que utiliza el arte para despertar la sensibilidad y atención de la respuesta empática del espectador. Goto y Collins se plantean el reto de conectar al público con los árboles mediante un dispositivo que transforma la actividad fotosintética provocada por la presencia de dióxido de carbono en el ambiente (producto de la respiración, de emanaciones de coches y otras fuentes), en sonido. De este modo consiguen una respuesta empática en el espectador, estableciéndose una relación humano-árbol. La pregunta que emerge de esta obra y que guia su investigación es: «¿Es posible crear un cambio si la gente interpreta y entiende la vida como interdependiente e interrelacionada con la naturaleza en nuestro medio ambiente? $)^{45}$ (Goto Collins, 2012, p. 1). Ya hemos visto que la conciencia ecológica emerge tanto del conocimiento científico del mundo exterior como de la emocion, que activa nuestros procesos mentales de salvación/recompensa ${ }^{46}$. Pero a pe recibir constante información sobre la crisis ecológica y sus graves consecuencias, continuamos perpecturndo un estilo de vida con un alta huell ecológica. Esto demuestra que solo el conos perpetur lo hechos no es lo que nos mus a que se hace Goto las siguientes: ipor qué sigue existiendo una contradicción entre nuestra forque se hace Goto las siguientes: ipor qué sigue existiendo una contradicción entre nuestra forma de pensa, sentir y actuar al respecto de nuestra réción con el entono? ¿Cómo mejorar los actitud/conducta que la realidad?

Para responder a estas cuestiones cabe señalar, en primer lugar, que la contradicción es ininfinito en un planeta de conforme lo purpes a

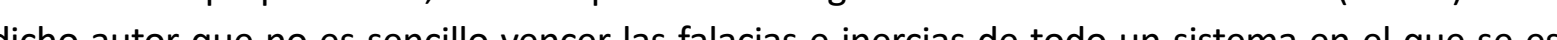
作

43 Traducción de la autora del original: Ecol-
ogy and environmental art in public place: lalking tree: won't you take a minute and 44 Según Goto explica en su tesis, la simpatia es solidaridad con los sentimientos rés. Estudios como el de Royzman y Ro
ent (2006) señalan que existe correlación con do mayor la simpatía con conocidos que según Stein, consiste en experimentar la de vista sin olvidarse de uno mismo, pero desinteresadamente. Según Sennet «tanto la simpatía como la empatía transmiten pero una es un abrazo, mientras que la otra comenta que ambos tipos de reconocimientos son necesarios en distintos momentos $y$ coperación (Sennet, 2012, p. 40).

45 Traducción de la autora del original: «ls it possible to reate change if people interpret and interrelated with nature in our 46 Con esto queremos referirnos a que
cuando en un aprendizaje obtenemos una

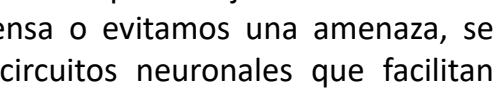
el aprendizaje de esa experiencia. Recorventana lel conocimiento, despierta cuando hay algo nuevo en el entorno. Ese "algo bupervivencia como último significado 
significar recompensa (placer) o castigo
(peligro) y que por tanto tiene que ver con
nuestra propia viday (López, 2013)

mente a continuación, algunos de esos factores más relacionados con nuestro tema, que, en consonancia con Albelda y los investigadores en Psicología ambiental José A. Corraliza y Cristin Huertas, impiden que se produzcan los cambios necesarios en la conducta ambiental y abarcan tanto la psicología como la economía o la organización sociopolítica: «[...] la mera difusió de informaciones sobre el cambio climático no necesariamente produce cambios coherentes racionales del comportamiento humano, de sus aspiraciones y los estilos de vida» (Huertas Corraliza, 2016, pp. 118-119)

Por un lado, existen factores a nivel externo: la lentitud de las transformaciones (irreversibles en muchos casos), la lejanía con respecto al origen de ciertos impactos ambientales o a los centros de decisión, la invisibilidad de las consecuencias de nuestro estilo de vida y su ocultación, la falta de empatia y lo criptico en ocasiones de la divulgación cientifica, la dificultad de interpretar las cifras y magnitudes del daño, la manipulación de los medios, la presión del mercado, el individualismo de nuestras sociedades, la ignorancia de los hechos cientificos, el retardo existente entre investigación y educación, los falsos mitos (como el de la eficiencia) y la e en la tecnología o la desproporción entre las dimensiones del problema y nuestra incidencia individual que genera impotencia (González Reyes, 2018, p. 238), entre tantos otros. Huertas y Corraliza señalan que «[...] el cambio climático no es tanto un problema ambiental cuando un problema de la humanidad». Y añaden que «[...] algunos problemas ambientales no tienen una solución meramente técnica, y requieren estrategias y soluciones para promover cambios en el comportamiento humano, personal y colectivo» (Huertas y Corraliza, 2016, p. 108). Pero vencer las inercias culturales personales $y$ colectivas exige el consenso científico y social $y$, sobre todo, el apoyo de los medios de comunicación para superar el «déficit de información» (Huertas y Corraliza, 2016, pp. 112-113); y difundir otro tipo de mensajes: relatos funcionales y positivos de transición, con los que buscamos contribuir desde este trabajo.

Por otra parte, a nivel individual, nuestro cerebro no comprende bien como amenaza los (Genemos tendencia a pensar que el resto de la población piensa como nosotros ya seamos proambientales o no, (efecto de falso consenso), pero pensamos que somos únicos a la hora de actuar (efecto de falsa unicidad), y consideramos que el resto actúa diferente a nosotros (Sevillano Triguero, 2007). Es decir, nuestro cerebro tiende a dificultar la cognición de la gravedad de los problemas ambientales o a distorsionarlos una vez somos conscientes de ellos, para conservar nuestra estabilidad emocional. Por ejemplo, tendemos a ignorar (incluso conscientemente) aquellas realidades que no nos convienen hasta agotar el tiempo para cambiarlas ${ }^{47}$. Rechazamos lo que nos causa desasosiego, lo que no nos encaja con nuestro posicionamiento, nuestros deseos o nuestras percepciones del pasado (González Reyes, 2018, pp. 238-239).

Esto nos lleva a preguntarnos: a pesar de la abundante información sobre la gravedad de la crisis ambiental, ¿ipor qué no actuamos? La adaptación a las circunstancias, aunque sean de la cisis am ciones adversas y ser resilientes. Control, autoestima, optimismo, aceptación a poy de la red co a asimilar mum a difiles (limén a asmilar momentos difices (lilion autores senalan que nus una estrategia humana evolutiva fundamental (Boyd, 2013). De ello se puede deducir que estas mismas herramientas que nos son tan úlles para mantener nuestro estado emocional estable, pueden jugar en nuestra contra, impidiendonos asumir la gravedad de la crisis ambiental que atravesamos y actuar en consecuencia. Esto nos lleva a reconocer que la comunicación de ideas negativas de colapso y desastres naturales no puede ser el único método de concienciación ambienta $\left.\right|^{48}$. Por el contrario, producen un efecto de saturación que provoca un rechazo de la información tanto por la "ecofatiga» ${ }^{4}$, como por la sensación de indefensión y baja valoración de los efectos de la acción individual frente a tan gran problema, según Huertas y Corraliza explican (2016). Así lo ha constatado el ecologismo que ha cambiado su discurso desde las visiones catastrofistas de los setenta, a la visibilización de soluciones (Albelda y Saborit, 1997). Como Carmen Velayos afirma, «no se trataria unicamente de preguntar por lo que perdemos no somos sostenibles, sino por lo que ganamos si lo somos» (Velayos, 2008, p. 143). Imaginar y entrever hasta dónde podemos transformar nuestro entorno mediante la creación colectiva de la comunidad, es un punto en común con un gran potencial entre el arte colaborativo y los movimientos de transición. «Necesitamos una visión para toda la especie humana acerca de lo que podemos tener, lo que podemos hacer $y$ en lo que podemos convertirnos. Necesitamos hablar tanto a las esperanzas como a los miedos de la genten (Shellenberger $y$ Nordahus, 2006,

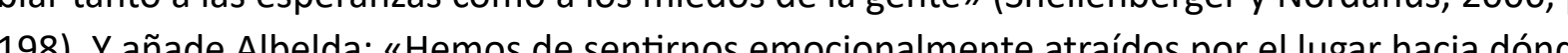
queremos ir, hacer deseables las representaciones de esa realidad que se nos muestra a través

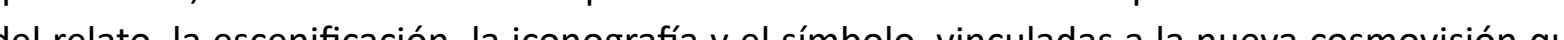
lática ecós
47 Al respecto, varios autores como La-
touche y Taibo refieren la metáfora de los entares:

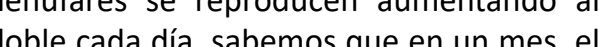
estanque estará colapsado de nenúfares,
quué día estaremos a la mitad de camino
coln colapsar el estanque? La mayoría de persoes que hasta el día 29 no se alcanzará la mitad del estanque. Es decir no se percibe la

48 Irónicamente en la cultura popular asistimos al auge de narrativas de ficción apocalipticas, señala José Luis Fernández in del mundo, el resultado se nos acaba pavisto cientos de veces en las pantallas, torconocida nos reconforta y y tranquiliza más
conseris lavovilizacióny (Fernández-Casadevante, 2015).

49 «La tendencia a rechazar asumir la so-
brerresponsabilidad de los hechos presen-

tados $y$, consecuententemente, a desconectar

rraliza, 2016, p. 113). 


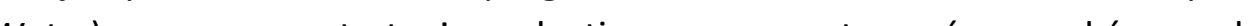
cosas si a hat Wat), proponen estrateglas colectivas que muestren como podran ser las lado, sabemos que el ser humano es imitador de otros semejantes por naturaleza. De ahí la conveniencia pedagógica de aprovechar esa facultad imitadora para la comunicación de modelos exitosos de cambios de conducta ambiental.

Para incidir aún más en nuestra defensa de la necesidad de comunicar relatos positivos para despertar la empatía, destacaremos los estudios de E. Royzman y P. Rozin (2006) sobre la para despertar la empatia, destacaremos los estudios de E. Royzman y P. Rozin (2006) sobre la symhedonia. En este estudio se distingue entre empatía por la desgracia ajena y symhedonia empatía por la buena fortuna de orro. Mrentras la primera se da a cualquier nivel de relación entre la alteridad y la persona que empatiza, según estos estudios, la symhedonia es dependiente de que exista una relación previa con la alteridad y, aunque ambas aumentan cuanto más cercana es la relación, la symhedonia aumenta aún más que la empatía. Otra diferencia fundamental que señalan es que mientras que la symhedonia es inherentemente placentera, la empatía no lo es. De ello deducen que las personas tenderán a evitar sentir empatía por la desgracia ajena y por el contrario, a maximizar la symhedonia. Llevándolo al terreno del ecologismo y contestando a nuestras preguntas iniciales, esto se podría traducir en que, como decíamos antes, las personas tenderán a rechazar o ignorar mensajes negativos (desastres ecológicos, extinciones, incendios,...) que puedan despertar su empatía y serán más propensas a recibir con alegría relatos positivos. Si bien, a la hora de hablar en positivo hemos de ser cautos especificando el grado de probabilidad de los objetivos que nos planteemos para evitar caer en ficciones utópicas. Un segunda consecuencia que se puede deducir es que, cuanto más relacionado esté el sujeto con el objeto de la empatía, mayor será la symhedonia que experimente. Por tanto para fomentar la conciencia ambiental y la transformación de la conducta se ha de promover la relación de sujeto con el objeto/sujeto a empatizar. Es decir, que cuanto más relacionado esté el público con

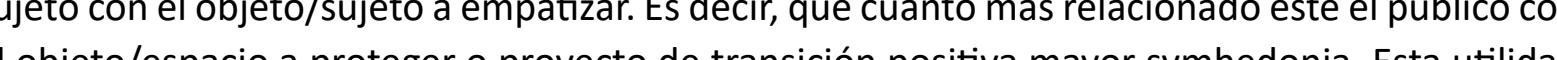

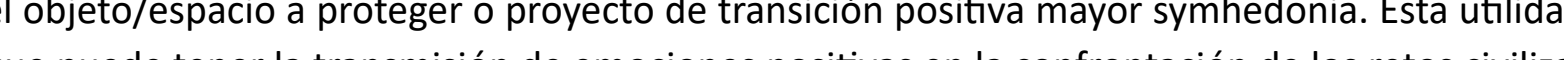
Trios ha sido bien entendida por que pus he ten la tran

resiliencia (García-Vesga y Domínguez-De La Ossa, 2013, p. 67). Veamos a continuación, cuáles 列 empáticas.

Como hemos mencionado, no solo necesitamos que las ciencias y las humanidades produzcan información veraz, si no que se comunique eficazmente, para lo que debe ser divulgada de modo que nos emocione, activando nuestros procesos mentales de salvación antes aludidos

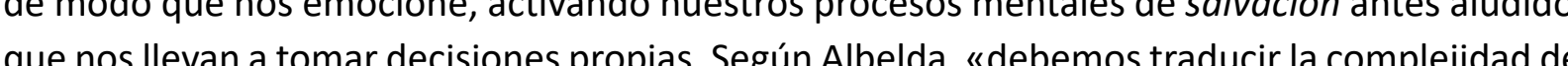

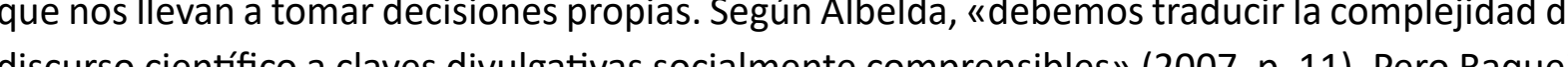
discursocies a comenta que la divunación cientica con argum ción enociona (2015, p. 69) de las na colivas decre documental La era de la estupdez o ecoficciones utónicas como los noosfericos). Frente a la escasa reacción que causan la estadistica o los números, la imagen se alza como una estrategia más eficaz a la hora de conmover al público (Slovic, 2007). El documental ha sido el género màs relevante y eficaz que el ecologismo viene empleando desde los años 70 . En sus inicios estab más centrado en mostrar una visión crítica, dramática y negativa o bien, en el otro extremo, un visión idílica de la naturaleza a preservar (Albelda y Sgaramella, 2015). En cualquier caso, el lenguaje audiovisual con su dominio del tiempo y el espacio, y su combinación de recursos como: narración, imagen, movimiento, sonido, música, zoom, efectos especiales, infografías, testimonios y cambios de escala entre otros, logra esa proporción justa entre emoción y transmisión de conocimiento. Con el tiempo, este lenguaje ha ido evolucionando y enriqueciéndose en recursos. Con la llegada de internet su alcance ha crecido exponencialmente siendo hoy «el principal medio de comunicación empática» (Albelda y Sgaramella, 2015, p. 16) tanto de realidades como de ecoficciones que, bien empleadas, pueden funcionar como inspiradoras de futuros utópicos y visualización de escenarios posibles. Raquejo considera incluso que la ficción puede ser más efectiva a la hora de sensibilizar y crear cambios de hábitos en la práctica, pues nos emocionan provocan empatía y nos motivan a proyectar nuestros deseos de supervivencia en el medio (2015). Al margen de las creencias religiosas (también con muy alto poder de convicción), el ser humano sigue sintiendo deseos de relevancia y totalidad que las ecoficciones pueden satisfacer (Raquejo, 2015, pp. 69-72). Pero el peligro de éstas es evidente: son simplificadoras, inexactas, tienden a caer en absolutismos y creencias fijas o bien en atribuir la salvación a agentes externos tienden a caer 


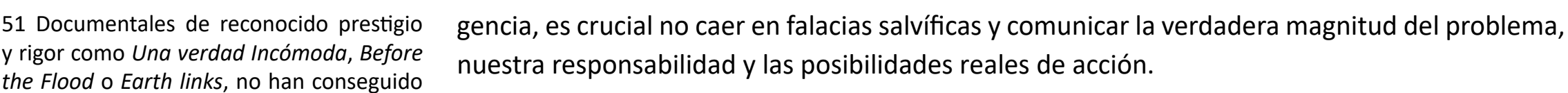

los cambios sistémicos que necesitamos (J). 52 Para más información consultar la web
http://www.dailymotion.com/user/AAA http://w wh
bierta/1

Realidad documental o ficción, la comunicación genera aprendizaje, pero ya hemos visto que no necesariamente cambios comportamentales ${ }^{51}$. «De aquí se deduce que el enunciado puntual delas verdades, por muy comparico que seay biendocur ve esté, manifiesta un 2017, p. 10; Sennet, 2012, p. lansformación social? Albelda y Sgaramella 列 la aproximación al territorio (site specific), el carácter vivencial o multisensorial, y las dinámicas de colaboración que permitan la participación activa. A pesar de carecer del control del tiempo $y$ el espacio del lenguaje audiovisual, estas experiencias permiten al público ser algo más que espectador de la acción, pasando de la observación a la interacción directa, la cocreación y, en general, a una experiencia más vivida que sin duda tiene el potencial de ser más pregnante que la mera observación. Volviendo al ejemplo del trabajo de Goto y Collins en Plein Air, los artistas ponen de manifiesto al espectador nuestra interdependencia de la naturaleza en un diálogo sin alabras que permite una relación directa, nunca antes experimentad del espectador con el arbol. Muestran una relación directa, nunca antes experimentada, del espectador con é la empatín una manera innovadora de comunicar conocimiento que emociona (a través de la empatía con los árboles) y que podría beneficiar el aprendizaje y la toma de conciencia ambentar en nuestro estudio, sin embargo, exploraremos la transformación social que pueden aportar los artistas no ya solo desde la comunicación y el fomento de empatia, sino también mediante el fomento de la symhedonia (relatos positivos). Necesitaremos para ello, como decíamos antes, relatos reales y factibles de transformación social en la vía de la sostenibilidad e intensificar el vínculo del público con el objeto de empatía (ya sea el entorno, una idea, un proyecto, un lugar, etc.).

Una manera de desarrollar la relación del público con el objeto es implicarlo en el proceso a creación. Como Gonzalez Reyes consta las construción jomunita es una de las cosas que más alegría y placer nos causa y e incita aún más la creación de colectiva en un bucle que se retroalimenta (2018). Por tanto, incluiremos proyectos artisticos que constituyan o dibujen transformaciones sociales donde la participación activa de la audiencia sea fundamental. Las pasadas acciones artísticas desarrolladas en la asociación multidisciplinar Aulabierta ${ }^{52}$ (Collados, 2012), así como otros proyectos desarrollados posteriormente como Aula-R (Sánchez-León
2013) nos condujeron a intuir que cuanto más implicado está el público en la obra, mayor posibilion titulado: Arte público de enfoque ecológico. Análisis de resultados según Suzanne Lazy. Producción propia como artista experimentador, informador, analista y activista (2013), ya comenzamos a defender que la acción, la participación y dotar al espectador de capacidad de decisión influencia de los relatos o proyectos positivos en el desarrollo de la implicación activa y la symhedonia.

En resumidas cuentas, todo lo anterior nos lleva a concluir que el arte tiene un papel que ugar en el desarrollo de la conciencia ambiental precursora del cambio de cosmovisión que plantea la transición a la sostenibilidad. El papel del arte en la ecología ha sido ampliamente estudiado en, por ejemplo, elcompendio Ante y Ecologla publicado en 2015 como resultado del $1+D+i$ Arte y Ecologia: estrategias de protección del medio natural y recuperación de territorios degradados, donde Albelda, entre otros autores, enumera algunos aspectos claves que el arte ecológico aporta: desarrolla la empatía a traves de la enoción y los relatos positivos; desarroll la imaginación como paso previo necesario a la acción; realiza propuestas de reequilibrio; contribuye a una iconografía más diversa y amplia de la crisis ecológica, realza la defensa de la diversidad y visibiliza procesos ocultos o difíciles de percibir, entre otros (2015 b). Pero como Albeld señala, los retos globales como la pérdida de biodiversidad, el cambio climático o el colapso energético ya no se pueden abarcar desde el arte solo con miradas poéticas, denuncias sectoriales o restauraciones puntuales. Necesitamos que el arte transmita las verdaderas dimensiones de esta crisis civilizatoria y adopte nuevas estrategias para llegar a una masa crítica de público con suficiente influencia para transformar la sociedad (J. Albelda, 2017 b). ¿ Podremos hacerlo sin contar con el apoyo de los medios de masas, siendo un activo periférico y sabiendo que comunicamos una verdad que se tiende a ignorar? Ante estos obstáculos el arte cuenta con varias cualidades que lo hacen idóneo para el trabajo con comunidades en transición.

En primer lugar, la rápida adaptación a los tiempos y la diversidad de relatos y formas que es capaz de crear. La hibridación de lenguajes y el difuminado de la frontora ene activo de cambio. Por tanto, en este estudio nos centraremos en aquellos proyectos artísticos donde el arte transciende la representación de la realidad y es activo, vital, incluso fundador de la acción que transforma el entorno. 

Sgaramella, 2015). Como afirman estos autores, la estética fija las ideas mediante la instauración de imágenes simbolicas y signos de identificación colectiva que aumentan la empatia. La creatividad es esencial en la construcción de un nuevo modelo para el que no existen guías del pasado, y que requicre un panamis a tesis queremos estudiar cómo se fomenta la transformación del entorno y la sistémica social a través de los proyectos artísticos, y qué efectos tiene en los propios artistas, en las comunidades con las que trabajan y en el ecosistema en su conjunto. No obstante, estamos de acuerdo con Albelda en defender la diversidad de actuaciones artísticas, todas necesarias, desde las más mediáticas, resolutivas, universales y amplias a otras más sugerentes o locales (Albelda, 2015).

En tercer lugar, la evolución del rol de algunos artistas en la sociedad desde ilustradores agentes activos de cambio, ha dotado al arte de una gran facultad para conectar a diferentes individuos, disciplinas, instituciones, sectores y comunidades en un desatio transalisciplinar. Si el conocimiento organizado en disciplinas separadas, el crecimiento económico sin límites y la tecnociencia nos han llevado al punto de enfrentarnos por primera vez a un desafío global de tal magnitud sin rutas prefijadas, parece lógico que no sean esas mismas herramientas las que solucionen el problema. Se hace necesario, pues, un cambio de cosmovisión que incluya un reordenamiento de los saberes y sus jerarquías, que rescate a la ética ecológica y a las humanidades y un nuevo modo de trabajar desde el conocimiento, que abarque la complejidad de la crisis (J. Albelda, 2017 b). Tanto la ya mencionada teoría de la complejidad de Morin, como la ciencia de la ecología y el estudio de la conciencia que hemos visto en este apartado, tienen un punto en común muy importante: el todo es algo más que la suma de sus partes. Esta idea apoya el argumento de la necesaria colaboración transdisciplinar entre arte y ecología, pues la crisis medioambiental es tan polifacética que no puede abordarse desde la separación disciplinar (A) belda y Sánchez-León, 2017), ni menospreciar la diversidad como fortaleza fundamental para la resiliencia. De este modo, la ideología se funde con la estética y el arte más vanguardista en las acciones del ecologismo mediático (Albelda y Saborit, 1997) así como, en el ámbito artístico, la ectética se vincula al posicionamiento ético, político y social. Es por ello que uno de los puntos

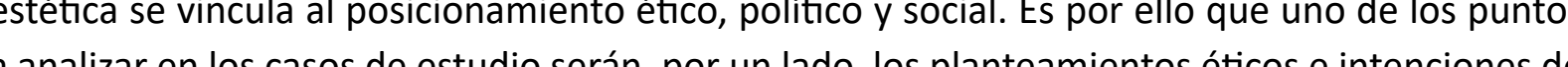
los participantes.

Una vez justificada la necesaria intervención del arte en la ecología y el ecologismo, y ana de pasar a destrollar el estudio de casos, se hace indispensable acto que justifiquen nuestros criterios de selección. El primero y más importante de ellos es el término arte ecológico. Dar una definición universalmente aceptada de arte ecológico no es fácil y veremos que tanto desde el punto de vista de los artistas, como desde los teóricos del arte y filósofos, no hay una definición común ni consenso en cuanto a sus funciones. Por tanto nos proponemos detallar aquí qué vamos a entender por obra de arte ecológico en este estudio, sin ánimo de establecer ninguna definición universal, conscientes de los límites de la objetividad a la hora de valorar y clasificar obras de arte y su impacto. En primer lugar repasaremos la visió de los artistas y teóricos, para después pasar al punto de vista de la filosofía y conformar nuestra posición.

En cuanto a la opinión de los artistas a la hora de definir el arte ecológico existe una gran variedad de posturas. El artista Tim Collins ${ }^{53}$ en su artículo «Expresión lírica, compromiso crítico acción transformativa: una introducción al arte y el medio ambienten" (2003), recoge la diversdad de opiniones de otros destacados artistas como Erica Fielder, Herman Prigann, Ann Rosenthal, Ruth Wallen and Jeroen Van Westen en la definición del arte ecológico. Entre ellos destacamos la aportación de Ann Rosenthal, ecofeminista, teorica y artista, autora de trabajos teóricos sobre eco-arte y su base ético-moral, que se han convertido en esenciales para muchos autores que trabajan en este campo. Según la misma, el campo que abarca el eco-arte es muy amplio, desde el arte conceptual al activista y colaborativo relacionado con la ecología, la historia am biental, lo social, el ecofeminismo, la arquitectura del paisaje, y la crítica a la posmodernidad. Según Rosenthal, algunos de los valores fundamentales que unen las formas y metodologías de los eco-artistas son los siguientes:

1. Ética de la tierra: asumir que todos los sistemas y seres estamos interconectados y somos interdependientes, incluyendo no solo a los humanos, sino también el suelo, los animales, el agua, etc.

2. Pensamiento sistémico: aplicar la visión ecosistémica de interdependencia al ecosistema humano. 
4. Diversidad social y biológica: entender la importancia de la diversidad como he-

3. La necesidad de un cambio urgente del modelo hegemónico de producción, conrramienta de la naturaleza para superar períodos de estrés (resiliencia) y aplicarla a todas las disciplinas, culturas y especies.

5. Justicia social y ambiental: defender el derecho de todas las especies a un ambiente saludable que sustente el ecosistema, que es la base de la vida.

6. Colaboración: tender puentes entre disciplinas, culturas, clases, géneros, comunidades, y especies, de modo que cada uno pueda realizar sus aportaciones para diseñar soluciones óptimas para todos.

7. Integridad: actuar siendo consecuentes con lo que valoramos (Collins, 2003).

Albelda propone una serie de características del arte de vocación ecológica que en

gran parte coinciden con las anteriores, pero añade las siguientes:

1. Diversificación de medios, procesos y temas.

2. Comunicación simbólica, emocional y empática.

3. Análisis de detalle y particularización temática frente a la simplificación característica de los media y los discursos ecologistas unidireccionales.

4. Disminución de la autoría y énfasis en proyectos colectivos y colaborativos (Albelda, 2015, p. 235).

Por otra parte, la artista Carmen Marín en su tesis titulada «Arte Medioambiental y Ecología. Paradigmas de comprensión, interpretación y valoración de las relaciones entre arte y ecología» (2015) añade que el arte ecológico incluye obras que tratan:

1. La existencia de límites biofísicos, dentro de los cuales se desarrolla la vida.

2. Una posición crítica sobre las posibilidades e incertidumbres del desarrollo de cor- 
55 Algunos autores diferencian entre de- por los environmental artist que utilizan la naturaleza como medio creador, concienciando verde de los supone apenas un acerca de sus procesos y fenómenos; el ecological art que muestra un grado creciente de de producción y consumo, sin cambiar las preocupación por la sostenibilidad, hasta las ecoventions que buscan remediar algún proexpectativas de crecimiento económico blema ecológico concreto (Arribas, 2015). Pero en concreto el campo que abarca el arte capitalista que ignora las externalidades y ecológico en nuestro estudio incluye aquellas obras que centran su atención en cuestiones
limites del mismo, y desarrollo de la sustentabilidad. Esta última se enfoca en redirec- como el equilibrio y reequilibrio ecosistemico, la sosteniblidad o más bien la sustentabilicionar el desarrollo hacia una base diferen- dad ${ }^{55}$, como apuntan Albelda y Rosenthal y abarcaría también las ecoventions, aunque en
te de creación de economía y sociedad, que no se base en el crecimiento económico esta tesis no incluyamos ejemplos concretos de éstas. Un ejemplo del universo de obras a

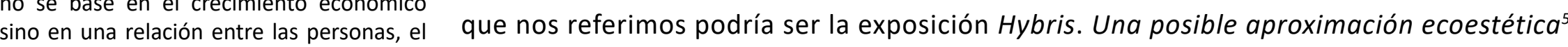
mundo que construimos y la biosfera, que celebrada en el Museo de Arte Contemporáneo de Castilla y León (MUSAC), 2017- 2018 garantice la justicia social $y$ ambiental. In-
cluye adecuar el consumo de recursos $y$ a

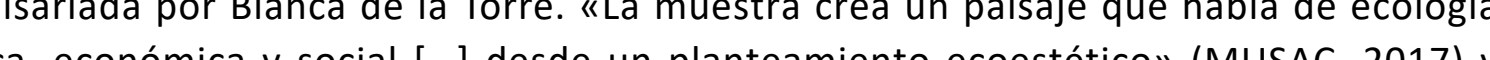
recoge una cuarentena de autores que trabajan la idea de equilibrio ecosistémico desde la naturaleza, lo simbólico o la implicación activa.

Para lograr estos objetivos el arte ecológico usa herramientas como la denuncia, la visibilización, la educación, la acción y la sensibilización, entre otras. Trabaja con modelos ecosistémicos tanto naturales como artificiales encaminados hacia la sostenibilidad, es te con los modos de prod por ello que los proyectos artísticos relacionados con la transición suelen contener cierto mensaje y/o crítica sociopolítica en una búsqueda de las verdaderas raíces del problema ambiental. Respecto a la cuestión ética, Fernando Arribas describe ampliamente las distintas posturas al respecto del valor estético y la función de concienciación ambiental (2015). Extraemos las siguientes ideas que aplicaremos a nuestra investigación a la hora de seleccionar los casos de estudio:

\section{HYBRIS Una posible aproximación ecoestética}

Crear para cambiar

Encuentro sobre prácticas artísticas y sociedades en transición

15 y 16 dediciembre 2017

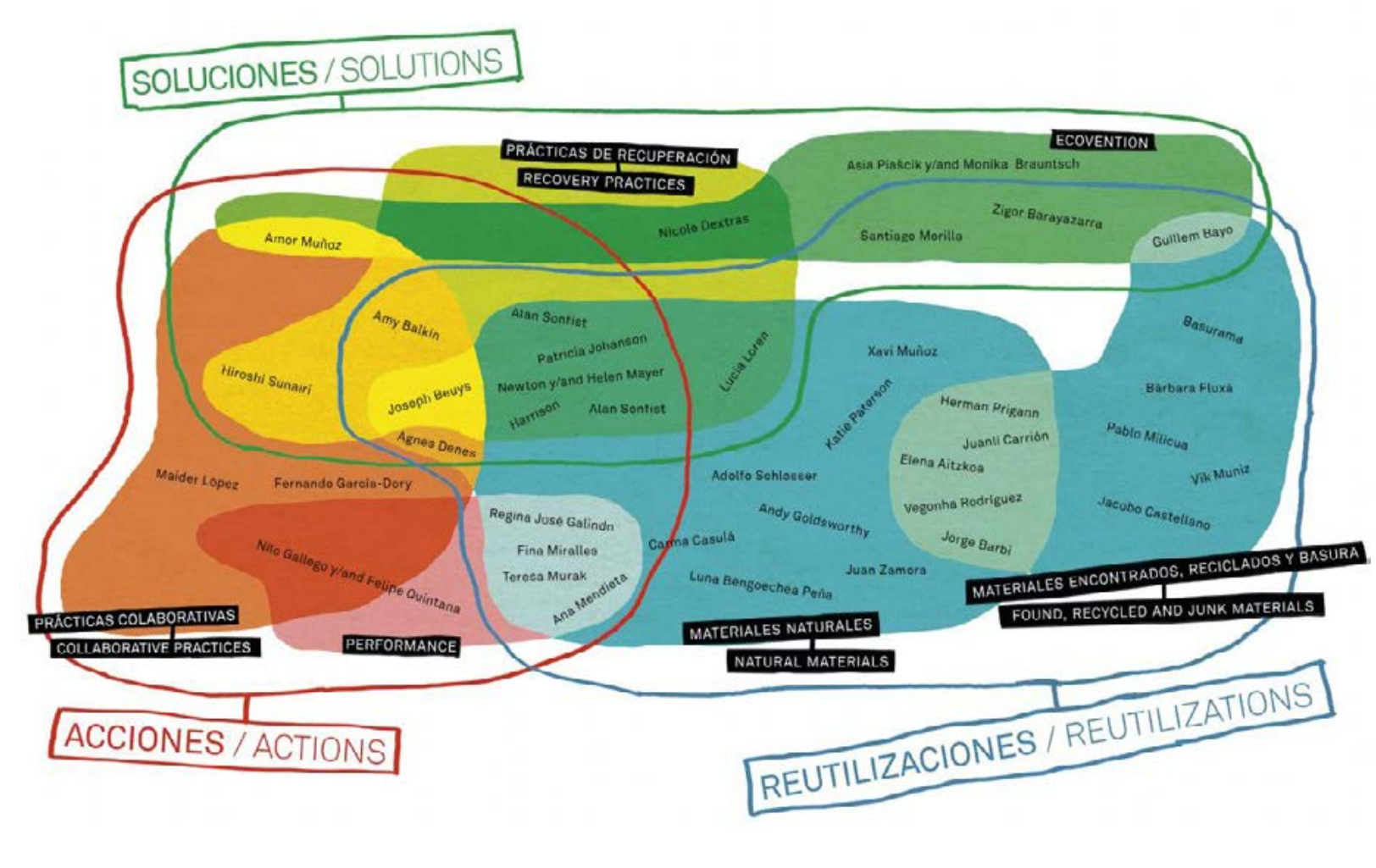

Imagen 2. Esquema de la exposición Hyb
la Torre y Jaume Marco para MUSAC

Respecto a la cuestión ética, Fernando Arribas describe ampliamente las distintas posturas al respecto del valor estético y la función de concienciación ambiental (2015). Extraemos las reducción de la huella ecológica y un me-
nor consumo de recursos. Bajo el epígrafe tos apartados prácticas a problemas ecológicos: el prime"prácticas de recuperacióno, las conocidas como Restaurationist Aesthetics, Remediation Art o Land Reclamation: Nicole Dex-
tras, Alan Sonfist, Lucia Loren, Patricia Johanson, Newton \& Helen Mayer Harrison. El segundo, las «Ecovention» que agrupa a: Asia Piaściky / Monika Brauntsch, Zigor
Barayazarra y Santiago Morilla. En el capituBarayazarra Y Santiago Morilia. En el capitu-
lo dos «Reutilizaciones», encontramos por un lado a artistas que trabajan con basurar lem Bayo, Basurama, Bárbara Fluxá, Pablo Junto a los a que unitiz y materiales naturales como base de sus propuestas artísticas: KaHe Paterson, Xavi Munoz, Adolfo Schlosser, sulá, Luna Bengoechea Peña y Basia Irland (aunque en la imagen falta), y entre estos dos grupos: Herman Prigann, Elena Aitzkoa, Juanli Carrión, Vegonha Rodríguez, Jorge
Barbi Dentro del grupo materiales naturales también están Regina José Galindo, Fina Miralles, Teresa Murak y Ana Mendieta que enlazan con el tercer epigrafe «Acciones», performance Nilo Gallego / Felipe Quintana, y otras conocidas como prácticas colaborar
tivas. Maider López, Fernando García-Dory, Agnes Denes, Joseph Beuys, Hiroshi Sunairi, mación véase: httr:///musacess/texposiciomación véase: http
nes/expo/?idd 6301

\section{Resaltamos que la propia exposición
es un ejemplo de viraje de actitudes en el}



57 El colectivo Julie's bicycle ofrece servi-
cios de calculadoraientes de huella de carbono que aplicaremos a nuestra investigación a la hora de seleccionar los casos de
estudio:

gratuitos en hitp $/ / M$
services/ig-tools

Las obras de arte ecológico que vamos a considerar cumplen dos condiciones, necesarias ambas: interés por tener una reducida huella ecológica y ocuparse de cuestiones relacionadas con la ecologí, va sea para destacar los valores de la naturaleza, como para informar/senstbilizar/denunciar o tratar los problemas ambientales y nuestra responsabilidad ante la crisis cocris cos el impacto que a los visitantes que recibe ysupopa hestadores en el medro fisco vallura. Comicnzan a aplicarse modelos de calculadora de huella de carbono para diferentes actividades dento del mundo de la cultu, como los que Julie's bicycle (La bicicleta de Julia ${ }^{57}$, pero aún es un tema muy complejo que presenta grandes incógnitas de medición. ¿Qué nivel de impacto es admisible? ¿Puede el valor cultural y de sensibilización compensar la huella ecologica o de carbono de la obra? ¿Cómo medir el efecto de sensibilización del espectador? Por ahora no existen herramientas objetivas de medición que abarquen la complejidad total de los impactos de una obra de arte, aunque existen otro intentos en España que merecen mencionarse como los trabajos de Carmen Marin de la Universidad de Pais Vasco (2010) y (2015). Por lo que respecta a este estudio, estamos de acuerdo con Sheila Lintott (2007) citada en (Arribas, 2015), en que se requiere un análisis caso por caso como e que someramente haremos en los capitulos tres y cuatro. No vamos a establecer, pues, ningú criterio máximo de huella ecológica tolerable, pero si nos centraremos en obras que la tengan en cuenta en su desarrollo. Por otro lado, existen otras condiciones que, aunque suelen darse en las obras de arte ecológico, no vamos a considerar indispensables como son el protagonismo de la naturaleza, entendida como entorno poco antropizado, o bien la intención del artista. Al respecto del primero coincidimos con Arribas (2015) y Marín (2015) en afirmar que no es condición necesaria que la naturaleza participe significativamente en la obra (un ejemplo serían las acciones del colectivo Platform (Plataforma) en exposiciones en el medio urbano como C Words: Carbon, Climate, Capital, Culture («Palabras C: carbono, clima, capital, cultura») de 2009. En por lo ano

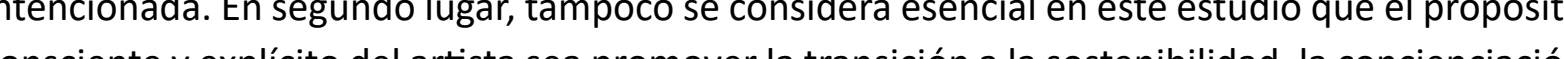

o transformación social. Como veremos en los capítulos de estudio de casos, en algunas obras manifiesta de los artistas es la concienciación ambiental y la transformación socia 政 vin pretender convencer al público ni enfocarse a un resultado (un ejemplo serían las obras que y Open Jar Collective.

Respecto al asunto de la estética, acordamos con Arribas (2015) y Brady (2007) que la actRe sisminución del valor estético del espacio natural per se sino que incluso puede contribuir a la apreciación de las cualidades del lugar que de otro modo pasarían inadvertidas. En su evaluación será importante tener en cuenta el estado previo a la intervención, pues no es lo mismo actuar en la naturaleza prístina que en un entorno ya degradado. Por tanto, reconocemos la ética como un aspecto decisivo para la apreciación estética de las obras de arte ecologico de acuerdo con la position eticista, pero no es el unico componente de su valor estético (Arribas, 2015, pp. 205-207).

En cuanto a la intención, frente a la posición de algunos artistas reacios a aceptar que su obra tiene el propósito de convencer o cambiar la actitud del espectador, como es el caso de los Harrison o Tim Collins, (Goto Collins, 2012, p. 138) reconocemos con A crbas que "[.] J educa charrison o Tim Collns, (Goto Collns, 2012, p. 138) reconocemos con Aribas que «[...] la educación moral consiste sobre todo en desarrollar la imaginación, los sentimientos y las emociones,

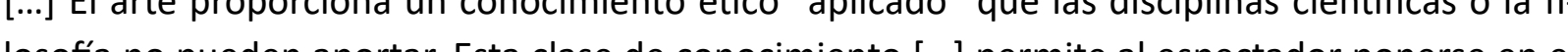
losofía no pueden aportar. Esta clase de conocimiento [...] permite al espectador ponerse en el lugar del otro" ", Y añade, "sson muchos los caminos para transmilir la sensibilización ecologica (Arribas, 2015, pp. 207-208). Continuando con los dilemas éticos en cuanto al argumento antconsecuencialista ${ }^{58}$ mencionado por Arribas, admitimos que no existe manera de medir objetvamente en la actualidad el efecto sensibilizador de las obras de arte ecológico por lo que nos ceñiremos a evaluar la coherencia entre intencionalidad y contenido/consecuencias de la obra.

Para finalizar, resumimos afirmando que no existe una posición cerrada desde el mundo de los artistas y teóricos, sino más bien una gradación de posturas. Como dice Carmen Marín,
«[...] no se puede normativizar cómo ha de ser una obra ecológica. Se pueden identificar, eso sí, «[...] no se puede normativizar cómo ha de ser una obra ecológica. Se pueden identificar, eso sín cual, hemos intentado al inicio de este apartado. Nuestra posición en este trabajo considerará que el Land Art, el environmental art, el arte ecologista mediático y las intervenciones mínimas
58 Según explica F. Arribas en Arte y Ecolo-
gí (2015) citando a N. Carroll: « [ [...] este

argumento viene a decir que es imposible a formación de nuestros juicios morales, como para educarnos moralmentey) N. Ca-
rroll, 2000, citado en (Arribas, 2015, p. 204) 
en la naturaleza de carácter más poético, quedarín fuera de la categoría del arte ecológico aue buscamos estudiar. Por tanto la misión del eco-arte que seleccionaremos no es meramene instrumental como en el ecologismo, no se limita solo a mostrar las imágenes del deterioro sino también a materializar, difundir, y acercar los retos de la vida buena generalizable, ampliar a iconografía y los relatos a través de un concepto ampliado de la estética y el arte que asuma los retos que impone la crisis ecológica con una huella ecológica admisible (Albelda, 2015). Por supuesto, este tipo de arte ecológico se relaciona directamente con las bases socioculturales, económicas y políticas que están detrás del deterioro del entorno. Así pues, lo político, lo financiero y lo cultural, devienen objetivo del arte ecológico también. Por tanto, entenderemos aqui por obra artística ecológica una gran variedad de prácticas de creación de alternativas, defensa, cuidado, conservación, construcción comunitaria, denuncia y restauración del medio ambiente, ya sea rural o urbano, que se posicionan políticamente dentro de las premisas ecológicas mencionadas al inicio de este apartado.

\subsection{EL VALOR DEL ARTE PÚBLICO COLABORATIVO EN LA TRANSICIÓN}

Como hemos visto en el apartado 2.1, en la creación de proyectos artísticos que constiuyen relatos positivos de cambio, la implicación del público en el proceso aumenta la empatía y por tanto fomenta la concienciación ambiental. La experiencia vivencial y multisensorial de y por tanto fomenta la concienciación ambiental. La experiencia vivencial y multisensorial de y en el espectador. No es casualidad que los proyectos de transición cuenten con la participació de la comunidad como herramienta de cambio, como veremos en el capítulo tres. Por estos motivos, nuestra tesis presta especial atención a explorar aquellos proyectos artísticos donde la participación del público es un factor importante. El arte público colaborativo ha sido estudiado por numerosos autores entre los que destacamos a Lacy, Lippard y Felshin, cuyos textos traducidos son recogidos por Paloma Blanco en el libro Modos de hacer. Arte crítico, esfera pública y acción directa (2005). También haremos referencia al texto de Iria Candela Sombras de ciudad. Arte y transformación urbana en Nueva York, 1970-1990 (2007) que repasa la evolución del arte público desde sus orígenes. La estancia de investigación en OTE, nos ha permitido tener acceso a la tesis doctoral no publicada de Lacy titulada: Arte imperfecto: trabajando en público. Un es- tudio de caso de los proyectos de Oakland (1991-2001) ${ }^{59}$, que aclara numerosas cuestiones que os planteamos al inicio de la investigación sobre las fronteras del arte, la función del artista los

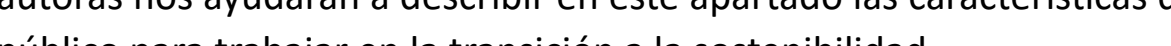
público para trabajar en la transición a la sostenibilidad.

\subsubsection{Arte público y transición}

Para justificar el valor del arte público colaborativo para los procesos de transición es necesario analizar dos aspectos principales. Por un lado qué características posee el arte público y por otro cómo es esa colaboración. Mierle Laderman Ukeles, Joseph Beuys y Allan Kaprow, entre otros, ya sentaron las bases de este arte participativo ampliando la función de los artistas como «escultores sociales» (Beuys, 1970) y del «arte como vida» (Kaprow, 2003), cuya creación incluye incluso nuestras «prácticas diarias» (Ukeles, 1969). Estos autores, junto a muchos otros, han contribuido en los ultimos sesenta años a la expansión del arte hacia la vida cotidiana, con un enfoque de responsabilidad eco-social - en el caso de Beuys- que reside en los fundamentos de lo que la artista británica Neal ha denominado transitional art ${ }^{60}$ (Neal, 2015). De este modo, el papel del arte en la transición a la sostenibilidad implica un arte al servicio de vida buena y del reequilibrio ecosistémico, en el que las prácticas vitales diarias conforman la escultura común que construye la sociedad. La obra artística trasciende el objeto, y su lugar se expande fuera del cubo blanco. El artista ya no es el único protagonista creador, y la coautoría y colaboración entre artistas-científicos-expertos y público es intensa. Asumiendo estas premisas en la delimitación de qué vamos a considerar arte en esta tesis, no entraremos a cuestionar los límites de la disciplina artística, pues ya lo hacen referentes como Kester, Lacy ${ }^{61} \mathrm{o}$ el pionero en arte ecológico Newton Harrison, sin encontrar una respuesta definitiva a esta eterna pregunta.

Valoramos, sin embargo, otros aspectos que interesan más a la transición, como la introducción de los artistas en diferentes áreas del conocimiento y su capacidad de incitar la transformación social, lo cual ha permitido abordar la complejidad de las urgencias globales ecológicas también desde lo artistico. En cualquier caso, interesa que los artistas sigan trabajando en este campo, entre otros motivos por la diversidad, sensibilidad, innovación, originalidad, creatividad

59 Traducción de la autora de: Imperfect
art: working in public: A C cases Study of the a

60 En adelante optaremos
como «arte transicional»

\section{Lacy se pregunta al respecto: « « iHasta} dónde, por ejemplo, un artista debe ir hacia ucación, para participar efectivamente en
unation asurtos civicos? ¿Qué sucede con una obra de uso? ?Hasta qué punto en el ámbito púvertirse en algo differente, como el jefe de una organización? En ese caso, esigue haciendo arte? ¿Y qué posición puede asumir un proyecto en la vida pablica, en equilibrio ad social, a menudo entendida de manedifierente "fuera" del arte?" Traducción de la autora de: «How far, for instance, endeavor, say politics or education, in orate in civic issues? Whe to a work of art when functhe public realm can an artist venture withhead of an organization? In that case, is he/ she still making art? And what position can project assume in public life, balancing tappings) and social utility, often under
stood differently "outside" of art?" (Lacy, 2013, p. 10). La misma Lacy admite que enlones diversas a cuál era la misión del artista: «Even among collaborators there were differences of opinion on what, in the end, was more central to our mission- making
an artwork, addressing a large public, or Hlugar del arte en et contexto de la crisis ecológica. Nuria Sánchez Leó 
Por otra parte Blanco nos acerca un artículo de Felshin de 1995 previo a su proyecto editorial «¿ंPero esto es arte?: El espíritu del Arte como Activismo» ${ }^{62}$, donde aporta una definició de arte público «Arte público sería todo arte dotado de un cierto compromiso político al que se le presupone una localización pública y una recepción participativa» (Blanco, 2005, p. 85). El artista público será pues para Felshin «[...] aquel cuyo trabajo es esencialmente sensible a los problemas, necesidades e intereses que definen esa entidad esquiva y difici de definir que es ese lugar y que muchos identifican con la comunidad o público» (Blanco, 2005, p. 85). Efectivamente, tanto las obras de arte público como las de arte transicional tratan en mayor o menor medida la cuestión política, se implican con el contexto social, suelen partir de un cuestionamiento previo a la comunidad y cuentan con una recepción participativa. A nuestro entender, ta y como señala Neal, tanto en arte transicional como en arte público, el modo en que se realiza la obra es tan esencial como el qué se hace: «la visión estética y el compromiso social son igualmente importantes» $)^{63}(\mathrm{Neal}, 2015$, p. 76).

Lippard en su texto Mirando alrededor: dónde estamos y dónde podríamos estar (2001) porta otra definición de arte público que resalta el estudio previo y la colaboración con el publico, características también de los proyectos de transición: «Yo definiría el arte público como cualquier tipo de obra de libre acceso que se preocupa, desafía, implica, y tiene en cuenta la opinión del publico para quien o con quien ha sido realizada, respetando a la comunidad y medio» (Lippard, 1995, citado en Blanco et al., 2001, p. 61). Este artículo de Lippard fue publicado originalmente en un compendio de Lacy titulado Mapping the Terrain: New Genre Public $\operatorname{Art}^{64}(1994)$. En su libro, Lacy destacaba las características del arte de nuevo género que hemos mencionado hasta ahora y añadía: el papel multidisciplinar y facilitador del artista, el desafío al establishment (institución) y la capacidad de vincular la crítica social y política aplicada al contexto local con el público en un proceso colaborativo (Lacy, 1995, citado en Blanco, 2005). Para la propia Lacy y para Arlene Raven, editora del libro Art in the Public Interest ${ }^{65}$, es esta última faceta lo más esencial y característico de estos proyectos. Estos trabajos al igual que los proyectos de transición, ofrecen modos de vivir y relacionarse alternativos a la corriente convencional. espectador ya no un mero consumidor de obras sino un agente activo productor de cambio, identidad y comunidad, aspecto éste que nos interesa sobremanera en el desarrollo de los proyectos de transición donde la memoria, la identificación y el sentimiento colectivo son mos prode cambio.
62 Felshin, N. (1995) But is it Art?: Spirit of
Art as Activism. Editado por N. Felshin. SeatPress, U.S.

63 Traducción de la autora del original
Aesthetic vision and social engagement are equally importants

64 Mapeando el terreno: arte público de
nuevo género. Traducción de la autora.

65 Arte en el interés público. Traducción de

atora. Arlene Raven (1994-2006) es ar-

tista feminista, critica, historiadora y educa-
dora. RAVEN, Arlene, Art in the public inter-
est, UMI Research press, 1989 . ción algunos de los autores que tratan de perfilar su descripción, recopilados por ritan a continuasu ya citado libro de 2007. Según esta autora «El arte público, tal y como lo entendemos aquí, úble precisamente se cuestiona el significado y las asunciones mismas del concepto experiencia espacial de su audiencia" como tema» (2007, p. 23). Esto nos sugiere que tal y como sucede con las propuestas de transición, el arte público parte de los intereses y problemáticas que el arte público debe ser «crítico y no oficial» (Candela, 2007, p. 148), aunque en el caso de yectos de transición tienen mucho de activismo político y protesta y, por supuesto, parten de la ciudadanía espontánea, buscando en ocasiones alianzas con las instituciones oficiales como en table a los tiempos y a la esfera pública cambiantes, sin establecer valores eternos e inmutables sobre lo que es el bien común (Candela, 2007, p. 160) y, de hecho, asíf funcionan los proyectos de transición que van evolucionando y cambiando conforme varín las circunstancias. Un ejemplo claro serín las convocatorias artísticas de Biodivers I $y$ ll que estudiaremos en elcapitulo cuatro, y que presentan una evolución en los requisitos de las obras admitidas al certamen desde un actitud menos consciente de los materiales, hacia requerimientos más en armoní con los entornos naturales dónde se ubican las piezas. 
- Arte no creado para ser expuesto en museos o galerías exclusivamente.

- Nueva relación con los medios de comunicación y las instituciones como entornos a ocupar.

- No se trata de obras de arte sino de un «arte de obras» donde importa tanto el cómo como el qué.

- Vinculación de la actividad artística con el espacio público. Es un «arte del lugar» es decir, de comprender los conflictos del contexto con el que se interactúa. Conlleva un análisis crítico de la realidad contextual ${ }^{66}$.

- Importancia del proceso por encima del objeto.

- Trabajo en red y apertura a la transdisciplinariedad (Blanco, 2005).

El arte público nos muestra distintas variedades, diferentes modos de hacer, que no constituyen categorías rígidas, como nos comenta Blanco citando a Lippard (Blanco et al., 2001), sino lexibles, que muchas veces se mezclan y entrecruzan, abriéndose a la transdisciplinariedad. En actualidad, internet ha abierto todo un mundo de nuevas propuestas relacionadas a menudo con el arte activista y en muchas ocasiones de marcado carácter colaborativo o colectivo, que global, superando fronteras, culturas y distancias:

Ya no se trata de buscar el ideal utópico de transformación total de la sociedad y sus estructuras, sino que, en su mayoría, son acciones particulares referidas a problemáticas locales, puntuales, a menudo relacionadas estrechamente con las mismos artistas, pero que demandan abrirse a un pensamiento global extenderse más allá de su ́rmbito y salir del peligro que supone el aislamiento, aprovechando y compartiendo todo el potencial subversivo contestatario que poseen (Blanco, 2005, pp. 192-193). narrativas de la crisis ecológica: el cambio climático y el pico del petróleo. Lippard insiste en hecho de que estas nuevas prácticas artísticas deberán mantener una actitud dual. Por un lado buscar su lugar en la crítica de arte, pues no son debidamente valoradas dentro del imaginario popular artístico contemporáneo, y por otro, procurar mantener un fuerte contacto con el contexto local y sus comunidades para ser coherentes, efectivas y enriquecedoras, opinión que comparte N. Felshin (Blanco et al., 2001). Esta autora destaca: «Estas prácticas culturales suponen la plasmación última de la urgencia democrática por dar voz y visibilidad a quienes se les niega el derecho a una verdadera participación y de conectar con un arte público más amplio (Felshin, 2001 citado en Blanco et al., 2001, p. 74).

Teniendo en cuenta todas esas características que definen el arte colaborativo, entre 2013 2015, Neal cuenta con los testimonios de hasta 64 personas entre artistas, profesionales académicos, de las cuales, quince trabajaron para identificar juntos los principios del arte transicional (Neal, 2015, pp. 10-11). Como veremos, tienen mucho en común con lo anteriormente dicho al respecto del arte público colaborativo. A continuación los traducimos y resumimos de original:

1. Intención: consiste en crear las condiciones para el cambio sin necesidad de un plan previo, respondiendo a una realidad del mundo, buscando una alternativa con apertura a lo que otros puedan aportarnos.

2. Ignición: es necesario encontrar las ideas que impulsen el momento de pasar a la ac-

3. Marco: conforma la estructura y la estética de un proyecto y crea un contexto o narrativa que explorar.

4. Trabajar con la comunidad: despierta el coraje necesario para encarar los retos globales que no podemos afrontar individualmente, $y$ construye resiliencia dando esperanza a los individuos en la comunidad.

5. Mediación: los mediadores son necesarios para hacer que el proceso fluya sin esfuerzo, cruzar fronteras entre disciplinas y sectores, crear redes y abrir puertas y caminos. A menudo son los propios artistas. 
67 Territorio debatido: hacia un enfoque
critico del arte público. Traducción de la aucritico der
tora.
Mantener un espacio: focaliza las actitudes y energías del grupo, da seguridad y matevializa la unión entre sus miembros.

7. Conexión: cuando se trascienden los límites del individuo y se construye una historia compartida, se crea un espacio para una narrativa holistica y coherente aue cic as grandes problemáticas ambientales con una narrativa local de comunidad y cambio positivo.

8. Trabajar desde lo común: frente a una cultura de la diferencia y la confrontación, se centra en lo común y el diálogo para entender y compartir las sensaciones del otro.

9. Colaborar: se trabaja con apertura en equipo y en un equilibrio complejo de tensiones para lograr un mejor resultado que a nivel individual.

10. Cambio: se puede fomentar desde la intención con la que comienza el proyecto y compartir para crear una gran narrativa del cambio (Neal, 2015, pp. 81-93).

Pasamos a continuación a explorar cómo se traducen estos principios y características en los modos de actuar en arte público aplicado a la transición.

\subsubsection{La participación y el proceso dialógico}

Decíamos al inicio de este bloque que para definir el arte público colaborativo es necesario analizar dos aspectos principales. Visto el primero (su caracterización), el segundo aspecto a tratar es cómo se desarrolla la colaboración. La participación normalmente se analiza superficialmente, siendo en realidad un punto crucial de toda obra de arte público. Este concepto ha sido profundamente estudiado por autores como Lacy, Borriaud, Kester $y$ Koh y en aplicacio a la transición también por el grupo que rodea a Neal en su libro. En principio, la colicación se supone se supone creador blic ${ }^{67}$, deserach $p u$ - dades y estrategias en esta cuestión, que pongan en valor estos nuevos formatos artísticos para que se introduzcan en los programas educativos de arte en escuelas y se generalice su entendmiento popular. En un esfuerzo por esbozar la cuestión, Lacy propone unas pautas para analizar la participación, clasificando en varios tipos de audiencia según la relación y la implicación del público con el proceso de trabajo del artista, es decir, su papel dentro de la estructura de la obra artística (1995). Esta clasificación supera la clásica relación del artista y el público como dueto o la categorización del mismo según raza, edad o género. Su propuesta se explica a través de un esquema de círculos concéntricos no jerarquizados ordenados de mayor a menor implicación. Las tipologías que Lacy describe y hemos traducido y resumido serían:

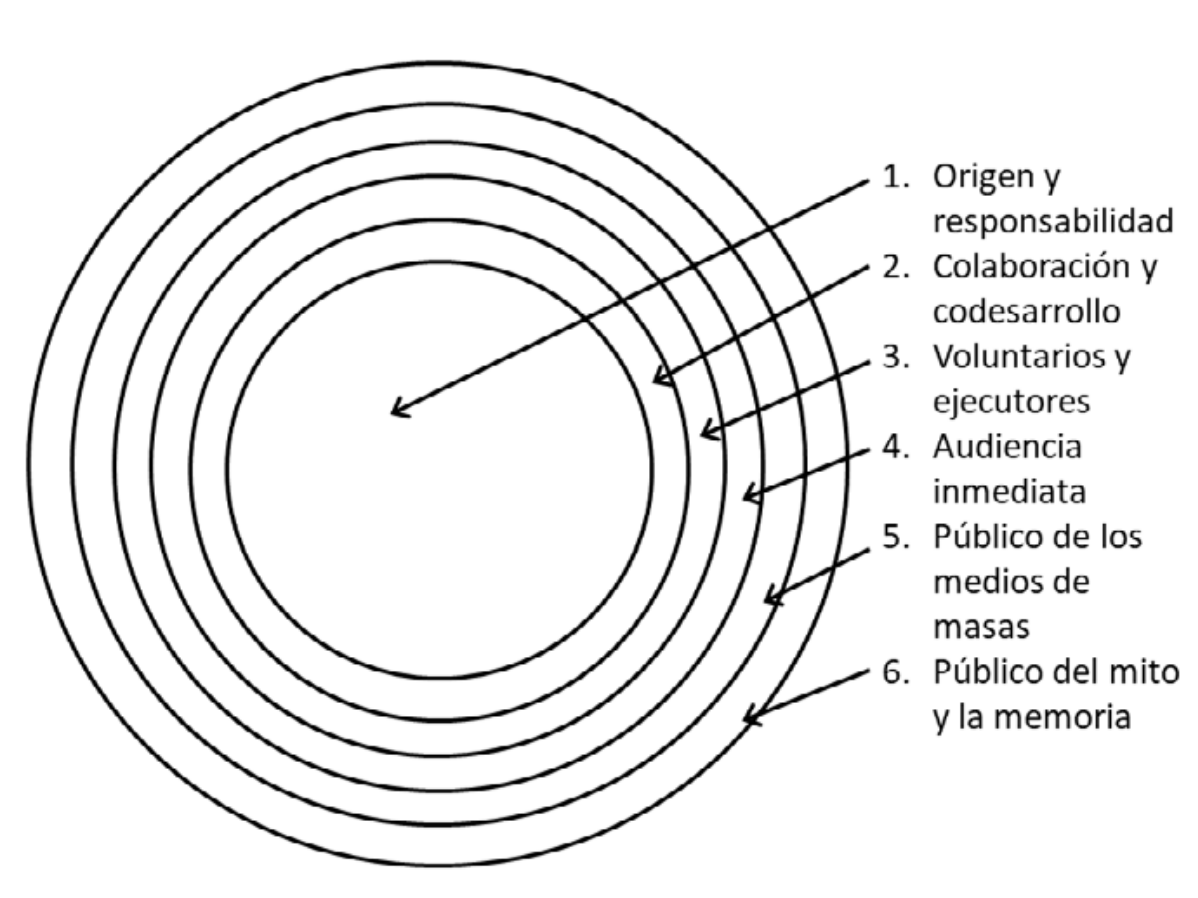

Imagen 3. «Grados de compromiso imaginario como una serie de círculos concéntricos, cada uno representa una
forma de interacción entre la realización y la espectación» Funete: elaboración propia desde (Lacy, 1995, p. 179). 
1 Origen y responsabilidad: el centro del círculo representa el origen creativo y por tanto simboliza el máximo en génesis y creatividad. Corresponde a las personas sin las cuales no existiría la obra.

2 Colaboración y codesarrollo: este círculo que rodea al anterior incluye a quienes colaboran o co-desarrollan junto a las y los artistas la obra y por tanto les corresponde parte de la autoría. Aunque su colaboración es crucial, la pérdida de algún miembro no impediría el desenlace de la obra.

3 Voluntarios y ejecutores: aquellas personas para y con quienes se crea la obra.

4 Público inmediato: es lo que tradicionalmente se entiende por espectador, los que tienen un contacto directo con la obra pero no han participado en su ejecución. Debido a las especiales caracteristicas del arte que trabaja con comunidades, si se trata de una obra de arte público adaptada al contexto, seguramente gran parte de ese público estará en cierta medida comprometido con ella más que el visitante ocasional de un museo.

5 Público de los medios de masas: en la actualidad es muy común que las obras tengan un alcance mayor a través de los medios de comunicación que del propio contacto con la obra. Internet ha facilitado y globalizado el acceso a obras artísticas por todo el mundo y por supuesto la bibliografía, retrospectivas, y cualquier tipo de documento expanden Ia influencia de la misma.

6. Público del mito y la memoria: corresponde a aquellos casos en los que la obra se convierte en un hito en la historia de la comunidad o bien pasa a la literatura del arte (Lacy, 1995, pp. 179-180).

Es importante señalar que los individuos no solo pueden pertenecer a una categoría fija y que las divisiones son, por supuesto, arbitrarias. Cuanta más responsabilidad asume un miem-

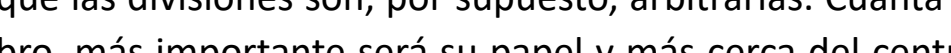
quiere decir que su participación sea más extensiva que la de otros miembros, pero sí más crucia. Asímismo, los y las participantes pueden moverse de una posición a otra del cir una crucial. Asi mismo, los y las participantes pueden moverse de una posición a otra del circulo durante posibilidad de actur. En los proyectos de transición como en Transition Town To spectador la perfectamente conscientes del poder de implicar a la población desde el origen de los proyec- tos y así lo hacen como veremos en el capítulo tres. En algunas de las propuestas artísticas que ar como por ejemplo en DUO, veremos que el público es más que un mero espectaprimera, segunda $y$ tercera. primera, segunda y tercera.

Como los autores de Playing for time. Making Art as if the World Mattered ${ }^{68}$ (Neal, 2015) comentan, a raíz de sus propias experiencias personales en proyectos de transición colaborativos, este modo de trabajo exige estar activamente abierto, grandes dosis de humor, apertura, capacidad de negociación y generosidad. Se trata de un modelo de trabajo poco común en la lógica del sistema convencional jerárquico, y en el que se sobrepone la sinergia a la competencia, la horizontalidad a la verticalidad y la ausencia de control sobre el ego creador. Todo ello sin renunciar al respeto del saber hacer del artista, ni al cuidado de la obra. Lacy ejemplifica bien esta última cuestión en sus trabajos conocidos como los Oakland Projects donde en cierto momento se dificulta el proceso de elecciones estéticas del proyecto The room is on fire. La artista, sin renunciar al proceso de transparencia en la toma de decisiones, aclara que: «era imperativo negociar con los jóvenes sobre las imágenes para los Oakland Projects, pero el proceso era negociador, no dirigido por los Jovenes»" (Lacy, 2013, p. 206). Precisamente el asunto de negociación exige destreza en lo que Kester denomina, prácticas dialógicas ${ }^{70}$. Según el sociólogo Richard Sennet: «Cubren el espectro que va del saber escuchar al comportarse con tacto, encontrar puntos de acuerdo y gestionar la desavenencia o evitar la frustración en una discusión diffcil» (2012, p. 20). El diálogo es una pieza clave en este tipo de obras, pero no cualquier diálogo. La conversación dialógica, a diferencia de la dialéctica ${ }^{71}$, prospera a través de la empatía por el otro, sin necesidad de llegar a un acuerdo común, pero con la curiosidad y la apertura activadas. Así, el diálogo con los habitantes, comenta Lippard (2001), se convierte en el principal medio para reflexionar sobre cuestiones ambientales y garantizar el arraigo de sus intervenciones en el lugar. Este espacio relacional creado es fundamental para fomentar la conversación y escuchar las opiniones, lo cual abre la posibilidad de que el público participante reinvente conjuntamente sus prácticas cotidianas, el significado de su entorno y reconecte con su paisaje y su cultura local. La subjetividad estética cartesiana del artista como genio, se sustituye por una reciprocidad que construye lo que la artista y critica Suzy Gablik denomina la intersubjetividad (1992). Un ejemcos co tuaciones en e pun
68 Intentando ganar tiempo. Hacer arte
como siel mundo importara. Traducción de

69 Traducción de la autora de: «Negotiating

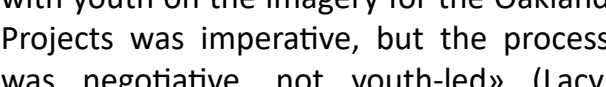

was negotiative, not youth-led)' (Lacy, 2013, p. 206). En este proyecto los estudiantes ponen en cuestión la decisión es-
tética de Lacy de montar una escenogratía epresentados al carecer de coches la gran

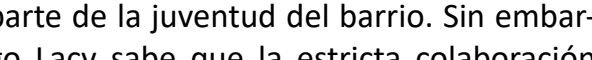
en las escalas a las que trabaja no produce (n) poderosoin debido a los sesgos que no solo buscar consensos (Lacy, 2013, p. 206) y logra mantener su
elección estetica dialogando con los participantes.

70 «"Dialógica", término técnico que desig-
na ala atención y la sensibilidad en relación con otras personasy (Sennet, 2012, p. 30) por tanto está relacionado con la definición de empatía de Sennet ya citada en la nota $44 y$ con un ejercicio exigente de observa-
ción fuera de nosotros mismos. «Fuua acutín para designar una discusión que no se resuelve en el hallazgo de un fundamento
común» (Sennet, 2012, p. 37)

71 Continuando con Sennet, el procedi-
miento dialéctico sería una manera de conducir una conversación, mediante un consin embargo en la dialósgica esan al as acuerdo. Sin embargo en la dialogica, «los individuos
no se adaptan perfectamente entre si como piezas de un rompecabezas), (2012, p. 44)
pero en el proceso de intercambio los in- 

(Sennet, 2012, p. 37).

En ocasiones, los procesos que dan forma a estos proyectos se parecen mucho a la peda72 Que utiliza
tral del trabajo. gogia, la educación ambiental institucional o el activismo ecologista. La habitual concepción que contrapone artístico a útil tampoco facilita su consideración como obra artística. Debemos señalar, aquí, que el arte transicional prioriza la utilidad en muchos casos, aunque no en todos. Esto nos conduce a la siguiente pregunta, ¿cómo distinguir la práctica del arte público o del arte tran-

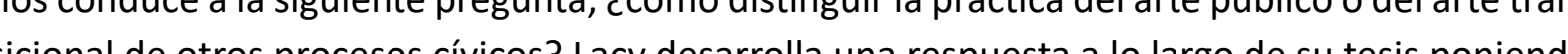
en paralelo dos nara en para lo dos narraciones, una socia dy ra artistica ruepuede a una perfor 12). En cu so a la in 12). En cuanto a la intención y al impacto, no es un arte al servicio de una agenda pública, sino un arte realizado para desentrañar y matizar cómo son las relaciones de los ciudadanos e instar a un cambio, decidido a lo largo del proceso por los propios participantes, no por la administra ción. Estéticamente, aunque los Oakland projects incluyen talleres, cursos y reuniones al uso, las performances no se corresponden con ninguna práctica convencional cívica, $y$ crean un espacio liminal nuevo que pernite a un pubico más amplio acercarse a realidades que le serían inaccesibles de otro modo ${ }^{14}$. Además de las actuaciones realizadas en espacios públicos, su acción se expande al museo con proyecciones y exposiciones que contribuyen a su entendimiento como obra de arte dentro de una performance duracional mayor que pretende activar el diálogo loca y la reflexión. Estos conceptos junto al análisis de la participación, la aplicación de los principios del arte transicional, la financiación y las funciones, se aplicarán en la evaluación de los proyectos de arte transicional que estudiaremos en los capítulos tres y cuatro. Se amplían a continuación matizando la intención, el impacto, la estética y las dificultades que pueden surgir durante el proceso creativo colaborativo.

\section{Puntos de tensión y puntos clave}

La reciprocidad y el ambiente de aprendizaje mutuo son aspectos claves en estos proceso de construcción según la experiencia de Lacy (2013). Pero como en todo proyecto donde conflu- yen personas con diferentes niveles educativos, distintas experiencias y por supuesto diversas subjetividades, surgirán momentos de desacuerdo. Como señalan los autores de Playing for time, será crucial la habilidad de los mediadores para negociar en un equilibrio de tensiones complicado (donde el artista tiene que mantener el ritmo y la intensidad de la participación sin acaparar la atención) (Neal, 2015). El artista Dougie Strang comenta estos puntos de tensión que suelen surgir en la colaboración en arte transicional:

He aprendido mucho: que las cosas nunca salen exactamente como tú las has planeado y que la tensión entre la preparación y la improvisación es a menudo fructifera, que la gente traerá differentes niveles de compromiso a un proyecto no correspondientes con sus papeles $y$ que tienes que aceptar esto colaborar satisfactoriamente (Strang, 2015, citado en Neal, 2015, p. 90).

Lacy también reflexiona al respecto en su tesis doctoral, donde señala puntos clave de tensión entre «la estética y la ética, la autoría/impulso creativo y la representación, la calidad y la imperfección» (Lacy, 2013, p. 14). Por ejemplo, ya es complicado traducir la experiencia de contexto y la comunidad en una forma representativa, dadas las diferencias en identidad y experiencia entre los creadores y los representados. Pero, además, diferentes niveles de entendimiento del arte producirán dificultades para llegar a un consenso en la estética de la propuesta, como mencionamos anteriormente.

Otro punto a lamentar, según Lacy, es la dificultad de incorporar modelos de cambio dentro de la cultura global, dado lo que ha denominado el «efecto teflón» (2013, p. 215). Es decir, que las ideas de cambio propuestas desde el arte se deslizan por la superficie de programa diseñados para otros fines, perdiéndose. Son imposibles de adherir a las instituciones públcas si no se desarrollan en programas o políticas, y las instituciones no siempre cuentan con la disposición o los recursos para ello ${ }^{75}$, ni los artistas tienen tal capacidad de liderazgo desde fuera de la organización. Este deseo de inclusión en las políticas públicas no debe entenderse como opuesto a la definición de arte público. Como decíamos, el arte público debe ser «crítico y no oficial» entre otras características (Candela, 2007, p. 148) pero también expandirse fuera del cubo blanco y no creado para ser expuesto en museos o galerías exclusivamente. Precisa-
75 Traducción de la autora: «Pero en los
intentos de cambiar permanentemente el sistema escolar o la formación policial, es aveños - un plan de estudios que los pebio en el enfoque de la formación alláaue bien recibidas, a menudo vacilaban en nuestra incapacidad para liderar el esfuerzo cional que, a pesar de la disposición favorable de sus lideres, no está preparada para
hacerlo por su misión, recursos, personal o hacerlo por su misión, recursos, personalo
estructura. Al tratar de encontrar el empuje para nuestras estrategias en los programas
y prácticas en curso, encontramos que la mayoría de las instituciones públicas no tiecompromiso de la juventudu" (Lacy, 2013, p. 164).

$$
\text { La función del arte en procesos de transición a la sostenibilidad: casos anglosajones y españoles. }
$$


mente en el caso de Lacy, sí se persigue esa alianza con la administración pública (Lacy, 2013). También las iniciativas de transición, aunque tienen mucho de activismo político y protesta por supuesto, parten de la ciudadanía espontánea, buscan en ocasiones alianzas con las instituciones oficiales como en el caso del MCT. Como Patricia Phillips comenta, el arte público debe ser temporal, adaptable a los tiempos y a la esfera pública cambiantes, sin establecer valores eternos e inmutables sobre lo que es el bien común (Candela, 2007, p. 160). "Ls casi inevitable que los artistas socialmente comprometidos encuentren, en su camino desde la conciencia de la injusticia a la investigación sobre sus causas, la relación del arte con la programación política y el cambio institucional» (Lacy, 2013, p. 163). Y añade «Lo que aprendí en los Oakland Projects fue la profunda intratabilidad de las instituciones» $(2013, \mathrm{p} .163)$. A pesar de contar con «e otencial de la institución en lugar del de la transformación individual» (2013, p. 163), Lacy se muestra decepcionada en cuanto a la posibilidad de esos vínculos con la administración cuando dice: «No estoy segura si ese ataque artistico a las grandes instituciones vale la pena más que su valor como modelo de cambio potencial» (2013, p. 164). Además Lacy señala el peligro de la cooptación, es decir que la institución neutralice al proyecto artístico absorbiéndolo si lo considera una amenaza. Sin embargo, Yiju Chen en su tesis doctoral «El valor estético en el diseño del ecohábitat» (2015)defiende que esa complicidad con instituciones locales es deseable para la implementación de cambios en la cultura genera y señala que la colaboración con la adm nistración representa una alternativa de subsistencia para estos artistas que suelen trabajar a margen de la comercialización, como en Un camino entre el Arte y el Medio Rural, un projar a a lave, será lestabe sunto las que transmir experiencias para constrir euna cultura de la resistucion cono ventre las que rance lesto en el capitulo cuatro con la red Ll Cubo Verde. Según vera des en los capictos tres y cuatro, la relación con las insticuciones puede ser complicada o ineficaz, como en el caso del proyecto We Universitat Politècnica de València, que ha apoyado los proyectos de Biodvers (atistico) Ve Universitat Politècnica de València, que ha apoyado los proyectos de Biodivers (artístico) y el
filtro verde de la localidad para depuración de aguas residuales.

Otro punto que puede dificultar nuestra capacidad de lidiar con el significado proporenguajes teóricos procedentes de diversas disciplinas (arte, sociología, educación, política, etc) y las diferentes maneras de entender que conllevan (Lacy, 2013). Estos lenguajes específicos dificultan el reto de estos proyectos de transición: lograr atraer a aquellos públicos poco o nada concienciados. Así, también estas diferencias de lenguajes y modos de entender se manifiestan en divergencias en los modos de medir la efectividad y los resultados en ciencias y en arte. Esta cuestión será tratada en el apartado 2.3.5.

\section{Modelos colaborativos}

Lacy considera que la crítica se ha quedado sin herramientas suficientes para valorar la nteracción artista-público, las intenciones del artista y la efectividad de las obras (1995). Por ello plantea una clasificación que sirva de herramienta para analizar las obras de arte público de ello plantea una clasticacion que siva de herramenta para analzar las obras de arte público de nuevo género. Es muy fán presuponer la conexión del artista con los participantes, pero muy complicado medirla. Un anallisis más profundo debería poner en relación la interación con el proposito del artista y las consecuencias reales de la pieza en el público contextual como intentamos realizar en esta investigación. Además está la cuestión de la intensidad, perdurabilidad y efectos de esa actuación. No todas las interacciones seran de la misma profundidad segú la implicación del artista, su adecuación al contexto, la receptividad del entorno, etc. Como ejemplo, Lacy muestra el siguiente esquema de tipos de interacción artista-público donde un línea continua va desde el artista experimentador, (el que menos interactuaría desde la base de arte público), hasta el activista. En cualquier momento un artista puede moverse a lo largo de espectro y posicionarse en cualquier punto intermedio. No hay límites fijos ni fronteras, solo aproximaciones.

PRIVADO

Ри́высо

$$
\bigcirc
$$
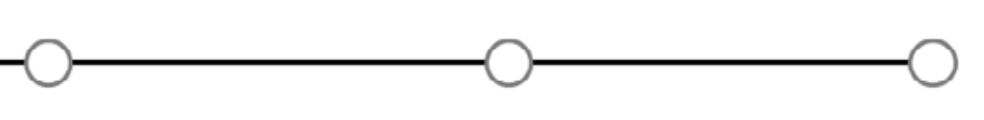

Artista
experimentado

Artista informador

Artista analista

Artista activista

Imagen 4. Continuo de roles no fijos para activistas artísticos fluctuando entre la expresión pública y la privada Fuente: elaboración propia a partir de (Lacy, 1995, p. 175). 

Las obras devienen más procesuales que objetuales y el nivel de adaptación de la obra al entorno social es mayor. La subjetividad individual se va sustituyendo por la intersubjetividad para construir de los participantes y la multidisciplinariedad.

Aunque en el compendio de Neal se pueden consultar proyectos de arte transicional de todos los tipos, en este estudio prestaremos especial atención a proyectos que son -o se acercan- al caso del artista activista, ya que son los mas colaborativos y suelen implicar cambios directos en el e caso pro el caso español, como es el caso de Granollers en transició o Aula-R. En territorio anglosajón es bastante más frecuente que cuenten con alguna financlación o soporte de organizaciones caritativas o públicas como el proyecto Dundee Urban Orchard (DUO) que cuenta con el apoyo de varias comunidades religiosas y The Trashcachers'Carnival financiado por el Arts Council England. Por último algunos proyectos cuentan con el apoyo institucional como en el caso de Carrícola, que es subvencionado por su propio Ayuntamiento en colaboración con la UPV.

\subsubsection{Intención}

Según decíamos en el apartado 2.3.2, Lacy resalta que el carácter artístico de este tipo de obras reside en la intención, el impacto, la estética o la calidad de la pieza.

La intención sugiere contextos de trabajo que pueden ser útiles para evaluar la obra. Como decíamos en el punto 2.3.2, el análisis de la finalidad del artista y participantes nos da pistas para ceciamos en construcción cle significado del artista Por ejempo puede serútil para la critica, evalurs lo la construcción de significado del artista. Por ejemplo, puede ser útil para la crítica, evaluar si la obra nes iniciales a veces incen es intencioembargo, tener el potencial de provocar un efecto en la sociedad (Collins, 2003). En el caso de que

se conozcan esas pretensiones iniciales, ¿cómo evaluar el sistema de valores del artista? ¿Qué se en caso? La respuesta no está exenta de subjetividad y opiniones encontradas. ente el propósito del artista es diferente de los resultados que se obtienen. hecho de que las intenciones sean buenas no deriva necesariamente en un buen trabajo. Para añadir más confusión aún, si la obra representa el sistema de valores del artista, cuando esa obra implca a otras personas en su realizacion, ya no se puede evaluar individualmente. Al margen de esto, respecto a la meta de transformación social surgen discrepancias entre los mismos artistas. De un parte algunos creadores han aportado soluciones y propuestas de cambio más o menos directas,

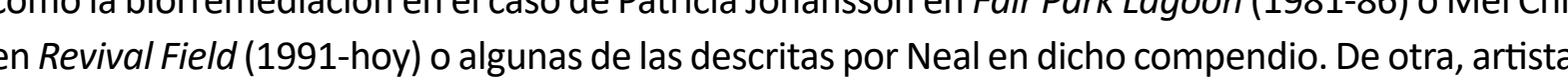
(a) de cambiar» las ideas del público, ni convencerles de cambiar su comportamiento (Goto Collins, 2012, pp. 138-139). Asimismo los artistas Reiko Goto y Tim Collins declaran que el arte no se ocup de dar respuestas correctas, ni soluciones definitivas a la urgencia de la crisis ecológico-social ${ }^{\text {to }}$ Su obra propone cambiar las preguntas que el público se hace respecto al medio ambiente, crear imágenes que resuenen en la conciencia, inspirar un cuestionamiento y mostrar otras alternativas y futuros posibles ahora solo en nuestra imaginación, pero más cercanos una vez imaginados. Observamos, por tanto, que existe una gradación de posturas en cuanto a la intención de transformación social, desde obras más prácticas y directas hasta otras sugerentes e inspiradoras; pero todas parten del principio ético de no dañar el ecosistema en el que trabajan (Collins, 2003). Considerando tonces la diversidad de posturas como una ventaja desde esta investigación se examinán varios

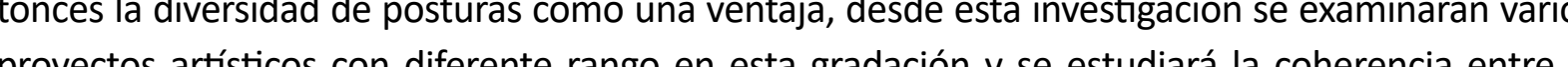
proyes a tiscos con autores y participantes directamente.

\subsubsection{Efectividad}

Hablar de efectividad de estas propuestas es suponer de antemano un impacto en los individuos que participan ${ }^{77}$ y que, conjuntamente con los artistas, pueden ejercer un impacto en la sociedad, transformándola. Pero en tal caso, ¿cómo medirlo? En general, sostiene Lacy, 

culta incluso su consideración dentro del campo del arte. A este respecto Gablik comenta que, en nuestra cultura «la noción de arte al servicio de algo es un anatema» (Gablik, 1995, citado en Neal, 2015, p. 14), lo cual contrasta con la fuerte vocación de utilidad de muchos de los proyectos que presentamos. Por otro lado, una lectura profunda de las implicaciones de un proyecto es casi imposible si no se está inmerso en el proceso, por lo que generalmente solo los artista y el público más implicado tienen una visión completa de la influencia del proyecto en la sociedad y en ellos mismos. Por ese motivo en esta investigación hemos tratado de participar en los proyectos en la medida de lo posible. Aunque somos conscientes de que no podemos tener una visión tan completa como la de los creadores, nuestra perspectiva nos permite evitar el sesgo emocional de estos. En cualquier caso, tampoco la visión de los participantes más implicados es completa puesto que, en función de la formación de cada participante y sus conocimientos, su valoración será más o menos precisa, pero siempre estará sesgada por su vínculo emocional con el proyecto. Lacy señala la multivocalidad (definida por ella como «una evaluación que incluye muchas voces pero es cualitativa, no cuantitativa (Lacy 2008)» (2013, p. 25) como un modo de contrarrestar el sesgo.

Dentro de las limitaciones señaladas para evaluar la efectividad, en primer lugar habra construir consensos, defender, ofrecer alternativas viables, concienciar $\mathrm{u}$ ofrecer soluciones un problema entre tantas otras funciones. También es muy importante diferenciar el arte como acompañamiento o ilustración de otros fenómenos sociales, de aquellos proyectos artísticos que empoderan a las comunidades realmente y empujan el cambio social. En algunos casos como en el proyecto Park Fiction ${ }^{78}$ es más sencillo evaluar la efectividad en los términos que estamos habituados en ciencias, ya que existe una necesidad pública que los artistas detectan defienden y apoyan dando finalmente una solución materializada. Pero, ¿cómo medir la concienciación ambiental que despierta público (implicados y espectadores) en el tiempo? Al Dunos artistas como N N rison ni sique decar los efectos de sus obras Segú los lucra vez causan ob puede ir hasta aquí, pero puede modelar el cambio y proporcionar laboratorios para nuevas formaciones y coaliciones" (Lacy, 2013, p. 217). Desde un punto de vista práctico, podemos entender entonces las actuaciones de estos artistas como proyectos piloto, maquetas de otras realidades que podrían funcionar a largo plazo en estos u otros contextos. Sus acciones están llevando el arte a nuevos territorios y desafíos ya cómo proyectos hipoteticos, temporales o como realidades que funcionan a largo plazo. Allá donde las estrateglas tecnocientificas habituales no ofrecen respuestas, estos artistas estan trabajando con las ideas y emociones de los habitantes,

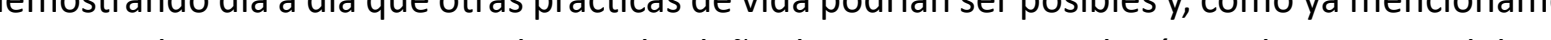
en apartados anteriores, no podemos desdeñar la importancia pedagógica de estos modelos.

Tradicionalmente se asocia el efecto de una obra de arte con su belleza o fealdad, lo sublime del resultado o su trascendencia. En el caso del arte público, ison la forma o la armoní en la composición, valores que se puedan medir realmente? Puede ser más lógico pensar que es más efectiva cuando el público interactúa más o se ve infuenciado en su comportamiento. Pero, ¿cómo medir la caldad de esa participación? ¿Cómo avenguar el nivel de impacto en las vidas de todos los tipos de público de una obra colaborativa? Las habituales formas de valoración, como la medida de la cantidad de asistentes no son suficientes para evaluar la intensidad del impacto. Obras con poco publico pueden tener un gran impacto y repercutir en las vidas de esas personas o viceversa. Una encuesta al final de la obra tampoco resuelve completamente este asunto. La filosofa inglesa Wallace Heim, ya realizo este ejercicio para la obra de los Harrison Greenhouse Britain, a petición del «Department for Environment, Food \& Rural Affairs (DERAA) »' el organismo público patrocinador de la obra artística. La autora reconoce en el informe las limitaciones de este tipo de análisis ${ }^{80}$. ¿ Podemos tomar como suficiente la medida de las opiniones subjetivas de unos cuantos participantes o espectadores? La extrapolación de resultados puede suponer colaboraciones que no se darían en otros casos aún con similares condiciones. Es más que nada, desde luego, pero no parece que produzca un resultado completo. Pueden sugerir potencialidades que no existen verdaderamente y llevarnos a plantear colaboraciones luego no produzcan ningún resultado patente. A pesar de ello, la autora defiende que el resulado sobrepa el ncarso hecho a los Harrison y concluye que, comparándolo con un anuncio de servicio público o campaña de los

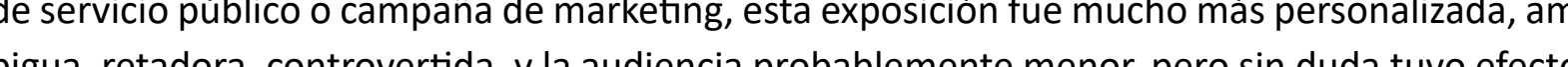
Transportó al público a un nuevo campo de conocimiento y a una nueva manera de hablar al respecto del clima (Heim, 2008).
79 El equivalente a nuestro Minist
agricuturar y medio ambiente.

80 Las limitaciones que señala Heim son: ad Interrumpiri la experiencia de la parersona en sobre el espectador e introducir otro sesgo,

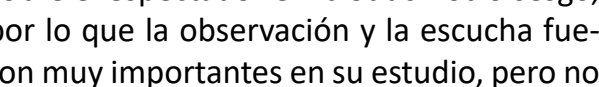
aparecen en la sestadisistica. Tambieñ destacal a fatta de tiempo y recursos para hacer después de la exposición (solo entrevista al 3\% de los vistantes), con lo que el tamaño
muestral es bajo y n n e es suficiente para exrapolar resultados. Por tanto, segun Heim, las conclusiones están basadas en la intui-
cion, la experiencia, sus spopias habilidades In cuanto a la evaluación cuantitativa, comenta que las preguntas eran redundan-
les para los visitantes ya conocedores del

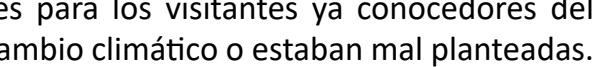
en el público que pueden verse solo con el iencia de esa persona, y que escapana a a la medicion a corto plazo. En opinion de Heim, la recomendación mas importante para me-

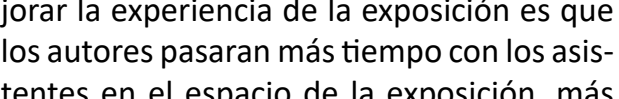
entes en el espacio de la exposicion, más
pue en seminarios y y charass, fomentando

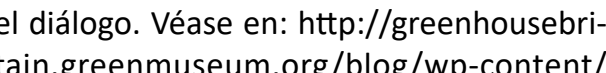
uploads/greenhouse-britain-evaluation-report-heim-public-v.pdf 
Considerando las limitaciones de la medición de la participación, otra opción sería calcular duración del cambio o la acción planteada. Los Oakland projects se prolongaron durante un

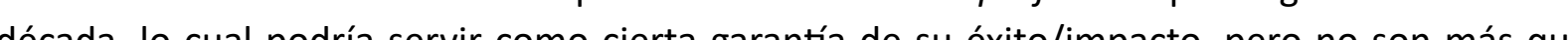
piezas de un ronpecaberas muchomayor Para poder acercarnos a una medida de efecto de tas obras demos conside pues no podremos medir los todo lo dicho anteriormente y, aun así, solo nos aproximaremos,

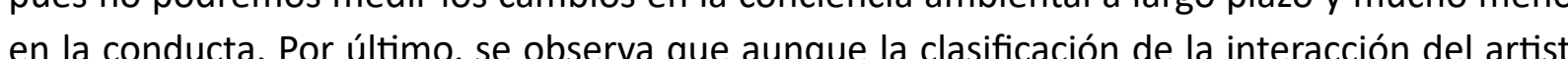
en la conducta. Por último, se observa que aunque la clasificación de la interacción del artista con los distintos tipos de público nos aporta la capacidad de colocar etiquetas a las obras y autores para poder entenderlos mejor, no se puede interpretar que una etiqueta es mejor que otra. Una obra de arte público no es más pública por alcanzar a más espectadores, sino que habrí que valorar ese alcance en términos de intensidad del impacto, perdurabilidad y duración. Nos interesa, pues, distinguir entre impactos inmediatos o a medio y largo plazo, siendo las obras más convenientes a la transición aquellas que tienen continuidad a la larga, y no las experiencias breves o demasiado específicas, por mucha afluencia de público hayan tenido. Convienen los proyectos semilla con capacidad de enraizar en lo local, reproducirse o ser extrapolables y escalables. Las monedas locales, por ejemplo, responden a estas premisas y la libra de Totnes ha sido un proyecto muy extendido en otras poblaciones aunque lamentamos que, precisamente su fama, que lleva a coleccionar los billetes como souvenirs, haya perjudicado su funcionamiento práctico (del Río, 2009, p. 29).

En resumen, a la hora de calcular el impacto de una obra colaborativa de arte transicional, podemos medir los cambios en el entorno que ha producido, por ejemplo, los cambios fisicos como la restauración de espacios en el caso de Fair Park Lagoon; el grado en el que la ejecución de la obra ha satisfecho las expectativas del público como en el caso de Park Fiction; si ha supuesto la creación de nuevas legislaciones o reglamentos; si ha dado lugar a nuevos proyectos o ha incrementado el número de interesados en la cuestión, ya sean instituciones, organizaciones o individuos. Los efectos en la conciencia ambiental del público asistente son más complicados de estimar. Para empezar hemos dicho que podemos medir el numero de participantes, pero para apreciar la intensidad de la colaboración se pueden realizar test de conocimientos, pero

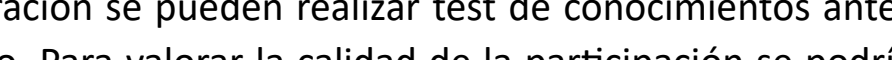
y dén asi, como ya hes cons pen conducta Para deducir una transformación comportamental habrá iue recurrir numbio en la encuestas y entrevistas. En algunos casos se podrán realizar además mediciones a corto y largo plazo de, por ejemplo, aumento o disminución de residuos, cantidad de presupuesto que se destina a productos ecológicos, nivel de consumo energético, entre otros. Pero en esos casos será dificil separar la influencia directa de la obra en la conducta, de otros factores y experiencias del individuo. Según nuestra propia experiencia en el proyecto colaborativo Aula- $R$ (Sánchez-León 2013), donde también tativas, uno de los grandes problemas es el sesgo de la subjetividad. Los encuestados no siempre son objetivos a la hora de responder, y probablemente despreciemos cierto grado de impacto cecto no real, producto del optimismo subjetivo, por lo que habrá que tomar los resultados de estas mediciones con cautela. De cualquier modo siempre habrá una cierta cantidad de impacto supuesto pero no real, y otra cantidad que no es posible medir. Por ejemplo, en este segundo caso durante la investigación se ha realizado un documental por parte del equipo del I+D Humanidades Ambien tales: estrategias para la empatía ecológica y la transición hacia sociedades sostenibles del que formamos parte. Dicho relato, que presentaremos más a fondo en el cuarto capítulo, repasa la relación entre la transición, la ecología y el arte en el pueblo de Carrícola. La proyección del mismo en festivales servirá para aumentar el público de los tipos «medios de masas» (5) y «memoria»(6) de la clasificación de Lacy. Además sirve para transmitir un modelo extrapolable que puede ser el germen de nuevos proyectos que influyan a nuevos participantes $y$ espectadores. Pero su efecto en esas otras audiencias alejadas en el tiempo y el espacio resulta tan enormemente complejo e inexacto de calcular, que solo se puede suponer cierto impacto con reserva.

Entramos en una zona subjetiva que habitualmente no se trabaja por parte de los artistas. En numerosas ocasiones los creadores se preocupan por la adecuación de su obra al entorno social, espacial, su receptividad, su duración, pero una vez terminado el proceso creativo no se toman medidas del impacto que ha tenido. La energía puesta en juego en proyectos de arte público es muchas veces tanta, que para cuando el proyecto finaliza todos los participantes $s$ encuentran demasiado agotados para hacer algo más que celebrarlo. Muchas veces la obra se abandona o se extingue por sí misma si es efímera, sin realizar ningún tipo de evaluación final. En nuestro estudio traremos de realizar este análisis mediante la toma de datos de las transformaciones del entorno, encuestas de participación/uso, observaciones y escuchas producto de la investigación acción participativa y entrevistas. 
81 El autonomismo defiende que: «las obras
de arte [...] son valiosas por si mismas, no en razón de su servicio a fines ulteriores, tales como la ilustración o la mejora moral,
Carroll, 2000, citado en (Arribas, 2015, $\mathrm{p}$. 203).

82 Los defectos (por ejemplo una alta huella de carbonol) y virtudes éticas (por ejemplo
contribuir a la concienciación ambiental) de la obra de arte ecológico serán tenidos en son por sí mismos condición necesaria ni suficiente para juzgar una obra como mala
o buena estéticamente (Arribas, 2015, pp. 203-207)

Ias II Jornadas de sostenibilidad en las instituciones culturales celebradas en ValenEn las II Jornadas de sostenibilidad en las instituciones culturales celebradas en Valencia en 2018 Miguel Angel Moratinos, presidente de la Red de Desarrollo Sostenible Española (REDS), citaba a Keynes «en el 2028 nuestros nietos descubrirán que lo bello es más importante que lo útil». Aunque dicho argumento nos sirve para apoyar la importancia de la estética en la sociedad -en línea con la posición autonomista ${ }^{81}$ 一, en esta investigación defendemos también lo opuesto al autonomismo: que el arte no solo puede ser algo bello sino también útil a nivel de enseñanza moral o de uso práctico. Belleza y utilidad no son condiciones opuestas y especialmente en el caso del arte público es común que sean obras prácticas que dan respuesta a necesidades reales de los participantes. En nuestra valoración estética de las obras de arte ecológico también cobra especial importancia la evaluación moral, en el sentido que le da el eticismo82. De modo que el aspecto ético será valorado en nuestros casos dee la cual debe asumir los retos que impone la crisis ambiental. Al ser un arte procesual, vivencial y colectivo, los valores estéticos deben superar el juicio estético subjetivo y buscar nuevas formas colectivar lo social Chen cita a Berleant:

La valoración estética no es una experiencia puramente personal, "subjetiva" en ella intervienen el conocimiento, las creencias, las opiniones y las actitudes que tenemos que son una parte inseparable de nuestra experiencia y que provienen de lo social, lo cultural y lo histórico. Estos factores dirigen nuestra atención, abriéndola y cerrándola para que comprendamos lo que está sucediendo y también, propiciando o impidiendo nuestra participación. En estas circunstancias, como en las otras, lo personal está impregnado en lo social (Berleant, 2002, citado en Chen, 2015, p. 47).

Especialmente en estos proyectos de transición que parten de las necesidades del lugar sus comunidades, la experiencia estética no solo está impregnada en origen de lo social, sino que es una experiencia vivencial colectiva. Su valoración dependerá, en gran parte, de la experiencia social dentro de la obra de sus participantes, de cómo los proyectos respondan a las ecesidades, deseos o expectativas del público, de la atmosfera durante el proceso creativo y la calidad de las relaciones entre el público participante.

Cada sujeto se convierte en autor y la experiencia del hacer, el goce de construir juntos su entorno. La reflexión experiencia del público participante en el proceso será un matiz a valorar en la calidad estética del proyecto. Ésta variará según el grado de implicación de los participantes, la cultura, las circunstancias del lugar y el tiempo, a medida que avanza y evoluciona el proyecto. Como apuntan los historiadores del arte, Ernst Gombrich y Jacob Burckhardt, «las obras de arte son productos sociales que se corresponden con los aspectos económicos y culturales de la época de la que son producto. La obra de arte como objeto artístico no está al margen de las reglas del mercado por tanto debe adaptarse al lenguaje social y al juicio colectivo (el gusto público) para conmociona al público de aquelia sociedad que trata de representar» (Gombrich, 2003 citado en Chen, 2015, p. 373). Ylo que dema par dos de vida más sostenibles; sin embargo, su comprensión de estas nuevas prácticas artísticas colaborativas no está aún al mismo nivel.

En cuanto a la valoración estética de la respuesta de los proyectos a las necesidades de la comunidad, ya hemos mencionado la importancia en los proyectos de arte público del lugar,
para determinar el marco de trabajo; entendido éste no solo como espacio, sino como comunidad, con su cultura y características propias. El lugar es crítico por su significado político, pero dad, con su cultura y caracteristicas propias. El lugar es critico por
ese significado se lo otorga el público, más allá de la geografía.

Elespacio estético es la creación de la audiencia: no requiere nada más que su mirada atenta en una sola dirección para que este espacio se vuelva "estético", poderoso, "caliente", penta-dimensional ... los objetos ya no comportan su significado diario habitual, sino que se convierten en la materia de la memoria y de la imaginación ... Cada pequeño gesto se magnifica, y lo distante se vuelve más cercano. (Boal, 1998, citado en Lacy, 2013, p. 202] 

mismo espacio en el que el Ayuntamiento de Hamburgo planeaba un centro comercial, la comunidad reclamaba un parque. El lugar, bajo la mirada de los habitantes se convierte en un espacio estético, poderoso y político. Pero en concreto, el escenario donde se desarrola tiene un papel fundamental a la hora de crear una atmósfera donde los participantes se relacionen como en un terreno de juego, en el que todos conocen las reglas. Se trata de un espacio liminal que elimina las jerarquías de la vida real. La estética reside, asimismo, en esa atmósfera que conmueve, que captura nuestra atención porque nos emociona. No tiene por qué ser algo visual o auditivo, sino un sentimiento de hermandad o de acuerdo, que emana del conjunto de elementos. En estos casos, la habilidad de los artistas para acompañar, mediar, impulsar y mantener esta atmósfera creativa y facilitar la intervención de otros profesionales influirá en la experiencia estética de la obra.

En los proyectos de arte público, la estética se halla también en los procesos y en cómo se desarrollan y el proceso fundamental, es dialógico. Ese diálogo puede establecerse entre las personas o entre ellas y su entorno. Chen, estudiando la estética en proyectos colaborativos de ecohábitat, profundiza en cómo es esa relación del participante con el entorno y cómo influye en la estética del proyecto:

Cuando hablamos de que una cierta "cualidad estética" está presente en la interacción de un sujeto con su hábitat, nos referimos a que en la percepción del entorno y en la interacción con éste, cada sujeto desarrolla una "receptividad sensorial", Esta receptividad permite a dicho sujeto generar respuestas creativas sensoniar. Esta recepividad pen este, a cadra sujujoto generar respuestas creativas un rastro a fectivo Postriom un rastro afectuo. Posteriormén esta huella puede serreconocida por el mismo para su imaginación en un proceso que se retroalimenta.(Chen, 2015, p. 38)

Por otro lado, Lacy comenta que parte de la calidad estética de la obra se debe al grado de excelencia del diálogo y las relaciones que se crean durante la colaboración. Esto depende de la participación, el nivel de implicación, la diversidad, la armonía y el empoderamiento de los participantes. La propia identidad de los participantes y el público aporta textura esética y significado político (2013). El artista debe cuidar la construcción de estos momentos de relación que luego serán incluso visibilizados en los ritmos, los gestos, los significados o los mensajes que los participantes lanzan (2013). Por tanto, la tarea estética del artista es encontrar la forma que mejor responda a las expectativas de los participantes y fomente relación entre ellos.

La imagen del proyecto ha de responder tanto a la intención estética como a la política paracumo tecisiva parsition 20 se sacrifić la tal In transition 2.0 se sacifico la homogeneidadestética de locumental, por evitar la contaminación que supondrian los desplazamientos en avión de la persona encargada de las grabarciones Las decisiones estéticas son criticas para el exito de la obra y por ello Lacy defiende su custodia como artista: «Todo esto no quiere decir que el proceso comunitario dominaba la toma de decisiones artisticas. La estética y la callidad de la producción técnica eran, como en cualquier obra de arte, cualidades que yo vigilé cuidadosamente. Eran críticas para el éxito de la obra» (Lacy, 2013, pp. 143-144). No es un compromiso fácil, y aún menos cuando se trata de un trabajo colectivo donde se persigue un consenso entre participantes con diversos niveles de formación y experiencia artística. Los artistas deben, como explica Lacy, equilibra la tensión entre complacer a los participantes sin dejarse desviar de un criterio estético elevado, para lo cual, en ocasiones, no es posible llegar a un consenso, (2013) pero si negociar como explicamos en el apartado 2.3.2 La participación y el proceso dialógico.

Por último, otros ingredientes clave de la estética en esta tipología artística son la emoción y la diversidad. Lacy lleva trabajando muchos años con este «lienzo de emociones mutivocales» procurando una estética que capture toda la variedad social y emocione (2013). Para ello utiliza el poder de la autorrevelación del participante que se implica profundamente legando a sus propias conclusiones. Por ejemplo en sus performance implica personas de distintos orígenes y escalas sociales en un espacio de igualdad, seguro para todos, donde poder expresarse libremente sin las cargas y prejuicios del día a día, y donde poder escuchar a los que son diferentes y entablar conversaciones insólitas. Esto aporta una gran y valiosa riqueza de matices que no se darían de otro modo.

Recapitulando, siempre y cuando se disponga de la información, nuestro análisis esté- 


\subsection{LA INTERSECCIÓN ENTRE ARTE COLABORATIVO, ARTE ECOLÓGICO Y ENFOQUE \\ TRANSICIONAL}

Como ya comentamos en el apartado 2.3.1 Arte público y transición, el arte transicional tiene muchas similitudes con el arte público colaborativo (Neal, 2015). En este apartado además veremos cómo arte colaborativo y arte ecológico comparten también algunas cademás verchos cón algunas características similares teniendo en cuenta la forma en que hemos definido arte ecologico. Existe por tanto, un espacio de intersección entre estas tres tipologlas que exploramos desde esta investigación. Para introducirnos en la cuestión, se recurre a un esquema ilustrativo realizado por los artistas ambientales Goto y Collins al que se le añade nuestra dimensión de ransición. A continuación se razonan brevemente los conceptos más importantes en común. Esperamos con ello llegar a perfilar la intersección entre los tres campos partiendo de las aproximaciones anteriores $\mathrm{y}$ teniendo en cuenta que son precisamente eso, aproximaciones y no definiciones categóricas.

El siguiente diagrama explica las zonas por las que se suele mover el artista preocupado por el medio ambiente y la sociedad. La mayoría de los artistas tienen elementos de dos o tres de las áreas y ninguna de ellas por sí sola es más importante que ninguna de las otras. El diagrama es en realidad un continuo y no una estructura jerárquica (Collins, 2003).

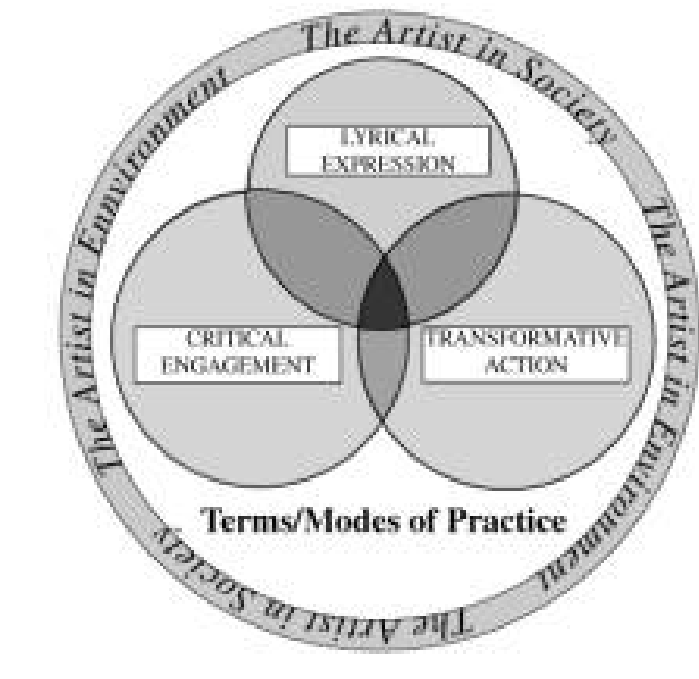

83 Los tres retos esenciales de la transición
son: descarbonizar la economía mundial, el reto de comprometer el movimiento am-
biental con la justicia y la equidad global el desafio de la conservación, de defender

Collins (2003).

Según estos autores, las expresiones artísticas más habituales son aquellas de carácter

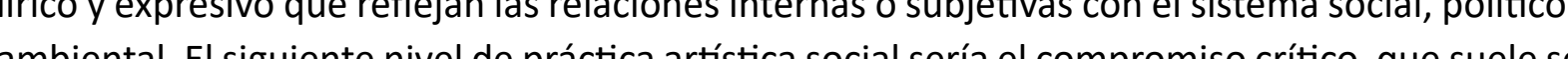

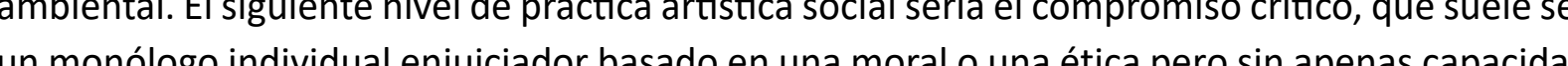

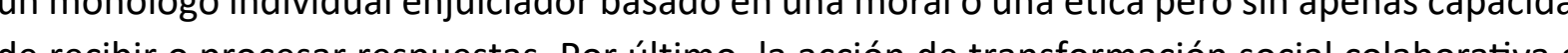

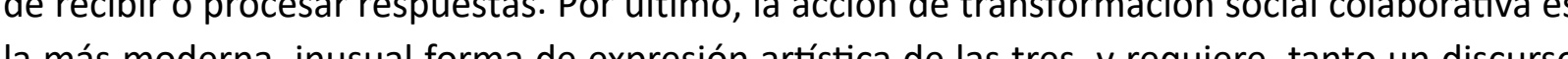
la más moderna, inusual forma de exprestón artística de las tres, v requé, tanto un discurso interno, como una distancia critica que esté basada en un conocimiento más objetivo. Suele incluir la acción comprometida y el diálogo colectivo. Hasta aquí, numerosas obras cabrian en este espacio intersticial entre las tres tipologias donde Goto y Collins situarian proyectos como el de 7000 robles de Joseph Beuys. Para ampliar este esquema a la definición de arte transicional que vamos a usar en esta investigación, habría que añadir un cuarto círculo que podriamos llamar enfoque transicional, por responder activa y localmente a los grandes desafios de la transición a la sostenibilidad, tener interés en una práctica artística de baja huella ecológica y tratar temas relacionados con el arte ecológico como los señalados en el apartado 2.2 Arte y Ecología. 


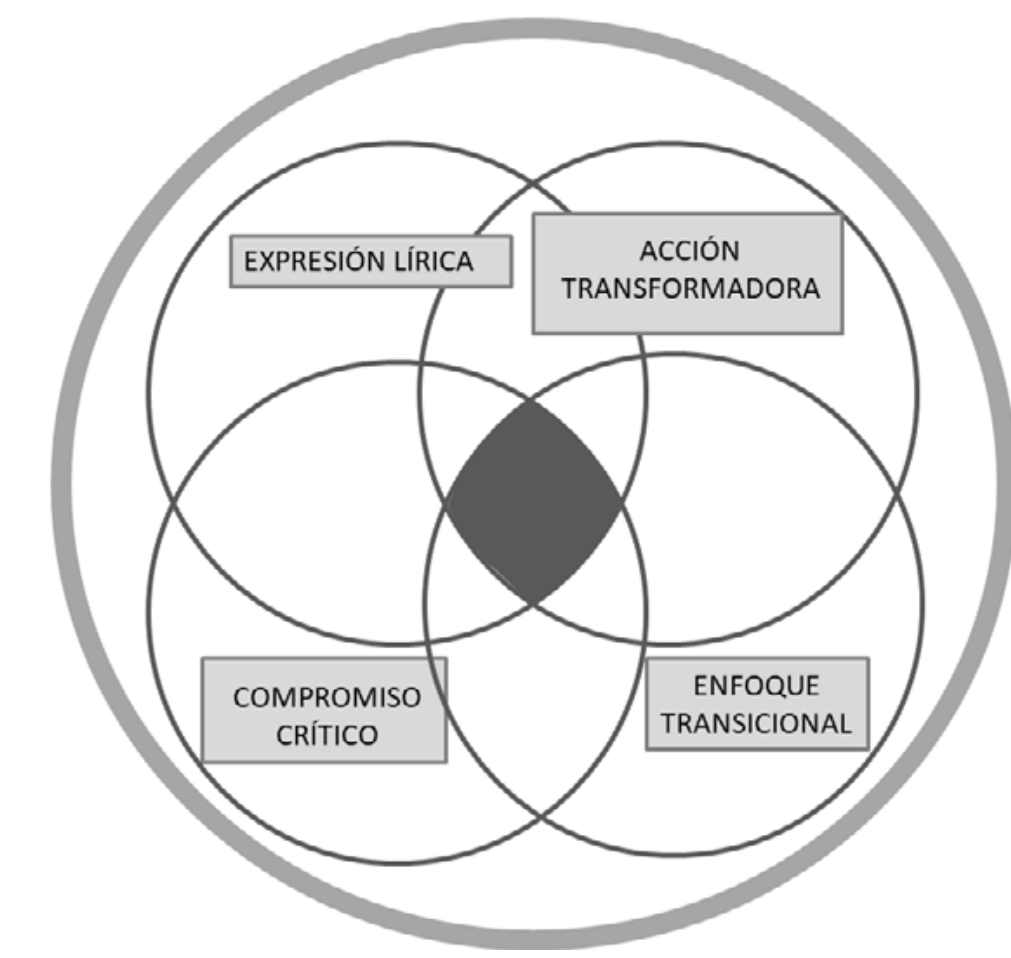
Figura 1. Representación gráica de los modos de hacer del artista enfocado hacia la transición. El área central más
oscura es la que trata de explorar el presente estudio. Fuente: elaboración propia.

A continuación mencionamos brevemente cuáles serían las características de esa intersec ción entre las cuatro áreas:

Como hemos visto, los modos de hacer que adoptan los artistas del arte ecológico tienen aspectos interrelacionados con el arte participativo y el arte transicional. El enfoque en el diálogo y las relaciones de estos dos últimos son medios para reflexionar sobre las cuestiones medioambientales, y estudiar los puntos de encuentro entre la ecología y la vida que ayudes mosicior nuestro lugar en la biofera y el entorno. Otro punto en común es la cuestión a (uer (site secific) y la loclización de

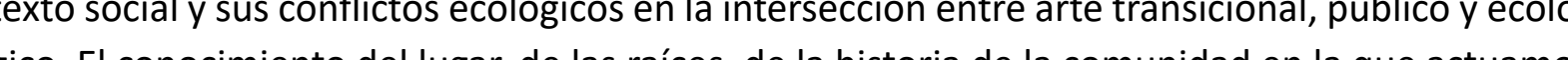

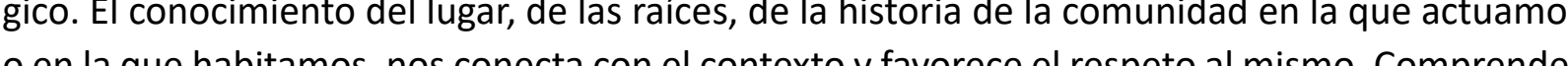
nuestra ecodependencia e interdependencia favorece una nueva relación del artista con el eco- sistema menos antropocéntrica, en donde hay una necesidad de enfatizar estas conexiones con tentomo más que de aislarse del mismo:

Hay necesidad de nuevas formas que hagan hincapié en nuestra interconexión esencial más que en nuestra separacion, en formas que evocan los sentimientos de pertenencia a un todo más amplio, en lugar de expresar el yo aislado y alienado... Por ejemplo, el exaltado individualismo no es una respuesta creativa a las necesidades del planeta en este momento (Gablik, 1992, citado en The Chartered Institution of Water and environmental management, 2012, p. 35).

Lo anterior, se puede relacionar con el concepto de vida buena de la ética ecológica si entendemos que una vida buena no puede darse sin tener en cuenta el contexto y lo social, es decir al otro y a lo otro (el entorno). La validez otorgada por estas prácticas artísticas a los procesos creativos colaborativos, a la introducción del arte en la vida, encaja con el concepto de vida buena en el sentido de vivir la vida como un proyecto creativo, pensando no solo en el individuo, sino en la calidad del sistema completo que habitamos y conformamos. De este modo, muchas obras direccionan su trabajo a cuestionar temas locales o globales que van coartando la vida buena en este planeta. De esto se deduce que el carácter político y crítico son otros importantes puntos en común: cuestionar, denunciar, crear conciencia partiendo de un pensamiento crítico sobre la comunidad y el ambiente para que se favorezca un cambio ecológico saludable.

La multidisciplinariedad, la superación de la autoría, el rechazo al arte como mercancía y la temporalidad de la obra son otros puntos fuertes en común. Es habitual la colaboración entre artistas, paisajistas, ingenieros, historiadores, biólogos, y ciudadanos, para crear juntos las acciones necesarias que fomenten un restablecimiento / recuperación / restauración, de entorno o que simplemente fomenten cambios ecológico-sociales y/o político-económicos. Ello implica en numerosas ocasiones, la superación del ego creador del artista en favor de una autoría colectiva y la imposibilidad, rechazo o desinterés en entrar en el circuito de la galería, museo u otras instituciones, ya que no hay producción de un objeto sino de procesos, que en muchas ocasiones son efímeros o de corta temporalidad. 

revelan verdades más profundas de la forma, la función y la interconexión universal» (Dave Pritchard, 2012, p. 5).

Respecto a la estética, comparten un concepto ampliado de la estética y el arte que va más á de lo belo o lo sublime y subray lo colectivo, lo diverso, lo funciontl lo diab́rgco olo efíme

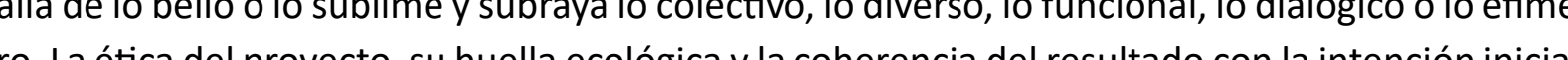
son aspectos decisivos par lo bre son aspectos decisivos reacios a aceptar que su obra tiene intención de convencer o cambiar la actitud del espectado (Goto Collns, 2012, p. 138), aqui si encontramos una intenión clara de transformación social, como declara Neal en Playing for time (Neal, 2015), y una preocupación por guardar una coherencia entre la estética y los principios éticos, manifestada por ejemplo, en la consideración de la huella ecológica de los proyectos. Continuando con los dilemas éticos, en ninguna de estas tipologías existe manera de medir objetivamente en la actualidad el efecto sensibilizador de las obras, por lo que nos ceñiremos a evaluar los efectos en el entorno y los participantes a corto plazo, el efecto en la comunidad local, las funciones ejercidas, la intencionalidad en relación al resultado, el contenido de la obra y su calidad estética.

Para concluir este apartado sobre el estado de la cuestión, podemos resaltar que los avances en la ampliación de las funciones del arte y la estética de las últimas décadas, gracias a los pensadores $y$ artistas públicos y ecologicos, han dado como fruto este nuevo arte transiciona. su inserción en el plano de la realidad permile poder hacer frente a un desafió global como la crisis ecológica con una nueva diversidad de estrategias. A pesar de ser sobradamente conocidos, se ha considerado importante realizar una definición de arte ecológico y arte público por separado, debido a la diversidad de criterios y para poder resaltar mejor los numerosos puntos común que existen, en la medida en que el arte ecologico se puede entender como una concreción temática del arte público. En el fondo, ambos tratan las mismas cuestiones: tanto lo ecológico como lo social deviene politico, quizás el hecho de que su desarrollo haya discurrido en paralelo les ha hecho compartir esta reacción común. Una vez planteado nuestro territorio de exploración, pasaremos a enunciar nuestra hipótesis de partida y comentar la metodología que seguiremos a lo largo de la investigación.

\section{HIPÓTESIS DE PARTIDA Y PLANTEAMIENTO DE LA}

INVESTIGACIÓN. CUESTIONES A EXPLORAR

En los últimos 50 años, el agravamiento de la crisis ecológica, el cambio climático, el nacimiento y desarrollo del ecologismo, junto a la evolución del arte (Collins, 2003) han propulsado el interés de los artistas por trabajar en esta parcela de la realidad. Esta investigción se enfoca en estudiar cómo es sa intervención del arte y los artistas en la transición mediante un estudio de casos en Españ y Reino Unido La idea principal que planteamos y que ya adelantamos en inicio de este capítulo es la siguiente:

Nuestra hipótesis inicial se basa en la capacidad del arte de potenciar la concienciación ambiental y la transformación social fomentando la participación y la empatía, entre otras funciones, en proyectos artisticos relacionados con la transición.

Las cuestiones que dan pie al inicio de la investigación y que trataremos de responder a lo largo de los siguientes capítulos son las siguientes:

La pregunta principal es, iccómo están contribuyendo las prácticas artísticas ecológicas a a transición a la sostenibilidad? Con esta cuestión buscamos demostrar nuestra hipótesis inicia con ejemplos tanto en el Reino Unido como en España, y analizarlos criticamente. Intentaremos identificar las nuevas, y no tan nuevas, funciones del arte insertas en estos proyectos y haremos especial hincapié en las prácticas colaborativas.

Las preguntas secundarias que enriquecen y ayudan a contestar la pregunta principal son las siguientes:

1. 1. ¿El arte ecológico asume funciones periféricas - de complemento estético- o constituye un elemento nuclear en las iniciativas de transición españolas?

2. 2. ¿Cuál es el papel del artista público en la transición a la sostenibilidad? ¿Ejerce un papel de liderazgo o de acompañamiento, muestra utopías o abre caminos?

3. ¿Hasta qué punto la creación artística puede modificar nuestras conciencias y traducirse en transformaciones comportamentales duraderas? El paradigma positivista de 
investigación que busca respuestas concretas y medibles no se adapta a los objetivos tosticas estudiadas. Es por ello que no nos presuntamos solo por los abras, sino hasta qué punto podemos esperar ciertos resultados largo plazo y evaluarlos.

4. ¿Hacia dónde se dirige la transición? Será necesario definir los principios de la transformación social en pos de la sostenibilidad. Esta definición será crucial a la hora de establecer unos criterios de selección de los casos de estudio.

5. ¿Se cumplen los principios del arte transicional en proyectos españoles y de Reino Unido?

6. ¿Puede el arte transicional representar la variedad de propuestas artísticas en torno al arte y la ecología?

7. ¿Se identifican los artistas seleccionados como artistas transicionales?

8. ¿Qué importancia tiene la participación y lo colectivo para el futuro de nuestras sociedades? ¿Cómo aportar desde el arte a la cooperación?

\section{OBJETIVOS}

La hipótesis principal y las cuestiones anteriores nos llevan a plantearnos los objetivos generales siguientes. Los objetivos básicos que perseguimos en nuestra investigación son

1. Localizar y estudiar casos reales en España y Reino Unido que estén utilizando la creación artística como herramienta en su proceso de transición hacia la sostenibilidad.

2. Estudiar cómo se emplea el arte en estos casos y cuál es su función: identificar los ejemplos, metodologías de autoexpresión, creación y cocreación y los recursos artísticos que se aplican a la concienciación ambiental en contextos de transición a la sostenibilidad desde un planteamiento transdisciplinar.

3. Analizar el papel del artista y las funciones del arte en la transición a la sostenibilidad.
4. Extraer de estos ejemplos un análisis comparativo de resultados que permita establecer conclusiones sobre las funciones, financiación, efectividad, intención, impacto, participación, alcance y aplicación de principios del arte transicional de las acciones artísticas llevadas a cabo en el campo de la transición.

5. Detectar fortalezas, y oportunidades derivadas del análisis anterior que permitan esbozar la capacidad de transformación social de los proyectos de arte transicional.

A fin de cumplir los objetivos generales anteriores formulamos los siguientes objetivos especificos:

1. Entender y profundizar en el MCT en España y Reino Unido.

2. Comprobar la extensión y manejo de los principios del arte transicional.

3. Establecer unos criterios de selección de casos.

4. Explorar, contactar personalmente e implicarnos el máximo posible con cada caso de estudio, para mostrar la capacidad del arte de crear vinculos emocionales que fomenten un progreso en la concienciación ambiental y que deriven en transformaciones sociales a pequeña o a gran escala.

5. Realizar obra artística propia teniendo en cuenta el estudio anterior para comprobar suposiciones y reflexionar al respecto.

6. Extraer conclusiones sobre la utilidad de los recursos artísticos en procesos de transición a través de la comparativa de casos.

\section{METODOLOGÍA Y MEDIOS}

Nuestra investigación no responde exactamente a un único paradigma, sino que se sitúa entre el paradigma crítico y el participativo según la clasificaciones de autores como Guba y Lincoln (1994), Vallés (1997) o Lincoln, Lynham \& Guba (2011). Se trata de un conjunto de acciones y un sumatorio de experiencias que confluyen en un punto común, y que enriquecen y guían la 
84 Según recomienda la guía para investi- investigación produciendo resultados y cuestionándose a lo largo de todo el proceso. Para situar Henfrey, 2013). La extracción de informa entrevistas por parte de los investigadas tratado de compensarse con nuestra implicación como voluntaria y ejecutora en algu-
nos de los proyectos como Nithraid, DUO

La cuestión ontológica: nos movemos entre el paradigma crítico en el sentido de que estuJamos cómo el arte se enfrenta a las estructuras de poder causantes de la crisis ecológico-socia (capitalismo, consul

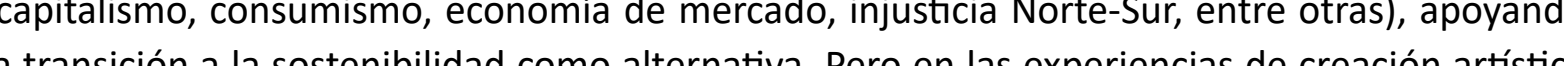
propias estudiano

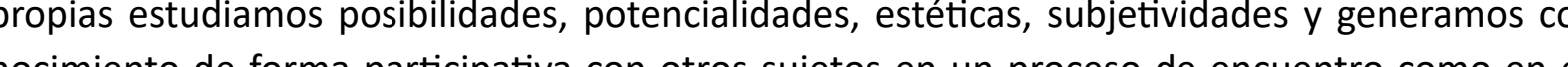
paris

A nivel epistemológico, respondemos al paradigma participativo en el sentido de que el conocimiento es experiencial, e incluye a veces la adquisición de habilidades $y$ competencias $y$ I paradigma critico, en el sentido de que aspiramos, en último término, a cambiar las estructu ras de poder dominante

Por último, en respuesta a la cuestión metodológica, nos situamos en el paradigma crítico, ya que nuestra última meta es la critica y transformación de las estructuras politicas, sociales, económicas y culturales. Los criterios evaluativos de la investigación se centran en el grado en que el estudio contribuye a desenmascarar prejuicios socialmente establecidos respecto al papel del artista y la medida en que proporciona un estímulo para la acción y la transformación de las estructuras existentes mediante la comunicación de relatos de transiciones positivas.

La estancia en OTE nos ha empujado a valorar técnicas cualitativas como la narración o la inducción y no solo la cuantificación o la deducción durante nuestro estudio. La metodologia a utilizar se basa principalmente en el estudio de casos y las metodologías cualitativas, como la Investigación Acción Participativa (IAP) $)^{84}$ en los proyectos de Nithraid, DUO y Biodivers, además de la entrevista. La lectura y estudio de casos actuales, abarca tanto la vertiente teórica como la práctica, y se considera importante analizar para ambas perspectivas tanto autores de referencia, como aquellos pensadores o artistas que todavía, debido a su novedad, no han alcanzado un reconocimiento notable, pero que resultan de plena actualidad. Nos situ no hos an cruce de disciplinas entre el Arte y la Ecologí, por lo que contemplaremos distintas áreas de cruce ría del arte) y autores pertenecientes a las mismas. Respecto al trabajo de campo, son básicos en este estudio la creación artística como experimentación y el posterior análisis de resultados, 作 como la investigación mediante la acción y la participación (IAP) en los proyectos de otros artistas.

El método de investigación seguido es un esquema de acciones de trabajo paralelas, un sumatorio de experiencias que confluyen en un punto común y que enriquecen vestigación produciendo resultados a lo largo de todo el proceso. La mecánica metodológica se resume en los siguientes pasos que continuamente se revisan y repasan, siendo un sistema iterativo que hace crecer la investigación y formularnos nuevas preguntas continuamente:

1. Revisión biblio y videográfica, estudio de autores y teorías. Adquisición de nuevos conocimientos.

2. Localización de proyectos que encajen con nuestros criterios de selección de casos de estudio dentro y fuera del MCT.

3. Visita personal a las propuestas artísticas a analizar, toma de datos, entrevistas a artistas, participantes y espectadores, y participación en sus actividades en la medida de lo posible.

4. Discusión de resultados respecto a los parámetros de estudio: adecuación a principios del arte transicional, intención impacto, estética, ética, financiación, efectividad y participación

5. Redacción de conclusiones parciales para artículos y comunicaciones.

6. Análisis general del papel del arte en la transición a partir de los casos de estudio y conclusiones.

Se recurrirá a la consulta de información a través de las recomendaciones de nuestros directores en las fuentes actuales al uso va sea en inglés, castellano o italiano, en formato digtal o analógico. También se recurre al visionado de documentales, vídeos o cualquier registro digital audiovisual o sonoro; asistencia a congresos, exposiciones, jornadas, festivales, cursos, conferencias y presentaciones de libros y otros actos que se vinculen a nuestra investigación. La experimentación artística nos obliga a la utilización de materiales propios de la creación, ya 
1. En primer lugar nombrar el empuje que supuso al inicio de la investigación para esta medo desde el proyecto Campo Adentro en Matadero de Madrid. En el mismo se estudian numerosos casos, proyectos y obras de hibridación entre arte y ecología de plena actua Iidad, la mayoria recientes o en activo. Esta congregación es un lugar de debate, reflexión e intercambio de conocimiento gracias al cual hemos podido conocer a los artistas de
Future Farmers y entrevistar al colectivo Open Jar Collective.

2. Coordinación del Diploma de Especialización en Sostenibilidad, Ética Ecológica y Educación Ambiental desde su puesta en marcha en 2015 hasta 2018 lo cual ha posibilitado profundizar en el campo de estudio y conocer personalmente a algunos de los autores aludidos en esta investigación como Jorge Riechmann, Fernando Arribas, Tonia Raquejo, Jose María Parreño, Antonio Turiel, Luis González Reyes, Ferran Puig, Yayo Herrero o Ricardo Almenar.

3. En segundo lugar, debemos remarcar el enriquecimiento que ha supuesto para esta metodologí la participación en la coordinación de las jornadas Ecoframes en el Instituto Valenciano de Arte Moderno (IVAM) (Valencia) en el que se ha estudiado y debatido Valenciano de Are Mo pecto a la transición a la sostenibilidad y su relación con el arte con figuras de renombre

4. Resulta de especial relevancia para nuestra investigación la concesión de una beca de estancia de investigación de seis meses en el grupo On the Edge Research liderado por la artista Anne Douglas en la Gray's School of Art de la Universidad Robert Gordon en Aberdeen, Escocia. Tanto la necesidad de realizar un estudio comparativo que amplíe nuestra perspectiva, como la calidad y profundidad de las investigaciones $y$ los investigadores reacionados con On the Edge Research, como l prestigio de a Universidad Robert Gordon

5. Por último, pero en absoluto menos importante, la participación en el equipo de trabajo del I+D+i Humanidades ambientales: estrategias para la empatía ecológica y la transición hacia sociedades sostenibles ha posibilitado el contacto directo con autores mencionados como Ernest Garći o Fernando Arribas. También hemos tenido la oportunidad de ser como Ems G invitadas a impattir una conferencia y participar en otra mesa de debate en las jornadas:

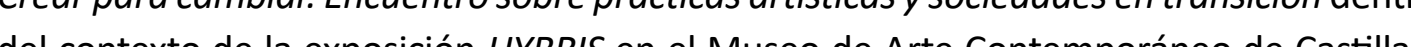
deón (MUSAC) 2017. Esto nos ha brindalo la ocasín pa profundizar en Castilla y León (MUSAC) en 2017. Esto nos ha binda la ocasion para profundizar en el contacto con la Red de Transición española. Asi mismo hemos participado con una comunicación en la I Conferencia Internacional sobre Humanidades Ambientales «Historias, mitos y artes para prever un cambios en la Universidad de Alcalá de Henares en julio de 2018. Producto del equipo de investigación de este $1+D$ es también la publicación del libro Humanidades ambientales: pensamiento, arte y relatos para el siglo de la gran prueba donde publicamos el capitulo «El papel del arte en la transición ecosocial: casos anglosajones españoles», (2018, pp. 147-163).

6. Respecto al trabajo de campo, en el estudio de casos de las iniciativas de transición se han seguido las indicaciones del Protocolo de investigación de la Transition Research Network (Transition Research Network, sin fecha) y de la guía «Transition Research Primer» (Brangwyn y Henfrey, 2013). La experimentación artística personal y el análisis de resultados se han iniciado con el proyecto Aula-R, realizado durante el Master oficial en producción e investigación artística 2012-2013. El análisis de resultados de sus dos primeros años de andadura del proyecto fue presentado en forma de poster en el II Encuentro de doctorado de la UPV en junio de 2015 y en formato de comunicación en el V Congreso de Educación Ambiental organizado por la Asociación Española de Educación Ambiental (2015). El objetivo de creación artistica se continúa con la obra colaborativa para la convocatoria Biodivers I/ «El hogar del pan». Se trata de la construcción colectiva de un horno moruno en el pueblo de Carrícola (Valencia) en la que profundizaremos en el capítulo cuarto. Para el seguimiento de resultados se han grabado imágenes, realizado entrevistas y tomado nota de la repercusión de la obra en el desarrollo económico y social del pueblo. 


\section{1. ÁREA DE ESTUDIO Y CRITERIOS DE SELECCIÓN APLICADOS}

La transición a la sostenibilidad es un fenómeno heterogéneo que está teniendo lugar simultáneamente en todo tipo de escenarios, desde paises en desarrollo hasta las primeras economías del mundo ${ }^{85}$. Dentro de esta diversidad hemos querido centrar nuestro estudio en dos áreas geogracas especícics: España y Reino Unido. El motivo de explorar dos páses de

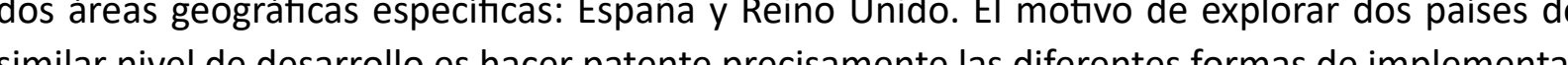
so ideas de e España, su elección viene justificada por la cercanía y la financiación de la investigación por parte de la Generalitat Valenciana. En segundo lugar, compensar el hecho observado de que exista una mayor presencia de casos anglosajones y nordicos en documentales y estudios sobre I MCT, en contraste con un menor registro de expenencias del Medteranneo y sur de Europa (Albelda, Sgaramella y Sánchez León, 2017), conncidiendo también con la opinión de la Red de Transición española ${ }^{86}$.

La investigación en Reino Unido viene motivada por varias razones fundamentales en este estudio. Para comenzar, el ámbito anglosajón cuenta con una tradición de artistas que vienen trabajando desde los años setenta en la relación del arte con el entorno natural desde el land art, el environmental art, el eco-art y el site specific tales como: Hamish Fulton, Richard Long, David Nash, Andy Goldsworthy, el colectivo de artistas Platform o Tim Collins y Reiko Goto residentes en la actualidad en Reino Unido - entre tantos otros. Por otro lado, Reino Unido ha sido fundador del Movimiento de Ciudades y Pueblos en Transición, tal y como hemos visto en el capitulo uno. En tercer lugar, nuestro estudio presta especial atención al arte colaborativo, donde la obra de Lacy - que ya revisamos previamente en el trabajo final de master (2013)- es primordial. La tesis doctoral de Lacy fue dirigida por nuestra codirectora Anne Douglas en la Robert Gordon University, desde la rama de investigación en arte público. Asimismo, a lo larso de su carrera, Douglas ha examinado una cuestión crucial para nosotros: el papel del artista profesional como catalizador del cambio social. Al mismo tiempo, el grupo OTE que lidera, abarca muchos aspectos de nuestro trabajo, desde la empatia, la participación, la función del artista o los modelos colabonativos. Muchos de los referentes principales de nuestro estudio, tales como Reiko Goto y Newton and Helen Mayer Harrison, entre otros, han trabajado con o bajo la supervisión de Douglas y su equipo. Todos estos motivos, entre otros, justifican nuestro interes Reino Unido y la realización de una estancia de investigación de seis meses en OTE. La estadía nos proporcionó la posibilidad de ampliar el abanico de experiencias y estrategias en torno arte y la transición.

Una vez justificado el marco geográfico y teniendo en cuenta la abundancia de proyectos de transición en Reino Unido, parecería lógico centrar la investigación en proyectos del MCT. Si embargo, a medida que profundizamos en el estudio, comprobamos que no resulta útil limitarnos exclusivamente a iniciativas que pertenezcan a dicho movimiento, ya que son escasas las que dan importancia al arte en sus actividades $y$, por otra parte, también se trabaja la transición desde grupos y artistas al margen del MCT. Por tanto, abriremos el foco para incluir proyectos que trabajen la transición en sentido amplo, pertenezcan o no al MCT. Es más, en algunos de los casos escogidos (Biodivers), el conjunto de acciones se enmarca dentro de los principios de la transición de modo intuitivo, pero sin conocer ni utilizar dicho término en el ámbito de su proyecto. Sin embargo, estas propuestas contribuyen a acercarnos a los retos señalados en el apartado $1.2^{87}$ del capítulo uno, que tomaremos como criterios de selección además de otros que señalamos a continuación:

1. Proyectos/iniciativas que tengan una vinculación especifica con lo local -el territorio o la población del lugar - ya que una de las claves de la transición es fortalecer la resiliencia local.

2. Que actúen (consciente o intuitivamente) de acuerdo con los principios de la transición mencionados en el apartado $1.2 \mathrm{y} / \mathrm{o} 1.3^{88}$ del capítulo uno.

3. Que hagan uso del arte como herramienta de fomento de la transición y, en especial, del arte público.
87 La lucha por descarbonizar la economía
mundial, el reto de comprometer el movimento ambiental con la justicia y la equi-

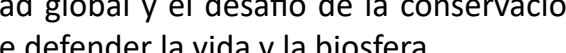

81. Asumir que es imposible un crecimienque el descenso energético es inevitable,

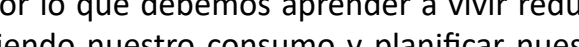

\section{Aumentar la resiliencia de nuestras co-
munidades ante los efectos del pico del pe-} tróleo y el cambio climático.

Importancia de actuar colectivamente
a construir formas de vida más conectadas, más enriquecedoras y que reconozcan los límites biológicos del planeta. 

obras. En primer lugar debemos señalar -como ya comentamos en el capítulo uno apartado 2.3- que trabajamos con un concepto ampliado del arte en sintonía con las ideas de Ukeles (e arte como práctica cotidiana, 1969), Kaprow, (identificación entre arte y vida, 2003) y Beuys (escultura social, 1970) para considerar piezas artísticas los proyectos seleccionados. De este modo las obras no siempre tendrán una materialidad explícita, sino que también considerare mos procesos, acciones y relaciones. Durante la investigación de iniciativas de transición, se ha entrevistado a los participantes de los proyectos para entender el rol del arte en sus actividades. En esa fase, su consideración sobre qué es una creación artística y qué no, es determinante a la hora de que valoren la presencia artística en sus acciones. Según Beuys: «nosotros, todos, somos artistas» (Harlan 2004), pero, ¿es una condición suficiente considerarse artista? Como y mencionamos en el capítulo uno apartado 2.3, los límites de la disciplina no están claramente marcados y en muchos casos encontramos proyectos similares que son considerados artísticos o no según quien ostente la autoría. Como nuestro objetivo no es normativizar un tema tan subjetivo y extenso, hemos optado por escoger solo proyectos con artistas involucrados y reconocidos, o bien que sus componentes consideran artísticas sus actividades, tienen relación con artistas o se reconocen a sí mismos como tales.

En segundo lugar, más que una búsqueda de artistas concretos, nos hemos enfocado en proyectos que puedan enmarcarse dentro de las premisas del arte ecológico que señalamos en el capítulo uno apartado 2.2:

4. Interés en la realización de la obra por tener una reducida huella ecológica como punto ético clave de la estética (Arribas, 2015, p. 201), aunque sin establecer ningún criterio máximo, pero bajo el convencimiento moral de que debemos afrontar la crisis ambiental.

5. Ocuparse de cuestiones relacionadas con la ecología y/o la transición como el reequilibrio, la sostenibilidad, la vida buena generalizable y otros señalados en la descripción del arte ecológico en el capítulo uno apartado 2.3.

Además, señalamos otras condiciones secundarias, aunque no indispensables, como son:

- El protagonismo de la naturaleza (entendida como entorno poco antropizado).

La intención del artista de prom o la transformación social.

Respecto a los artistas, durante el curso de esta investigación hemos sido conscientes de que no hay respuestas únicas, ni soluciones definitivas frente a la urgencia de la crisis ecológico-social. Tampoco existe una posición cerrada desde el mundo del arte sino, más bien, una gradación de posturas. En ese sentido, la diversidad de estrategias cobra importancia y por ello se ha mencionado la variedad de posicionamientos entre los artistas ecológicos, desde aquellos que se definen como artistas transicionales (Neal, 2015), los que no buscan un resultado concreto ni convencer (Los Harrison), los que aportan soluciones más directas (Betsy Damon en Living Water Garden, 1998) u otros que ayudan a cuestionar poéticamente nuestra relación con la naturaleza (Agnes Denes en Wheatfield - A Confrontation, 1982), por citar ejemplos de sobra conocidos. Muchas de las obras de estos artistas como Revival Field de Mel Chin (1991) pueden ver incluso cuestionada su naturaleza artísticas9. Llama la atención que a lo largo de pueden ver incluso cuestionada su naturaleza artisticas. Llama la atención que a lo largo del estudio, en ningún caso, aparte de la propia Neal, se han identificado como artistas transicio-
nales. De hecho, en el caso de The Stove o de Open Jar Collective, el término transición les resulta completamente desconocido ${ }^{90}$ y declaran no sentirse inmersos en la categoría de artistas transicionales ni seguir conscientemente los principios de la transición. De modo que, en el caso de estos creadores, hemos sido nosotros, desde los criterios de selección de esta investigación los que interpretamos su obra en estos términos. Del mismo modo, en el pueblo de Carrícola, como veremos en el capitulo cuatro, la transición a la sostenibilidad se sigue de un modo más intuitivo que cognoscitivo. Pero esto no es óbice para reconocer el valor de sus actividades en favor de la transición a la sostenibilidad. Para cerrar la aclaración de los criterios de selección el tipo de obra en cuanto a su técnica y género es abierto, haciendo hincapié en obras colaborativas. De esta manera seleccionaremos proyectos artísticos que tengan una vinculación con lo local, (ya sea con el territorio, la ciudad o su población), que actúen en consonancia con los retos y principios de la transición señalados (capítulo uno apartados 1.2 y/o 1.3) que traten temas propios del arte ecológico (capítulo uno apartado 2.3), donde los autores $y / 0$ participantes se identifiquen como artistas $y / 0$ tengan la intención de crear obras artísticas siendo conscientes de su huella ecológica.

Como primera conclusión de este estudio, podríamos resaltar la dificultad que ha supuesto encontrar proyectos reales y en vigor que cumplan los criterios planteados dentro del MCT,

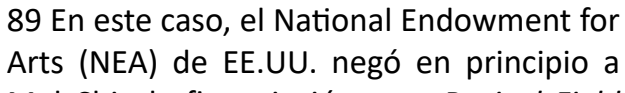
Mel Chin la financiación para Revival Field Nor no ser considerada por el Director del
NEA obra artística. Mel Chin recurrí esta

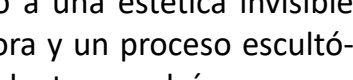
ico en el que las plantas esculpian un nueconsiguió la financiación del NEA gracias a véase: Finkelpearl. T (2000) Dialogues in public art: interviews with Vito Acconci, John Ahearn $\ldots$... [et al.,.
chusetts: The MIT Press.

Comunicaciones personales con Matt Cler Se The Stove (22 de Julio de 2016) y Collective (28 de junio de 2017). 
actuaciones colaborativas y su potencial efecto de transformación social justifican la necesidad

de indagar en este campo. Aunque podriamos haber aportado más ejemplos en este trabajo,

hemos seleccionado estos casos representativos de la variedad de posibilidades que mostramos

en las tablas 1 y 2: dos casos por cada área geográfica y, dentro de cada área, un caso en el que

los artistas promotores/participantes desconocen la definición y principios de la transición pero

la desarrollan intuitivamente, sin una intención expresa, y otro caso en el que los artistas cono-

cen el término, aunque no se identifiquen con la categoriá, pero su intención de transicionar es

clara y expuesta desde el inicio. Pasamos a continuación a detallar estos casos en profundidad

ver cómo se ajustan a nuestros criterios de selección.

\begin{tabular}{|c|c|c|c|c|c|c|}
\hline $\begin{array}{c}\text { CASOS Y PAís } \\
\begin{array}{c}\text { E= España } \\
\text { RU }=\text { Reino Unido }\end{array}\end{array}$ & 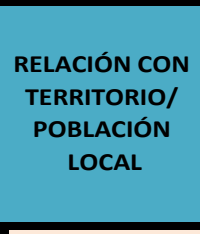 & $\begin{array}{l}\text { ACORED CON } \\
\text { PRRINIIINS DE } \\
\text { LA TRANICIION }\end{array}$ & $\begin{array}{c}\text { PRESTA } \\
\text { ATENCIONA S S } \\
\text { HULLLA } \\
\text { ECOLOLGICA }\end{array}$ & $\begin{array}{l}\text { TRAAT TEMAS } \\
\text { PROPOSOS DEL } \\
\text { ARTE } \\
\text { EColóGico }\end{array}$ & $\begin{array}{l}\text { PRoTAGONISM } \\
\text { OEDLA } \\
\text { NATURALZAA }\end{array}$ & $\begin{array}{c}\text { INTENCIÓN } \\
\text { EXPREAS DEL } \\
\text { ARTISTAI } \\
\text { PROVECTO DE } \\
\text { PROVOCAR } \\
\text { CAMBIOO } \\
\end{array}$ \\
\hline ALMÓCITA (E) & Sí & Si & Sí & Sí & No & Sí \\
\hline BIODIVERS (E) & sí & $\begin{array}{c}\text { Los desconoce } \\
\text { pero se } \\
\text { detecta } \\
\text { acuerdo }\end{array}$ & Sí & $\begin{array}{l}\text { Algunas } \\
\text { obras }\end{array}$ & Sí & $\begin{array}{c}\text { En algunos } \\
\text { casos }\end{array}$ \\
\hline THE STOVE (RU) & si & $\begin{array}{l}\text { Los desconoce } \\
\text { pero se } \\
\text { detecta } \\
\text { acuerdo }\end{array}$ & Algo & Sí & Sí & si \\
\hline $\begin{array}{c}\text { THE } \\
\text { TRASHCATHER' } \\
\text { CARNIVAL (RU) }\end{array}$ & si & si & Sí & Sí & Sí & Sí \\
\hline$D \cup O(R U)$ & Sí & Sí & Sí & Sí & Sí & Sí \\
\hline AULA-R (E) & sí & $\begin{array}{l}\text { Los desconoce } \\
\text { al inicio de la } \\
\text { obra pero hay } \\
\text { acuerdordo }\end{array}$ & Sí & Sí & No & Sí \\
\hline EL CUBO VERDE (E) & Sí & Sí & Algo & Algunos & Sí & \begin{tabular}{|l|}
$\begin{array}{l}\text { En muchos } \\
\text { casos }\end{array}$ \\
\end{tabular} \\
\hline
\end{tabular}

\begin{tabular}{|c|c|c|c|c|}
\hline $\begin{array}{l}\text { CASOS Y ́áRA } \\
\text { GEOGRÁFICA }\end{array}$ & $\begin{array}{c}\text { PERTENECE A } \\
\text { MCT }\end{array}$ & $\begin{array}{l}\text { ARTISTAS } \\
\text { FAMLLARIADOS } \\
\text { CON TRANSIIIÓN }\end{array}$ & $\begin{array}{c}\text { ARTE } \\
\text { COLABORATIVO }\end{array}$ & $\begin{array}{l}\text { PARTICIPANTES } \\
\text { FAMLIARRZLDOS } \\
\text { CON TRANSIIIÓN }\end{array}$ \\
\hline ALMÓCITA (E) & Si & No & Sí & $\begin{array}{l}\text { Sí en algunos } \\
\text { casos }\end{array}$ \\
\hline BIODIVERS (E) & No & $\begin{array}{c}\text { Síen algunos } \\
\text { casos }\end{array}$ & $\begin{array}{c}\text { Síen algunos } \\
\text { casos }\end{array}$ & No \\
\hline THE STOVE (RU) & No & No & Sí & No \\
\hline $\begin{array}{c}\text { THE TRASHCATHERS' } \\
\text { CARNIVAL (RU) }\end{array}$ & Sí & Sí & Sí & Sí \\
\hline DUO (RU) & No & Sí & Sí & $\begin{array}{c}\text { Sí en algunos } \\
\text { casos }\end{array}$ \\
\hline AULA-R (E) & No & Sí & Sí & No \\
\hline EL CUBO VERDE (E) & No & $\begin{array}{c}\text { Sí en algunos } \\
\text { casos }\end{array}$ & $\begin{array}{l}\text { Sí en la mayoría } \\
\text { de casos }\end{array}$ & No tenemos datos \\
\hline
\end{tabular}

Estos casos de estudio serán agrupados en los capítulos tres y cuatro según su pertenenPros paction a los principios de Neal (2015) y los puntos de tensión/clave. Producto de este análisis veremos qué funciones cumple la creación artística en estos contextos particulares para tratar de ampliar la comprensión del lugar del arte en la transformación social. En el capítulo cinco se realizará una comparativa de todos los proyectos que permitirá obtener conclusiones respecto del papel del arte en la transición a la sostenibilidad.

Ya que nos proponemos comprender el lugar que ocupa el arte en la transición, desentrañar qué aposta de diferente y detectar novedades, es preciso revisar las funciones que está desempeñando en contextos de cambio ecosocial. Intentaremos abarcar un amplio espectro de funcionalidades desde las más clásicas (representar, ilustrar, comunicar) hasta otras más actuales (empoderar, conectar disciplinas) sin pretender dar un listado cerrado de usos $y$, conscientes de que la evolución del arte dará lugar a nuevas utilidades. Mencionaremos brevemente aquellos proyectos de las iniciativas de transición españolas que han demostrado alguna relación con 


\section{FUNCIONES DEL ARTE Y ARTISTAS EN PROYECTOS DE TRANSICIÓN A LA SOSTENIBILIDAD}

Ya hemos introducido a lo largo del capítulo uno algunas de las funciones que está realizando el arte de modo general en distintos ámbitos. Nos proponemos ahora identificar cómo zando el arte de modo general en distintos ámbitos. Nos proponemos ahora identificar cómo se están cumpliendo esas funciones en con textos de transición. Como deciamos al respecto de la efectividad y la estettica en el capitulo uno, para un sector del mundo artístico, hablar de utilidad del arte es un anatema, (incluyendo, claro está, su valor de utilidad para educar en la ética ecologica). Los defensores del tarte por el arten claman su autonomia en nombre de la libertad creadora y muchos niegan la capacidad del arte para «educar moralmente» (argumento de la trivialidad cognitiva), o nuestra habilidad para comprobar sus efectos (argumento anticonsecuencialista) (Arribas, 2015, pp. 203-204). Por el contrario, hemos visto autoras como Neal que abogan por un arte transicional, definido como arte al servicio de la vida. Aunque en este texto coincidimos con Neal, pensamos que ambas posturas deben coexistir en un equilibrio diverso ya que, siguiendo un esquema biomimetico de pensamiento, la diversidad de posturas y la ausencia de dogmas en su definición, permite que el arte se adapte, mute e incorpore los cambios, es decir, le otorga resiliencia. Y sin duda, las funciones del arte se han ido diversificando conforme evolucionan las sociedades desde un arte más representativo e ilustrativo, hasta un arte cada vez más inmiscuido en asuntos sociales, un arte que valora el proceso y la acción, y no solo el resultado objetual. Si la necesidad del momento actual es aunar fuerzas desde todas las disciplinas, poner el arte a trabajar al servicio de una sociedad que necesita transformarse, tiene todo el sentido para nosotros $y$ pars otros muchos autores $y$ artistas (Balaguer; Novo;Albelda; Loren Haley; García Cano) Los tiempos instan a superar la concepción seneralizada del arte como ;e leite estético despojado de toda función salvo la ilustrativa/decortiva. Durante la investigación hemos podido corrobora nuda funciones citadas por expertos de distintos ámbitos queción cionas y menos populares que necesitarán ejemplificarse. Nos proponemos comprobar cuáles de estas funciones del arte están aplicándose a la transición y detectar nuevas aplicaciones. Para ell hemos encuestado y entrevistado a artistas y participantes de proyectos fuera y dentro del MC Respecto a éstos ulitus, en ade ante en este captulo, habra de entenderse que nos referimos solo a aquellas iniciativas de la Red de Transicion española que declaran incluir el arte en sus actividades ${ }^{9}$

\subsection{ILUSTRAR, REPRESENTAR, COMUNICAR}

Es de sobra conocido que el arte ha acompañado desde sus inicios (y sigue haciéndolo) a arquitectura y la ciencia aunque, al contrario de ésta última, su propósito no es la explicación

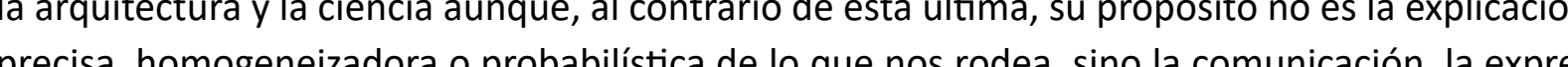
precisa, hom sión o la materialzacion de lo invisible (Klee) entre otras finallades (Novo, 2009). No obstante, el arte ha contribuido a la precision descriptiva del mundo en disciplinas como la botánica y la anatomía, entre tantas otras, que se han valido del dibujo y la ilustración científica durante siglos. Pero su valor en la transición no debe limitarse a la muestra de resultados tecno-científicos o al papel de complemento estético. El movimiento ecologista ha sabido comprender el potencial del arte para ilustrar el deterioro ambiental especialmente a través del documental y la imagen gráfica. Prueba de ello podemos citar el corto Breathe in, breathe out de la campaña de Greenpeace Defending Our Oceans de 2006, con cierto aire poético; o el escatológico audiovisual Cow $(2007)^{92}$ realizado por Johan Renk para la campaña sobre el cambio climático SOS Live Earth. Gracias a una estética atractiva se facilita la expansión del mensaje incluso hacia públicos no interesados en la sostenibilidad. Numerosas obras, como las de la exposición Vórtices de Daniel Canogar (2011) para el Canal de Isabel II o Greenhouse Britain (2007-2009) de los Harrison demuestran la capacidad de los artistas para visibilizar las consecuencias de la crisis ecológica, en muchos casos con la intención de convencer al público de cambiar sus hábitos como veremos en el siguiente epígrafe.

En cuanto a la aplicación del arte en proyectos de transición desde esta perspectiva, la icos para comunicarse co el público. Casi todas las iniciativas de transición cuentan con esta capacidad del arte para or- 
93 Véase en: http://andaluciaresiliente.net/ ganizar sus video-foros, comunicar sus actividades a través de cartelería y video o decorar sus espacios. Podemos mencionar asi sus a tividividades del grupo Granollers en transició (GenT): (GenT): su primer ciclo de cince lent Running, de Douglas Trumbull, Demain, de Cyril Dyon y Mellanie Laurent, In transition $1.0 \mathrm{de}$ Emma Goude) completando el ciclo con la presentación del libro Colapso, de Carlos Taibo, y una Intervención mural colaborativa en la calle: EnaMURát (Gent, comunicación personal, 24 de octubre de 2017). Para la intervención del muro se invitó a la ciudadanía a participar pintando y construyendo un huerto vertical. El objetivo de esta intervención era difundir el proyecto de GenT, así como hacer una reflexión sobre el espacio público y su uso. También se puede mencionar la actividad del grupo Jaén en transición (JET), que ilustra la actividad de varios grupos de transición de la región andaluza en una exposición fotográfica itinerante denominada «Semillas de Resiliencia» durante la campaña Andalucía Resiliente ${ }^{93}$.

\subsection{CONCIENCIAR}

En el capítulo uno apartado 2.1 se ha tratado de explicar cómo el lenguaje y la cultura contribuyen a avanzar en el conocimiento del mundo y, en combinación con la emoción, facilitan el aprendizaje y la creación de conciencia. Decíamos que la experiencia estética y la emoción el aprendizaje y la creación de conciencia. Deciamos que la experiencia estética y la emoción son elementos clave de toda obra artistica que pueden despertar la curiosidad hacia un nuevo conocimiento, por lo que contribuyen al aprendizaje y el desarrollo de la conciencia ambiental. Las campañas ecologistas como las antes mencionadas, o las institucionales (por ejemplo las de protección del bosque frente a incendios), tienen un claro objetivo de concienciarnos para transformar nuestras conductas respecto al entorno. Sin embargo, segun deciamos, entre los artistas existe toda una gradación de opiniones al respecto de convencer al público de cambiar su actitud o limitarse a cuestionar, sugerir, escandalizar,... Esta misma dicotomía la hemos encontrado en nuestros casos de estudio aplicados a la transición, como veremos en los capítulos tre y cuatro. En los casos de Biodivers o Nithraid, la concienciación es más bien una consecuencia posible, pero no un objetivo consciente de la acción artística y, en otros como DUO o The Trashcachers' Carnival, es claramente perseguido. En general, los grupos de transición aprovechan la capacidad concienciadora del arte de una forma básica, iniciática, por medio de documentales con los que suelen atraer a posibles participantes. Suele ser la fase inicial a partir de la cual se forma el grupo, un ejemplo claro de ello son los cinefórums del proyecto pionero de Totnes Transition Town en Reino Unido, el recién comentado ciclo de GenTo el organizado por el grupo Granada en transición (GET) (Lucas Valera, comunicación personal, 13 de diciembre 2017). La mitad de las iniciativas de transición encuestadas cuentan con esta función del arte en sus actividades y un ejemplo claro de su uso en otras fases del grupo sería el proyecto Tu basura por cultura ${ }^{94}$ del grupo de transición de Torrelavega y Comarca en Transición. En éste se premiaba los participantes (estudiantes de primaria y secundaria) con actividades artísticas gratuitas (taller de violonchelo, ilustración y teatro) a cambio de colaborar en un proyecto de compostaje en el huerto del colegio (Dolores Poliz, comunicación personal, 9 de enero de 2018). Arte a cambio de concienciarse del valor de la basura orgánica.

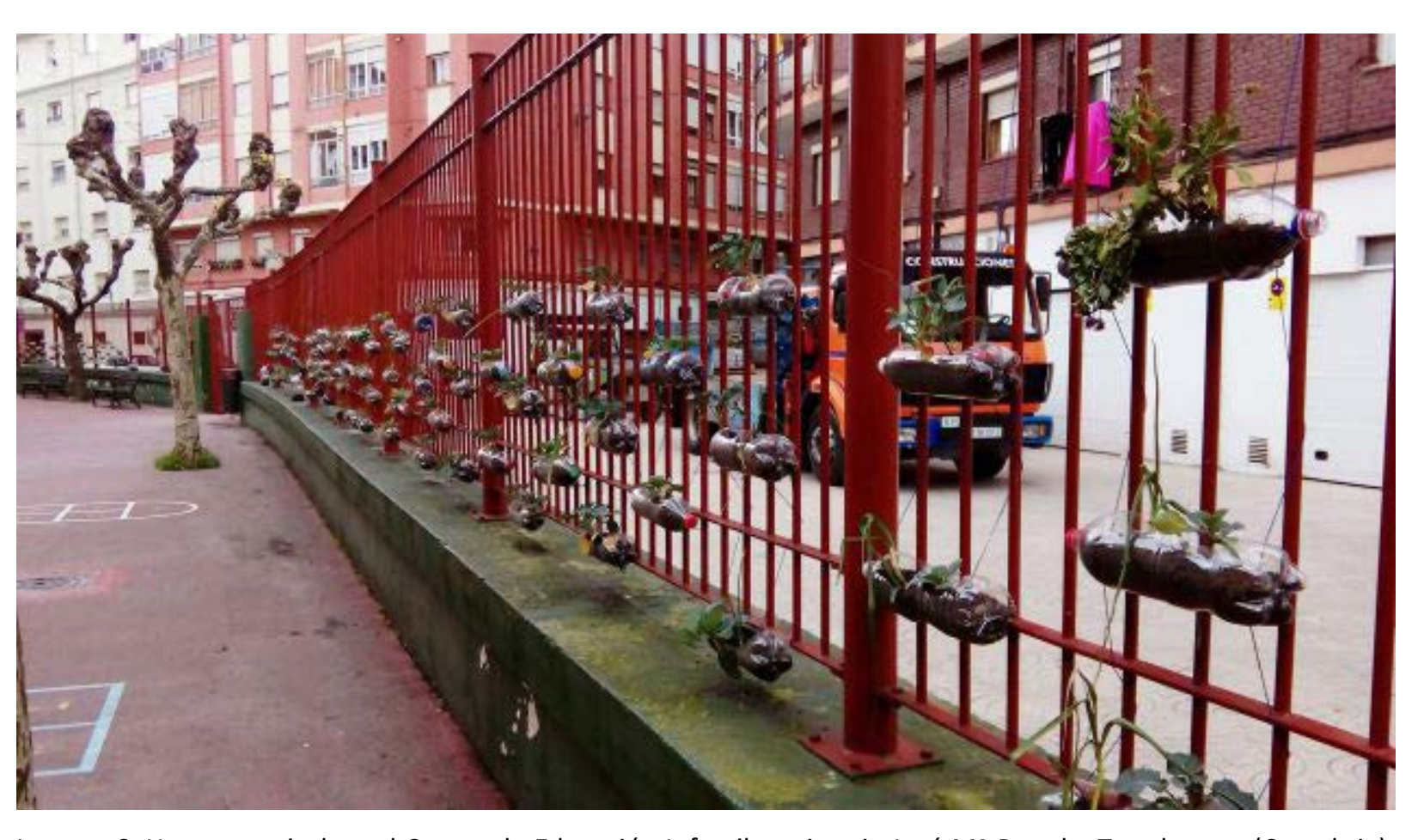

Imagen 6. Huerto vertical en el Centro de Ed
Fuente: Torrelavega y Comarca en Transición 


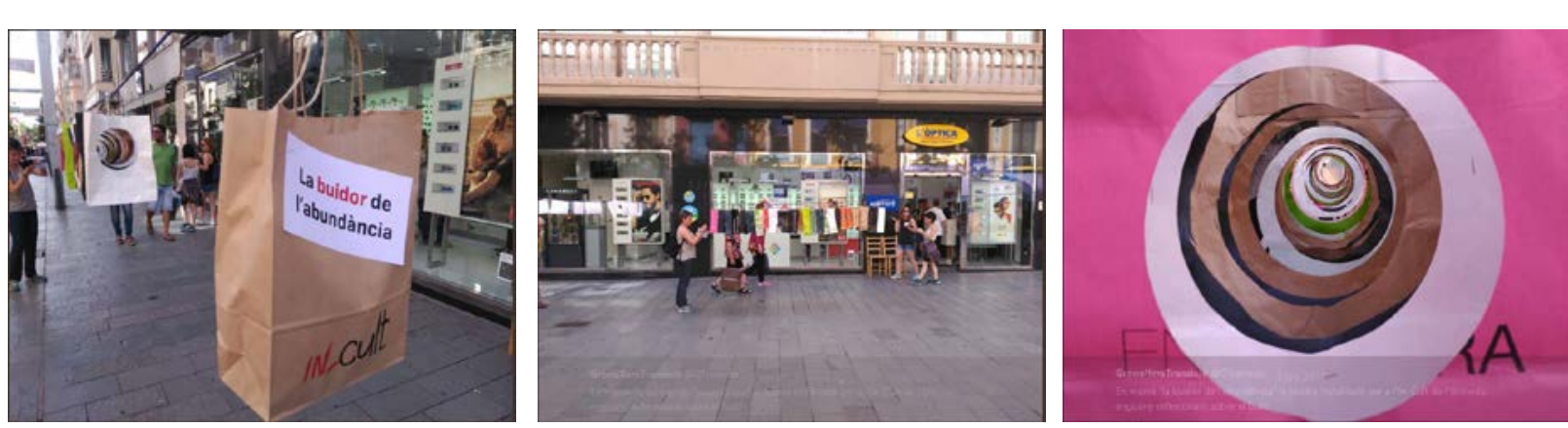

Inágenes 7, 8 y 9. La buidor de l'abundància. Fuente: GenT.

\subsection{DESARROLLAR EMPATÍA}

En el capítulo uno apartado 2.1 hemos comentado ya la importancia del relato por encima de las cifras y estadísticas y la identificación emocional por encima de la comprensión racional ( (n) de hacer cosas que la información no puede [.... lleva nuestra mente a nuevos lugares, llega a nuestro corazón y se basa en nuestros sentmientos visceraless) (The Chartered Institution of Water and environ Ethical Aesthetic Impulse, de los artistas Reiko Goto y Tim Collins, que activa nuestra empatía hacia los árboles como ya comentamos en dicho apartado. Dentro del MCT Hopkins añade a respecto del desarrollo de empatía: «mucha literatura medioambiental y sobre el pico de petróleo es muy fatalista y cargada de datos técnicos y la reacción de la mayoría es pasar de ella. ¿Cómo podemos diseñar caminos para el declive energético, que hagan sentir viva, positiva a la gente en este proceso de transformación de la sociedad?» (Ecohabitar, 2013). En el proyecto
Biodivers que estudiaremos en el capítulo cuatro, aportan una respuesta: el arte emplazado en

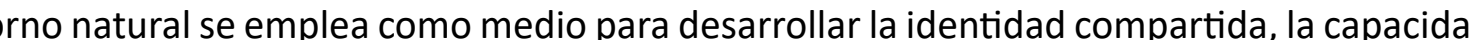
de observación y de escucha atenta. El descubrimiento de la obra y su relación con el medio, despierta la empatía con el entorno, favorece el encuentro, la atención consciente a lo que nos rodea. Áreas y paisajes antes poco frecuentados son ahora objeto de nuestro interés a través de la mirada atenta que inspira el arte. Asimismo, más de la mitad de las iniclativas de transición declaran ser conscientes de la capacidad empática del arte y utilizarla para atraer al público, pero no encontramos ninguna obra - aparte de los documentales mostrados - en la que se trabaje claramente esta habilidad dentro del MCT sin confundirla con la simpatí.

\subsection{IMAGINAR, CREAR VISIÓN}

Una de las primeras funciones que adjudicamos al arte es la de imaginar futuros, posibles o imposibles, alternativos, potenciales, utópicos o distópicos. La eco-narrativa ofrece numero sos ejemplos de ello desde la literatura ambiental, como la novela de ficción realista La banda de la tenaza (1975), la distopía Memory of Water (2014), la realista El corazón de la tierra (2001) la futurista especulativa The Fifth Sacred Thing (1994) entre tantas otras ${ }^{\circ}$. Desde la práctica de arte visual el grupo Platform en su manifiesto de 1993 comenta que, a la par que estas imáge nes se discuten, se describen y se desarrollan, van gradualmente adquiriendo forma y pasando del plano de la imaginación y el deseo a la realidad (The Chartered Institution of Water and environmental management, 2012, p. 32). El esfuerzo de imaginar un futuro diferente, como en el proyecto Plan de Acción ante el Declive Energético (EDAP) de Kinsale ${ }^{97}$, o como veremos en el capitulo cuatro con los proyectos We Live With Water y DUO, constituye un primer paso de la acción. Es necesario tener un objetivo para ver hacia qué queremos transicionar. De ahí la importancia de las eco-narraciones o de las visiones artísticas, utópicas o no. Es, por tanto, una función del arte propia de etapas iniciales de los proyectos. En el entorno del MCT «el "cuento futurista" o vision tale sirve a la colectividad para entusiasmarse en la construcción de escenarios posibles y deseables, diseñados desde el ingenio y la creatividad» (Zarzuela-Aragón, 2009). La imaginación de futuros posibles abre la puerta de la creación. No hay duda, pues, del rol de
96 Véase la web del $1+D$ Humanidades
ambientales para un listado más exhaustivo: http://ecohumanidades.webs.upv.es/ (9)

Proyecto «en el que se trabaja de manena visión de cómo ven su pueblo a 20-30 años vista, para luego volver a empezar tevecto pilito de este enfoque se realizó para 2005, con el soporte de su Ayuntamiento. Constituyo el proyecto de fin de curso de trataba de averiguar cómo kinsale podría "navegar" en estos tiempos de incertidumbre, proponiendo una visión clara de cómo puede ser un futuro de baja una hoja de ruta a seguir para conseguirlo. dría de la mitad del actual combustible fósil vace esto tendra efectos sobre todos los Ua la mayoria de aspectos de la vida juventud y la comunidad, la educación, la wivienda, la economía y la sostenibililidad, la yla energia») (Scotti, 2008, p. 41) 
98 Véase en: https://www.
watch?v=zyUquZUZBJc\&t=3s

99 Véase en: https://granollersentransicio
wordpress.com/2014/11/26/carril-bici-dela-transicio-a-lin-cult/ los casos de Almócita (que veremos en el capítulo tres) y Arico reconocen su empleo desde

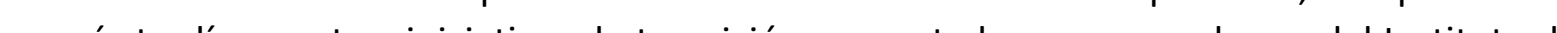

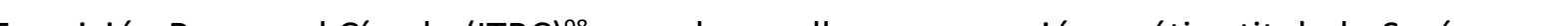

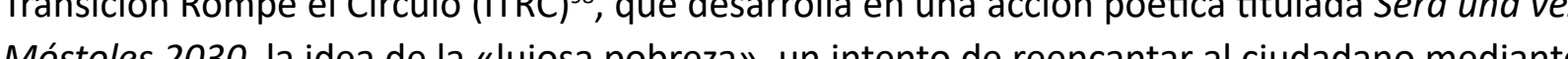
Móstoles 2030, la idea de la (lujosa pobrezan, un intento de reencantar al ciudadano mediante visiones de futuro estimulantes (Instituto de Transición Rompe el Círculo, 2015).

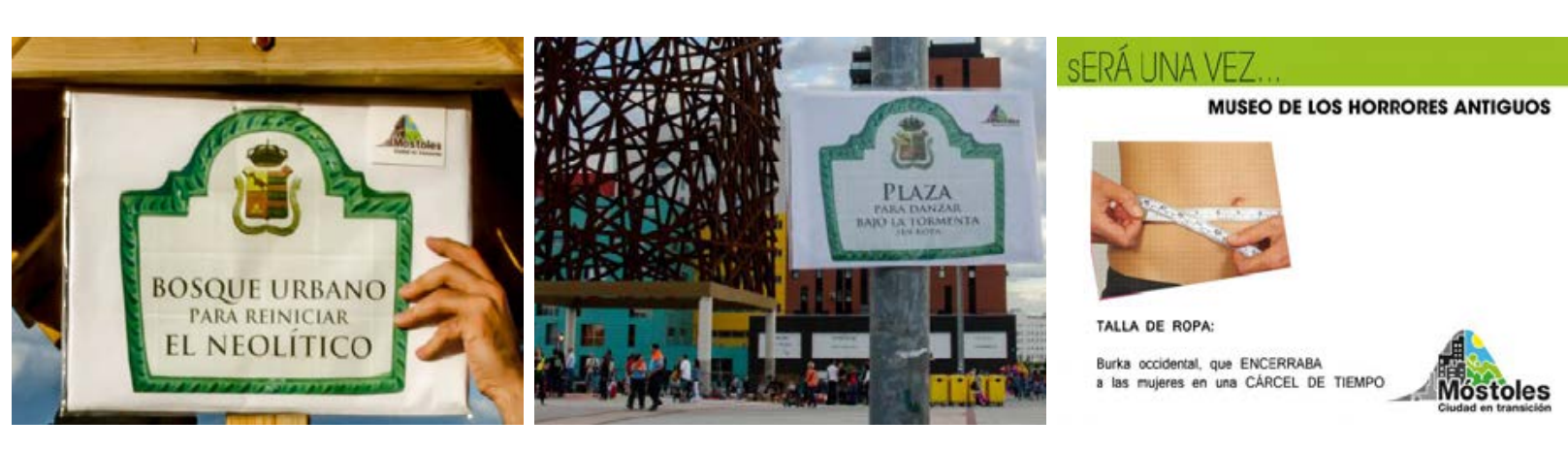
Imágenes 10 a 12. Distintas obras ubicadas en el espacio urbano que expresan visiones del futuro de la ciudad.
Fuente: ITRC

En una línea similar actúa el grupo de transición GenT con Carril bici de la transición (2014). Esta iniciativa ha colaborado en el encuentro artístico In-cult de Granollers junto a la asociación Granollers Pedala en la realización de este video, que relata la visión del presente y del futuro imaginado de la ciudad hasta 2030

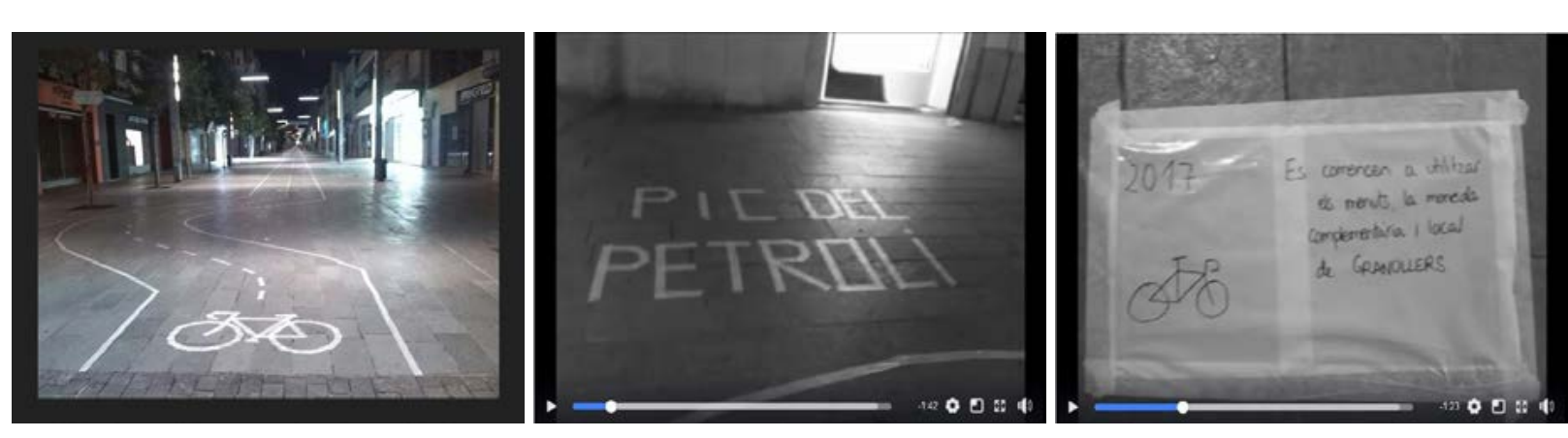

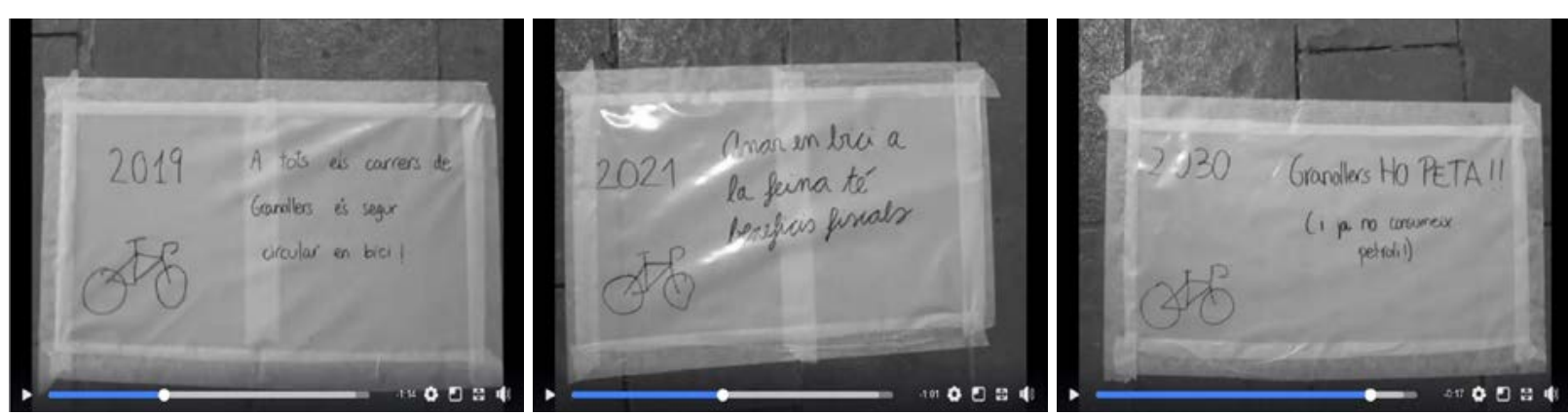

Imágenes 13-18. Fragmentos seleccionados del video Carril bici de la transición. Fuente: Granollers en transició
Granollers Pedala. Disponible en: https://www.facebook.com/granollerspedala/videos/417202438433096/

2.5 OFRECER SOLUCIONES ALTERNATIVAS O PROYECTOS PILOTO

«Construir alternativas es siempre un acto de esperanza -la encarnación del rechazo del presente» (Neal, $2015, \mathrm{p} .6$

Si damos un paso más desde la quimera inicial hacia la puesta en práctica de estas visiones imaginadas, se hace evidente que además de tener claros nuestros objetivos, es de suma importancia que éstos nos resulten atractivos y deseables (Albelda y Sgaramella, 2015, p. 14) la par que factibles. Jessica Domínguez, del Centro Unesco en el País Vasco comenta: «Todas las soluciones serán creativas, o no serán" y efectivamente, el arte tiene la facultad de contribuir, en ocasiones, a solucionar problemas puntuales, como en el caso de la rehabilitación de espacios o la planificación estratégica. Un ejemplo es el proyecto de los Harrison adoptado por el gobierno holandés Green Heart visión (1994-2002). Según comenta Newton Harrison al respecto del mismo, los artistas tienen «el poder de no tener poder ${ }^{100}$ (Harrison, 2017, 0:1:55) y eso les permite tener libertad para expresarse sin ser penalizados por decir lo que verdaderamente piensan. El reto para él es conseguir tener una voz en la mesa de negociación, y la forma de conseguirlo no es actuando como los planificadores sino a través del arte, siendo capaces de ver lo que ellos no ven. Una aproximación al margen de la ortodoxia aceptada puede ofrecer soluciones $y$ oportunidades que no se podrían alcanzar a través de los métodos convencionales (Collins, 2003). Pero, como dećamos, ninguna disciplina o sector por sí mismo puede dar respuesta a ta enom 


\subsection{CONECTAR, CREAR COMUNIDAD, REDES Y ESPACIOS DE RELACION ENTRE}

PERSONAS

A lo largo del capítulo uno hemos hecho alusión en varias ocasiones al papel facilitador de los artistas. Su habilidad para crear espacios de relación nuevos ha sido ejemplificada ampliamente con los Oakland Projects de lacy Sus performances trataban de poner en conexión colectivos del mismo barrio separados h hetuly sus por el miedo y a exclusín social ta misma autora firma haber persuido tambén la alianza con la adminstraćn pública (Lacy 2013) en sus proyectos, auncer pera de coptación. Tambén desd el MCT se busca esa collition

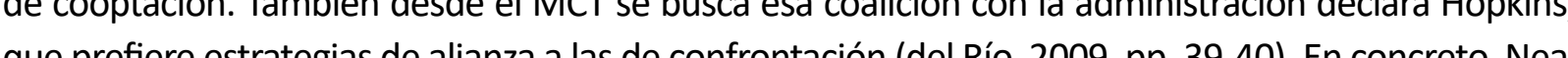
que prefiere estrateglas de allanza a las de confrontacion (del $\mathrm{No}, 2009, \mathrm{pp}$. 39-40). En concreto, Nea 8) y explica:

Chen destaca además la habilidad de los artistas para establecer contactos y redes locales globales (institucionales o no) entre las que transmitir experiencias para construir «una cultura de la resistencia» (Chen, 2015). Profundizaremos en estas redes en el capítulo cuatro, cuando presentemos la red de espacios de arte en el campo llamada El cubo verde.

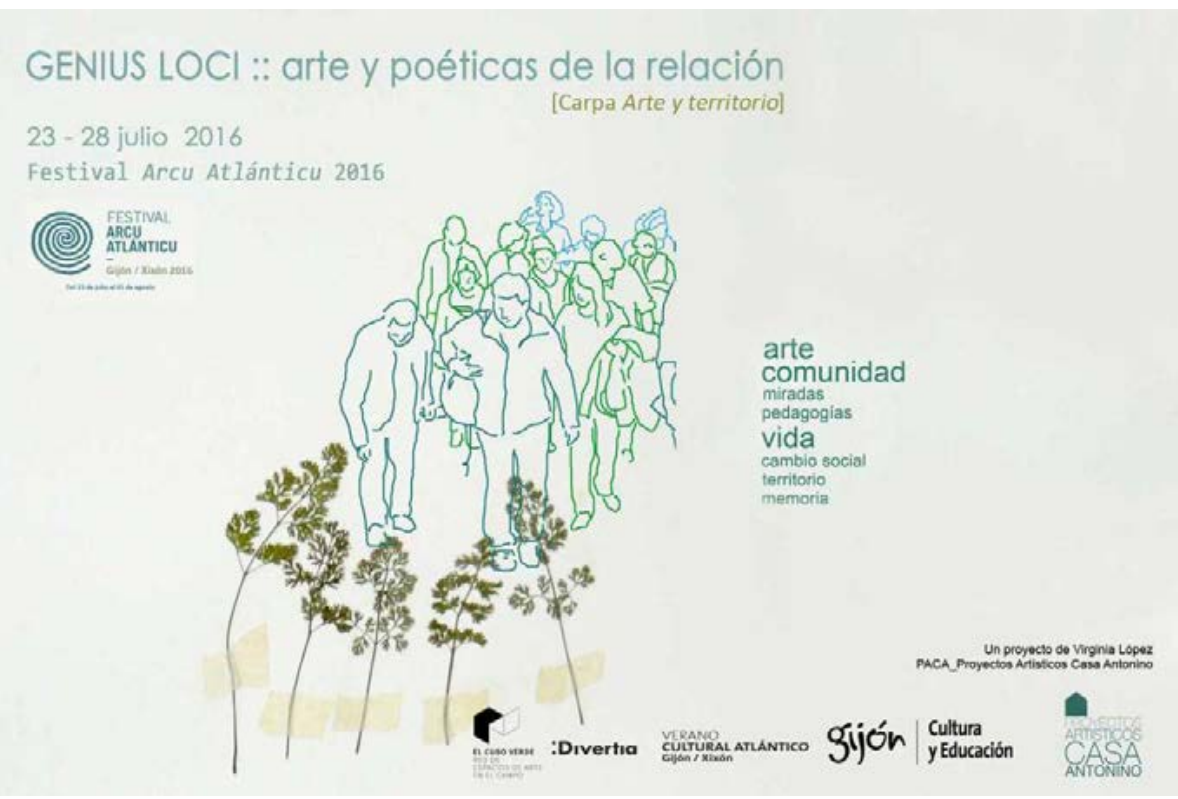
Imagen 19. Festival Arcu Attánticu de Gijón con presencia de la Red El Cubo Verde en 2016 en Gijón. Fuente: Diseño
de Virginia López Fernández, 2016.

Por otra parte, dentro del MCT en España encontramos varios ejemplos de producciones creativas que buscan crear comunidad y espacios de relación, como los festivales artísticos $y$ musicales de Almócita y Arico, que se estudiarán en el capítulo cuatro, donde los visitantes y habitantes son invitados a participar en la acción plástica o musical. También hemos encontrado varios casos de coros de transición, como los del grupo GET o Transició Vilanova i la Geltú 
101 Éste último especialmente activo, véa- $\quad(\mathrm{VNG})^{101}$ que reúnen una veintena de personas cada uno. Otro espacio relacional que conecta ge-pete.html al con un cáe y un espacio de taller donde intercambiar conocimientos sobre como reparar, coser, 102 Véase en: https://granadaentransicion.

reciclerial y un video explicativo en: ht-
tps://www.youtube.com/watch?v=chTyH-

tps://www
$7 J \mathrm{~h} G \mathrm{~W}$

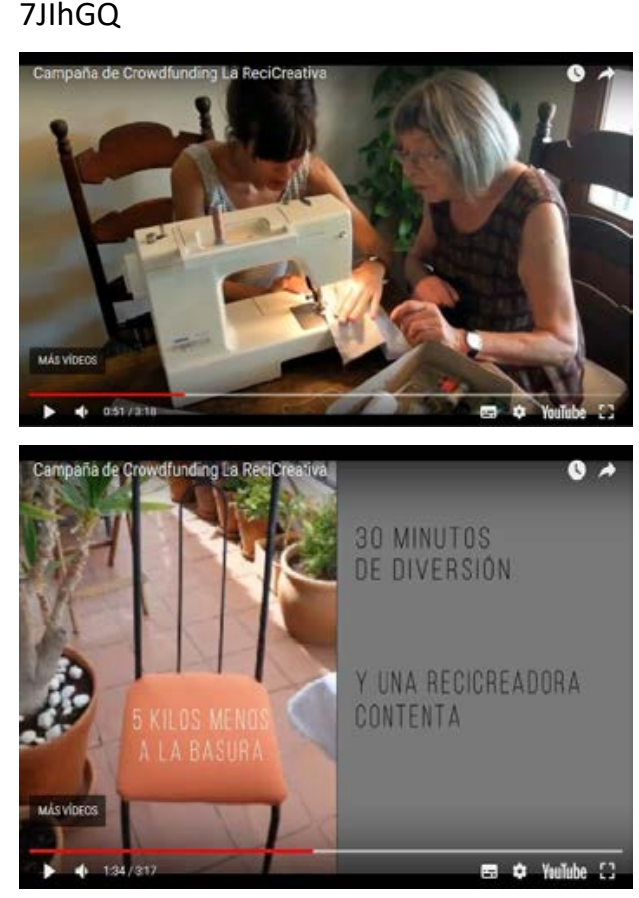

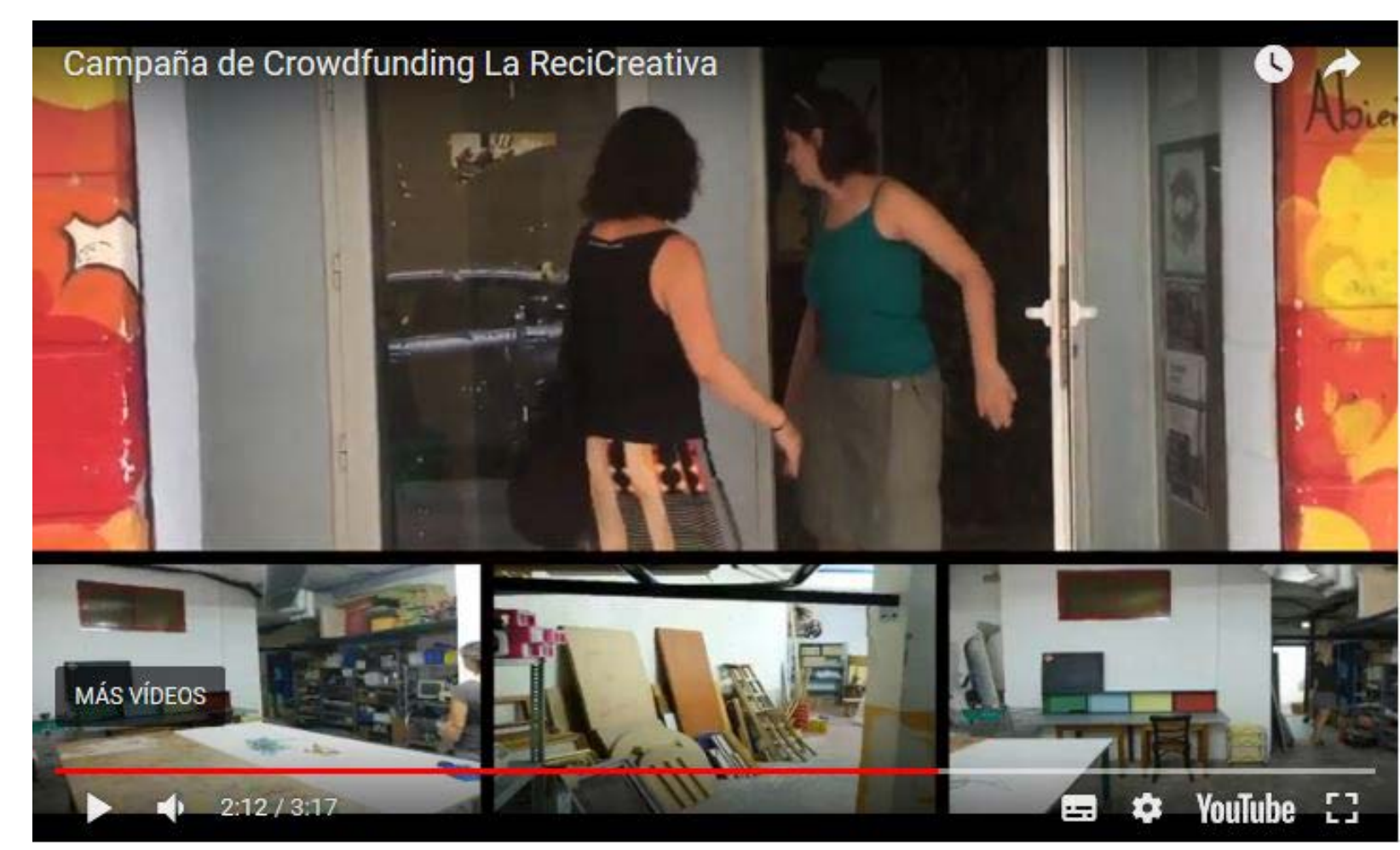

Imágenes 20, 21 y 22. Fragmentos del video promocional de la Recicreativa donde se puede ver el espacio. Fuente: https://www.youtube.com/watch?time_continue=18v=chTyH7JlhGQ

El diálogo es una pieza clave en el establecimiento de estas conexiones. Pero ya hemos comentado que no cualquier diálo en ta conversación dialógica exige habilidades especiales de comentado que no cualquier diâlogo. La conversación dialógica exige habilidades especiales de escucha atenta, asertividad, respeto, curiosidad y apertura. No se trata de una construcción de consensos, sino de facilitar el espacio para que todos y todas se encuentren y expresen como en los Oakland Projects. Es lo que Amy Sharrocks llama la arquitectura del momento construido entre las personas (Neal, 2015, p. 6). Así, por ejemplo, en los murales que se pintan cada año en el festival La Noche con Alma en Almócita intervienen los lugareños aportando sus ideas y opiniones que son recogidas por los artistas.

Hasta aquí hemos hablado de proyectos que potencian las relaciones entre individuos. en el capitulo cuatro con el provecto Nithraid, aue se centra fundamentalmente en crear un nuevo espacio de conexión entre la población de Dumfries y su rio, que permita reinventar un nexo de unión Otro ejemplo es la propuesta de Biodivers, donde los propios habitantes en conCon en esa nueva conexión.

\subsection{RESTAURAR, RECUPERAR EL ENTORNO}

Son de sobra conocidos los casos de artistas que trabajan en sus obras la restauración de espacios como Veden Taika de Jackie Brookner- (2007-9) o los ya mencionados Living Water Garden, (1998) de Betsy Damon, Fair Park Lagoon (1981-86) de Patricia Johansson o Revival Field (1991-hoy) de Mel Chin. Luis Balaguer reúne varios casos internacionales en «Sinergias entre las intervenciones artísticas en el territorio y la restauración ecológica: ámbitos para el encuentro» (2015). En nuestra investigación los casos de Biodivers (en el entorno natural) y Almócita (en lo urbano), que veremos en profundidad en el capítulo cuatro, ejemplifican cierta recuperación de espacios naturales y patrimonio arquitectónico a través del arte.

\subsection{CREAR SÍMBOLOS E IDENTIDAD}

Clive Adams, director del Centro de Arte Contemporáneo y Mundo natural del parque forestal de Haldon en Exeter (Reino Unido), comenta que, cuando la civilización se ha enfrentado a una degradación ambiental -como en Roma durante el s. I A.C. y en los sesenta ante la evidente destrucción de los ecosistemas que puso de manifiesto Rachel Carson-, «nuevas formas
103 Véase en http://jackiebrookner.com/ -taika/

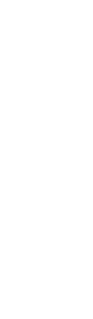



a lo largo de la historia por reyes, papas, presidentes y dictadores para definir su identidad legitimar su poder (The Chartered Institution of Water and environmental management, 2012, p. 36). Según comentamos en la anterior función de desarrollo de la empatía, recordamos más los símbolos, relatos e imágenes que las consignas, conceptos y estadísticas (Albelda y Sgaramella, 2015, p. 23). En la creación de símbolos el arte ha acompañado a numerosas revoluciones culturales e ideológicas, desde los totalitarismos a la revolución beat o feminista (Albelda y Sgaramella, 2015, pp. 12-13). Martinell, reconoce que: «los artistas son capaces de generar símbolos que permiten a la comunidad identificarse» (2018). El cambio de cosmovisión por e que apostamos necesita una estética que lo apoye y difunda, pero que permita la identificación de todos y todas, es decir, no funcionarían patrones simbólicos cerrados y excluyentes, sino una estética que prime precisamente la diversidad y la complejidad. Por ello, Albelda y Sgaramella comentan que una estética pural no es necesariamente menos empática que los modelos estéticos uniformantes (2015). En cualquier caso, «toda revolución exitosa utiliza la estética, la ime

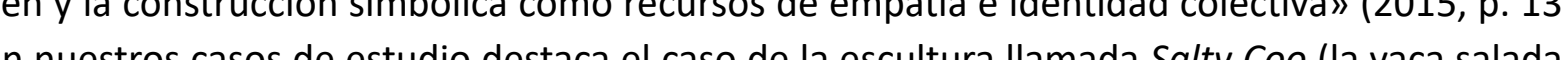
un simbolo inventado por los artistas de The Stove para el proy co Nithraid que raca salada), un pasado comercial delio, a través del cual se transportaba ganado. La escullura es procesionada por la ciudad y los ganadores de la carrera tienen el derecho a lanzar la sally Coo a la corriente, en un acto simbolico de reconocimento de su importancia en el pasado de la ciudad. En el caso de proyectos de transición, veremos en el capitulo cuatro, como en el pueblo de Almócita los murales artisticos de sus fachadas han contribuido a crear una identidad compartida lo cual, ha fomentado un cambio de actitud en sus habitantes. Aún es más patente esta creación de identidad a través del arte en el caso del pueblo de Carrícola, que considera la convocatoria artística Biodivers como un hito que ha marcado un punto de inflexión en la vida de la población.

2.9 FOMENTAR LA CIUDADANÍA CRÍTICA, AGITAR, DENUNCIAR

La Institución Chartered Instich of Water and Environmental Management (CIWEM), justifica en la Declaración de su política ${ }^{104}$

\section{Las artes a menudo nos ayudan a entender los problemas ambientales que enfrenta el mundo, y pueden traer algunas de las soluciones a su alcance, a escala humana. Ellas nos informan, inspiran y muestran cómo las cosas pueden ser transformadas. Esto es vital en la generación de pensamiento critico para nuestra gestión del medio ambiente (Management, 2009, p. 1).}

En España, Domínguez, del Centro Unesco en el País Vasco, coincide claramente: «el arte nos da herramientas para fomentar una ciudadanía crítica» (2018). Esta función de denuncia y pensamiento crítico es de las más primordiales y, en el campo ambiental, lleva poniendose en práctica desde los sesenta con obras, como por ejemplo, las de Nicolas García Uriburu. El artista y arquitecto argentino ha coloreado de verde las aguas de diversos lugares emblemáticos de mundo (Bienal de Arte de Venecia (1968), Fuentes del Trocadero en Paris (1972); fuente de otras) para protestar contra la contaminación de las mismas. Esta capacidad de los artistas para la denuncia atractiva ha sido aprovechada por las asociaciones ecologistas como Greenpeace. En 2010 colaboró con Uriburu en la tinción de verde de las aguas del río porteño Matanza-Riachuelo el Día Internacional del Agua, para protestar y reclamar, de esta forma, el saneamiento definitivo de la cunca, que fue incluida entre de los diez sitios más contaminados del munto (2013). Aunque lando ción de ción con tenido

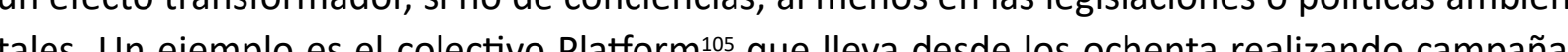

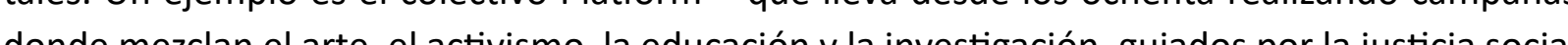
donde mezlan elarte, el activismo, la educación y la investigacion, guiados por la justicia socia y ecológica. En concreto, desde 1995, se han enfocado en los impactos de la industria del petróleo en lo social, económicoy mediombiental, denunciando, por ejemplo, la financiacion de los grandes museos británicos de arte contemporáneo a través de empresas como BP y Shell, que
104 Única institución benéfica con carácter
real —en el sentido monárquico del término- en Reino Unido dedicada al agua y la 105 Véase http://platformlondon.org/ 


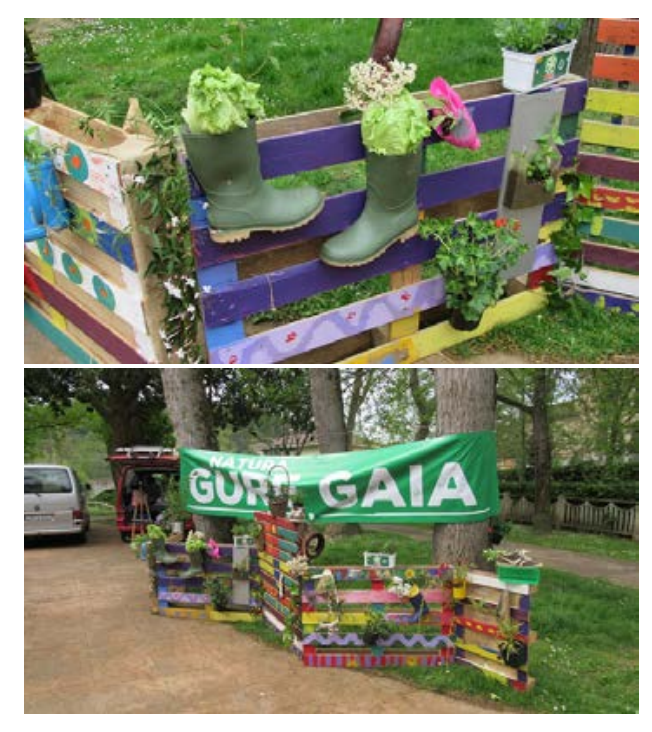

Imágenes 23 y 24. Pallets decorados cola-
borativamente para la acción reivindicativa. borativamente para la acción reivindicativa.
Fuente: Butroi en Transición

106 El Diccionario panhispánico de dudas
de la Real Academia Española en 2005 define empoderar (se): «calco del inglés to empower, que se emplea en textos de so-
ciología politica con el sentido de "conceder poder la un colectivo desfavorecido

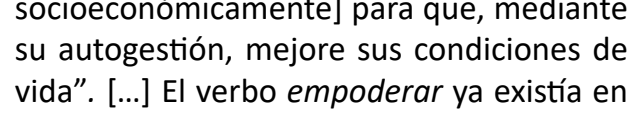
español como variante desusada de apode-
rar. Su resucitación con este nuevo sentido tiene la ventaja, sobre apoderar, de usarse hoy únicamente con este significado espe-
cíico.)

107 Véase en: http://www.cabanyal.com/
nou/portes-obertes/?lang=es tanto daño causan en paises del tercer mundo. Su insistente labor de denuncia artística ha sido al a financiación de la empresa petrolera $B$ 2017 (Romer y Richens, 2016).

La denuncia, la agitación o el fomento de la ciudadanía crítica están presentes en la mitad de las iniciativas de transición según consideran los grupos de GenT, Torrelavega y Comarca en Transición, Miengo en Transición, Butroi en Transición y Almócita Activa la Transición encuestados, aunque a un nivel muy básico desde lo artístico. Por ejemplo, Butroi en Transición en 2015, plantearon en Arrieta una acción creativa con pallets que fuera circular (completa, integral), colaborativa y educativa para los menores participantes y que luego sirviera para la acción estiva/reivindicativa Alternatiben Herria (personas alternativas). A raíz de ello, «más personas Arrieta y posteriormente en Bilbao conocen y comparten el interés ecologista del grupo de transición» (Zuluaga Martin y Lertxundi Aretxaga comunicación personal, 20 de marzo de 2018).

\subsection{EMPODERAR}

Empoderar ${ }^{106}$ es un antiguo verbo español que se ha retomado como traducción del inlés to empower, para recoger aquellas experiencias sociales en las que un grupo desfavorecido dquiere fuerza y puede ejercer presión social. Numerosos ejemplos responden a esta función

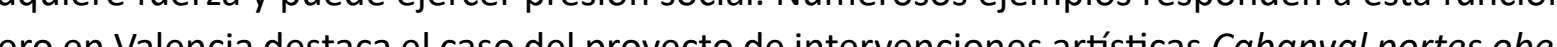
te la especula in es histórico barrio del Cabanyal pero poco a poco se convirtió también en a reflexiona sobre la ciudad, el modo de desa vollo popusto por la ideog - fexlexionar sobre la ciudad, el modelo de desarrolio propuesto por la ideologia neoliberal doluchas sociales y el activismo, organizados en el colectivo autogestionado Placionados con las luchas sociales y el activismo, organizados en el colectivo autogestionado Plataforma Salvem e Cabanyal-Canyamelar, junto a los vecinos y comerciantes, organizan - desde sus propias casas inclusive - una muestra artística que revela la realidad del barrio, llegando a los ocho mil vistantes en la última edición. Cada una de las convocatorias ha reunido entre 160 y 200 proyectos de artes plásticas, música, fotografía, vídeo, performance, teatro y danza repartidos por todo el barrio. En 2015, se consiguen sus objetivos: la retirada del proyecto de destrucción del Cabanyal yel inicio de su rehabilitación, por lo que la plataforma decide su desaparición. Pero surgen heveros de su estela como los proyectos Cabanyal Arxiu Viu y CraftCabanyal (Martínez Arroyo, 2016). En nuestros casos de estudio de los capítulos tres y cuatro no se halla representada esta función salvo de forma anecdótica en el Almouseum y el mural de Almócita sobre la mujer rura y en $D U O$, aunque no obstante, no hemos querido dejar de considerarla en este listado.

\subsection{CREAR RELATOS POSITIVOS DE CAMBIO}

Como Slovic (2007) y otros autores argumentan, la imagen despierta mayor empatía que la información científica, y es entonces dónde el arte entra en juego: «Cuando los hechos y las cifras por sí solos no pueden catalizar todos los cambios necesarios en el mundo, las artes no abren a diferentes formas de ver y sentir» (Neal, 2015, p. 75). Como hemos visto en el capítulo anterior, compartir relatos positivos fomenta la symhedonia (empatía por la buena fortuna de otro) lo cual, nos resulta más atractivo que los mensajes culpabilizadores y condenatorios clásicos del movimiento ecologista. No solo necesitamos relatos positivos imaginarios sino además que sean experiencias reales, factibles, verdaderas, como las que nos aporta el MCT. Y más difíc todavía, el gran cambio de paradigma que necesitamos no se limita a pequeños ajustes, sino que exige un alto nivel de creatividad para construir un nuevo modelo alineado con la ética ecológica y del que no tenemos precedentes históricos (José Albelda, 2017b). Las iniciativas de transición son conscientes del poder del relato optimista y el MCT se define principalmente como un movimiento de cambio positivo. Documentales transicionales como Demain (2015) o In transition 2.0 (2012) lo demuestran si los comparamos con otros como Home (2009) o Before the Flood (2016) que realizan más hincapié en el desastre ecológico que en la acción positiva.

Entre nuestros casos de estudio destaca la experiencia de Biodivers, que está siendo registrada en un documental que verá la luz en 2018 y en el que se busca compartir una historia positiva de recuperación del entorno, la población y la identidad del pequeño pueblo de Carricola, en parte, a traves del arte. Estudiaremos este caso en profundidad en el capitulo cuatro.

$$
\text { La función del arte en procesos de transición a la sostenibilidad: casos anglosajones y españoles. }
$$


El filósofo Fernando Arribas lo expresa claramente: «El arte proporciona un conocimiento ético "aplicado" que las disciplinas científicas o la filosofía no pueden aportar» (2015, p. 207). Albelda destaca tabo liberarios y artístios, para facilisa literarios y artísticos, para facilitar la comprensión del mensaje que la ética ecológica, el ecologismo y la ciencia llevan varias décadas advirtiendo (t. Albelda 2017). La comprensión de la crisis ecológica por el gran público consumidor es creciente desde los setenta, cuando artistas como Alan Sonfist, García Uriburu, Agnes Denes o los Harrison comenzaron a trabajar en sus obras con un marcado compromiso ambiental. A pesar de que proliferan en las últimas décadas las exposiciones, concursos y artistas dedicados a la relación entre arte y ecología, no podemos dejar de realizar un ejercicio crítico con los resultados de estas propuestas. Como advierte T.J. Demos, existe el peligro de aceptar propuestas artísticas que ejerzan un «lavado de conciencia verde» que simplifique la complejidad del problema y no ataque verdaderamente a sus orígenes (2013). Un ejemplo que podríamos señalar al respecto es el documental Before the Flood (2016), en el que gran parte del discurso se asienta sobre la idea de consumir energías renovables $^{108}$, en lugar de abogar por un descenso de nuestra dependencia energética y nuestro consumo. Otro peligro que sugiere Demos al que nos enfrentamos es la rendición de la crítica intelectual ante la urgencia del cambio climático, que nos hace vulnerables a las decisiones de los «expertos» y los gobiernos, que en muchos casos son dependientes de los mercados (Demos, 2009). La propia acción artística es todavía contradictoria con el enfoque ecológico. Existen honrosas excepciones, como el colectivo Platform, que desde sus inicios se plantea un ejercicio autocrítico de reducción de la huella ecológica. También merecen mencionarse la exhibición Hybris en el MUSAC de León o los recientes esfuerzos de la organización Julie's Bicycle por introducir calculadoras de huella de carbono en la actividad artística. Sin embargo, muchos artistas, exhibiciones $y$ concursos no se plantean sus efectos ambientales de un modo profundo. Por sus deplaz y debemos presur medio y de y sos prostenibles sobre son simplemente inviales desde una perspectiva ambientirly son simplent parte, ya es complicado atraer a las masas de público a los museos con propuestas tradiciona- les, cuanto más con prostas de enfoque ecologico de dificil comprensión y aceptación por sostenibles pero que lancen un mensaje contundente y que gradualmente se vayan adaptando a las ideas que predican o, si interesa mejor no hacerlas. Desde luego, el arte siempre ha sido vanguardia de la sociedad, y cuanto más sostenible sea mejor podrá la ciudadanía mirar hacia
otro nuevo horizonte.

Dentro de los ejemplos que manejamos, ninguno de ellos, tanto dentro como fuera de MCT en España o en Reino Unido, utiliza herramientas de calculadora de huella de carbono o de otro tipo en sus acciones. En cualquier caso, la mayoría afrma tener en cuenta su huella ecologica y tratar de reutlizary redur al maximo sus consus, aunque en varios casos como The

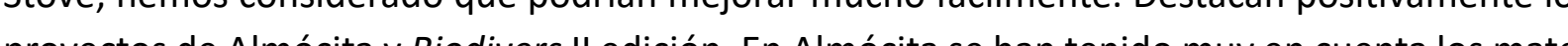
proyectos de Almócita y Biodivers II edición. En Almócita se han tenido muy en cuenta los materiales de los provectos artisticos solicitando certificados ecológicos, de reciclaje o bien optando por materiales locales. En la segunda edición de Biodivers se ha optado por imponer unos requisitos sobre los materiales a emplear por los artistas admitiendo solo materiales «naturales»100 vegetales o minerales fácilmente biodegradables o en armonía con el entorno.

\subsection{CONECTAR ÁREAS ALEJADAS DE CONOCIMIENTO}

John Hartley (Arts Council England), con una dilatada experiencia en grupos interdisciplinares, comenta que, «los métodos establecidos y las perspectivas basadas en la separación y el aislamiento de los problemas han resultado insuficientes para responder a los problemas complejos e interconectados del cambio climático y la crisis ecológica» (The Chartered Institution of Water and environmental management, 2012, p. 26). El ingeniero y Profesor honorario de la Universidad de Glasgow Mike Bonaventura, añade, «otras medidas científicas no están de la Universidad de Glasgow Mike Bonaventura, añade, «otras medidas cientificas no están
consiguiendo sus metas en los períodos de tiempo planteados. No hay suficientes resultados. El siguiente paso es la cultura. La transformación viene a través de la cultura» (Bonaventura $\mathrm{M}$ comunicación personal, 18 de julio de 2016). Pero no podemos obviar que el contexto cultural (y no solo el económico) influye en qué investigamos, qué enseñamos y cómo lo hacemos, desde qué perspectivas ${ }^{110}$. Como afirma el investigador en política medioambiental Dave Pritchard:
109 Nos referimos al concepto popular de ción humana.

110 Un ejemplo claro sería el sistema de
valoración académica de la investigación a determinantes para obtener financiación
detion tos sistemas de nombstigando. Pero, estivo. 

y tintoreros del Londres medieval, comenzó a darse lo que se podría llamar pensamiento interdisciplinar ${ }^{111}$. Esto pone de manifiesto que el taller, artesano en este caso, puede ser un buen lugar para la comunicación dialógica y la asociación informal (Sennet, 2012, p. 164). Lo mismo se podría decir de un laboratorio, un think tank, una obra artística colaborativa o una iniciativa de transición en la que confluyen personas de diferentes disciplinas y niveles educativos. La informalidad (especialmente en las obras artísticas y las iniciativas de transición) cenera un espacio liminal112 que permite un intercambio dialógico interdisciplinar, pero, iqué aporta el arte pacio liminal "que permite un intercambio dialogico interdisciplinar, pero, ¿qué aporta el arte de especial? Podriamos apuntar que la flexibilidad y los límites difusos de la práctica artística (sobre todo si comparamos con otras especialidades más segmentadas como la medicina) I otorgan la capacidad de adoptar y adaptar lenguajes y métodos propios de otras disciplinas, de llegar a espacios distintos a los artísticos $y$, por tanto, de incorporarse a debates en torno a de la crisis ambiental desde un posicionamiento más holístico. Como Pritchard señala,

No se trata de "usar el arte" simplemente como un medio para "comunicarse" sobre otra cosa. Se trata de adoptar un enfoque mas "ingenioso" que nos conecte de una manera diferente con el mundo en el que nos encontramos, y avive las chispas de esa mayor creatividad que necesitamos como sociedad para los desafios que

Aprender a trabajar transdisciplinarmente supone superar el paradigma educativo domiha fomentado una formación segmentada en sectores de información aislados unos de otros, sin aparente relación hasta el punto de llegar a ponerse en cuestión la utilidad de asignatura como la filosofía o la plástica. De continuar por ese camino, la relación arte y ecología es difícil que llegue a ser popularmente aceptada. Es por ello que Morin y otros autores (Kagan, Nicolescu) se plantean un cambio paradigmático de la lógica clásica que acepte distintas formas de conocimiento y estructuración de la realidad, el conocimiento y los métodos con que la ciencia opera y progresa. Desde la época medieval donde la música formaba parte indispensable del quadrivium, o el Renacimiento, dónde se les consideraba Artes Mayores, no se ha vuelto a otorgar esa importancia a las Artes. Con la llustración la especialización volvió la espa vuelto a otorgar esa imn ón intuición, la encion favor de la razón, apoyando

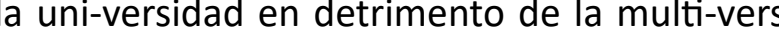
dad, ha llegado a su máxima expresión hoy en día. Ahora corremos el peligro de que el árbol no nos deje ver el bosque y el bosque está desapareciendo. Tanto Bonaventura como la política de CIWEM y muchos otros autores (Novo, 2009), señalan que es necesaria una visión de sistema completa, que reconozca la interdependencia de los sistemas naturales, socioeconómicos y ma completa, que reconozca la interdependencia de los sistemas naturales, socioeconómicos
culturales y que mejore la -insuficiente aún - investigación transdisciplinar combinando enfoculturales y que mejore la -insuficiente aún-investigación transdisciplinar combinando enfoques intuitivos y de improvisación con los métodos científicos. La obra de arte ecológico de los Harrison representa a la perfección este afán de reunir conocimiento científico, intuición y emoción. En Serpentine Lattice (1993), la poesía vertebra un discurso científico-ecológico de suma
importancia en la defensa del bosque húmedo de la costa oeste norteamericana, transmitiendo emoción, innovación, una nueva visión de conjunto y conocimiento interdisciplinar. Mucho más humildemente, en el contexto de la exposición de Biodivers, nuestra obra personal El hogar del pan -que se explicará en profundidad en el capítulo cuatro- pone en práctica la interdisciplinariedad, conectando artistas, arquitectos, habitantes, maestros de la piedra, aparejadores y panaderos en una obra común y colaborativa, donde cada uno aporta sus saberes y buen hacer. 
En cuanto a las iniciativas de transición, no hemos identificado esta función en ninguno de sus royectos a un nivel suficiente.

Hasta aquí hemos repasado de modo general las funciones de la actividad artística en la transición. Observamos que la calidad artística de los proyectos del MCT suele ser baja, pero no es objetivo de esta tesis evaluar su condición sino detectar su presencia y estudiar su utilidad para el cambio de paradigma. Hay que tener en cuenta, además, que hemos considerado no ntiendan como acción artística o haya hacer juicios subjetivos en cuanto a qué es arte y qué no. Por otra parte, al ser participativos, en muchos casos hemos ampliado nuestras expectativas en cuanto al resultado. En los siguientes captios difilidenticas cia, difícil identificación o novedad, serán estudiadas a través de nuestros casos de estudio.
CAPÍTULO 3. ACTIVIDAD ARTÍSTICA EN EL MOVIMIENTO DE CIUDADES Y PUEBLOS EN TRANSICIÓN

\section{REACTIVAR LA COOPERACIÓN DESDE EL ARTE Y EL} MCT

Jacob Burckhardt, historiador del siglo XIX, definía los tiempos modernos como una era de "terribles simplificadores» (Jacob Burckhardt, 1929, citado en Sennet, 2012, p. 393). No podemos negar que esa es, y cada vez más, la tendencia actual de la globalización: primar la homogeneidad, que no la igualdad, en detrimento de la diversidad, que tanto nos ha ayudado como especie. Se potencia así el miedo o el rechazo a lo diferente, al extraño, al extranjero. Si bien el ser humano es en esencia interdependiente y ecodependiente, la sociedad individualista actual se empeña en ignorarlo, promoviendo un modelo de enfrentamiento por encima de uno de colaboración, de aislamiento más que de cooperación, y de bienestar individual por encima del colectivo. En el terreno práctico, las nuevas formas de capitalismo priorizan el trabajo corto plazo (que coarta el apoyo recíproco entre compañeros) y la fragmentación institucional y educativa, a la par que el poder y la elite se distancian de sus responsabilidades con respecto a la sociedad y el medio ambiente -que quedan a merced de las fuerzas "equilibradoras del mercado» - (Sennet, 2012). Esto, junto a las desigualdades estructurales, están promoviendo un tipo de sociedad no cooperativa, con sujetos que evitan actuar en comunidad debido a la ansiedad que les causa la responsabilidad del lugar que ocupan en el mundo, así como gestionar las existentes y complejas formas del compromiso social (Sennet, 2012). Del mismo modo que nos abruma el compromiso con nuestros semejantes, puede abrumarnos el compromiso con nuestro entorno natural. Es decir, como ya hemos visto en el capítulo uno, la ansiedad o la saturación frente a la información ambiental puede provocar un rechazo o desconexión de la información misma tanto por la cofatio, comopor los sentimientos de indefensín e ineficacia de lacion individal ante las dinfansions de problema del cambio climático (Huentas y Corraliza, 2016) Senct cone las aue ese retrimiento produce una cegura con dos ingedientes psicoló.

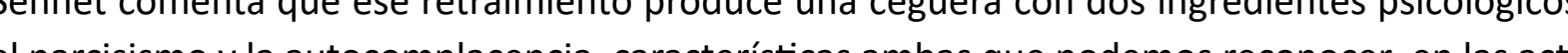

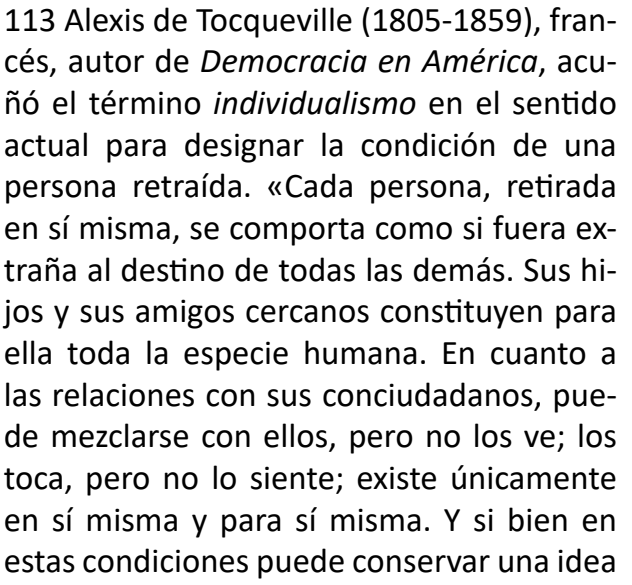

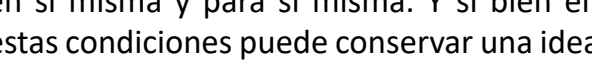
de familia, ya no le queda ninguna de socie-
dady) (Alexis de Tocaueville citado en Sennet, 2012, pp. 265-266). 
114 Traducción de la autora del original:
Foundation for Community Encouragement. véase les al respecto del medio ambiente. El narcisismo nos distancia de todo lo demás, situándo(a)

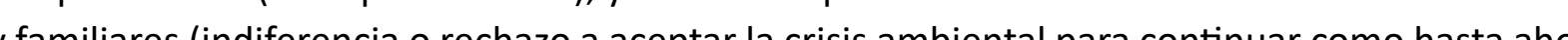
(a). «Cuando la autocomplacencia se une a individualismo la cooperacín se atria (Senet, 2012, p. 26). Por lo ton transición a la sostenibilidad, es comprender la magnitud de la crisis ambiental y contribuir a la los ojos y las mas a nud, es im J jos las manos a nuestro entorno y a los demás; en otras palabras, recuperar el sentimiento de responsabilidad que tenemos con la comunidad y el medio ambiente. Cuando se activa e compromiso con lo colectivo se acciona la cooperación. De esta manera, como contrapeso a la inercia individualista, aún subsisten fuerzas de asociación voluntaria, principalmente comunidades religiosas, sociedades de beneficencia, agrupaciones deportivas, asociaciones de amigos $y$ en general, grupos que comparten un interés común. Empero, estamos perdiendo nuestras habilidades para la cooperación abierta y dialógica. Las fuerzas institucionales son decisivas para hacer frente al individualismo (Sennet, 2012), pero cada vez hay menos confianza en nuestras instituciones y nuestros líderes. ¿Cómo podemos contribuir a reparar la cooperación y el daño ambiental?

Estamos impelidos a relacionarnos con el otro para nuestra supervivencia. Pero aún no nos relacionamos con la inclusividad, realismo, conciencia propia, vulnerabilidad, compromiso, apertura, libertad, igualdad y amor de una comunidad genuina [...] Es nuestra tarea - nuestra esencial, central y crucial tarea- transformarnos a nosotros mismos de meras manera en que la evolución del ser humano puede proceder (Peck, 1998, p. 165).

Como dice el psiquiatra y promotor de la Fundación para el estímulo de la comunidad114 Scott Peck, una de las claves está en promover la acción comunitaria, lo cual encaja con los principios de las iniciatis de transición (Aiken, 2012). De hecho la Red de Transición intosion cipios de las iniciativas de transición (Aiken, 2012). De hecho, la Red de Transición internaciona se define como una respuesta «liderada por la comunidad» (Transition Network, 2018) y su proposito como. medida que se organizan en torno al modelo de Transición» (Transition Network, 2018). En sus objetivos, el MCT hace énfasis en fomentar el compromiso comunitario como fuerza de movi- lización y transformación (Aiken, 2012): «La participación de la comunidad es absolutamente crucial para el éxito de la transición en su comunidad»115 (Hopkins y Thomas, 2016, p. 23). Asi dicho compromiso puede llegar a desempeñar un triple papel: un proceso, un agente clave de cambio o principio fundamental (Aiken, 2012), y un resultado, objetivo"16 de algunos grupos de transición (Fernandes-Jesus et al., 2017). En terminos generales, la cooperación en el MCr se ve reducida cuando no hay compromiso comunitario, y éste depende del contexto (Fernandes-Jesus et al., 2017, p. 1547). «Las desigualdades en los ingresos y la educación a menudo so Cudadana» (Putnam 2000, Oxendine 2004 citados en Fernandes-Jesus et al., 2017, p. 1548).

Por tanto, podemos decir que las iniciativas de transición se orientan a reparar tanto la cooperación en el seno de nuestras sociedades como el daño ambiental: asumen nuestra ecodependencia, aceptan la gravedad y urgencia de los problemas ambientales, crean espacios de posibilidad alternativos a las economías neoliberales dominantes (Fernandes-Jesus et al., 2017, p. 1547), proponen nuevas formas de actuación informal y colectiva desde la base y no rechaza alianzas con las administraciones. Esta última estrategia caracteriza al movimiento de transición y lo diferencia de otros movimientos de la izquierda como el decrecimiento, que, en mucho casos, rechazan este tipo de coaliciones con las instituciones ${ }^{117}$. Sin embargo varios estudios apuntan que el MCT necesita desarrollar una reflexión profunda sobre sus procesos de particpación comunitaria, que tenga en cuenta la complejidad de la noción de comunidad y participación, el conflicto, la exclusión y las estructuras de poder (Fernandes-Jesus et al., 2017); (Smith 2013, Brodsky 2017). Las iniciativas de transición parecen desarrollar principalmente lo que se puede llamar «modos débiles de participación», es decir, sus actividades se utilizan para difundir información sobre transición y para que las personas conozcan los principios y objetivos del movimiento, pero no para crear verdaderos espacios para la participación ciudadana, que partan de sus necesidades, aspiraciones y deseos (Fernandes-Jesus et al., 2017, p. 1555). En el estudio de iniciativas en Portugal se observa el traslado del discurso de la Red de Transición internacional (anglosajona) sin adaptación al contexto portugués, obviando las diferencias económicas, educativas y culturales de cada país (2017, pp. 1156-1157). Las autoras del estudio sostienen que «las estrategias para la participación de la comunidad deben ser específicas de los contexque "las estracias para la participación de la comunidad deben ser especificas de los contexparticipative (Fornandes-Jesus et al, 2017, p. 1547). También observan una apoximaciones dialogar a (

115 Traducción de la autora del original:
"Community involvement is absolutely crucial to the success of Transition in your Snificados que el MCT otorga a la dos Ifd. El concepto puede tener múltiples o simbólicas (Fernandes-lesus et al., 2017). Según Aiken, la Red de Transición de«antídoto del individualismo" (Aiken, 2014,
(a) pocentrismo, autocomplacencia, etc. frente
al problema ambientalt) lugar físico donde trabajar justos como grupo (Aiken 2012). Hay un tercer uso «más
sutil y subjetivo de "comunidad". Debido a $s u$ atractivo, rara vez es cuestionada $y$ freque se).

116 Llegando a superar incluso objetivos

las iniciativas de transición en Portugal:

(Participación de la comunidad en el mo-
vimiento de transición: puntos de vista y prácticas en iniciativas portuguesas) (Fer-

117 Por ejemplo en Totnes se ha logrado implicar al Ayuntamiento local de modo
que «podías encontrar a la alcaldesa de Totnes vendiendo entradas para el cinefórum del grupo de transiciónn" (Estibaliz Delgado, comunicación personal, 8 de enero
de 2018). Pero además el MCT está consi-

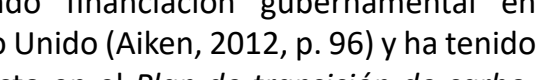
mpacto en el Plan de transición de carbono del gobierno laborista de dicho país en
2009. Incluso el entonces secretario de Es- 

l., 2017, p. 1554).

Cuál es el papel del arte y los artistas en estas iniciativas? La artista Fern Smith fundadora e Emergence ${ }^{118} \mathrm{y}$ una de las autoras del informe Cambio cultural: cómo los artistas están respondiendo a la sostenibilidad en Gales (Allen et al., 2014) contesta, «Los artistas siempre han sido 政 sociedad» (Hopkins, 2015). En cuanto a la cooperación concretamente, Neal arifma: "Ambos, transición y las artes, desencadenan valores intrinsecos de conexión y cooperación " "

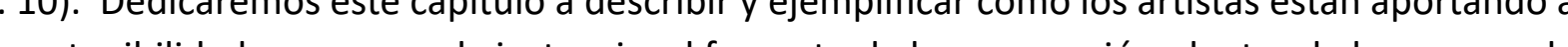
las sostenibilidad y, en segunda instancia, al fomento de la cooperación, dentro de los grupos de los grupos de transición y qué pueden hacer los artistas por favorecerlas.

Informalidad en los grupos: «Los momentos de crisis como este dejan al descubierto la (Sennet, 2012, p. 219). Es decir, que, ante la urgencia de la crisis ambiental, no es suficiente con作 corcado o de los lectores, y por tanto, discontinuidad de sus programas, entre otras). Además se hace necesaria

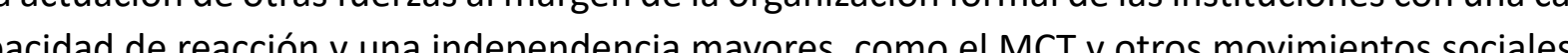
pacidad de reacción y una independencia mayores, como el MCT y otros movimientos sociales. En estos grupos se disfruta con la informalidad, al igual que en el trabajo artistico, y precisamente es la falta de una normativa y una estructura rigida, lo que les da capacidad de diversificarse y adaptarse a las circunstancias locales particulares. La misma, es uno de los instrumentos que ermiten según Sennet, que la cooperación sea un placer sostenible, ya que permite «sosegarse, sentirse cómodo en un lugar, dejar las presiones en suspenso y pasar el tiempo con otros por el mero placer de estar con ellos: todo eso contribuye a incrementar por medios informales el compromiso con un proyecto colectivo» (2012, p. 381).

Apoliticismo y trabajo con la diferencia: El MCT, tal y como en su origen el asociacionismo decimonónico (que luego dio lugar a la moderna organización conocida como grassroots) no se corresponde con ninguna ideología política concreta ${ }^{120}$. En lugar de concentrarse en la protesta contra el sistema o el gobierno o ejercer presión en las altas esferas de poder político contra en en colaboración, $y$ en el fortalecimiento del tejido comunitario (Fernandes-Jesus et al., 2017). Esa falta de ambicion pollica es muy criticada por otros movimientos (Chatterton y Culler, 2008) (Instituto de Transición Rompe el Circulo, 2015) que insinúan que su efecto sería mayor de ser más políticos. Pero esta sustitución de la protesta por la acción positiva puede entenderse tam bién como una posición política (Aiken, 2012, p. 96) (del Río, 2009, pp. 39-42) que complementa a la protesta y, a la vez, permite acoger -al menos en potencia - una mayor diversidad, lo cual favorecería la resiliencia. La red será más fuerte, cuanto mayor es el mosaico que la constituye. Pero la cooperación se enfrenta entonces a un problema de socialidad di21 ya que vivimos en una
sociedad compleja, Ilena de diferencia. En el movimiento de transición se intenta hacer frente mediante el contacto informal, pero existe el peligro de que los encuentros sean fugaces, poco dialógicos y a largo plazo no conduzcan a nada. Por otro lado, diversos autores están poniendo de manifiesto un problema aún mayor en estas iniciativas. Autores como Connors y Mc Donald (2011) y Grossman y Creamer (2016) señalan su «acercamiento pasivo a la diversidad y la inclusividad» (Fernandes-Jesus et al., 2017, p. 1547). Es decir, tienden más a actividades de vinculación, que favorecen reforzar identidades exclusivas y grupos homogéneos (Grossmann y Creamer, 2016), que a actividades puente (que abarquen personas de diversas clases sociales) (Putnam, 2000). El estudio realizado recientemente en grupos de transición en Portugal señal esa homogeneidad ya que, en su esa hom tivas suelen constar de 3 - indivduos con un perfl simlar. estre $30-45$ años, nivel de estudios (Fernandes-Jesus et al, 2017), lo cual no es representativo de la diversidad de la población por(Fernandes.Jesus et al., 2017), lo cual no es representativo de la diversidad de la población poractivamente incluir la diversidad de la sociedad (Fernandes-Jesus et al., 2017).

Otra crítica al MCT relacionada con la anterior es que evita tratar con la distribución del poder en la comunidad a mayor escala que la individual. En las iniciativas, la transicín interior se considera condición fundamental para conseguir cambio colectivo: "Cada individuo se considera un actor de cambio y es responsable tanto de una transición individual como se unmás ampla a propar los ideales de la transición: la transición interna alimenta el can más amplia al propagar los ideales de la transición. la transición interna alimenta el cambio

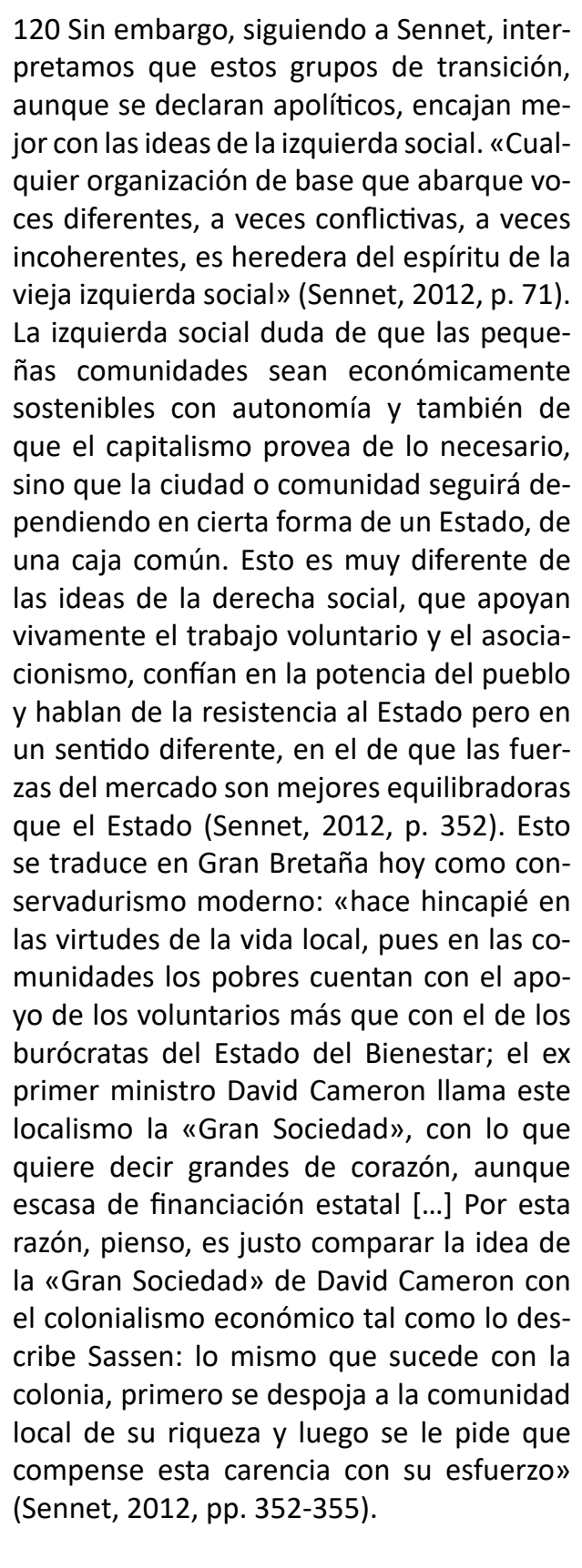

121 «La socialidad no es el acto de tender la 
acción conjunta. La socialidad es otra cosa
que solidaridad [...] La socialidad pide la
aceptación del extraño como una presencia valiosa en el medio propio» (Sennet, 2012 122 «Varios académicos han argumentado para expandirse mucho más allá de los

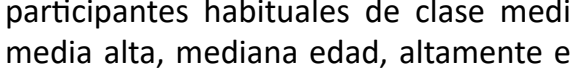
cados, blancos progresistas posmaterialis.
tas, que tienen el tiempo y el privilegio de participar en el activismo ambiental y que ya son conscientes del medio ambien
(Fernandes-lesus et $a$ (. 2017, 1550 )

123 Al respecto de la creatividad, recientemente se ha comprobado que el porcentaje
de personas creativas en el mundo del arte es mayor que en la comunidad científica debido en parte a anos circuitos cerebrales
deue el neurólogo inglés Mark Lythgoe lla ma inhibidores latentes. Estos inhibidores, nos permiten eliminar cualquier distracción
para concentrarnos en la tarea que estemos ejecutando, algo muy útili en el mundo
cintíco «Son unos circuitos cerebrales cientifico. «Son unos circuitos cerebrales
fabulosos para sobrevivir pero $-y$ este es el nuevo y sorprendente hallazgo- incom-
patibles con el pensamiento creativo. Los artistas son, en promedio, más creativos que los científicos, simplemente porque no
les funcionan bien los inhibididores atentes. En lugar de concentrarse en el objeto de su mente abierta al vendaval de ideas, consis-
tentes las unas y enloquecidas otras, que les

ta que el pensamiento creativo necesita de
este vendavaly (Punset, 2007, pp. 115-116).
Tor (5ernandes lesus etal, 2017, 1553)

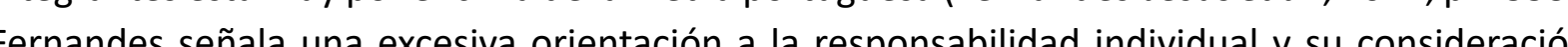
ernandes señala una excesiva orientación a la responsabilidad individual y su consideración de independencia en relación a una serie de estructuras (2017, p. 1557). Al atomizar la acción v no tratar custons de poder, se linnta la capacidad de tranformación, pues los individuos no tienen todos la misma potencia de acción, ni los mismos recursos y algunas cuestiones no dependen de nuestra facultad individual para transformar la sociedad (Fernandes-Jesus et al., 2017, pp. 1553-1554).

El desafío para los artistas aquí es dar sentido a la cooperación activa más que a la simple tolerancia, y eso no es fácil cuando se trabaja con personas de distintas tendencias políticas y procedencias. Otro riesgo importante es que la informalidad conduzca a la desorganización. Pero aun cuando se logre sortear, existe la posibilidad de que la acción del grupo de transición ce quede en una mera colección de anecdotas y no en un verdadero cambio de actitud, en una guía para la vida sostenible. Por ello los grupos prestan especial atención a la transición interior, como una profunda transformación de nuestra conducta y no solo una experiencia de puertas para fuera. Además es crucial que la vinculación que se establece en la comunidad tenga un objetivo, conduzca a alguna parte. La acción necesita una mínima estructura para ser sostenible.

Estructura flexible y creatividad: A este respecto el MCT sí que goza de unos objetivos claros, que hemos enumerado ya en el capítulo uno apartado 1.3 y que dotan a la acción de rimera fas. primeras fases pero que tiene, desde el principio, una fecha de disolución, de modo que evitan las posiciones de poder $y$ replicar estructuras jerárquicas. Obviamente, la creatividad ${ }^{23}$ artística puede desempeñar un papel importante en esos primeros momentos como impulsora inicial. Diversos estudios (Carson, Higgins y Peterson, 2003) confirman que las mentes creativas, son más receptivas a estimulos externos que la mente cientifica, por lo que el artista puede aportar mucho no solo al inicio, sino también a lo largo del proceso, en el papel de mediador que asiste, no que dirige. Es una tarea que exige grandes dosis de observación, paciencia y escucha atenta. El papel del artista es reunir o atrapar la poesía en lo que los otros aún tienen que observar o pueden despreciar» (Neal, 2015, p. 91).

Importancia de lo colectivo: «El aislamiento es el enemigo obvio de la cooperación» (Sen- net, 2012, p. 236). La anomia, es decir la sensación de no ser nadie, es uno de los estados de ánimo más frecuentes que podemos encontrarnos de cara al problema ambiental. La reacción de muchas personas es la desafección o indiferencia. Ya que la transición promueve valores culturales que trascienden el interés propio, unirse a un grupo de transición puede contrarrestar esta sensación. En la comunidad «se pueden nutrir la valentía y el coraje para encarar los retos globales los cuales, nos pueden hacer sentir desprovistos de poder para afrontarlos por nosotros mismos [...] en este contexto las personas actúan de modo diferente; se ven a sí mismos como integrados en, y parte de, un todo celebratorio mucho mayor» (Neal, 2015, p. 84). En los grupos de transición la acción colectiva local está en sus principios definitorios como camino hacia la resiliencia, pero también como su meta (Aiken, 2012). Al mismo tiempo, es lógico pensar que la cooperación comunitaria pueda contribuir a reforzar la identidad pero además, cuando se hace local, la naturaleza misma de la identidad se modifica, pasando a depender de referencias directas a las experiencias compartidas con otras personas a las que conocemos directamente, lo que crea una identidad compartida. «Estas conexiones renuevan la sensación de que las relaciones sociales son experiencias corporales profundas» (Sennet, 2012, p. 310). La creación artística en estos casos contribuye mediante la creación de símbolos identitarios o los propios procesos colaborativos, a reforzar el sentimiento de identificación como hemos visto en el capítulo anterio.

Proceso dialógico: lo ideal es que las iniciativas de transición trabajen la cooperación dialógica más que el trabajo jerárquico, lo cual entraña un tipo especial de apertura, que pone su servicio la empatia más que la simpatia, aunque ambas son necesarias. De este modo, el trabajo conjunto en una creación colectiva, como veíamos en el caso de Lacy en el capítulo uno, es el resultado de pequeños «dramas de concesión y afirmación» (Sennet, 2012, p. 31) en los que las habilidades de facilitación del artista pueden contribuir enormemente a que el proceso fluya. El artista tiene la difícil tarea de mantener viva la conversación, a la par que ser un buen oyente. Sennet estudia cómo el trabajo en el taller puede crear conducta social dialógica de varias formas y podemos aplicar algunas de sus conclusiones al trabajo artístico en un grupo de transición, especialmente en el campo de la resolución de conflictos durante la creación colectiva: «El artesano sabe algo importante en lo tocante al trato con la resistencia: que no colectiva 295). El artista colabortivo de enfoque ecóógco debe asimismo trabajar con la resistencia (en este caso diferencis socia (en este caso diferencias sociales, conflictos personales, egos,...) con habilidad y no con la fuerza. 
Tras la realización del IV Curso Oficial de Transición en Línea ${ }^{125}$ y con el apoyo de la Red de para detectar aquellas en las que a 2017 V junio de 2018. Tres de éstas no han contestado, por lo que no podvo"

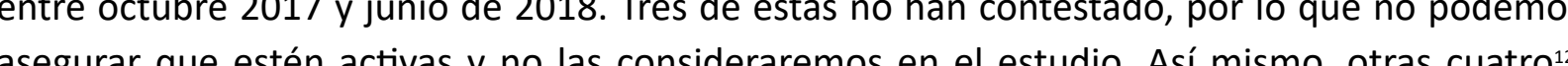

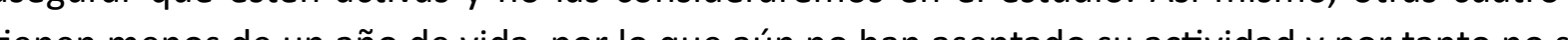

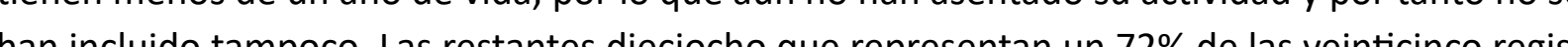
tradas un activon, han partipa do en estudo respondendo encuestas, concediendo ente-

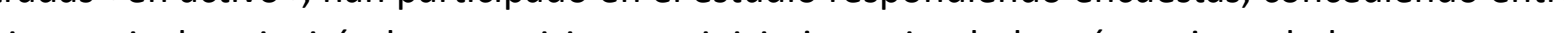
vistas o incluso invitandonos a visitar sus iniciativas, stendo la más antigua de la que tenemos datos Transicio VNG, creada en 2009 en Viclanova ila Geltru (Barcelona), $y$ estando la media de antigüedad alrededor de los 4,5 años. En total hemos realizado una veintena de entrevistas en persona, por videoconferencias o telefónicas y diez encuestas escritas.

\section{PRESENCIA Y FUNCIÓN DEL ARTE EN LA RED DE TRANSICIÓN ESPAÑOLA}

2.1 METOdología

Para analizar en profundidad la presencia artística y su función en los grupos de transición de España, hemos optado por una metodología de investigación acción participativa incluyendo de España, a realización de un curso de transición, un estudo culactructuradas, encuestas, participación en un encuentro sobre transición en el MUSAC de León ${ }^{124}$, visitas a iniciativas de transición en persona y análisis de páginas web, vídeos y perfiles o páginas de facebook. Esta aproximalion cualltativa nos ha permitido contrastar opiniones desde distintos puntos de vista ya fueran sus protagonistas, fundadores, nuevos miembros o exmiembros.

\subsection{PROCEDIMIENTO}

En esta parte de la investigación la mayor parte de los datos han sido recogidos mediante métodos cualitativos. El primer contacto se inicia generalmente por correo electrónico o mensaje en sus redes sociales $y$ se descarta seguir profundizando en aquellas iniciativas que ma nifiestan no tener ninguna relación con el arte. Por el contrario, sí se continúa con la fase de encuesta y entrevista con las que admiten tenerla. la encuesta contiene preguntas gene de

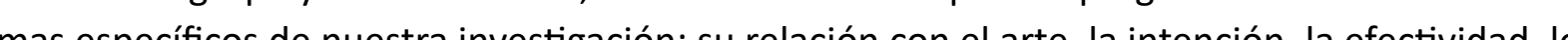

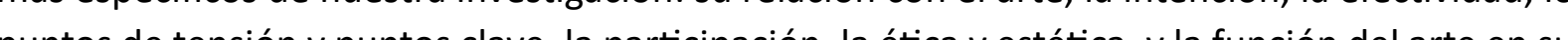
puntos de tensión y puntos clave, la participación, la etica yestética, y la función del arte en sus facilades. Las pregun son formladas con un lenguaje generaly facilitar a los encuestados expresarse sin restricciones. Las respuestas han sido en muchos casos consensuadas dentro de los grupos (Granollers, VNG, JET, Butroi), pero en otros casos hemos tomado la palabra de un miembro en representación de toda la iniciativa de transición, por lo que habrá que interpretar todos los resultados con cierta cautela. Las entrevistas han tenido un sobre cada grupo y sus actividades, además de siete bloques de preguntas relacionadas con te26 Agradecemos la cesion de datos del
mapeo de iniciativas en activo en España Transición española y transmitidos por comunicación personal.

127 Véase tabla anexo 1.

128 Reus en transició (Barcelona), La Alque ría de Quentar (Granada), Jesús en Transi(Málaga).

29 Véase un ejemplo en el anexo 2. 

nativa) grabadas $y$ transcritas.

Importancia otorgada al arte

Además se ha visitado en persona la iniciativa de Activar la Transición en Almócita, (Almería), por ser la que más relación declara tener con el arte y donde hemos podido entrevistar a cinco personas del grupo de transición, además de una artista y otros colaboradores.

\subsection{RESULTADOS}

De las dieciocho iniciativas en las que centraremos nuestro estudio, ocho (44\%) reconocen no tener ninguna relación con el arte. A raíz de plantear la cuestión, varias han reflexionado al respecto y han manifestado su intención futura de acercar aún más la creatividad artística en sus actuaciones, como es el caso de Jaén en transición (JET), que comentan: «Después de leer y responder al cuestionario nos hemos dado cuenta de que el arte debería tener un papel más destacado. En los manuales de Hopkins y Juan del Río se menciona frecuentemente, pero hasta el momento no hemos asumido su importancia. Sería importante conocer alguna forma de introducir la representación artística dentro de los movimientos en transición, a través de un formato asequible (folleto, guía o artículo)» (JET, comunicación personal, 8 de enero de 2018). Así mismo, merecen mencionarse los casos de Jesús en Transición y Segovia en Transición, este último impulsado desde sus inicios por el proyecto artístico en la naturaleza Tamanka Chavida la Escuelita $2^{130}$ En ambos existe una fuerte pulsión artística, aunque por su reciente creación (me nos de un año) aún no se ha podido manifestar en proyectos del grupo y no los hemos podido considera.

Por otra parte, diez iniciativas (56\%), sí consideran tener cierta relación con el arte en sus actividades y han sido encuestadas. Pero, ¿cuál es la trascendencia que le dan? Con mayor frecuencia (el $40 \%$ ) otorgan a los proyectos artísticos una importancia media dentro de sus programas, como podemos ver en el siguiente gráfico de sectores.

Iniciativas de transición españolas relacionadas con arte

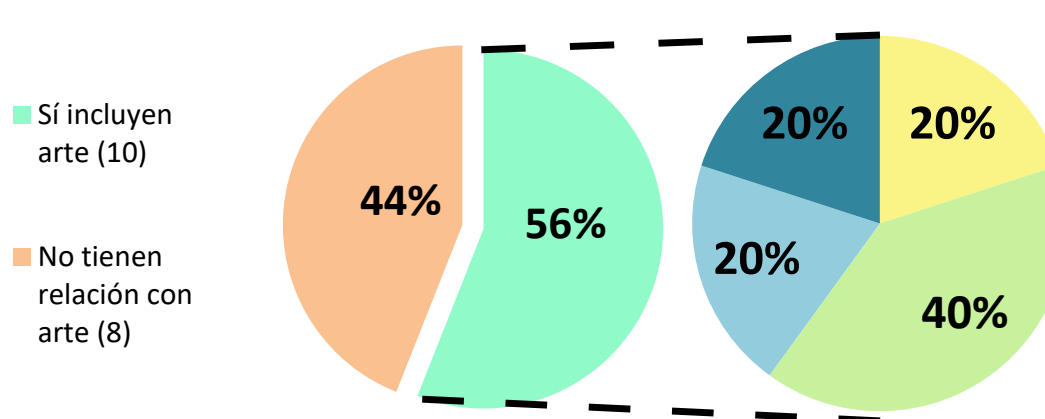

Puntual o poco

importante

Media (Miengo, GET, Granollers, ITRC)

Muy importante (Arico y Butroi)

- Fundamental o desde el inicio (Almócita y VNG)

Figura 2. Gráicos de sectores con
las. Fuente: elaboración propia.

En otros cuatro casos, Activando la Transición en Almócita (Almería), Arico en transición (Santa Cruz de Tenerife), Butroi en Transición (País Vasco) y Transició VNG (Barcelona), sus integrantes consideran muy importante, o incluso fundamental, el arte en sus actividades. Así que podemos decir que el arte ocupa un lugar importante o fundamental en el $22 \%$ de las dieciocho iniciativas de transición españolas y medio o puntual en el $33 \%$.

Centrándonos en los resultados de los diez casos relacionados con el arte, extraemos los siguientes resultados destacados:

1. En general están formados por un grupo nuclear de entre ocho y nueve personas de media (mínimo uno en Torrelavega y máximo quince en GET) más un número mayo de personas variable según el proyecto (hasta cincuenta incluso).

2. En un $40 \%$ de los grupos hay miembros que han realizado algún curso de transición.

3. Los proyectos artísticos han consistido en los siguientes que mencionamos brevemente. Analizaremos en profundidad el caso más llamativo, Activar la transición en Almó cita: 


\begin{tabular}{|c|c|}
\hline INICIATIVA & PROYECTOS ARTÍSTICOS REALIZADOS \\
\hline $\begin{array}{l}\text { Activar la } \\
\text { transición en } \\
\text { Almócita }\end{array}$ & $\begin{array}{l}\text { Museo fotográfico al aire libre Almouseum https://www.youtube.com/ } \\
\text { watch?v=bdUOKLxi8is } \\
\text { Festival arte en la calle La noche con alma, } \\
\text { https://www.facebook.com/almocitafestivalalma/ } \\
\text { Festival musical La noche de los candiles. } \\
\text { http://lanochedeloscandiles.blogspot.com.es/ }\end{array}$ \\
\hline $\begin{array}{l}\text { Torrelavega en } \\
\text { transición }\end{array}$ & $\begin{array}{l}\text { Tu basura por cultura: proyecto de huerto vertical en colegio al que se añade } \\
\text { fomento del compostaje a cambio de talleres gratuitos de música, teatro e } \\
\text { ilustración. } \\
\text { https://torrelavegaycomarcaentransicion.wordpress.com/2016/01/25/tu-basura- } \\
\text { por-cultura/ } \\
\text { https://torrelavegaycomarcaentransicion.wordpress.com/2016/01/28/1a- } \\
\text { jornada-en-infantil-de-tu-basura-por-cultura/ }\end{array}$ \\
\hline $\begin{array}{l}\text { Miengo en } \\
\text { transición }\end{array}$ & $\begin{array}{l}\text { Concurso de fotografía, taller de decoración navideña, taller de paquetería } \\
\text { ecológica, cinefórum, tour fotográficos. }\end{array}$ \\
\hline $\begin{array}{c}\text { Jaén en } \\
\text { transición (JET) }\end{array}$ & $\begin{array}{l}\text { Exposición fotográfica denominada "Semillas de Resiliencia" durante la campaña } \\
\text { Andalucía Resiliente: } 22 \text { fotografías en formato } 50 x 70 \mathrm{~cm} \text {. representativas de } \\
\text { distintas iniciativas de transición presentes a lo largo de la comunidad autónoma } \\
\text { andaluza. } \\
\text { htttp://andaluciaresiliente.net/mision/galeria-fotografica }\end{array}$ \\
\hline $\begin{array}{l}\text { Granada en } \\
\text { transición (GET) }\end{array}$ & $\begin{array}{l}\text { Taller de reciclaje creativo La recicreativa } \\
\text { https://granadaentransicion.wordpress.com/provectos-en-transicion/recicleria/ } \\
\text { https://www.youtube.com/watch?v=chTyH7JlhGO } \\
\text { Cine en transición } \\
\text { https://granadaentransicion.wordpress.com/provectos-en-transicion/cine-en- } \\
\text { transicion/ } \\
\text { Coro }\end{array}$ \\
\hline
\end{tabular}

\begin{tabular}{|c|c|}
\hline $\begin{array}{l}\text { Arico en } \\
\text { transición }\end{array}$ & 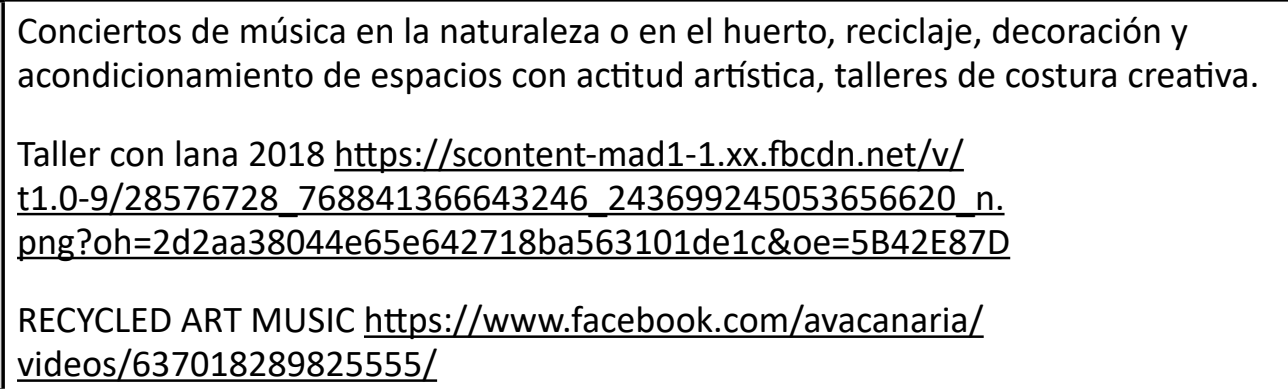 \\
\hline & 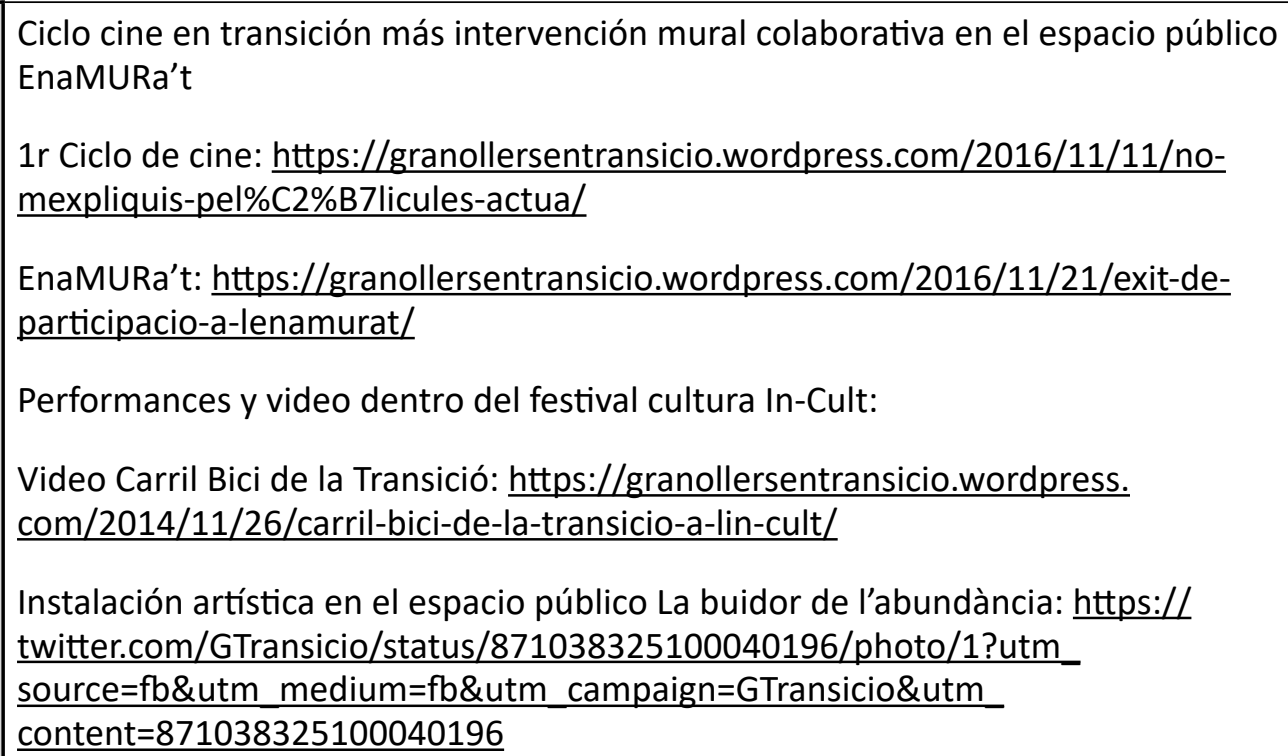 \\
\hline $\begin{array}{c}\text { Transició } \\
\text { Vilanova i la } \\
\text { Geltrú (VNG) }\end{array}$ & $\begin{array}{l}\text { Concurso anual de diseño de imagen de la moneda social La Turuta. } \\
\text { https://communities.cyclos.org/turuta/\#page-contentlid=7762070814181563711 } \\
\text { Coro: } \\
\text { http://transiciovng.blogspot.com.es/2018/01/el-cor-de-la-turuta-ret-homatge- } \\
\text { pete.html } \\
\text { https://transiciovng.blogspot.com.es/2018/03/nou-exit-de-participacio- } \\
\text { ciutadana-en.html }\end{array}$ \\
\hline
\end{tabular}




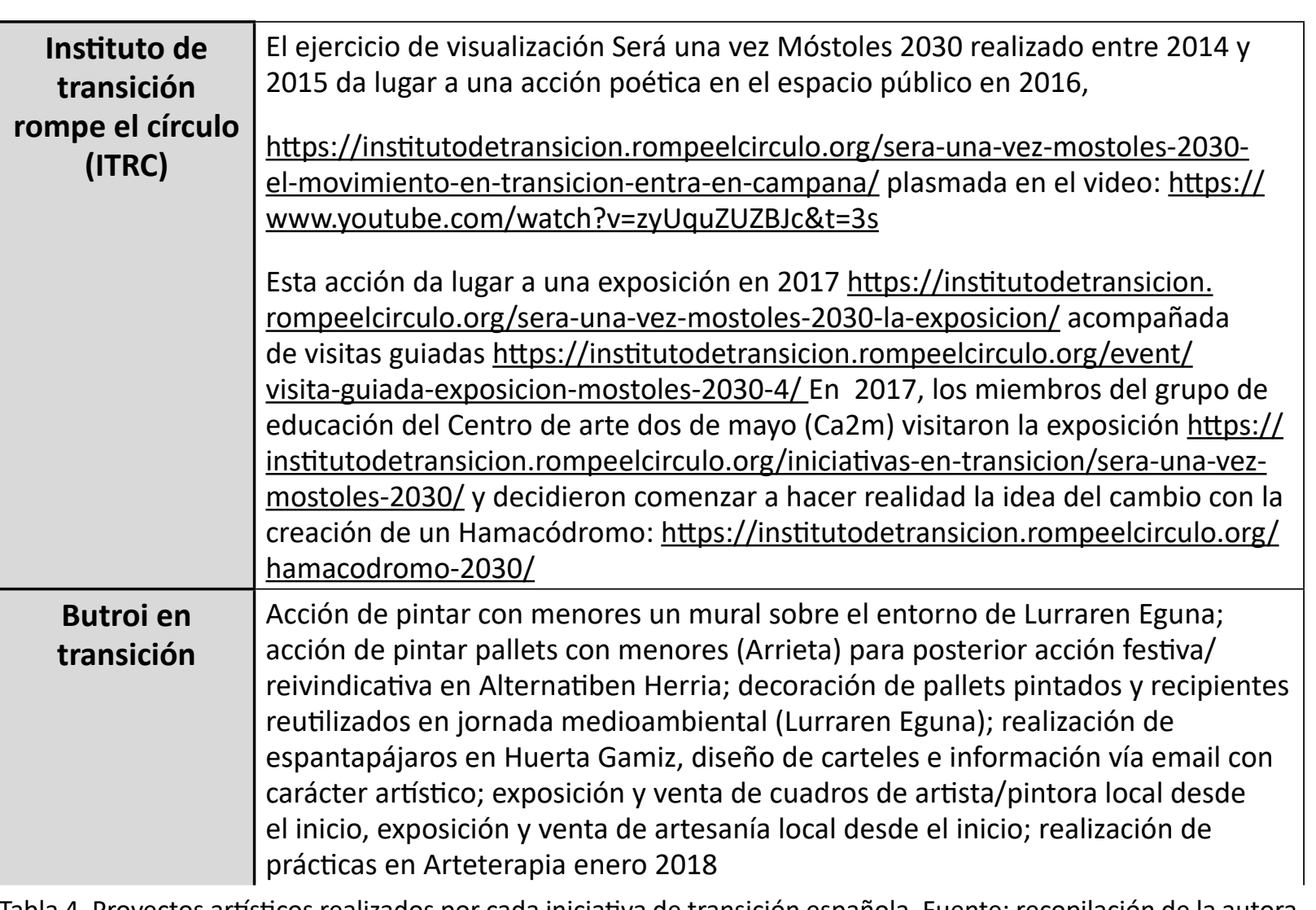

Tabla 4. Proyectos artísticos realizados por cada iniciativa de transición española. Fuente: recopilación de la autora.

4. En la mitad de los proyectos se ha contado con artistas invitados y en la otra mitad los artistas forman parte del grupo.

5. La mitad de los proyectos continúan la colaboración con artistas o bien la repiten anualmente.

6. Entre los resultados de estos proyectos destacan el caso de Butroi, VNG, Arico y Almó cita por su especial consideración del arte como herramienta para la transición. Maurizio Longano, de Arico, comenta: «Todo esto ha animado el pueblo, se ha generado economía. Hasta se han abierto cuatro tiendas de escalada en el municipio de Arico de 6.000 habitantes y concretamente una en Villa de Arico de 1.000 habitantes) (M.Longano, comunicación personal, 7 de diciembre 2017). También desde VNG resaltan: «Compartir música y cantos anima a entender que una sola voz es limitada, todas las voces juntas son bellamente potentes. Esta actividad es un gran cohesionador que empodera a las personas "tulo individual» (Carme Dastis Alonso y Ton Dalmau Llagostera, comunicación personal 10 de marzo 2018).

7. La implicación con el público es calificada como buena en todos los casos aunque, en su mayor parte, su implicación es como espectador o ejecutor. Solo en los casos de Almócita Butroi, VNG, ITRC y Arico, el público tiene un papel de mayor responsabilidad.

\section{TIPOS DE PARTICIPACIÓN DEL PÚBLICO}

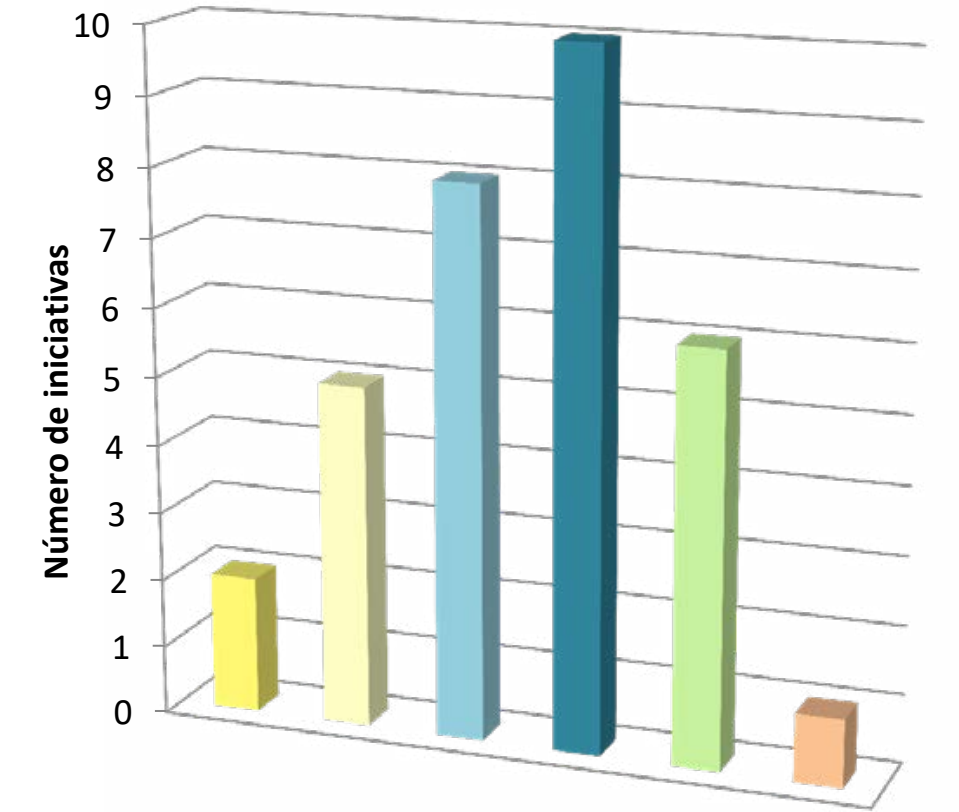

Origen y responsabilidad: Almócita, Butroi

Colaboración y desarrollo: Almócita, VNG, Arico, ITRC, Butroi

- Voluntarios y ejecutores: Almócita, GET, Granollers, ITRC, Butroi
- Audiencia inmediata: Todos

Público de los medios de masas: Almócita, VNG, Torrelavega, Arico, ITRC, Butroi memoria y el mito:
Público de la mem Almócita, VNG

Figura 3. Distribución de la participación del público clasificada en categorías de participación de Lacy en iniciativas de transición españolas. Fuente: elaboración propia.

8. Entre las funciones más habituales de la creación artística en los diez grupos encuestados se menciona en un $80-100 \%$ de los casos: 
- Ilustrar, representar, comunicar, difundir,

- Concienciar,

Ofrecer soluciones, mostrar alternativas reales o proyectos piloto, laboratorios de pruebas,

- Celebrar,

- Reforzar la identidad, crear símbolos.

En un 60-80\% de los casos reconocen:

- Fomentar la ciudadanía crítica, agitar, denunciar,

- Premiar, agradecer,

- Facilitar la comprensión del mensaje de la ética ecológica aplicándola

- Desarrollar empatía

- Empoderar.

Entre el $40-60 \%$ de los casos se identifican las funciones de:

- Conectar áreas alejadas de conocimiento,

- Construir consensos,

- Conectar personas con espacios, entornos o lugares

- Motor iniciador/generador de proyectos.

Por último, en menos del $40 \%$ de los casos se detectan las funciones de:

- Revitalizar el territorio (Luchar contra el éxodo rural, dinamizar el territorio, activarlo),

- Restauración o recuperación de un entorno
- Recaudar fondos

- Aumento de la resiliencia

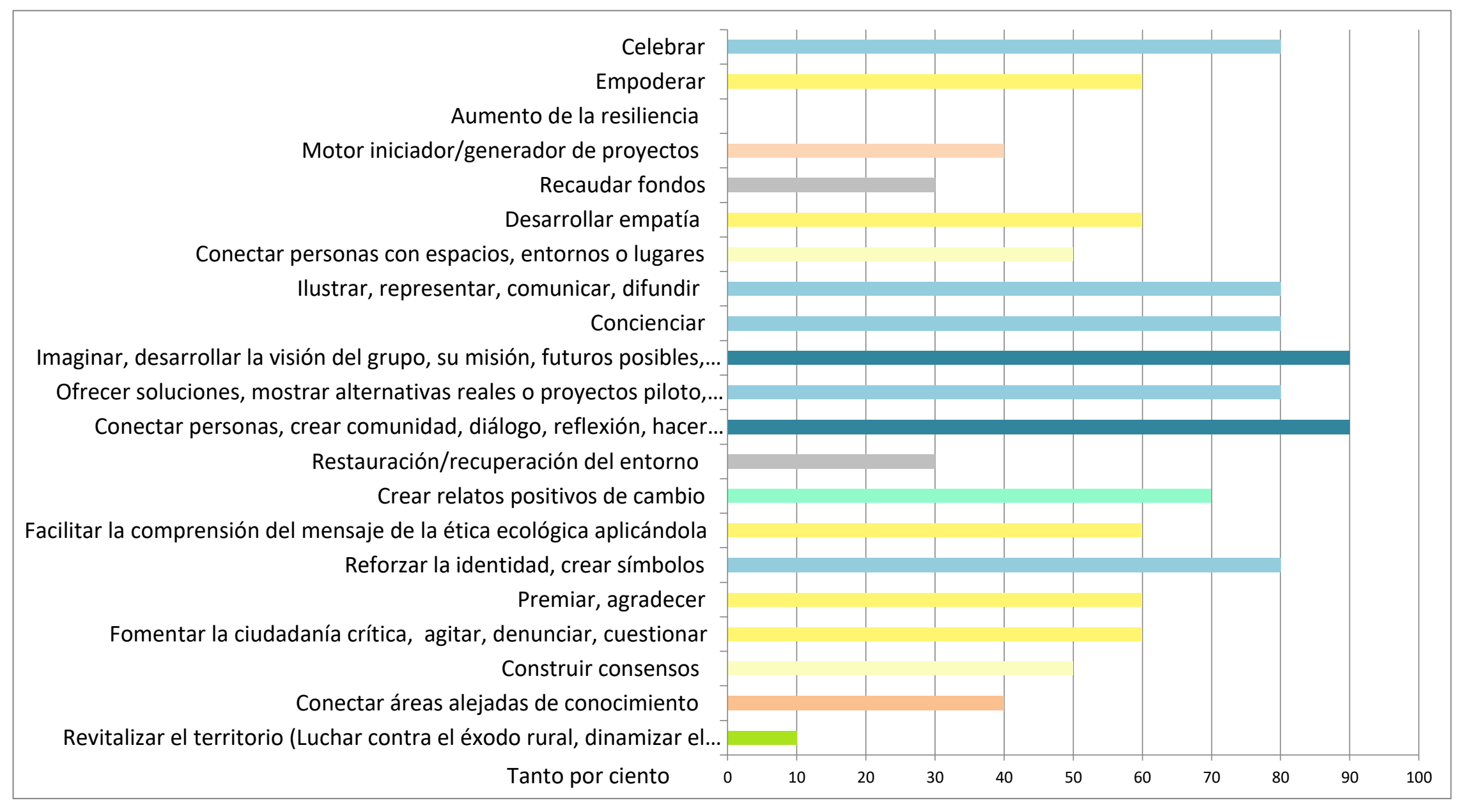

Figura 4. Gráfico de barras con funciones detectadas dentro del MCT. Fuente: elaboración propia.

La mayoría de las funciones anteriores son relativamente esperables y han sido revisadas en el capítulo dos. Pero de entre ellas queremos hacer hincapié en una de las menos comunes por ser menos previsible: la función de ignición, es decir, de generador de otras 

se en: http://fundacionrafael boticom/? pa a ge $\_$id $=67$

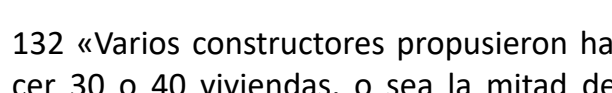

cer 30 o 40 viviendas, o sea la mitad de
pueblo otra vez $y$ se negó. Solo se dejó hacer un proyecto de cuatro casas ahi atrás otro de cinco al final del pueblo [...] se nego porque no se queria perder la identidad. La
identidad era un valor en alza, las casas al final se venden, si no se vende, no se vende mportante. [..... el Pleno del Ayuntamiento rian ni cambiar el $\mathrm{PGOU}$ evidentemente para hacer más viviendas, ni querían ese
tipo de construcción en el puebloy) (. Pine-
da, comunicación personal,29 de diciembre de 2017). a proyectos. El caso de Almócita, nos servirá para profundizar en como el arte puede transicín.

\section{ESTUDIO DE CASO: ACTIVAR LA TRANSICIÓN EN \\ ALMOCITA}

3.1 EL ARTE COMO MOTOR DE DINÁMICAS DE CAMBIO O IGNICIÓN

El presente estudio de caso pretende mostrar una función del arte diferente a las señaladas en el capítulo dos, pero mencionada en los principios del arte transicional de Neal: la ignición. Buscamos poner de manifiesto lacapacidad de la acción artística de actuar como precursoque ya existen números ejemplos de arte público en entornos rurales con intenciones similares que presentamos ${ }^{131}$, hemos escogido el caso de Almócita por ser el único dentro de la Red de Transición, pero además, porque revela una cadena de procesos que resulta dificil de identificar y visualizar en otros proyectos, por lo que este caso resulta especialmente valioso. Almócita e una población de menos de 150 habitantes en las Alpujarras almerienses. Como muchos mu nicipios rurales en España, se enfrenta a un fenómeno de despoblación preocupante, que ha motivado a la alcaldía de la población a repensar su futuro, planteándose la unión del arte y la sostenibilidad como herramientas alternativas de desarrollo, evitando la explotación urbanísti${ }^{2}{ }^{132}$ del entorno natural y el consecuente riesgo de pérdida de identidad. Según Sergio Pineda (Téenico del Ayuntamiento y Guadalinfo) «todo lo que estamos haciendo de renovación en el aspecto etico tiene un trasfondo final que es la despoblación» (Pineda, comunicación personal, 29 de diciembre, 2017). Desde 2015 forman parte de la Red de Transición española con un grupo de unas 35 personas (siendo de ocho a diez personas el grupo motor). Pineda expone que el arte ha sido la pieza fundamental desde el inicio de esta andadura cuando en 2009, realizaron un campo de trabajo internacional con participantes de diversos países de procedencia y que dio como fru- to la realización de un mural colaborativo llamado Almócita y una poesía pintada sobre fachad 列ciones ambas que se han sucedido cada año desde entonces. «El proyecto de inicio del arte de la poesía en las calles nos ha dado una identidad [...] ha cohesionado al pueblo y ha sido motor para otros proyectos globales» (Pineda, comunicación personal, 29 de diciembre, 2017).

A partir de ese momento, diversas propuestas fueron sucediéndose e impulsándose unas a otras. Propuestas artísticas como La Noche con Alma, el Almouseum y los murales o poesías de sus paredes encaladas se engran con otros proyectos en torno a la sostenibilida banco de tierras, domo de paja, huertos públicos, gallinero comunitario, grupo de consumo, Ecoencuen-

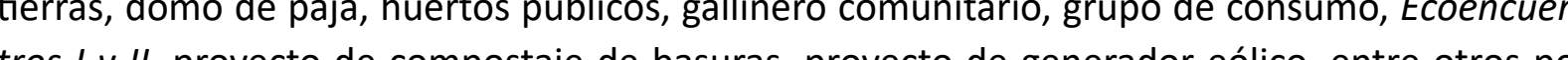
tros I y II, proyecto de compostaje de basuras, provecto de generador eolico, entre otros por éstas, son un las obras a un ticas como las progray

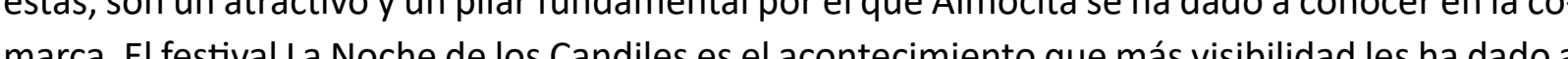
marca. El festival La Noche de los Candiles es el acontecimiento que más Visibilidad les ha dado a nivel internacional y nacional. Surge en 2009 como un proyecto reivindicativo contra el excesivo consumo eléctrico y el que se lleva a cabo un apagonngeneral en el pueblo. Durante una tarde entera solo se iluminan con candiles $y$ antorchas. Poco a poco, se le han ido uniendo actividades culturales, artísticas (música, artesanía, murales colaborativos) y asociadas al reciclaje (crea candiles reciclados). Cuentan desde 2013 además, con el candil más grande del mundo, certifcado como record Guiness y que funciona con los aceites reciclados cedidos por una almazara (de 500 a 600 I. de aceite). La Consejería de Turismo les ha reconocido como modelo de renovación turística de nueva creación. Se estima que entre 4.000-5.000 personas acuden a esta noche, y toda la comarca se beneficia de ello copando los alojamientos, lo cual estrecha lazos entre los pueblos vecinos (Pineda, comunicación personal, 29 de diciembre, 2017). Además se disponen medios de transporte entre municipios (coches compartidos, trenes, microbuses) para hacer la velada lo más sostenible posible. Actualmente se plantean un proyecto de Ecomuseo global en el que las piezas fundamentales son la ecología y el arte. Todas estas acciones con un pie en la sostenibilidad y otro en la creatividad, construyen un perfil ético que atrae a ciertos sectores de población cercanos al ecologismo, la agroecología, la espiritualidad o las prácticas artísticas. Constituyen en conjunto una estrategia que pretende enamorar al visitante. El resultado es que, en este año, cinco familias se han establecido o tienen prevista su inminente instalación que, pueblo, aumentando la población y rejuveneciéndola A continuación presentamos un estudio más detallado $y$ centrado 


\section{ADECUACIÓN A LOS CRITERIOS DE SELECCIÓN DE LA INVESTIGACIÓN}

El caso del grupo de transición Activar la transición en Almócita, ha sido seleccionado por cumplir con nuestros criterios señalados en el capitulo dos. En concreto, en este capitulo nos centraremos en aquellos casos de estudio que se consideran a si mismos una iniciativa de transición. Almócita pertenece a la Red de Transición desde 2015 y a la red Terrae ${ }^{133}$. El grupo surge, según comenta Pineda - uno de sus miembros- por la necesidad de organizar en líneas de trabajo concretas todas esas ideas que ya venían trabajando desde el ayuntamiento (Pineda comunicación personal, 29 de diciembre de 2017). En este punto remarcamos que sus actividades comenzaron mucho antes de conocer el concepto transicion, que fue introducido recientemente gracias a nuevos pobladores, atraídos por su linea de actución en consonencia intuitiva con las ideas acciones que do cacal. En general, su extrapolabilidad, les hace valloss como restivos de cambio y tienen la particularidad de hacer uso del arte (y en concre te del a colaborativo) como herran terta funda preocupación por la huella ecológica -como en el caso de la construcción del edifício del Domo destinado a centro de terapias alternativas - pero aún no han hecho hincapié en ello en otros proyectos artisticos v carecen de métodos de medición. Por untho tambien se ocupan de temas relacionados con la ecología y la transición, como la agroecología, el ahorro energético, la equidad o la bioconstrucción

En cuanto a los principios generales de la transición, Almócita realiza las siguientes accio-

Descarbonización de la economía

- Promover la sensibilización en cuanto al consumo energético con el festival La Noche de los candiles.

- El Ayuntamiento ha dejado de utilizar herbicidas y pesticidas en los espacios públicos.
Creación reciente de huertos comunitarios en ecológico, sin uso de fertilizantes ni pesticidas.

- Peatonalización del centro del municipio para favorecer el paseo a pie y la seguridad peatonal.

Compromiso del movimiento ambiental con la equidad y la justicia

- Festival anual Almomed: Medita por los Buenos Tratos, en noviembre desde 2011.

- Acciones simbólicas como el mural Homenaje a la mujer rural.

El desafio de la conservación

- En colaboración con las Universidades de Granada y Almería se han realizado varios cursos de formación relacionados con la conservación de fauna y flora como el reciente curso sobre libélulas de río.

- El pueblo celebra el día del árbol y realiza plantaciones puntuales. Tienen en proyecto iniciar un bosque mediterráneo en colaboración con varios expertos biólogos.

- En cuanto a los cuatro principios del movimiento de transición, Almócita responde de la siguiente manera:

Planificación ante el colapso energético: ahorro energético reutilización, reciclaje y reducción de residuos:

- Festival Noche de los Candiles: nace como un acto reivindicativo contra el excesivo consumo eléctrico que trata de sensibilizar a los habitantes. El apagón general durante una tarde entera se acompaña de antorchas, música, talleres y arte.

- Proyecto Residuo cero: se trata de un proyecto de compostaje de los residuos orgánicos en el que ya están participando siete familias que portan sus residuos orgánicos al avicompostero del gallinero comunitario y recogen a cambio los huevos. J. Alberto Bretones, miembro del grupo de transicion, calcula que en un año han ahorrado una tonelada y media de residuos orgánicos a los servicios de limpieza (Bretones, comunicación personal, 29 de diciembre de 2017). El objetivo a la larga es tener un espacio 
municipal de compostaje, con compostera y trituradora, implicar a todo el pueblo, y usar el compost para la regeneración de suelos y la agricultura.

- Proyecto de bioconstrucción: actualmente realizado el domo, primer edificio de bioconstruido con paja y adobe. En proyecto varios más con distintas técnicas.

- Conversión a agroecológico de parte de los agricultores.

- Proyecto de instalación de generador eólico y placas solares (aún en proceso) para dotar de electricidad al edificio del domo y con el objetivo final de ser autosostenibles energéticamente en todo Almócita.

- Fomento de la movilidad sostenible: 24 ediciones del día de la bici. Se plantea como un evento lúdico y familiar, centrado más en la concienciación que en lo deportivo.

- Ecoencuentros / y II (2016 y 2017) coorganizados con la asociación Trotamundos.

Medidas para el aumento de la resiliencia:

- La Noche de los Candiles beneficia a toda la comarca copando los alojamientos hoteleros en $30 \mathrm{~km}$ a la redonda y creando lazos con los pueblos vecinos con un concepto de turismo cultural de cercanía.

- Banco de tierras: gracias a la cesión de tierras, nuevos agricultores como Matías se instalarán pronto en la población.

- Apuesta por turismo sostenible, ético y activo (club de senderismo de Almócita, escalada, bicicleta de montaña) como fuente de conocimiento externo, de disfrute con la naturaleza y también de atracción de otro perfil de turistas al municipio, sin perder la identidad del pueblo ni convertirlo en la única fuente de ingresos. Carriles bici entre los pueblos, tres rutas de bicicta de montaña homolode homologadas por la Federación Internacional.

- Organización de la travesía de resistencia de la Federación Andaluza de montaña. Se ha elegido este tipo de prueba por ser solidaria, colaborativa, primando el trabajo en equipo por clubes por encima de la competitividad a nivel individual, lo cual, encaja
Los siguientes indicadores que nos otorgan pistas sobre el aumento de la resiliencia están seleccionados del Compendio de iniciativas de transición, (Brangwyn et al., 2010, pp. 26

- Porcentaje de alimento producido localmente: La mayoría de las familias disponen de su propio huerto para nutrir el núcleo familiar y, para las personas que no tienen tierras, se ha habilitado el huerto comunitario y se dispone también del banco de tierras. Además, el huerto comunitario dispone también de un gallinero común del que se alimentan y hacen cargo actualmente siete familias.

- Número de empresas de propiedad local: El Ayuntamiento dispone de dos locales para servicio de bar, un camping y un restaurante municipales que se licitan. En concreto el alquiler del restaurante puede reducirse hasta en un $45 \%$ si se cumplen las siguientes condiciones:

1. comprar a los agricultores locales

2. estar empadronados y residir en el municipio

3. disponer en la carta de una parte vegana

4. contratación local

5. productos ecológicos

- Cantidad de materiales de construcción renovables: Cuentan con un edificio construido con paja y adobe (domo) para la realización de talleres y tienen en proyecto realizar otros con superadobe, domos de madera para alojamientos del camping adobe $y$ tapial que se sumen al proyecto de Ecomuseo global.

- Distancia media a la escuela por parte de los estudiantes de la población: A pesar de su escasa población, Almócita no ha querido prescindir de su propia escuela. Al asociarse con los pueblos vecinos de Padules, Illar, Instinción y Rágol pueden disfrutar de un colegio rural con aulas comunitarias en cada población entre las que rota 
- Proporción de residuos compostables y compostados realmente: El Ayuntamiento tiene la intención de introducir en los negocios locales de su propiedad (camping y bares) materiales compostables para evitar todo tipo de propiedad (campin han com) maticho hecho, han comenzado a úzar plás los en los proximos festiva des. An fas cia en 2018 y se prevé también incorporarlos en los próximos festivales. Las familias implicadas en el gallinero comunitario se comprometen a incorporar estos residuos al avicompostero. Tambien se van a

\section{Acción local y colectiva:}

- Tejido asociativo: la población cuenta a pesar de su pequeño tamaño con varias asociaciones y centros representados también en el grupo de transición como: la Asociación de Mujeres, el centro Guadalinfo ${ }^{135}$, la asociación El Arbol de la Vida la asociación Trotamundos con su grupo de consumo Trotahuertos.

- El pueblo dispone de dos tipos de rutas guiadas. Una audioguía, producto de un (l) a n directo, a solicitud deana que la anterior, ideada von en valor los diferentes espacios que se están trabajando desde hace años y que se adapta a los diferentes eventos. (Pineda, comunicación personal, 29 de diciembre de 2017). Varios grupos de colegio han visitado el pueblo, y en su recorrido se les informa de la conciencia municipal al respecto de la sostenibilidad entre otros temas.

- Proyecto de horno comunitario con adobes tradicionales que está en la fase inicial de elaboración de adobes a finales de 2017.

- La apertura e implicación activa de los habitantes en las diversas actividades revitaliza la población y facilita el éxito de las mismas: La Noche con Alma, La Noche de los Candiles, la escultura del árbol de la música, los murales colaborativos, día de la bici, el belén de crochet entre tantas otras.

\subsection{ORÍGENES, OBJETIVOS Y DESCRIPCIÓN DEL PROYECTO}

Como hemos mencionado, los problemas de despoblación y el rechazo del Ayuntamiento de Almócita a refugiarse en el recurso de la urbanización, han conducido a esta población hasta la transición a la sostenibilidad. Fueron unos recientes pobladores, Paco García y Eva Ramírez, los que identifican los pasos - que sus habitantes ya llevaban años Gando de modo intutivo - como caracteristicos de los pueblos en transición. Aśi introdu-

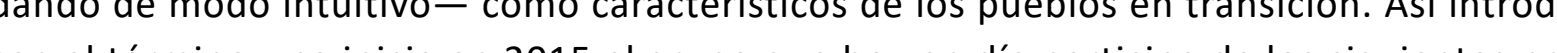
yectos junto a resto de hates:

\subsubsection{Festival La Noche con Alma}

Este festival es el contexto donde surgen y se desarrollan las actividades artísticas colaborativas de Almócita. Nace como resultado de un campo de trabajo internaciona (3)

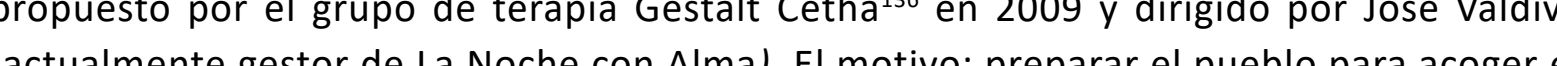
lactualme

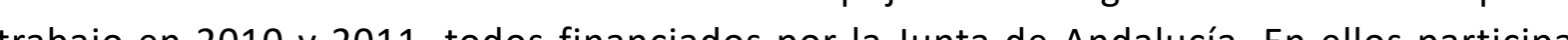
trabajo en 2010 y 2011, todos financiados por la Junta de Andalucia. En ellos participan

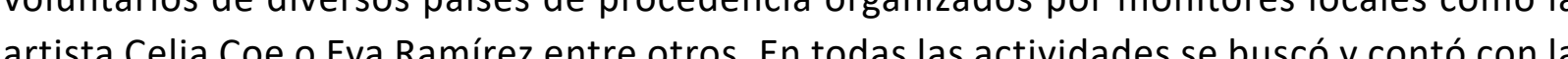

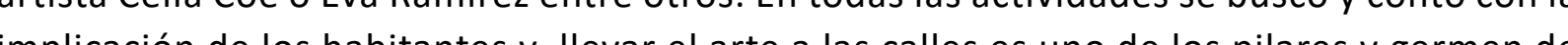
implicación de los habitantes y llevar el arte a las calles es uno de los pilares y germen de La Noche con Alma (E. Ramirez y J. Valdivia, comunicación personal, 2 y 4 de abril de 2018). El encuentro, que se realiza la última semana de julio, agrupa acciones artísticas en e espacio público, actividades circenses, poesía y música. Durante el festival, al que acuden unas mil personas, se pintan poemas de autores famosos o bien de habitantes del pueblo 
Además se organizan talleres de poesía, canto y danza entre otros. El grupo Cetha es el encargado de seleccionar a los artistas invitados basándose en criterios de cercanía y nuevos talentos. El Ayuntamiento asume los gastos de estancia y materiales de los artistas invitados y solicita a cambio que la temática de los murales esté relacionada con Almócita obras:

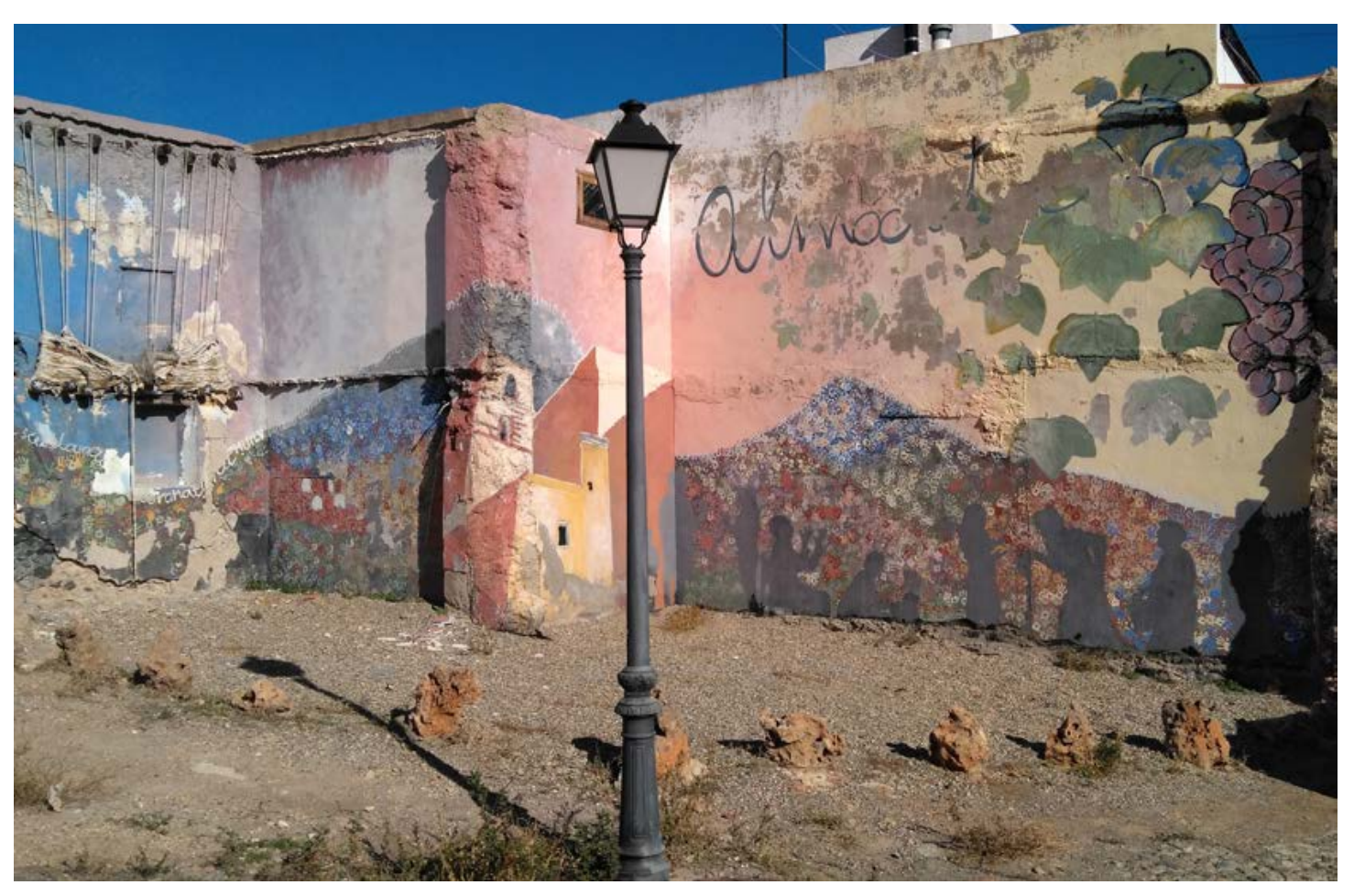

Imagen 26. Mural Almócita: trabajo colaborativo realizado durante el campo de trabajo en 2009. Fuente: Fotografí de la autora 2017.

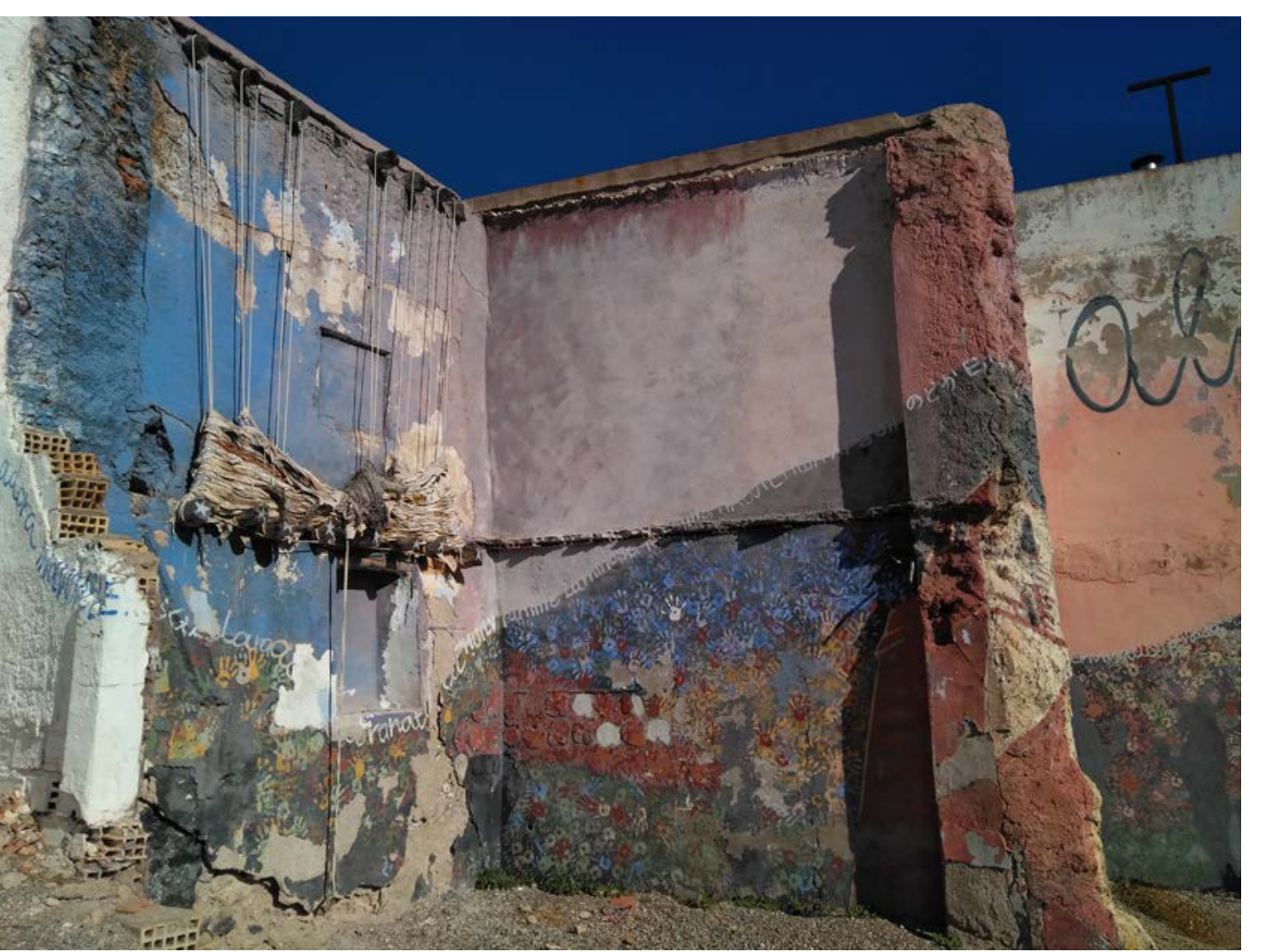

mágenes 27 y 28. Detalles del mural colaborativo realizado durante el campo de trabajo en 2009. Fuente: fotogra-

Mural Almócita: orquestado por Cetha y dirigido por Valdivia, colaboran artistas como Coe, voluntarios de otros países implicados en el campo de trabajo y vecinos. Pineda considera este proyecto y la participación de los a tistas y colaboradores como ufundamenta pra proyecto gla 2017). A partir de la experiencia de realizarlo, se propon otros espacios sure el proye 2017). A partir de la experiencia de realralo, se proponen otros espacios y surge el proyecto de la poesía en sus fachadas. Es uno de los murales más llamativos por tener varias técnicas -incluyendo el tejido de un tapiz con trapos donados por los habitantes- pero al no haber realizado un tratamiento de consolidación previo se está perdiendo. 


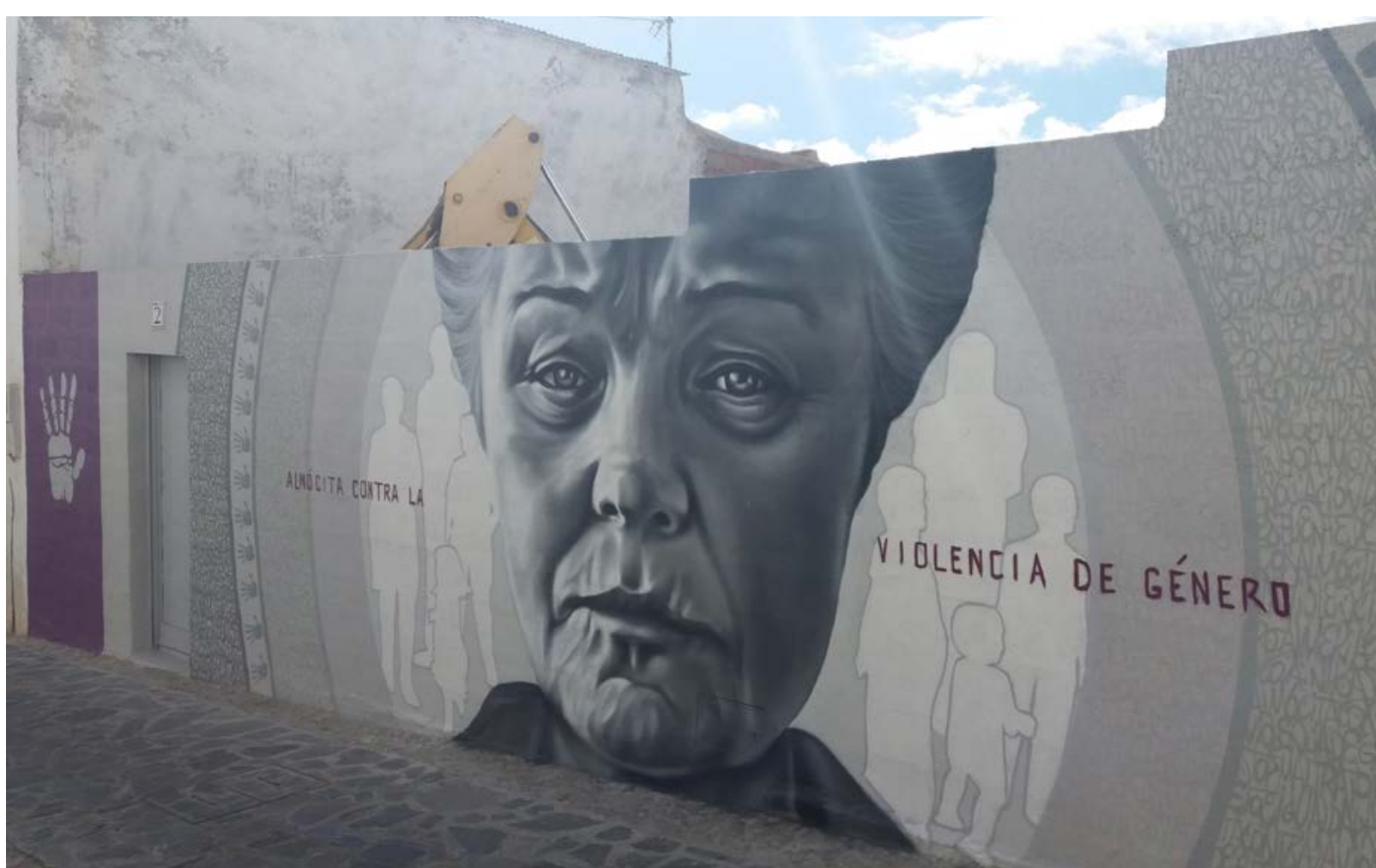

Imagen 30. Mural homenaje a la mujer rural. Fuente: Sergio Pineda 2018.

Otros murales son: el homenaje a la uva de barco (2010) y los trabajos de grafiti del artista Sovri: Abejaruco (2015), En un lugar de Almócita (2016) y La niña (2016).

Poesías: Hasta diez poesías jalonan las calles de Almócita. La mitad de ellas, de autores reconocidos, y la otra mitad, de los propios habitantes. Son los mismos autores los que dibuja su poesía en las fachadas seleccionadas o bien con ayuda de otros vecinos y organizadores del festival La Noche con Alma. Cada edición se pinta una al menos.

Mural homenaje a la mujer rural: Realizado por el grafitero Moxaico ${ }^{137}$ (pseudónimo de artista Daniel Fernandez), en colaboración con las vecinas de Almócita a propuesta del Ayuntamiento. Una asamblea de mujeres decide los motivos e ideas que quieren representar y Moxaico elabora tres propuestas de las que escogen una, añadiendo algunas modificaciones.
3.3.2 Árbol de la música

Este proyecto realizado también con el campo de trabajo en 2011, trató de rescatar a habitante más anciano de Almócita: un acebuche de 300 años. El árbol se debía trasplantar para

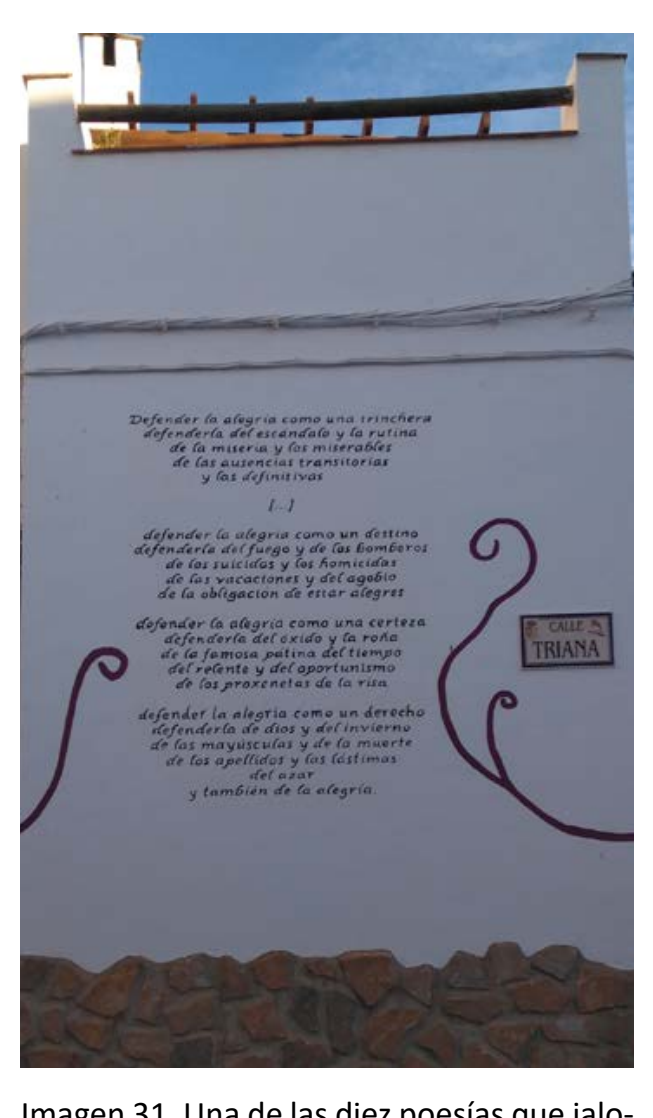

Imagen 31. Una de las diez poesías que jalonan las paredes de Almos
grafia de la autora, 2017 
138 Grizedale es un bosque en el distrito de permitir la construcción de la nueva carretera pero no sobrevivió. Sin embargo, en honor a su los lagos en el Norte de Inglaterra, donde longevidad y con la intención de honrar al bosque mediterráneo, se propuso darle un nuevo uso renta esculturas site specific desde 1977 artístico por el grupo de trabajo. Actualmente es una de las piezas artísticas más queridas $y$, a lo que pueden visitarse a pie o en bicicleta. largo del año, acoge las celebraciones del día del árbol y el taller de meditación y yoga para niños en noviembre, dentro del festival Almomed Medita por los Buenos Tratos. El viento abundante en noviembre, dentro del festival Almomed Medita por los Buenos Tratos. El viento abundante cuelgan de sus ramas.
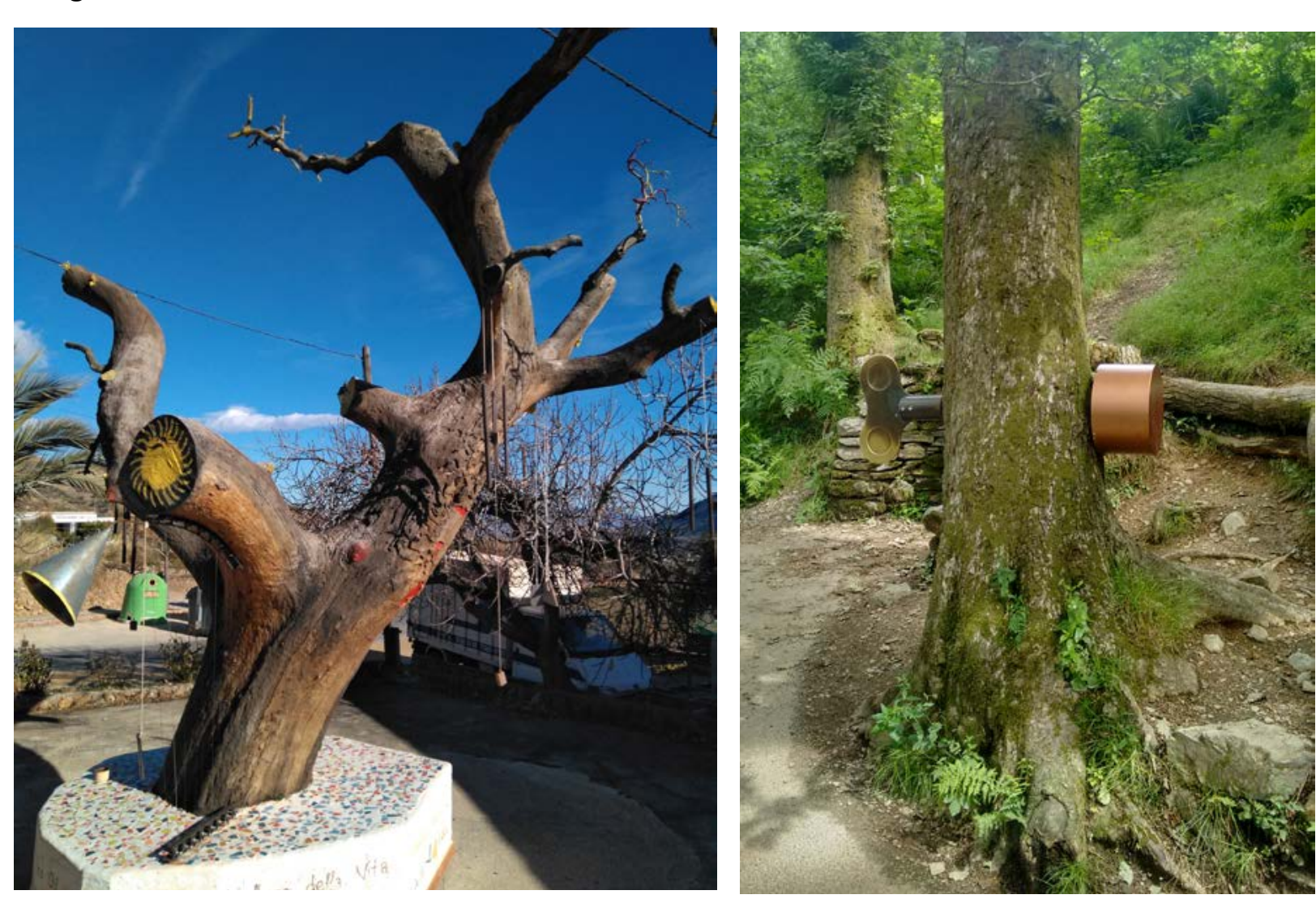

Imágenes 32 y 33. Escultura Árbol de la música con instrumentos musicales en Almócita y su equivalente en el 2016 respectivamente.

Encontramos en nuestra estancia de investigación en Escocia una obra relacionada con ésta en el famoso parque de esculturas en el bosque de Grizedale ${ }^{138}$ realizada por el colectivo de artistas londinense Greyworld ${ }^{139}$. En el caso de la obra de Almócita, aunque más sencillo en su

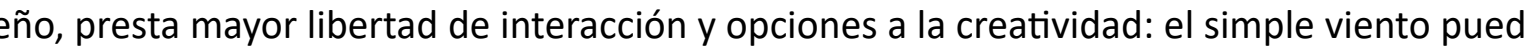
activar la obra que cobra vida por sí misma, y/o bien una o varias personas pueden activarla a la vez y crear música diversa e irrepetible. De este modo el público se siente atraído en repetidas ocasiones por esta escultura escuchando un resultado diferente cada vez. Se trata, pues, de una obra cambiante que mantiene unido a la vida del pueblo un habitante arbóreo muerto.

\subsubsection{Festival La Noche de los Candiles}

Se trata de un festival de música pagana de un fin de semana de duración que comenzó como una acción de protesta y concienciación sobre el consumo eléctrico en 2011 y se h convertido en el festival de mayor afluencia. Durante su celebración, se realiza un apagón generalizado toda una tarde y el pueblo se adorna con iluminación de velas y candiles. Entre las actividades de este encuentro (talleres de reciclaje y música, visitas guiadas, conciertos, mercadillo, danzas) destaca el encendido de la pieza artística el Candil más grande del mundo, obra considerada principal pieza escultórica de la población y realizada por el herrero y habitante: Francisco García.

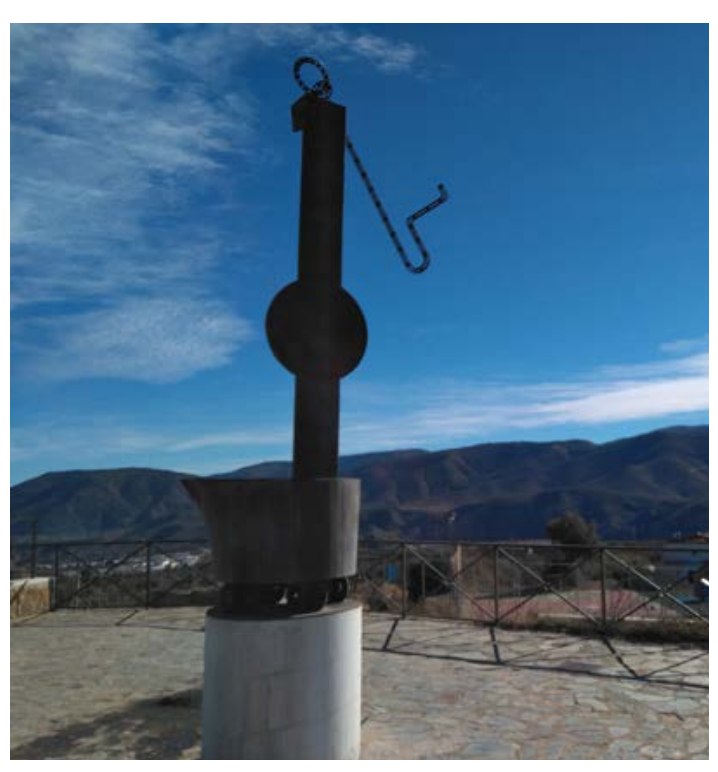

Imagen 34. El candil más grande del mundo. Fuente: Fotografía de la autora 2017.
139 La obra data de 2011 y también aúna Wica, arboles e interacción humana. En modo de caja de música. Cuando los paneran una melodía que se puede escuchar Esta obra permanente también instalada al aire libre, fue encargada por la Comisión

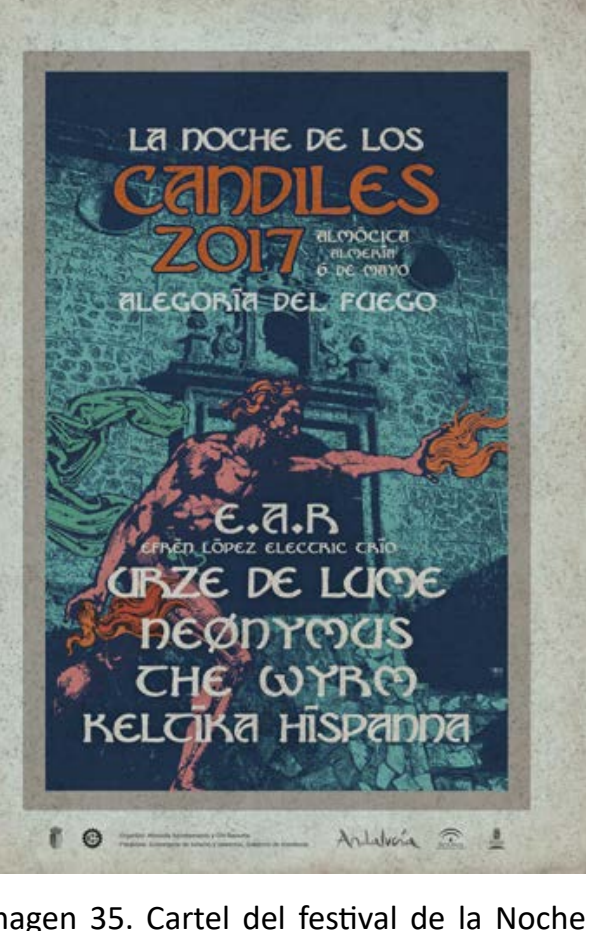
Imagen 35. Cartel del festival de la Noche
de los candiles. Fuente: Ayuntamiento de de los Car
Almócita 


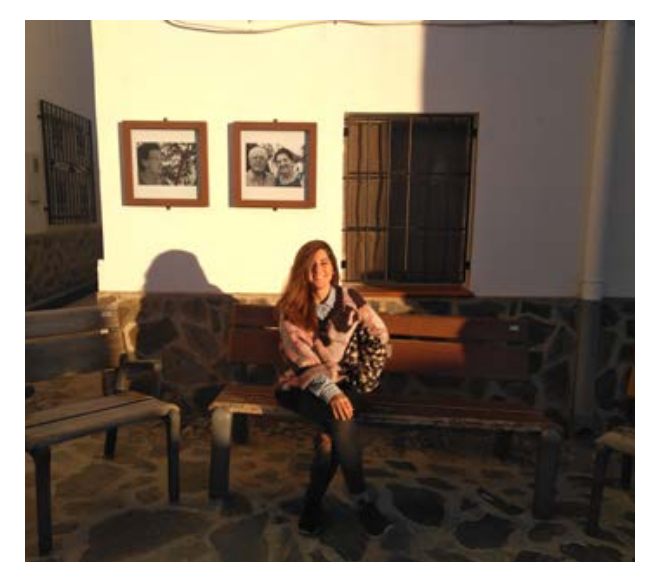

Imagen 36. Coe en Almouseum. Fuente: FoGin Imagen 37. Fragmento extraído del video de
Almouseum ${ }^{100}$ es un museo al aire libre situado en las calles de Almócita y producto de la convocatoria artística de la Diputación de Almería Alnomalía 2016-2017. Las cajas metálicas que o forman se pueden abrir para acoger diversas exposiciones de fotografía. Actualmente exhibe la colección fotográfica Voces con historia. Esta primera exposición se basa en una obra colaborativa anterior que hunde sus ráces nuevamente en los campos de trabajo. La artista coe, en-

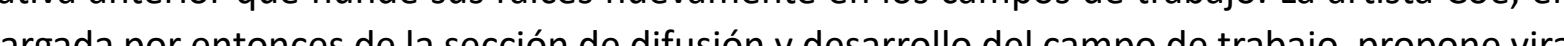
cer e Vistas a mayes de 75 antos que repesentan dexima vistas a mayores de 75 anos que representa Uas, en blanco $y$ no nas, en blanco y negro, que luego serán retocadas con un detalle de color. Esta multivocalidad se recoge en numerosos escritos que fueron reservados hasta la convocatoria de 2016-2017. I recorrido fotografico es fruto de las conversaciones que recogieron anécdotas, charlas, tradiciones, costumbres, curiosidades y refranes. Se seleccionaron algunas de las fotos más significativas donde sus habitantes se abren al mundo para acoger al visitante. Todo un homenaje a aquella generación narrado por sus mismos protagonistas.

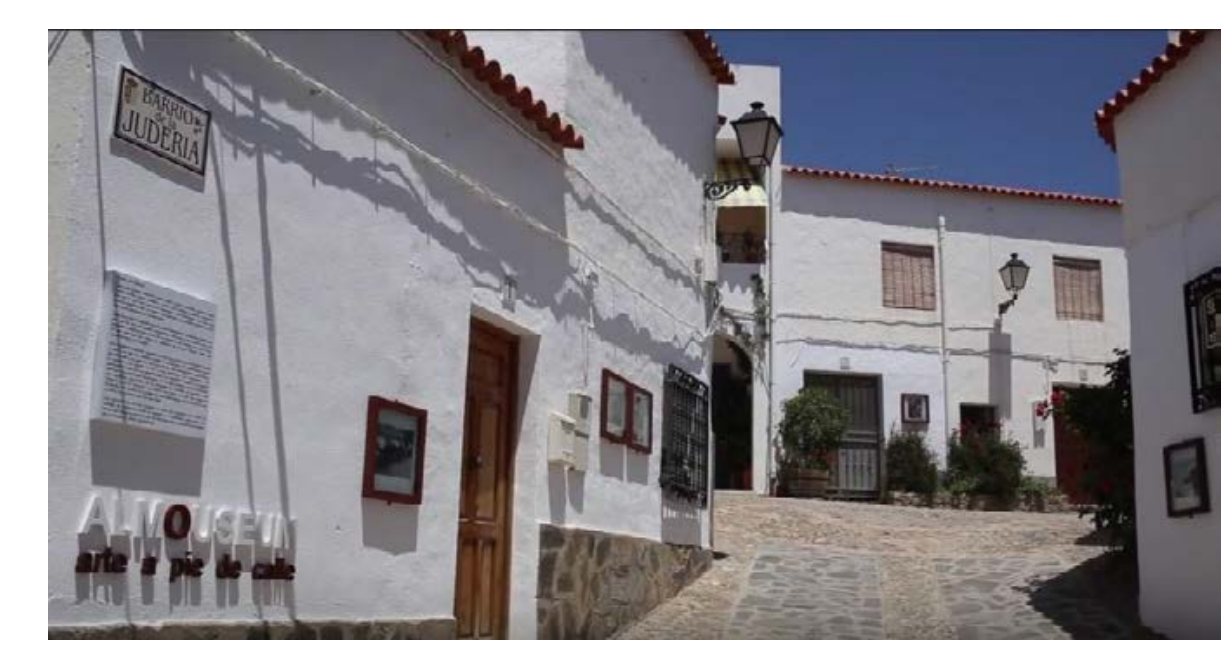
Imagen 38. Fragmento extraído del video de Almouseum realizado por Coe con imágenes de Ana Morales Ibáñed
Véase en: https://wwww.youtube.com/watch?v=bdUOKLxidis
En Almócita consideran este espacio como una obra artística y planean realizar una exposición de su construcción. Formará parte del Ecomuseo global en el que las piezas fundamentales son la ecologia y el arte. El edificio está pensado para la conexión con la naturaleza, talleres de yoga, meditación y terapias alternativas de uso público. Ha podido realizarse gracias a la financiación del Ayuntamiento y el apoyo del Programa de Empleo Rural (PER) de la Junta de Andalucía.

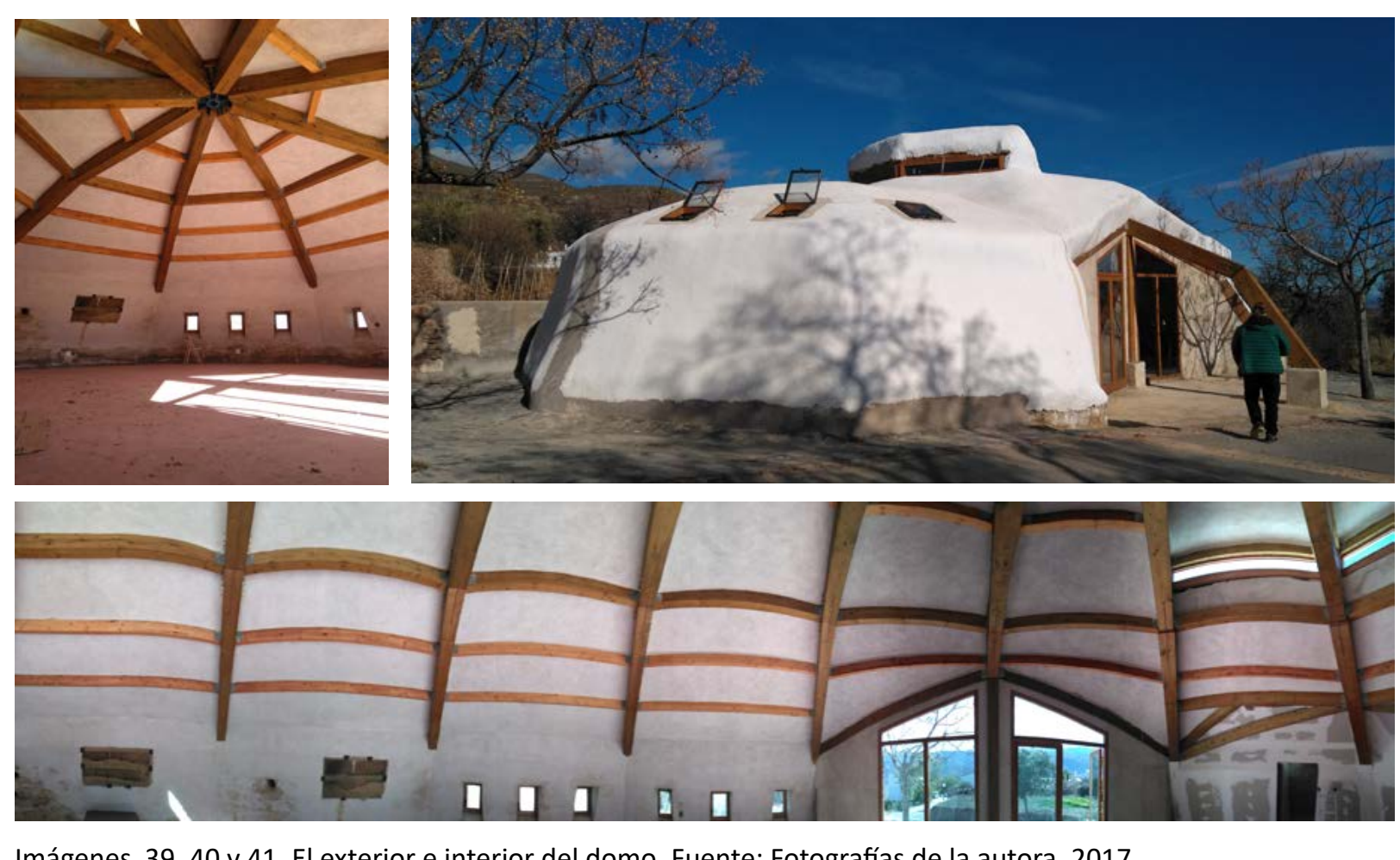

Imágenes 39, 40 y 41. El exterior e interior del domo. Fuente: Fotografias de la autora, 2017 
141 Véase en: http://www.ideal.es/
almeria/provincia-almeria/almocita-cultocandil-20180504130659-nt.html

142 Véase en: https://www.youtube.com/
watch?time_continue=36\&v=1sbU462z30\%

143 Véase en: http://www.iaph.es/web/ almocitaentransicion.htm!

\subsection{ANÁLISIS}

3.4.1 Participación Incluso las personas de avanzada edad demuestran un inesperado interés en las nuevas activida es, declaran Coe y Pineda. La colaboración ha abarcado todas las categorías de Lacy en función de cada proyecto, a excepción del tipo seis (público del mito y la memoria). Por ejemplo, en los campos de trabajo que dan lugar a los murales y las poesías, los vecinos e invitados al grupo de trabajo inicial decidieron en común dónde intervenir, qué hacer y posteriormente qué pintar y por tanto, los podemos considerar en la categorla uno. decisores y promotores desde el inicio. Además los habitantes colaboraron en su diseño (tipo dos) y ejecución (tipo tres) y por supuesto son parte del público espectador (tipo cuatro). En cuanto a los murales, encontramos todas las posibles combinaciones, los hay que se hacen en colaboración total entre vecinos y artistas desde el diseño (tipo uno) a la ejecución (tipo tres) - como el mural del campo de trabajo-, los que se diseñan previamente pero se ejecutan con participación vecinal (murales de La mariposa y Vista del pueblo), los que son diseñados en colaboración con el pueblo (tipo uno y dos) pero jecutados por artistas (mural del Homenaje a la mujer rural) y otros en los que el pueblo es solo espectador y los artistas lo realizan (Mural En un lugar de Almócita). Respecto al público de los medios de masas, La Noche con Alma o la Noche de los Candiles son acontecimientos conocidos en la comarca, seguidos en las redes sociales, las agendas de ocio comarcales y los periódicos provinciales como El ideal'14. Pero además, durante el resto del año numerosos visitantes acuden a visitar sus fachadas, ya que aparecen difundidas en varios blogs de senderismo y videos de youtube ${ }^{122}$. A nivel oficial también la Consejería de Cultura se ha hecho eco de sus acciones artísticas ${ }^{143}$ en el I Encuentro Patrimonio de Proximidad.

Respecto a la exposición Voces con historia del Almouseum, la participación de los hab 列 se puede entender, en ese sentido, como del tipo uno (origen y responsabilidad). Aunque a nive individual, realmente la no participación de algún miembro no habría impedido el desenlace de la obra, como define el tipo dos (colaboración y codesarrollo). En cambio, la ejecución ha corrido en su mayor parte por la artista y cuenta con espectadores y el público de los medios de masas

En conclusión, podemos decir que Almócita destaca, respecto a las obras artísticas analizadas en otros grupos de transicion, por lo participativo de sus acciones que invitan a todo todos los ejemplos estudiados dentro de la Red de Transición española.

\subsubsection{Puntos de tensión y puntos clave}

La financiación es un punto clave aunque no imprescindible, para desarrollar cualquier proyecto. Por lo general, Almócita es un municipio con bajo presupuesto y declaran tener dificultades para encontrar artistas que acudan, ya que solo pueden hacerse cargo del alojamiento, transporte y materiales. La inversión ha sido básicamente municipal aunque dependiendo del proyecto ha recibido el aporte de:

- Campos de trabajo 2009, 2010 y 2011. Financiados por la Junta de Andalucía.

- En La Noche con Alma, en 2017, por primera vez, se ha conseguido financiación por micromecenazgo a cambio de inscripción en talleres de poesía o danza.

- En la Noche de los Candiles colabora La Diputación de Almería.

- En el Ecoencuentro colaboran la asociación trotamundos con la mitad del presupuesto y una pequeña inversión de la Diputación de Almería para publicidad.

- El proyecto de Almouseum ha contado con la financiación de la Diputación de Almería al ser seleccionado en el proyecto Alnomalía 2016-2017 con 4.100€.

- El domo ha contado con la ayuda del programa PER de la Junta de Andalucía.

- Por último la concejalía de turismo ya ha mostrado interés en mencionarlos como referente de recursos turísticos de nueva creación incluyéndoles en sus publicaciones. 
ración con la administración pública. En este caso el denominado efecto teflón de Lacy no ha enido lugar, sino todo lo contrario. Es precisamente el Ayuntamiento quien ha sido el principa impulsor de las actividades artísticas y en pos de la sostenibilidad. Por tanto, las críticas hacia la colaboración con las administraciones públicas de otros grupos ecologistas o las reticencias de muchas iniciativas de transición a iniciarlas, contrastan con el caso de Almócita, que debe gran parte de su éxito al impulso del equipo municipal.

Un reto común a la hora de la creación colaborativa es el equilibrio entre colaboración-esos de algunos paisanos en relación a la localización en el espacio expositivo de las fotografías de Voces con historia. No obstante, los criterios esteticos y artisticos han prevalecido, aunque la estética de la obra, tales como renunciar a las cartelas.

\subsubsection{Intención}

Para valorar adecuadamente estas obras artísticas en su contexto es útil conocer las intenciones con las que fueron planificadas. Podemos decir que ha habido propuestas con una intención clara y definida desde el inicio, como en el caso del domo o el candil más grande del mundo, y otros casos en los que la intención inicial ha evolucionado y crecido de la mano de los artistas y colaboradores como en Voces con historia, el Árbol de la música o en La Noche con Alma. En cualquier caso, declara Pineda, los resultados han superado sus expectativas. En eneral, la postura del equipo municipal al respecto de sus propósitos es clara: luchar contra e despoblamiento y atraer a nuevos habitantes con un programa global atractivo encaminado a la sostenibilidad. Todos los proyectos, declaran, han de tener una base ética de respeto al medio ambiente v las tros los proyectos, declaran, han de tener una base ética de respeto al medio ambiente y las tradiciones (Pineda, comunicación personal, 29 de diciembre de 2017). Cuando se solicita la colaboración de artistas, se insiste en que se adapten a estas intenciones, respetando la personalidad propia de cada invitado. Respecto de las intenciones particulares de cad proyecto o artista, podemos decir que son diversas, pero se pueden resumir en las siguientes: desarrollar la visión del pueblo, atraer al público, estimular la imaginación, reforzar la identidad, embellecer, crear comunidad, conectar, restaurar el entorno construido, empoderar, agitar, de- uunciar, celebrar, construir consensos, concienciar, crear espacios de conexión, mostrar alternativas reales y servir de proyecto piloto.

En el caso de la artista entrevistada, Coe señala su voluntad en Voces con historia claramente: dar voz a las personas más ancianas del pueblo para valorar su pasado como fuente de conocimiento $y$ antecedente del pueblo. Considera que la implicación del público en la obra puede contribuir a la transformación social y resalta por ello el objetivo cumplido de hacer que a los jóvenes les resuene la voz de los mayores. Afirma que el resultado ha sido acorde con las intenciones inicias, pero no ha sido medido. En su práctica artística trata de seguir criterios de sostion sostein un modelo de desarrollo diferente.

\subsubsection{Efectividad}

En nuestro estudio de Almócita hemos realizado una visita, observaciones, siete entrevistas y dos encuestas. Realizaremos este análisis mediante los datos extraídos de la visita y actividades. Es por ello que no podemos ofrecer una lectura profunda de las implicaciones o a actividades. Es por ello que no podenos ofrecer una lectura profunda de las implcaciones o la aproximada.

Respecto al impacto de las obras artísticas en esta comunidad, podemos decir que, en especial el proyecto artístico inicial del campo de trabajo, fue el germen de otros proyectos como
La Noche con Alma y la poesía. En opinión de Pineda a nivel general: «si ha habido un cambio La Nocheco ha la acienso que ha habido un cambio en la for, la for va varido flores,...) (Pineda, comunicación personal, 29 de diciembre de 2017).

La asimilación de otros conceptos más relacionados con la sostenibilidad no se han medi- 
145 «Los niños de aquí, cada vez más, tie- do, pero Pineda hace una observación curiosa. En su opinión, están trabajando con la tradición nen idea de los conceptos de reciclaje, de la pues realmente las personas mayores siempre han tenido un estilo de vida sostenible en el

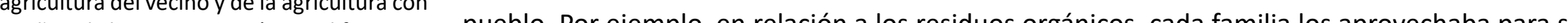
de aprender a mirar Para ellos no es raro pequeño corral particular. Ahora se les velde a solicitar, cue haga lo mismo pero pra un ben

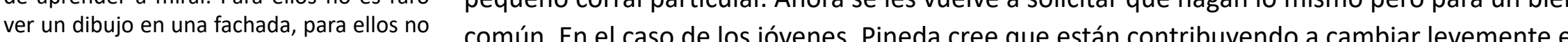

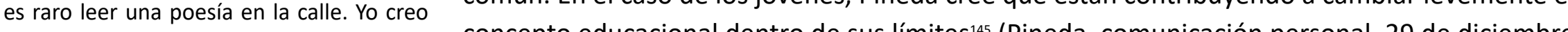
que son como pequeñas dosis de cultura zan su identidad» (Pineda, comun
personal, 29 de diciembre de 2017)

(Piciembre de 2017).

En cuanto a los resultados más patentes, podemos destacar que gracias a todas las medidas adoptadas por el Ayuntamiento dirigidas hacia la sostenibilidad, han atraido achino familias para instalarse como el caso de J. Alberto Bretones y Francisca Alpañez, (técnico deportivo profesora de voga respectivamente), miembros del grupo de transición desde su inicio y fundadores de la Asociación Arbol de la vida. Buscaban una nueva sede para su asoclación acorde sus valores y comentan:

Nosotros estábamos viviendo en Almería y buscando un entorno rural que fuese en esa línea; no solamente el irte a la naturaleza, sino que tuviera esos valores, asi que estuvimos viendo muchos pueblos de Almería de distintos sitios hasta que nos hablaron de Almócita. Vinimos aquía hablar con Paco (alcalde) y vimos que la idea que nosotros teniamos la tenian ellos aqui, o sea, ellos estaban en la misma linea intentando llevar hacia delante todos esos proyectos (F. Alpañez, comunicació personal, 29 de diciembre de 2017).

También es el caso de Paco García (Alcalde actual) y Eva Ramírez junto a su hija, que buscaban una sede rural para su grupo de consumo. Para Pineda, sin duda, el perfil ético que está

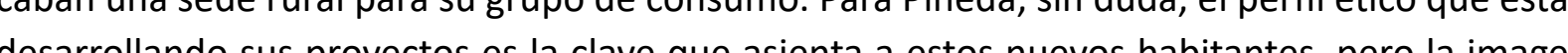
desarollando sus proyectos es la clave que asienta a estos nuevos habitantes, pero la imagen estética del pueblo constituye la primera fase de atracción de la localidad: «lo primero es que en Almócita te enamoras porque es muy bonito, los suelos, el arte, todo lo que hay» (F. Alpañez, comunicación personal, 29 de diciembre de 2017).

Otros resultados materialmente constatables son: la mayor visibilidad de los rincones del entorno urbano, la restauración de espacios y fachadas abandonadas o descuidadas y la mejonas ${ }^{146}$ de la limpieza de las mismas. Pineda observa un cambio en la actitud de los habitantes desde las primeras intervenciones murales que se veían como ajenas y extrañas, a actualidad, que se ha activado el ofrecimiento de los vecinos a acogerlas (Pineda, comunicación personal, 28 de marzo de 2018). A consecuencia de lo anterior, observa Pineda, incluso se ha
fomentado el debate artístico entre los vecinos.

En lo que atañe a las cuestiones ecológicas, se ha incrementado el número de interesados en las mismas, no solo por los nuevos pobladores, sino también por los agricultores oriundos, en las mismas, no solo por los nevos pobladoes, sino tambern por los agricultores oriundos, que han comenzado a interesarse por la agroescolc

En general, las iniciativas que se han tomado tienen un gran valor como relato positivo de . plantean tienen en su mayoría efectos a largo plazo, son susceptibles de crecer y evolucionar cada contexto de modo distinto. Almócita seguirá son suleciendo sus calles y ganondo atractivo cada cotractivo con cada festiva de La Noche con Alma, cada exposición en el Almouseum o cada mural. La le col proyecto de compostaje seguira atrayendo a nuevos pobladores en consonancia. El Ecomuseo global que planean que acoja rá medterránea, para de a bustos a poy trativo perfecto de como arte y sostenibilidad pueden impulsarse mutuamente.

\subsubsection{Estética y ética}

Ya hemos comentado en el apartado sobre la intención, que el equipo municipal presta mucha importancia a la base ética de respeto al medio ambiente del proyecto. Sin embargo, mucha imponcto Según Pin aún deberida en la cración de proyectos es el contenido, pero la parte estética según Prneda, la prionidad en la creacion de provectos es el contenido, pero la parte estética es también fundamental. yyo creo que es total provecte iscomprensible Al, poro la pon el proyecto actual, sin esos toques artísticos». Por ejemplo, cita el proyecto de panel solar y generadores
146 Los vecinos parecen encontrarse ahora
más motivados a mantenerlas en buen estado va que sus fachadas ahora son parte de su identidad.

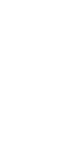


147 «Una anécdota muy graciosa es que, al que van a dotar de un recubrimiento artístico aún por realizar. Aun siendo prioritarios los
[...] en la noche de los candiles, tenemos un perfil muy peculiar de música. Música
pagana, antigua, música compleja de escuto pero para la gente de occher to, pero para la gente de ochenta años es
muy compleja. Y Yademás normalmente van asociados a estéticas un poco diferentes: la
barba negra, larga, tatuajes, de negro, $[. .$. pueblo. Bueno pues mujeres de ochenta y "oye los de la barba estos con los tambo. res tan raros, icuándo vienen? Que tengo
yo ganas de escucharlos, que hace tiempo

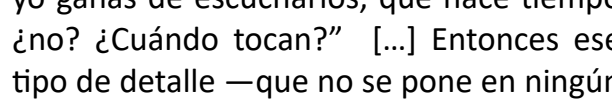
libro digámoslo asi- es lo más importante, yo creo que a través de todas esas cosas se liar en ese aspecto y sea cariñoso. Pues por ejemplo, me han contado anécdotas $[. . .1$ de
los primeros encuentros de yoga, $[. . .$, que
son unos encuentros en silencio. ces tú imaginate por un instante, por aquíla gente andando [...] pues había una actitud (20ión personal 29 de diciembre de 2017).

Respecto a la atmósfera y el espacio estético, dentro de las dinámicas de creación en Almocita, el equipo organizador de los diversos festivales hace hincapié en su interés nécdotas que Pineda señala147 ponen de manifiesto como la diversidad de habitantes acoge con avidez las manifestaciones artísticas. El hecho de que tanto los niños, como los mayores participen (aún a riesco de perder calidad técnica)-ya sea como público espectador en conciertos, pintando los murales o creando poesías - aporta riqueza a las obrasy solidez al

En el proyecto de Almouseum, la artista declara tener un fuerte compromiso de responsabilidad con la estética y, de hecho, solicita al Ayuntamiento participar en ta revisión de proyectos que vayan a exponerse en un futuro: upara mi no todo cabe aquí, comenta coe (Coe, comunicación personal, 29 de diciembre de 2017). La estética ha de cumplir con cieros criterios éticos de relación con el pueblo, de contenido, tener una historia de trasfondo. os de ralor especial dentro de esa tica cono muestra la exposición Voces con historio La artista entiende el modo de realizar la obra (mediante entrevistas distendla lacción de materiales (con ciertos criterios de sostenibilidad), así como la im agen fin en blanco y negroy su localizacion e interacion en el delicado contexto de las calles fipica en blanco y negro y su localización e integración en el delicado contexto de las calles típicas cesos colaborative co confirma la importancia de esos coloquios du ha man en los procesos colaborativos. Coe confirma la importancia de esos coloquios que ha mantenido con los protagonistas, que le han permitido crear momentos de apertura y recoger «auténticos tesoros» de información. Así mismo, manifiesta la influencia que la calidad de la conversación ha tenido en el resultado fotográfico haciendo que sea mucho más natural, mucho más real (Coe, comunicación personal, 29 de diciembre de 2017).

La elección de exponer el trabajo artístico en la calle es una declaración de intenciones. Por un lado acoger al visitante, abrirle las puertas a su intimidad, a su historia, a sus emociones plasmadas en la poesía y las imágenes. Por otro, dinamizar el espacio público, valorar y honrar a la mayor parte de la población que es de avanzada edad, darles un motivo para salir de casa. El marco de trabajo no podía ser otro que la propia comunidad.
La imagen del proyecto ha respondido a la intención estética y ética. Como artista, Coe Lenter por las peticiones de los lugareños en cuanto a la estética o el sentido de la obra. Por otra parte, los materiales elegidos para el Almouseum están en consonancia con el entorno (a) local).

\subsubsection{Papel de los artistas y funciones del arte en Almócita}

Comenta Neal que, dentro del compromiso optimista del MCT, encuentran múltiples papeles que los artistas juegan como: «los que se arriesgan, disruptores, retenedores de espacio, celebradores, narradores de la verdad, hacedores del fuego, poetas, soñadores, críticos, activadores de atención, solucionadores de problemas, constructores de puentes $y$ creadores de modelos alternativos del mundo" (Neal, 2015, p. 79). En nuestro caso, tanto Pineda como Coe identifan los siguientes roles del arte y los artistas en los diversos proyectos nombrados (Pineda y Coe, comunicación personal, 29 de diciembre de 2017)

- De liderazgo.

- De atractor del público, llamada de atención.

- Secundario, acompañamiento del proyecto con valor estético, decorativo.

- Transversal, difuso.

Almócita resulta ser el ejemplo dentro de la Red de Transición española donde el papel de la creación artística está más presente y obtiene una valoración más alta. Coe Pineda identifican las siguientes funciones a nivel genera: 


\begin{tabular}{|c|c|}
\hline $\begin{array}{l}\text { FUNCIONES DEL ARTE } \\
\text { EN ALMÓCITA }\end{array}$ & JUSTIFICACIÓN \\
\hline $\begin{array}{l}\text { Ilustrar, representar, } \\
\text { comunicar, difundir }\end{array}$ & $\begin{array}{l}\text { Sí, por ejemplo los murales de la hoja de barco ilustran su relación } \\
\text { pasada con este cultivo, el mural homenaje a la mujer rural comunica } \\
\text { valores de género y el Almouseum representa a la generación más } \\
\text { anciana }\end{array}$ \\
\hline Concienciar & $\begin{array}{l}\text { Sí, con el mural homenaje a la mujer rural se transmiten valores de } \\
\text { igualdad de género o el festival de la Noche de los Candiles recalca el } \\
\text { ahorro energético por citar algunos ejemplos. }\end{array}$ \\
\hline Desarrollar empatía & $\begin{array}{l}\text { Sí, la escultura del árbol de la música por ejemplo pretende conectar } \\
\text { a las personas con el mundo natural. }\end{array}$ \\
\hline $\begin{array}{l}\text { Imaginar, desarrollar la visión } \\
\text { del grupo, su misión, futuros } \\
\text { posibles, utopías o ficciones }\end{array}$ & $\begin{array}{l}\text { Sí, en los campos de trabajo de los que surgen los murales } \\
\text { Ayuntamiento y vecinos comienzan a cambiar su visión de Almócita. }\end{array}$ \\
\hline $\begin{array}{l}\begin{array}{l}\text { Ofrecer soluciones, mostrar } \\
\text { alternativas reales o proyectos } \\
\text { piloto, laboratorios de pruebas }\end{array} \\
\end{array}$ & $\begin{array}{l}\text { Sí, el domo o el museo al aire libre son proyectos que consideran } \\
\text { artisticos y muestran otras formas distintas a las convencionales de } \\
\text { construir y contribuir con la cultura. }\end{array}$ \\
\hline $\begin{array}{l}\text { Conectar personas } \mathrm{y} / \mathrm{o} \text { lugares, } \\
\text { crear comunidad, hacer redes, } \\
\text { crear espacios de relación, } \\
\text { mediar o facilitar }\end{array}$ & $\begin{array}{l}\text { Sí, ambos festivales que acogen artistas crean una atmósfera de } \\
\text { colectividad y un espacio de relación que se sale de la normalidad de } \\
\text { Almócita. }\end{array}$ \\
\hline \begin{tabular}{|l|}
$\begin{array}{l}\text { Restauración/recuperación del } \\
\text { entorno }\end{array}$ \\
\end{tabular} & $\begin{array}{l}\begin{array}{l}\text { Sí, en este caso el entorno urbano se ha rehabilitado incrementando } \\
\text { el respeto al mismo gracias a los murales en sus fachadas. }\end{array} \\
\end{array}$ \\
\hline $\begin{array}{l}\begin{array}{l}\text { Reforzar la identidad, crear } \\
\text { símbolos }\end{array} \\
\end{array}$ & $\begin{array}{l}\begin{array}{l}\text { Sí, las fachadas pintadas son un símbolo mediante el que se identifican } \\
\text { los lugareños. }\end{array} \\
\text { a }\end{array}$ \\
\hline $\begin{array}{l}\text { Fomentar la ciudadanía crítica, } \\
\text { agitar, denunciar }\end{array}$ & Sí, sobre todo persiguen agitar la vida en el pueblo. \\
\hline Empoderar & $\begin{array}{l}\text { Ś aunque anecdóticamente. Pineda y Coe creen que, por ejemplo, el } \\
\text { Almouseum sirve para dar visibilidad y voz a la tercera edad. }\end{array}$ \\
\hline $\begin{array}{l}\text { Crear relatos positivos de } \\
\text { cambio }\end{array}$ & $\begin{array}{l}\text { Sí, a través de las intervenciones artísticas han creado una historia } \\
\text { compartida nueva. }\end{array}$ \\
\hline $\begin{array}{l}\begin{array}{l}\text { Facilitar la comprensión del } \\
\text { mensaje de la ética ecológica } \\
\text { aplicándola }\end{array} \\
\end{array}$ & $\begin{array}{l}\text { Sí, por ejemplo el domo aplica los conocimientos sobre materiales y } \\
\text { responde a una ética de compromiso con el entorno. }\end{array}$ \\
\hline $\begin{array}{l}\text { Conectar áreas alejadas de } \\
\text { conocimiento }\end{array}$ & No lo consideran. \\
\hline
\end{tabular}

\begin{tabular}{|l|l|}
\hline Motor iniciador de un proyecto & $\begin{array}{l}\text { Si, los murales fueron el detonante de un cambio de actitud y refuerzo } \\
\text { de eidentidad que ha devenido en el festival La Noche con Alma y otras } \\
\text { acciones en el municipio. }\end{array}$ \\
\hline Celebrar & $\begin{array}{l}\text { Si, alrededor de la creación artística han surgido estos festivales de } \\
\text { tono celebratorio. }\end{array}$ \\
\hline Recaudar fondos & No lo consideran. \\
\hline Construir consensos & $\begin{array}{l}\text { Sí, por ejemplo en cuanto al tema de la lucha contra el maltrato se } \\
\text { realiza el provecto de arte comunitario Homenaje a la mujer rural, } \\
\text { entre la Asociación de Mujeres y un artista invitado. }\end{array}$ \\
\hline Premiar, agradecer & Sí, lo consideran pero no aportan ejemplos. \\
\hline Tabla 5. Funciones del arte identificadas por Pineda y Coe en el caso de Almócita. Fuente: elaboración propia.
\end{tabular}

\subsection{LA IGNICIÓN Y OTROS PRINCIPIOS DEL ARTE TRANSICIONAL EN ALMÓCITA.} CONCLUSIONES PARCIALES.

Como ya adelantamos en la introducción de este caso, de entre las funciones anteriores destacamos en Almócita la función del arte como motor o generador de otras dinámicas o proyectos, lo cual coincide con el principio de ignición del arte transicional. Veamos a continuación si nos encontramos ante un ejemplo de arte transicional y su función de ignición en particular.

1. Intención: Como ya hemos comentado, para nuestros criterios de selección, la intención expresa de los artistas de realizar arte ecológico o de contribuir expresamente a transición no es un criterio determinante. Para Neal, existe una disposición del artista a crear las condiciones para el cambio, pero tampoco hay necesidad de expresarlo o cumplir un plan previo, sino que se trata más bien de trabajar con apertura a la improvisación y el aporte de otros. No obstante, tanto para Neal como para nosotros, en el trasfondo sí que deben subyacer las cuestiones que la ética ecológica plantea. En este caso, los artistas invitados no tienen la intención expresa de contribuir a la transición ni tienen esas narrativas en concreto en cuenta a la hora de crear sus obras. Sin embargo, sí existe cierta intención de cambio social en algunas obras, que se manifiesta 
. Marco: en este caso los artistas no crean el marco sino que es el pueblo quien marca a ruta a seguir.

3. Trabajar con la comunidad: sin duda el trabajo artístico es con, desde y para la comunidad de Almócita.

4. Mediación: En algunas obras, como aquellas donde ha intervenido Coe, sí ha existido esa labor de mediación entre los habitantes y los voluntarios del campo de trabajo por ejemplo, o la Diputación de Almería, financiadora del Almouseum, pero en general, es el Ayuntamiento o el grupo de transición el que cumple el papel de facilitación.

5. Mantener un espacio: Las obras artísticas han contribuido a la mejor imagen del pueblo, han focalizado sus energías en un objetivo común y ahora se sienten más motivados en mantener sus fachadas en buen estado como parte de su identidad.

6. Conexión: La realización de las obras conecta a los lugareños entre sí y con los artistas, en especial en la obra Voces con historia.

7. Trabajar desde lo común: en diversas ocasiones Pineda pone de manifiesto los contrastes entre los habitantes y los artistas invitados a sus festivales u obras. Eso no impide el diálogo ni el encuentro, lo cual lleva a despertar el espíritu hospitalario de sus gentes. Por ejemplo, la asociación de mujeres y el grafitero Moxaico salvan sus diferencias trabajando por unos valores en común contra la violencia de género.

8. Colaborar: desde la experiencia del primer campo de trabajo, la colaboración artista-habitante ha sido una constante.

9. Cambio: existe una clara predisposición a cambiar manifestada por ejemplo en el Almouseum o algunos murales que aspiran a influir en la transformación social. Por ello trabajan en colaboración con el pueblo y los miembros del grupo de transición.

10. Ignición: según Pineda y Coe, el arte fue el germen de toda la actividad. Hasta aqui hemos visto cómo Almócita está iniciando su particular y humilde apuesta por el arte en el espacio rural. Su colección es modesta aún, comparada con otras experiencias (ulo cuatro. Pero, iqué diferencia la experiencia de Almócita de cualquier otro pueblo volcado en el arte como Fanzara'18? Para un transeúnte turista en Almócita, resultaría difícil percibir la conexión entre las obras de arte y otras iniciativas como el domo, e compostaje, la agroecología o el banco de tierras. Sin embargo, los efectos de un pro-

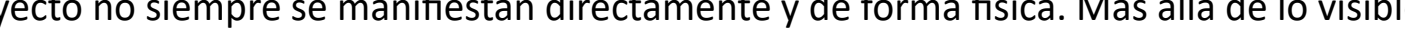
se hallan las intenciones originarias y los resultados inesperados que han excedido las expectativas iniciales. Lo artístico en Almócita ha resultado ser una chispa inesperada, un motor de ignición que ha activado otras propuestas en la vía de la sostenibilidad, que ha dinamizado el cambio hacia la transición. Tal y como los entrevistados mismos declaran, el arte en sus calles ha dotado de identidad al pueblo, constituyendo ahora su aspecto más llamativo. El éxito de esos otros cambios (domo, proyecto de compostaje, nuevos pobladores, etc.) en la localidad, habría sido distinto sin el efecto cohesionador que ha tenido lo artístico. Pineda llega a considerarlo una imagen de marca pero no solo en cuanto al resultado, también en cuanto al proceso de creación colaborativo que implica y que ha despertado una actitud más abierta en sus habitantes. Mientras en Fanzara los artistas son invitados a crear su obra, aquí el artista ayuda al pueblo crear la suya.

El lugar que ocupa el arte en el proyecto global de Almócita es insustituible, comenta P no se puede entender como arte transicional por si mismo fuera de su contexto, aunque haya sido valioso para empujar otros procesos en línea con la transición. El arte es una herramienta inesperadamente potente para afianzar los cambios, pero no son los artistas quienes lideran o guían ese cambio hacia la transición, sino que sus obras artísticas, en ese contexto concreto, tienen un efecto de ignición. No consideramos que se hayan cumplido todos los principios señalados por Neal (ni la intención ni la mediación) y, sin embargo, el arte es considerado una pieza clave en la dirección de la transición a la sostenibilidad en Almócita. Curiosamente la web de la Red de Transición no menciona en absoluto las obras artísticas de Curiosamente la we de la Red de Transición no menciona en absoluto las obras artisticas de

Comenzamos este capítulo comentando la influencia del arte en la creación de comunidad. Todos los encuestados coinciden en señalar que a través de las actividades conjuntas de creación artística en el campo de trabajo, los habitantes tomaban conciencia de que sus facha- 


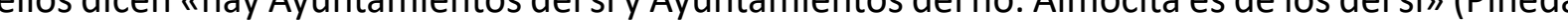
comunicación personal, 29 de diciembre de 2017). De hecho, comparado con el resto de grupos de transición estudiados en España, el caso de Almócita es el único en el que la institución de gobierno está involucrada directamente en la iniciativa de transición. Parece que el respaldo del Ayuntamiento a estas actividades desde dentro y fuera del grupo de transición potencia la participación y por tanto los resultados. Pero, ¿qué aporta esta actividad artística directamente al mensaje de la transición a la sostenibilidad? a raíz de todo este movimiento varios grupos de niños y adolescentes han visitado Almócita, o han participado en talleres de realización de adobe invitados por la Diputacion de Almería, Dur se les dan pinceladas sobre la conciencia municipal, declara Pineda.

En conclusión, la aportación del arte en este caso hay que entenderla a nivel de conjunto más que de forma directa, como una forma de impulsar los ánimos para emprender otros proyectos alternativos y atraer a pobladores en línea con la sostenibilidad, que compensen e despoblamiento y envejecimiento.

\section{EL PAPEL DEL ARTE EN EL MOVIMIENTO DE CIUDADES Y PUEBLOS EN TRANSICIÓN (MCT) EN REINO UNIDO}

"Cada movimiento, cada reunión de personas para lograr un cambio positivo, necesita sus banderas, sus conos. La transición no es una excepción» Rob Hopkins (2016, p. 39).

Como ya se ha mencionado, la mayoría de las publicaciones sobre el MCT se centran en el norte de Europa. Dentro de la abundante bibliografía anglosajona al respecto, encontramos varios textos sobre el papel del arte en la sostenibilidad (Allen et al., 2014; International Institute for Applied Systems Analysis, 2017; Julie's Bicycle, 2010) o la transición en sentido amplio (Neal, 2015); pero ninguna investigación específica como la que llevamos a cabo en esta tesis sobre la presencia de arte en el MCT. La investigación más cercana a nuestros objetivos es la del Instituto holandés DRIFT

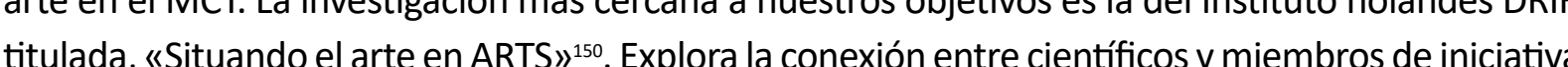

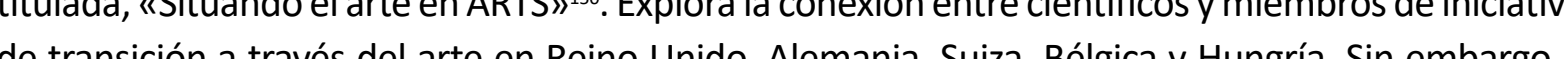
de transición a través del are en Reino Unido, Alemania, Sulza, Bélgica y Hungria. Sin embargo,

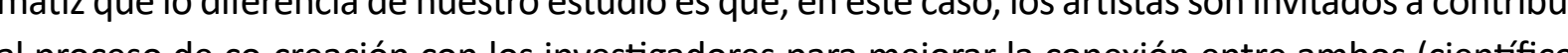
y proceso de co-creación con los investigadores para masorar la conexín entre ambos (cientificos y grupos). Pero el acercamiento entre artistas e iniciativas de transición no es un fenómeno previo existente, sino provocado por una subvesción de mil euros por cada uno de los cinco proyectos. Las conclusiones destacan que el resultado superó las expectativas en cuanto a mejorar la investigación conectar y catalizar el cambio, slendo el tiempo (tres meses) y la financiación, los factores limitantes para todos los casos. El estudio destaca el valor del arte como herramienta de compromiso y diseminación de mensaje y resultados. Los investigadores ampliaron su percepción de lo que el arte puede lograr en la mejora de la comunicación con el público, las diferentes metodologías y forma de explorar que pueden adoptarse, la multifacética forma de comprender y actuar de los artistas su libertad de movimiento de unos métodos a otros. Para finalizar, reconocen la necesidad de incoporar a los artistas en el proceso inicial de investigación para encontrar sinergias y dimensionar más adecuadamente el tiempo y el presupuesto a invertir - evitando tener que recurrir al altruismopero no aportan ningún resultado desde la perspectiva de las iniciativas de transición.

Desde la Red de Transición y su web se pueden extraer algunas pinceladas dispersas al respec to del arte en la transición que han ido aumentando con el tiempo. Durante su evolución desde Kin-

150 Traducción de la autora del original:
Putting Art into ARTS, dentro del proyecTO ARTS que son las siglas de Accelerating and Rescaling Transitions to Sustainability y re-escalando la transición a la sostenibilidad») financiado por la Unión Europea, es investigación en la transición (DRIFT) que nales para estudiar el ppapel ye li impacto de
las iniciativas de transición en las ciudades. 
sale, el MCT-como experimento social (Brangwyn et al., 2010) - ha ido madurando, evolucionando y autodefiniéndose. Si comparamos la primera versión del Compendio de iniciativas de transición 2008 con la última guía de 2016 titulada: La guía esencial para hacer transición, comprobamos que algunas de las características que han ido cobrando importancia en este crecimiento han sido: la transición interior, la creatividad y la celebración. Como Hopkins expresa: «Cuando llevas a cabo la transición en tu comunidad, invita siempre a la creatividad, el diseño y las artes» porque «Comienzan conversaciones. Personifican la sensación de que un futuro en transición puede ser más divertido que las alternativas que ahora mismo se ofrecen. Incorporan la posibilidad. Es atractivo (Hopkins y Thomas, 2016, p. 39). Como ejemplo remarca el éxito más allá de sus fronteras - y de todo pronóstico - que ha tenido el diseño del billete de diez libras de Totnes con la imagen de David Bowie.

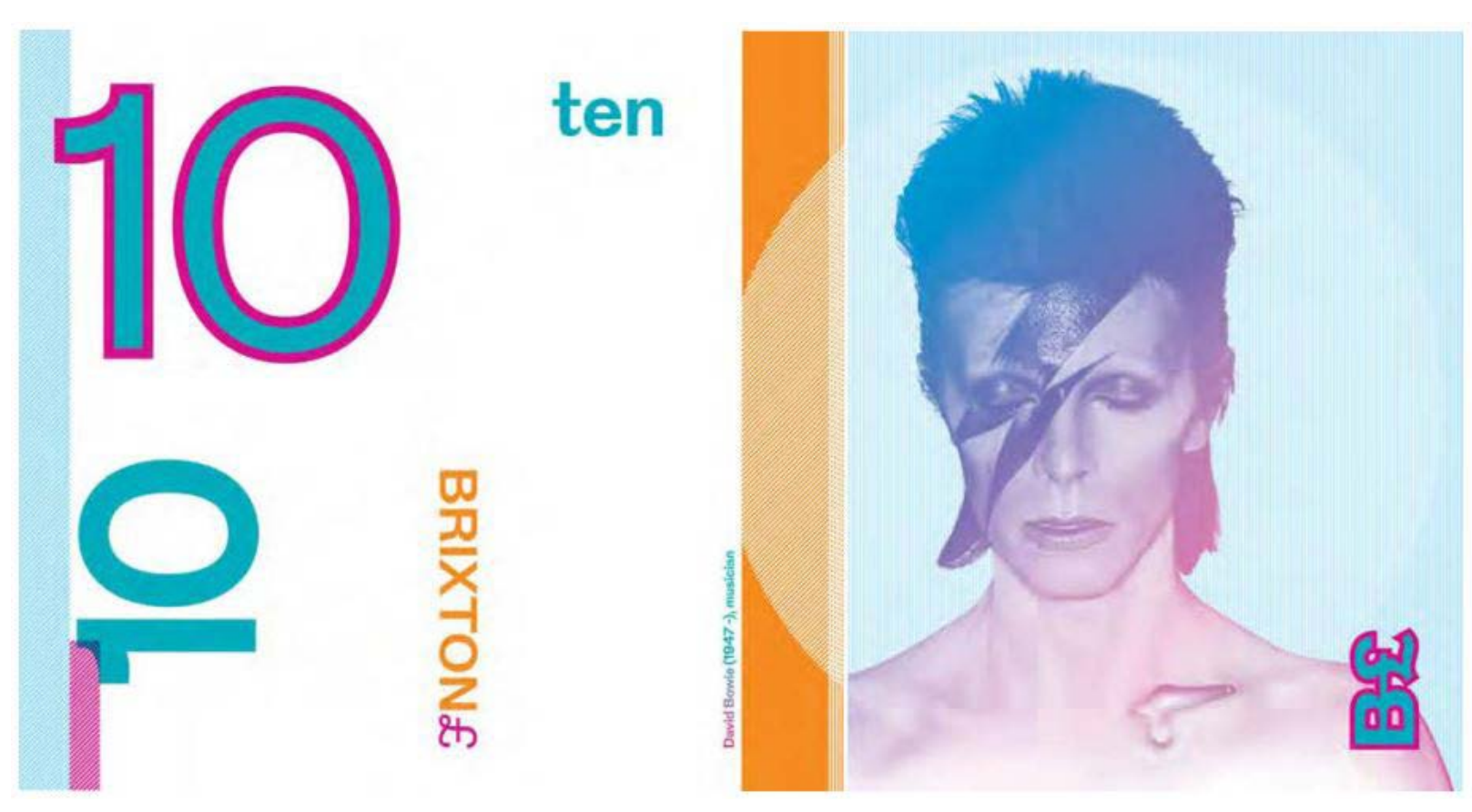

Imagen 42. Billete de la libra de Totnes con David Bowie. Fuente: (Hopkins y Thomas, 2016, p. 39)

La Red de Transición resalta el rol vital del arte en funciones típicas como la sensibilización, la yel desafí (Transition Network, 2010). Pero más allá de contribuir al atractivo de la imagen estética, gunas experiencias de la Red de Transición inglesa nos hacen conscientes de que la acción artís ca puede ser profundame enocionante y transformadora. Enfocanndonos en obras atsticas de iniciativas de transicion anglosajonas que incorporen la participación y el fomento de la cooperaparte $e_{15}^{151}$ (Ben-Tovim, 2012), (Neal, 2015, p. 97) o la Tienda de transición de Tooting ${ }^{152}$ (Neal, 2012) partetis (Ben-Tovim, 2012), (Neal, 2015, p. 97) o la Tienda de transición de Tooting ${ }^{152}$ (Neal, 2012)
con nada que vender pero mucho que ofrecer. Ambas facilitan espacios de diálogo e interconexión con nada que vender pero mucho que ofrecer. Ambas facilitan espacios de diálogo e interconexión nuevos, invitan a imaginar y a buscar nuestro lugar en el mundo que queremos vivir. La artista Ruth Ben-Tovim define su papel en estas propuestas: «Esto es lo que hago, esta es mi práctica, diseña y facilitar procesos participativos creativos que dejen volar nuestra imaginación, viajes que inviten a las personas a experimentar cómo podría ser realmente vivir en un futuro sostenible, qué pape podrian desempeñar y los pasos que podríamos tomar para llegar allí juntos» (Neal, 2015, p. 98). Como comenta Hopkins es algo más que arte y diseño, se trata de crear puertas de entrada haca otras alternativas (Hopkins y Thomas, 2016, p. 40).

En todo caso, la actividad artística relacionada con la transición en Reino Unido ha sido profundamente estudiada por la creadora británica Lucy Neal en colaboración con otros autores ${ }^{153}$, lo que les ha llevado a definir el transitional art y sus principios, como ya hemos visto en el capitulo uno, apartado 2.3. Neal recopila en el libro Playing for time. Making art as if the world mattered hasta 69 proyectos artísticos, aunque la mayoria de ellos no pertenecen a las mas de 300 iniciativas de transición de Reino Unido. Remitimos a esta publicación para una visión profunda del papel del arte en la transición desde la perspectiva inglesa, y extraemos de ella uno de los ejemplos más llamativos que cumple nuestros criterios de selección que estudiaremos a continuación.

\section{ESTUDIO DE CASO: TOOTING TRASHCATCHERS} CARNIVAL

Entre los numerosos ejemplos citados en este libro haremos mención a Tooting Trashcatchers' Carniva/154 2010, realizado por la propia Neal en colaboración con otros artistas y la comunidad de Tooting (Londres), para ilustrar una de las importantes funciones que el arte está cumpliendo en los grupos de transición: la celebración.

151 Traducción de la autora del original:
Transition town anywhere. Basada en la bra teatralizada de Neal de 2009 Plan de endos horas (Two Hour Energalquier parte for Town Anywhere), esta obra fue realizada
por las artistas Ruth Ben-Tovim, Lucy Neal, Sophy Banks, Jo Hardy, Chrissie Godfrey con ferencia de la Red de Transición de 2012 en cipantes, bajo las indicaciones de las artistas, imaginaron $y$ crearon un nuevo centro dada como la pieza con mayor éxito de la Vectiones promovidas. Véase en https:/// the-transition-town-anywhere-activity/

152 Traducción de la autora del original: de Ruth Ben-Tovim Ruth Nutter y Lucy Neal de transición Transition Town Tooting (Londres) para el Festival de arte Wandsworth.
Einanciada por Wandsworth Big Society y Cultural Wealth Fund, constituye el octavo encuentro de este tipo desde 2003. En esta "tienda» las artistas crean el espacio para es del barrio que podín reflexionar sobre sus vidas, recordar sus pasados, conectarse - imaginar su futuro. Véase el video de Emi政 es/p/tooting-transition-shop.html o http:// www.encounters-arts.org.uk/index.php/ tooting-transition-shop-2012/ para más in- 
153 «Hasta 58 "artistas transicionales" en
este libro muestran cómo se pone en mar-

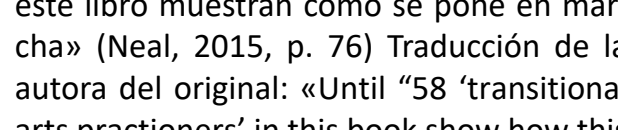
arts praction autora: Conar

155 Con esto nos referimos a trabajar con
nuestros valores, creencias e historias per作 entes ritmos de vida y los picos de intensa actividad favorecen que surjan conflictos $y$ algunos miembros abandonen. Es también bastante común que los grupos pasen más tiempo haciendo planificando que evaluando su trabajo como grupo, reflexionando sobre los logros consegudos o celebrandolos. Es por ello que desde la red transition network, han elaborado una guía para ser conscientes de esta tendencia y aprender a integrar el descanso, la reflexión ${ }^{156}$ y la celebración ${ }^{15}$. La experiencia de Hopkins en los últimos diez años en transición concluye que: "Reflexionar sobre lo que tugrupoestá haciendo y celebrar lo que habeis conseguido es una . Asi, la dinámica habitual de parte esencial de la transición» (Hopkins y Thomas, 2016, p. 41). Asi, la dinámica habitual de grupo soñar-planificar-hacer ha de completarse también con una importante fase de celebración que nutra a los individuos emocionalmente. La intervención artística tiene la capacidad de responder a esa necesidad de comunicación de las emociones, así como aunar información y reflexión desde una perspectiva sensible que contemple toda la diversidad de visiones. Además, ya mencionamos en el capítulo uno que el relato o la experiencia vivencial estéticamente atractiva nos emociona, y posee mayor poder empático que las cifras y estadísticas (Slovic y Slovic, 2005). Por tanto, tiene además el potencial de atraer a nuevos participantes. Por estos motivos, entre otros, la intervención artística en la celebración es una herramienta habitual. Un caso especialmente destacado es el de Transition Town Tooting (en el municipio de Wandsworth a sur de Londres) un grupo de transición en funcionamiento desde 2008 . En (asde 2008. En . iver chers' Conival revoluciono este bario del sur de la ciudad de Londres el 4 de Julo de 2010. cher Recurrieon al acto de transformar sus residuos en algo bello y divertido como una metáfora del6-320). Se vión que nessitas período de seis meses: alrededor de un millón de bolsas de plástico, medio millón de bolsas de patatas fritas además de media tonelada de mimbre y mucho otro material, para crear una elebración brillante y colorida, alimentada por esa comunidad particularmente tan diversa (Transition Network, 2010) y (Thorne, 2010). El propio Hopkins resalta la importancia de la diversidad y la conmemoración: «La diversidad abre la puerta a celebrar las diferentes formas que tenemos de expresar lo que tenemos en común. La celebración permite a las personas moverse cómodamente fuera de su zona de creativa» (Hopkins y Thomas, 2016, p. 25).

\subsection{ADECUACIÓN A LOS CRITERIOS DE SELECCIÓN DE LA INVESTIGACIÓN}

En este capítulo nos centramos en aquellas obras artisticas que parten o se desarrollan por los grupos de transición. En este caso el grupo de transición de Tooting es uno de los más antiguos en funcionamiento y las artistas Neal y Hilary Jennings se hallan entre sus fundadoras. Entre los motivos para seleccionarlo se encuentran los siguientes:

Es un proyecto específico de ese municipio que asume y aprovecha la diversidad humana local para aumentar la var convivencia. Durante su desarrollo, se tienen en cuenta los principios de la transición y se aprovechan los talleres de realización para ahondar en cuestiones como el pico del petróleo $o$ el cambio climatico ${ }^{158}$. De hecho, se llegan a realizar talleres especificos sobre estas cuestiones. El arte está presente en todas sus fases, desde el planeamiento por los artistas de los colectivos Emergency Exit Arts (Lucy Neal) y Project Phakama (Fabio Santos) junto a otros artistas colaboradores, hasta la organización del desfile. En el proceso de realización son temas fundamentales la reducción de residuos y la huella ecológica. Es más, uno de los objetivos del carnaval es reducir los residuos o, al menos, alargar su vida útil reutilizándolos. La protagonista verdadera del carnaval y motivo de celebración es la tierra, y nuestra relación con ella. Por tanto podemos decir que se ocupa de asuntos ecológicos y busca la concienciación y transformación social.

En cuanto al cumplimiento de los principios de la transición en sentido amplio o los de la Red de Transición mencionamos: 
Concienciación en cuanto al consumo de productos envasados.

- Uso de mecanismos no dependientes de energía eléctrica en el desfile.

Compromiso del movimiento ambiental con la equidad y la justicia

- El acto se estructura y apoya en la diversidad de nacionalidades, edades y religiones. Una de las carnivalistas más anciana, Jaya Patel, comenta: «Lo mejor de este carnaval es que ha traído a la comunidad entera desde todas las secciones, Óvenes y mayores, desde todos los orígenes étnicos» (Thorne, 2010).

El desafío de la conservación

- No hemos detectado acciones de conservación relacionadas.

Planificación ante el colapso energético: ahorro eneraético reutilización, reciclaje y reducción de residuos:

- Se fomenta la reducción de residuos, su reutilización y el ahorro energético.

Aumento de la resiliencia:

- El carnaval ha demostrado a este barrio de lo que pueden ser capaces cuando se nen. Esto dota a sus vecinos de una sensación expandida de cohesión y comunidad que puede fortalecer su resiliencia.

\section{Acción local y colectiva:}

- La actividad ha sido pensada desde y por esta comunidad, y desarrollada en colaboración con sus vecinos y el grupo de transición Transition Town Tooting asi como otros colectivos (BATCA ${ }^{159}$, policía, agrupaciones religiosas, entre otras).
Los orígenes del proyecto se remontan a una acción de carnaval anual en junio, llamada Funday (día divertido) ${ }^{160}$, desarrollada por la asociación BATCA y la comunidad de Tooting. Incluye un pasacalles festivo organizado en 2009 por Neal y Santos. Este proyecto piloto se presentó como Carnaval de recogedores de basura en Tooting al programa de copiloto se pron cional, como uno de los cuatro proyectos que se financiarían en 2010. «La idea era simple cional, como uno de los cuatro proyectos que se fina ciarian en 2010. MLa idea era simple

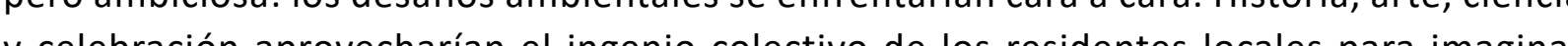
v celebración aprovecharian el ingenio colectivo de los residentes locales para imaginar yna historia colectiva positiva del futuro, algo que se pudera transmilir a los hijos, hietos y bisnietos acerca de cómo era vivir en 2010» (Neal, 2010).

El Secretario de Estado de Energía y Cambio Climático, Ed Miliband, concedió 20.000 E destinadas a los colectivos artísticos Project Phakama ${ }^{162}$ (con Fabio Santos) y Emergency Exit Arts (EEA) 1.3 (con Lucy Neal). Ambos lideraron este proy (con Fabio San Tooting junto a la iniciativa Transition Town Tooting. La misión: usar los residuos, el arte, el Tooting junto a la inicialva Transition Town Tooling. La misión. usar los residuos, el arte, carnaval, la celebración y el ingenio colectivo de toda la comunidad para crear un desfile a gran escala en el solsticio de verano de 2010. Usando el reciclaje como una metáfora, el objetivo es construir una visión futuro con un bajo consumo energetico para Tooting procurar que el proceso fuera atractivo (Transition Town Tooting, 2010a). Su preparación implicó a sesenta artistas y más de quinientos residentes de Tooting (Julie's Bicycle, 2010). Se realizaron talleres de costura, teñido, teatro, tejido, decoración, canto, panadería, tam bores, danza, creación de complementos, música con instrumentos del día a día, creación de figuras e incluso de historias, con materiales reciclados, donde se exploraba nuestra relación con la tierra, incluyendo actividades de sensibilización sobre cuestiones relacionadas con el cambio climático y el pico del petroleo (Neal, 2010). Además también se realizaron talleres especificos sobre ambos temas 164 que formaron parte de un ciclo de cuatro fases de trabajo inspirado en la espiral creativa de Joanna Macy
161 Desde su inicio, TippingPoint (Punto de

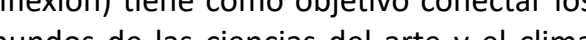
comisionando obras lar una masa critica de trabajo creativo en (line

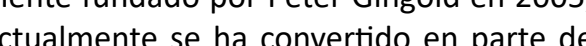
Julie's Bicycle en 2017. En el corazón de the trabajo se encuentra un programa inen rea el clima y la cultura desde estas dos mplias perspectivas. Véase en: https:// 62 Project Phakama (que significa ponerse de pie o capacitarse en 1996 como una es de LFT (Festival Internacional de Toatro Londres) en colaboración con la asociaión de teatro comunitario sudafricana Sibi. aveen Mary de Londres, Phakama conti-

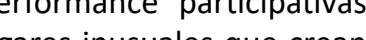
spacios compartidos dusuales que crean posible. Se enfocan en y y recibir in a traves de un proceso de afirma la vida y que permita a los jovenenes crecer $y$ desarry

163 Fundada en 1980, EEA es un colectivo 
de artistas, una compañía de artes al aire
libre de renombre y actualmente también una organización benefica con el objetivo de transformar radicalmente lo ordinario en do el cambio a través de a creatividad des de su sede en Londres. El edificio cargado de historia y construido originalmente para ser utilizado por la comunidad, mantien tps://eea.org.uk/

164 Por ejemplo cuarenta carnivalistas asistieron a la charla del profesor Mark Maslin sob 2010

165 La autora ha desarrollado un esquema de trabajo en talleres basado en la eco logia prón y con atudro fases sucesivas ranza, observar el cambio y seguir aselante (Macy y Young Brown, 2003)

\section{TRASHCATCHERS WORKSHOPS}

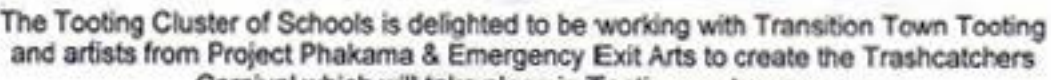

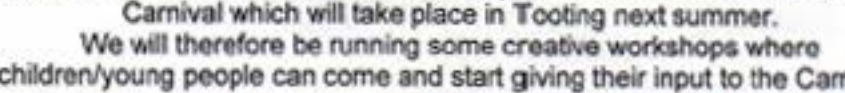

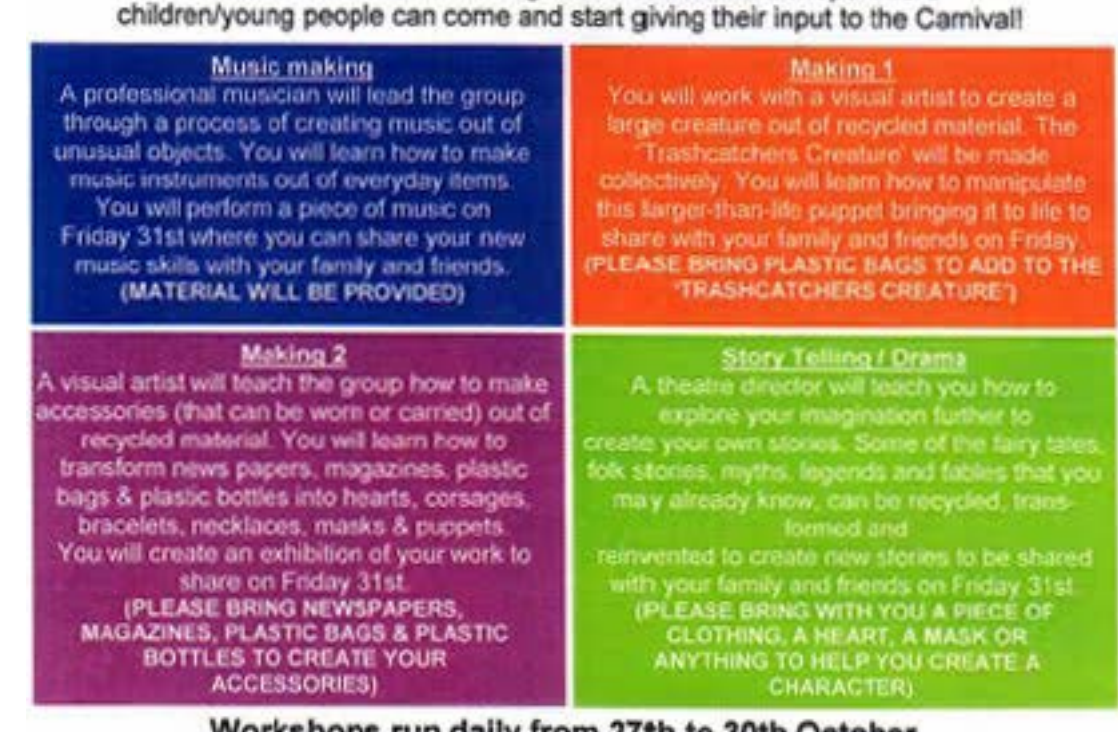<smiles>[13CH3][13CH3]</smiles>

For childrenlyoung people in school year $6 \&$ abovo ( To book a place call Faye on 02086825676 or $\mathrm{cm}$
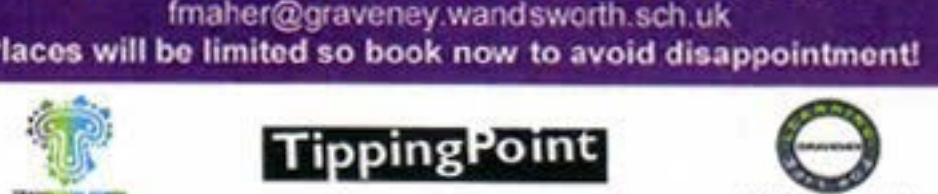

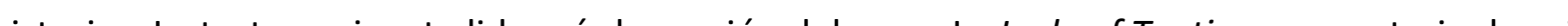

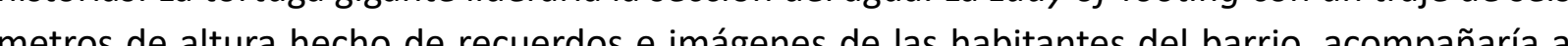

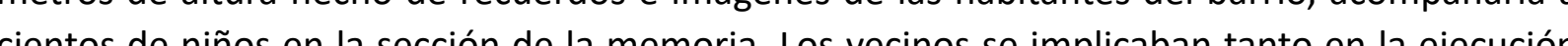

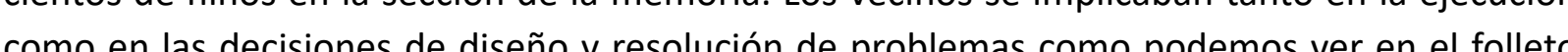
siguiente realizado por Transition Town Tooting en 2010 donde dice u Podris ser un carnivalsta siguiente realizado por Transition Town Tooting en 2010 donde dice: «Podrias ser un carnivalista [...] esto incluiría: coser, dar puntadas, diseñar, conseguir financiación, publicitar, [...] Podrías ser un campeón Trashcatcher [...] son un grupo clave en Tooting y Wandsworth que nos ayudan pensar el proyecto de manera creativa y colectiva. Trabajando colectivamente a través de diversos sectores resolvemos los retos del carnaval más rápidamente». plementos y figuras para el carnaval, teatro y cuentacuentos. Fuente: (Transition Town Tooting, 2010a) http:// trashcatchers.blogspot.com.es/2009/

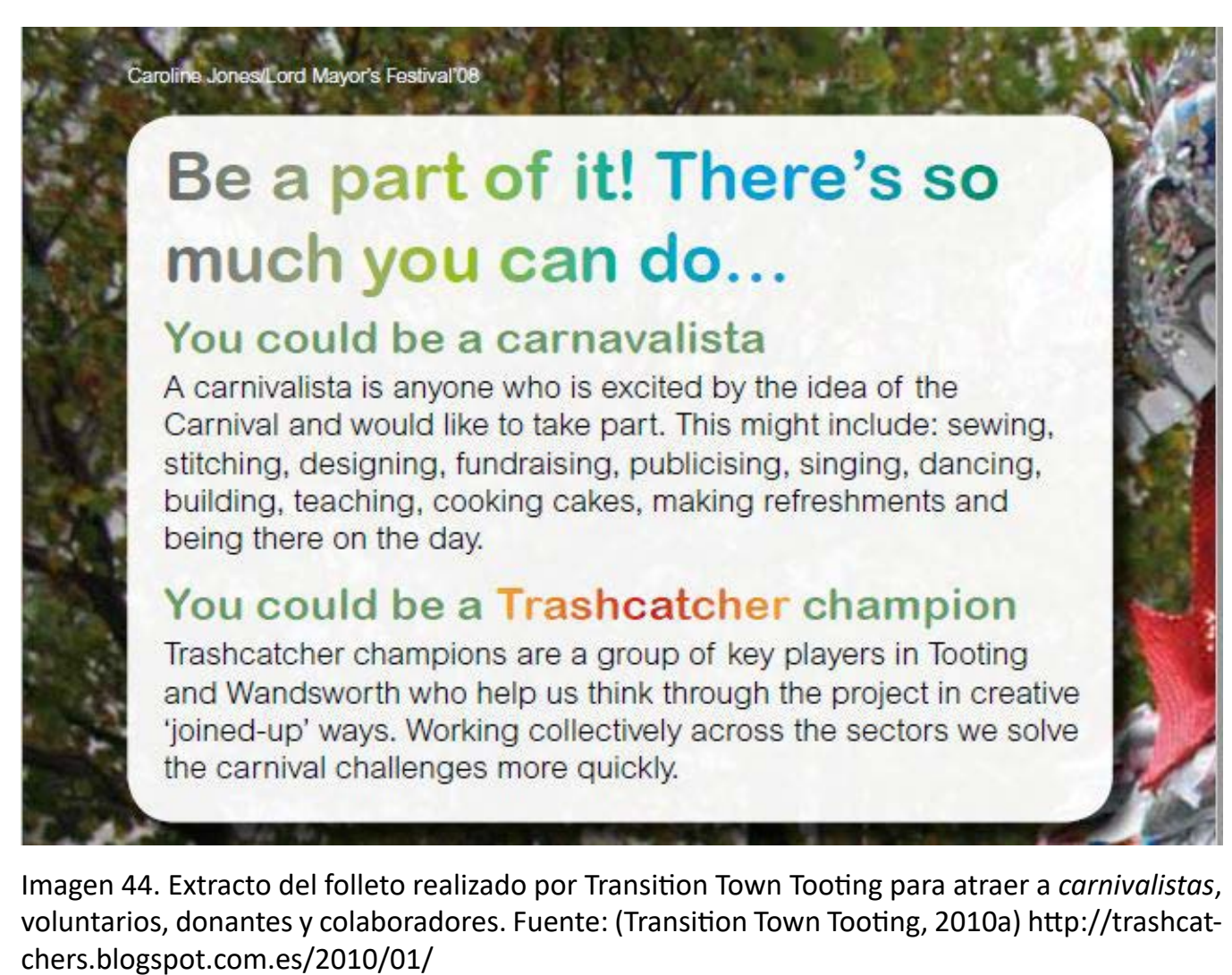

chers.blogspot.com.es/2010/01/ 
tróleo y con adaptación al cambio climático) con ilusión para Tooting (Neal, 2015, p. 316), (Transition

You can help turn trash into beauty for carnival

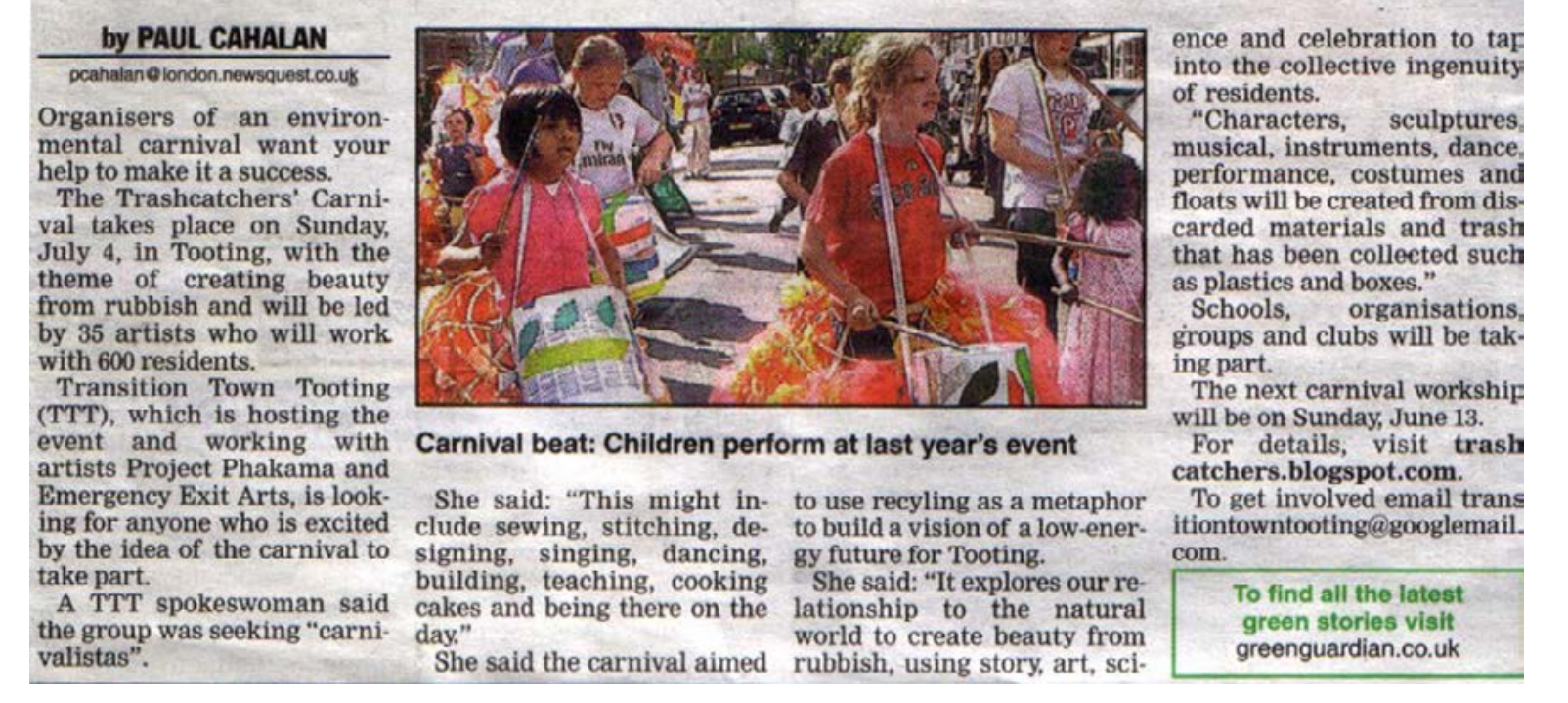

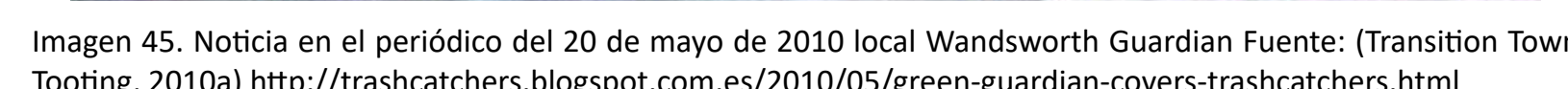

El concepto inspirador es una leyenda del este de África basada en el pájaro Sankofa, una criatura mítica que porta en un huevo la semilla del porvenir y que puede mirar hacia el futuro y el pasado a la vez, tal y como los participantes hacen en este carnaval. La historia procede del rey Adinkera, de la tribu de los Akan, del oeste de África, y viene a expresar que debemos mirar hacia atrás y extraer un aprendizaje para poder dar pasos hacia delante. Todo lo que hemos dejado atrás, perdido, olvidado, puede ser reclamado, revivido, preservado y perpetuado. De este modo, todos los residuos, los retales olvidados, los objetos perdidos, son rescatados para crear un futuro nuevo (sin dependencia del pe-

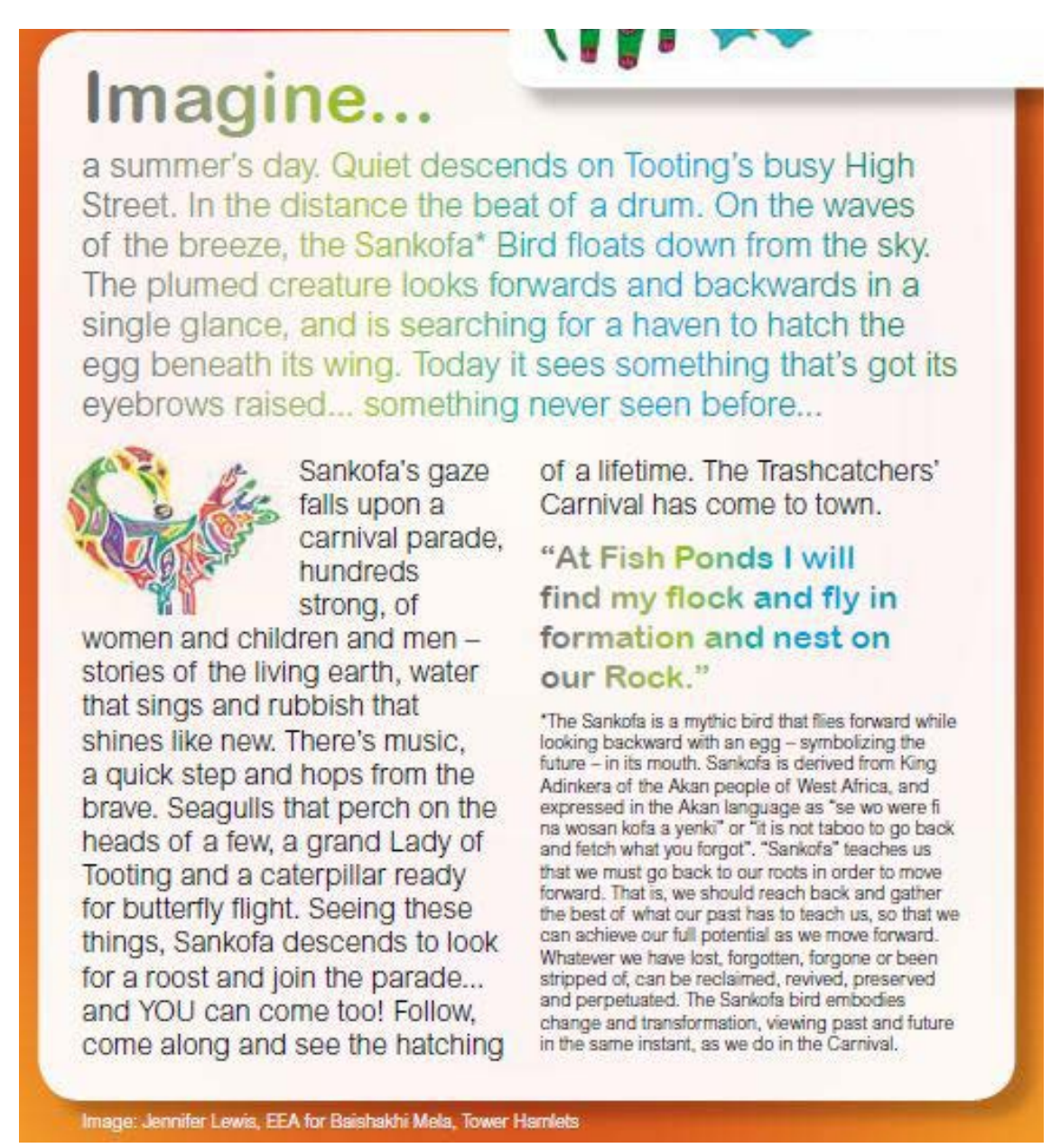

Imagen 46. Extracto del segundo folleto lanzado en mavo desde Transition Town Tooting en preparación del Carna-
val. Fuente: (Transition Town Tooting 2010a) http://trashcatchers. blogspotc.com es/2010/06/

Finalmente, el 4 de julio los cerca de mil participantes celebraron que un nuevo y buen futuro en la tierra podría ser posible atravesando la arteria principal de la ciudad, que suele acoger un tráfico de diez millones de coches al año. 

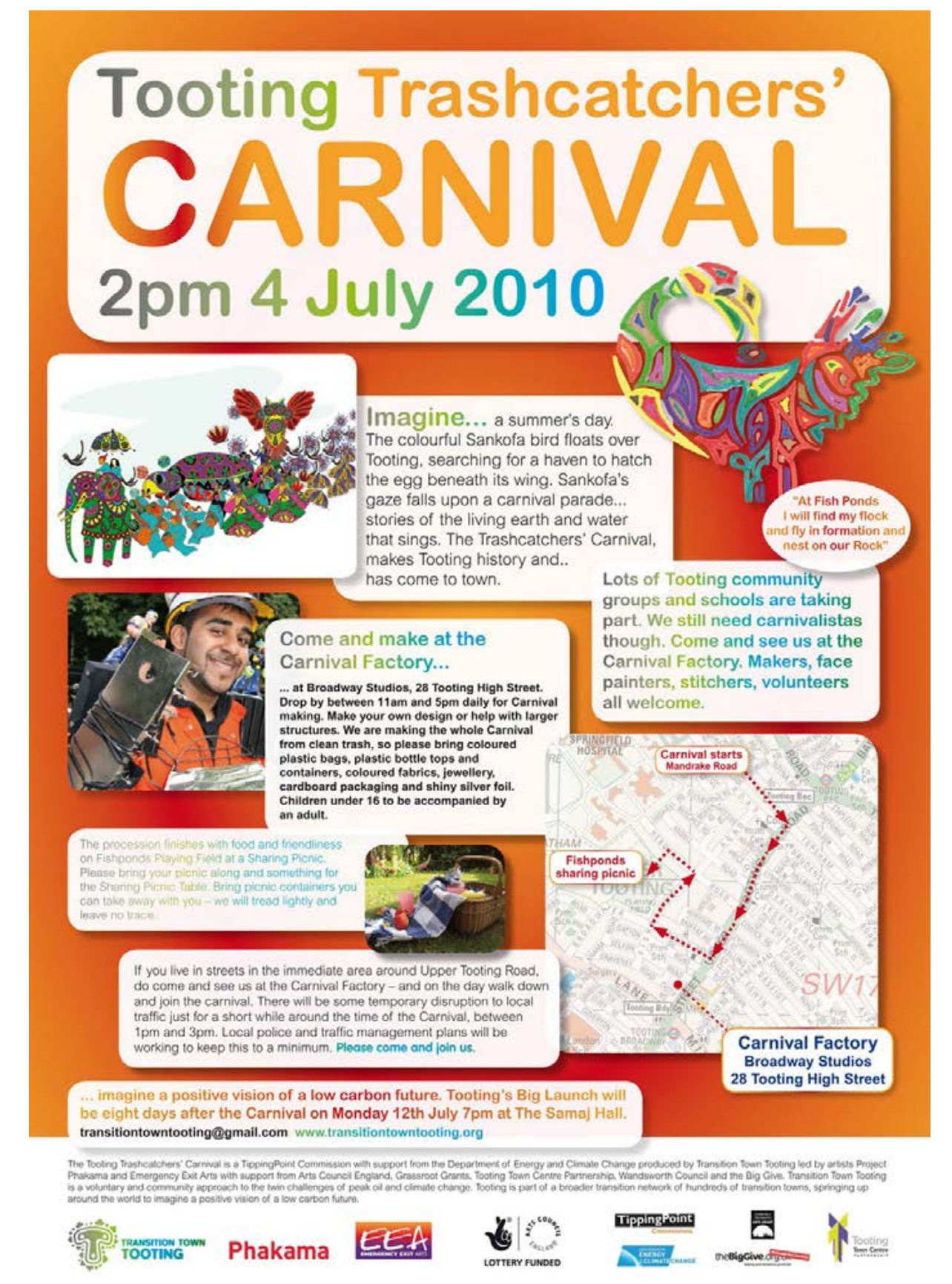

Imagen 47. Cartel preparatorio de Tooting Trashcatchers' Carnival. Fuente: (Transition Town Tooting, 2010a) http://
trashcatchers.blogspot.com.es/2010/07/ $\begin{array}{ll}\text { Tras unas tensas negociaciones con la empresa Transporte para Londres, el comandante } & 166 \text { Traduccín de la autora del original: } \\ \text { Transport for London, Police Borough }\end{array}$

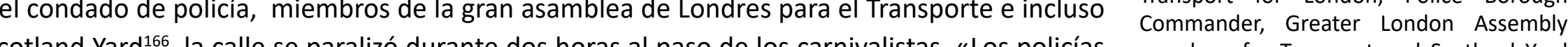
Scollon tomaron fotografias y las tiendas se vaciaron para mirar. Entregamos paquetes de semillas (reales) de Sankofa para el futuro. La gente se asomaba desde las ventanillas de los coches y autobuses con deleite» (Neal, 2015, p. 319).

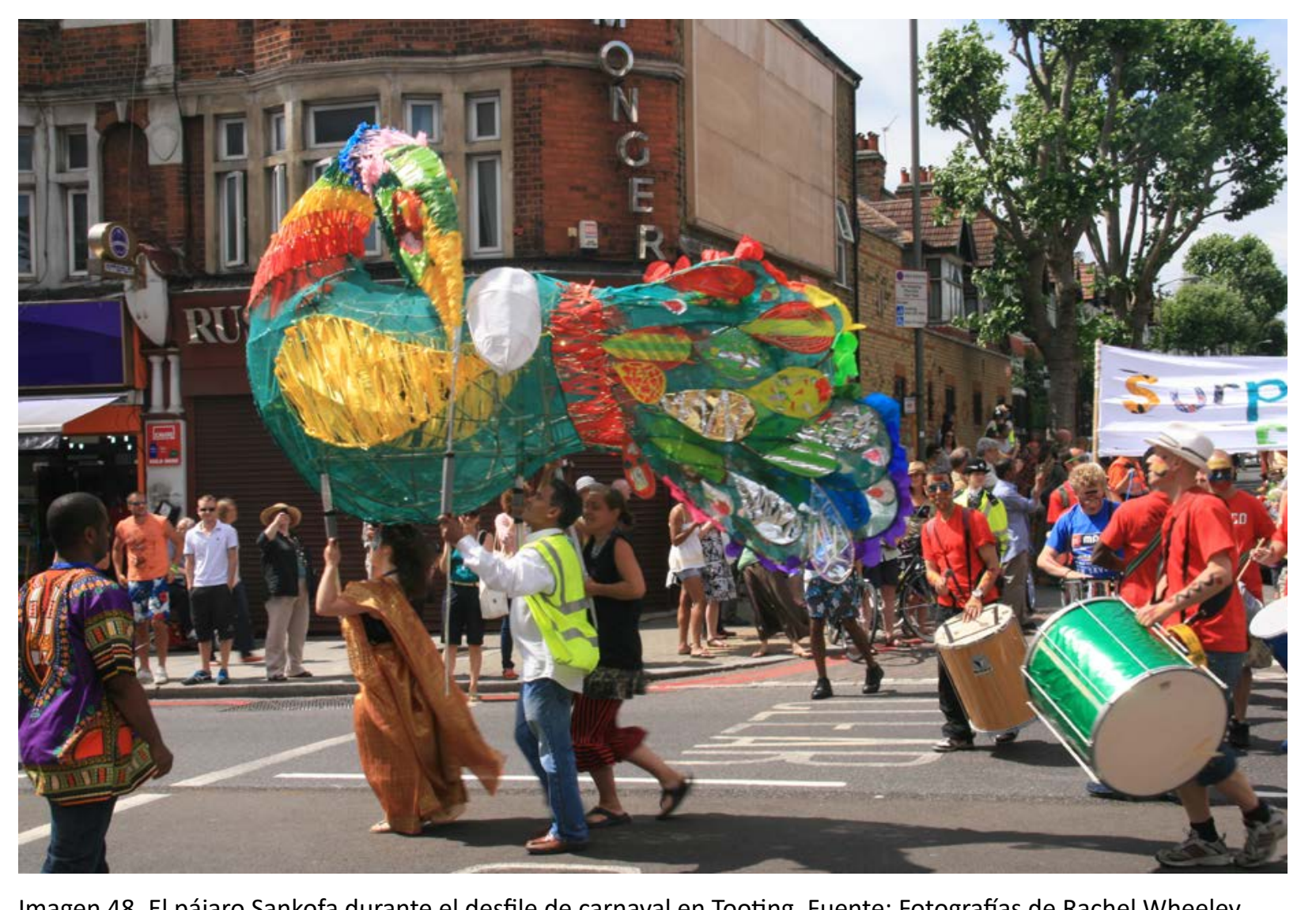

Imagen 48. El pajjaro Sankofa durante el desfile de carnaval en Tooting. Fuente: Fotografias de Rachel Wheeley.

El desfile acabó en una jornada distendida entre bailes, paseos en bicitaxi y fotografías en el parque de juegos abierto especialmente para la ocasión, Fishponds Playing Field, donde todos pudieron admirar el carnaval en su conjunto y compartir un picnic con más de 1.000 comidas 

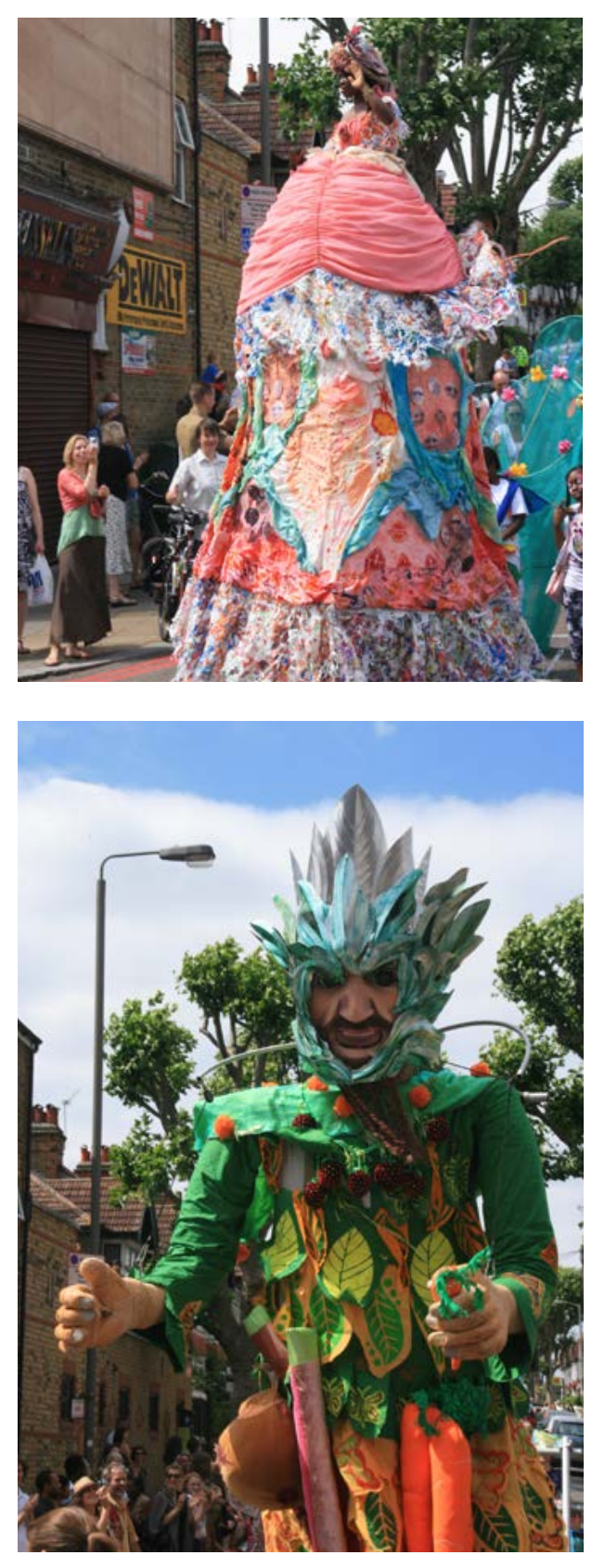
Imágenes 49 y 50. La Lady of Tooting $y$ gigante durante el desfile de carnaval. Foto
(Neal, 2010). Una niña de nueve años cantó des作 hemos hecho? una canción anti-apartheid folk de sudáfrica cantada en funerales y manifestacones. «Los carnivalistas sentían que eran parte de algo profundo, transformador e importante para sus vidas: una manera práctica de dedicar sus vidas al futuro de la tierra» (Neal, 2010).

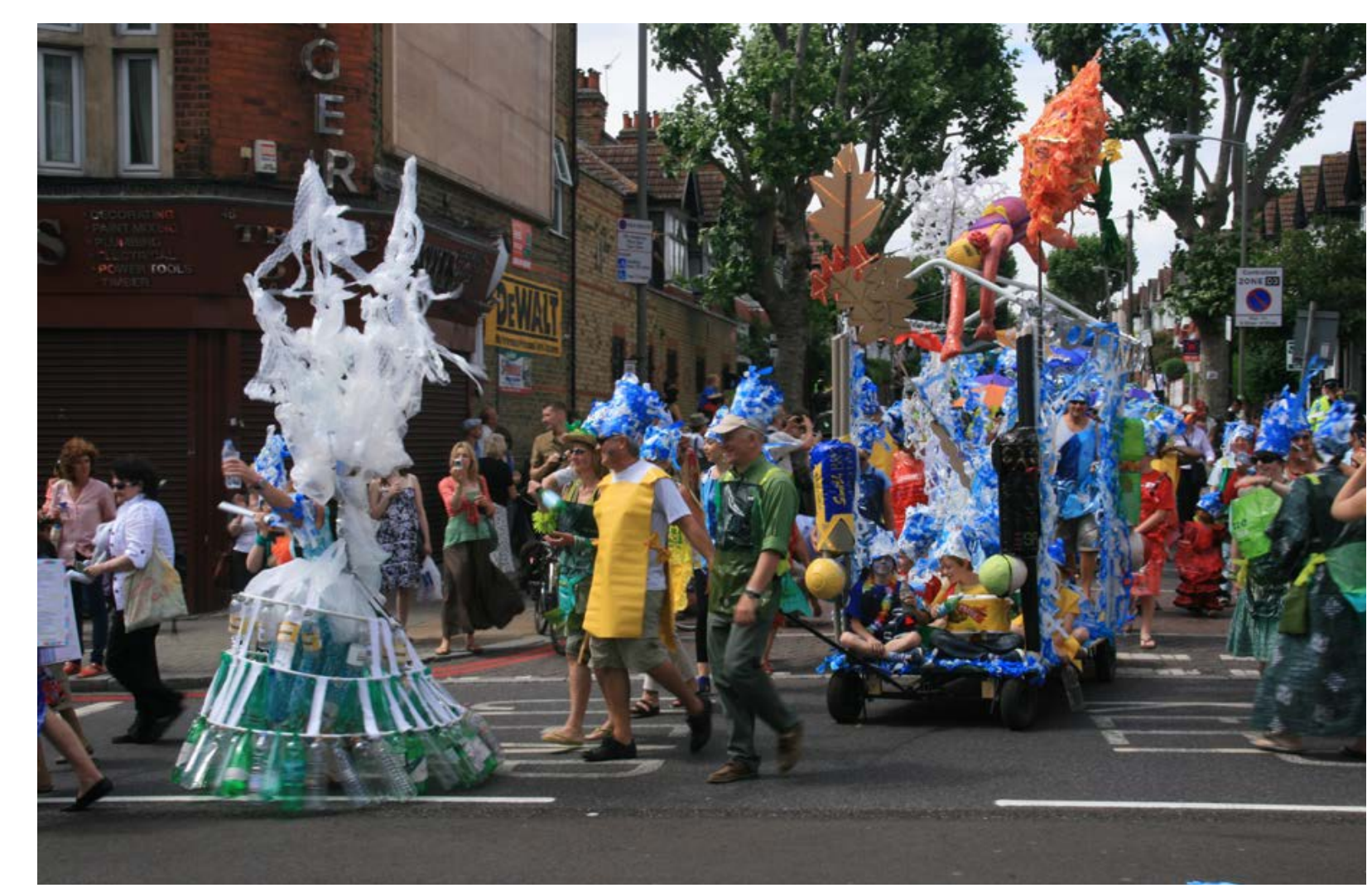

Imagen 51. El club de natación Lido de Tooting. Fuente: Fotografías de Rachel Wheeley.

La importancia del mismo trascendió más allá del grupo de transición. Demostró a los habitantes de Tooting de lo que eran capaces trabajando juntos, inspirándoles a imaginar una visión positiva del futuro, conectándoles y tendiendo puentes de un modo sorprendentemente divertido. El arte y la creatividad crearon el espacio, aunque temporal, para compartir la expe- rimentación y el aprendizaje en el uso de los recursos, lo cual afectaría a participantes y público para siempre removiendo sus consciencias (Neal, 2015, pp. 316-321).

5.4 ANÁLISIS

\subsubsection{Participación}

Numerosas asociaciones (Transition Town Tooting, SHARE Jardines Comunitarios, La Asociación de Ancianos Asiáticos, Asociación de la Comunidad Furzedown, El grupo juvenil Hub, etc.) ocho escuelas, varias tiendas, los hospitales de Springfield y St George's, el Gran coro Gustos, el Centro de arte Sprout, el club de natación de Tooting Bec Lido, el servicio de limpieza de calles municipal de Wandsworth entre muchos otros colectivos contribuyeron de algún modo a la celebración (Transition Town Tooting, 2010a). Pero también a nivel individual la colaboración de la comunidad es imprescindible en esta obra. Sin sus habitantes y entusiasmo no se habría podido llevar acabo. En cuanto a los tipos de participación de Lacy, figurarian todas las categorías desde el tipo dos al seis, puesto que los participantes -incluso hasta los niños que fueron un punto central de esta fiesta - tomaban decisiones en cuantos a los motivos que querían representar en el carnaval|167 (colaboración y codesarrollo) y el evento ha pasado a la posteridad en libros como el de Neal (público del mito y la memoria). Como Santos dice:

La forma en que Phakama trabaja, la forma en que yo trabajo, es realmente escuchar, se trata de escuchar las sugerencias, ideas, reflexiones, opiniones, experiencias de todos y ponerlo todo en una olla [.... Así que la estructura ofrece a las personas la oportunidad de explorar las formas de trabajar realmente. En la búsqueda de este fin de semana, lo que pretendemos hacer es eso, decirles: chicos tenemos que hacer un carnaval, una oportunidad emocionante y un proyecto emocionante, pero no vamos a estar haciéndolo nosotros mismos, no vamos a 
Los artistas plantean la idea del carnaval (origen y responsabilidad) pero dejan abierta negociación de cómo llevarlo a cabo. Han desarrollado por tanto, un papel de facilitadores o mediadores más que de protagonistas de la creación.

Destaca la diversidad de la participación tanto en edades, como en procedencias, nacionalidades y religiones y, de hecho, el barrio es reconocido por esta pacífica mescolanza de culturas. Los artistas que han sabido aprovecharla, han dirigido la acción y el tema de fondo, aunque han demostrado una gran habilidad consiguiendo involucrar a tantos habitantes en el desarrollo narrativo del carnaval y no solo en su ejecución. Un logro, sin duda, difícil de igualar, que sirve de ejemplo de integración y confianza.

\subsubsection{Puntos de tensión y puntos clave}

Dos cuestiones destacan en el proceso de desarrollo de esta obra. En primer lugar llama la atención que, en contraste con nuestro anterior ejemplo, la financiación ha sido mucho más abundante en este caso. Inicialmente reciben un empuje de $20.000 \mathrm{f}$ de la Comisión Tippingpoint. Además este carcición en recibir fondos del Arts Council of England (Neal, 2015, p. 316). Pero también ha recibido portaciones de otras entidades como Tooting Town Centre Partnership; Wandsworth Arts, Cultural Wealth Fund, Grassroots Fund, Extended Schools y The Big Give (Transition Town Tooting, 2010a). En total se recaudaron $80.000 \mathrm{f}$ en fondos y recursos (Neal, 2015, p. 318).

Por otro lado, la relación con la empresa de transportes de Londres, Transport for London, fue tensa en los últimos momentos. Teniendo en cuenta el tráfico que soporta la carretera Upper Tooting Road, un corte en la misma supone un gran trabajo previo con los servicios de emergencia, empresas de transporte, policía e incluso bomberos. A pesar de todas las reuniones precedentes, la petición de los carnivalistas de cortar la calle al tráfico fue denegada por la empresa de transportes a solo dos días de la acción. Los artistas coensar en la opción de transformar el desfile festivo en una cabalgata-protesta. «No estoy seguro de cómo me siento sobre la primera revuelta de la transición» (Neal 2015, p. 318) manifestó Hopkins al ser informado. Finalmente se autorizó la procesión, a pesar de la negativa de la empresa de transportes, gracias a la intervención del concejal Edward Lister, el miembro del parlamento Sadiq Khan yel miembro de la Asamblea de Londres Richard Tracey (Liddle, 2010). Scotland Yard dotó a la policía de Tooting de permiso especiales para llevar el control del acto (Neal, 2015) y el desfile pudo celebrarse en e tono pacífico y festivo que se había planeado. Una vez más se demuestra la importancia del apoyo institucional en las iniciativas de transición.

\subsubsection{Intención}

La intención inicial queda expresada desde el inicio del proyecto: celebrar nuestra relación con la tierra de un modo positivo en la comunidad de Tooting. Aunque en el trasfondo de esta intención se hallan ideas más profundas como dotar de poder de decisión a la comunidad, imaginar y construir soluciones diferentes y positivas al reto de construir una sociedad con bajo consumo de carbono, y demostrar que cada persona cuenta para el cambio. También pueden identificarse otras subintenciones, como expandir las ideas de la iniciativa de transición que produce el carnaval, contribuir a la concienciación ecológica, construir consensos en una sociedad muy diversa y ofrecer soluciones parciales al problema de los residuos. En cualquier caso, las dimensiones en participantes y financiación satisficieron las expectativas (Liddle, 2010). Sin embargo, no podemos evaluar la coherencia de los resultados en comparación con las intenciones iniciales pues no tenemos datos sobre los efectos, por ejemplo en el cambio de actitud, la reducción de residuos, o en el consumo de envases en la zona. Como ocurre en muchos casos, la puesta en marcha de la obra artística agota las fuerzas del grupo y no se evalúan a posteriori sus efectos. Aun asi hemos logrado recopilar los resultados que presentamos en el apartado siguiente. 
168 entre ellos las noticias de las seis en
punto en ITN, el periódico local Your Local Guardian y e blog de la Red de Transición
Transition Culture.

$169 \mathrm{El}$ texto reflexiona sobre la capacidad del arte de explorar nuevas formas de $\mathrm{h}$
frente al reto del cambio climático.

170 El carnaval fue nominado al mejo perma clima de 2011 esponsorizod por la cadena de supermercados Tesco, (e) cual se alegran de no haber ganado) (Neal,
2010, p. 4444). Lucy Neal ganó el premio del municipio de Wandsworth Green Champion Tooting en una fuerza motriz para el cambi (Your Local Guardian, 2010)

171 «Steven Cooper, de la Policía una idea fantástica y que le gustaría que una idea
volvera a sutse
ne, 2010).

"¿y para qué se hizo todo esto? Reuniendo diferentes partes de Tooting, ilustrando cómo la basura puede ser reutilizada para no siempre tienen que ser carreteras tambien pueden ser espacios comunitarios. Al hacer algo fuera de lo común, el equipo
de Lido ha ayudado a demostrar que las hay otras formas de vivir en un futuro con bajas emisiones de carbonom. Sue Rentoul,

El miembro del parlamento de Tooting Sa. diq Khan manifestó a la prensa: «El Carnava 172
Al respecto del impacto del carnaval en la consideración del arte como herramienta de

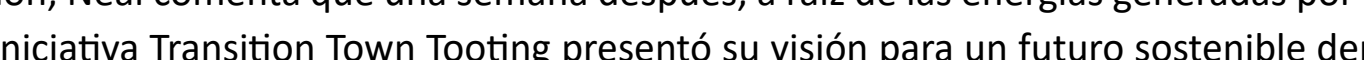
ro de 20 años, teniendo en cuenta el uso de la energía, la educación, el bienestar, el uso de la tierra, el cultivo de alimentos, el transporte, la salud y, como novedad, el arte. «Se reconoció que las comunidades locales (iy los artistas!) tienen un papel clave que desempeñar en la configuración de nuestro mundo» (Neal, 2010). Añade que una gran cantidad de proyectos de arte han salido a la superficie en Tooting fruto de esta acción. Además, el carnaval fue considerado en debate sobre culturas futuras en la Conferencia sobre cambio climático de las Naciones Unidas sobre el cambio climático (Your Local Guardian, 2010).

Otra consecuencia post-carnaval fue la celebración, al día siguiente, del Simposio: ¿Cómo aprenden las sociedades? Como indicamos en el apartado 5.1, la celebración y la reflexión sobre los logros conseguidos son necesarias para mantener una actividad sana en las iniciativas de transición. Este simposio constituyó un espacio para la meditación sobre lo aprendido en e evento desde un contexto más amplio. Hizo énfasis en la necesidad de la actuación tanto individual como colectiva, y acogió reuniones y debates entre participantes e invitados dirigidos por la Dra. Barbara Heinzen (experta en manejo de la incertidumbre en organizaciones) y Ann

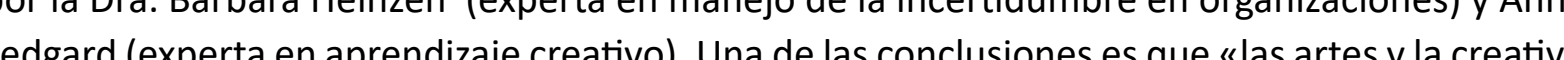
aprendizaje para siempre» (Neal, 2015, p. 320).

El acto fue objeto de seguimiento por parte de diversos medios ${ }^{168}$, dio lugar a un artículo escrito por Neal junto a Zoe Svendsen ${ }^{169}$ (Svendsen, Neal y Town, 2009) y obtuvo varios pre$\operatorname{mios}^{170}$

A pesar de no contar con datos sobre el cambio de comportamiento de la población a

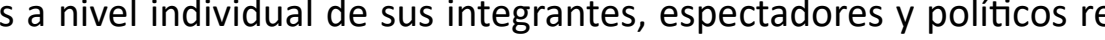
de Dave Mauger, que a raiz de esta actividad cambió su carrera de diseñador grático a gestor La función del arte en procesos de transición a la sostenibiliddad: casos anglosajones y españoles. nada de esto hubiera sucedido sin esa tortuga gigante ...) (Mauger, 2014).

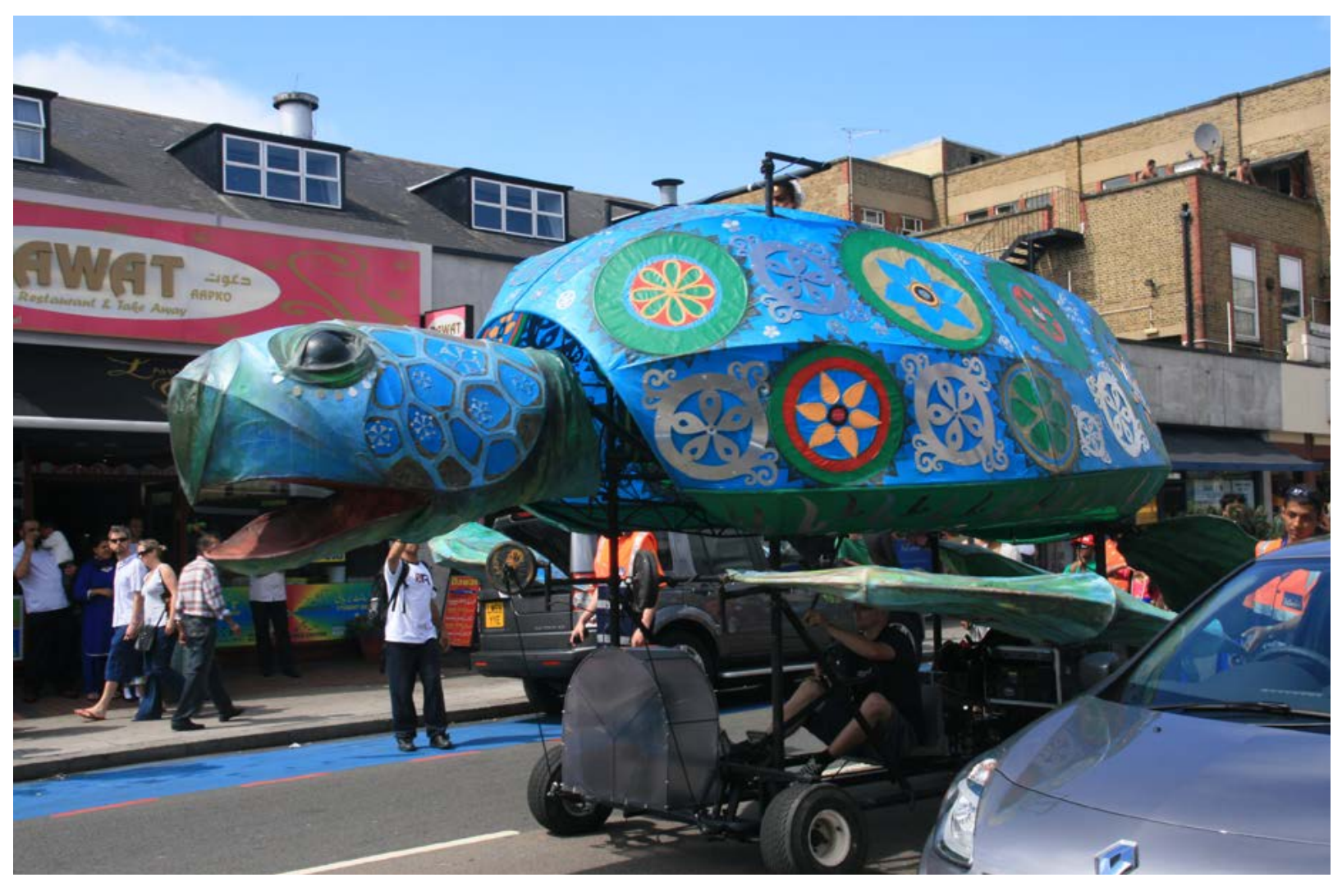
Transition Town Tooting ha logrado concluir escuelas, grupos comunitarios, empresas y Impresionante. Realmente espero que esto se convert.
2010).

Dave Mauger, participante invitado, comenta el enorme efecto de este carnaval en su
vida a tres años vista: «Habieindome criado ynacido en el suroeste de Londres $y$ habien-
do pasado la mayor parte de mi vida aqui, nunca antes había experimentado esta raeza. un verdadero sentido de comunidad unido para señalar el creciente problema celebrando con su comunidad mientras lo hace. El Carnaval Trashcatchers me impulsó mir el control del Festival de comida Tooting Foodival en 2013. También me he diversificado como voluntario en el Jardín Comuni-
tario TTT con niños de la escuula local, además de tomar un papel activo en Food Cycle

Imagen 52. La tortuga del carnaval de Tooting, Foto: Rachel Wheeley

\subsubsection{Estética y ética}

La obra estuvo supervisada en todo momento por los artistas de Emergency Exit Arts y Project Pakhama, junto a otros artistas que colaboraron puntualmente en los diferentes talleres. 


\subsubsection{Papel y funciones del arte en Tooting Traschcatchers ' Carnival}

Producto de la revisión del proyecto a través de libros y páginas web hemos deducido que el arte cumple, sobre todo, un papel de liderazgo en esta ocasión, a la par que de acompañamiento estético. De dichas fuentes también se deducen e identifican las siguientes funciones de arte en este caso:

\begin{tabular}{|c|c|}
\hline $\begin{array}{l}\text { FUNCIONES DE LA OBRA } \\
\text { TOOTING TRASHCACHERS' } \\
\text { CARNIVAL }\end{array}$ & JUSTIFICACIÓN \\
\hline $\begin{array}{l}\text { Ilustrar, representar, } \\
\text { comunicar, difundir }\end{array}$ & $\begin{array}{l}\text { Sí, se trata de un carnaval que ilustra la historia del pájaro Sankofa, } \\
\text { comunica las ideas del grupo de transición de Tooting y difunde su } \\
\text { existencia. }\end{array}$ \\
\hline Concienciar & Sí, trata de comunicar un nuevo tipo de relación con la tierra. \\
\hline Desarrollar empatía & $\begin{array}{l}\text { No es una función claramente detectada pero supuesta en los talleres } \\
\text { de cambio climático y pico del petrtóleo. }\end{array}$ \\
\hline $\begin{array}{l}\text { Imaginar, desarrollar la } \\
\text { visión del grupo, su misión, } \\
\text { futuros posibles, utopías o } \\
\text { ficciones }\end{array}$ & $\begin{array}{l}\text { Sí, usando el reciclaje como una metáfora, el objetivo es construir una } \\
\text { visión futuro con un bajo consumo energético para Tooting y procurar } \\
\text { que el proceso fuera atractivo (Transition Town Tooting, 2010a) }\end{array}$ \\
\hline
\end{tabular}

\begin{tabular}{|c|c|}
\hline $\begin{array}{l}\text { Ofrecer soluciones, } \\
\text { mostrar alternativas } \\
\text { reales o proyectos piloto, } \\
\text { laboratorios de pruebas }\end{array}$ & $\begin{array}{l}\text { Sí, se emplearon media toneladad de materiales que fueron } \\
\text { recolectados durante un perióodo de seis mesess alrededor de un millón } \\
\text { de bolsas de plástico, medio millón de bolsas de patatas fritas además } \\
\text { de media tonelada de mimbre y mucho otro material, para crear } \\
\text { una celebración brillante y colorida, alimentada por esa comunidad } \\
\text { particularmente tan diversa pero no es una solución a largo plazo. }\end{array}$ \\
\hline $\begin{array}{l}\text { Conectar personas y/o } \\
\text { lugares, crear comunidad, } \\
\text { hacer redes, crear espacios } \\
\text { de relación, mediar o } \\
\text { facilitar }\end{array}$ & $\begin{array}{l}\text { Sí, la actividad fortaleció el sentimiento de cohesión y comunidad hasta } \\
\text { el punto de impresionar a algunas personas como manifiesta Dave } \\
\text { Mauger. }\end{array}$ \\
\hline $\begin{array}{l}\text { Restauración/recuperación } \\
\text { del entorno }\end{array}$ & No se detecta al menos una restauración directa. \\
\hline $\begin{array}{l}\text { Reforzar la identidad, crear } \\
\text { símbolos }\end{array}$ & $\begin{array}{l}\text { Sí, las distintas comunidades de la sociedad de Tooting estaban } \\
\text { representadas en el carnaval mediante sus particulares simbologías } \\
\text { para reforzar la identidad plural de esta comunidad al sur de Londres. }\end{array}$ \\
\hline $\begin{array}{l}\text { Fomentar la ciudadanía } \\
\text { crítica, agitar, denunciar }\end{array}$ & $\begin{array}{l}\text { No es tanto una función de denuncia o crítica como de reflexión propia } \\
\text { sobre los recursos. }\end{array}$ \\
\hline Empoderar & $\begin{array}{l}\text { Sí. Los individuos se hacen conscientes del poder que tienen como } \\
\text { tales y como comunidad: «individualmente podemos parecer } \\
\text { insignificantes, pero cuando nos conectamos en una comunidad, } \\
\text { somos muy fuertes, podemos hacer una gran diferencia» (Thorne, } \\
\text { 2010). }\end{array}$ \\
\hline $\begin{array}{l}\text { Crear relatos positivos de } \\
\text { cambio }\end{array}$ & $\begin{array}{l}\text { Sí, la historia del pájaro Sankofa es un relato de aceptación del cambio } \\
\text { y la reflexión que nos invita a revisar ruestros errores del pasado sin } \\
\text { vergüenza, como algo positivo. El ejemplo de este carnaval ha pasado } \\
\text { a la historia a través de los libros que narran la experiencia como un } \\
\text { momento positivo álgido en la comunidad. }\end{array}$ \\
\hline $\begin{array}{l}\text { Facilitar la comprensión } \\
\text { del mensaje de la ética } \\
\text { ecológica aplicándola }\end{array}$ & $\begin{array}{l}\text { Sí, los talleres y charlas sobre cambio climático y pico del petróleo se } \\
\text { acompañan de un desempeño ético del carnaval aplicando principios } \\
\text { de reutilización y reducción de residuos. }\end{array}$ \\
\hline $\begin{array}{l}\text { Conectar áreas alejadas de } \\
\text { conocimiento }\end{array}$ & $\begin{array}{l}\text { Sí, el carnaval mezcló a los habitantes con artistas de todo tipo y } \\
\text { especialistas invitados a impartir charlas sobre cambio climático como } \\
\text { Mark Maslin. }\end{array}$ \\
\hline
\end{tabular}


173 De hecho, contaban con la colabora-
ción del centro urbano que cedió un espacio donde pudieran hacer $y$ almacenar las
figuras del carnaval. Cerca del final, de repente el centro retiró su apoyo y tuvieron ninguna explicación (Longhurst, 2016), mudándose a Broadway studios Tooting a finales de junio.

\begin{tabular}{|c|c|}
\hline $\begin{array}{l}\text { Motor iniciador de un } \\
\text { proyecto }\end{array}$ & 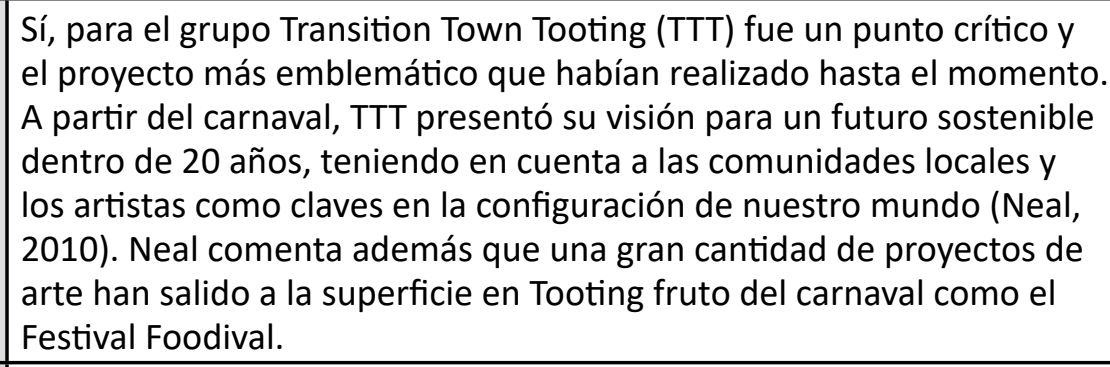 \\
\hline Celebrar & $\begin{array}{l}\begin{array}{l}\text { Sí, es la función principal del carnaval: celebrar nuestra relación con la } \\
\text { tierra. }\end{array} \\
\text { a }\end{array}$ \\
\hline Recaudar fondos & No. \\
\hline Construir consensos & $\begin{array}{l}\text { No se busca llegar a un punto común concreto sino más bien de } \\
\text { concienciar y estimular la autorreflexión de cada habitante. }\end{array}$ \\
\hline Premiar, agradecer & $\begin{array}{l}\text { Sí, la celebración es el premio para el grupo TTT y agradece al planeta } \\
\text { de un modo festivo por los recursos. }\end{array}$ \\
\hline
\end{tabular}

Tabla 6. Funciones del arte identificadas por la autora. Fuente: elaboración propia.

\subsection{RESULTADOS Y CONCLUSIONES PARCIALES}

La propia Neal, cocreadora de los principios del arte transicional, es una de las artistas fundadoras del grupo de transición de Tooting e impulsora de este carnaval. Además ella misma considera Traschcatchers' Carnival como un ejemplo de arte transicional en su libro Playing for time. Making art as if the world mattered. Desde esta investigación estamos de acuerdo en considerar que cumple todos los principios que ella señala en su definición a excepción del principio: mantener un espacio que no fue posible ${ }^{173}$. De esto se puede deducir que los principio definidos no son un listado exhaustivo.

Destacamos en este caso la función de celebración, entre tantas otras, porque tal y como lo expresa Neal, el verdadero corazón de esta obra es la celebración positiva y comunitaria de un futuro mejor (Samett, 2010, p. 00:45). La festividad en este caso va más allá, es el objetivo a cumplir y, a la vez, constituye el premio y la relajación para el grupo de transición. Esto lo acompañan con la reflexión durante el simposio posterior, por lo que cumplen con todos las fases que la Red de Transición aconseja. Pero muchos de los mejores momentos de este proceso se dan antes del carnaval, comenta Santos, durante su preparación, a través de una serie de encuentros donde los participantes descubren de lo que son capaces, aprenden, se conocen, se conectan con otros vecinos con los que quizás nunca habrían hablado (Transition Town Tooting, 2010b).

Una de las primeras características que saltan a la vista de este proyecto es el apoyo y la financiación que instituciones varias como Tipppingpoint o British Arts Council, están brindando los artistas que trabajen liderando la tranformacín social (Hopkins, 2015). Comparado con el caso español a diferencia es notable $y$ a indacán do las causas merece Comparado con más profunda que apuntamos, pero más profunda que apuntamos, pero que no podemos abarcar aqui

Una segunda observación es la sensación de empoderamiento que provoca en sus participantes. Los vecinos se hacen conscientes del poder que tienen como tales y como comunidad (Thorne, 2010). La misma Neal confiesa sentirse diferente a dos años antes $y$ ser más consciente ahora que estamos viviendo un periodo histórico de nuestro tiempo (Your Local Guardian 2010) Julie's Bicycle ñ 2010). e

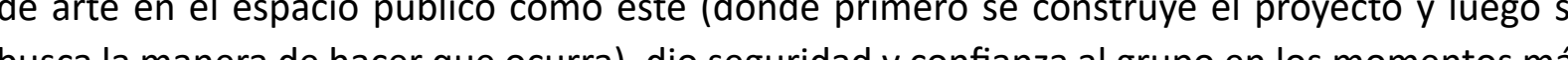
busca la mas a más curos, cuando parecia que no obtendron el permiso para realzar el carnaval, a dos días de su celebracion. Este trabajo colectivo, como ensayo de lo aue la com risis a capaz, contribuye a crear resiliencia y hacer frente a la anomia frente al desafío de la crisis ambiental, que comentamos en el apartado uno. Las hablidades y recursos descublertos, dejarán sin duda una huella positiva en la memoria de sus participantes. Jeny Walker, del grupo motor de TTT, comenta que fue un gran ejemplo de lo que son capaces de hacer como grupo de transición (aún sin permiso): «Cerramos la calle principaly tuvimos un carnaval, así que no hay nada realmente que no puedas hacer» (Longhurst, 2016).

Podemos afirmar que el carnaval y todas sus actividades preparatorias y paralelas, han respondido perfectamente al propósito del MCT: «Inspirar, alentar, conectar, apoyar y capacitar
a comunidades de todo el mundo a medida que se organizan en torno al modelo de Transición» (Transition Network, 2018). Y de hecho, esta inspiración y conexión ha traído nuevos miembros a la iniciativa de transición que han cambiado su estilo de vida, como comentaba Mauger. 
El fuerte sentido de comunidad del que parten en esta zona de la ciudad y que alimentan aún más con esta obra.

La habilidad de los artistas para fomentar un proceso creativo dialógico en el que tofuera informal, inclusiva, la metodologia en cuatro fases de Macy o el ejercicio de $a$ rueda de dar y recibir de Santos, subyacían dando estructura y sentido al proceso.

- Por otra parte, frente a las críticas a las iniciativas de transición sobre la homogeneidad de sus participantes y la falta de inclusión de la diversidad que vimos en el apartado uno de éste capítulo, esta actividad ha demostrado una notable desviación de la media. Desconocemos si han incorporado participantes de diferentes escalones económ cos o educativos, pero sin duda sí que han incorporado la heterogeneidad de edades, culturas y religiones del barrio. También han cumplido otros objetivos típicos de las iniciativas de transición como son: reactivar la cooperación, reparar el daño ambienta, crear espacios de participación alternativos y proponer nuevas formas de actuación informal y colectiva desde la base. La informalidad característica de un carnaval y de los talleres preparatorios donde se conversaba sobre el pico del petróleo, los residuos y el cambio climático, puede haber facilitado la asimilación del mensaje más que un charla o una clase. Pero tal y como el estudio de Fernandes señalaba, en esta ocasión tampoco se realiza ninguna crítica o propuesta a las estructuras de poder. Todo el carnaval se basa en el poder de cambiar como individuos y colectivo pero sin demar registra ningún cambio do durante el carnava te transición, corre el peligro de dis embargo, a nivel de la propia iniciativa de transición de Tooting, el canaval supuso un punto de inflexión que les fortaleció, les dio confianza en si mismos para soñar hacer crecer otros proyectos. Por ejemplo, a partir de entonces se lanzaron oficialmente como iniciativa de transición y organizaron las siguientes ediciones del Festiva roodival de un modo más ambicioso. En 2016 organizan el Tour de Tooting ${ }^{\text {ts }}$ un carnaval en la línea de Trashcatchers' Carnival que celebra la comunidad, el bienestar a sostenibilidad sobre ruedas y sin motor. A raíz de estos proyectos los miembros de grupo de transición identifican una forma de práctica artística propia del MCT. Esto ha (actividades de transición al menos en este grupo (Longhurst, 2016). 
CAPÍTULO 4 EL PAPEL DEL ARTE EN LA TRANSICIÓN EN SENTIDO AMPLIO

\section{INTRODUCCIÓN}

En el capítulo tres hemos presentado el papel del arte en iniciativas de transición que se reconocen como tales a sí mismas y adscritas al MCT, pero este movimiento en España es todavia una corriente en crecimiento con escasa presencia en el territorio (veinticinco iniciativas en activo en 2018), sobre todo si la comparamos con las experiencias en Reino Unido (alrededor de trescientas actualmente según la red transitionnetwork.org). Por otra parte, el concepto de transición es muy amplio y entendemos el MCT como una de sus múltiples manifestaciones posibles entre tantas otras (ecoaldeas, cooperativas, agricultura sostenida por la comunidad (CSA), etc.). De modo que encontramos numerosos proyectos y colectivos que trabajan desde el arte la transformación social hacia la sostenibilidad al margen del MC (Open Jar Collective, The Barn, Grizedale, Can de Farrera, Culturhaza, Joia, Campo adentro, etc.). A continuación presentaremos un estudio detallado de los cinco casos seleccionados, dos en Reino Unido (la obra Dundee Urban Orchard (DUO) y el colectivo The Stove Network) y tres en España (Biodivers en Carrícola, la Red El Cubo Verde y el proyecto Aula-R). De ellos, The Stove, Aula- $R$ y Carrícola han iniciado sus actividades hacia la transición de un modo intuitivo, con desconocimiento de sus principios y características. Por otra parte, DUO y El Cubo Verde sí están familiarizados con el concepto de transición desde sus inicios.

Aunque en estos proyectos la creación artística cumple diversas funciones de las señala das en el capitulo dos, identificaremos en cada uno una función innovadora y primordial que los caracteriza. Como en el capítulo anterior, analizaremos las obras artísticas de cada ejemplo en función de la participación, sus puntos de tensión y puntos clave, la intención, la efectividad, la estética y la ética. Por último, comprobaremos de qué modo responden a los principio del arte transicional y extraeremos unas primeras conclusiones por cada proyecto, para poder establecer una comparativa en el siguiente capítulo.

\section{METODOLOGÍA, PARTICIPANTES Y}

PROCEDIMIENTO

Al igual que en el capítulo anterior, la metodología se ha basado en la IAP incluyendo una estancia de investigación en Escocia que nos ha posibilitado la visita en persona de los casos de estudio en varias ocasiones. De ese modo, la mayor parte de los datos han sido casos de est dio ion van sido En ambas exprias en Escocia, hemos podido participar además en el destipantes.

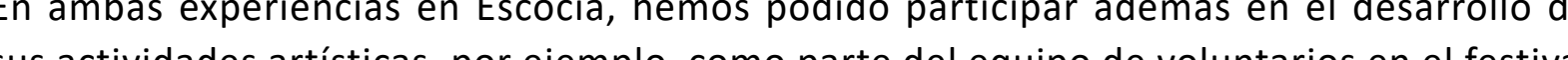

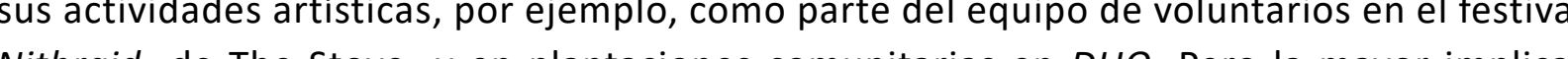
Nión haid de The im ción ha tenido lugar en los casos de Carricola y Aula-R, llegando a participar con una obra colaborativa en la convocatoria de arte en el paisaje Biodivers y llevando a cabo nuestro propio proyecto Aula-R en la Facultad de Bellas Artes San Carles de Valencia. El hecho de cipación y los efectos de la obra de arte en la conciencia ecológica de primera mano.

Las entrevistas semiestructuradas han sido realizadas en inglés y español, grabadas $y$ transcritas. También se han recogido por escrito notas, reflexiones y conversaciones es-

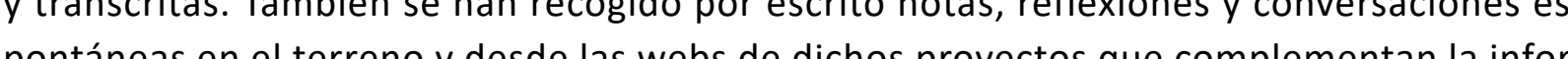
poncín En algunos casos como le DUO y The Stove, los artistas nos han invita a un mación. recorrido por la obra con la posibilidad de entrevistar y tomar fotografias de varios participantes y espacios. En el caso de Biodivers, la experiencia ha sido incluso más intensa, ya que hemos convivido con los habitantes del pueblo durante la realización de la pieza escultórica varios fines de semana durante la primavera de 2015. Por último en Aula-R hemos llevado a cabo una medición de resultados más profunda publicando sus resultados en un artículo y un poster en el V Congreso Internacional de Educación Ambiental en 2015. 
176 Por ejemplo un espacio fluvial, antes del río, ahora está abandonado al sustitutur el transporte por carretera al transporte flu177 Nos referimos, por ejemplo, a la coe-
xistencia de usos incompatibles en un mismo territorio, como la urbanización de una rambla, o como en este caso, la ocupación urbanistica de la llann
río en esta población.

178 En adelante los mencionaremos por su
original en inglés: We Live With Water $\mathrm{y} N$ Ni-

179 En adelante lo mencionaremos como
The Stove. Véase http://www.thestove.org 180 La población ha convivido con las creci-

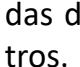

181 Hasta trescientos miembros en 2016

\section{ESTUDIO DE CASO: THE STOVE}

\subsection{EL ARTE Y SU FUNCIÓN DE CONEXIÓN DE ESPACIOS Y PERSONAS}

En el capítulo anterior hemos presentado la función del arte para revitalizar el territorio con problemas de desp circunstancias producto del sistema socioeconómico actual, entre ellas, la dispersión de la urbanización en el territorio, el alejamiento de la naturaleza que fomentan los estilos de vida consumistas, el cambio en los usos del paisaje heredado ${ }^{176} \mathrm{o}$ la tensión producida por una coexistencia forzada ${ }^{177}$ de usos del suelo irreconciliables. Todas estas claves se hallan en el trasfondo de los proyectos artísticos interrelacionados Vivimos con agua (2015) y la Carrera del Nith ${ }^{178}$ (2013) de colectivo artístico The Stove Network ${ }^{179}$, que se desarrollan en la ciudad de Dumfries, Escocia. Los habitantes han descuidado su relación con el río que la atraviesa, el Nith. El transporte por medios terrestres y aéreos ha despojado al torrente de su interés como ví fluvial vital para comercio. Además, aunque las crecidas anuales de este río eran un fenómeno recurrente y conocido $0^{180}$, el cambio climático las ha acentuado, creando probas de inumdaciontente y cobos ne

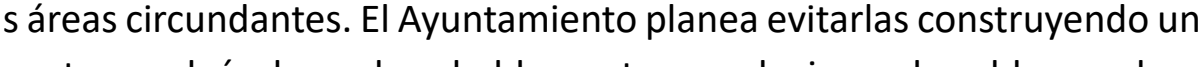
digs sien aumentando $y$, además, traslade el problema aguas abajo. Por otro lado, la revolucion en los transportes y los cambios económicos que ha conllevado la sociedad de consumo, han dejado sentir sus efectos también en la organización de la ciudad. Dumfries $h$ perdido espacios de interrelación accesibles a pie al trasladarse la vida comercial a los grandes almacenes de la perferia, ylos residentes a las urbanizaciones del extrarradio, dejando el centro de la ciudad (cercano al río) inanimado.

The Stove es un colectivo de artistas $y$ habitantes ${ }^{181}$ que se proponen «utilizar el arte para do lugares donde viven y la so involucrar ve en 2015). Se autodefinen cono jenals (The Stove, 2015). Se aut foutefnen como unn medio para que la comunidad creativa to que plantean en We Live With Water (Anderson et al., 2015) es una idea alternativa de cómo puede ser el futuro de Dumfries en 2065: en lugar de confrontar las fuerzas del río con una muralla que lo aísla, proponen facilitarle el paso para su crecida anual y un rediseño urbano que conviva y celebre las crecidas. La visión futurista complementa la idea subyacente del proyecto The Nithraid: reactivar la conexión entre la población de Dumfries y su río. El arte propone así un cambio de actitud hacia una convivencia duradera, que implica a largo plazo, mucho menos esfuerzo que la oposición constante.

\subsection{ADECUACIÓN A LOS CRITERIOS DE SELECCIÓN DE LA INVESTIGACIÓN}

El colectivo The Stove cumple nuestros criterios de selección señalados en el capítulo dos apartado 1 , como se indica a continuación:

1. Proyectos que tengan una vinculación específica con lo local: Promueven acciones artísticas vinculadas al espacio público de Dumfries, en ocasiones de modo colaborativo, con el objetivo de reactivar la vida pública de la localidad.

2. Obras que actúen (consciente o intuitivamente) de acuerdo con los principios de la transición. The Stove realiza las siguientes acciones:

Descarbonización de la economía:

- Proponen un modelo de ciudad con un centro público revitalizado donde se concentre el comercio, los servicios y la residencia, y que evite desplazamientos en coche a la periferia, donde se sitúan actualmente los espacios privados de los centros comerciales.

Compromiso del movimiento ambiental con la equidad y la justicia:

- Aunque The Stove no se define como un colectivo de arte transicional ni enfocado al arte ecológico en particular, su director Matt Baker declara que sí tienen un objetivo de justicia ambiental (M. Baker, comunicación personal, 18 de julio 
- Defienden el espacio natural del río, su vegetación y sus llanuras de inundación dyacentes en perjuicio de la zona urbana de aparcamientos existente actualmente.

183 Por ejemplo la sede de The Stove en el Dumfries, de high Street en el centro de cro instalado por las artistas del colectivo de Glasgow Open Jar Collective, con productos y de consumo responsable. Este espacio dad y misión de The Stove: activar el centro
de la ciudad, hacer el arte accesible para el publico en general y como lugar de encuentro para las comu
(The Stove, 2015).

3. Que hagan uso del arte como herramienta de fomento de la transición y, en especial, del arte público:

- Son responsables, entre otros proyectos, de la organización del Environmental Art

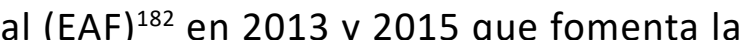
ambiente a través del arte en el entorno natural. En su política artística se incluven la participación y la comunidad como criterios de selección de propuestas (The Stove Network, 2015)

4. Interés en la realización de la obra por tener una reducida huella ecológica:

- Declaran su respeto por el medio ambiente en el desarrollo de sus actividades (The Stove Network, 2018) y cierto interés por tener una reducida huella ecológica, aunque carecen de herramientas de medición.

5. Ocuparse de cuestiones relacionadas con la ecología y/o la transición:

- Entre los temas del arte ecológico, les interesa el reequilibrio con el entorno, la justicia social y ambiental y el consumo responsable ${ }^{183}$. En las obras que presende las ideas de progreso ecóńmico y socil. Rechazen las soluciones tecnociende las ideas de progreso economico y social. Rechazan las soluciones tecnocientificas a los problemas ambientales y la idea de dominio de la naturaleza en favo del medio ambiente y la sostenibilidad como criterios de selección de propuestas (The Stove Network, 2015)
3.3.1 We Live With Water

185 La tasa de tiendas vacantes en 2018 es
casi del doce por ciento en Escocia. (Goodwin, 2017).

En los ultimos años Dumfries ha perdido parte del carácter de gran ciudad que tenía del centro de la ciudad, por los centros comerciales del extrarradio, ha derivado en que Dumfries sea considerado - incluso por sus habitantes - como una «ciudad fantasma» (Anderso et al., 2015). Por desgracia no es un fenómeno aislado. En todas las ciudades de Escocia se observa que los locales del centro se van quedando vacantes y vacíos al tener alquileres demasiado $\operatorname{costosos}^{185}$ que solo las grandes multinacionales pueden pagar, por lo que los negocios locales desaparecen. Esta situación empuja al colectivo de artistas The Stove a instalar su sede en la vía más importante del municipio, la High Street con el objetivo principal de intervenir y dinamizar el espacio público de Dumfries y atraer a la población al mismo, creando momentos y espacios de relación. El origen de este proyecto se puede rastrear hasta el Festival de Arte Ambientas (EAFS)186 en el verano de 2015, oranizado por los artistas Matt Baker $y$ Jan Hogas

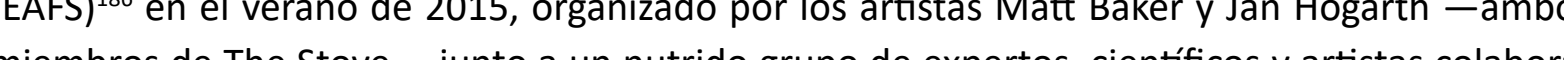

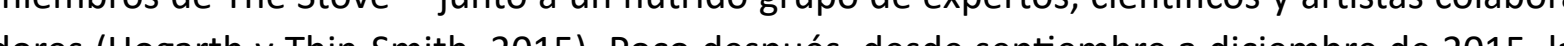
dores (Hogarth y Thin-S 1 h, 2015). Poco después, desde septien bre a dicy a bre de 2015, las

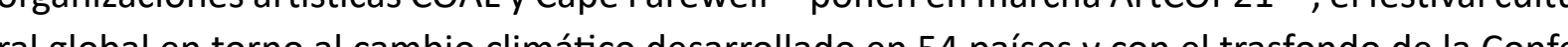
ral global en torno al cambio $\mathrm{Cl}$ Cático desarrollado en 54 paises y con el trastondo de la Conferencia de las Naciones Unidas sobre Cambio Climático (COP21) de diciembre de 2015 en París. La experiencia del EAFS animó a The Stove a presentar en el marco de ArCOP21 el proyecto Submerge. Así, durante una semana en diciembre de 2015, The Stove fomenta el diálogo sobre el cambio climático en la población de Dumfries mediante obras de arte interactivas, acciones públicas, debates y películas como parte de una exposición.

Se invita a artistas, individuos y grupos locales a explorar dicha problemática ambiental aplicada al caso particular de Dumfries, que sufre inundaciones anuales del Nith, cada año más acentuadas, desde que se tienen registros.Se discuten los controvertidos planes de prevención de desbordamientos del Ayuntamiento ${ }^{189}$ de entonces y se posibilita la oportunidad de imaginar un Dumfries del futuro con un enfoque alternativo. Una ciudad que recupere su importancia

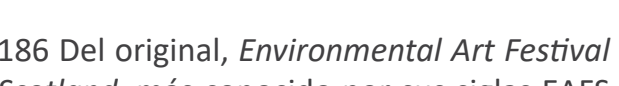

nocido por sus siglas EAFS www.gsabiosphere.org.uk/wp-content/ val-scotland-Report.pdf

187 COAL (the Coalition for Art and Sustainable Develooment) Véase www.projetcoal. www.capefarewell.com

188 Véase http://www.artcop21.com/

189 Como deciamos, el Ayuntamiento se

do una barrera de varios metros de altura. Desde The Stove interpretan que lo que se Cusca es «hacer que un área pequeña de ther fe araer inversiones privadas para a de los últimos viudad ha sido el manmás cuestionable durante el declive del capitalismo del siglo XX que no está logrando brindar bienestar
a la mayorí de la población en Escociay-
Ba 190 Anderson, K., Foster, K., Pacheco, R.,
ones, A., Slater, D., Bonaventura, M., McQueen, L., Baker, M., Zygadlo, M., Gott, l., White, S., Smith, M., Soutar, L., Dewar,
R., Powell, L. y Wheeler, K. (2015) We dores de propiedades. La estrategia de 
live with water. 2065: life today in Dum- como capital regional, que concentre a la población y servicios en su centro, que asuma y abrace fries River Town. Dumfries. Disponible uploads/2015/12/wiww_booklet.pd co, se vieran como una oportunidad positiva.

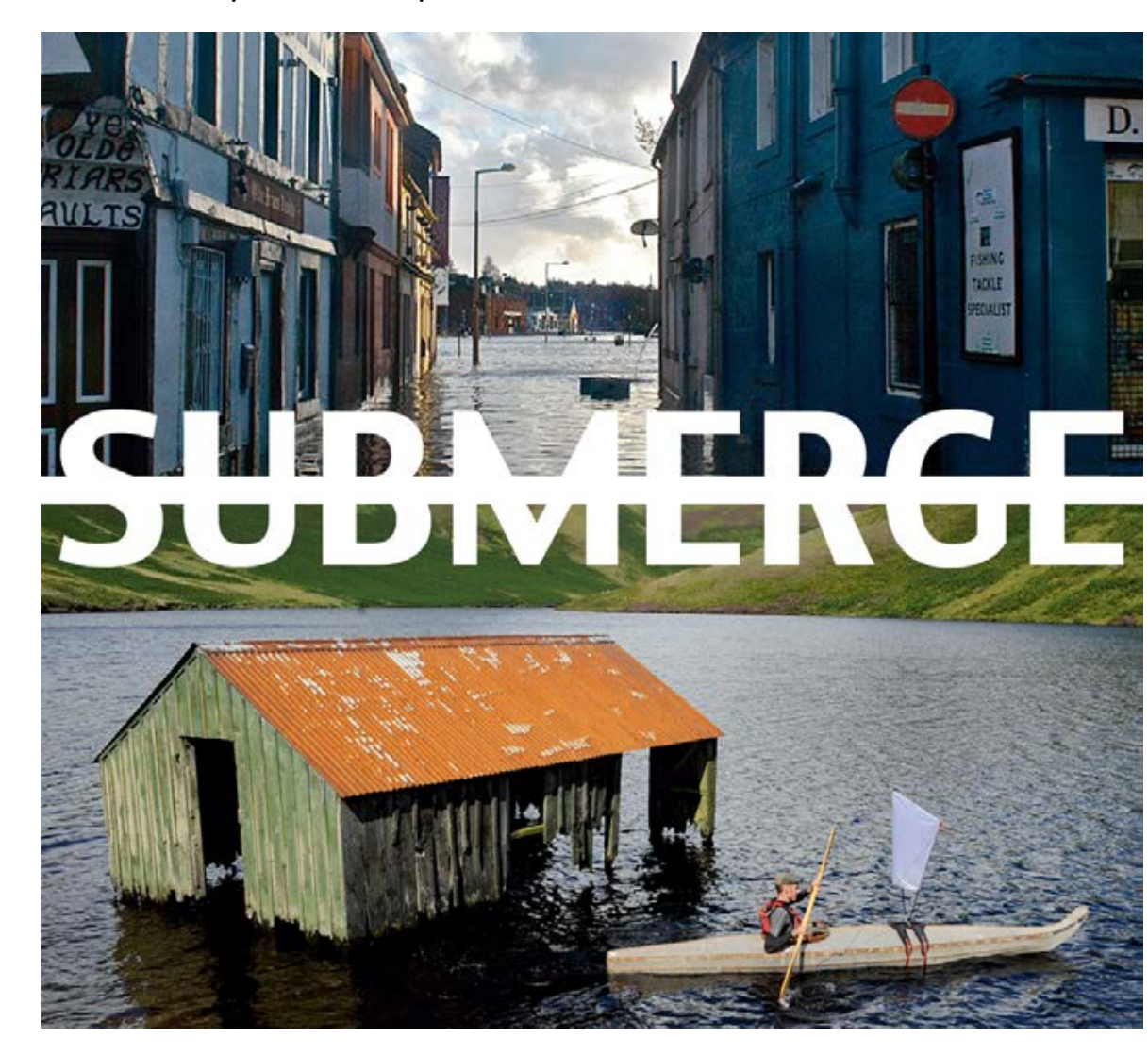

Imagen 53. Proyecto Submerge. Fuente: The Stove 2015

El resultado de esta visión es la obra We Live With Water ${ }^{190}$, una colección de relatos futuristas en la que diversos escritores locales plantean una perspectiva de Dumfries en 2065 muy distinta a los planes municipales. en lugar de confrontar las fuerzas del rio, proponen facilitarle el paso para su crecida anual, contener el desarrollo urbano e incluso retirar los negocios y aparcamientos que ocupan la orilla de inundación del Nith (en la imagen 54 zona 5). De ese modo, se crearía un corredor verde a lo largo de la corriente que absorbería las crecidas y acogería otros usos compatibles con las mismas como, la producción de alimentos y energía, el ocio, la cultura y la educación. Lejos de ser una retirada penosa, se piensa hacer de ello incluso una celebración que reúna a la población en torno al río. Para ello, desde 2013 se organiza la Nithraid, obra colectiva que presentamos a continuación.

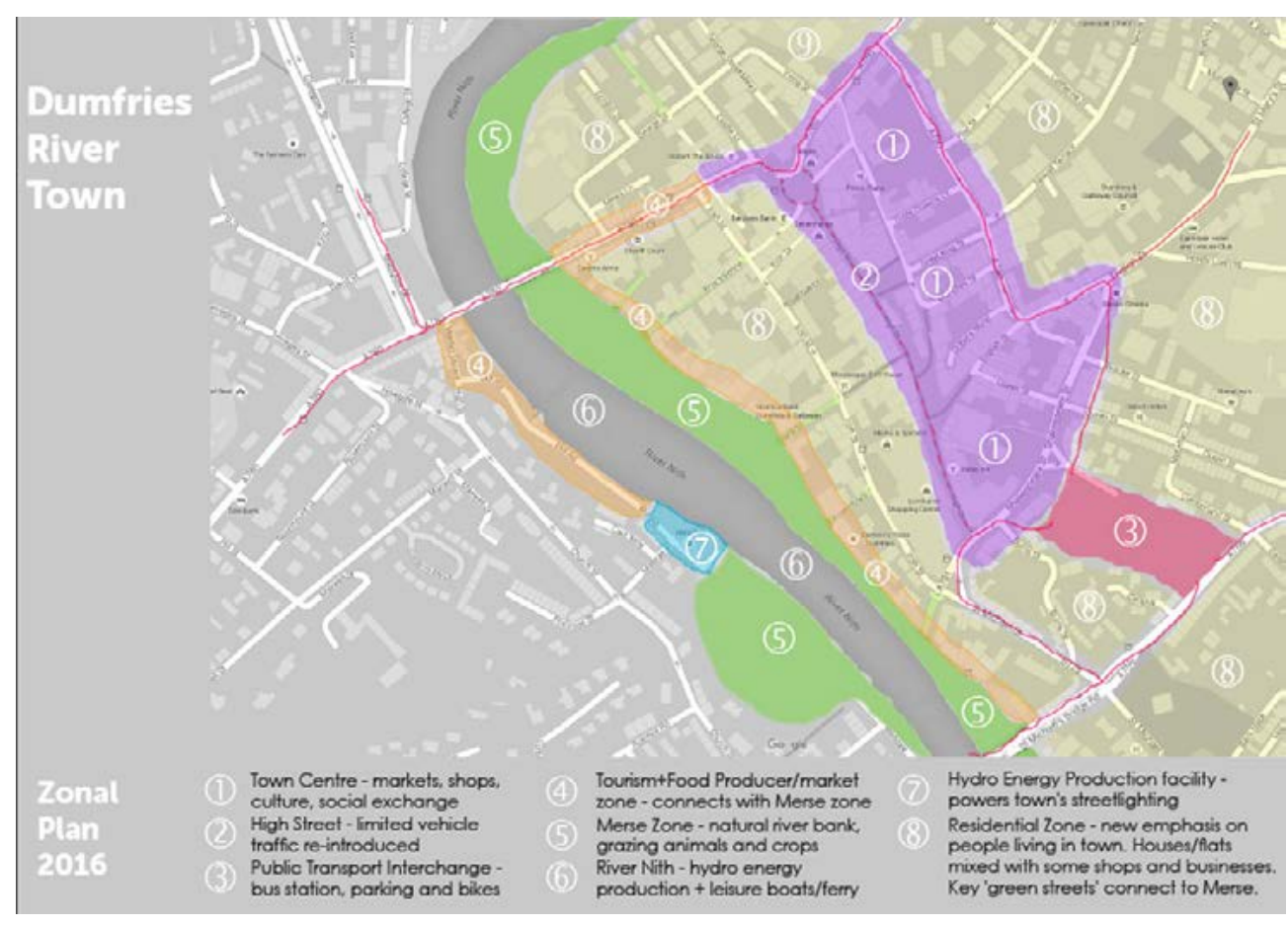
Imagen 54.010

\subsubsection{The Nithraid}

La Nithraid 191 se concibe como una obra de arte público y consiste en una carrera festiva en barco a lo largo del Nith, acompañada de talleres eco-artísticos, obras de arte visual, artes escénicas, música y comida. Celebra la presencia del rio, su importancia como via de conexión de Dumfries con el resto del mundo a través del comercio y la energía de la vela. Invita al público a descubrir de nuevo el Nith y los espacios que lo rodean, a establecer una nueva relación con él mientras esperan a que lleguen los barcos.

91 Véanse todas las ediciones en: http:// www thestove.org/nithraid/ $y$ para un vi-
festividad en 2015: https://vimeo.com/173162644 o https://vi- 
192 No solo se trata de una adaptación a e para intentar sacar un provecho de ella como veremos más adelante.

Es una apuesta por la resiliencia' ${ }^{192}$ en lugar de la oposición constante. El festival nació en el seno activar la vida en el centro de la ciudad, revalorizar el río organizando actividades en espacios públicos infrautilizados $y$ crear oportunidades creativas para que los locales participen activamente en el futuro 193 Una representación de una vaca de de la ciudad fomentando la idea de que «Dumfries es lo que todos hacemos juntos» (The Stove, 2015). cristales de sal símbolo del ganado y de di- Coincide con la marea más alta del año, y los veleros parten de Carsethorn a veintiún kilómetros río cho condimento, productos básicos que se abajo. Antes de la carrera, la escultura de la Salty $\mathrm{Coo}^{193}$ desfila por la ciudad y espera en la meta a los
comercializaron en el pasado a lo largo del ganadores, que tendrán posteriormente el derecho a sumergirla en el Nith. Nith.

194 Por ejemplo en 2015 fue la aceptación a cargo de Dillon Colthart y Jordan Chisholm; 2017 la relación con los vikingos.

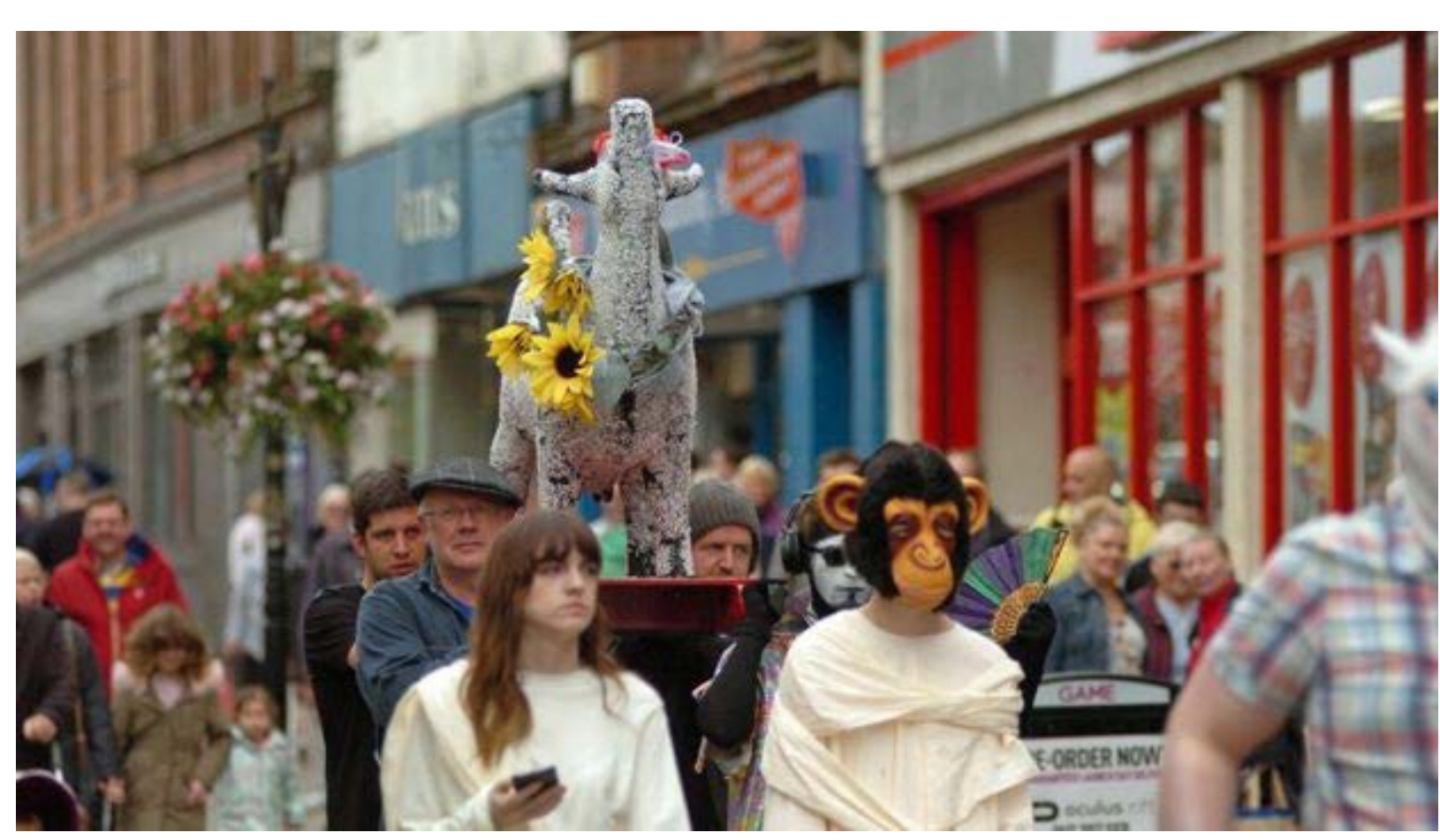
Imagen 56.2016.
201

Cada año el festival se centra en un tema ${ }^{194} \mathrm{y}$ la puesta en escena del desfile es encargada a un grupo distinto de creadores.

La función de los artistas, en este caso, es la de imaginar y plantear otros futuros, y facilitar una nueva conexión de los habitantes con el Nith y con el espacio público natural de un modo participativo. El arte contribuye a crear una historia compartida, una nueva tradición que algunos comienzan a creer centenaria. Trabajan con el espacio común para unir en lugar de separar aunque para ello propongan una rendición que ceda el área que le corresponde a la riada. La carrera reúne cada año a más participantes alrededor de la ribera, y poco a poco está tejiendo una nueva conexión entre la población y el agua, invitando a una modificación de los hábitos sociales.

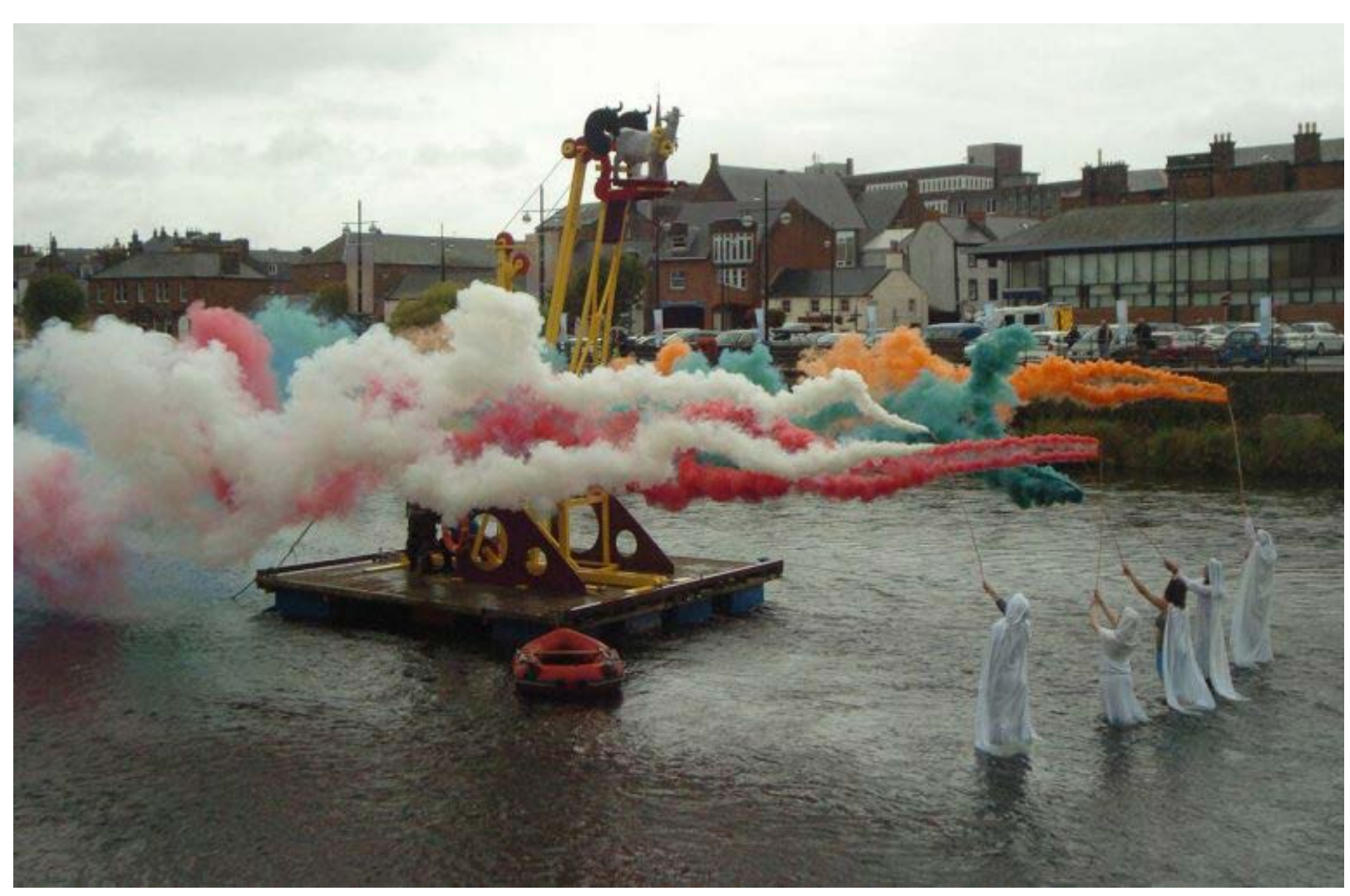

Imagen 57. Parte del desfile de la Salty Coo. Fuente: Kirstin McEwan, 2016. 

ción es fundamentalmente de dos tipos: por un lado, los habitantes son invitados a desarrollar juntos la visión del futuro de la ciudad y participan en su codesarrollo con sus relatos (tipo dos). Por otra parte, la obra final es compartida en formato de publicación física y digital (tipo cuatro).

Aunque carecemos de datos concretos de las seis ediciones de Nithraid, podemos decir que en general, la participación ha aumentado de 2.000 (2013) a 4.000 (2017) participantes (The Stove, 2015). Durante las seis ediciones The Stove ha invitado al público a participar en todas las fases de esta obra de arte público, como ellos mismos la califican. Desde la implicación en la procesión o la carrera, a la construcción de escenarios, creación y diseño de los elementos estéticos asi como en los talleres del día de la carrera. De esta manera, la colaboración en la $\mathrm{N}$ thraid es más variada que en We Live With Water abarcando todos los tipos, del dos al seis. En cuanto al tipo de participación dos (colaboración y codesarrollo), cada año el tema del festival y la dirección artística del desfile se encarga a artistas locales, en especial jóvenes que inician sus carreras profesionales, dándoles la oportunidad de crecer laboralmente. Así, en 2017 siendo el ema central la cultura vikinga, el colectivo de artistas locales de clown Moovement Coollective (MooCoo) acompañó a los artistas Longfada Viking Group que exploran la antigua presencia vikinga y la influencia cultural nórdica histórica y actual en Dumfries \& Galloway.

Juntos procesionaron la Salty Coo a través de la ciudad fusionando la cultura vikinga con la sensibilidad de los payasos para crear un espectáculo interactivo con los espectadores, que combina la herencia cultural y la payasada. El objetivo es desafiar la imagen popular de los vikingos como invasores sangrientos destacando su larga coexistencia pacífica en la zona (Anderson, 2017).

Imagen 58. La Salty Coo
Kirstin McEwan, 2017.

También invitan a artistas cercanos a la filosofía del acto a mostrar y compartir sus obras en talleres previos y durante elfestival. Un ejemplo es el de la artista invitada Kathy Hinde que expuso su obra Luminous birds en el marco del festival 2016, cuyo tema central eran las migraciones. La muestra se acompañaba de una obra colaborativa y tres talleres artísticos.

En cuanto a la siguiente clase de participación (voluntarios y ejecutores), los numerosos voluntarios (alrededor de cuarenta en 2017) son parte imprescindible en la organización. Cad año se realiza un Ilamamiento al que personalmente acudimos durante el curso de esta investgación en 2016. Pero, la participación que persigue The Stove principalmente es la del tipo cuatro, el público inmediato. De los 31.000 habitantes de la ciudad, cada año acuden alrededor de 4.000 personas para ver a los barcos ganadores cruzar la linea de meta y disfrutar del ambiente familiar y festivo.

II

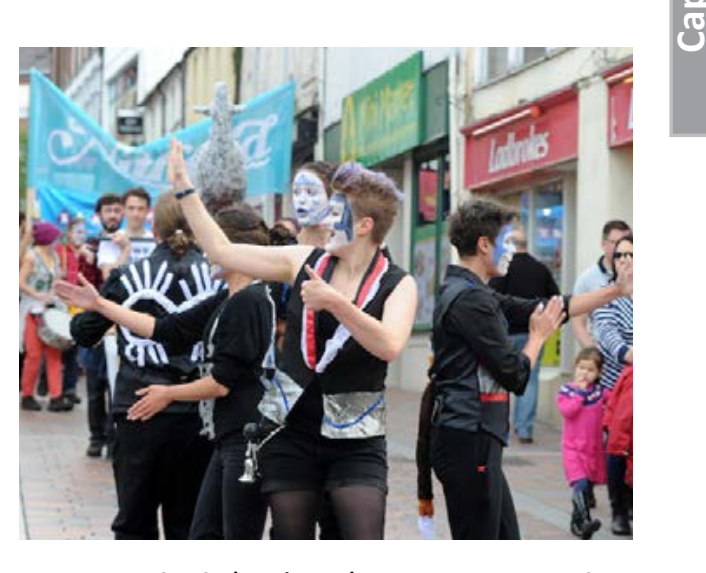

Imagen 59. Colectivo de payasos Moocoo liderando la procesión de la vaca salada
en Nithraid 2017. Fuente: Kirstin McEwan,
2017. 
195 Como por ejemplo véase: http://www.
bbc.com/news/uk-scotland-south-scotbbc.com/news/
land-41202807

196 El Consejo Dumfries \& Galloway Council

El público de los medios de masas sigue las noticias al respecto a través de periódicos ${ }^{195}$ y we

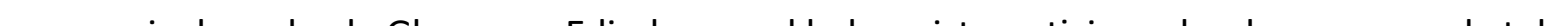
197 La fundación benéfica Barfil Charitable colectiva de la región y algunos confunden esta nueva festividad con una tradición centenaria. Trust y Holywood Trust, organización benéfica que financia prácticas de trabajo en The Stove para dar oportting

\subsubsection{Puntos de tensión y puntos clave}

198 The People's Project es una ONG creada en 2008 por Mark Jardine para reactivar Galloway Desde 2005 colad en Dumfries la opinión pública la oportunidad de decicon parte de los presupuesustos de la Lotería Nacional. Las subvenciones van desde 5.000 hasta 50.000f. Véase en: https://www.thepeoplesprojects.org.uk/

Los proyectos de The Stove se centran en cinco áreas clave: Visión de futuro, alimentación Lestadiadas responden a la primera idea y Nithraid incluye también lo visual, la alimentación y la música (The Stove, 2015). Tanto los tenderetes e comida durante la Nithraid como su café sin ánimo de lucro durante el año, son importantes ara atraer al público y crear un lugar de encuentro y por ello se encargó la cafetería a las artistas de Open Jar Collective.

Otro punto fundamental en todo proyecto es la financiación. En el caso de Nithraid es

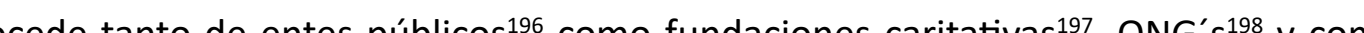
pã́as privadas de la zona qu panías privadas de la zona que apub 550.000 f de finacion $550.000 \mathrm{E}$ de financiacion públca nacional al margen de la privada, lo cual supone un empuje importante tanto para los proyectos, como para la economía de los artistas y la región. El 31\% de las subvenciones obtenidas, se dirige hacia trabajos artísticos y negocios locales y ese porcentaje crece año tras año. De esto se deduce que la relación con las instituciones es fluida aunque exista desacuerdo en el desarrollo urbano. Destacamos las oportunidades laborales remuneradas que ofrecen a jóvenes artistas y la valoración económica del trabajo creativo que realizan. No obstante, el trabajo voluntario de artistas involucrados también es común, sobre todo en el equipo de comisariado.

Algunos puntos clave que diferencian esta celebración como obra de arte público de cualquier otra carrera de barcos - además de la implicación de los habitantes en el proceso de dise- ño y ejecución - son: la organización del desfile por artistas diferentes cada año, las actuaciones performances organizadas en torno a la llegada de la Salty Coo a la zona de Mill Green y sentimiento ritual que cubre la experiencia. El hecho de sumergir la escultura en las aguas de mano de la tripulación ganadora como símbolo de reconocimiento del Nith, es el momento más intenso de la festividad. La estetica y el ritual establecido por los artistas potencian la simbología del acto. Sin embargo, existe cierto desfase entre los valores éticos profundos de respeto a la naturaleza ( $y$ en concreto al rio) que subyacen en el acto, y por otro la materialización estética, que es muy mejorable en cuestión de huella ecológica ${ }^{19}$.

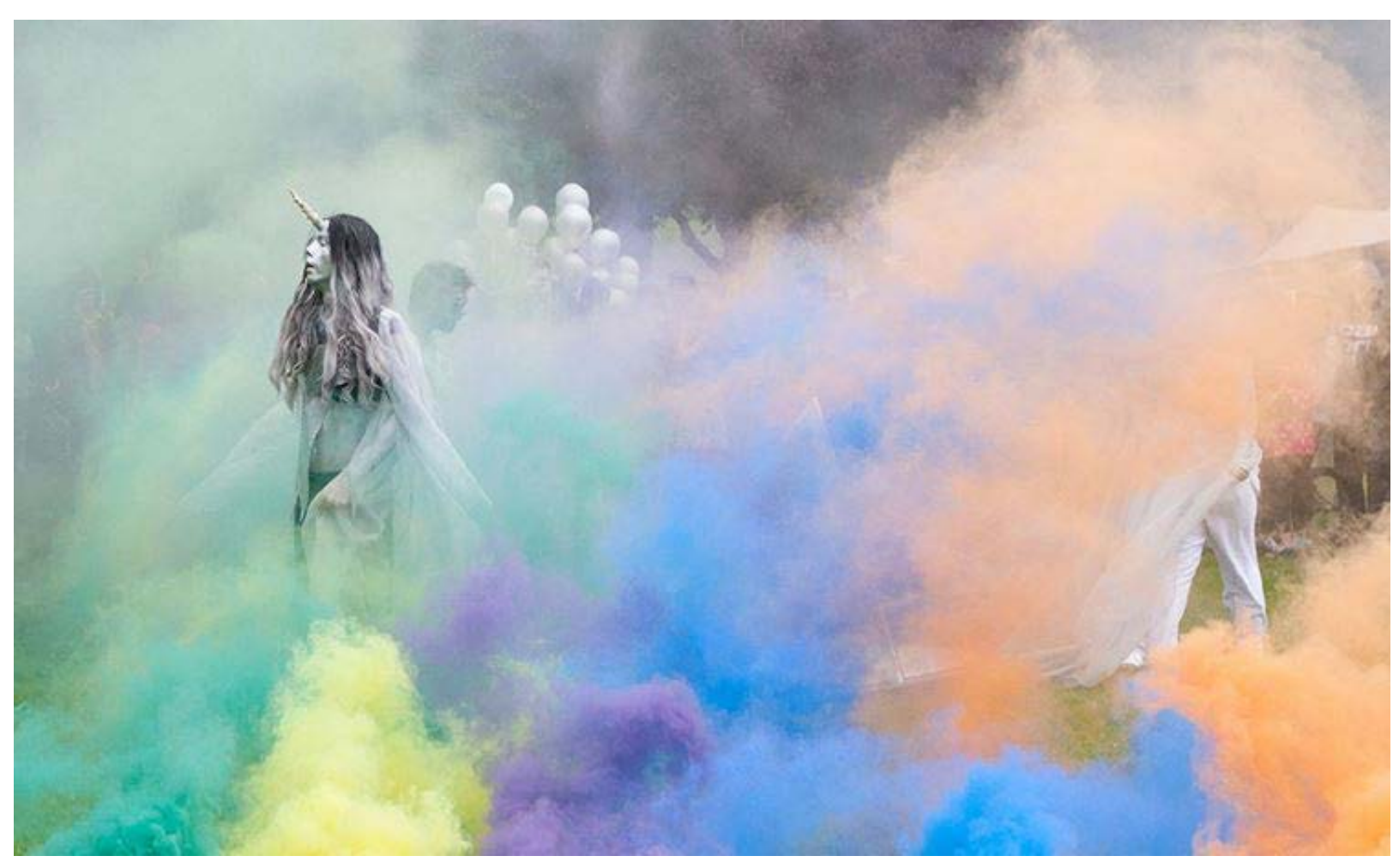

Imagen 60. Performance en Mill Green a la llegada de la Salty Coo. Fuente: Colin Tennant, 2015

Las tensiones preexistentes en el territorio son la motivación que da sentido a ambas propuestas artísticas. En primer lugar, la oposición al río por parte de los negocios de la zona urbanizada de la llanura de inundación, secundada por el equipo municipal, que apoya un modelo de

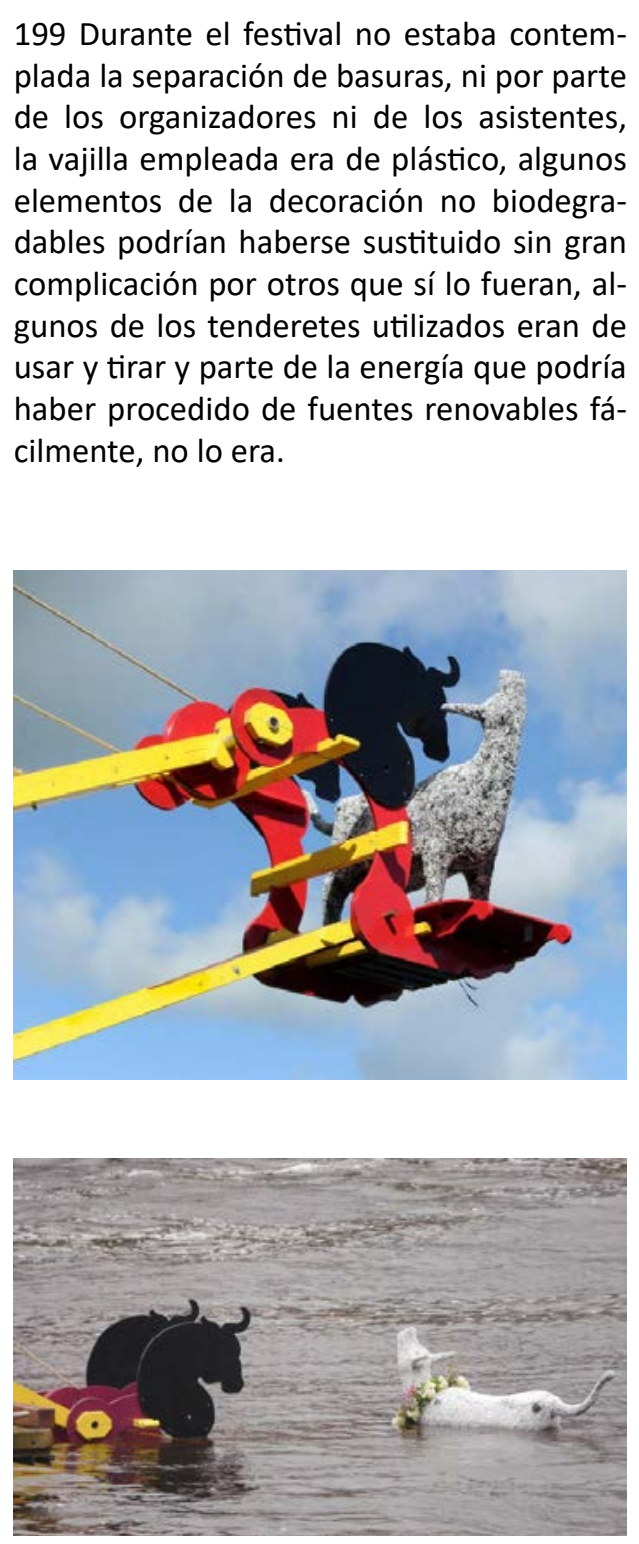

Imágenes 61 y 62 . Inmersión de la Salty Coo
en el Nith a coro de la triplucaión ganadoen el Nith a cargo de la tripulación ganado-
ra. Fuente: Colin Tennant 2015 . 
200 Sus objetivos son: «Utilizar las artes urbanismo y vida en desequilibrio con la realidad del entorno actual y del cambio climático. Es ar si mismos, y los lugares en que viven y un ejemplo de esa ceguera narcisista y autocomplaciente que mencionamos en el capítulo tres. la sociedad en general. Ser abierto e inclusi- En lugar de buscar la cooperación con el río, el Ayuntamiento adopta una postura de superiori-

vo, ofreceienno onortunidades prácticas para
la participación en actividades creativas. Ser inquisitivo y arriesgado, sin miedo a ser diferente. Ser transparentes $y$ colaborativos
en la forma en que trabajamos, aportando trabajo creativo que sea desafiante $y$ que incluya la calidad en el proceso así como en
el producto» (The Stove, 2015). Definen el el productor' (The Stove, 2015). Definen el
arte público como todo lo anterior, utilizando cualquier forma de práctica creativa en 201 Aunque The Stove no exprese intencio-
nes ecológicas, resulta curioso que los artis nes coologicas, resulta curioso cue los
tas como kathy Hinde y provectos invitados tas como Kathy Hinde y proyectos invitados
(Maklab e Incredible edible) en 2016, si manifiestan ese interés (comunica,
nal, 3 de septiembre de 2016).

censión surge en contra de a a rerior a que ejercen los artistas y habinntico. Una segunda

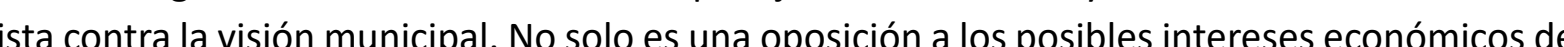

Ay contravision municipal. No solo es una oposición a los posibles intereses economicos del

Ayuntamiento, sino oposición al modelo de desarrollo capitalista y la organización urbana que de estos artistas no es trabajar contra la resistencia del río sino entenderla como un hecho interesante por sí mismo. Las crecidas anuales, lejos de ser vistas como un problema, se tratan as como una oportunidad. Es una postura mucho más resiliente pues, más allá de la adaptación propone aprovecharlas para crear energía, fertilizar los campos, remodelar el paisaje y ser motor de construcciones escultóricas.

Un tercer conflicto relacionado con los anteriores al que tratan de hacer frente desde The Stove es el abandono del centro de la ciudad como lugar de encuentro y disfrute del espacio promueve (Baker, 2015). Como mencionamos en el apartado uno del capítulo tres, la propuesta público, por los centros comerciales privados. De ahí su elección de situarse en el corazón de problema, el centro de la ciudad. El desfile de la Salty Coo y la carrera del Nith son una búsqueda por recuperar espacios de convivencia y por crear momentos de reunión.

\subsubsection{Intención}

La experiencia de The Stove con EAFS y Submerge sugiere cierto direccionamiento hacia metas de transición ecosocial. Sin embargo, en sus objetivos colectivos ${ }^{200}$ The Stove no se plantea cuestiones ecológicas directamente. De hecho, ninguno de los artistas entrevistados vinculados al proyecto directamente afirma focalizar su producción en el arte ambiental o arte ecológico, aunque ya comentamos que sí declaran interés en la justicia ambiental201. Resulta interesante ver cómo de un modo inconsciente, las circunstancias ambientales y sociales actuales han conducido su visión de Dumfries hacia objetivos más en consonancia con la transición ecosocial de lo que se planteaban inicialmente. En su desarrollo tienen en cuenta seguir ciertos principios éticos de respeto al medio ambiente y consideración de la huella ecológica, aunque on mejorables según lo observado.

En cuanto a la intención de Submerge, coincide con las primeras fases de las iniciativas de transición vistas en el capitulo tres: el desarrollo de la visión colectiva. El proyecto explora las posibilidades de adaptación a las nuevas condiciones del río y su nivel en el futuro. El conjunto de relatos producto de estas jornas es visionario pero no lo suficientemente realista como de re haber sido tomado en serio. No obstante ya hemos comentado la imporia como vara haber sido toma do serio. No obstante ya hemos comentado la importancia de estas visiches pa a a lo

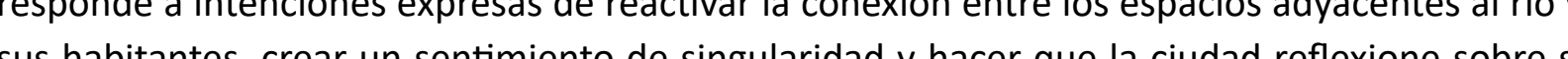

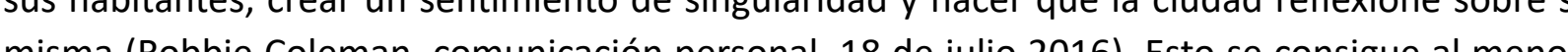
misma (Robbie Colen en esta fecha señalada en la que acuden más de 4.000 personas. Sin embargo, los resultados

\subsubsection{Efectividad}

En cuanto a los efectos inmediatos de We Live With Water podemos apuntar que todo quedó en una anécdota política sin mayor repercusión ${ }^{202}$. A medio o largo plazo no hemos detectado otras consecuencias por ahora, pero el proyecto continúa siendo válido como maqueta y visión que dirija la actuación pública a la espera de un equipo de gobierno que tome más en y visión que dirija la actuación pública a la es
serio sus propuestas de rediseño urbanístico.

El proyecto Nithraid es tan amplio y participan tal diversidad de personas a distinto grado de implicación, que sería muy difíil evaluar exactamente los efectos. Por ello, para poder estude implicación, que sería muy dificil evaluar exactamente los efectos. Por ello, para poder estudiar mejor la función de The Stove y de Nithraid visitamos la población en dos ocasiones (julio septiembre de 2016). Durante nuestra segunda visita participamos en el equipo de voluntario de la Nithraid y pudimos entrevistar a otros compañeros y habitantes de Dumfries, pero en un es que a ninciento es que, a nivel inmediato, el festival esta adquiriendo notoriedad año tras año y los habitantes
acuden y participan en este día festivo. Sin embargo a medio o largo plazo los testimonios que
202 El miembro del parlamento inglés Ri-
chard Arkless visitó Dumfries en diciembre de 2015 para inspeccionar las secuelas de Durante su visita recogió una copia de We live With Water para llevar al Parlamento de seguirm para la coundad pero no ha llegado
más allá (Baker, 2015). 
recogimos no apuntaban a un cambio positivo en su relación con ese entorno concreto más allá de ese día del año. El hecho de que cada año el desfile, las actuaciones y performances sean ncargadas a artistas diferentes despierta la curiosidad de los asistentes motivándoles a repeti al año siguiente. De este modo The Stove crea un espacio y un momento de relación intensa con el río a largo plazo. Aunque el impacto es de corta duración, tiene continuidad y mediante esa constancia, año tras año construen una tradión. Los efectos en el cambio de actitud de la población con respecto al río aún no se han medido pero se podría proponer la realizació de una encuesta a los asistentes cada año, que pudiera verificar si existe un cambio o no a largo plazo en sus comportamientos.

\subsubsection{Estética y ética}

En ambos proyectos residen valores éticos de respeto a la naturaleza, equilibro ecosistémico y rechazo al antropocentrismo que consideramos en esta investigación como parte de los valores estéticos. Dentro de esta atmósfera de respeto por el entorno natural (incluso en detrimento del urbano), comprobamos - tras la vivencia como voluntaria y asistente a la Nithraid - que no se corresponde tanto con valores ambientales como con objetivos de índole social. Observamos que los artistas no expresan ningún mensaje explíito, ni tienen intención de concienciar al público asistente. Más bien se ocupan de crear un marco de trabajo, un espacio relacional que atraiga el interés y deje surgir el diálogo entre los asistentes libremente. En las conversaciones que entablamos con algunos voluntarios, comprobamos que no enlazan los problemas interrelacionados del urbanismo, las crecidas, el modelo económico de desarrollo y el cambio climático en Dumfries, aunque no se ha realizado al respecto un estudio profundo. La festividad no parece despertar ningún movimiento en las conciencias en favor del río por ahora, pero al ser una actividad familiar, es posible que el mensaje cale en los más jóvenes y éstos tomen posiciones en el futuro.

La imagen del acto juega con la simbología y la tradición evocando una atmósfera ritual en momentos puntuales que emociona al espectador. La vaca es un animal espiritual que simboliza la abundancia, la fertilidad y la riqueza en varias culturas antiguas, desde Egipto hasta La India, y también, en la mitología del Norte de Europa. Sin embargo, en este caso su elección responde al pasado comercial del río y no tanto a la mitología. Aunque el colectivo de artistas MooCoo en 2017 la han relacionado de modo sarcástico con el ser mitológico nórdico Auõumbla 203 . La estetica de dicha escultura varia cada año en fur la pieza en si por un lado y por el otro, su banorituaten las aguas a argo de los vencedor carga de significado simbólico.

\subsubsection{Funciones del arte}

Considerando ambas obras analizadas como complementarias, la principal función del arte en este caso es la de (re)conectar personas y espacios (el Nith y sus alrededores) y fomentar una nueva articulación de la vida urbana de Dumfries. Hasta aquí hemos visto proyectos que fomentan la relación entre personas o grupos pero no entre personas y elementos concretos fomentan la relacion entre personas o grupos pero no entre personas y elementos concretos
del entorno, considerados con derecho propio por encima de las necesidades humanas. Aunque Dumfries comparte con Almócita la problemática social de la despoblación - del centro de la Dumfries comparte con Almócita la problemática social de la despoblación - del centro de la
ciudad en este caso- su enfoque se centra más en promover un cambio de actitud en las perciudad en este caso- su enfoque se centra más en promover un cambio de actitud en las personas, que conlleve a posteriori los
hemos detectado son las siguientes:

\begin{tabular}{|l|l|}
\hline $\begin{array}{l}\text { FUNCIONES DE LAS OBRAS } \\
\text { WE LIVE WWTHH WATER Y } \\
\text { NTTHRAD }\end{array}$ & \\
\hline $\begin{array}{l}\text { llustrar, representar, } \\
\text { comunicar, difundir }\end{array}$ & $\begin{array}{l}\text { Si, se busca comunicar una nueva visión de futuro, representar el } \\
\text { pasado comercial del río y difundir las actividades de The Stove. }\end{array}$ \\
\hline Concienciar & No especialmente. \\
\hline Desarrollar empatía & Si, se pretende empatizar con el río y sus espacios. \\
\hline $\begin{array}{l}\text { Imaginar, desarrollar la visión } \\
\text { del grupo, su misión, futuros } \\
\text { posibles, utopias o ficciones }\end{array}$ & $\begin{array}{l}\text { di, el proyecto We Live With Water es una visión cocreada del futuro } \\
\text { de Dumfries en 2065. }\end{array}$ \\
\hline
\end{tabular}




\begin{tabular}{|c|c|}
\hline $\begin{array}{l}\text { Ofrecer soluciones, mostrar } \\
\text { alternativas reales o } \\
\text { proyectos piloto, laboratorios } \\
\text { de pruebas } \\
\end{array}$ & $\begin{array}{l}\text { Sí, We Live With Water plantea un nuevo rediseño urbano con } \\
\text { numerosas ideas para reactivar el núcleo del municipio. }\end{array}$ \\
\hline $\begin{array}{l}\text { Conectar personas, crear } \\
\text { comunidad, hacer, redes, } \\
\text { mediar o facilitar }\end{array}$ & $\begin{array}{l}\text { Sí es uno de los retos principales de The Stove en Dumfries, } \\
\text { dinamizar el espacio público del centro de la ciudad. }\end{array}$ \\
\hline $\begin{array}{l}\text { Restauración/recuperación } \\
\text { del entorno }\end{array}$ & $\begin{array}{l}\text { No directamente aunque sería un resultado derivado del proyecto } \\
\text { We Live With Water si llegara a realizarse. }\end{array}$ \\
\hline $\begin{array}{l}\begin{array}{l}\text { Reforzar la identidad, crear } \\
\text { símbolos }\end{array} \\
\end{array}$ & $\begin{array}{l}\begin{array}{l}\text { Sí, tanto la vaca salada, como la temática anual y la propia } \\
\text { celebración, contribuyen a crean una simbología y una identidad. }\end{array} \\
\end{array}$ \\
\hline $\begin{array}{l}\text { Fomentar la ciudadanía } \\
\text { crítica, agitar, denunciar }\end{array}$ & $\begin{array}{l}\text { Sí, el proyecto We Live With Water sobre todo, anima a tomar una } \\
\text { perspectiva crítica con respecto a las decisiones del Ayuntamiento } \\
\text { sobre las inundaciones. }\end{array}$ \\
\hline Empoderar & $\begin{array}{l}\text { No en estos proyectos concretos, pero sí en otros proyectos de The } \\
\text { Stove. }\end{array}$ \\
\hline $\begin{array}{l}\text { Crear relatos positivos de } \\
\text { cambio }\end{array}$ & 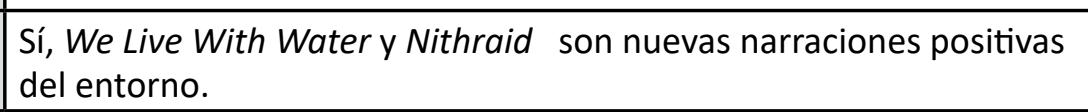 \\
\hline $\begin{array}{l}\text { Facilitar la comprensión del } \\
\text { mensaje de la ética ecológica } \\
\text { aplicándola }\end{array}$ & No. \\
\hline $\begin{array}{l}\text { Conectar áreas alejadas de } \\
\text { conocimiento }\end{array}$ & No. \\
\hline $\begin{array}{l}\text { Motor iniciador de un } \\
\text { proyecto }\end{array}$ & Sí, The Stove busca activar el centro de la ciudad. \\
\hline Celebrar & $\begin{array}{l}\begin{array}{l}\text { Sí, la celebración es la motivación que reúne a la población en torno } \\
\text { al rio en la Nithraid. }\end{array} \\
\end{array}$ \\
\hline Recaudar fondos & No. \\
\hline Construir consensos & Sí, se busca virar la actitud de la población al respecto del río. \\
\hline Premiar, agradecer & $\begin{array}{l}\text { Sí en el sentido de que se celebra al río y sus inundaciones como algo } \\
\text { positivo, algo que celebrar. }\end{array}$ \\
\hline $\begin{array}{l}\text { Conectar personas con } \\
\text { espacios, entornos o lugares }\end{array}$ & $\begin{array}{l}\text { Sí, es el objetivo fundamental de la carrera por el Nith estimular la } \\
\text { relación de los habitantes con su ribera. }\end{array}$ \\
\hline
\end{tabular}

Tabla 7 . Funciones del arte identificadas por la autora. Fuente: elaboración propi.
Si analizamos el proyecto desde los diez principios del transitional art vistos en el capítulo uno apartado 2.3, se detecta que responden a la mayoría:

1. Intención: Sí, existe una intención de reactivar el centro urbano de Dumfries que llam a a la actuación y transforma las perspectivas de inundación del futuro en una nueva realidad.

2. Ignición: No, el proyecto de Nithraid inspira el proyecto de We Live With Water dentro del marco del ArtCOP21 pero aún no se ha pasado a la acción en la remodelación urbana.

3. Marco: Sí, los artistas delimitan con We Live With Water un marco de actuación: el presente y futuro del rio y de la ciudad con respecto al cambio climático y dentro del contexto de la sociedad de consumo.

4. Trabajar con la comunidad: Sí, se trabaja con, por y para los habitantes en la ceremonia festiva.

5. Mediación: Sí, los artistas actúan de facilitadores de una nueva relación con el agua y con el espacio del río.

6. Mantener un espacio: Sí, el mantenimiento de su sede en el número 100 de High Street es crucial para sus intenciones de dinamizar el centro de Dumfries pero también lo es la celebración, año tras año, en The Mill Green, a las orillas del río. La reclamación de estos espacios de llanura de inundación para el disfrute ciudadano compamacion de devolución al río focaliza y materializa sus objetivos.

7. Conexión: Sí, mediante la carrera anual del Nith, pretenden conectar a la población con el torrente creando una nueva tradición compartida.

8. Trabajar desde lo común: Sí, trabajan con el espacio público común para unir, aunque para ello propongan una rendición que ceda la llanura de inundación. 
9. Colaborar: Sí, la colaboración en la Nithraid es fundamental y numerosos voluntarios oman parte en la organización

10. Cambio: Sí, el cambio de actitud que proyectan en We Live With Water y Nithraid es solo una invitación sutil pero la constancia puede favorecer sus efectos a largo plazo.

Resulta llamativo que, a pesar de cumplir casi todos los principios del arte transicional, ninguno de los artistas entrevistados de The Stove (Robbie Coleman, Jan Hoggarth y Matt Baker) considera su obra como arte ecologico o transitional art (comunicación personal, 18 de julio de 2016). Sin embargo, tienen claro que sus acciones se pueden describir como arte público ya que el carácter participativo y la coautoría son sus principales características. Este modo de construir una festividad juntos, en lugar de ofrecerla como un proyecto prediseñado del Ayuntamiento, ofrece la oportunidad a los participantes de activarse en la vida pública de Dumfries, lo cual es el objetivo principal de The Stove. De manera que esta celebración, no podria darse de otro modo que no fuera colaborativamente. La participación es, pues, a la vez objetivo y herramienta

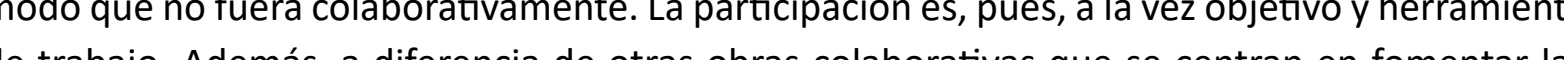

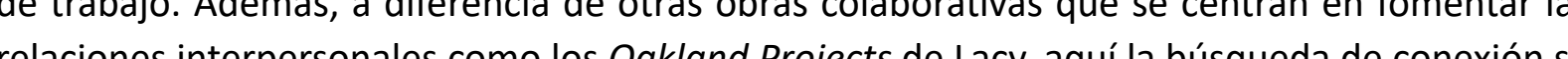
expande a las personas con su entorno fluvial con un ente inanimado pero dinámico, elín.

Según lo visto aquí, observamos que la actividad de estos artistas ejerce un papel de liderazo de la vida cultural de Dumfries. Además The Stove crea espacios y momentos de participación activa para que la comunidad se reconstruya y, en ese sentido, contribuye al fomento de la cooperacion de la qu hablamos en el tercer capitulo. Como ejemplo, solo en su prir levaron a cabo noventa y cuatro actividades entre talleres improvisaciones, conciertos, exposiciones y conferencias por las que

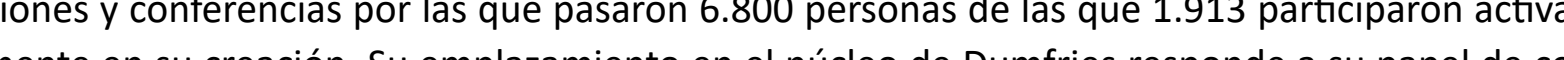
y no hemos encontado ninún sisto y no hemos encontrado ningún sistema de medición aplicado hasta ahora. Del mismo modo, se las propuestas para as artes escénicas por Julie's Bicycle, y de las que ya hemos hablaco. propuestas para las artes escénicas por Julie's Bicycle, y de las que ya hemos hablado.

Al respecto de la aportación de esta obra a la sostenibilidad, podemos aplicar la reflexión Haley, que resalta la importancia de hacernos las preguntas correctas a la hora de establecer nuestros objetivos de transición. Como primer paso sugiere cuestionarnos, conocer y tener cla-
Tue es a un nivel más profundo lo verdaderamente contrario a la sostenibilidad. Cita varios ejemplos:

«¿́Lo contrario de protección puede no ser vulnerabilidad, sino defensa?:Lo contrario de determinación puede no ser debilidad, sino evolución?:̇ Lo contrario de economía de mercado puede no ser pobreza y hambre, sino justicia socialic contrario de autonomí puede no ser dependencia, sino colaboración? ilo opuesto

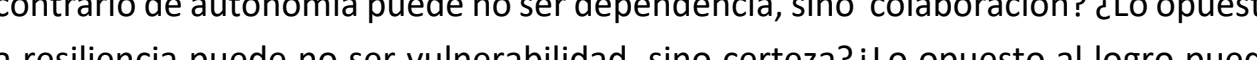
cor

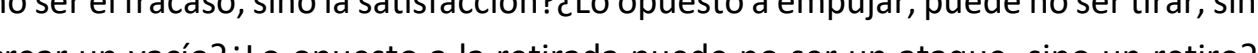
chear un vaclo? llo opuesto a betirada prede no ser un ataque, sino un retrozs

Stove no es una utopía sino toda una realidad en por ejemplo, el condado de Pierce El río Puyallup que había sido rectificado y aislado con barreras arquitectónicas en el siendo objeto de un proceso de restauración ecológica. Hoy en día el gobierno del
condado está comprando terrenos ribereños para devolver al río las zonas de inundación propias

Estos puntos serían de aplicación a ambos proyectos estudiados. La visión de los artistas 作 luchar contra las fuerzas del río, sino facilitarle el paso para su crecida a so una fies. Asumir a a so una fiesta. Asurirán acen cios y apacan negocios y aparcamichos que ocupan la zona de inundación de $\mathrm{N}$. Es una actiud de resiliencia

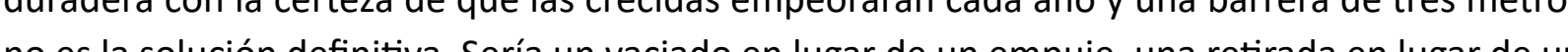

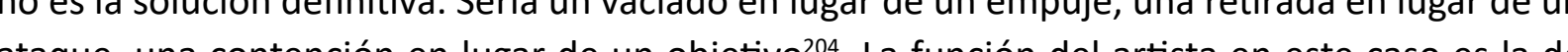
ataque, una contención en lugar de un objetivive04. La función del artista en este caso es la de imaginar y plantear otros futuros posibles, soluciones altemativas. Esta visión de retirada voluntaria y resiliente contribuye a cambios en el paradigma de nuestra relación -eminentemente dominante en occidente-con la naturaleza. Crear comunidad en armonía con su entorno es la respuesta de The Stove ante los futuros retos del cambio climático. 
205 Que ya definimos en el capitulo uno
apartado 1.2. (nota 23). 206 En adelante lo mencionaremos por
sus siglas en inglés: Dundee Urban Orchard
(DUO).

\section{ESTUDIO DE CASO: DUNDEE URBAN ORCHARD}

4.1 EL ARTE EN LA CONSTRUCCIÓN DE RESILIENCIA Y FUTUROS ALTERNATIVOS

Uno de los pilares principales de la transición es el aumento de la resiliencia 205 mediante e fomento de la diversidad, de lo local y lo colectivo. Como veiamos en el capitulo tres, la acción comunitaria que parte del propio contexto facilita la creación de referencias cercanas y una identidad compartida, que ayude a afrontar los grandes retos ambientales superando la anomia, la desafección y la indiferencia. Esto exige grandes dosis de creatividad, complicidad y capacidad de visión comunitaria a largo plazo, que el arte puede facilitar. Respecto a la visión, en los estudios de caso anteriores (The Stove, Trashcachers' Carnival), subyace la capacidad del arte de visibilizar lo intangible, ya sean emociones, deseos, relaciones o futuros imaginarios. Así mismo, hemos resaltado el poder de convocatoria del arte y la capacida de implicar a púb co en el proceso creativo. Todos estos factores se presentan en el proyecto Huertos urbanos de Dundee 206 realizado por los. Todos Sarah Gittins y J (World porvenir de la local Re lo sino que superan el

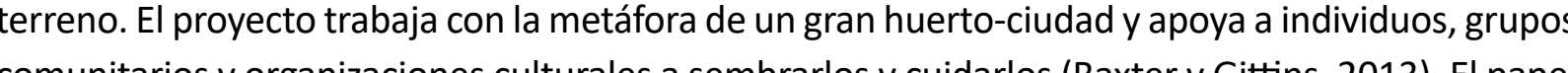
comunitarios y organizaciones culcurales a sembrarlos y cuidarlos (Baxtery Githin, 2013). El pape de Gittins y Baxter ha sido fundamental como motores y mediadores en el proceso, pero, no más mantenidos por la comunidad dispersos en el espacio público fundamentalmente. Los artistas favorecen asi la conexión entre personas e historias que de otra forma no tendrían relación, dando fuerza a una iniciativa colectiva de resiliencia, de cambio positivo, diversa y descentralizada.

\subsection{ADECUACIÓN A LOS CRITERIOS DE SELECCIÓN DE LA INVESTIGACIÓN}

Hemos elegido el caso de DUO por cumplir nuestros criterios de selección señalados en el capítulo dos apartado 1 , como se indica a continuación:
1. Proyectos que tengan una vinculación espećífica con lo local: Al igual que en el caso de The Stove, Baxter y Gittins buscan reactivar los espacios públicos de la localidad ubicando en ellos acciones antisticas colabricion. Especial atencion prestan a las biblotecas,

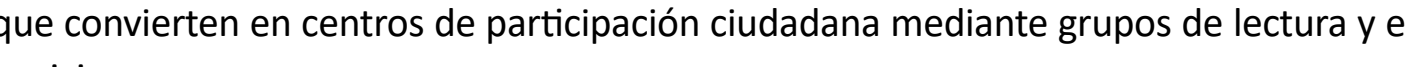
posiciones.

2. Obras que actúen (consciente o intuitivamente) de acuerdo con los principios de la transición. Aunque $D U O$ no se define como un colectivo de arte transicional ni enfocado arte ecológico en particular, demuestran acuerdo con:

Descarbonización de la economía:

- Proponen un modelo de ciudad alternativo a la corriente capitalista con un enfoque particular en la sostenibilidad de los alimentos. Fomentan la concienciación del público sobre el origen de los alimentos, su traslado a miles de kilometros y su empaquetado excesivo, y proponen una alimentación de kilometro cero y una recuperación de nuestra conexión directa con el planeta, y otras personas, a través del cultivo comunitario.

Compromiso del movimiento ambiental con la equidad y la justicia:

- DUO está comprometido con la planificación a largo plazo para un futuro sostenible y equitativo en Dundee (Baxter y Gittins, 2013). En sus performances la justicia social ambiental están representadas por sendos dragones, inspirados en el Escudo de Armas de la ciudad y realizados en sus talleres creativos. Según declaran, «la justicia social y la justicia ambiental, son los fuegos gemelos que animan DUO» (Baxter y Gittins, 2013). El desafio de la conservación:

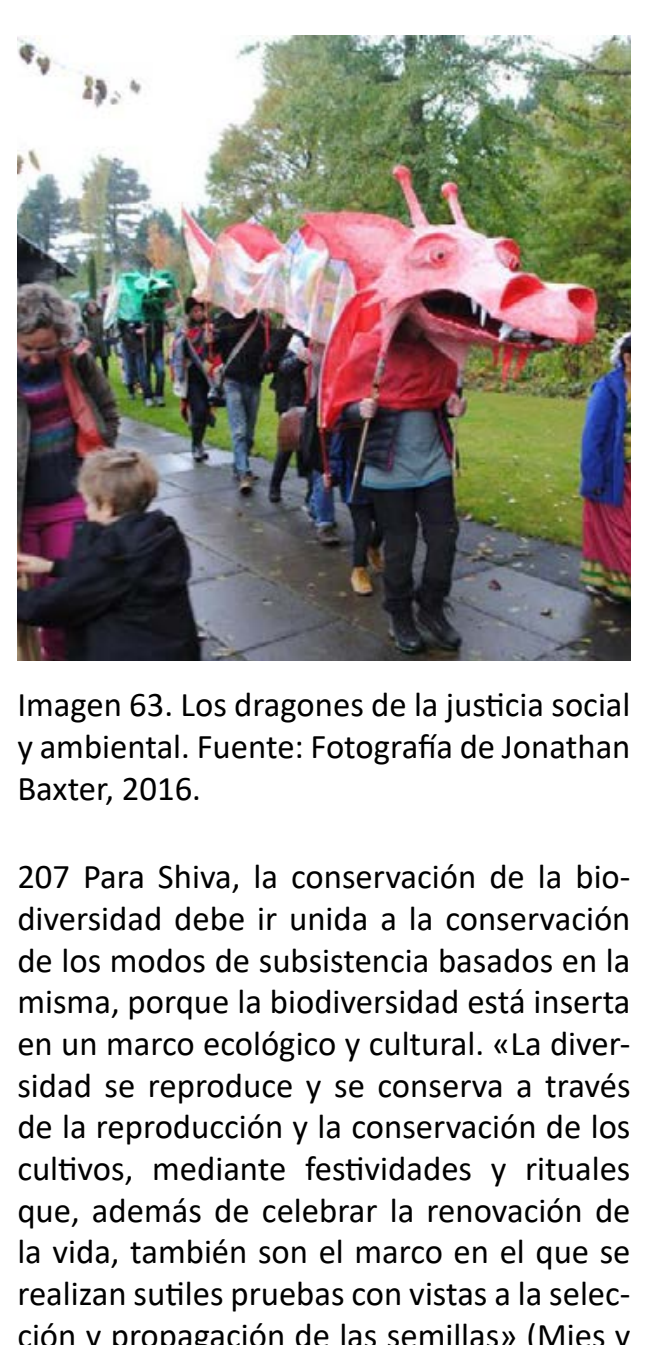

- Uno de los objetivos declarados de DUO es la mejora de la diversidad biológica y cultura de Dundee. El concepto de biodiversidad de Vandana Shiva ${ }^{207}$ es una inspiración para e proyecto que les ratifica en la relación de la misma con la cultura y la necesidad de proteger ambas.

3. Que hagan uso del arte como herramienta de fomento de la transición y, en especial, del arte público: La participación a través del arte es el eje de muchos de sus proyectos y clave en el desarrollo de $D U O$ como veremos más adelante. 
5. Ocuparse de cuestiones relacionadas con la ecología y/o la transición: Los artistas cumplen muchos de los criterios del arte ecológico señalados en el capítulo 1 apartado 2.3. y consid a DuO co co unsumo ético, el fomento de lo local, de lo colves temas principales que les conectan con la cransicion. pendencia de los seres y sistemas, y la defensa de la dusticia socialy a mbiental. Entienden la importancia de la diversidad social y ambiental y aplican las ideas de Vandana Shiva a y guardan, como veremos, una postura altamente crítica con los modelos de desarrollo capitalista.

\subsection{ORÍGENES, OBJETIVOS Y DESCRIPCIÓN DEL PROYECTO. LA CIUDAD HUERTO} El artista, el poeta, es un cultivador de grietas.

$$
\text { (Novo, 2009, p. 108) }
$$

El nacimiento de DUO está relacionado con el interés de estos artistas por los espacios comunes como las bibliotecas, amenazadas de desaparecer en su contexto. Para apoyar el uso de dichas estructuras púbicas y fomentar uncuestionamiento que avive la participación civica, organizan dos tipos de actividades. Por un lado, grupos de lectura -sobre arte, espacio cívico, poesía, etc. - abiertos a toda la población y por otro, un programa expositivo con performers, cantantes e instalaciones entre otras propuestas. Con ello consiguen un doble objetivo: sacar el arte fuera del cubo blanco e introducirlo en el espacio público para dinamizarlo. Es, en este marco de conversación y lectura, donde se planta el germen de DUO.

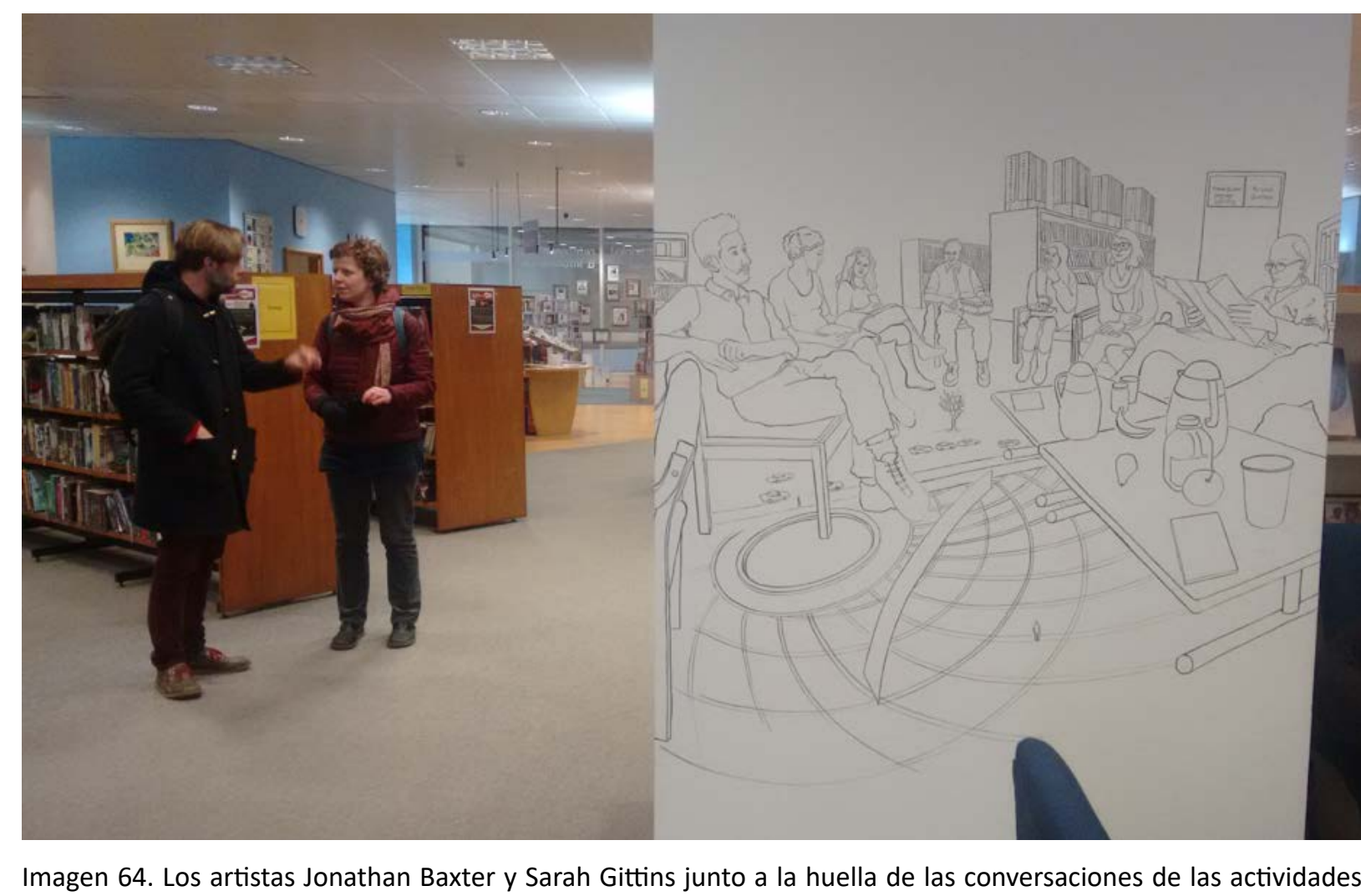
Imagen 64. Los artistas Jonathan Baxter y Sarah Gittins junto a la huella de las con en 2011 durante el Dundee Live Festival y ubicada en el centro comercial Welllgate. Fuente: fotografía de ta autro 2016.

Surge del esfuerzo colectivo por leer cómo es Dundee entre textos, pensamientos y capas de realidades diversas. Por un lado la precariedad económica, el desempleo, los negocios cerrados, la pobreza alimentaria; por otro, la ceguera autocomplaciente a ver esa realidad, clásica apuesta del capitalismo por el derroche, la inversion, la construcción de otro centro comercial en mitad de un flamante desarrollo portuario costero de lujo en Dundee: el Waterfront development ${ }^{208}$,

¿Cómo podría ser Dundee? ¿Qué futuro le espera? Producto de estos diálogos, los artistas proponen la metáfora de la ciudad-huerto como una visión de partida que pertenece a una de las muchas capas de la imaginación y la posibilidad que habitamos (J. Baxter, comunicación personal 12 de diciembre de 2016). Frente a un modelo de desarrollo urbanístico en profundo

208 La ciudad se ha embarcado en un pro-
yecto de desarrollo urbanistico costero a 30 años (2001-2031) que ocupa 240 hectáreas y se extiende $8 \mathrm{~km}$ a las orillas del río Tay.
Con un coste de 1 billón de libras Dundee City Waterfront es un proyecto estratégico, que pretende impulsar a la ciudada a la fama para visitantes y negocios. Incluye la consde jardines y huertas en la que se ha podide

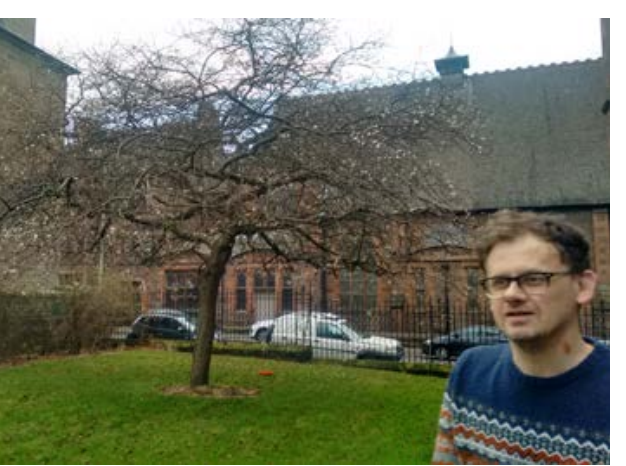

Imágen 65. Ali Wilson trabajador en la bizona coublica Arthurstone situada en una zona conflictiva de la ciudad que Baxter y
Gittins tienen intención dea tivar para evitar que el centro cierre. Detrás de él, el cerezo plantado en el huerto de la misma 

os), se comporte como un jardín dependiente del mundo natural y sus ritmos. Una ciudad horti-cultural en el sentido de cultivar una cultura ciudadana que a su vez mantenga los cultivos. Una vez imaginada, dice Baxter, la semilla de ese huerto queda plantada en nuestra mente (comunicación personal, 12 de diciembre de 2016). ¿Qué podemos aprender de los huertos como modelo de desarrollo urbano sostenible? ¿Cómo sería Dundee si los patios y espacios ajardinados en desuso fueran huertos? La respuesta del propio grupo de lectura introduce los huertos comunitarios en la ecuación de su futuro inspirándose en el concepto de escultura social de Joseph Beuys y la defensa de la biodiversidad de Vandana Shiva (Baxter y Gittins, 2013).

Pero en esta ocasión los artistas no se conforman con representar la idea como en el caso de We Live With Water. Al igual que en el mito platónico se mueven de las sombras al exterior, aquí transforman el blanco y negro de estos textos y dibujos en color y realidad. "De algun manera, cuando caminamos por Dundee estamos atravesando una obra de arte, una impresión de Gittins en la que Dundee es un enorme y antiguo huerto cubierto de bandadas de aves atradas por su vegetación» (Baxter, comunicación personal, 12 de diciembre de 2016). El proyecto trabaja con la ciudad entera en su conjunto aprovechando los espacios ajardinados y las comunidades que ya existen para sembrarlos y cuidarlos (Baxter y Gittins, 2013). Desde sus primeros intentos de establecer huertos en espacios públicos como la residencia universitaria de Abertay University - que no prosperó-, hasta los actuales veinticinco espacios horticolas comunitarios han pasado cinco años. Dispersos por la ciudad, en zonas públicas y privadas, en barrios conflictivos o de alto nivel, cada uno de ellos tiene particularidades y colectivos responsables diferentes, desde bibliotecarios a voluntarios de la iglesia, alumnado del colegio o individuos en sus jardines privados. Los artistas contribuyen tanto a crear el interés colectivo para plantarlos, como a mantener el cuidado de los mismos y conectarlos mediante una red ${ }^{209}$.Los objetivos son varios:

1. Animar a la población a habitar toda la ciudad, acceder a todos los espacios verdes - comunitarios y a todos los espacios públicos en general, incluso los de las areas más deprimidas (como la bibloteca Arthurstone) o los más modernos (como los jardines Slessor en el nuevo desarrollo costero o el jardín compartido por el Museo de arte contemporáneo Dundee Contemporary Arts (DCA) y el centro Dundee Science Centre (DSC). Para ello, colaboran con otras organizaciones comunitarias como Bonnie Dun-

dee o comunidades religiosas.

2. Mejorar la biodiversidad biológica y cultural y celebrarla mediante obras artísticas exhibiciones, actividades, comisariados $y$ talleres de arte en los espacios públicos $20 . A$ rios, como espacios expositvos, una oprtunidad para cualquier artista de mostrar su rios, cor elo ción de serigrafías realizadas en sus muchos talleres de creación.

3. Fomentar la conciencia del origen de los alimentos y, en concreto, del sistema industrial de producción asi como del desempleo, la pobreza alimentaria y la falta de visión social, medioambiental y económica de la localidad.

4. Originar espacios creativos donde quepa la participación y que aporten el coraje y juicio necesarios para unos procesos políticos más abiertos.

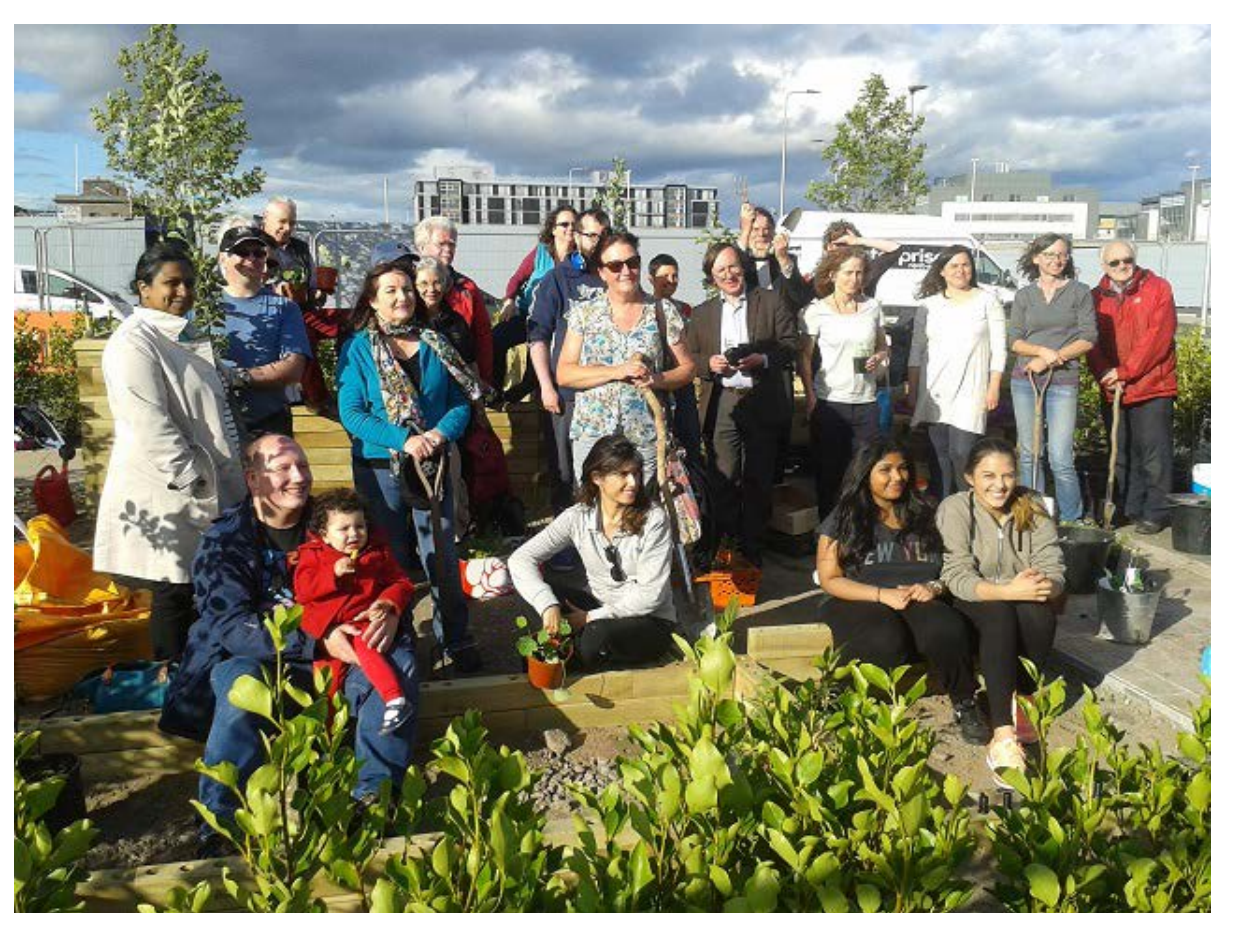

Imagen 67. Slessor Gardens, uno de los huertos creados. Fuente: fotografí de bautora, 2016.

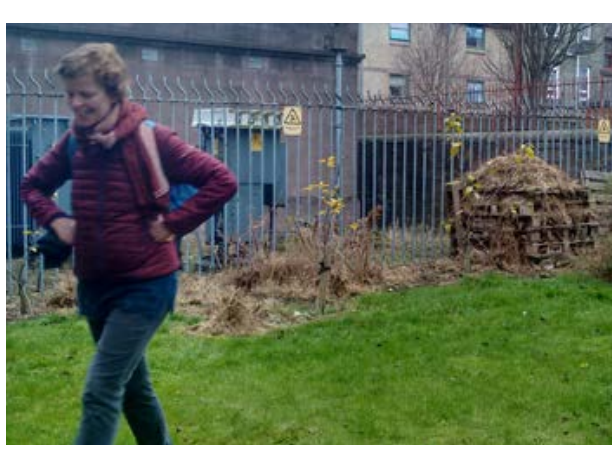

Imágen 66. Gittins en el mismo espacio de Arals fondo. Fuente fot para insectos crea-

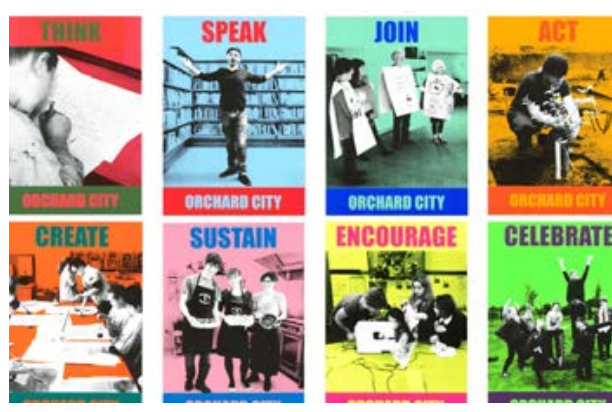
magen 68 Serierafias realizadas en sus talleres artísticos abiertos sobre la ciu-
dad-huerto que homenajean a las personas y los valores que sostienen el proyecto. Des-
de 2014 los carteles han recorrido la ciudad (y otras ciudades) en una variedad de actividades artísticas y comunitarias con la inten-
ción de reconocer su papel en la sociedad y la labor $y$ generosidad de estos centros sos. Fuente: https://dundeeurbanorchard. net/orchard-city-posters/

210 Para consultar un listado de la gran canfidad de talleres, exposiciones, charlas, y zadas por DUO, véase: https://dundeurba- 


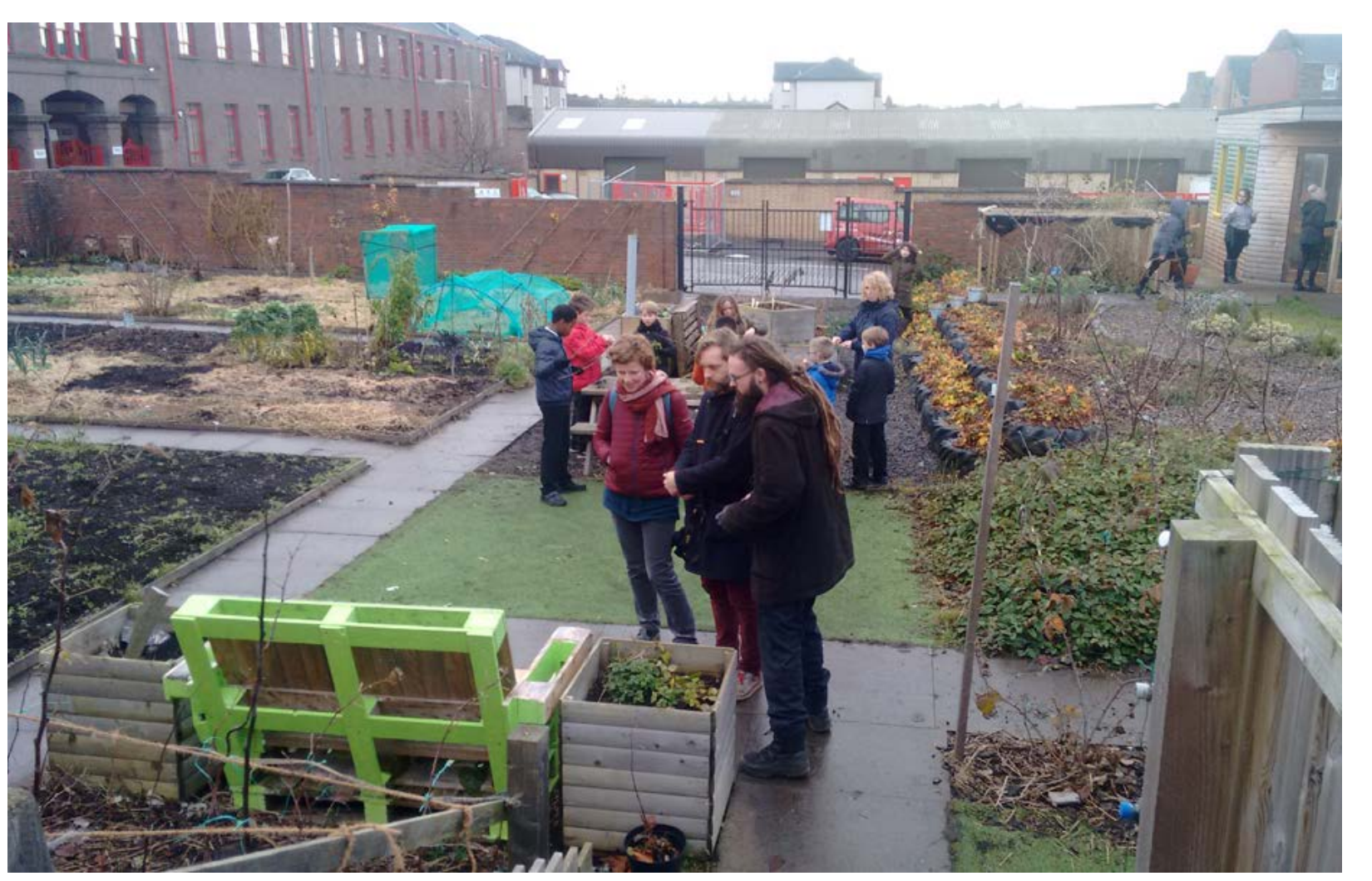

El caso de DUO destaca especialmente por la implementación de la participación en su desarrollo: en primer lugar la toma de decisiones es colaborativa desde la idea original que da lugar al proyecto artístico. Por otro lado, los procesos participativos son a la vez herramienta de creación y objetivo del proyecto. Además, la intervención es más diversa y ocurre con mayor presencia en todas las fases del proceso de creación -comparado con los casos de estudio anteriores-, incluido el tipo uno, origen y responsabilidad: los artistas coinciden con Lacy en que el sentimiento de implicación en el proyecto prospera cuando los participantes son invitados proceso de decisión desde el inicio. Baxter señala que hay diferentes niveles de respuesta y compromiso, pero es importante no discriminar ningún tipo de contribución. De este modo, la colaboración se halla en el germen de $D U O$ desde el grupo de lectura que comienza a trabajar las ideas de los huertos comunitarios. En este caso, aunque los artistas - que trabajan colaborativamente- motivaron el encuentro y mantuvieron viva la conversación a través de textos, metáforas y exposiciones, fue la conversación dialógica entre los participantes la responsable creadora.

En cuanto al tipo dos, colaboración y codesarrollo, se pueden incluir aquí a las numerosas personas que mantienen y se responsabilizan de los huertos, como los miembros de asociación Bonnie Dundee, los trabajadores de la biblioteca Arthurstone o del centro religioso Maxwell.

Baxter y Gittins, acostumbrados a trabajar con arquitectos y creadores, buscaron conscientemente desde el inicio la implicación de otros públicos para invertir el proceso: primero cear la obra con personas alejadas del mundo del arte para después invitar a los artistas a interinvitados, como el narrador Owe Pilgrim que ha creado una historia para DUO o los bailarines Joan Cleville y Solène Weinachter (anteriormente de Scottish Dance Theatre), creadores de un baile comunitario para DUO
Imagen 69. El huerto realizado sobre tierrac consagradada del centro Maxwell, con un grupo de escolares en prácticas
al fondo. Al frente Jack Pocock, coordinador del huerto junto a los artistas Baxter y Gittins Fuente: fotografía de la autora, 2016 .

En el tercer tipo, voluntarios y ejecutores, podemos enmarcar los numerosos colaboradores que han participado en plantaciones, talleres y actos entre los que nos incluimos al haber de acceso libre conscientemente, ya que consideran que instalar grandes barreras de acceso implica un mensaje desincentivador de la participación ${ }^{211}$

En cuanto al público inmediato, sus performances, pasacalles y talleres han atraído una gran afluencia de asistentes de todas las edades. El público de los medios de masas es abarcado principalmente a través de las redes sociales. Aún es pronto para hablar del sexto tipo de participación - público del mito y la memoria - pero los cinco años de andadura de DUO y su proyección futura, auguran una larga continuidad y notoriedad al proyecto. participado como voluntaria en una plantación en Slessor Gardens. La mayoría de huertos so 
Para Baxter existe un equilibrio delicado entre el apoyo o la indiferencia de las institucioque se cierre a un diálogo (comunicación personal, 12 de diciembre de 2016). Un punto clave consiste en encontrar esa armonía entre no ser cómplice de las entidades que critican, pero tampoco ser demasiado polémicos, explican. Por ejemplo, en principio el Ayuntamiento dio una amplia bienvenida a $D \cup O$, que motivó un acuerdo para instalar huertos solo en lugares donde había grupos con una comunidad asentada que los mantuviese y tuviera la propiedad de la tierra. Pero, según Baxter, en todo acuerdo siempre hay que romper una regla, de modo que, cuando surgió la oportunidad de apoyar a una persona individual para transformar el jardín .

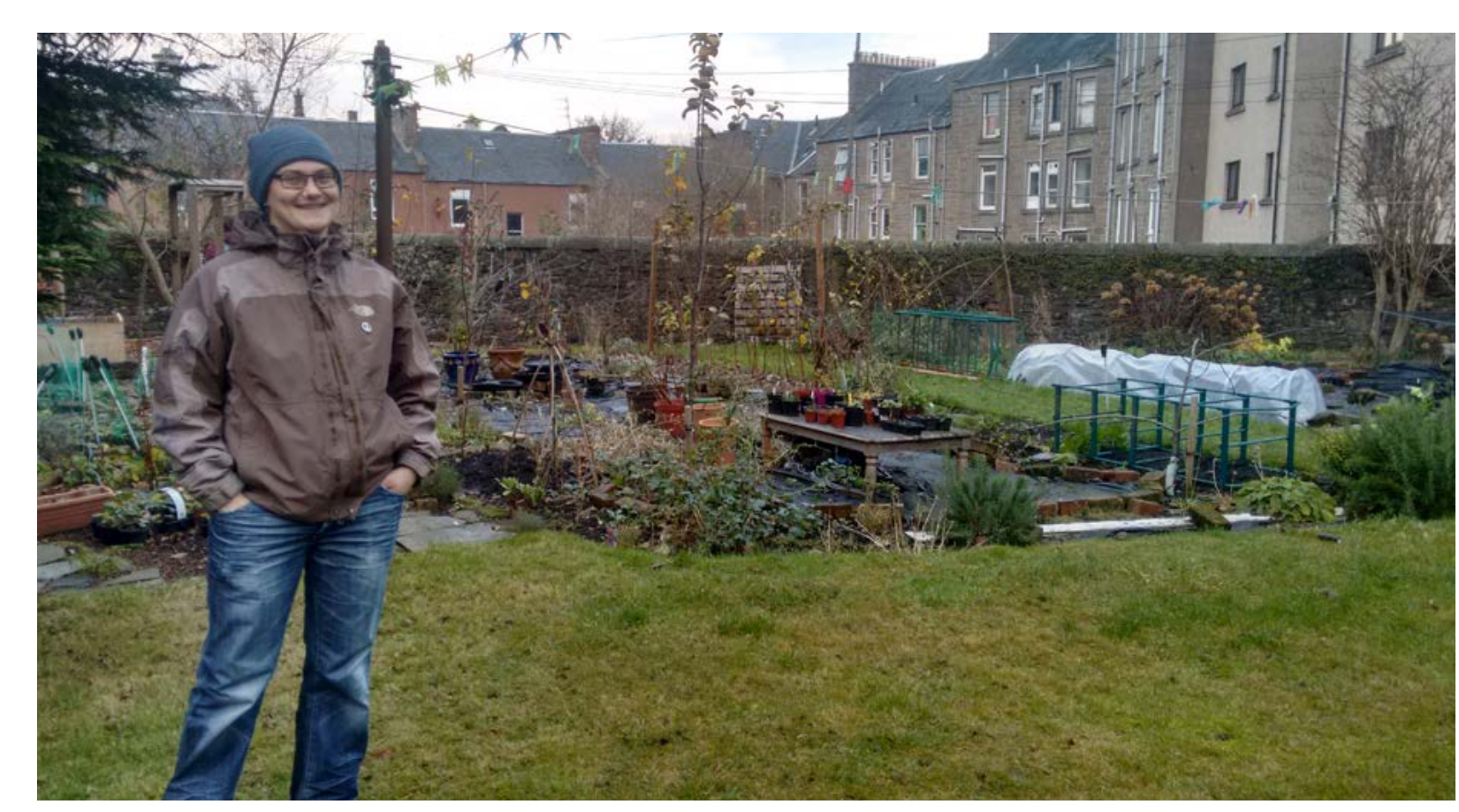

Imagen 70. Shonagh Glen única cuidadora de este jardín trasero vecinal que antes era solo un manto de césped sin

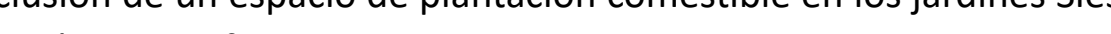
silencio continuo de las autoridades motivó a los artistas a plantear en 2015 la exposición Trabajo de sombras, en las vallas frente el emplazamiento solicitado. Basado en los escritos de Ivan Illich, representaba a un grupo de escolares de la Academia Braeview caminando con palas rastrillos hacia una forma elíptica: un agujero donde se podría plantar un árbol. El objetivo de la instalación era reflejar «la naturaleza precaria de muchos proyectos de arte socialmente comprometidos y la incapacidad de los organismos públicos para crear un futuro sostenible tan para jóvenes como para adultos mayores» (Baxter y Gittins, 2015). Esta tensión inicial se tradujo después en un momento clave que decanto al gobierno municipal por autorizar la instalación del jardín comestible y el huerto en Slessor Gardens.

Otro obstáculo a mencionar es la falta de visión estratégica a largo plazo de los organismos $^{212}$ : «Algunos espacios presentan un enorme potencial pero no significa nada sin personas sin instituciones que empiecen a cambiar su política» comenta Baxter (comunicación personal 12 de diciembre de 2016). Un ejemplo claro de que el cambio de visión necesario ocurre a medida que construimos nuevas posibilidades, es el Centro Maxwell. Hoy es uno de los ejemplos de huerto comunitario más exitoso de toda la red, y cuatro grupos de escolares durante el curso y una veintena de niños en verano acuden a realizar actividades educativas. Sin embargo, cuando el gerente y parte de la comunidad comenzaron el proyecto en 2013 en la tierra consagrada abandonada detrás de la iglesia, la opinión generalizada era reacia a perturbar el suelo sagrado. Muy lentamente la comunidad al completo se fue habituando al huerto, aficionándose a la belleza del mismo y hoy en día se replantean que la tierra consagrada no tiene por qué ser un espacio muerto.

El cuidado y la atención son ingredientes clave para el éxito de DUO, declaran Sarah y Es por ello que ejecutan talleres de planificación, siembra, poda y cosecha de huertos regularmente en toda la ciudad. Además también cuentan con un Comité de mantenimiento y cuidados para la red $D \cup O$. Inspirado conjuntamente por el Manifiesto sobre el Mantenimiento de Mierle Laderman Ukeles (1969) y el Ejército de Payasos Rebeldes, dicho comité organiza actividades de celebración en apoyo de la biodiversidad y la diversidad cultural en Dundee (Baxter y Gittins,

Find

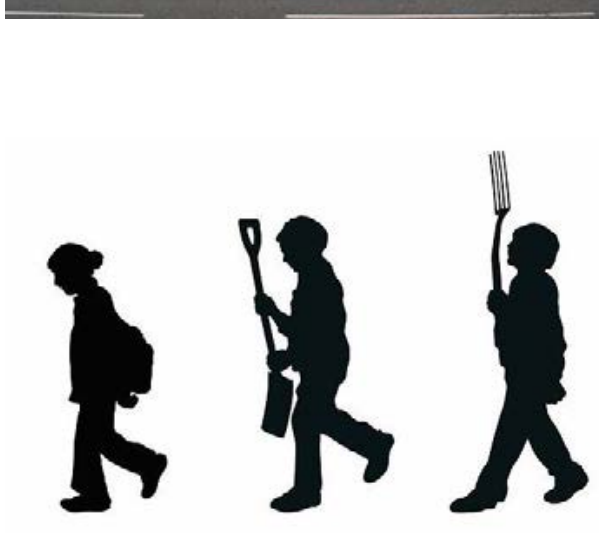
char hard http.//dev.sharingnothoarding.org/ 212 Por ejemplo en uno de los emplaza-
mientos con mayor potencial por estar
dentro de la residencia de estudiantes de Universidad de Abertay, el huerto se ha cerrado por el temor a que en verano cuan-
do no haya estudiantes se seque (Baxter,
comunicación personal, 12 de diciembre de 2016). 
- La Comisión Forestal de Escocia para los árboles.

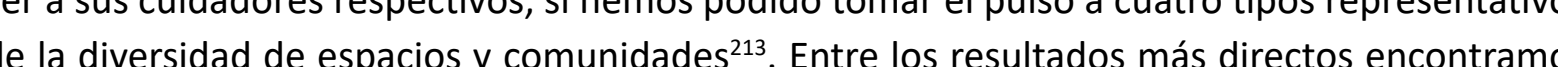
de la diversidad de espacios $\mathrm{y}$ comunidades ${ }^{213}$. Entre los resultados más directos encontramos un evidente aumento de la biodiversidad vegetal y animal urbana. La habitual manta uniforme especialmente a las aves y es habitual la construcción comunitaria de «hoteles» para insectos.

Por otro lado, numerosos jóvenes se benefician de entornos de aprendizaje más empáti- La iglesia del Oeste de Dundee con una espacio de oficina y una tienda de manzanas.

Pero por otra parte algunos miembros de la red, como el Centro Maxwell, se quejan de que los programas escolares no incluyen este tipo de actividades como una extensión de la escuela en sus presupuestos. Una importante acción voluntaria y comunitaria compensa los escollos financieros. Pero, por encima de todo, los an vistas resaltan la lentud participativos y transformadores como éstos aunque, por otra parte, entienden que la transformación social profunda no puede venir impuesta de hoy a mañana.

\subsubsection{Intención}

DUO identifica varias situaciones de la actualidad social de Dundee que pretende responder mediante su acción artística. El marco de acción viene determinado por la dinámica de desarrollo económico y urbanístico capitalista, la situación de pobreza alimentaria en la ciudad par que la existencia de espacios verdes en desuso- y el escaso acceso público a participar n los procesos de decisión sobre el futuro ta intención ye los artistas parte de crear un espacio cítico de pos decisión sobre el futuro. La intención de los artistas parte de crear un espacio critico de participación, materializar las ideas y deseos de la población local frente a esas pro-
blemáticas, sin imponer su criterio, implicar a los habitantes en los espacios públicos y trabajar con ellos en los asuntos que les interesan directamente. En el trasfondo de su acción subyace la metáfora de la ciudad-huerto que pretende conectar la diversidad cultural con la biológica y crear comunidad como respuesta ante los desatios de la crisis ecosocial. 


\subsubsection{Estética y ética}

En cuanto a la estética del proyecto, decíamos que un aspecto clave que consideramos es la ética que respalda al mismo. En el caso de DUO los valores de justicia ambiental y social y la

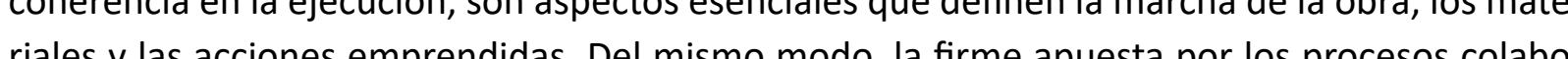
riales $\mathrm{y}$ las acciones emprendidas. Del mismo modo, la firme apuesta por los procesos colaborativos desde el inicio ha delimitado el marco de trabajo producto de la conversación dialógica fomentada en los encuentros en la biblioteca. Esta vivencia social es un aspecto fundamenta para los artistas que buscan crear un espacio crítico y diverso de intervención social. De hecho, a experiencia de participar en sus actividades nos demuestra que el proyecto abarca todas las edades y distintas comunidades culturales de Dundee.

Los artistas demuestran habilidad para acompañar el proyecto, impulsarlo o mediar con las instituciones dejando espacio para que crezca por sí solo y facilitando la intervención de otros profesionales como ingenieros forestales y trabajadores sociales. No quiere decir esto que abandonen todos los aspectos estéticos de la obra en los participantes. Los artistas desa rrollan en talleres colaborativos la imagen del proyecto mediante serigrafía'a18, pero también con intervenciones en los espacios, performances, instalaciones, pasacalles y otros actividades culturales. Más allá de impartir lecciones sobre los retos ambientales, buscan crear una atmósfera de hermandad, imaginativa, que dé pie al compromiso social con otras personas y disfrutar del proceso.
La función que destacamos en DUO por su novedad, por encima de otras ya vistas, es . versidad, sino fortalecer la cooperación y conocimientos de la comunidad frente a la situación de escasez alimentaria. Precisamente uno de los indicadores de resiliencia en los proyectos de transición es el número de jóvenes menores de dieciseis años capaces de cultivar dieciséis variedades diferentes de plantas. En este caso, podríamos decir que los numerosos huertos a los que acuden escolares favorecerían los resultados de dicho indicador. Resumimos en la siguiente tabla el resto de funciones que hemos identificado:

\begin{tabular}{|c|c|}
\hline FUNCIONES de DUO & JUSTIFICACIÓN \\
\hline $\begin{array}{l}\text { Mlustrar, representar, comunicar, } \\
\text { difundir }\end{array}$ & $\begin{array}{l}\text { Sí, en las paredes de la biblioteca ilustran las primeras } \\
\text { reuniones, los dragones representan sus valores de justicia } \\
\text { social y ambiental l las acciones de serigrafía sirven para } \\
\text { difundir el proyecto. }\end{array}$ \\
\hline Concienciar & $\begin{array}{l}\text { Sí, aunque no como un objetivo principal sino derivado de los } \\
\text { encuentros y el trabajo en el huerto. }\end{array}$ \\
\hline Desarrollar empatía & $\begin{array}{l}\text { Sí, el trabajo en el huerto promueve la observación directa } \\
\text { de la naturaleza y sus ciclos, este encuentro forja por un lado } \\
\text { un vículo y por otro un mejor entendimiento de nuestra } \\
\text { ecodependencia. }\end{array}$ \\
\hline $\begin{array}{l}\text { Imaginar, desarrollar la visión del } \\
\text { grupo, su misión, futuros posibles, } \\
\text { utopias of ficciones }\end{array}$ & $\begin{array}{l}\text { Si, el proyecto se basa en la visión imaginada del futuro de } \\
\text { Dundee desde sus reuniones en la biblioteca Central y su } \\
\text { puesta en práctica. }\end{array}$ \\
\hline $\begin{array}{l}\text { Ofrecer soluciones, mostrar } \\
\text { alternativas reales o proyectos } \\
\text { piloto, laboratorios de pruebas }\end{array}$ & $\begin{array}{l}\text { Sí, Los veinticinco huertos en funcionamiento son una } \\
\text { alternativa real de consumo de proximidad. }\end{array}$ \\
\hline $\begin{array}{l}\text { Conectar personas, crear } \\
\text { comunidad, hacer redes, mediar o } \\
\text { facilitar }\end{array}$ & $\begin{array}{l}\text { Sí, los artistas median con las instituciones para obtener } \\
\text { permisos para los huertos y fomentan el trabajo colectivo en } \\
\text { ellos. }\end{array}$ \\
\hline $\begin{array}{l}\text { Restauración/recuperación del } \\
\text { entorno }\end{array}$ & $\begin{array}{l}\text { Sí, en algunos casos se han restaurado lugares abandonados } \\
\text { como el terreno consagrado detrás de la iglesia en el Centro } \\
\text { Maxwell. }\end{array}$ \\
\hline
\end{tabular}




\begin{tabular}{|c|c|}
\hline $\begin{array}{l}\begin{array}{l}\text { Reforzar la identidad, crear } \\
\text { simbolos }\end{array} \\
\end{array}$ & No encontramos indicaciones claras de esta función. \\
\hline $\begin{array}{l}\text { Fomentar la ciudadanía crítica, } \\
\text { agitar, denunciar }\end{array}$ & $\begin{array}{l}\text { Si. De hecho se trata de uno de los objetivos principales del } \\
\text { proyecto: fomentar la participación de la ciudadanía en el } \\
\text { diseño de su futuro. }\end{array}$ \\
\hline Empoderar & $\begin{array}{l}\text { No exactamente, puesto que no se centra en un sector de la } \\
\text { población oprimido o desfavorecido sino que busca mejorar la } \\
\text { participación en los procesos de decisión y la autosuficiencia de } \\
\text { toda la ciudadanía. }\end{array}$ \\
\hline Crear relatos positivos de cambio & $\begin{array}{l}\text { Sí, se contribuye a crear un relato positivo de cómo convertir } \\
\text { nuestras ciudades en lugares productivos que nos hagan más } \\
\text { resilientes, nos ilusionen y alimenten el cuerpo y la mente. }\end{array}$ \\
\hline $\begin{array}{l}\text { Facilitar la comprensión del } \\
\text { mensaje de la ética ecológica } \\
\text { aplicándola }\end{array}$ & $\begin{array}{l}\text { Sí, se aplican los conceptos de biodiversidad (biológica y } \\
\text { cultural) de Vandana Shiva, justicia social y ambiental. }\end{array}$ \\
\hline $\begin{array}{l}\text { Conectar áreas alejadas de } \\
\text { conocimiento }\end{array}$ & $\begin{array}{l}\text { No se busca la colaboración interdisciplinar premeditadamente, } \\
\text { aunque puede surgir en el proceso. }\end{array}$ \\
\hline $\begin{array}{l}\text { Motor iniciador de dinámicas y } \\
\text { proyectos }\end{array}$ & $\begin{array}{l}\text { Sí, las acciones artísticas y los grupos de lectura iniciados } \\
\text { por los artistas buscaban activar la ciudadanía y dan lugar a } \\
\text { proyectos como Sharing not hoarding, charlas, conferencias, } \\
\text { talleres, etc. }\end{array}$ \\
\hline Celebrar & $\begin{array}{l}\text { No especialmente, aunque la celebración es parte de algunos } \\
\text { de los momentos de relación como la fiesta de la recolecta que } \\
\text { tuvo lugar en el Jardín Botánico de Dundee en } 2016 \text {. }\end{array}$ \\
\hline Recaudar fondos & No. \\
\hline Construir consensos & $\begin{array}{l}\text { No exactamente, DUO intenta hacer reaccionar a los } \\
\text { ciudadanos frente al sistema de producción alimentaria, pero } \\
\text { se acepta y celebra la diversidad de reacciones. }\end{array}$ \\
\hline Premiar, agradecer & No. \\
\hline $\begin{array}{l}\text { Conectar personas con espacios, } \\
\text { entornos o lugares }\end{array}$ & $\begin{array}{l}\text { Síes objetivo de DUO conectar a la comunidad con la } \\
\text { producción de alimentos todas las áreas de la ciudad, desde las } \\
\text { más favorecidas, a las menos. }\end{array}$ \\
\hline Aumentar la resiliencia & $\begin{array}{l}\text { Sí, aunque los autores no mencionan la resiliencia como } \\
\text { objetivo, se puede deducir de suactividad que están ayudando } \\
\text { a construir una comunidad más preparada ante los posibles } \\
\text { cambios energéticos del futuro en Dundee. }\end{array}$ \\
\hline
\end{tabular}

Los casos de DUO y de The Trashcachers' Carnival, son los únicos dos ejemplos identificados en los que los artistas conocen el arte transicional. Como primera conclusión podemos decir que, además, en DUO se identifican todos los principios del mismo ya mencionados, aunque en ningún momento los artistas se han identificado como artistas transicionales:

1. Intención: en primer lugar, el propósito de los artistas de promover una transformación de la sociedad que enfrente la realidad social y ambiental de Dundee es claro y definido, aunque se concreta en colaboración con los participantes.

2. Ignición: Su papel como activadores de la sociedad abiertos a las especificidades del lugar es un ejercicio de autocontención y conversación dialógica. A partir de esta proyecto surgen otros como Sharing not hoarding.

3. Marco: El marco de trabajo abarca toda la ciudad como un lienzo en blanco donde los artistas invitan a participar tanto a la población en general, como a otros artistas.

4. Trabajar con la comunidad: Hay un menor protagonismo de los artistas y mayor de las comunidades que, al sentirse dentro de un proyecto vivo y no aislado, encuentran apoyo en otros miembros.

5. Mediación: El artista en este caso ha mediado con las comunidades, entidades e individuos invitándoles a crear su propio huerto y facilitando el proceso.

6. Mantener un espacio: El espacio y su mantenimiento es un punto clave que da estabi-

7. Conexión: Conecta personas e historias que de otro modo no tendrían relación, dando fuerza a una iniciativa de cambio positivo.

8. Trabajar desde lo común: Lo común, en este caso, son los espacios y estructuras públicas como la biblioteca, la alimentación y el goce de disfrutar cultivando.

9. Colaborar: La colaboración es un factor esencial. 
10. Cambio: Finalmente, el cambio físico en los espacios es mucho más patente en unas iniciativas que en otras, pero se ignora el cambio en las actitudes con respecto al conmo a la relación con el espacio público. Los artistas no han realizado ninguna medición.

En este proyecto se supera la mera representación que realiza The Stove en We Live With En ese sentido es un la acción. 10 artítico reside en el proceso participativo de construcción del proye que llama a mósera cre mósfera creativa de sus talleres yotras activides. Pero lo que más caracteriza a DUO es ser un precto que verdaderamente practica la incorporación honesta y abierta de la participación en el proceso de deciśn desde el ongen, incluso áses de pensar y esta red de huertos urbanos. De este modo, los artistas consiguen mucho más de lo que les sería posible actuando en solitario. El proceso de cocreación forma parte de una dinámica creativa compleja, un equilibrio entre la negociación, la apertura de corazón y la autocontención del ego creador. Baxter y Gittins se desplazan de la clásica posición del artista que impulsa unas expectativas - en cierto modo ya predeterminadas - para tomar una posición mucho más incómoda, una actitud no planificada donde tomar lo que se les ofrece confiando que las posibilidades de la sorpresa emerjan. La cooperación resultante en este caso es un ejercicio duradero e independiente de la presencia del artista. Por tanto, los efectos de DUO pueden prolongarse al margen de los momentos puntuales de creación artística, aunque estas intervenciones son necesarias para reforzar las ideas y aportar nuevas energías e impulso.

Este tipo de proyectos artísticos son muy convenientes para propagar las ideas de la transición a la sostenibilidad, porque entran en las vidas del público por medio de algo que todos tenemos en común y muy presente en nuestra cotidianidad. la alimentación. Es además un proyecto accesible en cualquier fase del proceso, facil de entender, con capacidad de crecer expandiendose por los numerosos jardines escoceses y extrapolable a cualquier otra ciudad del país (la climatologia juega mucho en su favor). Además, frente a las imágenes negativas de colapso, el decrecimiento, la autosuficiencia y el empobrecimiento, ofrece una mirada positiva del trabajo en el huerto como algo lúdico, que aporta valores inmateriales como la conexión con otras personas y con la naturaleza y un reencantamiento de la vida en comunidad.
Su valor artístico reside en el proceso de nacimiento del proyecto, la labor de mediación Co

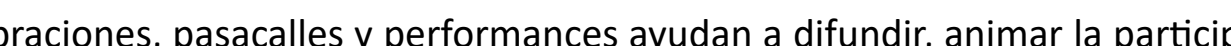
ción, visibilizar resultados, concienciar, celebrar y fortalecer $D U O$. Más allá de plantear su propia obra artística o un nuevo diseño urbano al Ayuntamiento, los artistas ayudan a que sean los habitantes de Dundee los que reflexionen y co-creen su obra: el diseño propio de un futuro resiliente.

\section{ESTUDIO DE CASO: CARRÍCOLA}

\subsection{EL ARTE COMO REVITALIZACIÓN DEL TERRITORIO RURAL: CARRÍCOLA}

Carrícola es un pequeño pueblo de la Comunidad Valenciana que destaca por su clara apuesta por el arte como herramienta para crear un futuro alternativo para la localidad, en consonancia con las ideas de la transición a la sostenibilidad. Hace ya tiempo que el arte contempo-

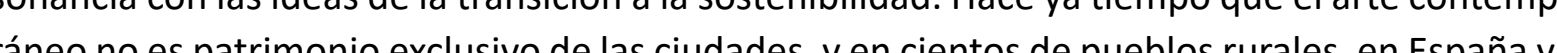
extranjoro, aprecen estas opciones. Un ejemplo $y$ encientos de pueblos rurales, en España y

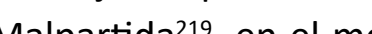

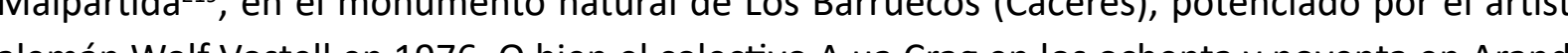
de Duero (Bursos), que reuní a un grupo de artistas como Rafoel Lama o R fo Criado, ju de Duero (Burgos), que reunia a un grupo de artistas como Rafael Lamata o Rufo Criado, junto a otras diez personas, demostrando que es posible crear, investigar y mostrar arte contemporáneo fuera de los centros capitales (Archivo Documental de Artistas de Castilla y Leon, 2012). Màs recientemente encontramos que, en Genalguacil20 (Malaga) con menos de 500 habitantes, Ilevan apostando desde 1994 por unas residencias artísticas bianuales que tienden, cada año más, al arte colaborativo y la relación con la naturaleza. En El Carpio (Córdoba), en 2002 se engendra Scarpia ${ }^{221}$, que con catorce ediciones ha logrado implicar a la mayoría de los 4.500 carpeños. Actualmente el Ayuntamiento ha absorbido la dirección y gestión de esta convocatoria, que fue creada originalmente por el artista Miguel Angel Moreno, con el afán de analizar y poner en práctica enseñanzas y experiencias relacionadas con el arte público participativo. Otra iniciativa en Córdoba es $Z^{222}$ (llamada así por el ceceo de la zona) en Montalbán, que huyendo de la idea
219 Más información en: http://museovos-

220 Más información en:http://www.genal-
guacil.es/es/Arte $y$ _cultura//Encuentros_

guacil.es/es/Arte_y_culturtorterentacion/ 221 Más información en: http://scarpia.
es /2015/ / autora tuvo el gusto de participar en la primera edición en 2005. 
222 Más información en: http:///jornadas-
dearte.blogspot.com.es/ 223 Más información en: http://www.mon
lle.es/cementerio-de-arte-presentacion 224 Más información en: http://inland.org/ mos podido tomar parte dentro de su pro-
puesta Grupo de Estudios en Matadero de puesta G

225 Más inform
trowhouses.org/

226 Más información en: https://villa-

227 Más información en: http://en.contextishalfthework.net/about-apg/artist-placement-group/ encionar tam-

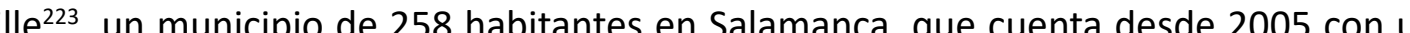
conterio de arte de $90.000 \mathrm{~m}^{2}$ ideado con el objetivo de engarzar el concepto vanguardista con lo rural y lo lúdico (Maulén, 2016). Por último, nombramos Campo adentro ${ }^{224}$, un proyecto muy amplio de producción social y cultural creado por el artista Fernando García Dory. En su seccion de proyectos artísticos (2010-2014), invita a artistas o abre convocatorias para llevar a cabo intervenciones en relación al contexto de un territorio o pueblo concreto. Promueve la integración del artista en la vida del pueblo durante el periodo de residencia para conocer y responder a la realidad del lugar mediante la práctica artística con intención transformadora. Se enfatizan los procesos colaborativos aplicados al contexto y las acciones que doten a estas comunidades rurales de sus propios medios y recursos de expresión y creación cultural (García-Dory, 2009).

A nivel internacional podemos mencionar Project Row Houses ${ }^{225}$ (PRH), una organización in fines de lucro en uno de los barrios afroamericanos más antiguos de la ciudad Houston dedicada al arte y la cultura comunitarios. Fundada en 1993, persigue fomentar una presencia creativa positiva en la comunidad desde el arte público, para transformar el entorno social. También en EE.UU. encontramos The village of Arts and humanities ${ }^{226}$ en el norte de Filadelfia. Esta comunidad, convencida de que el arte y la cultura transforman vidas y colectivos, sostiene un programa de aprendizaje y otro de construcción a través de las artes. Su objetivo es apoyar sus habitantes a ser agentes de cambio positivo, dando la oportunidad a todos los jóvenes de participar en actividades culturales que fomentan el pensamiento creativo, preservando el patrimonio y respetando el medio ambiente.

Este surgir del arte contemporáneo en entornos rurales ha sucedido de modo similar en Reino Unido. Entre los antecedentes podemos citar el grupo de artistas Artist Placement Group (APG) 227 (1966-1989), que promovía diversas experiencias de localización de artistas en conextos poco habituales como las industrias del acero, minas, oficinas del gobierno, etc. Una de las conclusiones principales, y axioma central del grupo, es la idea desarrollada por Barbara Stevani: «el contexto es la mitad del trabajo» (Douglas et al., 2016, p. 141), en el sentido de que la expresión artística está abierta a la influencia del entorno donde se desarrolla/ubica, siendo ese influjo e implicación de los habitantes más importante que el artefacto producto. De 2001 a 2004, un grupo de investigadores y artistas, entre ellos Douglas, se reúnen para responder a la pregunta: «¿Cuál puede ser el papel del artista contemporáneo en contextos rurales remo- tos? [ ] en el comienzo del milenio, el contexto dominante del arte contemporáneo visual era urbano y metropolitano. Cualquier intento de hacer arte en contextos alternativos necesitaba negociar contra esta dominación, sus asunciones y estéticas» (Douglas et al., 2016, p. 1). En el artículo que recoge parte de la experiencia «"El contexto es la mitad del trabajo": desarrollar la investigación doctoral mediante la práctica de las artes en la cultura» (2016a), Douglas describe las características de estas actuaciones (relación de la comunidad con el territorio, actuación site specific, intención de cambiar el presente para mejorar el futuro, trabajo colaborativo que prioriza las formas de vivir al interés individual del artista), coincidiendo con nuestros criterio de selección y señala el valor de resiliencia del arte público para la cultura investigadora:

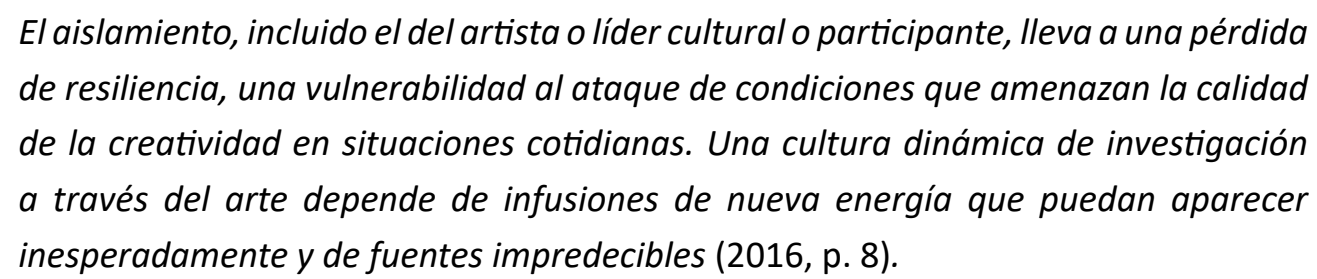

Asimismo, en España, la historiadora del arte Noelia Centeno investiga algunas de estas manifestaciones del arte lza su formación. Segú hemos podido comprobar personalmente, $y$ tal y como comenta Centeno, en un entorno tan pequeño estas actividades tienen gran relevancia, aunque por otro lado se enfrentan a las inercias y falta de costumbre de los lugareños. Pero, una vez vencidas las reticencias iniciales, surgen momentos y espacios de colaboración inesperados, insólitos hasta entonces y, poco a poco, el pueblo va identificándose en las obras y acostumbrándose al ir y venir de los artistas y sus extrañas - peticiones. Tras un tiempo, después de tanto detenerse y escucharse, comienzan a entenderse mutuamente y a sentir esas piezas como suyas. Centeno añade: «Muchas veces la labor pedagógica más complicada es con las instituciones, no con el pueblo. Faltan muchos apoyos y les convencen argumentos más pragmáticos: Esto genera economíay (Martin Rodrísuez, 2016). Centeno alega también que la convivencia de los artistas en estas experiencias, con los locales, sive de banco de pruebas de sus ideas iniciales. En muchos cas 
En este panorama de municipios rurales que apuestan por el arte contemporáneo, Carricola cumple gran parte de las características mencionadas hasta ahora, pero resalta por vario motivos: su interés por la sostenibilidad, su escasa población -alrededor de 95 habitantes en 2017 (Generalitat valenciana, 2017)), a pesar de lo cual cuentan con Ayuntamiento propio - y su proceso abierto de toma de decisiones. Como en el caso de Almócita, estudiaremos el papel de traido a más de ochenta artistas en sus dos ediciones de 2010 y 2015. Sin embargo, al contrario que el pueblo almeriense, en esta ocasión no hay una iniciativa de transición concreta, pero si un contexto político, social y económico orientado a la sostenibilidad, que pone en práctica la transición de un modo orgánico, intuitivo, sensible a las realidades de su entorno, como veremos a continuación.

\subsection{ADECUACIÓN A LOS CRITERIOS DE SELECCIÓN DE LE INVESTIGACIÓN}

Destacamos aquí las diversas actuaciones de Carrícola que están en consonancia con nuestros criterios de investigación señalados en el capítulo dos.

1. Proyectos que tengan una vinculación específica con lo local: Biodivers tiene su origen en la casuística del territorio particular de Carrícola, y muchas de sus obras están ligadas a sus habitantes, el paisaje, sus deseos y necesidades. En algunos casos la acción es necesariamente colectiva, aunque impulsada desde el Ayuntamiento.

2. Que hagan uso del arte como herramienta de fomento de la transición y, en especial, lución de este pueblo que les ha reforza lo en su elección por la sostenibilida en evor

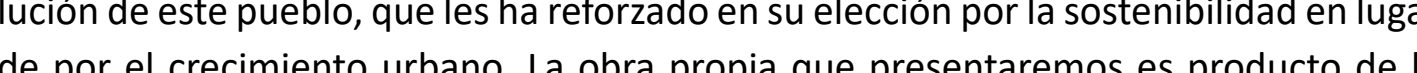
de por elcecinito urbano. ta colaboración con los lugareños.

3. Interés en la realización de la obra por tener una reducida huella ecológica: Aunque no aplican calculadoras de huella de carbono ni de ningún otro tipo, en la selección minerales.

4. Ocuparse de cuestiones relacionadas con la ecología y/o la transición: En general Biodivers es un ejercicio de crítica aplicada al modelo de desarrollo habitual de las zonas rurales. Busca demostrar un nuevo modo de relacionarnos con el paisaje y de progresar con una imagen consecuente. Entre las más de ochenta obras artísticas participantes entre sus dos ediciones, hay una amplia variedad de intenciones y no se puede decir que todas tengan objetivos relacionados con la sostenibilidad. Pero en el caso de nuestra obra propia que presentaremos más adelante, los objetivos si se reaci con el ahorro enerático, a alimentación de proximidad, la creación de resiliencion y fomento de lo colectivo.

5. Obras que actúen (consciente o intuitivamente) de acuerdo con los principios de la transición: Debemos remarcar en este punto que Carricola no pertenece a la red de pueblos en transición. Sin embargo, destaca la familiaridad por parte de la población y, sobre todo, de los miembros más activos del pueblo y los cercanos a la alcaldía, con conceptos básicos como el pico del petróleo, el decrecimiento, la autolimitación, permacultura y la agricultura ecológica. Aunque oficialmente existe el puesto voluntario de alcaldesa, las decisiones se toman en la práctica en concejo abierto e incluntaen el planeamiento y desarrollo urbanístico las preocupaciones ambientales, como 
también. Por ejemplo este año se han regalado bolsitas de rafia, con compost de Carrícola dentro, a cada participante.

El desafio de la conservación:

En junio de 2010 el pueblo se adhirió al supertesting Felix Rodríguez de la Fuente organizado por la fundación homónima y convocado a nivel nacional, con el objeto de fotografiar y catalogar su flora y fauna a través de la Fundación Biodiversidad Proyecto Life UE y la Federación Española de Municipios y Provincias (FEMP). Consta de jornadas divulgativas y cursos de fotografía y exposiciones itinerantes.

- La práctica pionera de la agricultura ecológica desde 1982 ha permitido disminuir el uso de fertilizantes y pesticidas procedentes del petróleo.

- El proyecto de compostaje comunitario de sus residuos La basura es nuestra financiado por La Caixa y con la colaboración de la Universidad de Elche, pone a disposición de los habitantes que voluntariamente colaboren, dos contenedores de madera y realizados por artesanos locales. Aunque parado durante una década por incompatibilidades con el El Plan General de Ordenación Urbana (PGOU), ya se encuentra en marcha en la actualidad, reutilizando para abono de las tierras circundantes los residuos orgánicos de los hogares, así como parte de las aguas fecales (Bellón, 2014). Cada mes se recogen unos ochocientos kilogramos que disminuyen considerablemente su factura de la gestora de residuos (Altabert, comunicación personal 21, abril, 2018). Esto pone al pueblo a la cabeza de la región en materia de recogida selectiva de la fracción orgánica (Consorcio de Residuos V5 - COR, 2017).

- El PGOU anterior eliminaba la creación de suelo industrial y tan solo contemplaba la instalación de empresas de energías renovables, la planta de compostaje y una pequeña zona urbanizable (Altabert, comunicación personal, 21 abril 2018).

Compromiso con la equidad y la justicia ambiental y social:

- A través de la asociación FADEMUR (Federación de Asociaciones de Mujeres Rurales) se presentó al Ministerio de Igualdad el Programa Inclusost Carricola, programa para se presentó al Ministerio de Igualdad el Programa Inclusost Carricola, programa para la inclusión social y laboral de las mujeres de Carricola a través del aprovechamiento pus habitat 5U, 2010)

- Cada año, el día de la mujer se realiza un encuentro con las mujeres de los seis pueblos de alrededor Se aprovechan estos momentos para hacer concienciacion ambienta
Ha colaborado con la Sociedad Española de Agricultura Ecológica (SEAE) con la firma de un convenio en 2011 para el impulso del agroturismo y la producció ecológica y ha organizado el Curso sobre diversificación productiva, agroturismo y producción ecológica.

- Finalista por el Ministerio de Medio Ambiente, y Medio Rural y Marino en la categoría de menos de mil habitantes de los Premios Life Capital de la Biodiversida el 15 de septiembre de 2010, año internacional de la biodiversidad.

Además, sin habérselo propuesto específicamente, encontramos que muchas de sus acciones encajan con los principios de transición propuestos por el MCT. A continuación, detallamos las razones para considerar las actuaciones de este municipio paralelas a las de un pueblo en transición:

Planificación ante el colapso energético: ahorro energético reutilización, reciclaje y reducción de residuos:

- En lugar de instalar una costosa y ruidosa depuradora convencional, Carrícola luchó por convencer a la administración pública de instalar un filtro verde natural ${ }^{23}$ (Consorcio de Residuos V5 - COR, 2017). Tras años de disputa y en colaboración con el Departamento de Ingeniería Hidráulica y Medio ambiente de la Universitat Politècnica de València, se consiguió emplazar y se encuentra actualmente en funcionamiento (Campus habitat 5U, 2010) 
Construcción bioclimática del Centro de interpretación medioambiental de la umbría el Benicadell La almendra de paja $2^{229}$ Un edificio de hecho de piedra, tapial y paja que aloja numerosas actividades de educación ambiental.

- Limpieza y mantenimiento del Paraje Natural Municipal de las Arcadas durante un perído de tiempo con una brigada de burros que mantenín las sendas a la par que ab riodo de nabane ivo de los animales.

- Un reciente proyecto del Instituto Valenciano de Competitividad Empresarial (IVACE) de la Consellería de Economía Sostenible, Sectores Productivos, Comercio y Trabajo financiará, en 2018, la sustitución de las luminarias públicas por tecnología LED, de mayor eficiencia energética, así como relojes astronómicos y reguladores de flujo lumínico, que adecúan la cantidad de luz a la hora y necesidad real de iluminación. Se calcula .

- También se ha contemplado la posibilidad de instalar una planta fotovoltaica para abastecimiento de energía eléctrica para todo el pueblo en un lugar que no altere la visión estética tradicional del municipio. Pero la crisis económica y los cambios en la normativa a nivel nacional han paralizado el proyecto (Bellón, 2014).

\section{Aumento de la resiliencia:}

Los siguientes indicadores, que nos otorgan pistas sobre el aumento de la resiliencia, están seleccionados del Compendio de iniciativas de transición, (Brangwyn et al., 2010, pp. 26-27):

- Porcentaje de alimento producido localmente: Carrícola está rodeado de agricultura ecológica y convencional que autoabastece a la población y además se exporta a Frania, Alemania Dinamarca e Inglaterra. Cuenta tambín con una panadera instalada cal vocatoria Biodivers ${ }^{230}$

- Número de empresas de propiedad local: Apoyo desde el Ayuntamiento a diversas iniciativas empresariales (hostal-restaurante y bar) cediendo o alquilando sus locales a bajo precio para fomentar el tejido económico. Existe también una empresa familiar del tipo Sociedad Agricola de Transformación (SAT) ${ }^{231}$ llamada La Vall Bio que se dedica
- Distancia media al lugar de trabajo por parte de los trabajadores de la población: La empresa La Vall Bio se encuentra en el mismo pueblo por lo que sus trabajadores van andando 0 en desplazamientos muy cortos, los $n$ colegio. Se desconocen el resto de desplazamientos en este estudio.

- Cantidad de materiales de construcción renovables: Cuentan con un edificio construido enteramente con materiales renovables: L'Ametla de Palla.

- Proporción de bienes esenciales que son manufacturados en la comunidad o a una distancia dada: Apoyo a la producción local mediante la constitución de un mercadillo de productos ecológicos, artesanía, cosméticos, panadería, ropa, bisutería y agricultura 位 propio pueblo de Carrícola en colaboración con el artista turco Can Altay, dentro de la convocatoria artística Campo adentro.

Acción local y colectiva:

Existe una tendencia clara de los habitantes a apostar por la acción local manifestada por ejemplo en

- La fuerza de actuar localmente se potencia gracias a que, a pesar de ser el pueblo más pequeño de la comarca, cuenta con su propio Ayuntamiento y su modo de tomar decisiones abierto a las sugerencias de todos los lugareños.

- Convenio de colaboración con la UPV para la realización de proyectos artísticos, de ingeniería y patrimonio que aumentan el abanico de acciones innovadoras y específicas.

- Proyecto Biodivers / y II, que ha servido entre otras funciones para revalorizar espacios abandonados, singularizar al pueblo, unirlo en un proyecto conjunto, reforzar su identidad, responder a sus deseos y servir de medio de expresión de sus habitantes en colaboración con los artistas.

- A raíz de Biodivers se funda el colectivo de lugareños El Lagarto ${ }^{232}$ con el objetivo de «dar a conocer de una forma lúdico-educativa el municipio, su entorno natural, su 

circuito urbano y el camino del barranco y el Castillo.

- El edificio bioclimático L'Ametla de Palla lleva acogiendo desde 2011 en sus siete ediciones hasta ahora, el Encuentro ecologista del país valenciano ${ }^{233}$.

- Así mismo, el Ayuntamiento decide una serie de acciones paralelas que alimentan el atractivo turístico del pueblo. Todas estas acciones contribuyen a enriquecer el tejido económico local, de un modo respetuoso con el entorno:

- Organización de la maratón de Carrícola llamada MIMAMUCA (acrónimo valenciano de Mitja Marató de Muntanya de Carrícola) que ya lleva siete ediciones.

- Reutilización del edificio de la antigua escuela que estaba en desuso, para alquiler y actos varios.

- Se ha habilitado un área como parking de caravanas y camping.

Por todos estos motivos argüidos hasta ahora, consideramos que Carrícola es un ejemplo de modelo de transición exitoso, caracterizado por una gestión institucional que equilibra desarrollo y visión mediom eiental sostenible, por el respeto y conservación a su entorno naturat y por una recuperación de su patrimonio. Pero, desde esta investigación nos interesa centrarnos en qué papel ha juodo el arte en esta evolución. En los siguientes apartados estudiaremos con mances con ejemplo de obra artística colectiva con aspiraciones de transformación social propia.

«Si no es sostenible, no lo hacemos, Susana Cháfer, alcaldesa de Carrícola.

5.3.1 Biodivers

i con Avuntamiento propio más pequeño de la comarca del Valle de Albaida a los pies del Benicadell, en Valencia. Era una antigua alquería islámica hasta 1609 año de expulsión de los moriscos. Conserva antiguos vestigios de la época islámica como la torr de vigilancia del s. XII, la iglesia orientada a la Meca que fue mezquita hasta 1578 y las canalizaciones del sistema de riego árabe que incluyen varias arcadas de los siglos XIII y XV y aún hoy se utilizan, adaptadas para el riego por goteo. Está rodeado de tierras agrícolas y es pionero desde los años ochenta en agricultura ecológica, constituyendo aproximadamente el cincuenta por cien de sus cultivos actualmente. Sin embargo, muchos de los campos están en estado de abandono por ser sus propietarios demasiado mayores para trabajarlos. Las nuevas generaciones se marcharon a los pueblos de la periferia para trabajar, primero en la industria textil y, cuando ésta entró en crisis, en el auge de la construcción. Hoy día, a pesar de la falta de empleo, siguen considerando el trabajo en el campo como algo denostado de lo que no se puede vivir (Cam pus habitat 5U, 2010). Habiendo tenido la posibilidad de crecer urbanísticamente, como (Campus hes otros puebs nicipionto

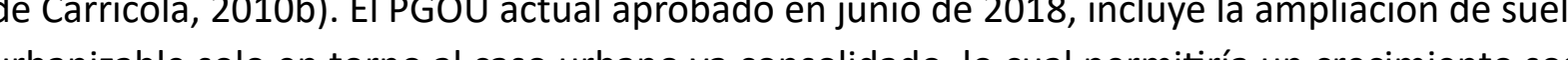
urbanizable solo en 180 ha caso urbano ya consoldodo, lo cual peluciona tenible hasta unos 180 hablantes enveinte años. Esto, vendrá a solucionar el problema de la supervivencia del pueblo que carece actualmente de casas en venta (Susana Cháfer, comunicación personal, 20 de junio de 2018). En el año 1991, el pueblo llegó a su mínimo de habitantes (67), con una media de edad bastante avanzada de entre setenta y tres y setenta y ocho años ${ }^{235}$, que no puede cuidar de los campos ${ }^{23}$, comenta Altabert (comunicación personal, enero de 2015). Según un estudio realizado por una de sus habitantes (Remei, ex redactora de Canal 9 RTVV), pueblo inevitablemente desaparecería en cincuenta años (Bellón, 2014). La paulatina pérdida mastenible.
su identidad rural y hacerlo más

235 Entre el 91-2001, el índice de vejez según datos de Escribano Pizarro, J. (2004)
«La población de la tercera edad en la Vall d'Albaida: distribución y equipamientos"),
en II Congrés d'Fstudis de lu vall d'Albaida. Onteniente. Disponible en: https:///www. academia.edu/3644726/La_población_de_distribución____equipamientos.

236 Por lo que muchos de abandonan al desconfiar los propietarios y propietarias de pertsonnteada de alquilarlos (comunicación El papel del arte en la transición en sentido amplio. Nuria Sánchez Leó 

que nuevos pobladores jóvenes se establezcan con sus familias. Se necesita una estrategia de desarrollo rural que integre las nuevas necesidades de los pobladores, siendo coherentes con el respeto al medio ambiente y el tamaño del municipio, que no tiene previsto en su PGOU ampliar suelo industrial ni apenas el urbanizable (Campus hablat $5 U$, 2010 . El reto no Carrícola necesitaba un plan innovador y atractivo a lo cual responde la convocatoria Biodivers. Según comenta Altabert, el antecedente que precede a dicha convocatoria es la llegada de una subvención para restaurar el patrimonio arquitectónico circundante:

- La restauración del Castellet, una torre rehabilitada por la Diputación y el Ayuntamiento de Palomar, declarado BIC por la Consellería de Patrimonio de la Generalitat Valenclana, fue posible gracias a la concesión del $1 \%$ Cultural del Ministerio de Fomento en sus dos fases 2009 y 2010

- Actuaciones en los barrancos del Castellet y d'At, por parte del Ministerio de Medio Ambiente y Medio Rural y Marino a través de la Confederación Hidrográfica del Júcar (CH) y para recuperar el buen funcionamiento hidrallco; la realzación de tratamientos de vegetación tipica de ribera, la adecuación de ciertas áreas como zona social, lúdica y recreativan (Campus habitat 5,2010 ). En épocas anteriores, estos parajes estaban mejor conservados gracias al ganado y las huertas cercanas. Hoy día el abundante follaje supone un peligro en caso de incendio. Estas actuaciones de limpieza forestal han permitido visibilizar de nuevo varias arcadas árabes de regadío que prácticamente habían desaparecido en la maleza y llevaban años sin ser vistas.

- Restauración del lavadero municipal y recuperación del paraje la Font del Gatell.

- Restauración de las antiguas escuelas.

Una vez terminadas las restauraciones, los habitantes se preguntan por su futuro y cómo podrán mantener estos paisajes recien rehabilitados protegidos y en buen estado, ya que el clima o la vegetación volverá a degradarlos si no se cuidan. La situación se debate públicamente. Una de las ideas sugeridas fue realizar una convocatoria artística de intervenciones en el paisaje que emplace las obras en estos parajes, con el fin de revalorizarlos y ganar atractivo paisajístico y turístico. Surge así la convocatoria Biodivers ${ }^{1237}$ en 2010, en la que las intervenciones artísticas en el territorio funcionan como herramientas de protección del entorno natural y arquitectónco. Al éxito de esta convocatoria le sigue en 2015 una segunda edición, Biodivers II. El objetivo general de estas convocatorias «es conseguir una visión estética y coherente en mitad de un anbiente absolutamente respetuoso con el medio ambiente» (Ayuntamiento de Carrícola, 2010a). Biodivers se apoyó entonces en los conocimientos de Roman de la Calle, (en aquel momento presidente de la Real Academia de Bellas Artes de San Carlos), y Joan Peiró, (vicerrector de Cultura de la UPV por entonces) (Consorcio de Residuos V5 - COR, 2017). La convocatoria Biodivers 2011 Espai d'Art Medioambiental es un ejercicio de política directa aplicada al territorio: un propuesta vecinal bien acogida por el organismo gobernante que cumple con el objetivo de los movimientos de transición de implicar a las instituciones desde el primer minuto. El Ayuntamiento de Carrícola lanza una invitación abierta a artistas, y a todo tipo de personas interesadas con inquietudes artísticas, a instalar sus obras en los parajes naturales sufragando parte de los gastos en materiales y manutención. Para sorpresa de todos, 56 personas responden a la llamada, entre ellos algunos carricolinos y artistas del lugar como Miguel Ferri y Pedro Altabert.

En esta primera edición no hay criterios de selección, y todas las propuestas son admitidas sin planier estipulan unas bases que desestiman la utilización de materiales artificiales como el plástico, siliconas y aluminios, finalmente se admiten junto a la madera, el hierro, el vidrio y la piedra, por lo que se instalan obras de dudosa armonia con el entorno. Con ayuda de las gentes de lugar, comienza la instalación de las 59 obras integradas en los parajes naturales ${ }^{238}$ y se realiza un catálogo llamado Biodivers I. De cualquier modo, tal y como sucede en el caso de Genalguaci - Almócita mencionados, Biodivers I consigue singularizar y marcar en el mapa a esta pequeña y desconocida localidad, comenzando a suscitar interés por los aficionados al senderismo, la naturaleza, el arte o el deporte.

El éxito del primer encuentro plantea la idea de realizar la cita bianualmente. Pero el esfuezzo econónico, temporal y humano que conlleva posterga la repetición el acto hasta cuatro años más tarde. A medida que las obras se integran en el paisaje, también se desintegran, y para 2015 algunas se habian deteriorado tanto que son retiradas.
237 Más información en: https://biodi-
vers2015.wordpress.com/

238 Véanse planos de Biodivers I en anexo 


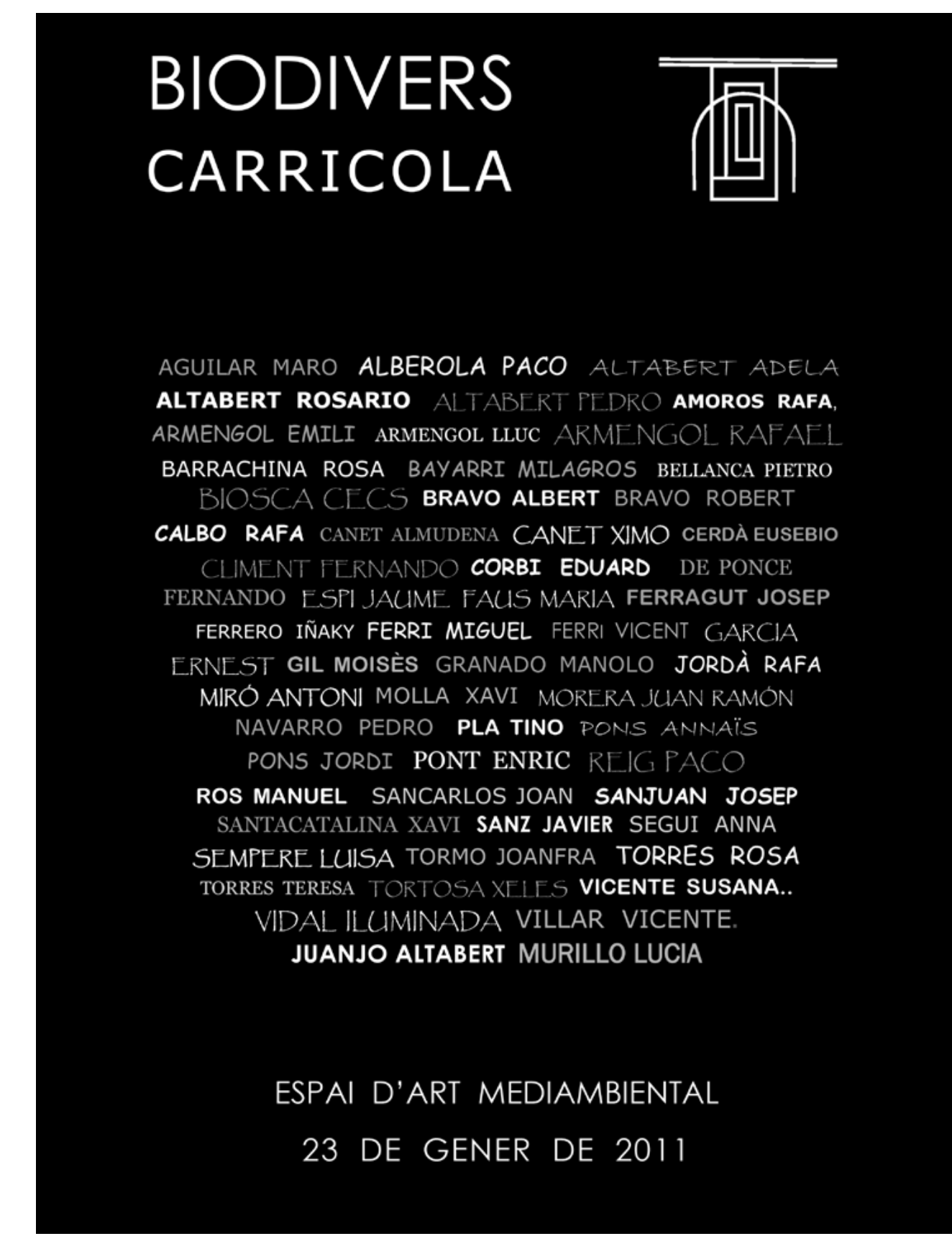

Imagen 73. Listado de participantes en Biodivers I. Fuente: Pedro Altabert
La convocatoria Biodivers 2015 aglutina a 38 artistas y 26 obras $^{239}$, alrededor de la premi-

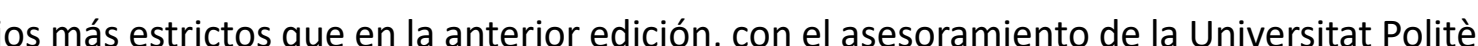
nica de València y teniendo en cuenta: la integración en la naturaleza, el camuflaje, la sorpresa, la armonia, el respeto ecológico, la puesta en valor de zonas degradadas u olvidadas y criterios noterales que permiten, únicanente, el empleo de matenales vegetales, aninales o minerales no artificiales. Hoy dia, ya se han integrado en el medio hasta desaparecer algunas de las obras de la segunda edicion ta años. La tercera edición está prevista para 2018.

5.3.2 Obra propia: El hogar del pan

total.

240 El jurado de expertos estuvo forma-

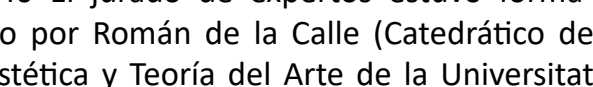
de València), J. Albelda, y Joan Peiró (profesores de la Facultad de Bellas Artes de San
Carles, Universitat Politécnica de Valècia)
junto a miembros de la Alcaldía y un artista de la población vecina de Albaida. 241 Proyecto presentado por Pablo Guillén
Marzal y Nuria Sánchez León en noviembre

Hemos tenido oportunidad de realizar parte de esta investigación desde el propio territorio al haber sido seleccionados ${ }^{24}$ para participar en Biodivers 2015 con la obra El hogar del pan. Esto nos ha apoyado en el mérodo de lavestigación Acción Partic catva (IAP). Nuestra intención era experimentar en primera persona el proceso de construcción colaborativa de una obra de arte ecológico partiendo de las necesidades y deseos de la población de Carrícola.

El proyecto nace a raíz de nuestras visitas a la población en 2014. Las interacciones surgidas con la comunidad de vecinos nos han dado la oportunidad de conocer, poco a poco, mucho de lo que este lugar podía ofrecer. Una de las cosas que llamó nuestra atención fue que la única panadera en el pueblo, Marta Feliu, carecía de horno para cocer el pan. En muchas poblaciones en todo el mundo los habitantes han compartido y aún hoy comparten hornos comunitarios. Hasta hace pocas décadas Carricola disponia de uno, pero una rotura unida a la legada de los modernos hornos eléctricos acabó con esta tradición. Feliu habla manifestado su interés al Ayuntamiento en crear un proyecto de horno. La convocatoria de Biodivers era la ocasión perfecta para dotar a Carrícola de su propio horno comunal mediante la intervención artística. Con esta pieza buscamos:

1. Crear una obra colaborativamente, partiendo de la situación particular del lugar y sus gentes. 

fuerce la cooperación a la hora de compartir los recursos (leña) pues el calor del horno dura hasta veinticuatro horas.

3. Que actúe como punto de encuentro y reunión mientras se cocinan los alimentos. Un aportación al tejido social del pueblo que pretende crear comunidad «a fuego lento», de un modo acorde a los principios de la transición a la sostenibilidad.

4. Ampliar la oferta de elementos de uso público comunes tanto para los habitantes, como para los visitantes que deseen disfrutar de su entorno natural.

5. Contribuir a otro modelo de sociedad y alimentación, fomentando el consumo de proximidad, la disminución de la huella de carbono, el ahorro energético, las prácticas del compartir y la desaceleración de los ritmos de vida.

6. Recuperar una tradición del pasado que les ayude a ser más resilientes frente a los posibles desafíos que la crisis energética y ambiental pueda plantearles.

Conscientes de la importancia de la implicación de los habitantes desde el inicio, el proyecerencias y adaptada a os para ello elementos naturales que podemos localiza e merrespondiente huella de carbono de los desplazamientos de malent. Por está realizada por Vicent Bohigues, maestro mam postero de la zónem, con piedra de un antiguo margen cercano. Para el horno en si, utilzamos la tradicional técnica del homo moruno, con arcila del vecino pueblo de Castellón del Rugat, arena y paja, que forman una estructura sólida y resistente que alberga en su interior el fuego, el hogar para la elaboración del pan o de cualquier otro alimento. Las obras se prolongaron durante los fines de semana de cuatro meses, incluyendo un largo periodo intermedio de parón por secado. Su emplazamiento, en la zona urbana, permite el uso público para la población de Carrícola como horno y cómo símbolo de unión de los habitantes alrededor del hogar. Por otro lado, invita a los visitantes a disfrutar de una variante al clásico picnic, al tiempo que cumple un función estética y de recuperación de tradiciones sostenibles. Hoy en día, el horno está disponible al uso, se ha utilizado en diversas festividades y ha dado un empuje a la consolidación de un pequeño negocio de panadería en Carrícola.

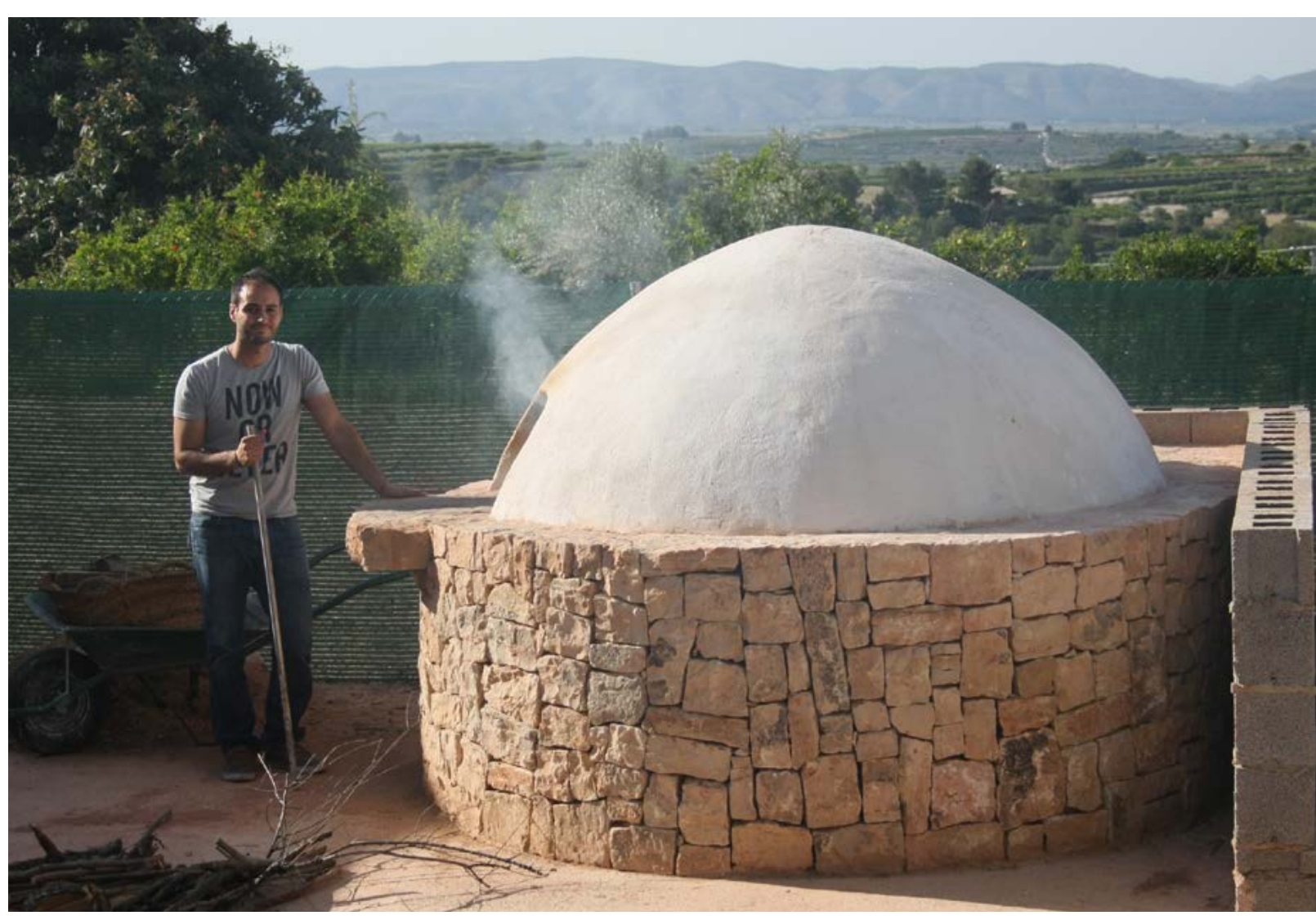

Imagen 74. Pablo $\mathrm{G}$
autora, mayo 2015

\subsection{ANÁLISIS}

Antes de comenzar este análisis sobre la influencia de estos itinerarios artísticos en la transición, quisiéramos puntualizar que vamos a considerar, por un lado, la influencia de la convocatoria artística Biodivers en su conjunto, en el presente y futuro del pueblo ${ }^{243}$. Por otra parte analizaremos también nuestra obra en particular, El Hogar del pan, de un modo crítico que nos aporte un aprendizaje para futuras experiencias.

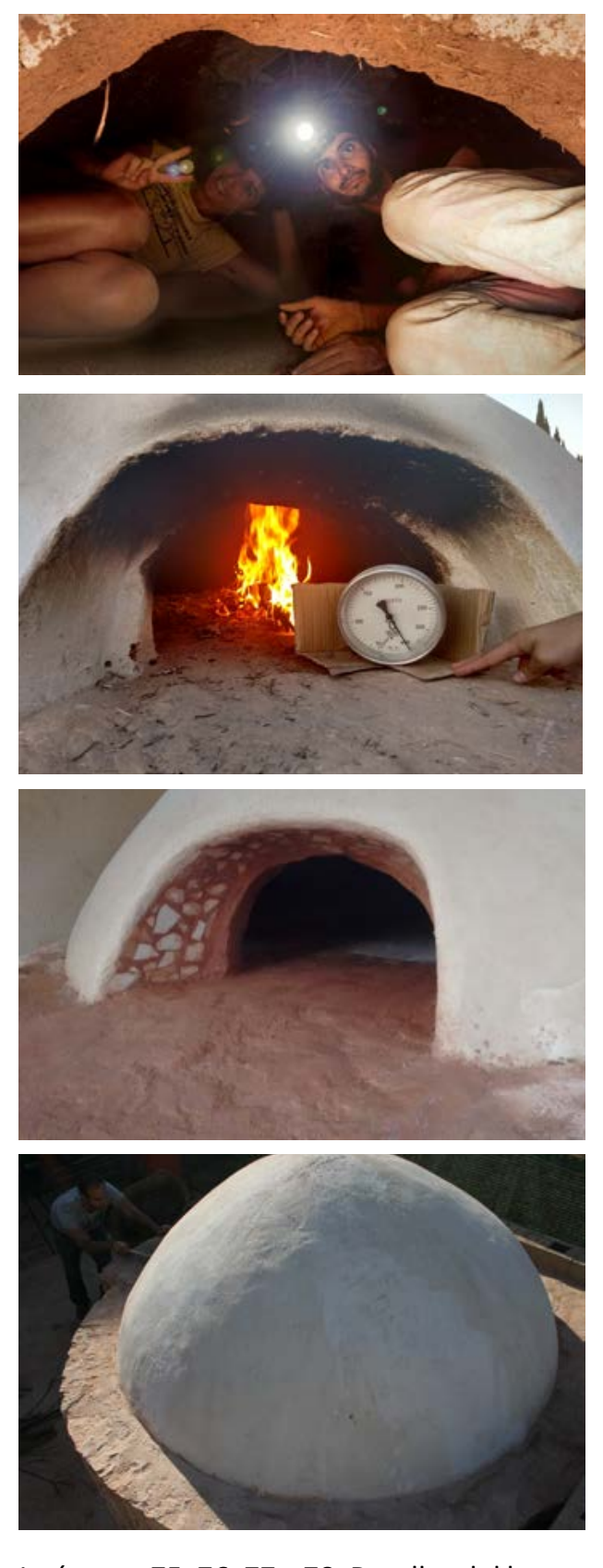

Imágenes $75,76,77$ y 78 . Detalles del horno
en funcionamiento. Fuente: fotografías de en funcionamiento.
la autora 2015-2016. 
243 Para un estudio más detallado de las
obras en particular, se puede consultar el artículo de María Eugenia Rojo Mas (2015) titulado: "Creaciones valencianas y eco"Biodivers Carricola "s o medioambienta catálogo de Biodivers 2010 (Bayarri et. al. 2010) o bien la web de Biodivers:
biodivers2015.wordpress.com/

244 Traducción de la autora: Mujeres en la
calle. En la obra reza el texto siguiente: $E$ n enero de 1965 Carmen tenía unos 80 años. Su nieta, Carmen Blasco, que ahora en 2015
tiene la edad de 82 años, nos cuenta que su abuela desapareció durante tres noches por la montaña. Un domingo después de acompañar a sus hijos se va a visitar la ermita, pero la curiosidad hizo que tomara un ca da ni abrigo en pleno invierno. Después de estar todo el pueblo buscandola durante 4 días, cuando ya la creían muerta, la enconhaća leña Y cargando con ellas al cuentlo llevo al pueblo. Cuando la encontraron estaba en buenas condiciones de salud y hablaba del tiempo que habia estado desaparecida como una buena experiencia, como vos parajes, y fascinada por haber dormido bajo un cielo lleno de estrellas.

245 Pablo Guillén Marzal y la autora Nuria Sánchez León.
En cuanto al primer tipo de participación (origen y responsabilidad), la convocatoria Bio-

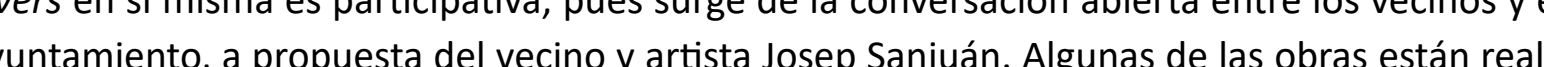
a vecino y artista Josep Sanjuán. Algunas de las obras están reali2adas por los propios habitantes, como Plenitud de la tardor, (2010) de Adela y Rosario Altabert de inspiración y sin las tradiciones, historia o memorias del propio lugar que sirven como no lexistirian. Este es el caso de la pieza Mujeres en la calle de Lucia uan, donde la autora recopila vivencias y memorias de las mujeres del pueblo representando la curiosa historia de Carmen en cerámica (Bayarri et. al., 2010).

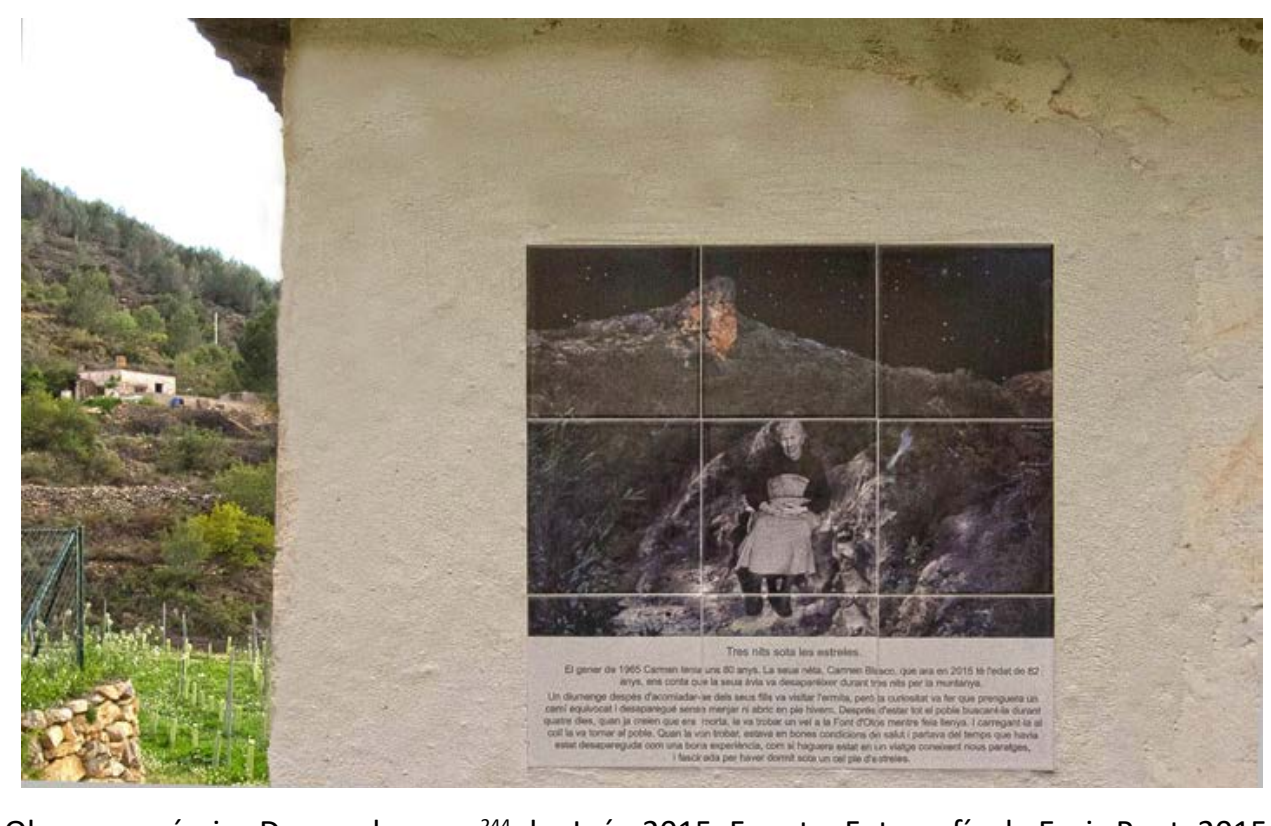

Imagen 79. Obra en cerámica Dones al carrer 24 de Juán 2015. Fuente: Fotografía de Enric Pont, 2015

En cuanto a nuestra obra, propuesta por un aparejador y una artista245 en colaboración, la idea

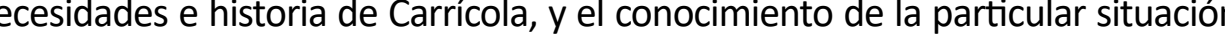
del negocio de panadería, de modo que en ese sentido, compartimos la responsabilidad de su origen.
En cuanto a la colaboración tipo dos (codesarrollo), como dice su alcaldesa Susana Cháfer, parte, desde el diseño del horno se contó con la opinión de Feliu'246, la panadera, y los miembros del Ayuntamiento, adaptando las dimensiones y emplazamiento del diseño original a las Bohigues en la construcción de la base, como uno de los co-autores imprescindibles de la obra.

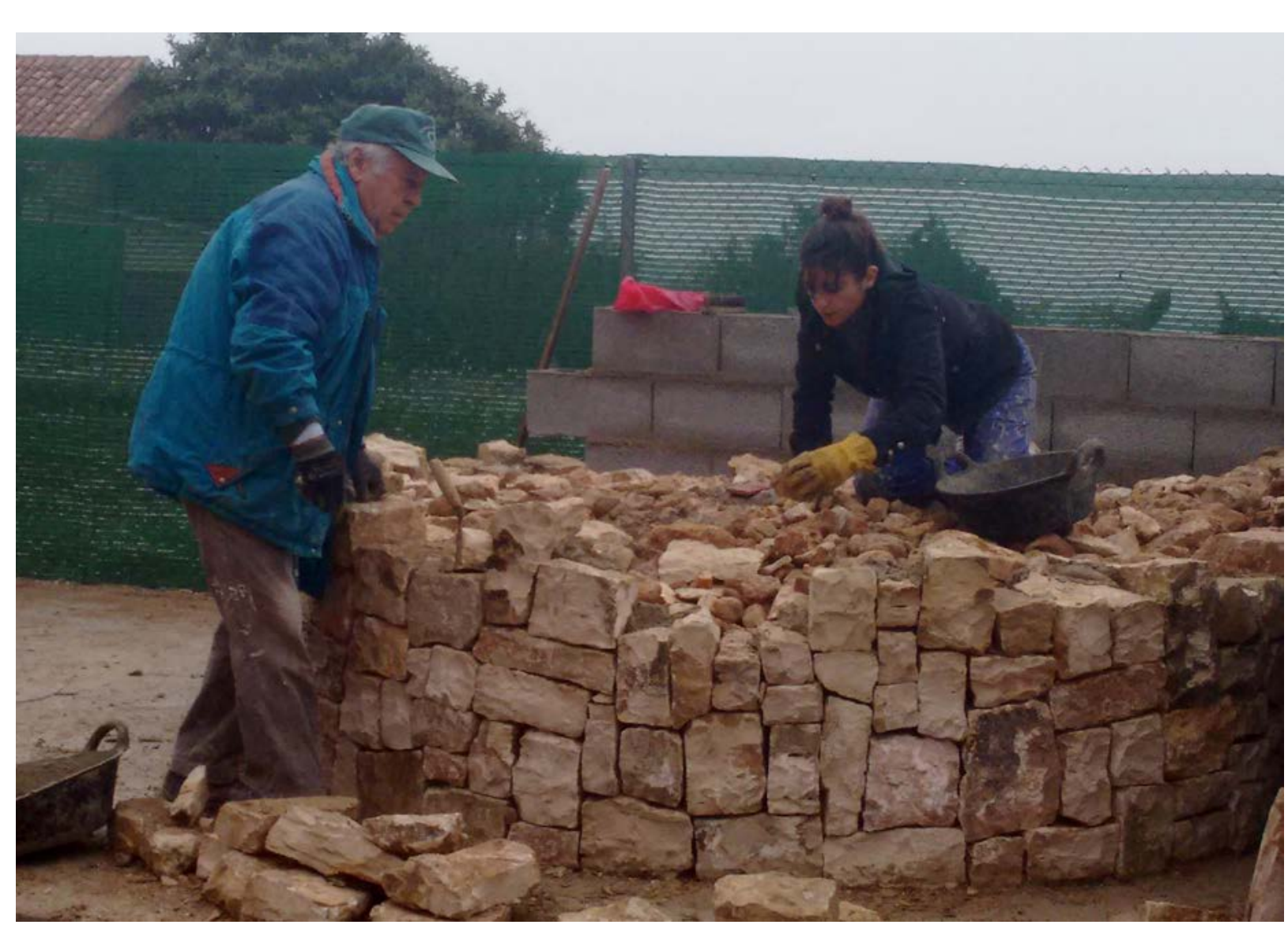

Imagen 80. Vicent Bohigues construyendo la base del horno y la autora. Fuente: fotografía de la autora, 2015.
246 Esta persona abandonó el proyecto y
el pueblo antes de acabarse la construcIOn pasando el testigo a Ruth Palaci, quien

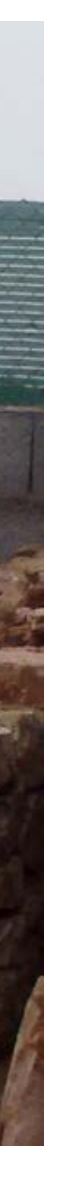


"EL HOGAR DEL PAN “ Vicent Bohigues rematant la base de pedra seca del forn Pablo i Nuria, que ja tenen la primera fase amb el pis col-locat.

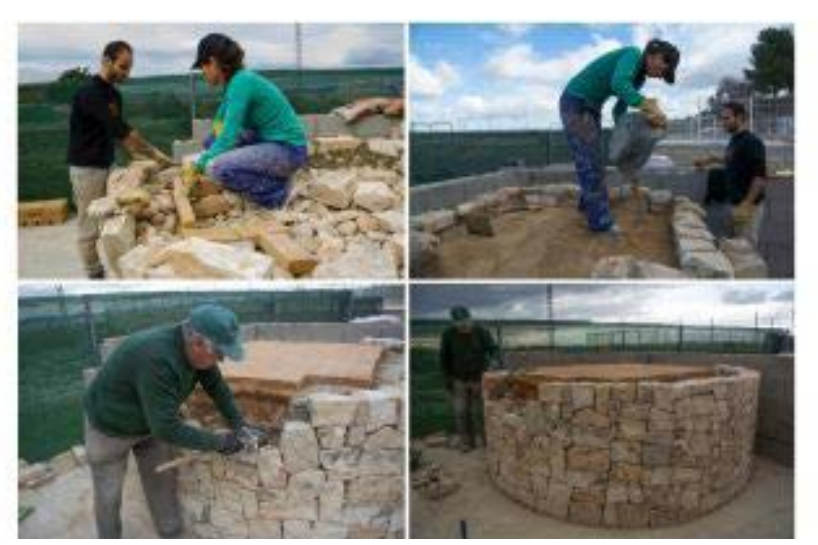

Imagen 81. Blog de Biodivers con comentarios sobre el avance de las obras durante su construcción: Tra.

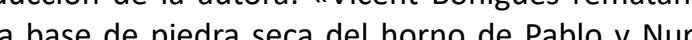
que ya tienen la primera fase con el suelo colocado Fuente: fotografias de Altabert, $2015 \mathrm{https} / / /$ biod vers2015.wordpress.com/2015/02/16/cap-de-se-

Tipo tres (voluntarios y ejecutores): En varias obras de Biodivers los vecinos participan durante Azael Pérez Diálogos de encuentro en la cul enseña a las gentes del pueblo la técnica japonesta mejicano par 作
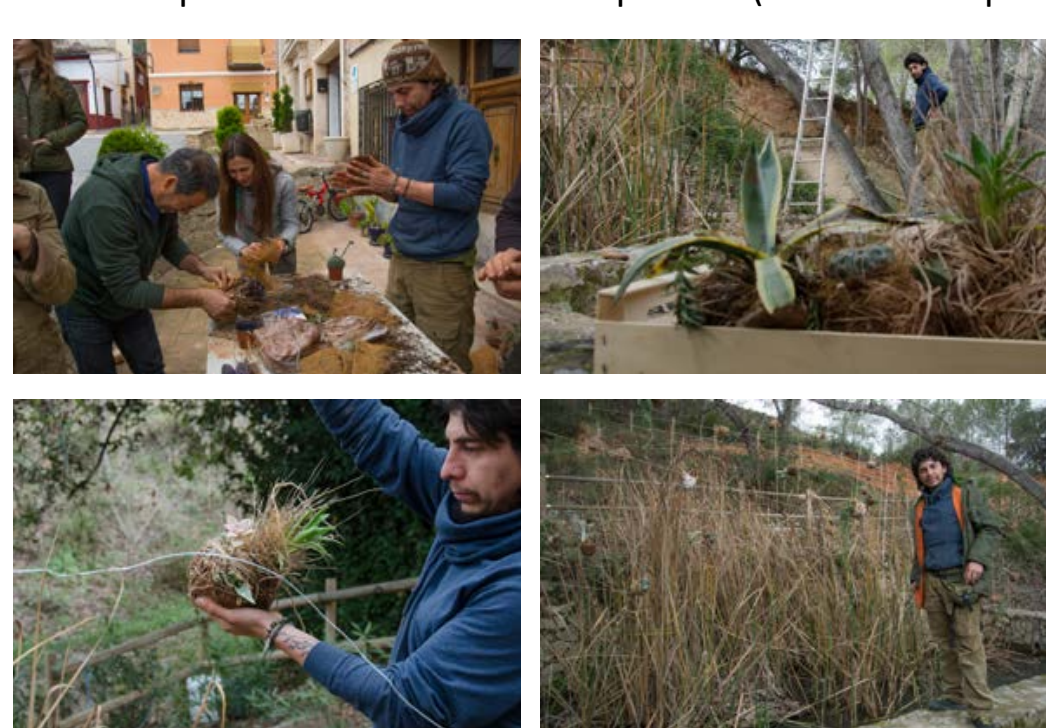

mágenes 82-85. El artista Pérez reali-

n colaboración con los lugareños
fuente: fotografías de Altabert, 2015 .
En nuestro caso en particular, aunque como artistas hemos «liderado» -en forma . Durante su construcción contamos desde el inicio con Juan Martí Martí, agricultor y jubilado. Posteriormente otras personas del pueblo se implicaron de alguna u otra forma ya fuera prestando sus herramientas, compartiendo su experiencia y conocimientos o simplemente haciendo compañia. Con la perspectiva del tiempo, tres años después, entendemos la importancia de esa colaboración inicial como factor fundamental para desarrollar el sentimiento de propiedad compartida del horno. Llama la atención que ninguno de los jovenes del pueblo se interesara en la fase de construcción, pero en su lugar acudieron otras personas de nuestro entorno deseo de ver terminada la obra activaron a un grupo de vecinos, y juntos logramos finalizar la fase de construcción. Fueron unas horas de trabajo colectivo frenetico y emocionante. Mano a mano, veíamos ascender el muro de barro mientras crecía a la par un sentimiento de unión. Las posteriores fases de vaciado y enlucido, ya más tranquilas, no precisaron de la colaboración colectiva aunque toda ayuda era bien recibida.

\section{EL FORN}

Posted on $\underline{27 \text { febrer, } 2015}$

Cap de setmana a tope per fer la segona fase del forn, amb la col.laboració d' amics i gent de Carrícola, que sempre està a punt per tirar una mà. Gràcies a tots.

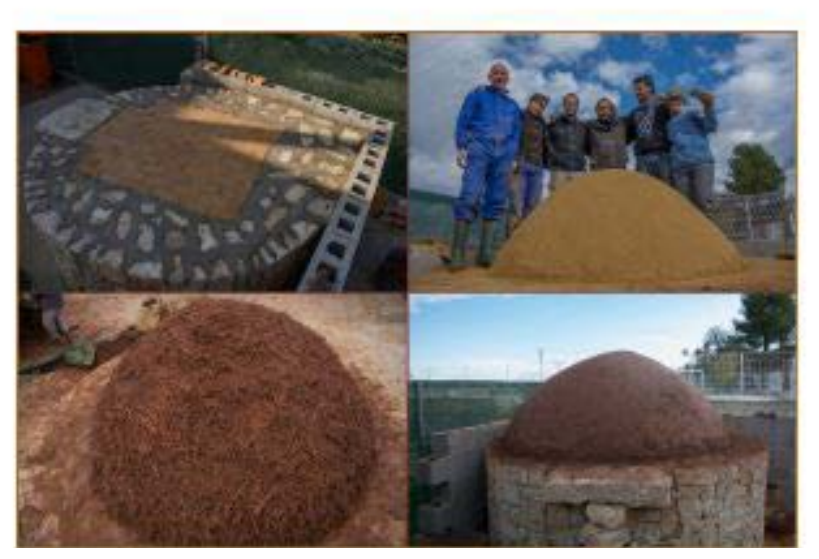

Senes 86-89. Blog de Biodivers. Traducción de fase del horno, con la colaboración de amigos $y$ la gente de Carrícola, que siempre está a punto para Char una mano. Gracias a todos.» Fuente: fotografías

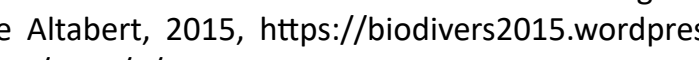




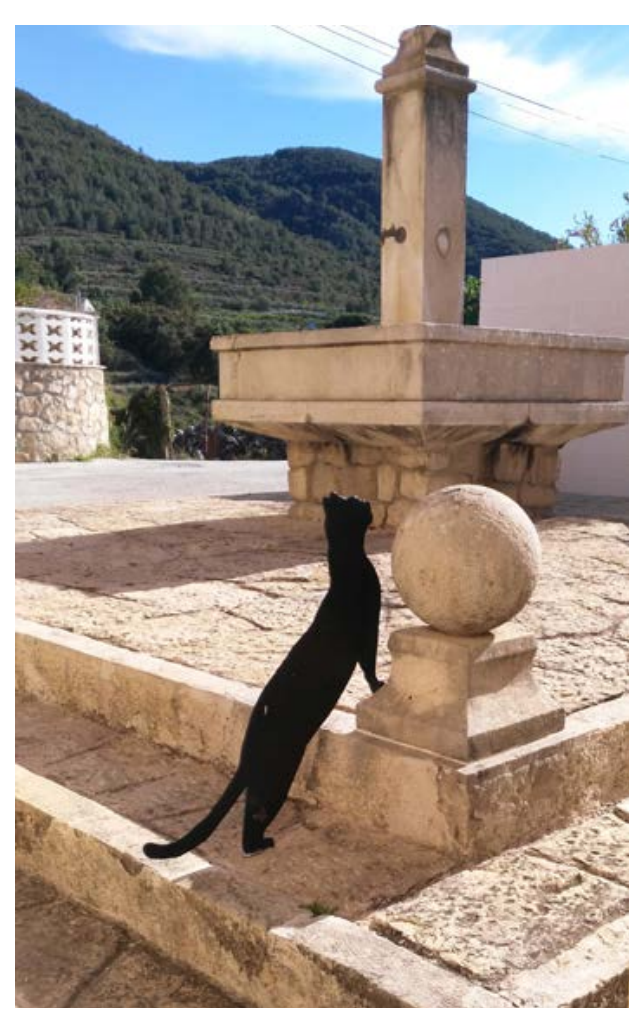

Imagen 90. Obra No som quatre gats? De Maro Aguilar: Fuente: fo

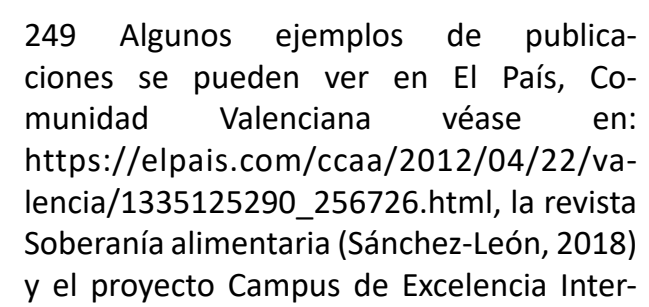
Soberania alimentaria (Sáncher-León, 2018
y el provecto Campus de Excelencia Inter-

Cómo es de esperar en una creación colectiva de estas dimensiones, surgen numerosos momentos emotivos, de tensión y de celebración. Pero nos ocuparemos aquí de señalar solo los puntos que consideramos que influyen en el papel de la convocatoria Biodivers en la transición a a sostenibilidad. En primer lugar, respecto al apoyo institucional, los inicios no fueron sencillos: De la Calle comenta diversas dificultades, como los esfuerzos de la alcaldía por encontra participantes y respaldo de otras entidades, la distancia de Carrícola con el ámbito artístico y con esferas de influencia, así como los conflictos organizativos (2012). Como hemos visto en el caso de Almócita o DUO, el soporte de las instituciones puede determinar el éxito o dejar pasar un proyecto inadvertido. Un punto clave que supuso un cambio positivo a este respecto, fue la incorporación del propio Román de la Calle, entonces presidente de la Real Academia de Bellas Artes de San Carlos, al proyecto como presidente de Biodivers Carrícola 2011. S presencia y amparo favorecieron el interés y la participación de la comunidad artística, y pronto mundo del arte para atraer artistas de calidad y asegurar cierto impacto.

Asimismo, volvemos a remarcar que en una convocatoria como ésta, la implicación de los habitantes $-\mathrm{y}$ cuanto más involucrados en decisiones trascendentes desde el origen mejorresulta crucial para el éxito de la propuesta. Si Biodivers ha supuesto un giro para Carrícola sido porque el pueblo entero, en conjunto y con coherencia, se ha lanzado en esa dirección.

En concreto, en nuestra obra, como en todo trabajo de equipo, puede haber momentos de tensión. Sin duda, el instante crítico tuvo lugar en una fase de la construcción en la que, debido a la envergadura del horno, necesitamos más mano de obra ${ }^{254}$. El espíritu participativo de la convocatoria se hizo patente en ese momento de tensión que impulsó la colaboración y sin el cual, el horno, no sería «tan de Carrícola»"55. No obstante hemos de admitir que no se logró suficiente poder de convocatoria en el pueblo y entendemos ahora que es preciso, en este tipo de obras colaborativas, elaborar una estrategia que motive la participación. Por ejemplo, una fórmula podría consistir en una charla previa con un constructor de hornos reconocido como Matéu Ortoneda - con quien nosotros mismos aprendimos - o un pase de diapositivas que visualice proyecto final y motive la participación, anunciar el calendario de acción o la organización de la ejecución como taller de aprendizaje para interesados en este tipo de iniciativas. Esto nos lleva a plantearnos que, en residencias artisticas como esta, que tienen un periodo de duración que va de unos pocos días a unas semanas, ¿es realmente un tiempo suficiente para que la acción del artista se implique verdaderamente en el lugar? El artista turco Can Altay (invitado desde la convocatoria Campo Adentro a intervenir en Carrícola en 2012) y la artista madrileña Lucia Lore
Valenciano, véase en: http://campushabi-
tat5u.es/wp-content/uploads/2011/07/ Biodivers-Carricola.pdf. Sin embargo, no hemos encontrado ningún estudio académi-

250 Sin embargo, no hemos encontrado ningún estudio académico sobre Biodivers a 251 Véase el tráiler en: http:///ecohumani-
dades.webs.upv.es/documental/ 252 Véase en : http://ecohumanidades.
webs.upv.es/ $\mathrm{com} /$ el atardecer y todavía con mucha arcilla por poner, varios lugareños se lanzaron a amasar barro con sus botas $y$ colaborar en todas desa y sus padres danzzaban encima de una
capa de barro, mientras Pedro Altabert $y$ arcilla para hacer más masa. Esteban Cháer (teniente alcalde), los habitantes Bruno nuestros colaboradores Felicia Samper, Adrián Llorens, Thamas Decker y yo misma, Camos haciendo crecer las capas del horno pañeros. Entre todo el tumulto, personal
del hostal, grababa toda la escena a petición nuestra. Finalmente, avanzado el crepusculo, cerrábamos la cúspide de barro de
b que es hoy el horno de Carrícola, tras halo que es hoy el horno de Carricola, tras ha-
ber puesto en movimiento alrededor de dos

mil kilogramos de material, princi
con la energía de nuestras manos. 
255 Un año después, por casualidad, escu- (invitada a realizar una intervención en 2015 por el Ayuntamiento), representan dos extremos chamos como una guía turística les habla- de comportamiento del artista en el medio. Altay propuso la construcción de varios carromatos

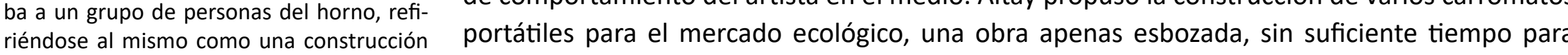
realizada por los habitantes del pueblo en conocer a los lugareños y sus verdaderas necesidades. Los mismos fueron quienes ejecutaron conjunto, algo
escuchar. a costosa obra por su cuenta, sin apenas colaboración por parte del artista que ya había tenido 256 En varias conversaciones con las gentes del lugar han expresado sus reticencias a tica cuya ejecución tuvo que ser completamente asumida por los carricolinos.

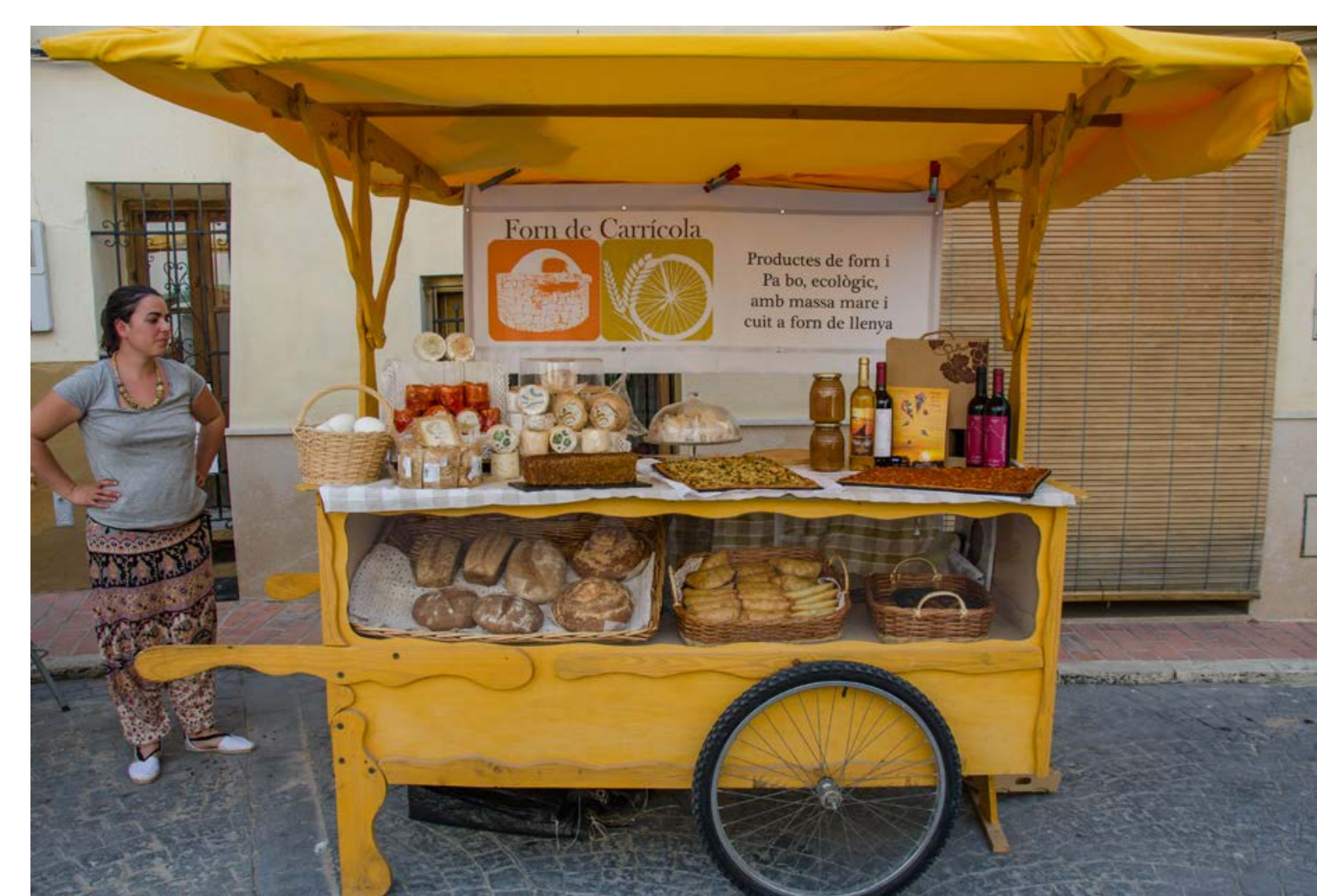

Imagen 91. Ruth Palaci la panadera junto a uno de los carromatos del mercado agroecológico. Fuente: Fotografía

Sin embargo, Loren desarrolló y ejecutó, en colaboración, una idea mucho más sencilla pero asequible y simbólica para el pueblo, que lanza un mensaje alto y claro (visible desde Goo- gle Maps) respecto a la propiedad de la tierra de labor y al problema de la falta de relevo genera cional. Por tanto, concluimos que existe un equilibro delicado en cuanto al nivel de participación que Loren conoce y sabe emplear. Demasiada colaboración - tanta que sustituya al artistaescasa, deja al público indiferente.

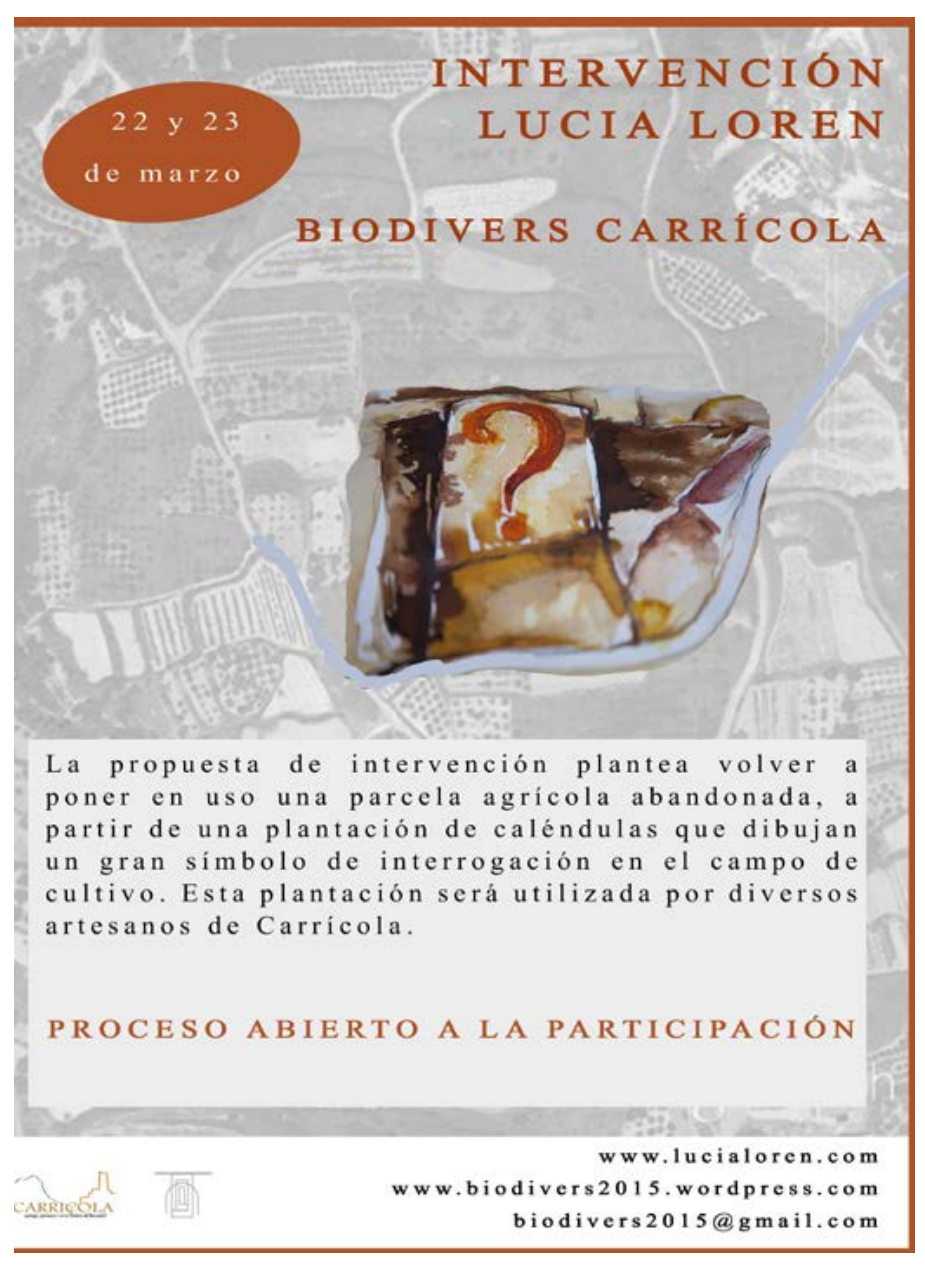

Imagen 92. Cartel convocando a la participación en la obra de Loren
diseño de Altabert.

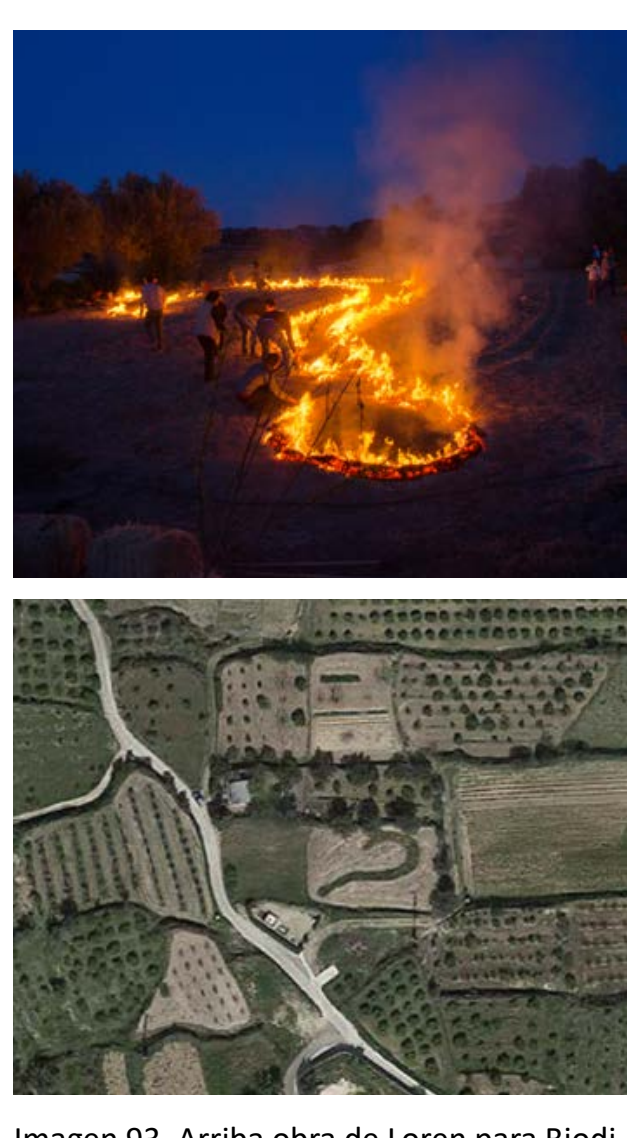

Imagen 93. Arriba obra de Loren para Biodivers 2015, aunque realizada con posterioriman esta interrogación que los carricolinos mantienen con riego por goteo $\mathrm{y}$ usan en sus platos $y$ esencias artesanales. Fuente: fotografías de Altabert 2016-2018

Imagen 94. Abajo vista de satélite de la obra de Loren en una de las muchas parcelas sin cultivar por falta de relevo generacion.
Fuente: extraída de Google Maps. 


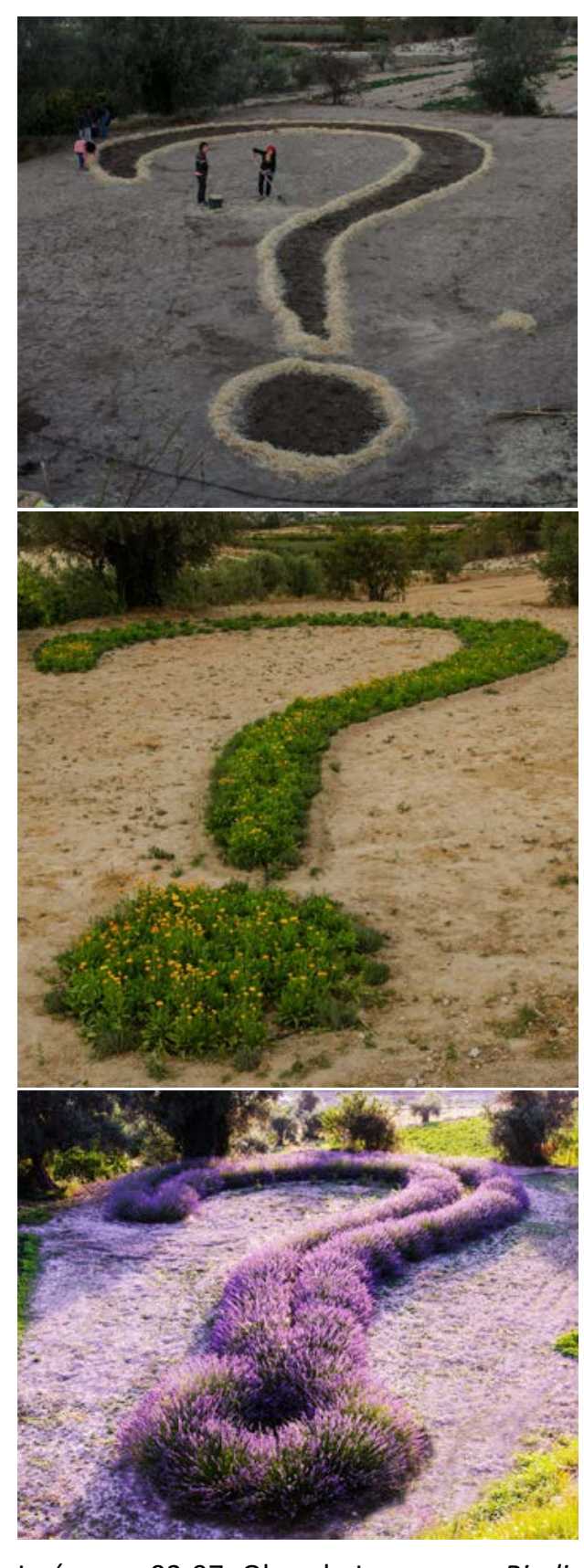
Imägenes 93-97. Obra de Loren para Biodi
vers 2015. Fuente: fotografatias de Attabert vers 2015.915.
$2016-2018$.
En cuanto al apoyo institucional y la financiación, todos los participantes seleccionados 列 tos en materiales, desplazamiento y dietas. Esto influye en la calidad de las piezas presentadas or tanto en su poder para despertar empatía. En nuestro caso recibimos un apoyo extra debido la envergadura de la pieza. El Ayuntamiento de Carrícola fue sumamente generoso sufragando todos los costes materiales asi como las dietas y alojamiento durante la construcción. Otras fuentes de financiación han sido el Patronato Provincial de Turismo, València Terra i Mar, que ha colaborado con el Ayuntamiento de Carrícola en la señalización de las obras artísticas de Biodi vers. También han recibido el apoyo de La Agència Valenciana del Turisme que ha incorporado estos itinerarios artísticos dentro de la Red de centros de arte contemporáneo del entorno rural. Esta red pretende ampliar la oferta cultural del interior de la Comunitat Valenciana para contribuir así a su desarrollo turístico.

Por último, otro punto clave en la función de concienciación ecológica de esta convocaria, es la necesaria coherencia entre la estética y la ética que respalda el proyecto. La no biodegradabilidad de algunas obras de la primera ydicín crica que respalda el proyecto. La no bio

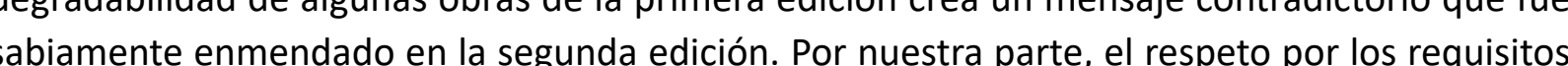
sobre materiales determinó la elección del modo de construcción (horno tradicional moruno) y las materias primas a usar (arcilla, paja, barro, agua y piedra del lugar fundamentalmente).

\subsubsection{Intención}

Las intenciones de Biodivers responden en mayor medida a dar respuestas alternativas desarrollo social y urbano frente a los graves problemas de despoblamiento y protección del patrimonio y el paisaje, que a un interés concreto en la concienciación ambiental. Si bien, el del parimonio yel paisaje, que a un interés concreto en la concienciación ambiental. si bien, el modo elegido para enfrentar estas cuestiones cruciales ha sido la creación artistica sostenible en coherencia con la etica de progreso urbano de Carrícola. Pero, como ocurre en el ejemplo de Almócita, para el vistante al parque de esculuras que reciba solo el plano informativo con las rutas, ni las preocupaciones de sostenibilidad ni las intenciones son evidentes ${ }^{257}$. Sería aconsejable en este punto incluir información sobre la convocatoria, la ética ecológica del pueblo y los requisitos materiales de cada edición, para que se comprenda la visión del proyecto en general.
Coincidimos con Rojo $(2015$, p. 799) en lo discutible de algunas intervenciones, que distraen

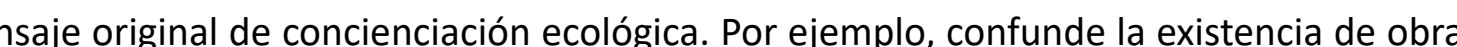
biodegradables en avanzado estado de degradación como Pulpo de río 258 comparado con la presencia de otras obras de hierro intactas en su forma, aunque oxidadas. Nuevamente nos encontramos con la contradicción señalada por Demos entre el mensaje y el medio, en exhibiciones en torno a la sostenibilidad que no comportan - al menos no en todas las piezas - consideraciones de la huella de carbono, huella ecológica, reversibilidad, biodegradabilidad de la intervención etc. (2009, p. 19).
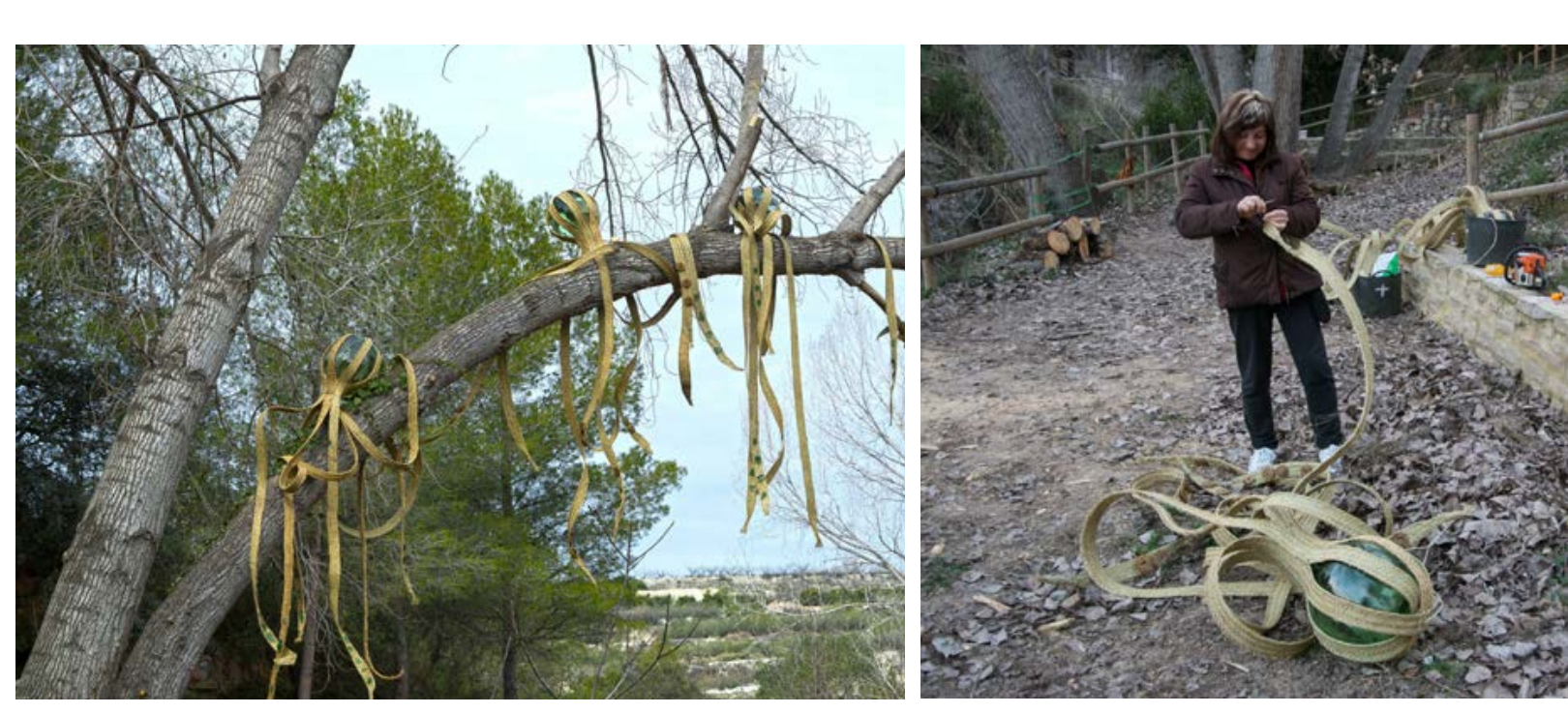
Imagen 98. La obra Polp deriu hect
fuente: fotografiá de Enric Pont.

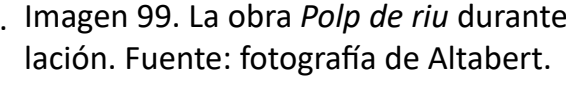

n cuanto a nuestras intenciones prácticas concretas, ya se han señalado en el apartado 5.3.2, pero en el trasfondo de éstas existe la intención de crear un tipo de obra artística que nos abra a nuevas formas sociales, que mejore las condiciones de la comunidad a través del arte, que supere la representación del problema e implique al espectador como fuerza activa, como parte del problema y la solución a la par. Es un arte político en el sentido que trata la «ética de lo colectivo» (Riechmann, 2014, p. 30). Perseguimos un nuevo ideal de belleza más acorde con la moral ecológica, la justicia ambiental-social y el equilibrio de la relación ser humano-naturaleza,

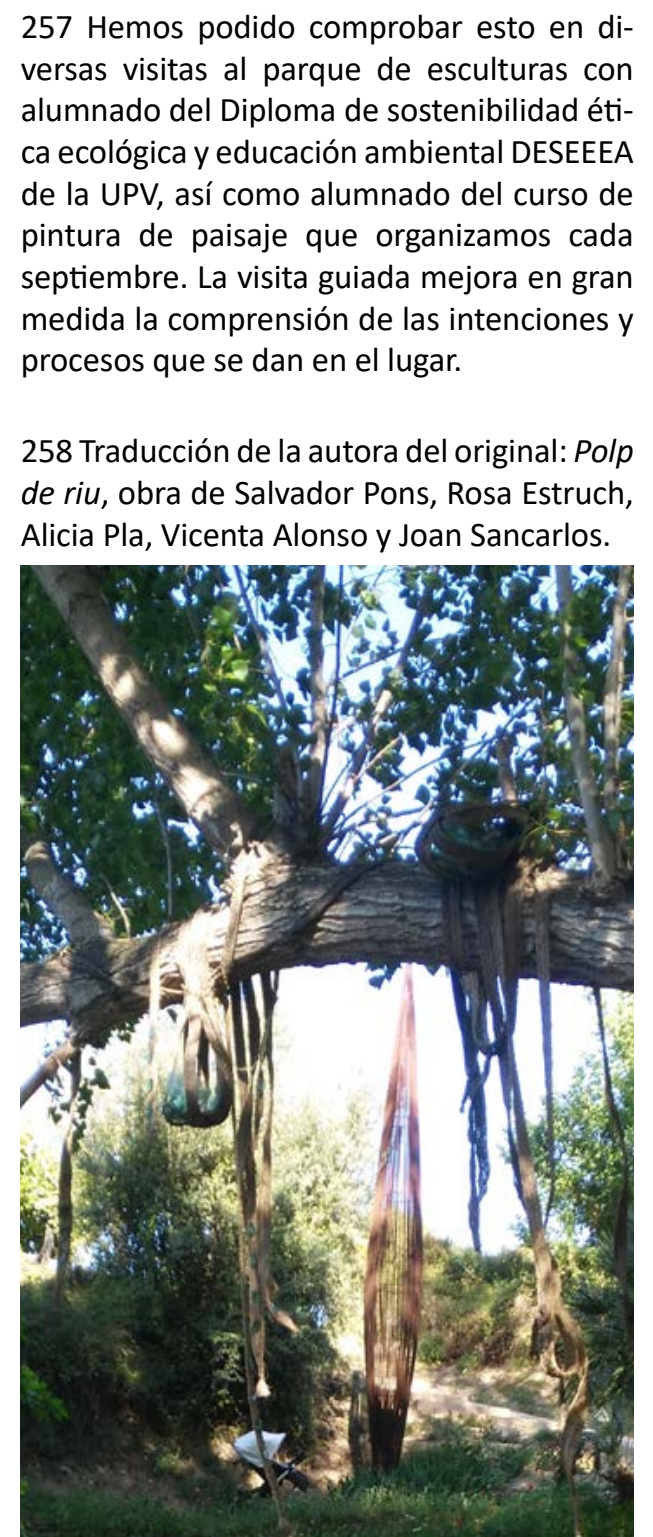

magen 100. Polp de riu en primer plano soXiprer (Ciprés) de 2010 a y detrás, la obra en acero. Fuente: fotografía de Arantxa Fernández Alcayde 2018. 
259 Sí existe, un estudio detallado de que con la estética de las formas. Sin embargo, nuestras intenciones iniciales no se han visto la media maratón MIMAMUCA, que correspondidas en cuanto a nivel de participación y sobre todo, una vez terminada la obra. Los se celebra desde 2012, y su impacto correspond positivo. Véase en: Soler Vayoann. $y$ sal comunidad y refuercen la identidad del pueblo no se han visto colmados al nivel que esperábamos. Concluimos que no hemos sabido transmilir estas intenciones o encontrar los momentos caso de Carrícola en la comarca d La Vall d'Albaida (España)", Revista de 69. Disponible en: http://www.pasoso $/ 4$. org/Publicados/15117/PAsosos51. pdffpage=49

5.4.4 Efectividad

260 Al respecto la alcadesa comenta sión del bar-tienda municipal y además pagaba la mitad del consumo eléctrico. Y ahomensual de $216 € /$ /mes" y y además: «ta con cesión del hostal-restaurante genera el 10\% de los recursos ordinarios del presupuest

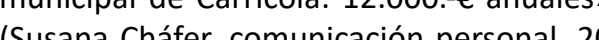

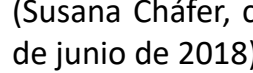

A nivel general Biodivers ha supuesto un lanzamiento de Carrícola al panorama nacional como referente de pueblo en transición a la sostenibilidad. Como alternativa artística al museo,

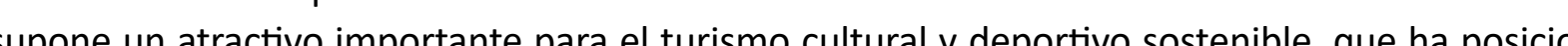
nado a una a tequiva localidad en el mapa Aunque no era esa su intención en un pincipoy de

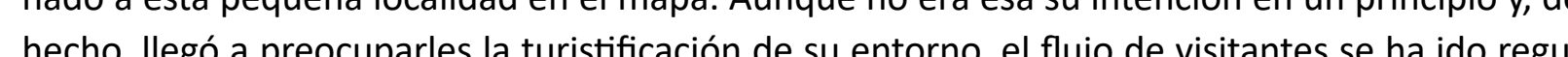
larizando y en la actualidad unadie percibe la afluencia de visitantes como una invaíno (Sus na Chéfer, con la na Cháfer, comunicación personal, 20 de junio de 2018). A pesar de que no existen mediciones al respecto del numero de visitantes totales a Biodivers ${ }^{29} \mathrm{o}$ los beneficios económicos que $h$ comportado (Rojo Mas, 2015), para sus habitantes, no hay duda de que ha facilitado el éxito de otras actividades sociales y económicas como el mercado de artesanía y productos ecológicos y de proximidad de los fines de semana, las dos casas rurales que se han habilitado, el proyecto de camping con alojamientos bioclimáticos, el hostal y el bar ${ }^{200}$. Producto de ello, se ha publicado un catálogo de la primera edición de la muestra, y está en camino el de la segunda. Además, de la Calle propuso crear en paralelo a las actividades un programa de Jornadas Bienales de Reflexión sobre el Paisaje (2012) con publicación de actas, que finalmente no ha sido llevado a cabo.

tros proyectos que se apoyan en el parque escultórico son el servicio de visitas guiadas convocatoria haya contribuido al crecimiento de la población directamente, sí se observa por parte del Ayuntamiento que «forma parte de una manera de entender y de hacer que junto con otros proyectos municipales han atraído a población a Carricola» (Susana Cháfer, comunicación personal, 20 de junio de 2018). Un indicativo de ello es que la población ha aumentado, al con- trario de la tendencia en los pueblos rurales agrícolas (Escribano Pizarro, 2004, p. 6), llegando (1) 105 personas en 2013 (Generalitat valenciana 2017) lo cual, supone un aumento del 13\% desde la primera edición de Biodivers en 2010. Considerando la época de crisis económic de entonces, es un gran logro. Si comparamos con el mínimo poblacional alcanzado en 1991, el aumento actual es del $42 \%$ (Generalitat valenciana, 2017).

Por otra parte, en cuanto a los efectos en la concienciación ambiental no se han recopilado datos al a que trabaja la purio sus itinerarios artísticos y los valores ecoéticos sobre los que se sust

Podemos decir que el provecto artístico de Biodivers es algo más que un laboratorio de alternativas del medio rural, es toda una realidad perdurable, con capacidad de crecery renovar su atractivo en futuras ediciones (ya está prevista la tercera) y perfectamente extrapolable.

En cuanto a los efectos concretos de nuestra obra, el primero y más evidente ha sido el apoyo al negocio de panadería llamado El forn de Carrícola, creado por Palaci en abril de 2016, en el que colabora ocasionalmente Giner.

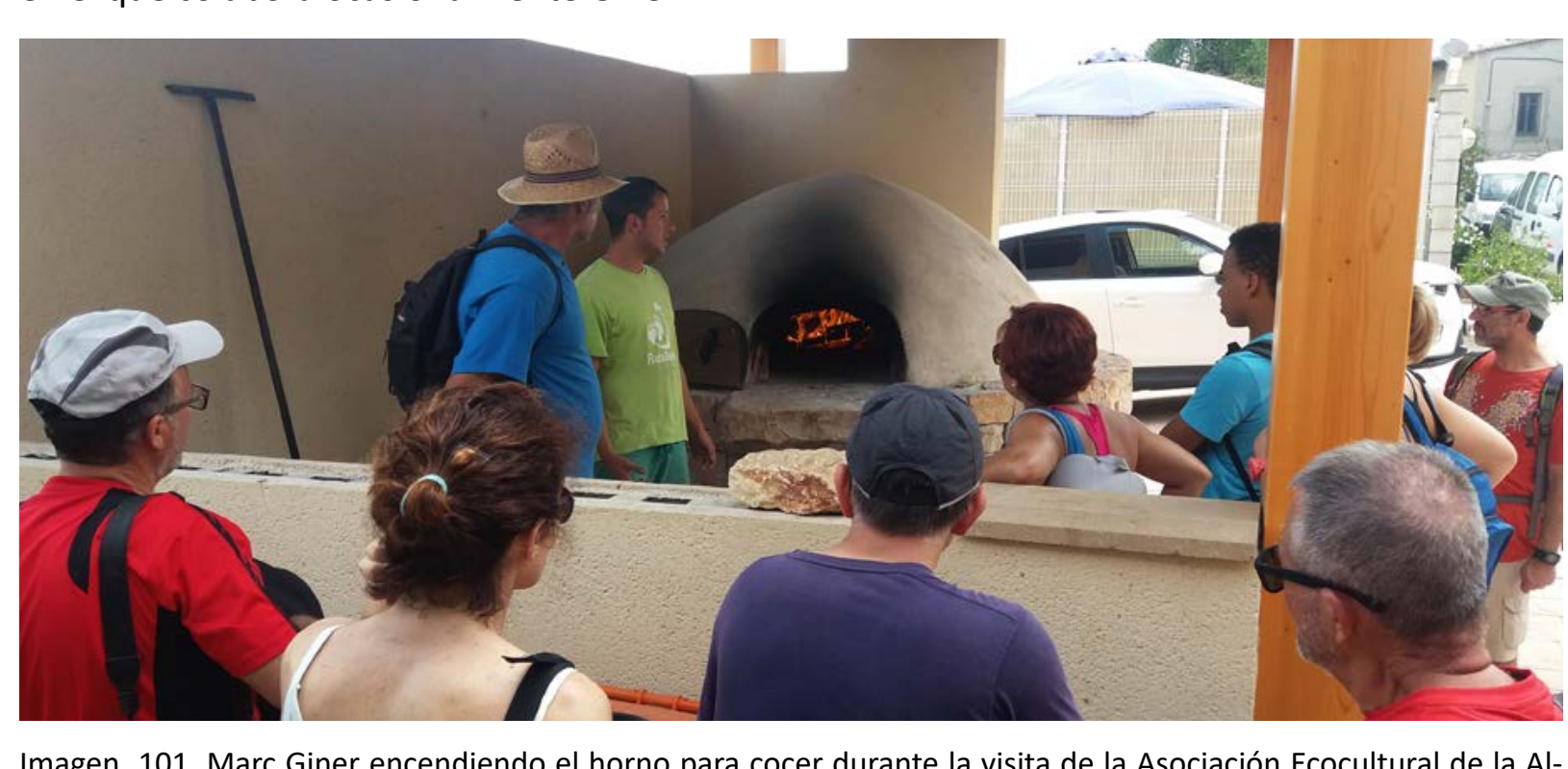
Imagen 101. Marc Giner encendiendo el horno para cocer durante la visita de la Asociacín Ecocultural de la Al-
cudia de Crespins La Garrofera, en julio de 2016. Fuente: fotografía de Altabert: https://biodivers2015.wordpress.
com/visites/
261 Trad
fardatio

262 Según listado del Ayuntamiento: dieVése su álbum devisias con cosde 2011 . titutos, asociaciones, academias, etc. en:
https://biodivers2015.wordpress.com/visihttps:

Forn de Carrícola

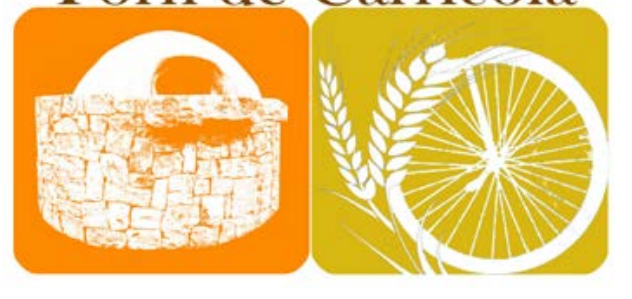

Imagen 102. Logotipo de la empresa Forn Imagen 102. Logotipo de la empresa Forn
de Carrícla con la imagen del horno. Fuen-
te: diseño de Ruth Palaci. 
a decisión de Palaci de continuar con la panadería ecológica en Carrícola, es clave para 作 amasado techando el espacio del horno y con la intención de cerrarlo:

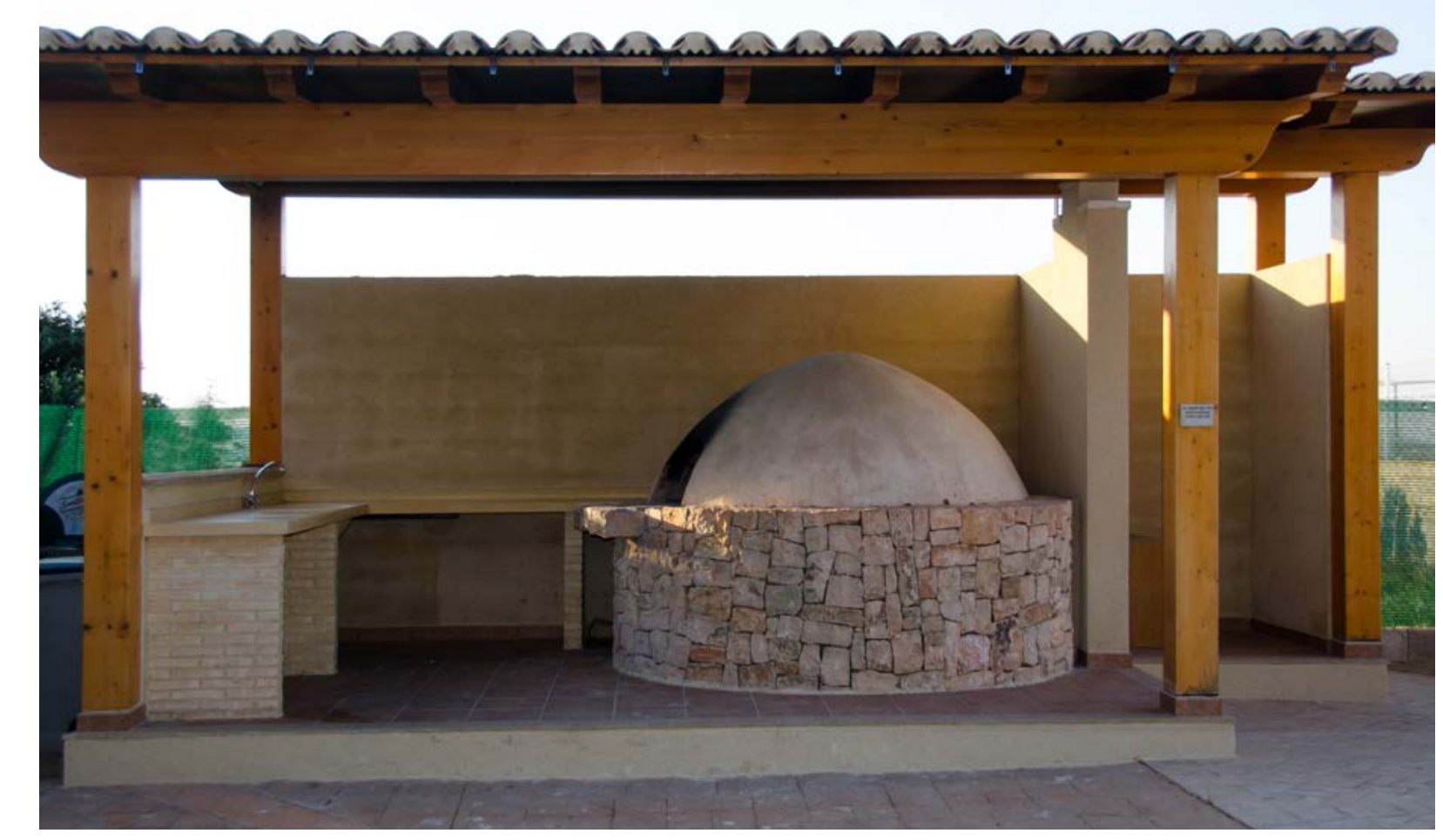

Imagen 103. Estado actual del horno
Fuente: Fotografías de Altabert 2018.

Durante el primer año de vida de la panadería (2016-2017), el horno era encendido dos veces por semana por Palaci y Giner para cocer los productos que servía tanto en el mercado groecológico de Carrícola los domingos, como en otros mercados y grupos de consumo. Según comenta Palaci, tras decidirse a apostar por el medio rural para «demostrar con la práctica que otro mundo, además de ser necesario, es posible» (Ruth, 2016) el horno le facilitó un empuje en sus nuevos planes de vida. Su funcionamiento, exclusivamente con leña que la misma Palaci recogía, supone cierto ahorro energético que no hemos podido medir, además de un beneficio para el campo por eliminar materia inflamable. Sin embargo, esta fatigosa tarea resulta ser (a) pa pan artesanal y ecológico, en veladas como la de San Juan o durante las escuelas de verano.

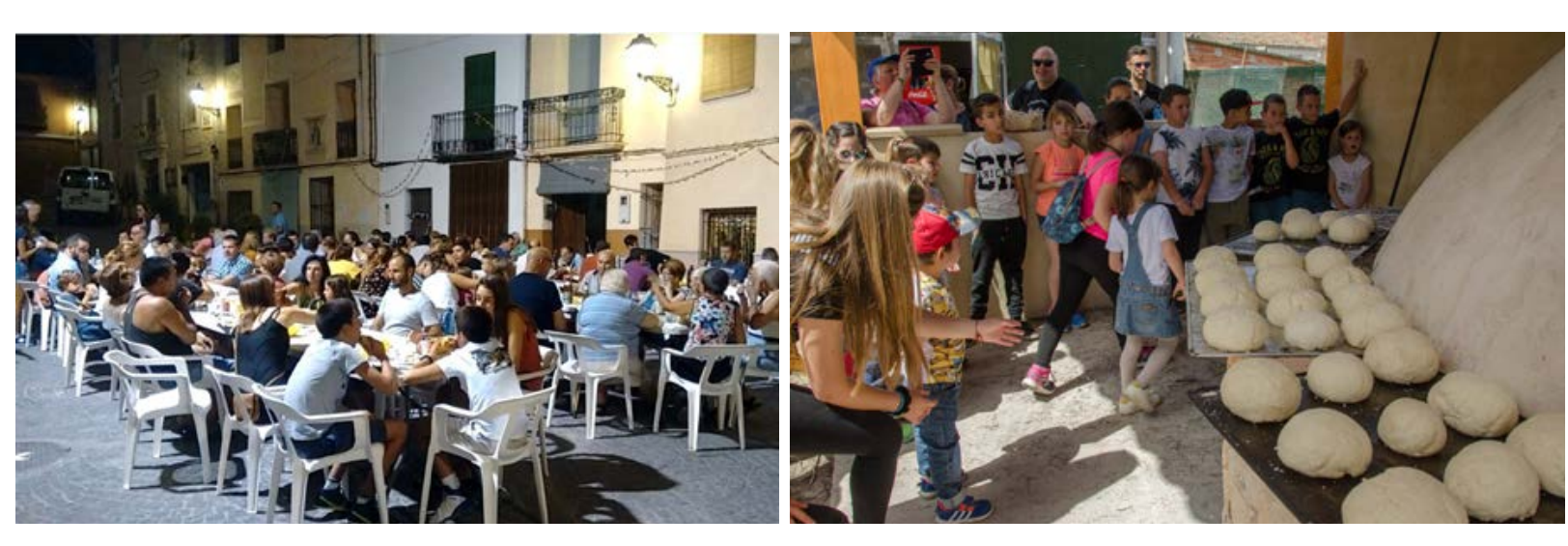

Imagen 104. Cena popular al arie libre en Carrícola. El Imagen 105: uno de los tallleres de pan con niños durante los niños y cocido en el horno, gracias al taller de pan orga-
nizado por Palaci. Fuente: fotografias de la autora 2015 .

A nivel de fomento de la colectividad, si bien es cierto que los habitantes aprovechaban los momentos de encendido del horno por Palaci para cocer sus alimentos, una vez se abandona su uso frecuente, los habitantes han vuelto a sus hornos eléctricos ${ }^{263}$. Concluimos que el proyec-

\subsubsection{Estética y ética}

Gracias a Biodivers la postal urbana es un ejemplo de fusión entre arte y naturaleza. De crucial importancia son los valores ecoéticos que residen en el espiritu de la convocatoria y que 

Montenmedio (Cádiz) (Marín Ruíz, 2015, p. 125). Entre sus obras distinguimos dos tipos de piezas, aquellas que se referencian a sí mismas, son autónomas y podrín emplazarse en casi cualquier otro lugar, y otras piezas específicas para el lugar que no reclaman esa autorreferencialidad, sino que necesitan el entorno concreto para tener sentido, como el horno o la obra Diálogos de Pérez hecha con la técnica kokedama. La intervención artística se hace con la pretensión de vincular temáticamente la obra al lugar para el que se diseña. Asimismo, la predisposición de la población a colaborar con los artistas amplía la variedad de tipos de proyectos a plantear (esculóricos, colaborativos, vivenciales,...) y la calidad del resultado de los mismos. Esta atmósfera de trabajo es fomentada no ya desde los artistas en exclusiva, sino también desde el propio Ayuntamiento. En cuanto a nuestro horno, las necesidades del lugar y sus gentes han marcado tanto su emplazamiento en el casco urbano como sus dimensiones y materiales. Aunque el proyecto original planteaba un recubrimiento estético inspirado en las formas de nido de Andy Goldsworthy, en virtud de la practicidad, $\mathrm{y}$ a solicitud del Ayuntamiento, se prescindió de complementos estéticos para adoptar una forma sencilla y un acabado en colores naturales y armoniosos con el entorno. La vivencia social a lo largo de los meses que se prolongó la construcción y después durante el servicio prestado a Palaci, tejió un nexo entre nosotros y la población a nivel persona que aún hoy perdura con fuerza.

\subsubsection{Funciones del arte}

Como en el caso de Almócita, podríamos citar numerosos motivos por los que lo artístico juega un papel fundamental en el municipio según sus propios habitantes, pero la función principal se puede resumir en que Biodivers ha contribuido a revitalizar Carrícola a dos niveles principalmente: la reactivación del territorio por puesta en valor de espacios abandonados y el rejuvenecimiento de la población por la llegada de nuevos pobladores jóvenes. Pero no solo, a continuación desarrollamos más en detalle estos aspectos: programas para niños y jóvenes, promueven un cambio de actitud respecto al medio ambiente, programas para ninos you potencian la capacidad de observación, la empatía y despiertan la aptitud artistica fomentando a la par há solidario. Cada año reciben la visita de decenas de colegios e institutos que recorren sus tres circuitos señalizados y mapeados: los caminos del agua, el circuito urbano y el camino del barranco divertido, singular y rico en referencias culturales cercanas.

2. El arte cataliza procesos de transformación del territorio:

Biodivers nació en un contexto de apoyo a la puesta en valor y recuperación de espacios naturales y una mejor comprensión del patrimonio de Carricola acompañando y valorizando su arquitectura árabe y evitando su olvido y degradación. La rehabilitación de los márgenes puso al descubierto las arcadas del s. XIII antes ocultas por la maleza. La ubicación de las obras en estas rutas y entornos antes poco frecuentados atrae a los visitantes, que contribuyen al mantenimiento de los caminos y, sobre todo, a un cambio en la percepción del territorio revalorizando zonas en desuso que ahora son itinerarios culturales. Cháfer destaca el acierto que supuso vincular las obras artísticas a esos espacios y comenta que uun Biodivers sin vinculación a un entorno no tendría sentido» (Susana Cháfer, comunicación personal, 20 de junio de 2018).

3. El arte contribuye a la recuperación de la memoria, de la identidad y la dinamización de la vida en el territorio:

Muchas de las obras de Biodivers parten de deseos, memorias y conocimientos específico de los propios habitantes como la construcción del horno. El artista se convierte en cómplice de habitante materializándolos, facilitando la acción colectiva y la implicación directa. Esa colaboración refuerza su identificación con las obras, a medida que participan y relatan su propia historia y, en mayor o menor grado, actualizan su entendimiento del arte contemporáneo. Además, et hecho de que la mayoría de los habitantes participe de algún modo u otro en la convocatoria 
264 La MIMAMUCA cuyo lema es «Depor- potencia un sentimiento de pertenencia e identidad. Esta marca identitaria creada a través del te, montaña y arte» recorre en sus siete arte, visibiliza sus singularidades en el contexto de la comarca, lo cual atrae a visitantes durante divers, «el hecho de que la prueba discurra todo el año.

en paralelo a esta exposición al aire libre es turistica asi como un medio de generar seny la comarca» (Soler Vaya y San Martin Gondemuestra que ambos eventos (MIMAMU
CAy Biodivers) se benefician mutuamente.

4. El arte se ha convertido en un elemento de desarrollo económico y valor cultura:

El atractivo singular de Biodivers ha posibilitado el éxito de otras acciones de resiliencia todavía en fase inicial con casitas de construcción bioclimática- o el Encuentro Anual Ecologista del País Valenciano, diversificando el tejido económico. Esto ha permitido a nuevos pobladores instalarse, lo cual rejuvenece a la población - ha pasado de una edad media de 55 años antes de Biodivers a otra de 35 años en 2012 - que ya cuenta con nueve niños.

\begin{tabular}{|l|l|}
\hline \multicolumn{1}{|c|}{ FUNCIONES } & \multicolumn{1}{|c|}{ JUSTIIFICACIÓN } \\
\hline $\begin{array}{l}\text { Ilustrar, representar, } \\
\text { comunicar, difundir }\end{array}$ & $\begin{array}{l}\text { Sí, algunas de sus obras representan a la naturaleza, elementos del } \\
\text { patrimonio o bien al convocatoria en sí comunica valores de armonía } \\
\text { con el entorno y protección del paisaje. }\end{array}$ \\
\hline Concienciar & $\begin{array}{l}\text { Si, aunque no como un objetivo principal sino secundario derivado de } \\
\text { la actividad de educación ambiental que realiza El Fardaxto. }\end{array}$ \\
\hline Desarrollar empatía & $\begin{array}{l}\text { Sí, durante las visitas guiadas de EI Fardatxo se busca despertar } \\
\text { empatía y desarrollar sentimientos de ecodependencia. }\end{array}$ \\
\hline $\begin{array}{l}\text { Imaginar, desarrollar la } \\
\text { visión del grupo, su misión, } \\
\text { futuros posibles, utopias o } \\
\text { ficciones }\end{array}$ & $\begin{array}{l}\text { Si, la preocupación por el futuro de estos parajes les ha conducido por } \\
\text { la senda del arte. }\end{array}$ \\
\hline $\begin{array}{l}\text { Ofrecer soluciones, } \\
\text { mostrar alternativas } \\
\text { reales o proyectos piloto, } \\
\text { laboratorios de pruebas }\end{array}$ & Sí, el proyecto es más que un laboratorio, es una realidad. \\
\hline $\begin{array}{l}\text { Conectar personas, crear } \\
\text { comunidad, hacer redes, } \\
\text { mediar o facilitar }\end{array}$ & $\begin{array}{l}\text { Sí, mediante obras colaborativas como el horno o la obra de Loren y } \\
\text { Pérez antes mencionadas. }\end{array}$ \\
\hline $\begin{array}{l}\text { Conectar personas con } \\
\text { espacios, entornos o lugares }\end{array}$ & $\begin{array}{l}\text { Sí, es un objetivo expresado reconectar a la comunidad con los } \\
\text { espacios patrimoniales recuperados como la zona de las arcadas. }\end{array}$ \\
\hline
\end{tabular}

\begin{tabular}{|l|l|}
\hline $\begin{array}{l}\text { Restauración/recuperación } \\
\text { del entorno }\end{array}$ & $\begin{array}{l}\text { Si, se busca recuperar espacios paisajisticos y patrimoniales como las } \\
\text { arcadas y l torre. }\end{array}$ \\
\hline $\begin{array}{l}\text { Reforzar la identidad, crear } \\
\text { símbolos }\end{array}$ & $\begin{array}{l}\text { Es la función rrincipal del proyecto. Crear una identidad compartida } \\
\text { que los identifique en la comarca. }\end{array}$ \\
\hline $\begin{array}{l}\text { Fomentar la ciudadanía } \\
\text { crítica, agitar, denunciar }\end{array}$ & No se encuentra documentada. \\
\hline Empoderar & No se encuentra documentada. \\
\hline $\begin{array}{l}\text { Crear relatos positivos de } \\
\text { cambio }\end{array}$ & $\begin{array}{l}\text { Si, se contribure a crear un relato alternativo y positivo respecto al } \\
\text { desarrollo rural l la despoblación. }\end{array}$ \\
\hline $\begin{array}{l}\text { Facilitar la comprensión } \\
\text { del mensaje de la ética } \\
\text { ecológica aplicándola }\end{array}$ & No es una función claramente detectada. \\
\hline $\begin{array}{l}\text { Conectar áreas alejadas de } \\
\text { conocimiento }\end{array}$ & $\begin{array}{l}\text { No se busca la colaboración interdisciplinar premeditadamente, } \\
\text { aunnue surge en proyectos como el nuestro en el que colaboran } \\
\text { aparejadores, artistas, mamposteros, arquitectos y agricultores. }\end{array}$ \\
\hline $\begin{array}{l}\text { Motor iniciador de } \\
\text { dinámicas y proyectos }\end{array}$ & $\begin{array}{l}\text { Si, Biodivers reactiva otros proyectos como el mercado y el tejido } \\
\text { económico local. }\end{array}$ \\
\hline Celebrar & $\begin{array}{l}\text { No especialmente, aunque la celebración es parte de algunos de los } \\
\text { momentos de relación, como la fiesta de inauguración y nuestra obra } \\
\text { se utiliza en algunas fiestas municipales. }\end{array}$ \\
\hline Recaudar fondos & $\begin{array}{l}\text { No directamente, pero el atractivo de Biodivers atrae visitantes que } \\
\text { suponen unos ingresos sustanciales para los negocios de la zona y el } \\
\text { Ayuntamiento. }\end{array}$ \\
\hline Construir consensos & No se ha detectado claramente. \\
\hline Premiar, agradecer & No se ha detectado claramente. \\
\hline Aumento de la resiliencia & $\begin{array}{l}\text { No directamente, pero Biodivers ha contribuido al éxito de otras } \\
\text { acciones como el compostaje o los negocios locales que sí contribuyen } \\
\text { a la resilencia. }\end{array}$ \\
\hline Revitalización del territorio & $\begin{array}{l}\text { Sí, revitalización a dos niveles principalmente, a nivel de reactivación } \\
\text { de algunos territorios abandonados y de rejuvenecimiento de la } \\
\text { población por llegada de nuevos pobladores. }\end{array}$ \\
\hline
\end{tabular}

Tabla 9. Funciones del arte identificadas por la autora. Fuente: elaboración propia. 
En cuanto a los principios del arte transicional podemos decir que tanto Biodivers como El hogar del pan, encajarían en su definición por los siguientes motivos:

1. Intención: Sí, Biodivers tiene intenciones claramente expresadas relacionadas con la sostenibilidad, al igual que el horno.

2. Ignición: Sí, el proyecto artístico ha impulsado otros proyectos y negocios locales, un empuje crucial para el negocio de pan en sus comienzos según Palaci.

3. Marco: Biodivers marca la ética y las pautas de acción aunque en su primera edición se distorsionó al permitir todo tipo de obras, incluso algunas contradictorias con su mensaje.

4. Trabajar con la comunidad: Sí, toda la comunidad participa de algún modo u otro en Biodivers y muchos también en el horno.

5. Mediación: No tanto a nivel general en Biodivers como en las obras colaborativas en concreto. Sin duda durante la construcción del horno experimentamos la dificultad de ejercer el papel de mediadores, pero por otro lado, todo lo que dimos fue devuelto enriquecido gracias a la colaboración.

6. Mantener un espacio: Sí, se trabaja para revitalizar el territorio en general y zonas en desuso en particular. El horno busca reactivar el espacio público.

7. Conexión: Sí, tanto Biodivers en general como nuestra obra en particular persiguen crear espacios de relación.

8. Trabajar desde lo común: Sí, ya sean los espacios, las memorias o la historia.

9. Colaborar: Sí la colaboración como hemos visto es un factor fundamental.
10. Cambio: Sí, se busca cambiar la relación con el paisaje, el destino de los terrenos rehabilitados, el futuro poblacional del pueblo en sí $y$ en concreto nosotros, modo de producción del pan y los comunes.

Sin embargo, el arte transicional es aún desconocido para los artistas participantes en ambas ediciones y solo en nuestro caso, reconocemos identificación con dicha etiqueta a posteriori.

Al contrario que en Dundee y Dumfries, en Carrícola hemos podido estudiar el efecto del arte para la transición en una comunidad pequeña y con una sensibilización previa a respecto de la sostenibilidad. El impacto de las intervenciones artísticas parece más patente en este caso y en Almócita, que en los proyectos anteriores en ciudades grandes. De hecho, de entre las diversas iniciativas innovadoras en su contexto, Biodivers es el proyecto más emblemático de Carrícola y, posiblemente, el más conocido por su atractivo visual. La relación de respeto y protección de este pueblo con su paisaje es excepcional en el panorama español que en general acostumbra a una visión antropocéntrica de crecimiento

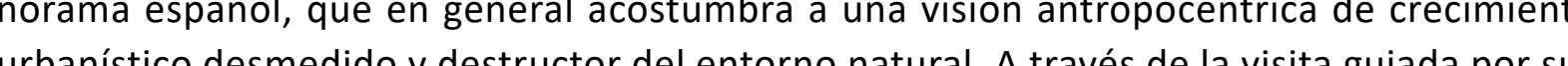
urbanistico desm diner por estos habitástes, muchos de ellos agricultores ecológicos. En Canicola la naturaleza está mucho más presente en el día a dia, generosa unas veces y agresiva otras, pero siempre percibida como necesaria. Y es que nuestro concepto de paisaje y la relación con él, dependen de la triada cultura-economia-poltica y, cómo no, de los medios de masas (Calle y Forriols, 2012). ¿Cómo vamos a cambiar nuestra relación con el entorno mirando hacia él desde la cultura del bienestar y la política del crecimiento económico? Sin embargo, Carrícola lo ha conseguido y su apuesta ha acabado convirtiéndose en su seña de identidad. Pero ¿qué tiene esta pequeña localidad, que no tenga el resto, para definirse a través de un diálogo respetuoso con el entorno? Un dato importante es que Carrícola siempre ha optado por permanecer rural y pequeño, pero independiente. No cabe duda de que el empuje de Ayuntamiento es fundamental en este caso para la instauración de modelos sostenibles de gestión de los recursos y del patrimonio cultural, social, histórico y natural (Rojo Mas, 2015, p. 790). Por otro lado, de la Calle nos recuerda que la idea de paisaje, como concepto subjetivo y constructo humano que es, cambia de una generación a otra, se construye según las herencias del mercado y la cultura (2012). De la misma forma, puede que fuera 
cambio iniciado en los ochenta, a la producción ecológica lo que ha virado el punto de vista de estas gentes y les ha preparado hacia una relación que asume más su ecodependencia $y$ tiende menos a la dominación del entorno. Aunque nos pueda recordar al ejemplo de Almócita, en este caso, la agricultura ecológica es un pilar iniciático básico, antes incluso que la creación artística; las obras de Biodivers salen del casco urbano para revalorizar también los entornos naturales y las restricciones materiales son más estrictas. Es decir, establecen una nueva relación con el paisaje desde el compromiso previo, ya iniciado, con una ética de la sostenibilidad. De este modo, Biodivers ha servido, fundamentalmente, para rescatar espacios perdidos y cristalizar esa nueva relación con el paisaje que les singulariza y fortalece su identidad. Esto facilita el éxito de otras acciones de resiliencia como, la agricultura y la panadería ecológicas, el compostaje, el proyecto de aguas residuales, el mercadillo otros negocios locales, lo cual, a su vez, ha permitido el establecimiento de nuevas familias. Frente al mensaje pesimista habitual al respecto del despoblamiento rural, Carrícola envía una postal positiva: se puede continuar siendo pequeño y rural, adaptarnos a las nuevas circunstancias ambientales, asumiendo nuestra ecodependencia y aprovechando las ventajas de la tecnología aplicada al contexto con mesura. El municipio es, por tanto, un modelo de resiliencia a través del arte, que pone de manifiesto el papel activo de la creación artística en la transformación social (Rojo Mas, 2015).

Por otra parte, Biodivers actúa en el territorio para transformar tanto a los habitantes como a los visitantes. Su programa de educación ambiental y visitas guladas ha abiefo rutas físicas, pero también vías verdes de conocimiento. De la mano de la estética medioambiental constituye una herramienta para capturar la mirada hacia la naturaleza que unifique. Pero ¿sentir una mayor vinculación desde lo visual con el lugar supone un cambio positivo en nuestro compromiso ecológico? Como decíamos en el capítulo uno, pensamos que no siempre, y por ello hemos planteado el horno como una obra colaborativa que implique a espectador no solo con la vista, sino con su intención y acción. La construcción del horno ha sido una experiencia de aprendizaje en todos los sentidos a nivel humano $y$ cognitivo. Lo ha sido una extico y tranformador reside en los procesos de dálogo, encuentro y colaboración pro. . de sus her un arte que promovemos es fundamental también para la vida del horno después de Biodivers, ya que la intención es que sea utilizado y compartido. No solo debe ser una pieza exposiunión de sus genter unión de sus gentes al calor del fuego. El horno engarza con las ideas de la transición en varios sentidos: promover la producción local265, el fomento de los comunes y los espacios
públicos, invitar a la cooperación y crear comunidad. Aunque reconocemos que no hemos públicos, invitar a la cooperación y crear comunidad. Aunque reconocemos que no hemos uso compartido ${ }^{267}$. Otras críticas que debemos mencionar son:

- No haber conseguido implicar a los jóvenes en el proceso constructivo.

- No hemos logrado fomentar la costumbre en los lugareños de encenderlo por si mismos salvo en los casos de Palaci y Giner. La avanzada edad de sus habitantes asi como la lentitud del proceso 268 y la incomodidad de buscar leña para encenderlo son los principales motivos argüidos (P. Altabert, comunicación personal, 21 abrit 2018).

- El resultado estético final es sencillo y práctico, en colores que armonizan con el entorno y acorde con los requerimientos de los habitantes. Pero precisamente por su sencillez y sentido utilitario no da pie a considerarlo como una obra artística para los visitantes. Sin embargo, hemos preferido responder a las necesidades reaan antes que realizar un acabado artistico, pero superfluo.

Rojo (Rojo Mas, 2015) menciona otras críticas a la convocatoria general como calcular Was, 20 a priori mediante un estudio de impacto ambiental, analizar nuevas vías de difusión e incluir el medio audiovisual como herramienta de registro. Quisiéramos añadir aquí que, tras tres años, se echa en falta cierta señalética que indique mejor las rutas y algunas cartelas de obras que faltan por deterioro. Para la tercera edición se podría aplicar una calculadora de huella de carbono que permita identificar puntos a mejorar. Aunque si pensamos en el proyecto a cuatro años, las principales emisiones de carbono procederán sin duda de los vehículos que trasladan a los visitantes a Carrícola. El pueblo, como muchos otros en el medio rural, carece de parada de autobús y tren. De hecho, la nueva planificación ferroviaria nacional favore la desaparicín de paradas de tren provinciales cono vecina de Albaida. Carrícola ha de plantearse sus comunicaciones en un escenario futuro de
265 De modo que la panadera no deba des-
plazarse a otros pueblos para hornear el pan que produce en Carricola.

266 Aunque ha sido realizado con materiase han desplazado desde Valencia (a novena kilómetros) y otros puntos en vehículo privado varios fines de semana para ayudar
en su construcción por lo que suponemos
una alta huella de carbono.

267 Durante un año la panadera lo ha esta-

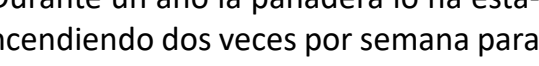
Ts habitantes también que llevabanan a por sus verduras y platos $y$ evitaban encender tro energétictco ha compensado en parte la rro energético ha compensado en parte la
huella de carbono antes mencionada para huella de carbonc
su construcción.

268 En el caso del horno a leña, necesita ser comendido entre dos y cocinar (en funchión de la temperatura
ganen calor. 
6.1 OTRAS MANERAS DE APORTAR DESDE EL ARTE A LA TRANSICIÓN

Hasta ahora hemos presentado proyectos artísticos colaborativos ubicados en entornos urales o urbanos que:

1. parten de las ideas de los habitantes invitados u organizados por un artista o colectivo

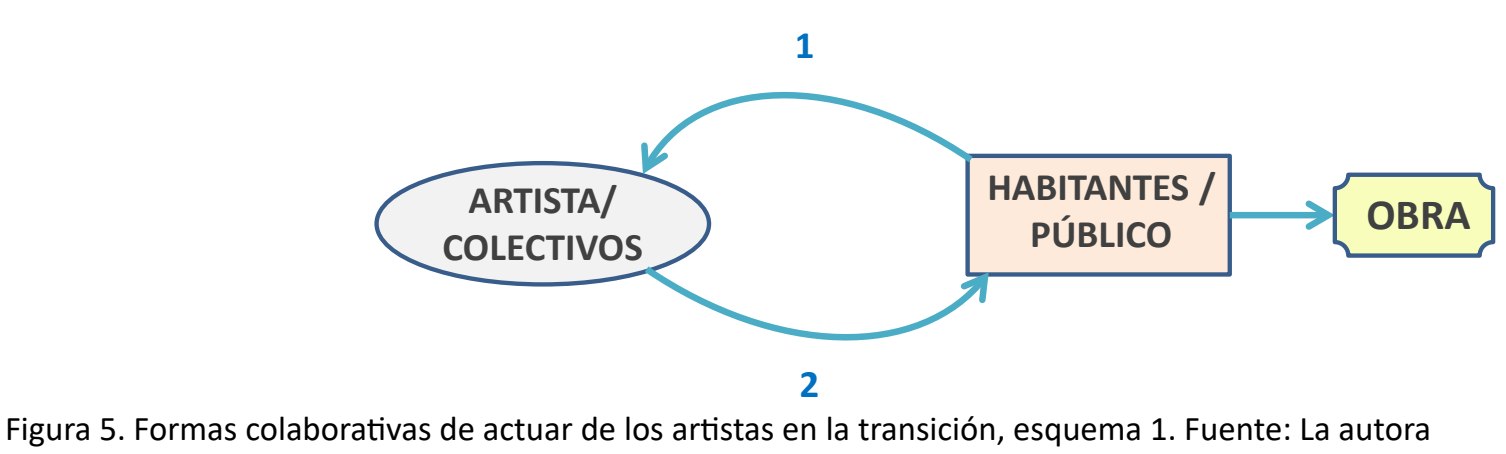

2. o bien son artistas inicialmente dispersos, que se organizan entre sí para animar a los habitantes a colaborar en un proyecto común (The Trashcatchers Carnival, The Nithraid y We Live With Water).

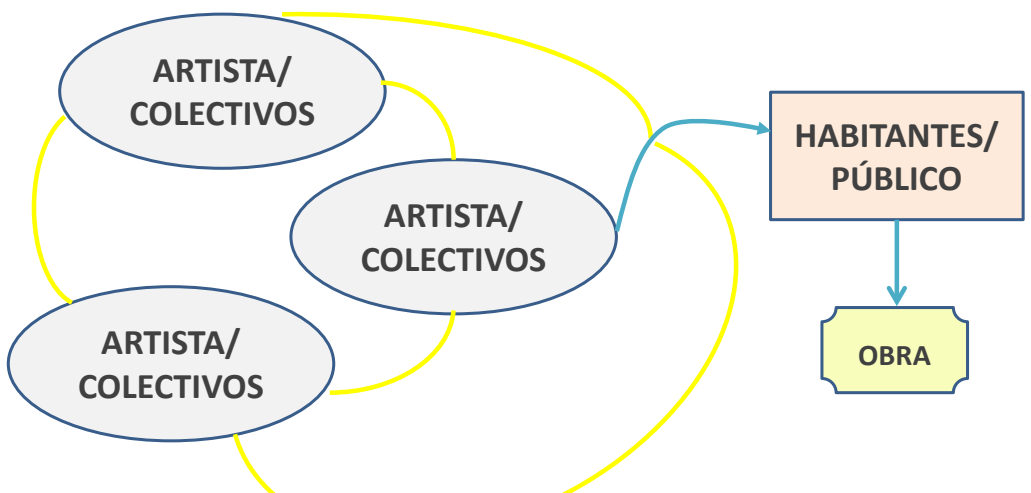




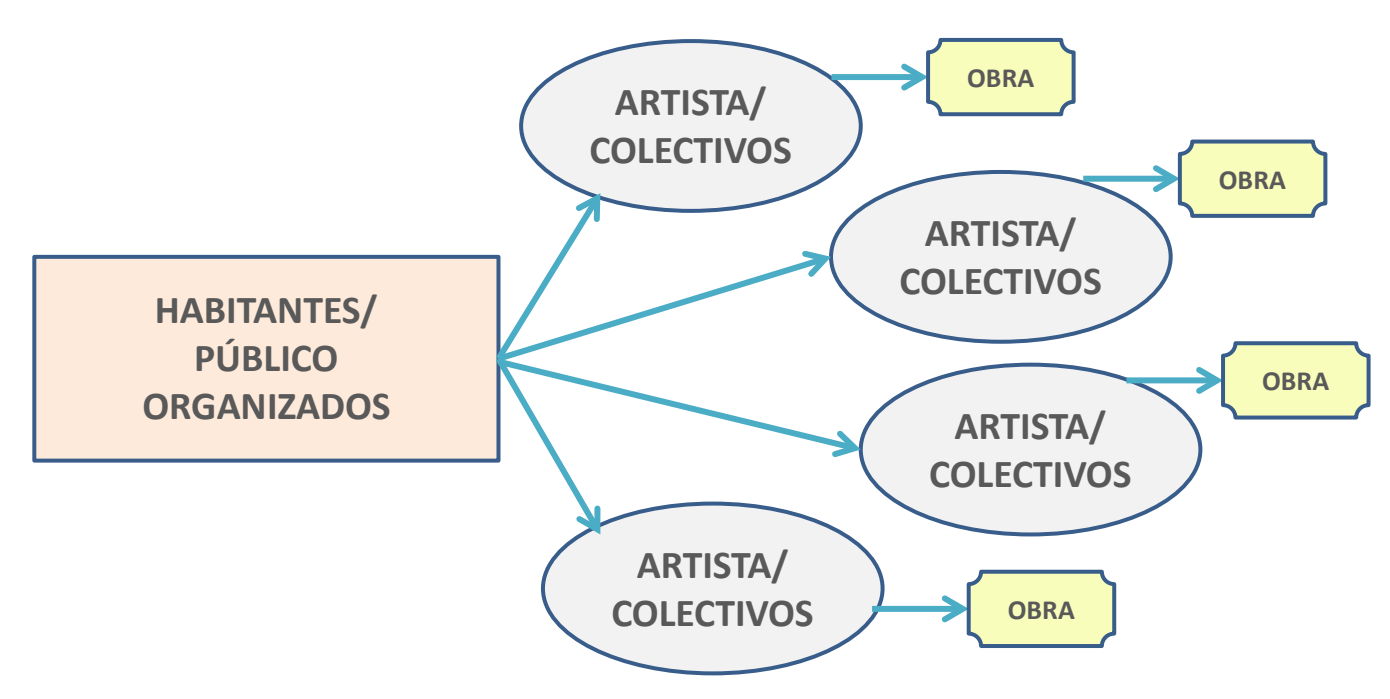

Figura 7. Formas colaborativas de actuar de los artistas en la transición, esquema 3. Fuente: La autora

Pero es objeto de esta tesis presentar la diversidad de formas de transitar hacia la sostenibilidad desde el arte. Es por ello que en este apartado nos referimos a un siguiente paso: 4. redes de proyectos artísticos que conectan artistas o proyectos de arte de diversa índole relacionados con la sostenibilidad y que incluyen diversas formas como las anteriores.

Se trata de proyectos habitualmente no localizados en territorios concretos, itinerantes o virtuales, que realizan una labor de apoyo reseñable en la intersección entre el arte y la sostenibilidad. La mayoría han surgido a principios del siglo XXI con la aparición de internet y gran parte continúa en activo desde entonces.

\section{RED}

269 Véase en: http://eco-publicart.org/

270 Véase en: https://web.archive. org/web/20170\%og $25950 / \mathrm{http}: / /$ greenmuseum.org/

271 Véase en: http://www.greenarts. org/

272 Véase en: https://ecoartscotland. net/

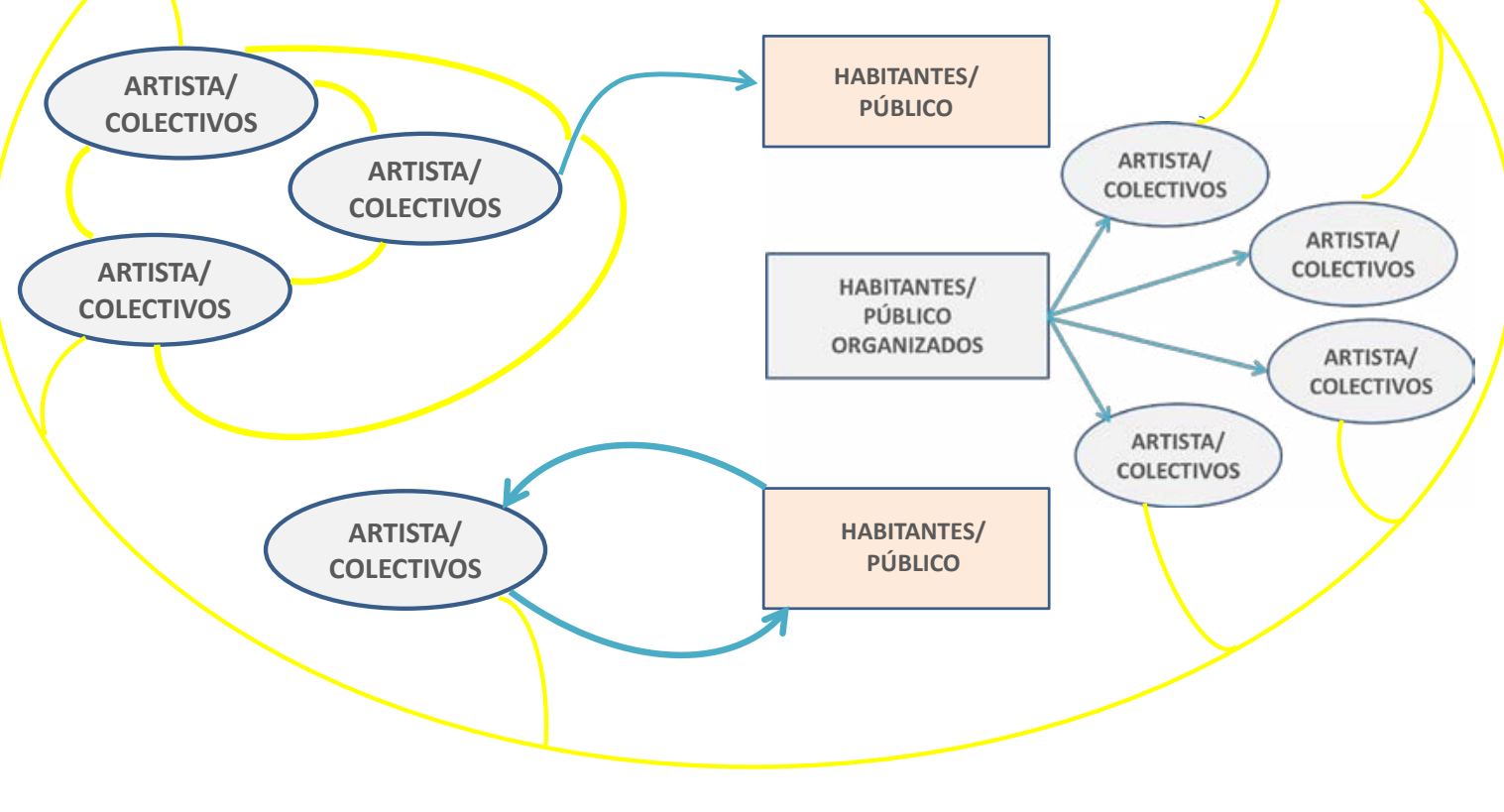

273 Véase en: http: //www desde 2014 no realiza actualizaciones.

Figura 8. Formas colaborativas de actuar de los artistas en la transición, esquema 4. Fuente: La autora

Muchos de ellos son bases de datos donde se comparte información sobre artistas y obras (Eco public art database ${ }^{269}$, Green museum ${ }^{270}$, Green arts ${ }^{271}$, etc.), otros profundizan más añadiendo (Eco pubicicis, in noticias, inauguraciones, chalss, publimacios

Por último están aquellas redes colaborativas que se establecen no solo con los fines anteriores, sino además con el objetivo de apoyarse mutuamente, compartir oportunidades, establecer un diálogo, organizar un programa de encuentros, debates y foros que contribuyan a la expansión y puesta en práctica del mensaje de la sostenibilidad desde el arte. Es el caso de 
274 Véase en http $/ 1$
org/ttcoming-up

\section{Véase en: https://www.creativecar-
bonscotland.com/project/green-tease/}

276 Véase en: https://www.juliesbicycle

277 Véase en: https://ccanw.org.uk/

278 Véase en: https://ecogerminar.org/

279 Véase en: http://www.cultura21 net/

280 Véase en http://www.sustainableprac-

281 Véase en: https:
com/ecoartnetwork

282 Véase en: $h$ ttp://fundacionrafaelboti.
com/?page_id=67

283 «Es una plataforma de coopera

fortalecimiento de los essacios culturales
independientes de España y estrecthar su independientes de Espanãa y estrechar su
colaboración con los espacios de Portugaly colaboración con los espacios de Portugal')
(Red Transiberica de espacios culturales in(Red Transiberica de espacios culturales in-
dependientes, 2013) Véase en: http://www.
transiberica.org/ 284 Para ver el caso de una red formal se en : http://www.redruralnacional.es/-/ encuentro-de-las-redes-rurales-nacionales-the-5th-nrn-meeting-2014-2020-am-
sterdam-holanda- ola Red Europea de Desastrerdam-holanda-ola Red Europea de Desa-
rrollo Rural en: https://enrd.ec.europa.eu/ rrollo Rural en: https://enrd.ec.europa.eu/
networking /nrn-profiles es que en 2016 or-
ganizaron un encuentro en Amsterdam so- mergence ${ }^{274}$, Green Tease ${ }^{275}$, Tippingpoint $t^{276}$ o Centre for Contemporary Art and the Natura (127) Practice in the Arts ${ }^{230}$ o Ecoart Network ${ }^{281}$ a nivel internacional. Toda esta diversidad de estructuras es una valiosa red de apoyo para los creadores que encuentran inspiración en sus pares y ganan visibilidad y veracidad ante la comunidad investigadora. Su existencia y progresión a lo largo papel del arte en la transición a la sostenibilidad.

En el caso español encontramos, por ejemplo, la red Periféricos que aglutina proyectos de arte contemporáneo en la provincia de Córdobaa ${ }^{282}$; la Red Transibérica de Espacios Culturales Independientes en España ${ }^{283}$ desde 2013, que incluye también Portugal, y destacamos la novedosa creación (en 2015) de una red informal ${ }^{284}$ de espacios de arte en el campo ${ }^{285}$ llamada El Cubo Verde ${ }^{286}$. Al igual que en los ejemplos anteriores, su principal objetivo es conectar artistas, experiencias y proyectos, y facilitar el intercambio de información y oportunidades entre ellos. Es una red abierta que se nitera al rural) mediante las prácticas artísticas (EI Cubo Verde, 2015). Está constituida por alrededo de sesenta artistas, investigadores, espacios y proyectos, algunos de reciente creación como Proyectos Artísticos Casa Antonino ${ }^{287}$ (PACA) desde 2014 en Asturias, y otros que llevan más de una década, como Can de Farrera, desde 1996, en las montañas del Pirineo en Lérida. La metodologia se ha basado tambienn en las entrevistas y encuestas a sus miembros y estudio de los contenidos de sus webs y publicaciones. Además, pertenecemos a esta red desde 2016, por lo que hemos podido seguir su evolución a través de las redes sociales.

La contribución de El Cubo Verde a la transición a la sostenibilidad es indirecta, mediante el apoyo y difusión de proyectos/centros o artistas que sí tienen inquietudes directas en cuanto a la sostenibilidad. De modo que, para conocer los efectos de cara a la transición se debe estudiar, por un lado, cómo es el apoyo de la red a estos proyectos y, por otro, cómo cada uno de los sesenta proyectos que aglutina, está aportando a la transición ${ }^{288}$. Fundamentalmente vemos que la red da soporte en cuanto a difusión, intercambio de conocimientos y conexión. Pero ¿qué han obtenido más allá estos centros desde el soporte de la red? La artista Coco Moya destaca la sensación de sentirse arropada, que contrasta con el habitual aislamiento de los entornos ruraes y añade: «el hecho de trabajar en red hace que surjan colaboraciones, proyectos comunes, etc. Todo esto hace que el apoyo entre unos y otros dificulte la caída de cualquier proyecto»
(C. Moya, comunicación personal, 29 de mayo de 2018). Otros encuestados destacan la sensación de visibilidad a nivel exterior, la inspiración que encuentran en otros proyectos afines, los contactos personales y la posibilidad de establecer sinergias. Sería interesante además que la red sirviera como una estructura que les permita acceder a convocatorias públicas o privadas

de financiación. El peso burocratico que eso requiere es superior a lo que ahora
soportar la organización, por lo cual, dicha idea está en pausa en la actualidad.

\subsection{ADECUACIÓN A LOS CRITERIOS DE SELECCIÓN DE LA INVESTIGACIÓN}

El motivo de seleccionar El Cubo Verde como caso de estudio responde al aluvión de redes - algunas bien conocidas ya desde los noventa - de este tipo surgidas en el mundo anglosajón, y por contrapartida, su escaso número en España. Buscamos, con esta presentación, dar dea del amplio abanico de opciones del arte en la transición en nuestro país. Sus características responden a los criterios de selección que nos hemos propuesto:

1. Proyectos que tengan una vinculación específica con lo local: Los proyectos que se

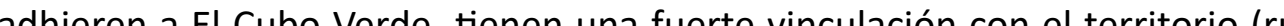
especial con los lugares y la población de los que parten. Por ejemplo, en su decálogo especial declaran «Promover actividades artisticas, educativas, cientificas y sociales que generen propuestas coh can valores como el respeto a la cultura autóctona, la contabución a nuevas formas de pensamiento coherentes con sus entornos y la sostenibilidad demografica de estos núcleos de población. Apuestan tambien por establecer nexos bidreccionales entre Io 政 Cubo Verde, 2018).

2. Obras que actúen (consciente o intuitivamente) de acuerdo con los principios de la transición: Aunque el concepto de transición no se menciona explíitamente en su decálogo más reciente (El Cubo Verde, 2018), sí aparece en anteriores versiones (Álvarez et al., 2018). En su VI encuentro, manifiestan interés en la conservación, tanto varez et al., 2018). En su Vl encuentro, manifiestan interés en la conservación, tanto 
los núcleos de población, el medio rural y natural, su entorno, su cultura y su diversi列 de las actividades programadas» (EI Cubo Verde, 2018). En la entrevista realizada a la red, Moya comenta que: «Cada proyecto tiene sus propios objetivos, pero la sostenbilidad es uno de los aspectos con los que trabajan la mayor parte de los espacios (comunicación personal, 29 de mayo de 2018). Por tanto, identificamos acuerdo con los principios de la transición en un sentido amplio y diverso, sin acogerse por ahora una definición concreta. Por ejemplo, el centro onubense Valdelarte ${ }^{289}$, expresa su interés en desarrollar la conciencia medioambiental y el buen vivir, apoyar la transición contribuir a un desarrollo responsable y sostenible desde el medio rural haciendo hincapié en la alimentación, el empleo y el decrecimiento entre otros (Álvarez et al, 2018). El proyecto gaditano Bee time ${ }^{200}$ señala la construcción de resiliencia o el valenciano Mandarina Borda busca generar conciencia ecológica.

3. Que hagan uso del arte como herramienta de fomento de la transición y, en especial, del arte público: Aunque a nivel de red declaran no tener objetivos de contribución la sostenibilidad específicos (C. Moya, comunicación personal, 29 de mayo de 2018), si se ocupan de dar difusión a proyectos que sí los tienen por lo que su aportación es indirecta. Muchos de los proyectos que integran esta red trabajan con el arte como herramienta de fomento de la sostenibilidad y de prácticas de vida en equilibrio con sus respectivos entornos. Como por ejemplo el proyecto Mandarina borda291 sobre agroecología, permacultura, cultivo en mandala, geometría y cocina energética. En sentido particular, muchos de los proyectos se enfocan en concreto en el arte público como herramienta de activación, implicación y reflexión en el medio rural. Un ejemplo sería el proyecto Campo adentro ${ }^{292}$, que entre 2010 y 2014 ha producido veintidós proyectos colaborativos en el medio rural aplicados al contexto, con intención transformadora a nivel socio-político y económico, y vocación de utilidad.

4. Interés en la realización de la obra por tener una reducida huella ecológica: Existe Interés en tener una reducida huella ecológica, aunque como red no lo manifiestan, ni usan calculadoras de huella de carbono pero, a nivel particular, algunos proyectos cómo Paraisu rura|293 en Asturias, manifiestan preocupación por su huella y encuentran que, una manera ética de reducir el posible impacto de su convocatoria artistica

5. Ocuparse de cuestiones relacionadas con la ecología y/o la transición: Como red algunos de sus miembros han mencionado como temas de interés la cultura, la conciencia ecológica, la sostenibilidad, el desarrollo rural sostenible, la naturaleza, el paisaje, la transición, el decrecimiento, la resiliencia, la proximidad, y la agroecolóí (Álvarez et al. 2018). En concreto, en los encuentros se tratan temas comunes como el in tercambio de experienciss, metodologís y programaciones $y$ compartir dificitades, tercabéticas, visies éticas y utópicas a la hora de implicar al contexto (c. Mades, comulacion person 29 de mayo de 2018). En muchas ocasiones, los temas aue comunich de la tras coction de la en el ecofeminismo - como la convocatoria de 2018 del Foro de Arte Relacional (FAR) y la convocatoria para la Blenal de Miradas de Mujer 2018 de Valdelarte, otros en reinventar tradiciones y oficios sostenibles como Mutur Beltz en Vizcaya que trata de responder desde la agroecología, la práctica artística y el diseño a la pérdida del pastore 政 transformación cultural y ecosocial mediante la experimentación artística.

\subsection{ORÍGENES, OBJETIVOS Y DESCRIPCIÓN DEL PROYECTO}

Según la última versión del decálogo de El Cubo Verde (2018), su misión es «promover el encuentro e intercambio de conocimientos entre diversas "experiencias" de arte en el campo" con la ide de calidad que avale estos proyectos. La intención de descila

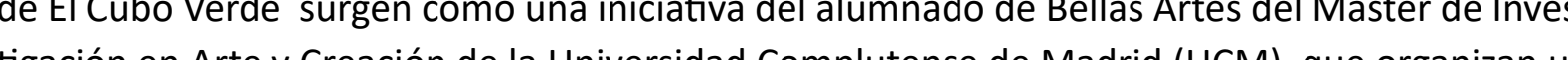
tigación en Arte Creacion de la Universidad Complutense de Madrid (UCM), que organizan un que con que conecte proyectos -ya sean centros de arte, artistas individuales o colectivos, espacios dos con el arte, la ecología y el mundo rural. Desde 2015 se han celebrado seis encuentros, la 
294 A excepción de uno en Plasencia acogi-
do por Imago Bubo y otro en Gijón organi-

295 Véase en: http://biblioteca.ucm.es/

296 Véase en: https://imagobubo.org/

compartir los modos de hacer de cada agente y su conociminto para facilitar la extrapolación de sus propuestas y el trabajo en red. Para ello han creado en 2018 un archivo permanente y en crecimiento de publicaciones de los miembros de la red, en la Biblioteca de la Facultad de Bellas Artes UCM ${ }^{25}$, Madrid, y un apartado específico en la web del Proyecto de I+D+i Humanidades ambientales. Estrategias para la empatía ecológica y la transición hacia sociedades sostenibles HAR2015-67472-C2-1-R MINECO/FEDER,UE. En su mayoría son experiencias autogestionadas, sostenibles en el tiempo y en el entorno, implicadas en las problemáticas y especificidades locales de su contexto social y natural. Por ahora no hay un criterio de entrada salvo el interés en formar parte de la red (C. Moya, comunicación personal, 29 de mayo de 2018).

Como hemos visto en el caso de estudio anterior, la idea de llevar el arte al entorno campestre es una práctica cada vez más frecuente, pero no por ello está exenta de dificultades. David G. Ferreiro, del colectivo placentino Imago Bubo ${ }^{296}$ comenta: «cuando pedimos apoyo por parte de las instituciones en los pueblos que nos movemos, muchas veces nos miran extrañamente, pues aquí no se con lo por otras vías» (Beldad, 2017). Las reticencias iniciales, el rechazo a los foráneos, la precariedad económica, la falta de hábito, la necesidad de visibilizarse y conectar con las redes del arte contemporáneo, son algunas complicaciones que la red puede ayudar a enfrentar mediante el intercambio de experiencias e información. Desde El Cubo Verde se defiende que «la opción de realizar un proyecto a largo plazo en el campo es realista y eficaz, aunque rescata una vieja utopía de emancipación del mercado del arte, un arte estrechamente vinculado con los procesos vitales y con valores más allá de lo economicoy (Et Cubo Verde, 2015).

\subsection{ANÁLISIS}

A la hora de realizar el análisis de la actividad artística de El Cubo Verde en la transición 政 junta y, por otro, aproximarnos a una visión que trate de abarcar todo el espectro de situaciones

\subsubsection{Participación}

La participación en la red es abierta a cualquier interesado y fluida en la medida que los participantes estén familiarizados con la web y el resto de herramientas informáticas que los

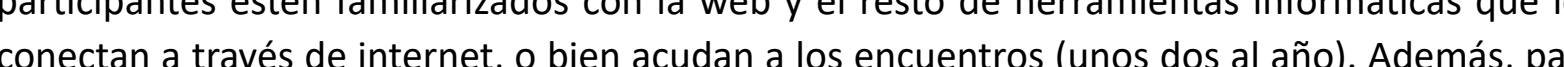
conpliar las posibildes de in a ba antes mas posichonente

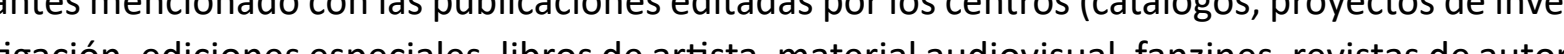
tigación, ediciones especiales, Ibros de artista, material audiovisual, fanzines, revistas de autor), especis e investigadores que forman parte de la red, asi como reseñas o articulos en revistas riencias de otras redes anglosajonas, antes mencionadas, que carecen de ella.

\section{Esta recopilación tiene entre sus objetivos:}

- «Estrechar lazos entre el ámbito académico, institucional y de investigación y la práctica artística desarrollada en el marco de la red.

- Generar un espacio de documentación estable, físico, unificado y de referencia para su consulta por parte de destudintes, docentes e investigadores, que de esta manera acceden a proyectos, convocatorias, procesos y metodologías desarrolladas en espacios geográficamente dispersos por toda España.

- Visibilizar artistas, proyectos e investigaciones recientes en los que la práctica artística se vincula con la ecología social, ambiental y subjetiva.

- Generar relaciones armónicas no duales (centro-periferia, campo-ciudad) de transmisión e intercambio de conocimiento» (PACA, comunicación personal el 10 de abril de 2018). 

PACA , en: «No se trata de «llevar» la cultura sino de crearla en comunid tambièn a las necesidades del pueblo o la zona» (Beldad, 2017). Aunque no tenemos datos representativos de toda la red, en la encuesta realizada, los miembros que han contestado atestiguan todos los tipos de participación a excepción del tipo seis (público del mito y la memoria), y en especial los tipos tres (voluntarios y ejecutores) y cuatro (audiencia inmediata) como suele ser habitual.

\subsubsection{Puntos de tensión y puntos clave}

A nivel de la red es preciso reconocer, como punto clave, el apoyo institucional que ha recibido desde el comienzo por parte de profesores de la Facultad de Bellas Artes de la Universidad Complutense de Madrid como Tonia Raquejo y José María Parreño, así como del servicio de Biblioteca de la misma Universidad. Por otro lado, una cuestión que ha suscitado mucho debate en la red es la necesidad de formalizarse como asociación o federación, o bien continuar como red informal. El Cubo Verde carece de financiación actualmente y el principal argumento para asociarse o federarse es precisece de financiación actualmente y el principal argumento para asociarse o federarse es precisamente poder optar a concursos, subvenciones, etc. Conse-
cuencia de lo anterior es la controversia al respecto de los criterios de admisión en el proyecto, que por ahora son abiertos. Cualquier miembro puede sugerir otros espacios y proyectos con la condición de que estén en activo y tengan vocación pública. A este respecto, Jorge Gallardo de Bee time, asocia la idea de continuar como red informal como una opción de identidad múltiple, rizomática, plural, diversa y alternativa al clásico fenómeno de la representatividad. Lo considera un acercamiento a estructuras más «naturales» a pesar de que les haga a veces más «inoperativos» (comunicación personal, 21 diciembre 2017). La decisión por ahora es continuar como red informal.

Respecto a los miembros de la red, la economía de los centros y proyectos que la conforanimales y huertos que les permiten subsistir», cuenta Moya (Beldad, 2017). Laf estos grupos y artistas suele ser a través de otras vías de ingreso distintas a su actividad artística.

Sobre todo procede de otros trabajos externos, como talleres y cursos, comenta Joan Vendrell de Cacis Forn de la Calç 299 y docencia, según Verónica Álvarez de Valdelarte. En algunos casos ofrecen servicios a organismos públicos como el comisariado (Cacis Forn de la Calç), y en me nor medida cuentan con subvenciones públicas/privadas (Beetime). Frente a esta precariedad de los artistas que pasan por estos espacios y del sustento de los espacios mismos (Vendrell, de los artistas que pasan por estos espacios
comunicación personal 1 de julio de 2017).

En cuanto al trabajo de estos agentes en el mundo rural, en el VI encuentro de El Cubo Verde se debate sobre algunos de los puntos de tensión a los que se enfrentan los centros, los artistas y los propios pueblos, como el paternalismo o el externalsmo. Por un lado, el medio rural se enfrenta a la posible depredación de manos del "artista paracalista" $y$, por otro, a su posterior turistificación. Esto puede dañar tanto a las relaciones sociales, como al medio ambiente del lugar, señala Vendrell. Las residencias artísticas que ofrecen muchos de estos espacios tienen un periodo de duración que va de unos pocos días a unas semanas. ¿Es un tiempo anterior caso en Carrícola un ejemplo de obra que no cubre las expectativas del pueblo po escasa presencia del artista. Por tanto, un punto clave para compensar la falta de tiempo será que el artista realice un esfuerzo previo de reconocimiento del lugar, incluidos sus habitantes. or otra pare los espacios de arte se enferiontanes que son una de las principales causas por las que se disuelven los proyectos, señala Coco Moya. Otro punto clave, pues, será la dialógica que apuntábamos en el capítulo tercero. La escucha atenta el respeto, antes que el ansia de innovar o imponer con una obra.

\subsubsection{Intención}

En cuanto a las intenciones de la red, quedan claramente definidas en su última versión del decálogo de mayo de 2018:

1. Sostenibilidad demográfica de los núcleos de población, el medio rural y natural, su entorno, su cultura y su diversidad. suficiente para que la acción artística se implique verdaderamente en el lugar? Ya vimos en e

299 Véase en: $\mathrm{http}: / /$ www.cacis.cat/index-
cast_web_files/index.html

300 Nos referimos al tipo de artista que reavia $y$, por tento, sin concia suficiente previa y, por tanto, sin conexión profund
la gente que habita los espacios.

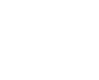


301 Advertimos que no son datos represen-
tativos de toda la red por el bajo número de respuestas obtenidas hasta ahora.

302 Véase en: https:///elcuboverde.org/mis
2. Universalidad, transversalidad y multidisciplinaridad.

3. Compromiso de los diferentes agentes que conforman la red para la colaboración y puesta en común de las ideas y materiales generados.

4. Respeto de los habitantes, el entorno y la cultura autóctona en el desarrollo de las actividades programadas.

5. Desarrollo e investigación de propuestas artísticas y culturales que contribuyan a crear una nueva forma de pensamiento y acción en nuestros entornos (empatía ecológica).

6. Se propiciará un flujo bidireccional de las prácticas contemporáneas artísticas entre lo rural y lo urbano.

Llama la atención que no se haga alusión a la transición a la sostenibilidad; de hecho, a nive general, la red se plantea objetivos de conexión más que de contribución a la sostenibilidad por si misma, lo cual, se deja a exploración de cada miembro (El Cubo Verde, comunicación personal 29 de mayo de 2018). De los miembros encuestado s01 el 75\% admite tener objetivos de aportación la transición aunque solo el $40 \%$ lo expresa explícitamente. Sin embargo, todos los que han contestado por ahora considra que su práctica artística apoya la transición a la sostenibilidad, aunque sea indirectamente.

\subsubsection{Efectividad}

Como red, su aporte a la sostenibilidad se basa principalmente en actividades de difusión. En su decálogo de 2018 El Cubo Verde se plantea claramente los siguientes objetivos:

1. El fomento de la creación artística en espacios de arte en el campo.

2. Constituir una plataforma de referencia, indicativa o aval de calidad.

3. Dar visibilidad a los espacios que formen parte de El Cubo Verde tanto dentro de la red (hacia los otros espacios) como fuera de la red (público general y artistas interesados en el tema). Dentro de este objetivo pretenden: the

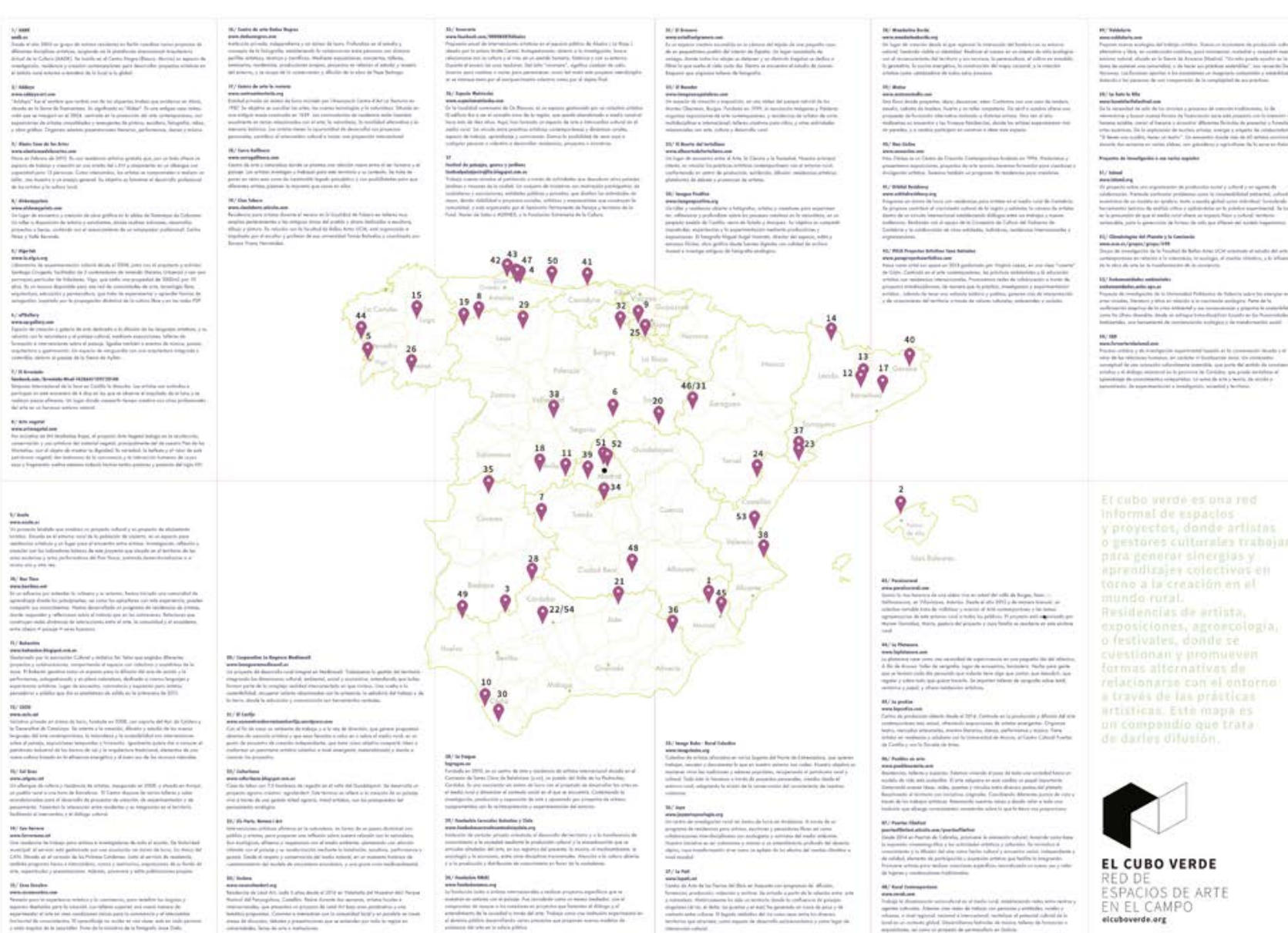

Imagen 106. Mapa de miembros de la red El Cubo Verde. Fuente: El Cubo Verde, elaborado por Coco Moya, véase en: https://elcuboverde.org/mission/

- Presencia digital a través de sus redes sociales y web.

- Canalizar información a través de sus listas de correo.

- Buscador para artistas y centros a través de su listado web de centros y el mapa anterior. 
Grupo de correo electrónico y agenda web de eventos y de iniciativas artísticas rurales ara el público. Información de convocatorias abiertas, residencias, certámenes.

- Bolsa de intercambio de información. Como el archivo permanente ya mencionado.

- Bolsa de trueques/voluntarios, recursos, materiales, servicios relativos. Por ejemplo: «investigadores que encuentran aquir un apoyo, espacios que pueden amplificar su difusión exposiciones, congresos, dudas sobre financiación, becas,.... (El Cubo Verde , comunicación personal, 29 de mayo de 2018).

- Crear actividades (que puedan itinerar) exposiciones, rutas, encuentros, talleres. Se está levando a cabo mediante la creación de una obra artística en formato de cubo de $20 \mathrm{~cm}$ de lado por cada espacio o artista, con la idea de poner en valor el planeta Tierra para generar conciencia ecologica. Se acompañan de unos botes de tierra procedentes de cada lugar que se conservarán en el archivo permanente de la UCM. Las piezas se han expuesto en la convocatoria Trastellaor 2018 del centro valenciano Mandarina Borda, e itinerarán a aquellos espacios que quieran plantear algún evento-muestra en torno al tema. Es una forma de presentar a los miembros de la red y visibilizarlos.

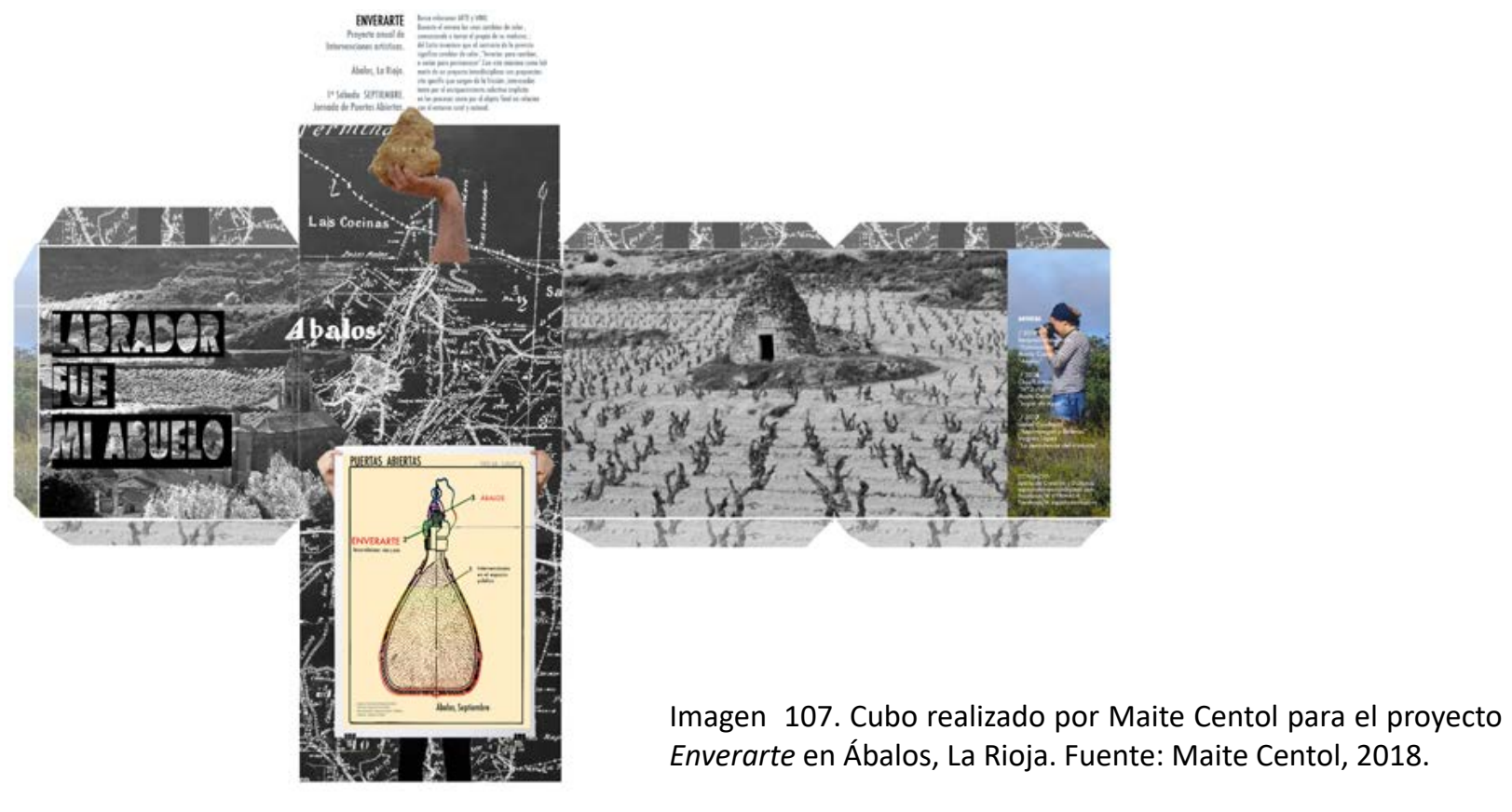

- Generar fondos. Por ahora no se ha detectado actividad en cuanto a obtención de financiación.

En cuanto a los efectos de cada miembro en particular, no tenemos datos representativos comunicación personal 1 de junio de 2018) o incluso la colaboración con instituciones como desarrollo de un plan de paisaje asocia a nuevo Plan Gen Sánchez, comunicación personal 3 de junio de 2018).

\subsubsection{Estética y ética}

Respecto a cuestiones éticas, en sus intenciones mencionadas en el apartado anterior están implíitos sus valores éticos como red. Destacan la sostenibilidad, la universalidad, el compromiso de compartiry el respeto por los habitantes, el entorno y la cultura autóctona. Aunqu el marco de trabajo es, en la mayoría de casos, el mundo rural y sus vicisitudes (despoblamiento, el marco de trabajo es, en la mayoría de casos, el mundo ruraly sus vicisitudes (despoblamiento, programas culturales escasos, etc.), proponen tambien el contacto bidireccional con lo urbano. La diversidad de miembros otorga riqueza de puntos de vista y actitudes al dialogo en la red, el intercambio y la resiliencia. A nivel de red, la ńica obra conjunta que exhibición de cubos antes menciona de red, la unica obra conjunta que han realizado es la exh bición de cubos antes mencionados. La imagen responde a sus valores eticos $y$ estéticos pues son cubos reutlables, impresos en canton, se evitan los plasticos y la homogeneidad de dimensiones y forma unifica el conjunto. Ningún cubo es mayor que otro, como responde a su organización horizontal. La exposición de cubos, como la red, no tiene un lugar fijo e itinera por
la geografía visitando los espacios.

A nivel de sus miembros, algunos de los consultados declaran tener en consideración la

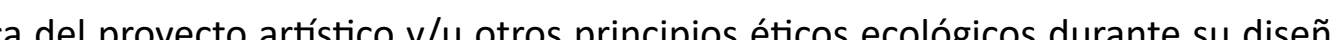
hue impla huella ecolóscan, pero ninguno hasta ahora, que conozcamos, ha aplicado calculadoras de huella ecologica o de carbono. Los proyectos son may diversos estéticamente como para tratar aquí uno a uno, pero, en general, el drálogo con los habitantes y el respeto al entorno son puntos comunes como comenta PACA, al igual que muchos otros proyectos, «encuentra su razón de ser 
en hacer actividades que conecten con el interés del pueblo y en establecer un diálogo con el paisie que habitan" (Beldad, 2017).

\subsubsection{Funciones del arte}

Aunque cada espacio, centro y artista tiene su propia idea sobre su función, en general, estas iniciativas, precarias en la mayoría de casos y «extrañas» en el lugar, ofrecen otras maneras de más amplio, es una formaconsciente $r$ respetuosa de bcionas

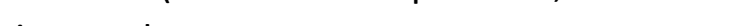

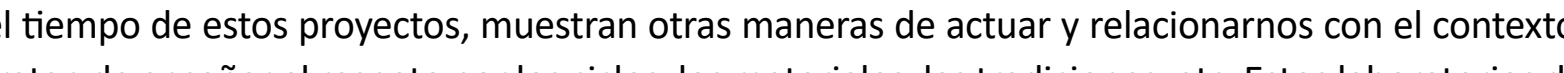
explan de ensenar el experiencias introducen diversidad y atractivo en sus contextos. Suponen una irrupción de nuevas experiencias sobre viejas rutinas. A pesar de no tener datos representativos de toda la red, si podemos decir que todas las funciones del arte presentadas a los encuestados han sido identificadas como mínimo en dos casos y con respecto a la red identificamos las siguientes:

\begin{tabular}{|l|l|}
\hline $\begin{array}{l}\text { FUNCIONES del ARTE EN EL } \\
\text { CUBO VERDE }\end{array}$ & \multicolumn{1}{|c|}{ JUSTIIIICACIÓN } \\
\hline $\begin{array}{l}\text { Ilustrar, representar, } \\
\text { comunicar, difundir }\end{array}$ & Si, la misión de la red es principalmente comunicar. \\
\hline Concienciar & Sí, se busca concienciar sobre el planeta con la acción conjunta Tierra. \\
\hline Desarrollar empatía & Si, se menciona explíititamente en su decálogo. \\
\hline $\begin{array}{l}\text { Imaginar, desarrollar la } \\
\text { vision del grupo, su misión, } \\
\text { futuros posibles, utopías o } \\
\text { ficciones }\end{array}$ & $\begin{array}{l}\text { aptercambio de experiencias en la red tiene como objetivo } \\
\text { aprender como otros van avanzando. }\end{array}$ \\
\hline $\begin{array}{l}\text { Ofrecer soluciones, } \\
\text { mostrar alternativas } \\
\text { reales o proyectos piloto, } \\
\text { laboratorios de pruebas }\end{array}$ & $\begin{array}{l}\text { Sí, la red trata de compartir soluciones y alternativas que está } \\
\text { sucediendo en todo el territorio ibérico. }\end{array}$ \\
\hline
\end{tabular}

Conectar personas, crear

comunidad, hace,
mediar o facilitar
Conectar personas

Conectar personas con

Conectar personas con
espacios, entornos o lugares

Restauración/recuperación

del entorno

Reforzar la identidad, crear

símbolos

Fomentar la ciudadanía

crítica, agitar, denunciar

Empoderar

Crear relatos positivos de

cambio

Facilitar la comprensión

del mensaje de la ética

Conectar áreas alejajas de Sí poner en contacto a investigadores artistas y espacios de distintas

Conectar areas alejadas de

Motor iniciador de
dinámicas y proyecto

Celebrar

\begin{tabular}{|l|l|}
\hline Celebrar & No como red en si misma. \\
\hline Aumento de la resiliencia & Sí en el sentido de compartir recursos e información que ayuden a \\
superar obstáculos $y$ evite el abandono de provectos
\end{tabular}

\begin{tabular}{l|l} 
& superar obstáculos y evite el abandono de proyectos. \\
\hline Construir consensos & No la red aboga por ahora por un formato diverso no
\end{tabular}

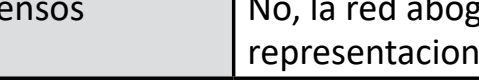

\begin{tabular}{|l|l|}
\hline Premiar, agradecer & No se detecta. \\
\hline Recaudar fondos & No se detect. \\
\hline
\end{tabular}

Revitalizar el territorio

(Luchar contra el éxodo

rural, dinamizar el territorio,

Fabla 10. Funciones del arte identificadas por la autora en la red El Cubo verde. Fuente: Ia autorach 
Y añaden:

- internacionalizar el entorno a través del voluntariado y acogida de artistas de todo el mundo (El hacedor, comunicación personal, 5 de junio de 2018).

- fomentar la creatividad y ampliar la mirada (Pilar Soto, comunicación personal, 6 de junio de 2018).

\subsection{RESULTADOS Y CONCLUSIONES PARCIALES}

En cuento a la red, aunque declaran no conocer el arte transicional, algunos de sus miembros sí lo reconocen y, a nivel de red al menos, cumplen todos sus principios:

1. Intención: Sí, la red tiene intenciones claras de contribución a la sostenibilidad y así lo expresan en su decálogo.

2. Ignición: Sí, el intercambio de información puede ser el detonante de otros proyectos como lo ha sido el archivo permanente en la UCM. De hecho, se plantean como uno de sus objetivos: «Promover actividades artísticas, educativas, cientificas y sociales que generen propuestas coherentes con el entorno específico de cada agente» (El Cubo Verde, 2018)

3. Marco: Sí, su marco de trabajo viene definido por su decálogo y abarca sobre todo espacios de arte en el campo y sus circunstancias.

4. Trabajar con la comunidad: Sí aunque indirectamente. La red trabaja con los miembros pero no directamente con sus comunidades de origen, aunque muchos de sus miembros se enfocan en el trabajo con las comunidades locales, como por ejemplo Valdelarte en Huelva: se encargan de la recuperación y cuidado del territorio como la recuperación de senderos y meandros de agua en desuso, las eras y otros lugares comunes olvidados (Checa, 2016).

5. Mediación: Sí, la red es un mecanismo de mediación entre distintos miembros y agen-
6. Mantener un espacio: Sí, el archivo permanente de la red o la web son espacios mantenidos por todos.

7. Conexión: Sí, es un objetivo fundamental expresado como misión en su decálogo.

8. Trabajar desde lo común: Sí, en la red lo común es más bien intangible, son las situaciones que atraviesa cada espacio, y la red ejerce de herramienta de acompañamiento, terapia y apoyo.

9. Colaborar: Sí, es un objetivo fundamental expresado en su decálogo.

10. Cambio: Sí, es un objetivo fundamental expresado en su decálogo.

Decíamos en el capítulo uno que ante la inoperatividad de los gobiernos e instituciones algunos casos como el de las zonas rurales, se hacen necesalias otras alternativas no form les como la que representa El Cubo Verde o el MCT. Como hemos podido comprobar, en estos grupos se disfruta con la informalidad, con salirse de estructuras jerárquicas y ordenadas. Precisamente su heterogeneidad les da capacidad de diversificarse y adaptarse a las circunstancias locales particulares.

El Cubo Verde y sus miembros se alejan consciente y valientemente de los centros y audiencias habituales de creación, para enfrentar los retos globales ambientales también desce as periferias y el campo, espacios olvidados en muchos casos y que acucian aún más las consecuencias de la crisis ecosocial. Por tanto, entendemos su labor como muy necesaria y que aporta diversidad al abanico de contribuciones del arte a la transición, aunque, como decíamos al comienzo de este estudio de caso, el aporte de la red a la sostenibilidad es indirecto. A partir del estudio de El Cubo Verde concluimos que sus principales labores actualmente son la difusión, el fortalecerse mutuamente y la conexión. Dichas tareas son importantes como medio de visibilización de sus miembros de cara al resto de la sociedad, pero sobre todo entre sí. Por un lado, la existencia de una red como esta en internet, emite un mensaje a la comunidad internacional sobre la vitalidad del arte en espacios rurales dedicados a la sostenibilidad en España. Por otro, la red contribuye a la creación de una comunidad de apoyo (aunque sea virtual) y facilita la cooperación entre ellos. La lucha diaria en los espacios aislados del campo puede ser desola- 


\section{OTROS PROYECTOS: AULA-R}

de proyectos impulsados, disminución de contacto con la heterogeneidad de posiciones al respecto del arte y la transición en el contexto

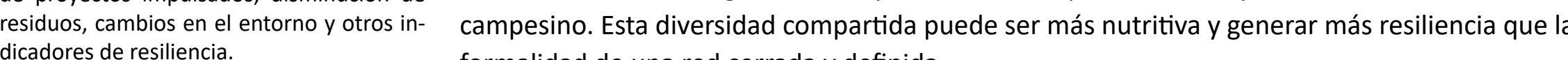
formalidad de una red cerrada y definida.

Por otra parte, la red provee de una visión panorámica de las capacidades del arte para, no

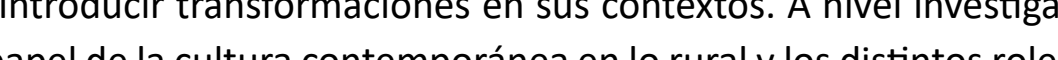

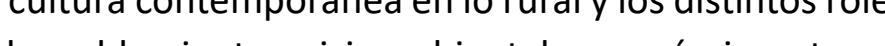
que se ejercen frente a los problemas de despua con formación del paisaje. El debate en el seno de la red desvela nuevas dimensiones y capas desapercibidas desde lourbano, yvisibiza las amenazas yoportundades quevive elcampo español. No obstante, nos gustaría sugerir desde aqui que se podria incluir un ejercicio de autoanálisis de su propia acción como red. Por ejemplo, la introducción de medios digitales para los encuentros que disminuyan el número de desplazamientos o una recopilación de los resultados y logros de los proyectos que reúnen , para mostrar una idea de la fuerza de su acción conjunta. Pensamos que esto último les permitiria visibilizarse y ganar consideración como fuerza cultural, que juega un papel determinante a la hora de orientar un cambio del sistema de valores actual en la dirección de la transición en el campo.

\subsection{LA SOSTENIBILIDAD EN LA PRÁCTICA ARTÍSTICA Y LA GESTIÓN CULTURAL}

Hasta ahora hemos estudiado el papel de lo artístico en entornos públicos ajenos al arte como ciudades, pueblos y proyectos en el campo. Quisiéramos finalizar este capítulo realizando un esfuerzo de autoanálisis de las prácticas artisticas y su relación con la sostenibilidad desde las propias entidades artisticas, con un ejemplo de obra propia que se enmarcaría en el tipo de la figura 5 del apartado anterior 6.1 junto a DUO. A este respecto, la Red Española para Desarrollo Sostenible ha convocado sendas jornadas durante los años 2016 y 2017 tituladas: Sostenibilidad e Instituciones Culturales, donde se destaca el papel de la cultura para acercarnos a las diecisiete metas de los Objetivos de Desarrollo Sostenible (ODS). A nivel internacional, en el ámbito muséstico nos queda mucho camino por recorrer, comenta Joan Llinares gerente del Ayuntamiento de Barcelona y gestor cultural (Red Española para el Desarrollo Sostenible, 2017). Por ejemplo, sorprende que actualmente el Código deontológico para los museos elaborado por el Consejo Internacional de los Museos (ICOM), no haga mención alguna a la sostenibilidad ${ }^{30}$ (International Council of Museums, 2013). Quizás, para compensar este hecho el ICOM eligió el tema «Museos para una sociedad sostenible» para celebrar el día de los Museos en 2015. Previamente en 2014 el Comité para la Conservación del ICOM elaboró una Declas en 2015. Previamente en 2014 e co más allá de la cuestión del ahorro energético en los Museos me pautas mejor consol de la climización y alsturento (Comité para la consenvación del ICOM, 2014).

Al margen de organismos oficiales, destaca la actividad de asociaciones como COAL en Francia y Julie's bicycle en Reino Unido, a quienes ya hemos mencionado anteriormente. Ambas organizaciones sin ánimo de lucro realizan un gran esfuerzo por hacer de puente entre el sector cultural y la sostenibilidad ambiental. Laura Pando, de Julie's bicycle, tiene una visión positiva al respecto, y señala un aumento del interés desde la gestión cultural en los últimos diez años cuyos resultados se puede comprar en su informe Sustaining Great Art305 (2017). Producto culo (2017). en 2016 ible, 2017). Un punto importante en dicho país es la apuesta por la sostenibilidad que ha realizado en 2012 el Consejo
304 Véase en http://icom.museum/file-
admin/user_upload/pdf/Codes/code atmin/user_uplo

305 Véase en: httrs://www.artscounciliorg. ning\%20Great\%20Atrownoroport-file//5ustai-

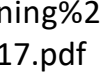


306 Evelio Acevedo director gerente del de las Artes de Inglaterra (ACE), la agencia pública que gestiona las subvenciones al arte y la cul-
Museo Thyssen-Bornenta los resultados del estudio de la huella Limited durante la exposicio Young Global Hopper, entre junio y septiembre de 2012 .
3575 toneladas de CO, el $91 \%$ de las cua les procedian de los desplazamientos de los
320.000 visitantes - sel $30 \%$ a pie, el $27 \%$ en coche, el $23 \%$ en metro y el $15 \%$ en au-
tobús) (Sanz, 2012) - y solo el $5 \%$ del desexposición, solo 1.136 personas habrián podido disfrutar de la obra de Hopper pro-
duciendo la misma cantidad de emisiones.

307 Véase en: http://www.vesos.es/es/

308 Véase en Measuring the environmental impact of temporary exhibitions: A meth-
odology to encourage sustainable practice

(2015) Disponible en: httrp:///smat
greendesign.com/es/riba-awards/ (nistos de sostenibilidad en las bases reguladoras de estas ayudas. espacio cultural de la Casa Encendida, a cargo del coordinador de medio ambiente Pedro Rubio. No solo se han centrado en el ahorro enersetico sino tambern en la autogeneración de con pane - dentenimiento de un huerto escolar. En cualquier caso, el mayor porer huell de carbono de una exposicín es precisamente el causado por el público asistente lu desplaraminto a museo. Por eso se debe insistir desde todos los tipos de espacios tura en el uso de medios de transporte de baja hue de carbono y adés tomar medidas

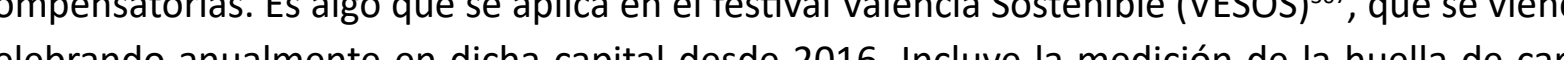

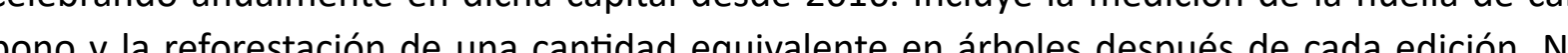

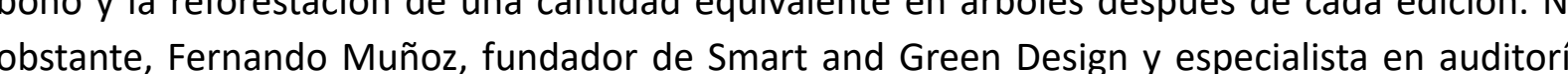
oxpos, fundador de Smart and Green Design y especialsta en auditoría medioambiental de exposiciones, comenta que aún existen muchas reticencias en el panora ma museistico español y en la administración a realizar exposiciones sostenibles porque se les compensatoras. Es alo que se aplica en el festival Valencia Sostenible (VESOS) 307 , que se Vine asocia un sobrecoste irreal, debido a la falta de conocimiento al respecto (2018). Muñoz señala la ausencia de herramientas que demuestren las ventajas de realizar un proyecto sostenible propone un modelo de calculadora para exposiciones temporales y una metodología ${ }^{308}$ desarrollada en el departamento de Construcción y diseño sostenible de la Oxford Brookes University en Reino Unido (Muñoz Gómez, 2018).

Acercándonos aún más a nuestro entorno académico, la Universidad como institución cultural, símbolo del avance de la sociedad, tiene la responsabilidad de servir como modelo promover la investigación desde el centro de la transformación social. Además, debe formar los estudiantes como ciudadanos críticos y sujetos creativos con capacidad de desarrollar respuestas ante los nuevos escenarios de crisis ecosocial. Hasta la actualidad, de hecho, se han dado numerosos pasos a nivel de ahorro energético, reciclaje y reducción de residuos entre otros aciertos pero, como apunta el estudio titulado: «Universidad sostenible, ¿cuál puede ser el problema?», aún queda mucho trabajo por hacer en el entorno universitario (Velazquez et al., 2006). En concreto, el panorama en las facultades de Bellas Artes en España al respecto de medio ambiente es dispar y mejorable. El paso durante nuestra formación por cuatro facultades ( AA.), Granada y Valencia) ha sido el germen del proyecto que estudiaremos a continuación, $A u-$ $(a-R, y$ que ya presentamos, en parte, en nuestro trabajo fin de master (Sánchez-León, 2013) y en el artículo presentado al $V$ Congreso Internacional de Educación Ambiental de 2015 titulado: «Proyectos coparticipativos de educación ambienta sitaria: Aula-R» (Sánchez-León y Albelda, 2015).

\subsection{ADECUACIÓN A LOS CRITERIOS DE SELECCIÓN DE LA INVESTIGACIÓN}

A continuación, mencionamos los motivos que justifican la inclusión de Aula-R en este A pítulo dos.

1. Proyectos que tengan una vinculación específica con lo local: La idea parte de la detección de conflictos y necesidades en nuestro entorno inmediato, la Facultad de Bellas Artes San Carles de Valencia, y es en ella donde se aplica.

2. Que hagan uso del arte como herramienta de fomento de la transición y, en especial, del arte público: Nuestro papel como artista es el de ser una facilitadora de contextos, propio de la tipología del artista activista de Suzanne Lacy, pero la clave fundamental que hace funcionar al proyecto es la participación activa del público.

3. Interés en la realización de la obra por tener una reducida huella ecológica: Durante la realización de esta obra se ha tenido muy en cuenta la reutilización de materiales y se ha reducido al mínimo imprescindible la compra de material nuevo.

4. Ocuparse de cuestiones relacionadas con la ecología y/o la transición: Los objetivos del proyecto engarzan con los del arte ecológico y la transición ya que pretendemos del proyecto engarzan con los del arte ecologico y la transición ya que pretendemos
fomentar el cambio de los hábitos consumistas e individualistas en la práctica artística 
5. Obras que actúen (consciente o intuitivamente) de acuerdo con los principios de transicion:

Descarbonización de la economía:

Se persigue una disminución del transporte de materiales y personas al aumentar e intercambio entre estudiantes.

Compromiso con la equidad y la justicia ambiental y social.

- Las altas tasas universitarias y el elevado coste del material de BB.AA., dificultan el seguimiento de sus estudios a parte del alumnado. Nuestro objetivo también es aliviar el gasto y distribuir materiales desde los que más acumulan a los que menos tienen.

\section{El desafío de la conservación}

- No se han planteado objetivos a este respecto.

\subsection{ORÍGENES, OBJETIVOS Y DESCRIPCIÓN DEL PROYECTO AULA-R}

Aula-R es un banco de materiales dónde los alumnos pueden depositar/coger libre y gracomo práctica cotidiana la sonsicion a 作 ve de lica de diato de actuacion. la Faculad de Bellas Artes de Valencia. El problema detectado es el mismo terminar su ciclo de vida útil, que son rechazados por el alumnado por falta de espacio o por finalización de sus estudios y sin embargo, son susceptibles de ser reutilizados por otros estuantes. Por otro, la situación de precariedad económica y el coste añadido en materiales que supone un grado en BB.AA. influye en la calidad matérica de sus proyectos artísticos. Además, la acum para el centro a la hora de gestionarlos como residuos, según requiere el Sistema de Gestión Ambiental (en adelante SGMA) de la UPV ${ }^{310}$.

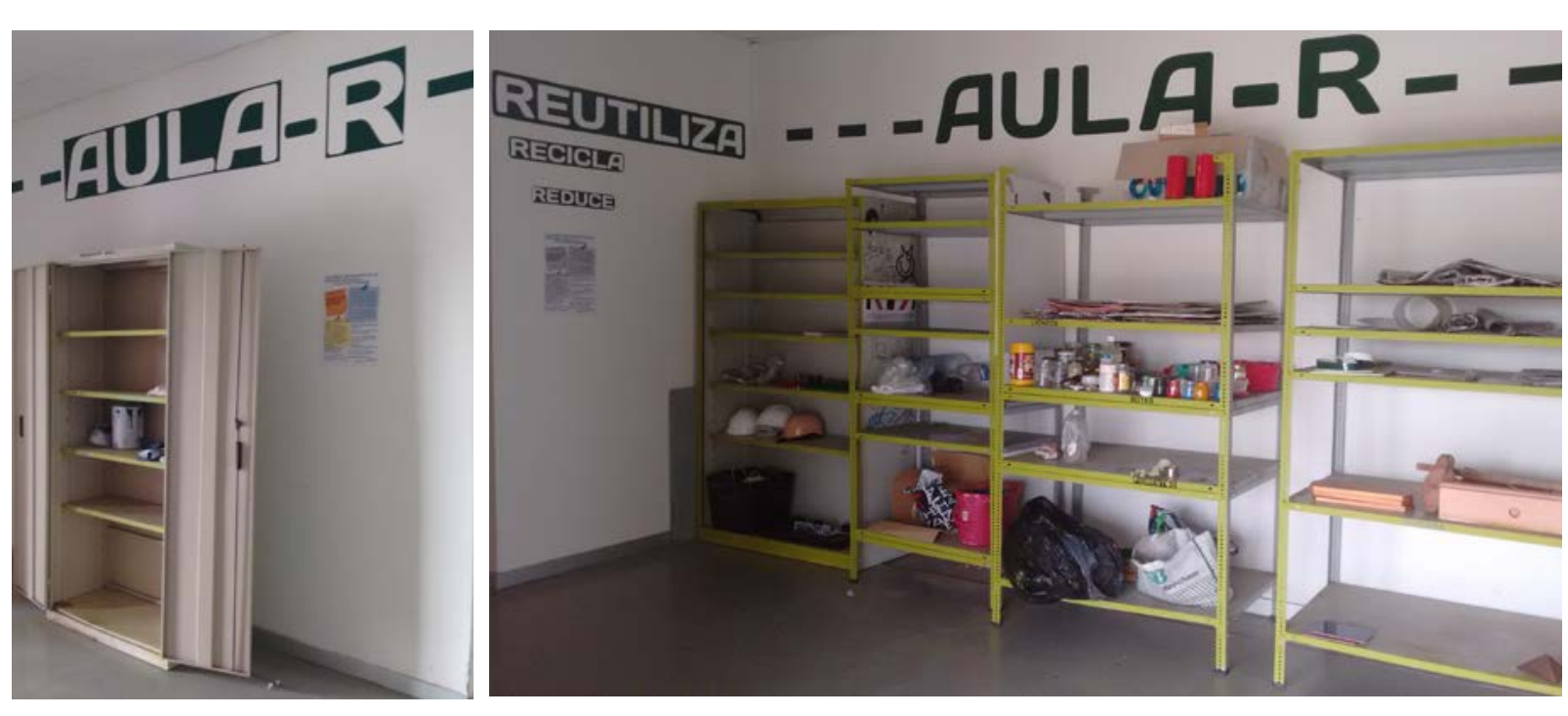

Imágenes 108 y 109. Los espacios de Aula-R en la actualidad. Fuente: fotografías de la autora, 2016.

Con este proyecto se pretende:

- Fomentar una cultura ambiental y un uso más sostenible de los recursos y la energía.

- Reutilizar materiales que aún no han terminado su ciclo de vida útil.

- Reducir residuos de actividades artísticas.

- Dar respuesta a la necesidad del alumnado de disponer de un lugar para el intercambio libre y gratuito de materiales usados relacionados con las prácticas artísticas que en la facultad se desarrollan.
310 Véase en: Sansano del Castillo Irene.
Sistema de Gestión Ambiental de la Universidad Politecrica de Valencia. Guía para los de la UPV [en linear U Jas Ambientales Planificación Urbanistica y Ordenación de los Campus. Valencia. Noviembre de 2009 . 2012\} disponible en refe: 1 de diciembred 
311 Véase en: http://hdl.handle.
net/10251/35686

312 De una población total de: $\mathrm{N}=2481$ es tullantes matriculados ese año. Dato aportado por el servit
pia facultad.
Compartir la situación de precariedad por la que atraviesa la Universidad Pública y sus estudiantes, ahorrando en la compra de materiales y la gestión de residuos.

- Actuar como portal de encuentro, donde el alumnado contacte para ponerse de acuerdo, no solo para reutilizar; sino para comprar materiales de segunda mano o de forma común, ahorrando gastos de viajes, exceso de material, etc.

- Servir de experiencia piloto exportable a otras facultades de BB.AA.

Para llevar a cabo este proyecto se acondicionó un espacio en la Facultad de Bellas Artes de Valencia a modo de banco de materiales. La donación y/o apropiación del material se realiza en condiciones de total gratuidad y libertad de horario y los materiales se disponen en orden clasificados en estanterías. encontrar una descripción exhaustiva del mismo en: Arte Público de enfoque ecológico. Análisis de resultados según Suzanne Lazy. Producción propia como artista experimentador, informador, analista y activista (2013) ${ }^{311}$. A continuación pasaremos directamente a su análisis que nos brindará la suficiente información para su evaluación posterior.

\subsection{ANÁLISIS}

\subsubsection{Participación}

Origen y responsabilidad: En todo proyecto de carácter público es imprescindible conocer el interés de la audiencia potencial, sobre todo si se espera colaboración de ella, como en este caso. Para ello el método cuantitativo elegido fue la realización de encuestas, con un margen de error del $10 \%$ y un nivel de confianza del $95 \%$, mediante un modelo con tramos de respuesta prefijadas de modo que se redujese la subjetividad. la encuesta cumple además otros objetivo importantes, como despertar en el alumnado el deseo de tener un espacio de reutilización -al sentirse decisores de la utilidad de la inicitiva - $v$, también, dar publicidad previa a prón -a informando tanto a a umn do como a profesorado. Se encuestaron 301 personas escogidas azar entre todos los cursos de grado, licenciatura y master en otoño de 2012312. Entre el 65-75\% de estos estudiantes demostró mucho interés en que Aula- $R$ se formalizara. Entre el $85-95 \%$ estaba dispuesto a colaborar con Aula- $R$, aunque no se especificó qué tipo de colaboración. Se pretende que sean los mismos usuarios los que se responsabilicen del espacio, como beneficiarios directos del mismo y sus recursos. Por tanto, consideramos que esta obra no se habría puesto en marcha sin estos resultados previos ni se mantendrá sin la participación del alumnado y, por ello, los consideramos dentro de este tipo de audiencia.

Colaboración y codesarrollo: La obra se instaló con el permiso de decanato y la colaboración de algunos compañeros. Además se hizo coincidir con otra actividad de mercadillo de trueque organizado por el profesor Cha se he Luelmo, para establecer sinerglas. Durante su vida, la Unidad de Medo Ambiente de la UPV y la delegación de alumnos han colaborado en varias ocasiones cediendo materiales, con financiación o colaborando en la remodelación del espacio en 2015. Algunos miembros del profesorado insisten a sus estudiantes en su uso, aunque no tantos como nos gustaría.

Voluntarios y ejecutores: en esta categoría incluiríamos a todos los estudiantes que participan donando o cogiendo material del espacio. Se ha intentado, en la medida de lo posible, interactuar con los usuarios poniendo en cada material aportado una pegatina como la siguiente interactuar con los usuarios poniendo en cada material aportado una pegat

Deseogue Ste giste 25 .... que nos cuentes cómo y dónde lo has usado en: aulaerre@yahoo.es
o en la página aulaerre en facebook Imagen 110. Pegatina realizada para adherir a los
materiales y seguir su registro. Fuente: la autora.

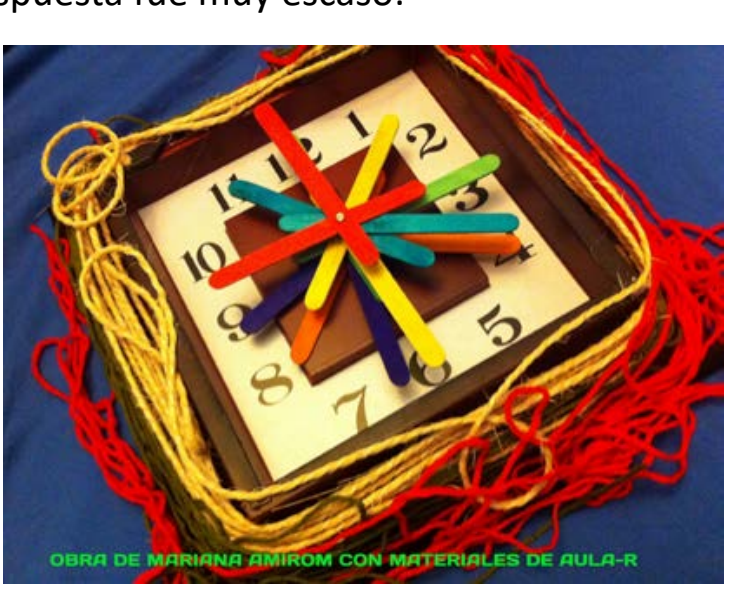

Imagen 111. Obra realizada con material recogido por Aula-R. Fuente: fotografías de Mariana Amirom. 


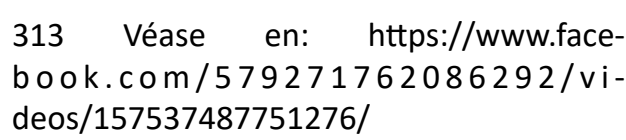
314 Véase en: http://madamecornucopia.
wix.com/madamecornucopia

315 Véase en: https://www.face
book.com/579271762086292/vi deos/958301007516697/

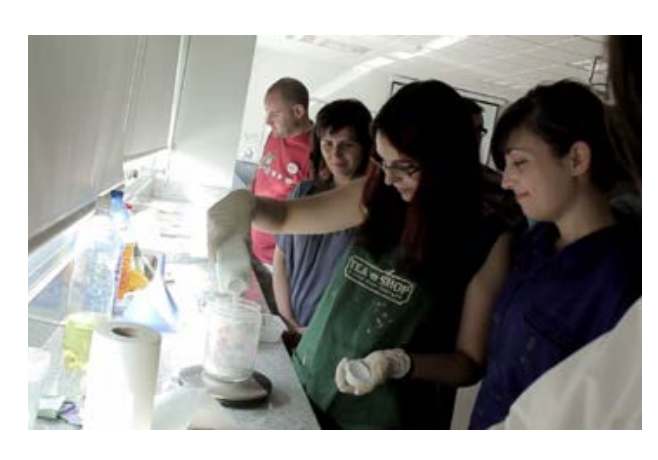

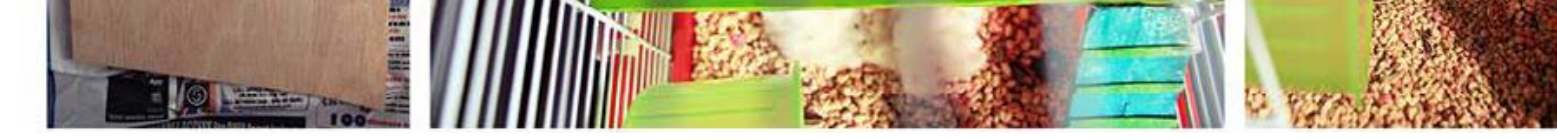

Imagen 114. Material recogido por la alumna Lur C.G. y uso que le otorgó. Fuente: fotografias de Lur C.G.

Público inmediato: en este caso se trata de la comunidad universitaria de la facultad (participante o no), que ronda los 2.500 estudiantes al año, así como los asistentes a la exposición que comentaremos más adelante en la sala valenciana La Mutante.

Público de los medios de masas: el servicio de la UPV TV realizó un pequeño reportaje a cumplir tres meses ${ }^{313}$. Por otra parte, colaboramos con la productora Madame Cornucopia ${ }^{314}$ que produjo un audiovisual ${ }^{135}$ dónde se narra el proceso de desarrollo de Aula- $R$ y algunas entrevistas a usuarios escogidos al azar que dan su opinión sobre el proyecto.

genes 112-113. Fotogramas extraído Imagenes 112 -113. Fotogramas extraídos pia para Aula-R. Fuente: Madame Cornuco-

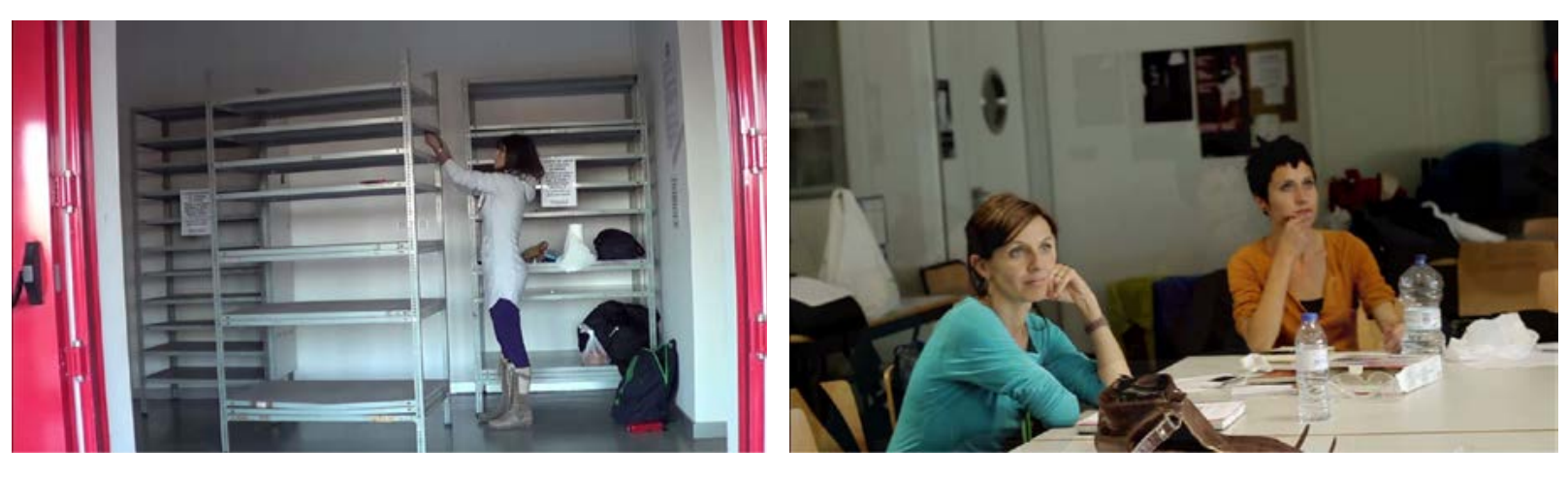
Imágenes 115-116. Fotogramas extrádos del video realizado por Madame Cornucopia para Aula-R. Fuente: Ma dame Cornucopia.
Público del mito $y$ la n

\subsubsection{Puntos de tensión y puntos clave}

Un asunto que creíamos en principio clave, pero que no ha funcionado, era convertir a Aula- $R$ en un punto de encuentro donde las personas se pusieran de acuerdo para reutiliza vender, comprar materiales de segunda mano o de forma común, ahorrando gastos de viajes, exceso de material, etc. Para ello se dispone de un tablón de anuncios situado en el espacio físico que ocupa Aula-R y una página pública de facebook ${ }^{316}$. El uso que se la ha dado es escaso.

Como en todo proyecto colaborativo, la difusión es un punto importante. Pero nuestra filosofía de difusión trata de ser coherente con la ética del proyecto y no consumir recursos, apoyándonos más en la relación directa, el boca a boca y las charlas informativas clase por clase. Se ha realizado además de modo digital por correo electrónico, blog y facebook ${ }^{317}$. El uso de códios cion

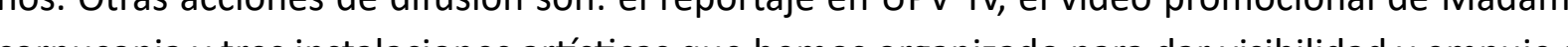

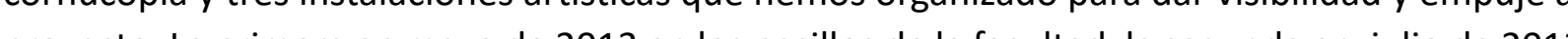
proyecto. La prim in en mayo de 2013 en los pasilos de la de a bibli maco de actuaciones del prove de la biblioteca en septiembre de 2014

Contar con el apoyo de miembros de Decanato, la delegación de alumnos, la Unidad de la para su difusín y realizacín. Por ejemplo, el servicio de conserjerí ha do so ma ma fondo de objetos perdidos y el servio de limpera cola con de vez an cuado, aportano

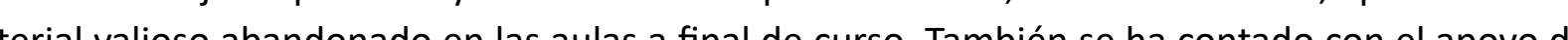
terial valioso abandonado en las aulas a final de curso. Tamblén se ha contado con el apoyo de dicha delegación para hablar del proyecto a los nuevos estudiantes en las jornadas de recepción

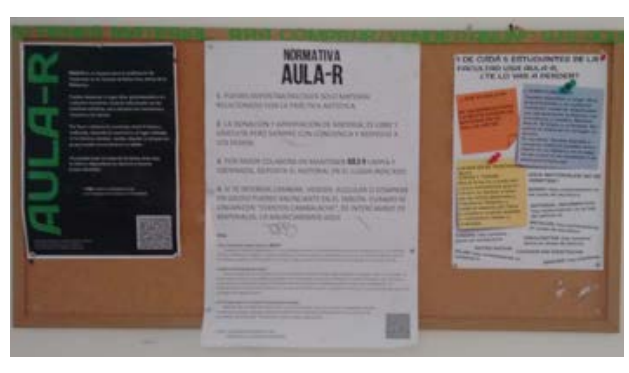

Imagen 117. Tablón de anuncios de Aula-R.

16 Véase en : https://www.facebook.com/

317 Véase en https://www.facebook.com/
Aulaerre-579271762086292/

318 Véase en: http://www.upv.es/contenidos/BBBFBA/noticia__8368655.hthml 
319 Aunque debemos añadir honrosas ex- cada septiembre. Un punto fundamental habría sido contar con el apoyo de todo el profesorado, Albelda, que en las su docencia como José hablar de Aula-R $\mathrm{y}$ otros profesores o bien, han llegado a plantear ejercicios de clase con material exclusivo de Aula-R.

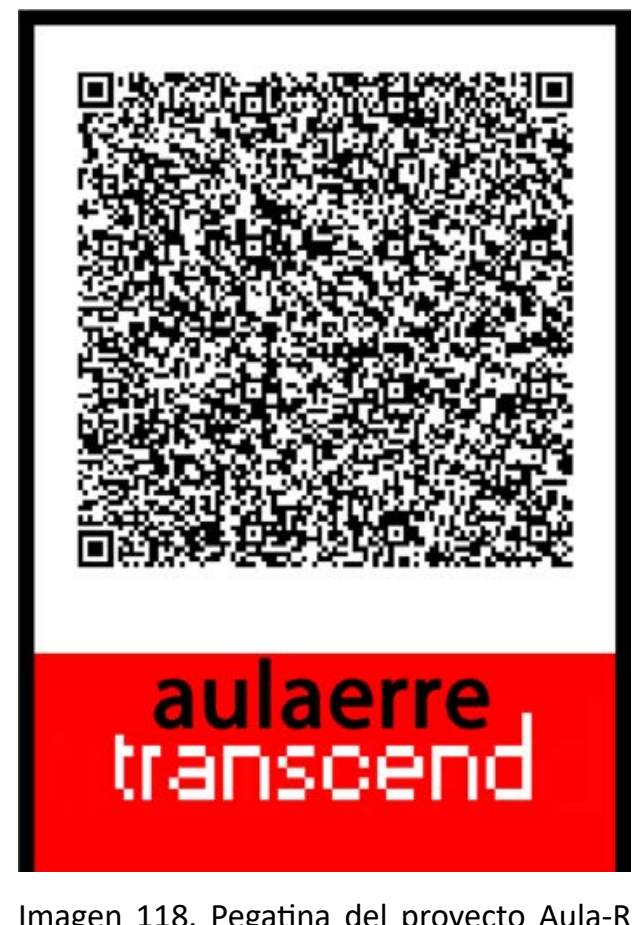

Imagen 118. Pegatina del proyecto Aula-R
con el código Qr realizado por Trascend. con el código Qr
Fuente: La autora.

320 En cuanto a los materiales hemos contado con: estanterías en desuso donadas
por la facultad, diez contenedores de plástico de treinta litros de capacidad donados por la Oficina Verde de la luYv, señalética del espacio utilizando recortes de vinilo verde $y$
negro residuales, cedidos por el Laboratorio

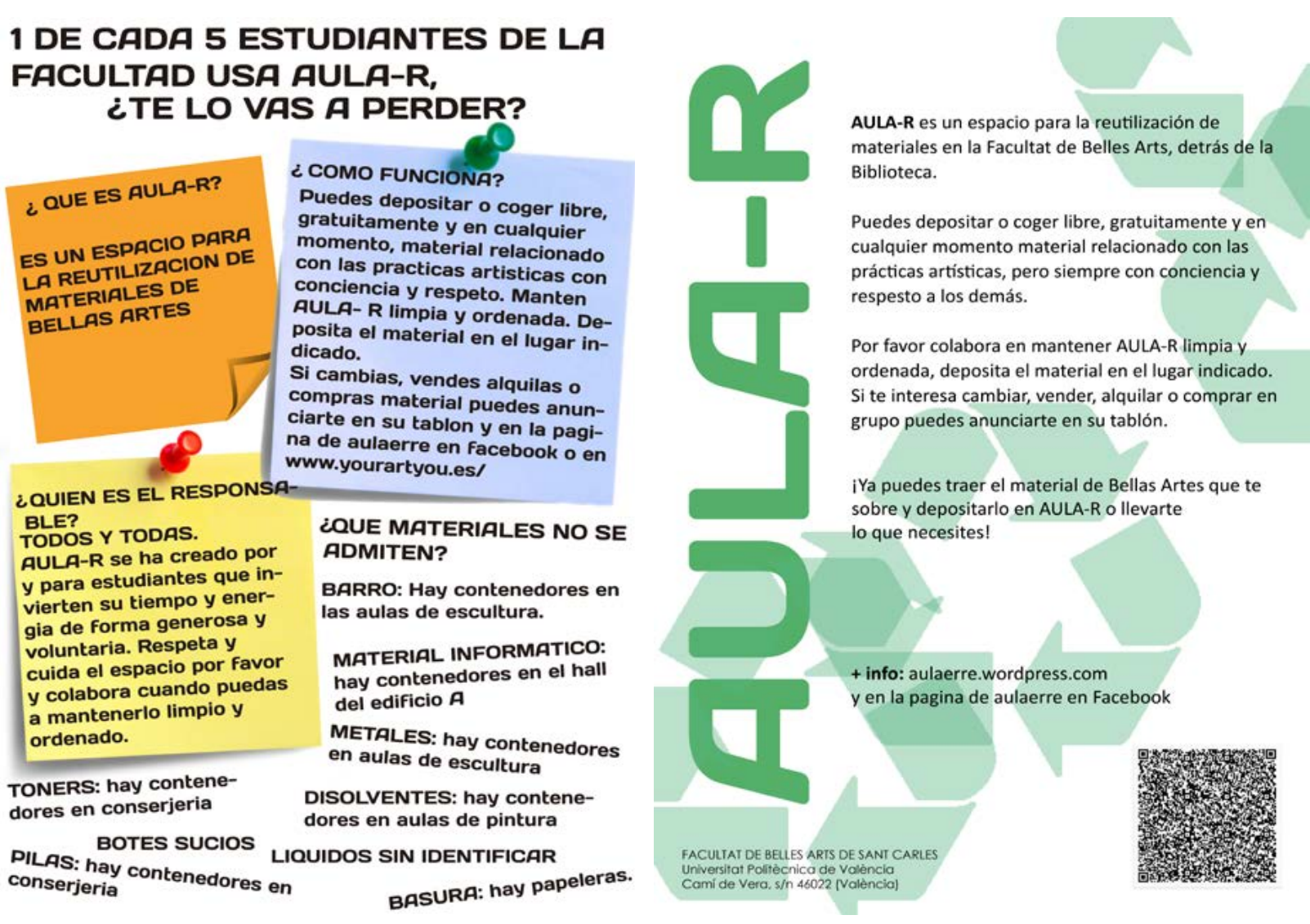

Imágenes 119 y 120. Cartelería del proyecto. Fuente: izquierda la autora, derecha: Nayra Pimienta.

Los puntos de tensión y obstáculos detectados son:

En cuanto a la cuestión económica, se solicitó una subvención a través de la UPV que no fue concedida, pero aun así el proyecto pudo realizarse gracias a que apenas conlleva gastos ${ }^{320}$, y a la aceptación de Aula-R por parte de la Dirección de la Facultad de BB.AA.
«La rapidez (de pocos segundos a horas) con que se apropian los usuarios de los que le resta credibilidad.

de Recursos Media del Departamento de

Aula-R es poco difundido por el profesorado en sus clases.

- Carecemos de un equipo de colaboradores en la creación y mantenimiento del proyecto, lo cual, ralentiza las acciones y empobrece los resultados. Cada curso hay que repetir acciones de difusión entre el nuevo alumnado y volver a contactar con la delegación de alumnos que cambia sus integrantes.

- No hemos conseguido que el alumnado entienda Aula-R como un bien común y se responsabilice del espacio, su limpieza y orden a pesar de que en la encuesta inicial entre el $85-95 \%$ de encuestados manifestó su interés en colaborar en su mantenimiento ocasionalmente. Durante estos años hemos debido seguir haciendo una labor $\mathrm{de}$ mantenimiento esporádica ante la falta de respeto de algunos estudiantes que resta limpieza al espacio provocando rechazo.

- La falta de solidaridad, de conciencia ambiental, la distancia y el hecho de que muchos estudiantes ya afirman reutilizar todo su material, disminuyen las donaciones» (Sánchez-León y Albelda, 2015)

- Otra cuestión que ha sido muy discutida en varias ocasiones es la ubicación, que ha de ser un espacio discreto, frecuentado y accesible. Por eso se situó cerca de las taquillas del alumnado y al lado de las máquinas de café. Actualmente pensamos que la ubicación ideal sería delante de la conserjería, que tiene más visibilidad y los usuarios poco respetuosos lo tendrían más difícil a la hora de dejar basura.

\subsubsection{Intención}

Nuestra intención en esta obra ha sido responder a una necesidad real de nuestro conexto cercano de un modo colaborativo, mediante prácticas artísticas colaborativas y dentro 
321 Véase en: https://Www.academia.
edu/27983832/PROYECTOS_COPARTICIPATAL_EN_EL_\%CCA\%81MBITO_DE LA_DOCENCIA ART\%C3\%8DSTICA UNIVERSITARIA_AULA_R de los residuos en un contexto tan a splio como Cos ridos en un con Jítice. y la cooperación evitar la sobreproduccín, reducir el consumo compulivo in 322 Véase en hatps:///www.academia.
edu/27983977/Evaluaci\%cC3\%B3__de_la_ tico_coparticipativo_de_reutilizaci\% C3\%B3n_de_materiales_AULA_R_en_\%y la cooperación, evitar la sobreproducción, reducir el consumo compulsivo e innecesario y colaborar con en el ahorro en gastos de materiales, en recursos y energía.

\subsubsection{Efectividad}

Teniendo en cuenta la gran cantidad de residuos que se generan a lo largo de los estudios en BB.AA y el gasto que supone para la facultad gestionarlos, para los estudiantes comprar el material $y$ B.AA y gasto que supone para la facultad gestionarlos, para los estudiantes comprar el material y para el medio amblente el consumo en recursos y energla, la opción de la reutilización de materiales resulta enormemente atractiva y conveniente para todos $y$ todas. No podemos saber cuántos ma teriales han recirculado y alargado su vida útil gracias a Aula-R, pero podemos evaluar otros datos como la participación, que nos aportan pistas sobre sus resultados. Transcurridos dos años desde su Implantación, realizamos una evaluación del proyecto para el V Congreso Internacional de Educación Ambiental donde presentamos un artículo ${ }^{321}$ y un poster ${ }^{322}$ (ver en anexo 5) publicados en abierto. La metodología consistió en un muestreo cuantitativo mediante encuestas, con un margen de error de $5 \%$ y un nivel de confianza del $95 \%$. La población a muestrear son los estudiantes de grado en BB.AA. grado en Restauración y Másteres de Arteterapia y de Producción Artística UPV ( $(\mathrm{N}=2450)$ a la que se encuestó mediante un muestreo aleatorio simple y tamaño muestral de 292 encuestas. Los principales resultados de la encuesta son:

- «El 80\% del alumnado conoce Aula-R principalmente por haber visitado el espacio físico, en segundo lugar por referencias de compañeros, en tercero por la jornadas de recepción de estudiantes, y llama la atención que solo en cuarto lugar, a través del profesorado.

- Del alumnado conocedor del proyecto, el $16 \%$ ha donado de media en 7 ocasiones en los dos primeros años, en su mayoría por motivos de solidaridad. Es decir, tan solo el $13 \%$ de los estudiantes totales conoce el proyecto y se solidariza para donar (figura 10). El principal motivo para no donar materiales es el olvido (figura 9), seguido de que gran parte de los
El 24\% de los conocedores de Aula-R afirma haberse apropiado de material de media 4 veces (figura 10). Es decir, el 19\% del alumnado total ha cogido material en alguna ocasión por motivos económicos o de urgente necesidad, siendo la conciencia ambiental un motivo menor De nuevo, del hecho de no haber donado nunca antes ${ }^{323}$ (figura 9).

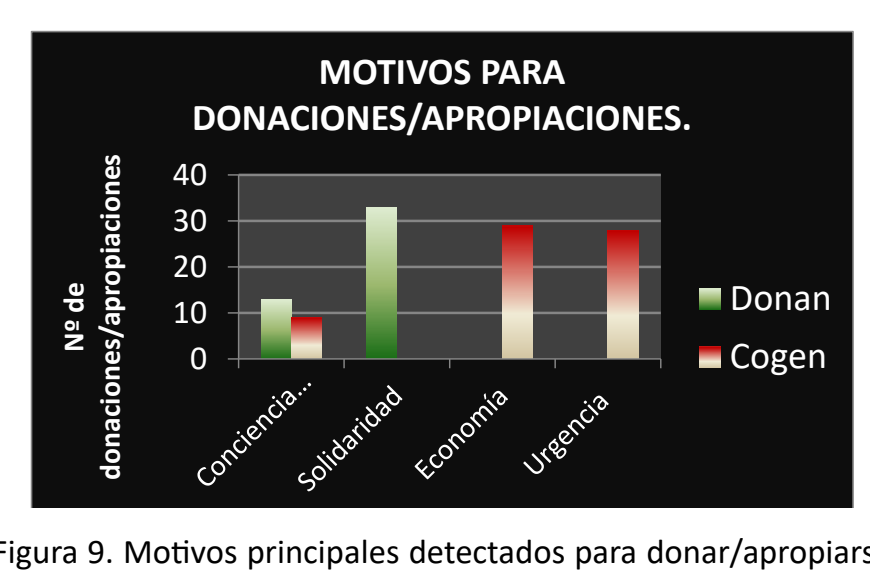

Figura 9. Motivos principales detectados para donar/
de materiales de Aula-R. Fuente: elaboración propia.

- La utilidad (figura 11) se ha clasificado en 5 tramos de muy alta a ninguna. El $41 \%$ de los conocedores del proyecto no le dan ninguna utilidad real en su caso particular, puesto que nunca han donado o cogido nada. E $21 \%$ de los conocedores, a pesar de haber cogido o donado en alguna ocasion, le da utilidad baja. El $19 \%$ cree que en su caso ha sido median mente útil. El 12,5\% le otorga una alta utilidad y por último solo el $5 \%$ lo clasifica como de muy alta utilidad. Es decir, que el $29 \%$ del alumnado total lo considera de utilidad media a muy alta. El $50 \%$ del alumnado a pesar de conocer el proyecto, no lo han insertado en su vidas como una opción habitual » (Sánchez-León y Albelda, 2015).

Aula-R también ha servido para dar empuje a otros proyectos de concienciación ambiental que espontáneamente se han sumado como:

1. La obra artística Best Seller presentada en la convocatoria PAM PAM $2015^{324}$ de Juan Carlos Rosa, realizada con ropa de segunda mano recogida -en parte- en Aula-Ry que reflexiona sobre el exceso de materiales y el cambio hacia un estilo de vida basado más en el compartir usuarios. Aquellos que nunca ha donado, no haber contribuido previamente. 324 Véase en: https://www.juancarlosro-

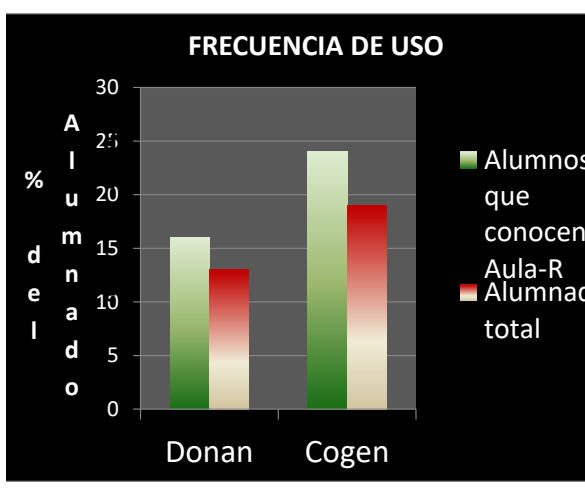

Figura 10. Grá́ico de barras sobre tanto por de materiales en Aula-p. Fuente: elabis

ción propia.

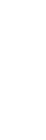




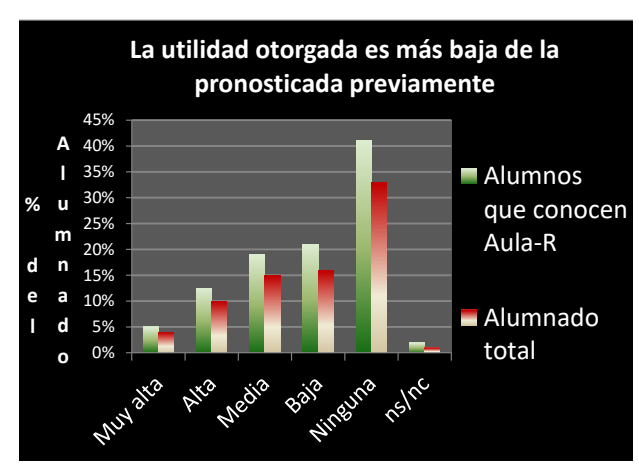

menos en consumir.

2. La plataforma web de venta de material artístico de segunda mano mediante el comercio electrónico: Your art you ${ }^{25}$, creada por Salvador Sultán y Alejandro Iborra.

Al margen de los posibles efectos en la concienciación ambienta|326, para los docentes permite la inclusión en la docencia de prácticas especificas de arte y reciclaje y para los estudiantes, favorece la experimentación ensayando nuevos materiales que de otro modo el alumno no podría adquirir.

Figura 11. Utilidad otorgada por el alumna-
do gue conoce y desconoce Aula-R. Fuene

Proyecto colaborativo "Dona tu ropa al Arte": recogida de ropa en Aula-R

325 Véase en: https://www.facebook.com YourArtYoushop

326 Durante la realización de las encuestos testiment 2015 hemos recogido divesos testimonios positivos de estudiantes al
respecto de la idoneidad del proyecto y el
agradecimiento por haberlo hecho realidad.
*Facultad de Bellas Artes :: Agenda *: Del 1 al 15 de Julio de 2014 :" Proyecto colaborativo "Dona tu ropa al Arte"
recogida de ropa en Aula-R

DONA TU CUERPOA LA CIENCIA

ROPA AL ARTE!

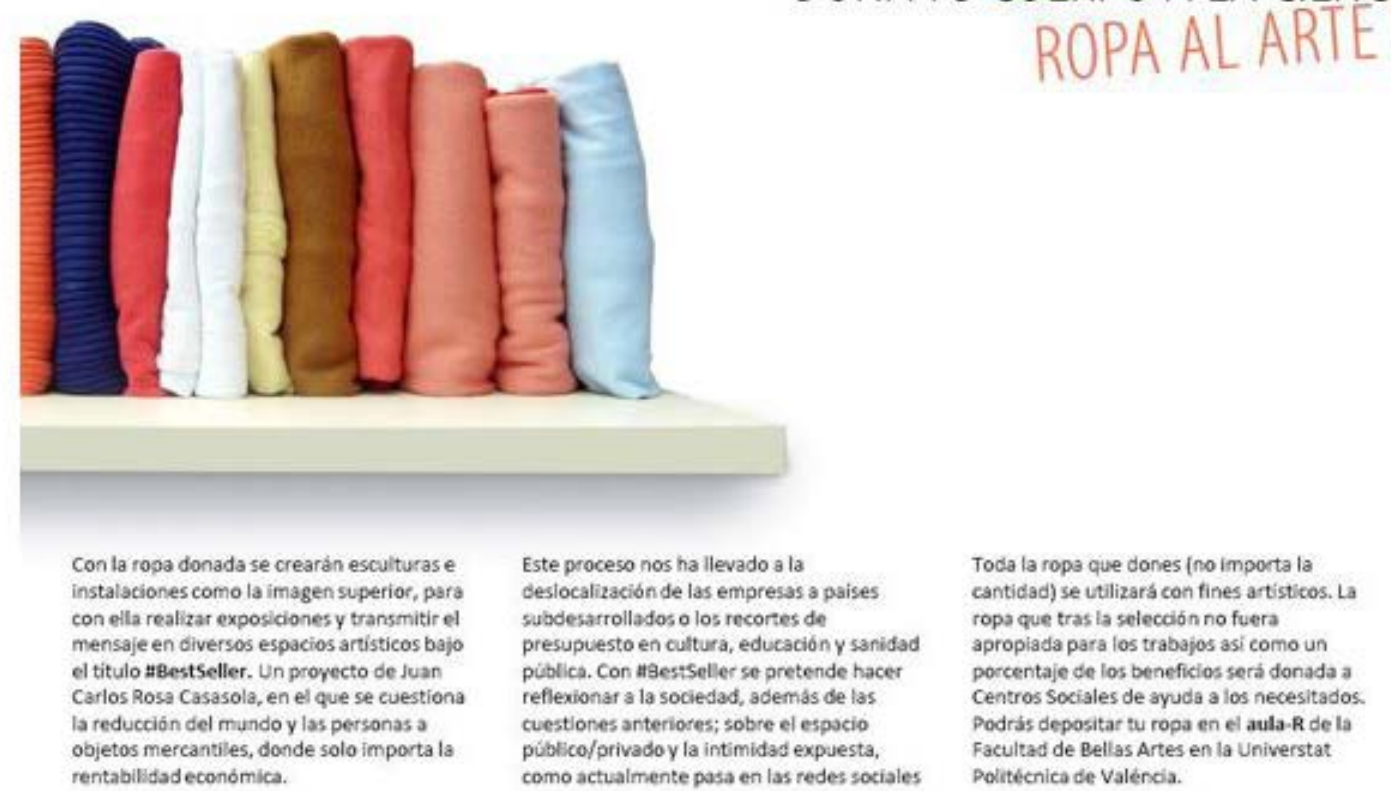
Imagen 121. Cartel anunciador de la obra de Juan Carlos Rosa solicitando material a depositar en Aula-R. Fuente:
extraílo de: http://www.upv.es/entidades/BBAA/infoweb/fba/info/887513normalc.html. Véase en: wwW.juancarloscasasola.com
La perdurabilidad es otro aspecto que valoramos, pues el objetivo es que el proyecto sea mpo, se implante con éxito e incluso se pueda exportar a otras facultades. En se sentido entenos Aula-R como proyecto piloto, extrapolable tanto en España como en el extranjero. Por ejemplo, la Facultad de BB.AA. de Sevilla se ha interesado por el proyecto, as como, la Gray's School of Arts de la Robert Gordon University en Aberdeen, Escocia, donde hemos sido invitadas por la asociación estudiantil Go Green a presentarnos en 2016

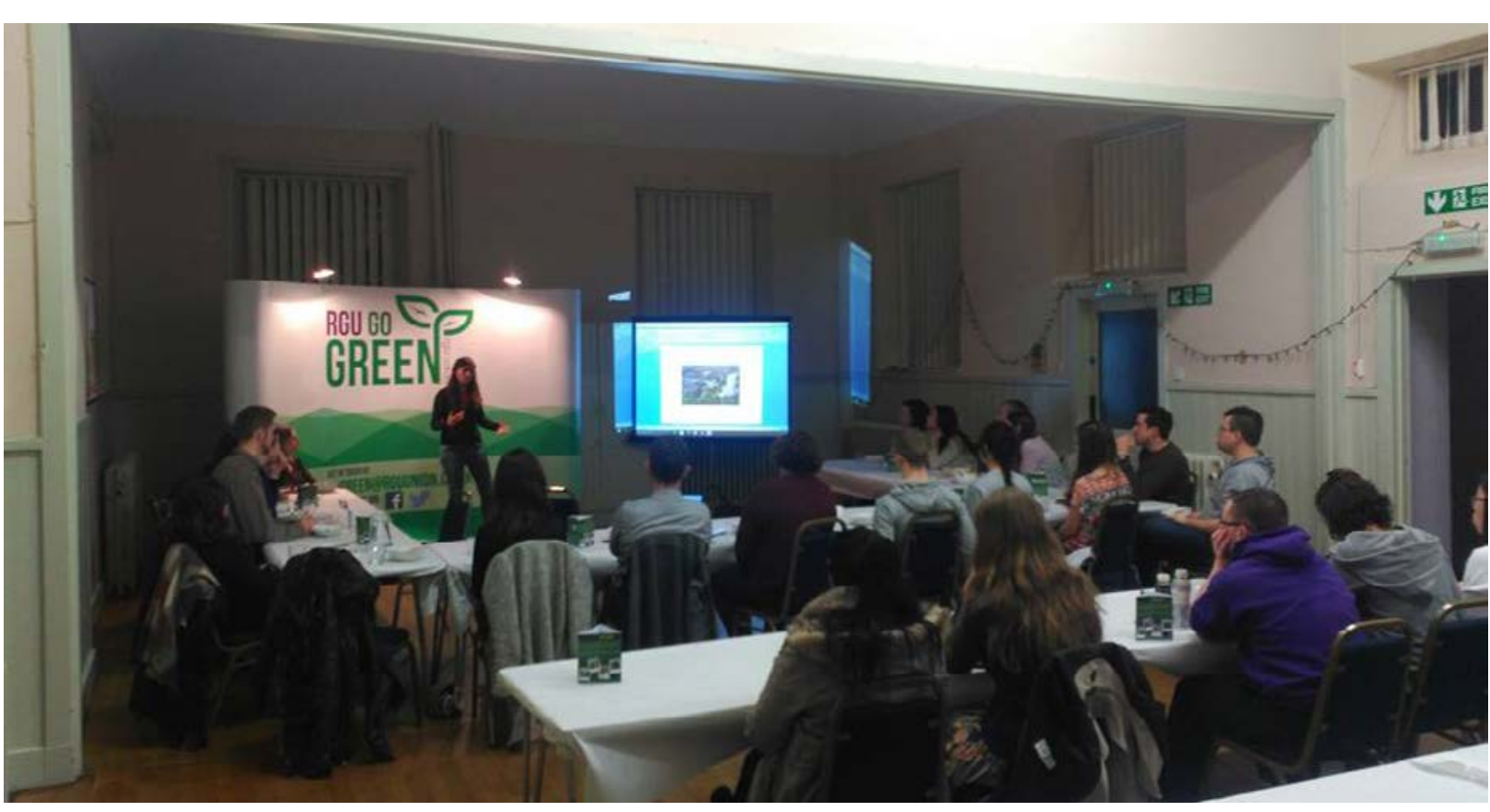
Imagen 122. La autora presentando Aula-R $\mathrm{y}$ otros proyectos artísticos colaborativos
bert Gordon University en Aberdeen. Fuente: Fotografifia de Caroline Gausden 2016 .

7.4.5 Estética y ética

La ubicación de Aula-R en la facultad de BB.AA. es un ejercicio de autocrítica a nuestra propia huella ecologica como artistas y un intento de reducirla segun nuestros valores ecoéticos. En cuanto a sus virtudes artisticas, en primer lugar se trata de un arte de procesos a 

del público. En segundo lugar, los resultados de la encuesta hicieron patente la importancia de mejorar y cuidar la estética del espacio. La imagen del proyecto inicial ha sido renovada en 2015 , como se puede observar en las siguientes imágenes 123-124, implicando a la delegación de alumnos. Esta invitación a co-crear la nueva imagen pretende crear un sentimiento de coautoría que incentive la participación

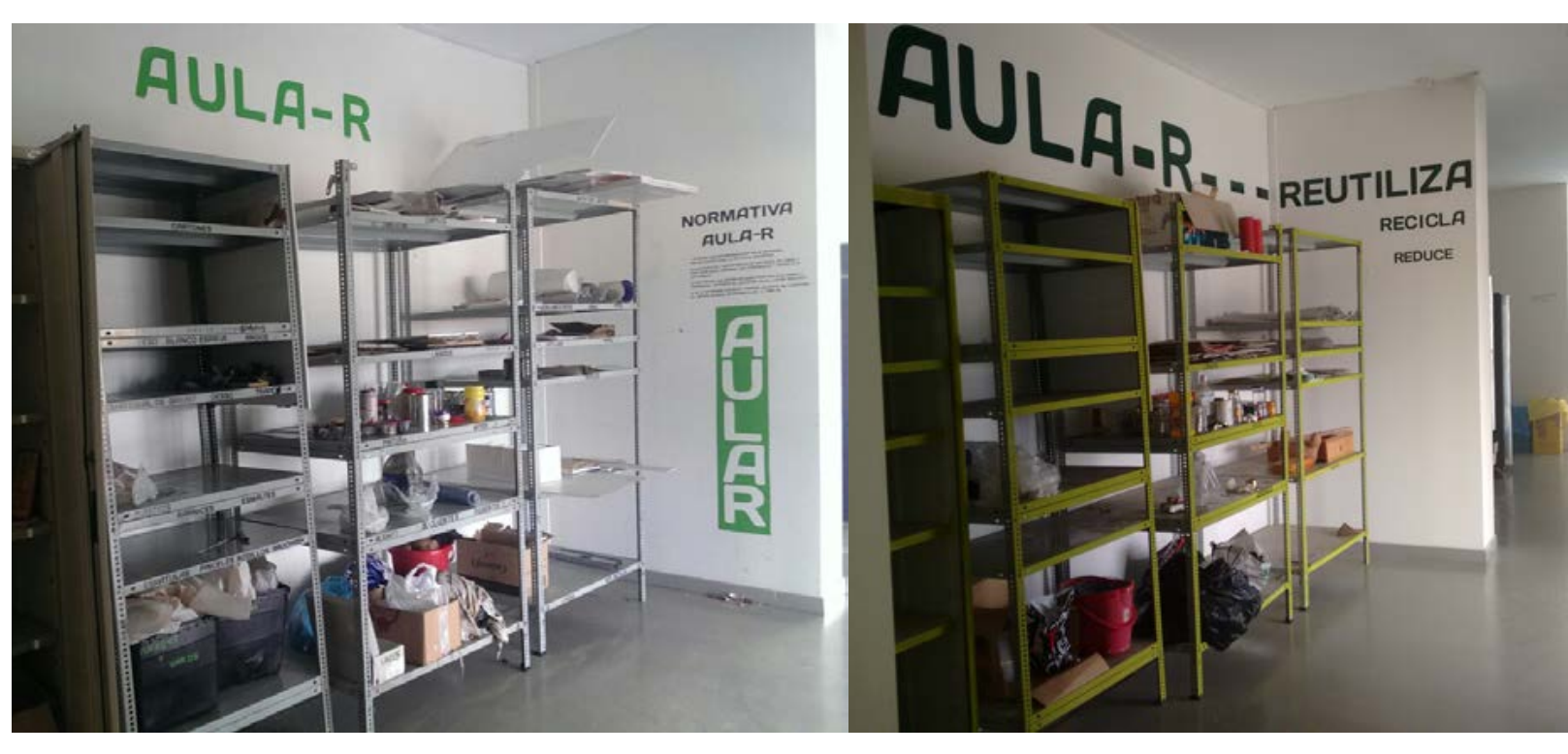

Imágen
2015.

Por último, queremos destacar dos instalaciones artísticas realizadas para promociona ula- $R$ au sirven para dar visibilidad y empuje al proyecto. En el caso de la primera instalación al cumplir tres meses realizamos una acción de promoción del espacio en los pasillos de la fácultad con la colaboración de la doctoranda Almudena Rodríguez Tortajada. El material utilizado fueron algunas de las encuestas contestadas por los alumnos varios meses antes, y fotografías de los materiales depositados en Aula- $R$ hasta el momento, que suspendidas de hilos, marcaban el camino hacia Aula- $R$ desde varias entradas de la facultad.

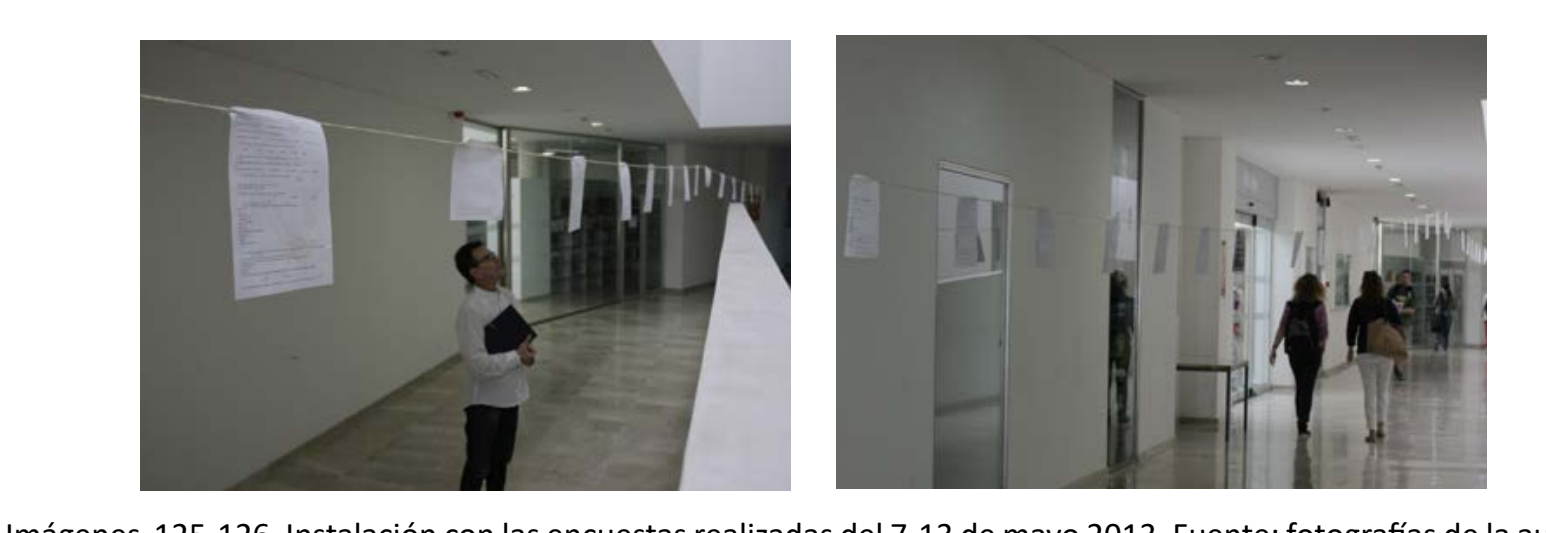

Imáge
2013.

En el segundo caso, participamos en el apartado Tácticas Vinculantes, dentro del proyecto Selecta 13 en la sala ta Mutante de Valencia. La instalación pretende trasladar simbólicamente a la galería el proyecto original de Aula- $R$ y continuar su labor de concienciación ambiental a través de la reutilización. Para ello se realiza un taller colectivo de jabón con el aceite reutilizado y recolectado de los compañeros del Master de producción e investigación artística UPV, dándole forma de tubos de óleo, pinceles y otros útiles de la eráctica artística. Ese jabón será después presentado en la galería y puesto a disposición práctica artistica. Ese jabón será después presentado en la galería y puesto a disposición del público que puede apropiarse del mismo tal y como en Aula-R los usuarios se apropian de los materiales. La intención es realizar un gesto simbolico, representativo de la filosofía de Aula-R en el que el espectador sea activo y participante. Se emplean además otros elementos como:

1. Proyección de una de las estanterías reales del proyecto: El espectador puede introducirse entre el proyector y lo proyectado creando una distorsión como recordatorio de nuestra huella ecologica. La imagen de la estantería que se proyecta es fija y sobre ella, se colocan los jabones a disposición del espectador para que se los lleve. Se acompaña de bolsas con instrucciones de cómo hacer jabón casero con el aceite usado.

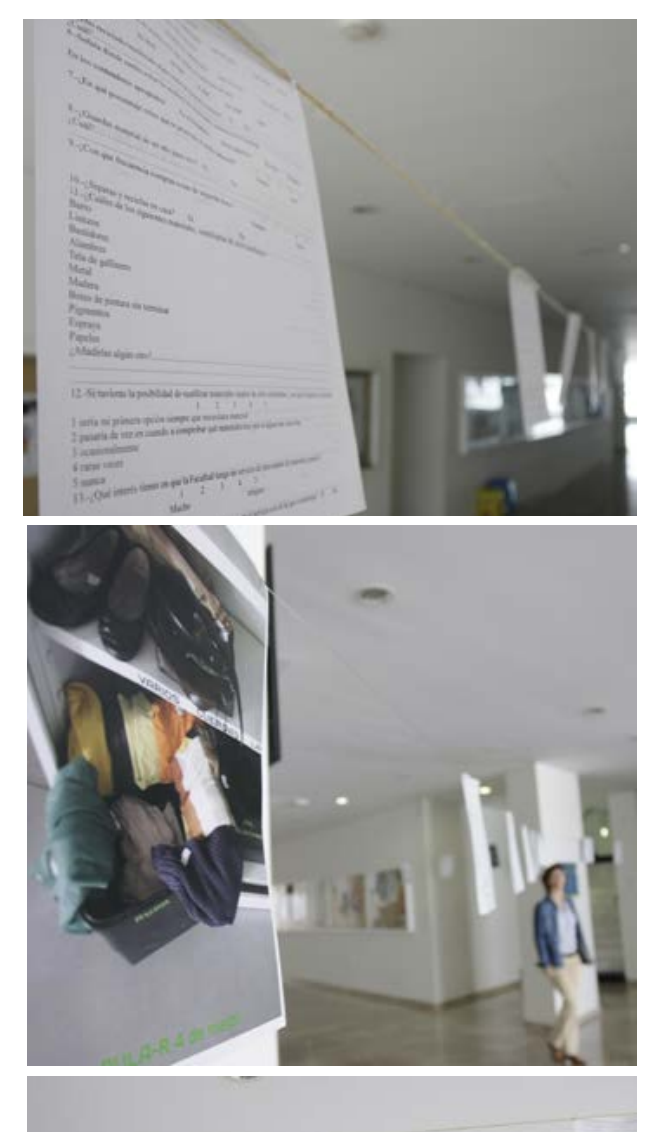

5 Saladereposicions
Josep Renat

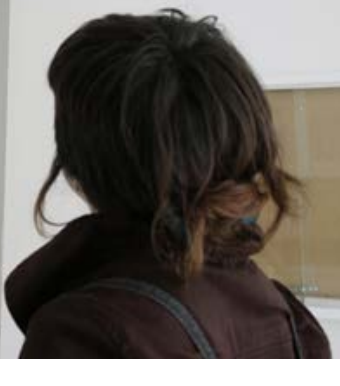

Imágenes 127-129. Instalación con las encuestas realizadas del 7-13 de mayo 2013 
Imágenes 131-133. En el centro la provección de la estantería real de Aula-R en la pared sobre la que se sitúan los
abones. A la izquierda las bolsas para llevar los jabones con los datos de Aula-R e instrucciones de cómo hacer jabón casero en su interior. A la derecha los jabones anclados a la pared dispuestos para que los espectadores se apropien de ellos. Fuente: fotografias de la autora 2013.

2. Proyección del vídeo realizado en colaboración con la productora Madame Cornucopia: es una manera sencilla, rápida y directa de mostrar el proceso y resultados de Aula-R.

3. Cartografías que muestran las cantidades, fechas, materiales, procedencia, propietarios y destino de los materiales a partir de información recopilada.

Con todas estas acciones tratamos de mejorar la imagen del proyecto de un modo participativo acorde a nuestras intenciones.
Aula- $R$ tiene un cometido principalmente práctico, pero además podemos identificar otras funciones como las siguientes:

\begin{tabular}{|c|c|}
\hline $\begin{array}{l}\text { FUNCIONES del ARTE EN } \\
\text { AULA-R } \\
\end{array}$ & JUSTIFICACIÓN \\
\hline $\begin{array}{l}\text { llustrar, representar, } \\
\text { comunicar, difundir }\end{array}$ & $\begin{array}{l}\text { Sí, se comunican ideas sobre reutilización, reciclaje y reducción de } \\
\text { residuos y consumo energético a través de la página de facebook }\end{array}$ \\
\hline Concienciar & $\begin{array}{l}\begin{array}{l}\text { Sí, se busca concienciar sobre los residuos y nuestra huella ecológica } \\
\text { como artistas. }\end{array} \\
\end{array}$ \\
\hline Desarrollar empatía & No se ha pretendido \\
\hline $\begin{array}{l}\text { Imaginar, desarrollar la } \\
\text { visión del grupo, su misión, } \\
\text { futuros posibles, utopías o } \\
\text { ficciones }\end{array}$ & No se ha pretendido \\
\hline $\begin{array}{l}\text { Ofrecer soluciones, } \\
\text { mostrar alternativas } \\
\text { reales o proyectos piloto, } \\
\text { laboratorios de pruebas }\end{array}$ & $\begin{array}{l}\text { Si, el proyecto funciona como proyecto piloto con la esperanza de } \\
\text { instalarse en otras facultades y entornos comunes (comunidades de } \\
\text { vecinos, asociaciones,...) }\end{array}$ \\
\hline $\begin{array}{l}\text { Conectar personas, crear } \\
\text { comunidad, hacer redes, } \\
\text { mediar o facilitar }\end{array}$ & Sí, es un objetivo fundamental. \\
\hline $\begin{array}{l}\text { Conectar personas con } \\
\text { espacios, entornos o lugares }\end{array}$ & No se ha pretendido \\
\hline $\begin{array}{l}\text { Restauración/recuperación } \\
\text { del entorno }\end{array}$ & No se ha pretendido \\
\hline $\begin{array}{l}\text { Reforzar la identidad, crear } \\
\text { símbolos }\end{array}$ & No se ha pretendido \\
\hline $\begin{array}{l}\text { Fomentar la ciudadanía } \\
\text { crítica, agitar, denunciar }\end{array}$ & No se ha pretendido \\
\hline Empoderar & No se ha pretendido \\
\hline $\begin{array}{l}\text { Crear relatos positivos de } \\
\text { cambio }\end{array}$ & $\begin{array}{l}\text { Sí, demostramos con el análisis de su uso que hay cooperación y } \\
\text { solidaridad entre los estudiantes. }\end{array}$ \\
\hline
\end{tabular}




\begin{tabular}{|l|l|}
\hline $\begin{array}{l}\text { Facilitar la comprensión } \\
\text { del mensaje de la ética } \\
\text { ecológica aplicándola }\end{array}$ & $\begin{array}{l}\text { Si, aplicamos al proyecto los conceptos de la ética ecológica como } \\
\text { la cooperación, la reutilización, etc. y emitimos un mensaje a la } \\
\text { comuninad artistica universitaria de responsabilización de su huella } \\
\text { ecológica. }\end{array}$ \\
\hline $\begin{array}{l}\text { Conectar áreas alejadas de } \\
\text { conocimiento }\end{array}$ & No se ha pretendido \\
\hline $\begin{array}{l}\text { Motor iniciador de } \\
\text { dinámicas y proyectos }\end{array}$ & $\begin{array}{l}\text { Sí, a raíz de Aula-R hemos apoyado otros proyectos artísticos y de } \\
\text { negocio. }\end{array}$ \\
\hline Celebrar & No se ha pretendido \\
\hline Aumento de la resiliencia & Sí, en el sentido de compartir recursos e información. \\
\hline Construir consensos & No se ha pretendido \\
\hline Premiar, agradecer & No se ha pretendido \\
\hline Recaudar fondos & No se ha pretendido \\
\hline $\begin{array}{l}\text { Revitalizar el territorio } \\
\text { Luchar contra el érodo } \\
\text { rural, dinamizar el territorio, } \\
\text { activarlo) }\end{array}$ & No se ha pretendido \\
\hline
\end{tabular}

Tabla 11. Funciones del arte identificadas por l a autora en Aula-R. Fuente: Ila autora.

\subsection{RESULTADOS Y CONCLUSIONES PARCIALES}

Aunque esta obra se realizó mucho antes de conocer el arte transicional, se pueden identificar en ella sus principios:

1. Intención: Sí, tenemos intenciones expresas de contribución a la sostenibilidad.

2. Ignición: Sí, el intercambio de recursos puede ser el detonante de otros proyectos como en el caso del artista Rosa.

3. Marco: Sí, el marco de trabajo viene definido por la actividad artística en la facultad.

4. Trabajar con la comunidad: Sí, Aula-R se basa en fomentar la concienciación ambiental indirectamente.
Mediación: Sí, durante la realización del proyecto hemos actuado como facilitadores del proceso.

6. Mantener un espacio: Sí, aunque el objetivo es que el espacio sea autogestionado y mantenido por la comunidad.

7. Conexión: Sí, es un objetivo fundamental conectar recursos con nuevos usuarios.

8. Trabajar desde lo común: Sí, hemos creado un espacio común dentro de la universidad pública.

9. Colaborar: Sí, es un objetivo fundamental la colaboración espontánea, anónima y voluntaria que mantenga el proyecto.

10. Cambio: Sí, es un objetivo fundamental cambiar nuestros comportamientos durante la creación artística.

El camino hacia la transición forma parte de un proyecto de transformación social necesariamente colectivo, que se materializa con microproyectos locales y cotidianos como éste. sariamente colectivo, que se materializa con microproyectos locales y cotidianos como este. Aula- $R$ pretende construir entre todos y todas espacios de vinculo e intercambio a través de pro-
cesos colaborativos y autogestionados. Como artistas en este caso, actuamos de facilitadores de contexto, pero la verdadera acción procede a diario de los usuarios: sin público no hay proyecto. Por lo demás, si se desea que iniciativas como Aula- $R$ perduren, resulta imprescindible la implicación de todos los sectores de la comunidad universitaria: decanato, delegación de alumnos, estudiantes y muy especialmente profesorado.

De modo general, nos sentimos satisfechas del resultado del proyecto a pesar de no haber cumplido las expectativas que las encuestas prometían sobre responsabilidad del espacio. En cumplido las expectativas que las encuestas prometian sobre responsabilidad del espacio. En cuanto a la efectividad del proyecto a nivel de intercambio de materiales, los pronósticos de las 500 personas) ha interactuado con Aula-R en sus dos primeros años entre cuatro (para coger) y siete veces (para donar) de media y solo el $29 \%$ le otorga cierta utilidad, en comparación co el 70\% de alumnos que se manifestaba interesado antes del proyecto (Sánchez-León y Albelda, 2015). La mayoría de participantes lo hace por razones de ahorro económico en primer lugar, 


\section{CAPÍTULO 5. DISCUSIÓN DE RESULTADOS}

Siendo una idea tan simple, sorprende que aún no esté funcionando en más facultades de BB.AA. La inercia cultural de la anterior época de bonanza económica y el hecho de que el estudiante de BB.AA. siempre ha reutilizado y reciclado material a su manera pueden ser una explicación aunque, según nuestro estudio, es la falta de costumbre la causa principal para no participar.

En resumen, lo que hoy es un proyecto piloto con muchas posibilidades esperamos que siga creciendo y extendiéndose a otras facultades de España. Pero para que su efecto transformador de la práctica artística sea mayor, será conveniente hacer un ejeccio previo de informa

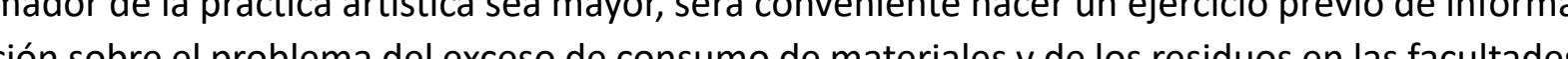
Solo si la con probida universtaria entende y acepta que existe un situación proble

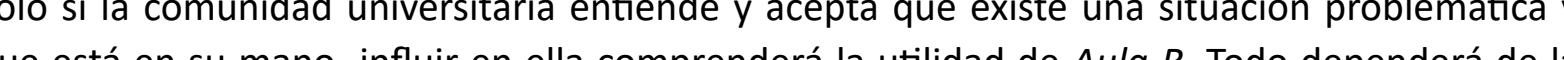
que está en su mano infur en ella comprenderá la unillad de $A u l a R$. Todo dependerá de la concienciación previt éxito de la idea.

\section{ANÁLISIS Y DISCUSIÓN DE RESULTADOS.}

Antes de adentrarnos en el análisis de resultados general, debemos mencionar las limitaser tomados con cierta cautela. En primer lugar, los ejemplos analizados de obras fuera de la Red de Transición son solo cinco, lo cual no representa la gran variedad de proyectos que encontramos en la geografía española y que cumplirían nuestros criterios de análisis. Es por ello por lo que hemos querido incluir en el análisis la red de El Cubo Verde, que aglutina el sentir general de muchos de estos proyectos. Pero no debemos tomar las respuestas de la entrevista a la red por representativas de absolutamente todos los proyectos que aglutina. Por otra parte, en los proyectos del capítulo cuatro las funciones del arte han sido identificadas por nosotros en base a linformacín recopilada y las entrevistas, pero hemos de reconocer nuestro propio sesco de subjetivida

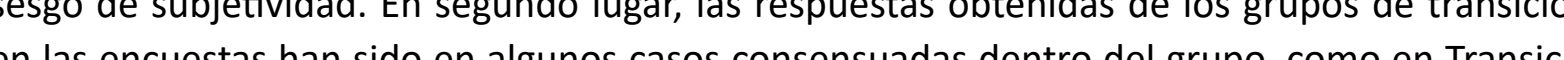
VNG Bu roi, JeT y Gricto

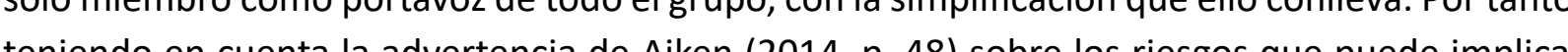
teniendo nor consuric investigar (por consumir el escaso tiempo de los individuos en estos grupos) y hacer crítica en estos grupos tan frágiles (que puede afectarles en la fe en el colectivo necesaria para seguir adelante) como los que forman la Red de Transición, queremos dar a entender nuestras conclusiones como sugerencias y orientaciones. Buscamos, sin annimo de ser taxativos, esclarecer cómo puede introducirse el arte en una iniciativa de transición o bien en la transición en sentido amplio, y qué beneficios puede aportar. Es este el primer paso para dar respuesta a lo que desde JET se nos proponía: «Sería importante conocer alguna forma de introducir la representación artística dentro de los movimientos en transición, a través de un formato asequible (folleto, guia o artículo)» (comunicación personal, 8 de enero de 2018), y que puede desembocar en una posterior guía procedimental sobre los modos de introducir el arte en las distintas fases de la transición. 


\subsection{PARTICIPACIÓN}

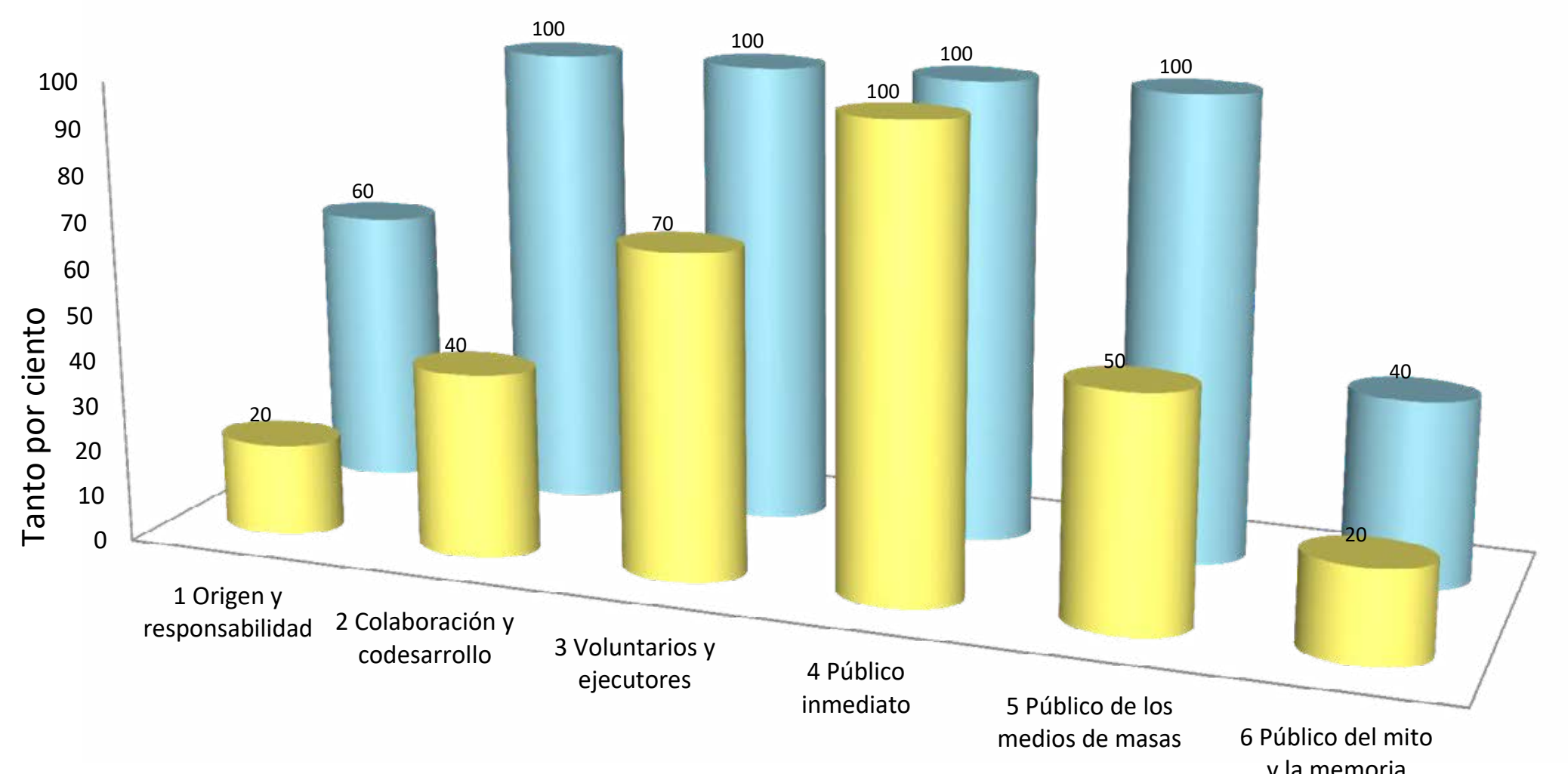

Dentro de la Red de transición obra artistica como red, aquí nos interesa más reflejar los tipos de participación que se suelen dar enlos proyectos que forman la red (y que abarcan los tipos uno al cinco), que la actuación interna de El Cubo verde. En la mayoria de los proyectos vistos fuera de la red (The Stove, DUO, Aula-R) la participación es objetivo y además herramienta, lo cual concide con la situación dentro de la Red de Transición como señalamos en el capítulo tres apartado 1 al respecto de las iniciativas portuguesas (Fernandes-Jesus et al., 2017).

Tanto dentro como fuera del MCT, la participación como voluntarios ejecutores y como público inmediato es lo más habitual, seguida de la colaboración/desarrollo y el público de los medios de masas, debido en gran medida, a internet, que ha facilitado la difusión de proyectos. Sin embargo, los extremos de esta gradación de la participación (tipos uno y seis) son los tipos menos usuales y más dificiles de implementar. En cuanto a las diferencias entre estos dos grupos dentro y fuera de la Red de Transición, es notable que la participación se desplace hacia la expectación, sobre todo en el caso de Transición, es notable que la participación se desplace hacia la expectación, sobre todo en el caso de iniciativas de transición, mientras que en los ejemplos fuera de la red seleccionados la participación
está más repartida en los cuatro grupos centrales. Es lógico si pensamos que en DUO, The Stove y El Cubo Verde hay artistas profesionales del arte público que tienen más experiencia en cómo fomentar la colaboración. Esto viene a relacionarse con lo defendido por Fernandes al respecto de su estudio de las iniciativas de Portugal, que también en muchos casos desarrollan «modos débiles de participación», es decir, sus actividades se utilizan para difundir información pero no para crear verdaderos espacios para la participación ciudadana. Gittins y Baxter de DUO son un ejemplo de buenas prácticas a la hora de incitar el diálogo crítico y abierto que da lugar al origen del proyecto. En lugar de partir de un plan prediseñado plantean una pregunta fértil y plena de semillas: ¿Cómo queréis que sea Dundee en el futuro? Así, originar la participación tipo uno implica preguntar al público qué queremos hacer, la colaboración tipo dos, cómo queremos hacerlo y el tercer tipo con quién y cuándo.

mplementar obras participativas nos permite conocer en parte cómo son las relaciones de los ciudadanos e instar a un cambio. Hemos podido comprobar esto en persona en las dos obras de realzación propia (Hogar del pan y Aula-R), donde nos han sorprendido tanto la generosidad y entrega de muchas personas como el desinterés de otras. Marín ya señala la conveniencia de usar obras de tipo colaborativo para lograr impactos más positivos en el medio cultural y social $(2015$, p. 464). Pero, dentro de las obras colaborativas, ise podría deducir que a mayor variedad de categorías de Lacy implicadas

A lo largo de estos ejemplos hemos visto diferentes formas de inspirar a la comunidad en un proyecto común. En Almócita y Carrícola el impulso artístico parte de la propia población y los artistas son los invitados a participar, en DUO y Aula-R parte de un artista o colectivo que pregunta 

espacios públicos y la pobreza alimentaria, es lo que lleva a los participantes a visualizar que existe 329 Un reciente estudio publicado en la un problema y a plantearse cómo será el futuro de Dundee y qué pueden hacer. Una vez existe revista Science cuantifica que el número suficiente masa crítica ${ }^{329}$ los seguidores harán de esos pocos innovadores unos líderes del cambio minimo de personas comprometidas en un sector poblacional debe ser el $25 \%$ para im-
pulsar su criterio minoritario hasta un punto
de inflexión en el que se aceptará por la masuficiente masa criticia ${ }^{32}$ )
(Escribano Pizarro, 2004).

\section{PUNTOS DE TENSIÓN Y PUNTOS CLAVE}

Este listado de puntos clave, de tensión y obstáculos que hemos recopilado a lo largo del estudio de casos no pretende ser exhaustivo, pero sí compartir algunas observaciones comunes de cara a futuros proyectos artísticos colaborativos relacionados con la sostenibilidad. Destacaremos aquí las observaciones más frecuentes, como son la oposición o indiferencia del público, el apoyo institucional, la financiación y la coherencia entre estética y ética.

\begin{tabular}{|c|c|c|c|c|c|c|c|}
\hline \multicolumn{8}{|c|}{ PUNTOS DE TENSIÓN } \\
\hline Financiación & & & & & & & \\
\hline \begin{tabular}{|l}
$\begin{array}{l}\text { Formalización como } \\
\text { entidad }\end{array}$ \\
\end{tabular} & & & & & & & \\
\hline \begin{tabular}{|l}
$\begin{array}{l}\text { Externalismo o } \\
\text { paternalismo }\end{array}$ \\
\end{tabular} & & & & & & & \\
\hline Turistificación & & & & & & & \\
\hline \begin{tabular}{|l|} 
Oposición o \\
indiferencia a la obr
\end{tabular} & & & & & & & \\
\hline PUNTOS CLAVE & BIODIVERS & ALMÓCITA & THE STOVE & $\begin{array}{c}\text { TRASHCATCHER'S } \\
\text { CARNIVAL }\end{array}$ & DUO & AULA-R & EL CUBO VERDE \\
\hline $\begin{array}{l}\text { Crear un espacio de } \\
\text { encuentro }\end{array}$ & & & & & & & \\
\hline Difusión & & & & & & & \\
\hline Apoyo institucional & & & & & & & \\
\hline \begin{tabular}{|l|l|l} 
Ubicación \\
\end{tabular} & & & & & & & \\
\hline \begin{tabular}{|} 
Temporalidad de la \\
acción
\end{tabular} & & & & & & & \\
\hline Dialógica & & & & & & & \\
\hline $\begin{array}{l}\text { Contar con apoyo de } \\
\text { personalidades } \\
\text { referentes } \\
\end{array}$ & & & & & & & \\
\hline \begin{tabular}{|l} 
Coherencia estética. \\
ética \\
\end{tabular} & & & & & & & \\
\hline $\begin{array}{l}\text { Mantenimiento, } \\
\text { cuidado }\end{array}$ & & & & & & & \\
\hline \begin{tabular}{|l|} 
Voluntarismo \\
\end{tabular} & & & & & & & \\
\hline $\begin{array}{l}\text { Crear una visión de } \\
\text { futuro }\end{array}$ & & & & & & & \\
\hline
\end{tabular}

Figura 13. En azul los puntos clave y de tensión en cada proyecto analizado. Fuente: elaboración propia.

Es evidente que el número de participantes y la calidad de su colaboración influirán en cualquiera de los casos. Del mismo modo, la oposición o indiferencia del público será un obstáculo a su desarrollo, que puede conducir al abandono del proyecto, como advierte El Cubo Verde. En ese caso el papel del artista como creador, agitador y mediador es fundamental. En DUO hemos registrado un buen ejemplo de esta 
330 Que actualmente ya organiza un curso función del artista en relación a las instituciones (haciendo presión, pero sin oposición) y participantes de pinturar de
nicipio. (cuidando los espacios, estimulando la crítica y la conversación con eventos artísticos puntuales pero constantes). Por el contrario, en el Hogar del pan y en Aulla-R, hemos reconocido la necesidad de aplcar nuevas estrategias que despierten la implicación y apuntado algunas opciones, como mejorar la comunicación previa al proyecto, proveer de información sobre el problema de los residuos, generar previamente interes en la construcción en tierra invitando a un experto, crear un taller de la experiencia constructiva, etc. señalados en el capítulo cuatro apartados 5.4.2. y 7.5 respectivamente. Po otro lado, la relación poco profunda que los artistas puedan establecer en Carrícola o Almócita puede llevarles a la propuesta de obras que no engarcen con el contexto social ni físico, algo habitual en las convocatorias de intervenciones en espacios naturales según Marín (2015, p. 229). Sería interesante para estos proyectos primar la participación de artistas locales, o bien promover la relación del artista yel pueblo antes de comenzar la obra con una visita guiada, un tiempo de inmersión o una beca de residencia. En el caso de Carrícola, aumentar el contacto con la Facultad de BB.AA. de la Universita Politècnica de València ${ }^{300}$ puede propiciar futuras intervenciones más apropiadas al lugar. Otra opción para Biodivers sería cambiar la fórmula de la actual convocatoria cada cuatro años por establecer un programa de residencias que acoja a un número reducido de artistas anualmente que vayan renovando el parque de esculturas constantemente. Aunque esto presenta el inconveniente de que se perdería el efecto llamada de la gran inauguración, por el contrario es posible que atraiga un flujo de visitantes más repartido en el tiempo.

A pesar de que muchas organizaciones de activismo ecológico rechazan el apoyo institucional en todos nuestros casos de estudio ha sido altamente valorado. Efectivamente ya hemos comentado que para el movimiento de transición la alianza coherente con los sectores de poder es un objetivo y, de hecho, la fuerza de empuje principal en Carrícola y Almócita es el propio Ayuntamiento. El caso opuesto serían DUO y The Stove que, a pesar de ser altamente críticos con las instituciones de gobierno en sus ciudades, guardan un delicado equilibrio entre la cooptación y el enfrentamiento. De cara a la transición, según estas experiencias, sería conveniente combinar una postura abierta a la colaboración con autoridades yentidades de poder cuidando de no perder de vista los verdaderos objetivos de cambio sistémicos, a capacidad critica, ni caer en imposturas propias del mercado lo cual consider mos que en DUO han sabido levar a h ráctica. En cuanto a la financiacín las diferencias registrada en ambáreas geoŕficas de estudio han sido tan notables que bien merecen un ańlisis apad

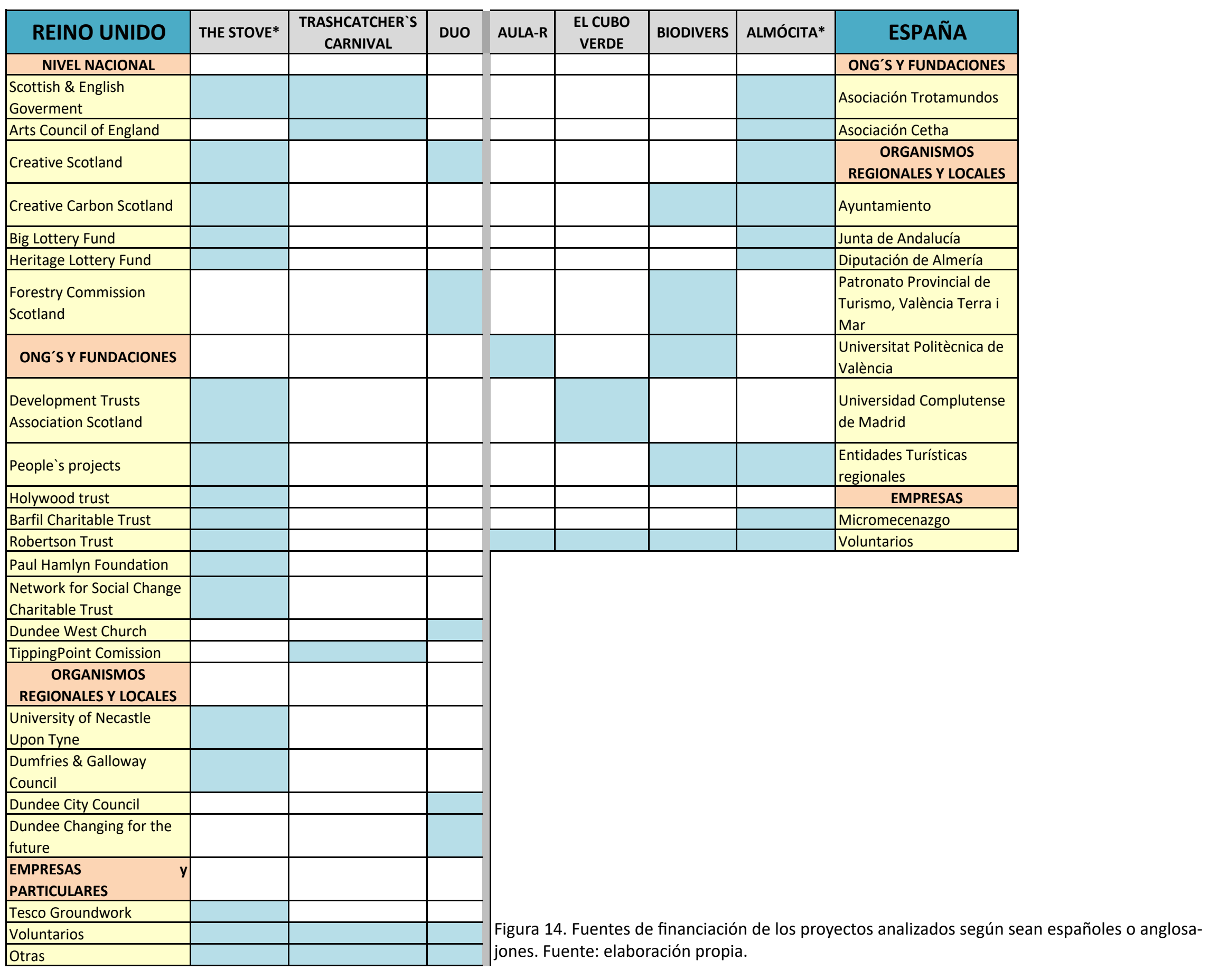

Discusión de resultados. Nuria Sánchez León 

sos, ap mediante requerimientos emente motivando el interés de la gestion cultural en ser sostenibles tivos como The Stove se ha recaudado la suma total de $1.218 .713 \mathrm{f}(1.386 .720 €)$ en el período 2011-2017 entre financiación pública y privada, de los cuales un 16\% procede de organismos oficiales locales, el 22\% de fuentes regionales privadas y el resto de fuentes nacionales (Carso Trotter, 2017). Esto se ha traducido a su vez en una ganancia de independencia año tras año, n 47 contratos a artistas regionales, y el desarrollo de numerosos proyectos artísticos entre los que se encuentran los relacionados con la sostenibilidad que hemos visto: We Live With Water, Submerge para ArtCop 21 y la Nithraid. Esta última ha supuesto un gasto de alrededor de 15.000 €/año (unos $17.000 € /$ año) en sus ediciones de 2016 y 2017. En el caso de Trashcatchers' Carnival, se recaudaron en total $80.000 \mathrm{f}$ en fondos y recursos de diversas organizaciones privadas y públicas que se invirtieron en el carnaval y las conferencias posteriores. Por el contrario, en los casos españoles, solo se detecta apoyo a nivel regional o local y a través de las Diputaciones provinciales (la Diputación de Almería financia el Almouseum con $4.100 €$ por ejemplo), los Ayuntamientos (Almócita y Carrícola financian sus convocatorias artísticas propias, llegando recurrir en el caso de Almócita incluso al micromecenazgo) o las Universidades (la Universita Politècnica de Valècia colabora con Biodivers y con Aula-R, o el profesorado dla Universita a a Cubo Verde. No se detecta en ninguno de estos casos españoles apoyo de empresa va a lcubo pensar que el apoyo a las artes en general, $y$ la consideración de la sostenibilidad en la cultura en Reino Unido son mas instituciones artisticas oficiales españolas como el Instituto Nacional de las Artes Escénicas y de la Música no hemos encontrado declaraciones en relación a la sostenibilidad de los eventos artísticos que rige (música, teatro, danza y circo) (Consejo Lstatal de las Artes Escénicas, 2013). Apenas un número de 2011-2012 de la Revista de la Subdirección General de Museos Estatales trata el tema de la sostenibilidad en los museos y la cultura (Subdirección General de Museos Estatales, 2012) y desde el Instituto de Patrimonio Cultural se ha organizado un congreso en 2017 al respecto, pero nada concreto para el caso de las artes visuales por ejemplo. Mientras tanto, en Reino Unido, el Arts Council England fue el primer organismo de financiación cultural en el mundo en incluir

informes ambientales como requisito de financiación, lo cual ha derivado en un $22 \%$ de disminución en el consumo energético desde 2012 (Julie's Bicycle, 2017, p. 1). En 2013 el Arts Councl England ya recoge la resiliencia y la sostenibilidad en su estrategia renovada para 2010-2020 dentro de sus cinco objetivos principales: «Las artes, los museos y las bibliotecas son resilientes y ambientalmente sostenibles» (Arts Council England, 2013). Se comprometen asi con la adopción de medidas para la sostenibilidad ambientaly la reducción de la hulla de carbono, tanto en el Arts Council England como en las organizaciones que financian. Incluyen un Servicio de Adquisiciones del Gobierno para ayudar a las organizaciones de arte y cultura a pagar menos ser más eficientes desde el punto de vista energético y trabajan en asociación con Julie's Bicycle (a) carbono e incorporar la sostenibilidad ambiental en su trabajo. Desde este estudio queremos resaltar la ausencia -por lo anocemos en 2018- de todo este abanico de medidas y opciones en nuestra área geográfica. Esperamos que los recientes encuentros sobre Sostenibilidad en instituciones culturales organizados por REDS en España comiencen a movilizar el panorama en la península para alcanzar, e incluso superar, el nivel anglosajón lo antes posible. No queremos decir con ello que haya que trasladar el modelo inglés, puesto que responde a su propio proceso y tradición cultural de mecenazgo de las artes y su sentido de comunidad ${ }^{332}$. Probablemente la aplicación en España de la sostenibilidad en las artes tenga que realizarse de otro modo (quizás más desde a bajo hacia arriba como va lo están haciendo los miembros de El Cubo verde) menos dependiente de la financiación privada y más del Estado o de la propia comunidad, pero sí podemos compartir objetivos y comenzar a reclamar que los organismos oficias incluya requisitos de sostenibilidad en los procesos de subvención a las artes.

Otro punto que se revela muy importante en nuestro análisis es mantener la coherencia de la estética y la ética del proyecto. Marín estudia la importancia del impacto en el medio físico de obras paradigmáticas del arte ecológico y encuentra una correlación entre las ideas y la ética que inspiran al artista y los procedimientos mediante los que se expresa: uso comedido de los recursos materiales y energí, $y$ ent sos de estudio no están exentos de contradicciones (por ejemplo la primera edición de Bios carers consumo de materiales en The Nith Raid) pero, también, de casos ejemplares como Trashcatchers' Carnivaly DUO.

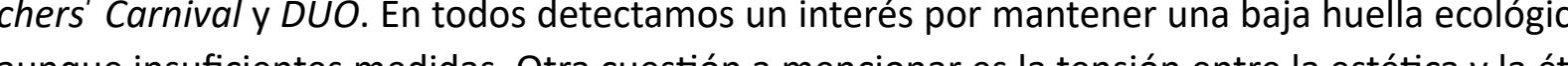

332 En este sentido, durante nuestra es-
tancia de investigación en Escocia pudimos

proyectos, museos, etc. siendo su cultu-

ra más proclive a subvencionar, incluso de 
rivado en una pérdida de creatividad. Consideramos que debíamos haber tenido en cuenta aqu las palabras de Lacy al respecto de los Oakland Projects «era imperativo negociar con los jovenes sobre las imágenes [...] pero el proceso era negociador, no dirigido por los jóvenes» (Lacy, 2013, p. 206).

\subsection{INTENCIÓN}

Como ya decíamos en el capítulo uno, no consideramos esencial en este estudio que el propósito consciente y explíito del artista sea promover la transición a la sostenibilidad, de hecho, los resultados obtenidos en nuestra investigación sobre la intención de estas obras apoyan esta idea inicil Sin en idea inicial. Sin embargo, hemos querido profundizar hasta qué punto estos casos persiguen es intención y si los resultados que obtienen responden a sus pretensiones iniciales. En general, ninguna de estas propuestas está al servicio de una agenda pública o administración, sino que aspira a desvelar cómo son las relaciones de los ciudadanos e instar a un cambio, decidido a lo largo de proceso por los propios participantes.

La tabla siguiente pone de manifiesto que, de los siete casos de estudio, cuatro de ellos tienen una intención consciente y expresada de promover la transición ecosocial (tercera fila). En otros dos casos, la insción se dinge hacia pa sostentilimo por desconocimiento del concepto de transición por entonces (Carrícola y Aula-R). Por último, The Stove declara no tener una intención expresa de promover la transición o la sostenibilidad en si, pese a que sus objetivos $y$ resultados encajan con esta estructura de pensamiento. Observamos pues que hay toda una gradación de posturas al respecto. Por tanto, frente a la pregunta de si es necesario tener una intención expresa para actuar en consonancia con la transición, corroboramos que no es necesario. ero, podemos preguntarnos si son más efectivos aquellos proyectos que tienen la pretensió declarada de contribuir a la transición a la sostenibilidad. De los cuatro casos que han expresado su intención claramente, todos cumplen y tres de ellos incluso superan, sus expectativas. Este re-

\begin{tabular}{|c|c|c|c|c|c|c|c|}
\hline & BIODIVERS & ALMÓCITA* & THE STOVE* & $\begin{array}{c}\text { TRASHCATCHER'S } \\
\text { CARNIVAL }\end{array}$ & DUO & AULA-R & $\begin{array}{l}\text { EL CUBO } \\
\text { VERDE }\end{array}$ \\
\hline Las expectativas se .... & superan & superan & incumplen & no podemos evaluar & superan & incumplen & cumplen \\
\hline $\begin{array}{l}\text { Los artistas expresan intención de } \\
\text { transformación social }\end{array}$ & Sí & si & Sí & si & si & si & si \\
\hline La intención de promover la transición es & inconsciente & consciente & inconsciente & consciente & consciente & inconsciente & cosnciente \\
\hline \multicolumn{8}{|l|}{ INTENCIONES } \\
\hline \multicolumn{8}{|l|}{$\begin{array}{l}\text { Responder a un problema concreto del } \\
\text { contexto local }\end{array}$} \\
\hline \multicolumn{8}{|l|}{$\begin{array}{l}\text { Inspirar cultura del compartiry la } \\
\text { cooperación. Fomentar intercambios. }\end{array}$} \\
\hline \multicolumn{8}{|l|}{$\begin{array}{l}\text { Efectos prácticos: Reducir el consumo, } \\
\text { concienciar, reducir huella ecológica }\end{array}$} \\
\hline \multicolumn{8}{|l|}{\begin{tabular}{|l}
$\begin{array}{l}\text { Dar respuestas alternativas de desarrollo } \\
\text { social y urbano frente a problemas de } \\
\text { despoblamiento }\end{array}$ \\
\end{tabular}} \\
\hline \multicolumn{8}{|l|}{ Fomentar la sostenibilidad } \\
\hline \multicolumn{8}{|l|}{$\begin{array}{l}\text { Desarrollo e investigación de propuestas } \\
\text { artísticas y culturales que contribuyan a } \\
\text { crear nuevas formas de pensamiento y } \\
\text { acción. }\end{array}$} \\
\hline \multicolumn{8}{|l|}{$\begin{array}{l}\text { Recuperar tradiciones } \mathrm{y} \text { crear espacios } \\
\text { que construyan comunidad }\end{array}$} \\
\hline Desarrollar una visión de futuro & & & & & & & \\
\hline$\frac{\text { Fomentar el pensamiento critico }}{\text { Celebrar }}$ & & & & & & & \\
\hline
\end{tabular}

Figura 15. Análisis de las intenciones de cada proyecto, en azul las detectadas. Fuente: elaboración propia. 

de la creación a través de la imaginación y los pensamientos del espectador. En su opinión, no se puede ser rígida en el mensaje porque perderíamos el espacio de la imaginación; la obra debe ser ambigua, abierta, dejar lugar para diferentes interpretaciones porque eso desarrolla $\mathrm{e}$ compromiso con la obra (Kathy Hinde, comunicación personal, 3 de septiembre de 2018). Marín distingue tres grupos de artistas en cuanto a la intención: los que solo buscan expresarse en la naturaleza (Udo, Goldsworthy); los que abordan soluciones técnicas que no profundizan en la raíz del problema y los que, «precedidos por la figura de Beuys, adoptan una visión global que enlaza el deterioro ambiental y los costes sociales que acarrea con las políticas economicistas» (Marín Ruíz, 2015, p. 473) como Hans Haacke, Mark Dion, Maria Thereza Alves, Edward Burtins$\mathrm{ky}$, Alfredo Jaar, etc.; pero resalta, «aún son muy pocos los que declaran explíititamente poseer una ideología ecologista» (Marín Ruíz, 2015, p. 473). Todos los artistas que hemos estudiado aquí sí se plantean como objetivo una transformación social y buscan claramente concienciar o convencer al público. Por ello, la intención más ampliamente compartida es contribuir a crear nuevas formas de pensamiento y acción en la sociedad desde la práctica artística. Aunque coemo gicos o transicionales como apunta Marín.

La segunda división a señalar es una cuestión de clasificación. Por un lado, los artistas que se identifican con el arte ecológico o con el arte transicional, y por otro los que, por el contrario, lo rechazan o bien no se plantean ninguna etiqueta. Algunos de los artistas de El Cubo Verde, Trashcatchers' Carnival y nosotros mismos, nos podemos considerar artistas transicionales o artistas ecolóficos. Pero en el caso de The Stove o DUO, es nuestra mirada razones para entender estas obras como arte ecológico o arte transicional (apuesta por lo loca lo coctivo, conservación ob ento local y humanos). El desconocimiento del término, el desinterés de los artistas en etiquecosómicos yhumanos). Gl csconocinicnto de las clasificaciones.
Marin Ruiz, 2015, p. 481), son algunas de las razones para desmarcarse

Dentro de cada caso de estudio ya se han comentado en detalle los resultados que hemo podido observar. Nos limitaremos aquí a presentar una visión panorámica de todos los casos que nos permita justificar posteriormente las funciones que está ejerciendo el arte en estos
entornos para acercarnos a una transición ecosocial.

En primer lugar, debemos comenzar este apartado conscientes de las limitaciones de las herramientas de análisis, que nunca podrán abarcar absolutamente toda la gama de impactos fícos y socio culturates de la obra, como ya mencionam ampliado la fisicos y socio cullo transformación . En vista de que todos los proyectos estuplados tienen intenciones de

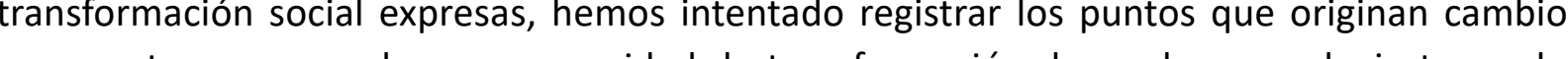
en su entorno para valorar su capacidad de transformación de modo general, sin tomar los resultados como absolutos ni objetivos totalmente. Nos enfrentamos aqui a una incapacidad de medir los efectos, en muchos casos subjetivos, personales, indetectables, a largo plazo, o que dependen de una relación compleja de muchos factores. Por estos motivos nos hemos limitado a realizar una redacción de efectos cualitativa sin establecer una clasificación que jerarquice qué proyectos son mejores o cuáles han producido mayor efecto. Cualquier ordenamiento incluiría cierto grado de subjetividad y no sería extrapolable al variar las condiciones de cada escenario. Aun así, interesa analizar hasta cierto punto los efectos resultantes de estas propuestas artísticas ya que es un ejercicio poco habitual en obras colaborativas artísticas (po agotamiento de energías o desinterés de los artistas en la medición, etc.), que permite poner de manifiesto el valor de estas formulas para la transición. A la vista de los resultados destacamos las siguientes observaciones:

Para fomentar una transformación social profunda como la que perseguimos, interesan los proyectos con efectos a largo plazo. La mayor parte de estas propuestas (cinco) tienen efectos a la larga, accesible cotidian periódicos, (The Nith Raid) difícilmente pueden aspirar a cambios profundos a largo plazo. Por ejemplo, el carnaval de Tooting ya no contribuye a concienciar a más personas, ni está fomentando la cooperación. Sin embargo, Biodivers continua atrayendo a visitantes, futuros 
pobladores, persiste en su labor de educación ambiental y crece su influencia con la difusión de su modelo. Es lógico afirmar, pues, que la presencia constante del provecto tiene relación proporcional con su efecto a largo plazo.

\begin{tabular}{|c|c|c|c|c|c|c|c|}
\hline $\begin{array}{l}\text { CARACTERIZACIÓN DE } \\
\text { EFECTOS }\end{array}$ & BIODIVERS & ALMÓCITA & THE STOVE & $\begin{array}{c}\text { TRASHCATCHER'S } \\
\text { CARNIVAL }\end{array}$ & Duo & AULA-R & EL CUBO VERDE \\
\hline \multirow{2}{*}{\multicolumn{8}{|c|}{$\mid$\begin{tabular}{|l|l|} 
c corto plazo \\
A medio plazo
\end{tabular}}} \\
\hline & & & & & & & \\
\hline \multicolumn{8}{|l|}{\begin{tabular}{|l|} 
A largo plazo \\
Oango
\end{tabular}} \\
\hline \multicolumn{8}{|l|}{$\mid$\begin{tabular}{|l|} 
Proyecto puntual \\
Proyecto periódico
\end{tabular}} \\
\hline \multicolumn{8}{|l|}{ Proyecto constante } \\
\hline \multicolumn{8}{|l|}{$\begin{array}{l}\text { Proyecto extrapolable, } \\
\text { reproducible }\end{array}$} \\
\hline \multicolumn{8}{|l|}{$\mid$\begin{tabular}{|l|} 
Proyecto escalable \\
Accance local
\end{tabular}} \\
\hline \multicolumn{8}{|l|}{ Alcance regional } \\
\hline \multicolumn{8}{|l|}{ Alcance nacional } \\
\hline \multicolumn{8}{|l|}{ Alcance internacional } \\
\hline \multicolumn{8}{|l|}{$\begin{array}{l}\text { Fomenta la cooperación, } \\
\text { crea comunidad }\end{array}$} \\
\hline \multicolumn{8}{|l|}{\begin{tabular}{|l|}
$\begin{array}{l}\text { Generador de otros } \\
\text { proyectos }\end{array}$ \\
\end{tabular}} \\
\hline \multicolumn{8}{|l|}{$\begin{array}{l}\begin{array}{l}\text { Presencia en espacio } \\
\text { cotidiano }\end{array} \\
\text { (a) }\end{array}$} \\
\hline \multicolumn{8}{|l|}{\begin{tabular}{|l|} 
Incluye educación ambiental \\
\end{tabular}} \\
\hline \multicolumn{8}{|l|}{$\begin{array}{l}\text { Contribuye a disminuir la } \\
\text { huella ecológica }\end{array}$} \\
\hline \multicolumn{8}{|l|}{$\begin{array}{l}\text { Cambios en personas } \\
\text { detectados }\end{array}$} \\
\hline \multicolumn{8}{|l|}{$\begin{array}{l}\text { Restauración de } \\
\text { espacios/entornos }\end{array}$} \\
\hline \multicolumn{8}{|l|}{$\begin{array}{l}\text { Contribuye a atraer } \\
\text { población }\end{array}$} \\
\hline \multicolumn{8}{|l|}{$\begin{array}{l}\text { Incluye una reflexión sobre } \\
\text { el proyecto }\end{array}$} \\
\hline 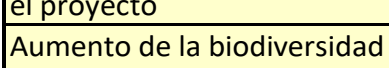 & & & & & & & \\
\hline & & & & & & & \\
\hline
\end{tabular}

Figura 16. Aproximación y caracterización de los efecto causados por cada proyecto. Fuente: Elaboración propia.

la reproductibilidad del proyecto en otros contextos es también una característica interecol caso de los proyectos de The Stove consideramos que no son extrapolables pues parten de un paisaje, una problemática ambiental y una situación política y social muy concretas. No obstante, todos los proyectos tienen capacidad de crecer y expandirse. Ambas características son muy convenientes para contribuir a la transición a la sostenibilidad.

Es común lograr un alcance local y regional aunque los niveles nacionales e internacionales son más complicados ${ }^{334}$. Solo Trashcatchers' Carnival ha conseguido por ahora relevancia a todos los niveles ${ }^{335}$ (y próximamente Biodivers con el documental), pero al ser una acción casi puntual (solo repetida en el Tour de Tooting seis años después), no pensamos que consiga lograr que sus efectos perduren a largo plazo sin recordatorios periódicos. En cualquier caso interes como modelo susceptible de ser aplicado en otras poblaciones, quizás por otros grupos de transición.

Otro efecto alcanzado en todos los casos, aunque no siempre directamente perseguido, es fomentar la cooperación y crear comunidad. En casos como Almócita, la reacción de aceptación fomentar la coope eimplicación de

Es importante señalar como la mayoría de estas propuestas han potenciado o generado otros proyectos, artísticos o no, que contribuyen en conjunto a un cambio sistémico. El ejemplo más claro es la contribución de Biodivers al teijdo económico social de Carrícola, 0 el empuje que se ha dado en Almócita a otros proyectos como el de compostaje. Asimismo, actúa en sinergia con otras acciones de educación ambiental como las charlas sobre cambio climático antes del Carnaval de Tooting o las visitas guiadas en Biodivers.

Resulta llamativo que Almócita y Carrícola hayan Ilegado a soluciones similares paralelamente, a pesar de que solo Almócita pertenece a la Red de Transición. El tipo de efectos registrados (como el aumento de población) también se asemeja, con la salvedad de que Carrícola tiene más proyección nacional gracias a la difusión en medios, su experiencia en agricultura ecológica y la próxima presentación del documental. Por tanto, el hecho de estar en contacto con la Red de Transición, no es un factor determin que sí resulta al menos conveniente.
334 Aunque Aula- $R$ ha sido presentado en
Escocia, no consideramos esto suficiente presencia a nivel internacional. Del mismo modo, El Cubo Verde como red puede semundo pero no quiere decir que esté ejer35 A nivel regional ha obtenido varios premios: a nivel nacional es mencionado en nuNeal y Zoe Svendsen (2009) y el libro Plalingred; a nivel making art as if the world ma-
tternacional, aparece en el libro Guía para el movimianto de transición cia sobre cambio climático de las Naciones cia sobre cambio climatico de las Naciones
Unidas de Copenhague en 2009 (Your Local 

Candiles de Almócita. Ninguna de estas propuestas ha realizado una medicín le sus propios impos enos propustas ha realizado una medición de sus propios ciados y direccionados hacia la transición como Trashcacthers' Carnival o DUO han councien-

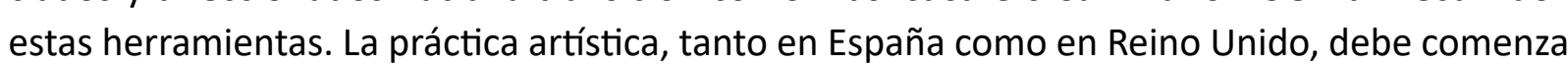
a reflexich a reflexionar y mejorar acerca de sus impactos negativos si buscamos dar una imagen coherente y convincente del mensaje de la sostenibilidad. Del mismo modo, debemos comenzar a visibilizar los impactos positivos que refuercen nuestra posición como herramienta a tener en cuenta en procesos de transición ecosocial.

\subsection{ESTÉTICA Y ÉTICA}

Según hemos planteado en el capítulo uno apartado 2.3.5, el modo en que estos casos responden a sus planteamientos éticos relacionados con la sostenibildad es un aspecto primordal, aunque no e in ico, para valor la calldad estética. Una huella ecológica baja (como las de El Cubo verde y Aula- $R$ que prácticamente no consumen materiales ni generan residuos) es necesaria al menos como intención que modere las elecciones a la hora de materializar la obra, pero no implica que pueda calificarse por ello de exitosa como hemos visto. Es preciso también estudiar las intenciones en el trasfondo de estas propuestas pues, en algunos casos, las recuperaciones ambientales tienen más que ver con intenciones de crear nuevos negocios que con cambios sistémicos profundos (Marín Ruiz, 2015, p. 475). Pero no es ese el caso de ninguna de estas propuestas, que responden todas a intenciones verdaderas de transformación social en linea con los valores de la transición a la sostenibilidad.

Respecto al proceso de construcción colaborativa, al ser un arte de procesos y de acción intangible, no podemos utilizar métodos físicos para valorarlo pero destacamos los siguientes puntos:

- La habilidad de DUO de fomentar un diálogo rico y diverso previo al proyecto que to-

- La calidad y profundidad de la vivencia social y emotiva de Trashcatchers' Carnival, no solo el día del desfile sino en el año previo a su realización.

- Las relaciones humanas que se establecen en las obras colaborativas de Almócita y Biodivers, como la intervención de Loren, el taller de kokedama de Pérez o las que hemos establecido personalmente durante la construcción colaborativa del horno.

- La experiencia emocionalmente satisfactoria de los participantes en los huertos de DUO como el de Glen, que tanto le ayudan psicológicamente.

- El estímulo para la reflexión que supone la experiencia personal directa en el carnaval o la del cultivo para los niños del Centro Maxwell.

- La calidad del diálogo y la información compartida en la red El Cubo Verde en contacto directo con experiencias de arte muy valiosas para la transición

- El ejemplar esfuerzo de DUO por la inclusión de participantes de diversos estratos sociales.

- La habilidad de los artistas especialmente en Trashcatchers' Carnival y DUO, para facilitar una atmófera creativa compartida sin jeraqús, cono una expen colectiva y un espacio liminal, donde participantes y artistas compartían poder de decisión. No obstante, en ambos casos la estetica del proyecto ha sido negociada y no cedida a una de las partes. Tomamos estos ejemplos como guia para futuras obras en cuanto al fomento del diálogo diverso y la negociación estética.

En resumen, podemos afirmar que la imagen de estos proyectos es heterogénea y diversa en sí misma, lo cual, lejos de ser visto como incoherencia estética, es consecuencia de su fusión
con el contexto y los participantes. Una imagen excesivamente rígida y cerrada limitaría la participación en contra de las intenciones del proyecto. A ese respecto en Aula-R y El hogar del pan hemos tratado de ser flexibles y estar abiertos a sugerencias respecto de la imagen de la obra. En Aula-R, la renovación de la imagen del espacio y su ubicación ha sido consultada con el alum nado y financiada por la delegación de alumnos de BB.AA. La experiencia previa en El Hogar de pan en cuanto a ceder la imagen del proyecto, nos sirvió para aprender que el nuevo aspecto y 
336 El Diccionario panhispánico de dudas ubicación de Aula- $R$ debía ser mejorado aceptando sugerencias sin perder la prerrogativa de decidir de la Real Academia Española en 2005 de- como autores de la obra. De ese modo, la ubicación se ha mantenido pero se mejoraron el aspecto theower, ciología política con el sentido de "conceder poder [a un colectivo desfavorecido socioeconómicamente] para que, mediante su au-
togestión, mejore sus condiciones de vida". [.... El verbo empoderar ya existía en espac resucitación con este nuevo sentido tiene ventaja, sobre apoderar, de usarse hoy únicamente con este significado especifico. rae es/dpd/srv/searchise: hetp.//lema. También la Fundación Fundeu dice: «Empoderar es un antiguo verbo español que
la vigesimotercera edición del Diccionario la vigesimotercera edición del Diccionario
académico recoge ya con el nuevo significaacademico recoge ya con el nuevo significa-
do con el que se utiliza: "Hacer poderoso fuerte a un individuo o grupo social des vorecido"». Véase en: https://www.-unndeut,
es/recomendacion/empoderar-un-antiguo-verbo

\subsection{FUNCIONES DEL ARTE}

Ante fenómenos críticos (como la pasada crisis económica) la cultura suele pasar a un segundo plano, considerada also complementario pero no necesario o primordial. En gran parte, entendenos que se debe a la comprensión tradicional del papel del arte como representación de la realidad pero nos hemos combargo, socir la a valorar jus-

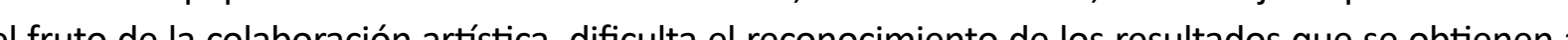
trás del a través del arte y por ello es importante visibilizar estos procesos.

Todos los datos anteriores nos llevan a identificar ahora las funciones que el arte está desempeñando en estos contextos. En el caso de Almócita y otros proyectos de transición, son los proAula-R somos nosotros, como implicados en ambos proyectos, quienes las identifamos. En los casos de Trashcatcher' Carnival DUO y The Stove, as deducimos por nuestra exp clólísis de casos. Por útimo, en El Cubo Verde se han concluido gracias a a implicacín person el analisis de casos. Por ullimo, en El Cubo Verde se han concluido gracias a la implicación persona

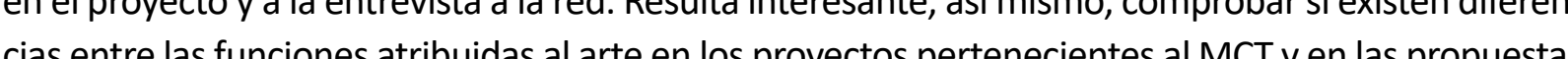
cias entre las funciones atribidas a arte en los proyectos pertenecientes al MCT y en las propuestas fuera del MCT.

En general hay bastante similitud entre los dos grupos (no hay muchas diferencias mayores del 30\%) y destacamos solo las diferencias más llamativas:

- La función del empoderamiento, dentro de la Red de Transición se ha identificado en un $60 \%$ de los casos, mientras que fuera de la red no hemos identificado claramente ningún ejemplo. El motivo puede ser la manera de entender el término que suele confundirse con fomentar la participación en procesos de

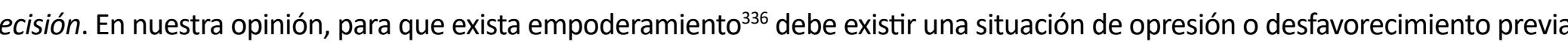
de una parte de la población y una intención clara de activar ese sector poblacional y dotarle de poder de decisión.

FUNCIONES DEL ARTE DENTRO Y FUERA DEL MCT

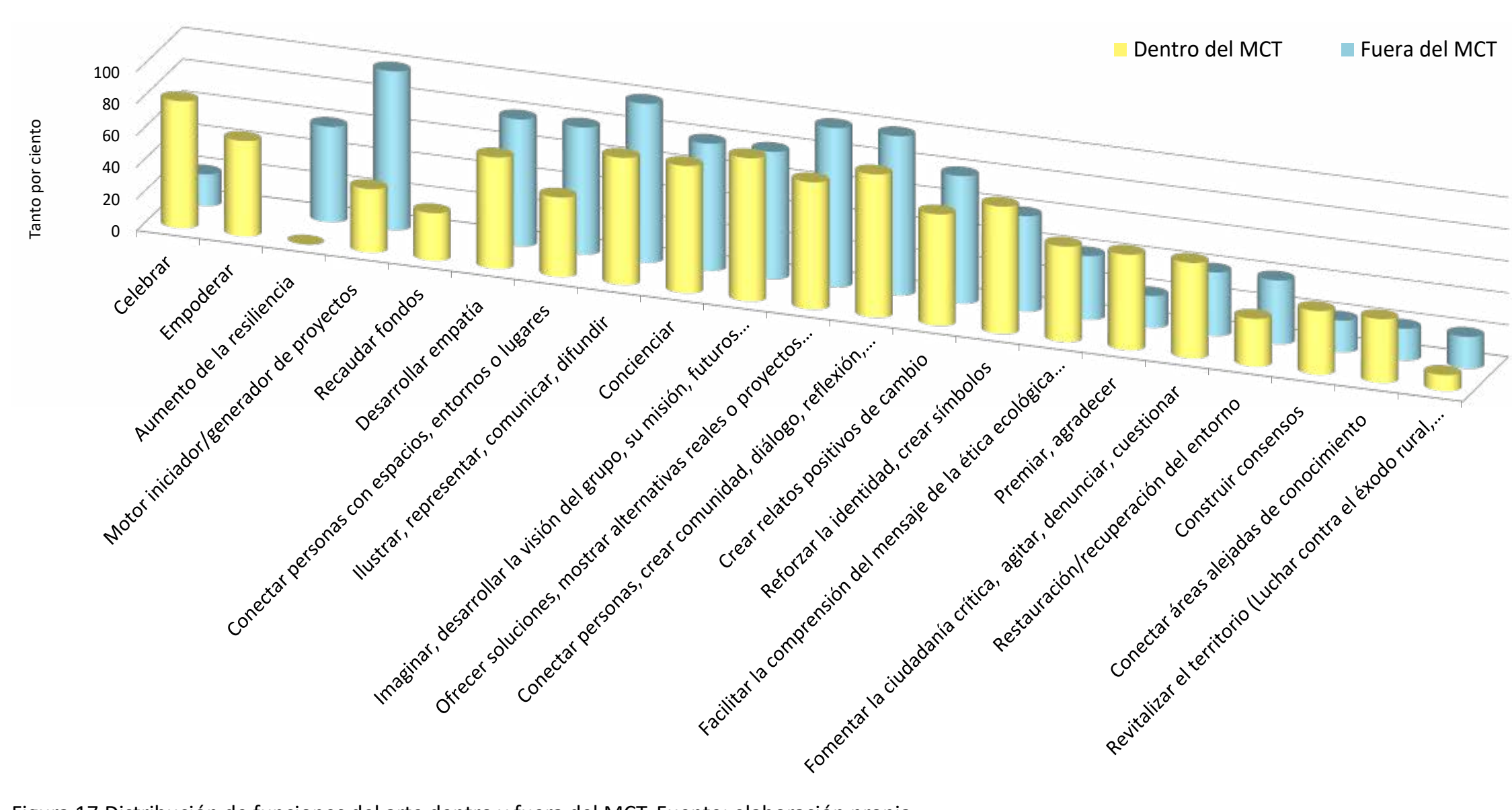

Figura 17.Distribución de funciones del arte dentro y fuera del MCT. Fuente: elaboración propia.

Respecto a la función de resiliencia no hemos podido obtener datos de la Red de Transición, por lo que no podemos realizar la comparativa.

- En cuanto al papel de estas obras como motor de generación de otras dinámicas y proyectos, se identifica sobre todo fuera de la 
red, ya que las creaciones artísticas dentro de la Red de Transición española suelen tener cometidos más sencillos, pragmáticos, utilitaristas (para difusión, premiar, ilustrar, etc.). Esto explica también los resultados mayores en la Red de Transición en cuanto a las funciones de celebración y recaudación de fondos. Estos resultados coinciden con el análisis del papel del arte dentro de los grupos de transición:

\section{Papel del arte en la Red de transición española}

De atractor del público, llamar la atención

Secundario, acompañamiento de proyecto con valor estético, decorativo

Transversal, difuso

De liderazgo

Tanto por ciento

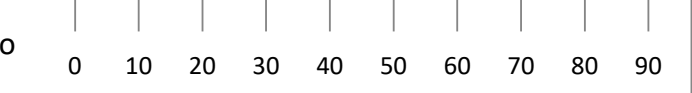

Figura 18. Gráico de barras con frecuencia de detección de determinados papeles del arte en la Red de Transición
Fuente:
- El rol del arte en la Red de Transición española es principalmente secundario y de tracción del público. Solo los casos de Almócita y Transició VNG lo consideran como guía que puede liderar sus actividades. Por el contrario, es evidente que en los casos fuera de la red seleccionados para esta tesis, el arte es un aspecto fundamental, y por ello los hemos seleccionado, por lo que una comparativa entre dentro y fuera del MC en este caso no tendría sentido.

En cuanto a las similitudes entre las funciones del arte dentro y fuera del MCT observamos que las funciones más frecuentes son similares en ambos grupos y se repiten entre un $80-100 \%$ de los casos:

- Ilustrar, representar, comunicar, difundir

- Concienciar

- Imaginar, desarrollar la visión del grupo, su misión, futuros posibles, utopías o ficciones

- Ofrecer soluciones, mostrar alternativas reales o proyectos piloto, laboratorios de

- Conectar personas, crear comunidad, hacer redes, mediar o facilitar

Por otra parte, también existen coincidencias en las funciones menos comunes $(<40 \%)$ como son:

- Construir consensos

- Revitalizar el territorio (luchar contra el éxodo rural, etc.)

- Conectar áreas de conocimiento alejadas (interdisiciplinariedad, transdisciplinariedad)

- Recaudar fondos

Es importante en especial reforzar la aportación que el arte puede realizar en las funciones menos comunes, pues habitualmente son también difíciles de identificar para el espectador o los grupos de transición. Por ejemplo, no es evidente para un visitante la influencia indirecta en el repoblamiento que están teniendo las obras artísticas de Almócita y Carricola. Tampoco es 


\section{PRINCIPIOS DEL ARTE TRANSICIONAL}

En el libro Playing for time. Making art as if the world mattered Neal y sus colaboradores describen las características del arte transicional uniendo las grandes narrativas de la transidescriben las caracteristicas del arte transicional uniendo las grandes narrativas de la trans ción a las caracteri principios que hemos comentado en los casos de estudio. Hemos comprobado a lo largo de los capítulos tres y cuatro que la mayoría de estos principios se cumplen en nuestros siete proyectos investigados. En cada propuesta destaca un principio o dos por encima del resto. Por ejemplo en Almócita destaca el principio de ignición, en Carrícola mantener un espacio natural es el centro de la acción; trabajar con la comunidad para provocar cambios en la ciudad es lo que más destaca en The Stove; en Trashcatchers' Carnival la mediación y la colaboración serían los más claros; en DUO trabajar con la comunidad para fomentar la participación es el principio mejor definido en Aula- $R$ de nuevo mantener un espacio donde se practique la colaboración es lo principal por último en El Cubo Verde destaca el principio de conexión. Se detecta incumplimiento de algún principio solo en tres casos (Almócita, The Stove y Trashcatchers' Carnival). Esto nos lleva a preguntarnos si se ha de cumplir todo el postulado para considerar la obra como arte transicional. Entendiendo que la obra de la propia Neal Trashcatchers' Carnival, no cumple exactamente el primer (intención) y sexto principio (mantener un espacio), entendemos que no es un listado exhaustivo. Cuando además recurrimos a los casos que se recogen en su publicación, encontramos obras que ni siquiera llegan a cumplir tres de éstos. Por ejemplo la obra Rannoch Wolf ${ }^{37} \mathrm{de}$ Dougie Strang incluida en dicha publicación no representa un ejemplo de contribución artística definición (a pesar de no cumplir apenas ninguno de sus principios) entendemos que numerosas prácticas artísticas podrían calificarse como arte transicional. De hecho, consideramos que es un listado bastante general de principios donde cabrían obras de nula contribución a la sostenibilidad como las de Cristo y Jean-Claude que sí cumplirian algunas de estas caracteristicas (intención, marco, trabajo con la comunidad, mediación, trabajo desde lo común, colaboración). Por anto, concluimos que aunque las obras cumplan los principios del transitional art esto no parece determinante a la hora de establecer sí un proyecto fomenta la transición a la sostenibilidad en mayor o menor medida. Producto de lo anterior nos preguntamos cuántos y cuáles de estos principios se han de cumplir para entender una obra como de arte transicional. ¿Será el transitional art capaz de aglutinar y representar la variedad de propuestas artísticas en torno al arte a ecología? ¿Puede una obra que no cumpla los criterios del arte ecológico ser considerada de arte transicional? En nuestra opinión, las intervenciones paisajísticas en la naturaleza de Cristo y Jeanne Claude a pesar de cumplir algunos de estos principios no tienen sentido en una categoría como ésta. Es más, según Neal las prácticas de arte transicional comparten características con el llamado Arte público de nuevo género (Neal, 2015). Cualquier obra de las estudiadas en esta investigación se puede definir como arte para, con, desde, en, según, hacia, sobre, mediante la comunidad. Pero nos planteamos qué diferenciaría una obra de arte público cualquiera, de una obra de arte transicional, si los principios son casi los mismos. En base a lo anterior consideramos que deben existir una serie de principios bésicos no negociables para considerar la obra como arte transicional De lo contrario la etiqueta pierde todo el interés por vasa y genera obra

Proponemos que si existe interés en mantener la etiqueta de arte transicional, para definir estas obras y diferenciarlas del arte público y de obras que nada tienen que ver con los intereses de la sostenibilidad, debemos incluir un principio ético de intención en tener una huella ecológica baja, otro de responder a los principios de la transición a la sostenibilidad (ya sean los de UICN o los del MCT) y uno más de interés en tratar temas del arte ecológico, como advertíamos en nuestros criterios de selección de casos. De este modo podremos excluir de esta catiano abras como los empaquetamientos de Cristo y ean-Claude uotras de arte público que no tion interés en temas de transición. 
338 El Iiderazo en este marco artisico
no debe entenderse en sentido economí CAPÍTULO 6. CONCLUSIONES

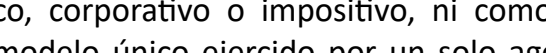

responsable que dirige. De hecho, las obras

que hemos presentado son colaborativas

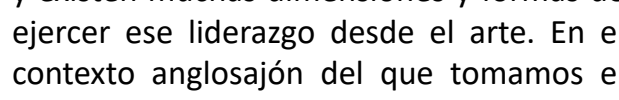

término, se entiende que los artistas como

mente una organización, sino a desarrollar tienen receptivo y en movimiens que manparticipante, construyen diálogos, comunile y Douglas, 2009c. La dea procede de la
contribución práctica de los artistas a la (acy olos Harrison que hemos revisado esta tesis. El artista va más allá de lo que se convencional de obras de arte yextiende su práctica a otras áreas de la realidad como lo tas, construyendo alternativas para los de-
safios ambientales y sociales. Para profundizar en el desarrollo de la idea del artista como líder véase el articulo «The Artist as Leader Research Report, Perfor ARTE

\section{CÓMO CONTRIBUIR A LA TRANSICIÓN DESDE EL}

A continuación trataremos de dar respuesta a las preguntas planteadas en el capítulo uno prado . Hipótesis de partida y planteamiento de la investigación. Cuestiones a explorar. La pregunta principal que nos hacemos es, icómo están contribuyendo las prácticas artísticas ecológicas a la transición a la sostenibilidad? En el limitado ámbito de las humanidades ambientales existe acuerdo al respecto de la capacidad de la cultura y el arte en sus distintas manifestaciones -ya sean literarias, plásticas, escenográficas, etc. - de contribuir a la concienciación ambiental, asi como de abordar los retos ambientales de forma práctica. Pero, más allá de este campo de estudio o a nivel popular aún detectamos reticencias y desconocimiento sobre la aplicabilidad del arte a la ecología y la transformación social, como se ha puesto de manifiesto en tres y cuatro, hemos visto aue la ceación a tistica está desempeñando funcions secundaias, C Corsales - sobre todo, dentro de la Red de Transición - como la celebración

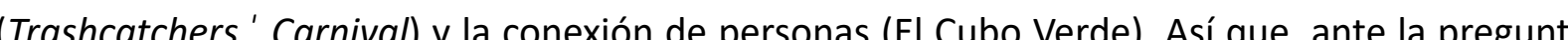

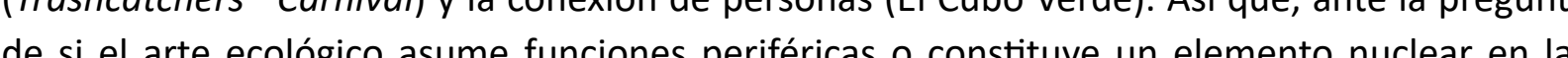

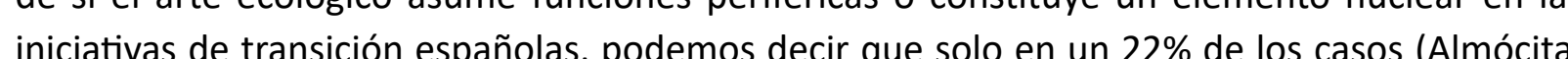
Transició VNG Arico y Butroi) se oct un valor muy importante $22 \%$ de los casos (Almócita, cas, como en elcaso de la ignicín de dińmicas de transición en Almócita No practicas a tistien Españ es uno de la ignición de dinámicas de transición en Almócta. No obstante, el MCT en España es un movimiento pequeño, en comparación con todas las iniciativas de arte que se relacionan con la sostenibilidad. Es principalmente fuera de las Redes de Transición donde hemos ido descubriendo otros cometidos menos comunes, pero de liderazgo, de la transformación social como: la construcción de resiliencia $(D U O)$ ), la conexión de personas y entornos (The Stove), la revitalización del territorio (Biodivers) y la aplicación de la etica ecológica a la creació artística (Aula-R) entre otras. De modo que, respondiendo a nuestra tercera cuestión (¿cuál es el papel del artista público en la transición a la sostenibilidad? ¿Ejerce un papel de liderazgo $0^{338} \mathrm{o}$ de acompañamiento, muestra utopías o abre caminos?) podemos afirmar que estos artistas no solo acompañan las transiciones, sino que también guían y facilitan nuevas reconfiguraciones de la comunidad para afrontar los desafios del cambio de paradigma civilizatorio. Sin la pretensión de abarcar todas las formas posibles de llevar esto a cabo, hemos querido centrarnos en las prácticas colaborativas por su capacidad de influir -más que los discursos y la ideología - en el cambio de valores necesario para el nuevo modelo ecosocial (González Reyes, 2018, p. 234). El estudio de casos trata de dar unos apuntes que nos permitan sistematizar prácticas, conoce puntos fuertes, ventajas, debilidades y oportunidades. No obstante, llama la atención que en los casos escoceses (DUO, The Stove y Trashcatchers' Carnival) es un artista o colectivo el que lidera la transformación social en colaboración con los habitantes, mientras que en los ejemplos españoles de Almócita y Carricola, no existe un único artista o colectivo que canalice la acción hacia objetivos concretos, sino que diversos creadores son invitados a participar en el lugar. Podemos decir que en esos contextos el arte es una herramienta que los habitantes deciden emplear en su proceso de transformación, y los artistas, en colaboración con los vecinos, sus implementadores. De ese modo, habitantes y arte - que no artistas concretos - son el motor de la transición en Almócita y Carrícola. En este sentido podríamos convenir con García Cano (2014) que es el lugar el que aporta al arte y no solo el arte al lugar. De ello se deduce que los proyectos que logran consolidarse en el tiempo no siempre son aquellos liderados por un artista en particular que guíe la acción, de hecho no suelen serlo, sino también los que surgen colectiva y mayoritariamente del propio lugar, sin que sea válido un único modelo como ejemplo genera de funcina to (Albelda, Sgaramella y Sánchez-León, 2017). Por tanto, concluimos quera presente estudio confirma elvalor del arte como herramienta para gener prormacín ecosociliniciolos por antistas $/ 0$ habitantes en necesara colaboración.

Consideramos importante visibilizar estas prácticas artísticas y su función en la transición por los siguientes motivos:

- El arte se enfrenta al desafío de hacer valer su papel más allá de funciones ya sobradamente conocidas como la comunicación y el complemento estético. Pero resultan difíciles de visibilizar algunas aplicaciones que hemos visto en el capítulo cuarto como el refuerzo de la resiliencia o la revitalización del territorio.

- Especialmente algunas obras de tipo colaborativo o procesual resultan complicadas de identificar como arte por el gran público y, por tanto, no siempre se reconocen los 
- También resultan invisibles, en muchos de estos ejemplos, la acción e intención del artista difuminadas en la participación, pero son esenciales para guiar y acompañar la obra en muchos casos.

¿Hasta qué punto la creación artística puede modificar nuestras conciencias y traducirse en transformaciones comportamentales duraderas? En el capitulo uno hicimos hincapie en el desarrollo de la empatía y la symhedonia como uno de los primeros pasos de la concienciación. De hecho, entre el $70-80 \%$ de los casos de estudio dentro y fuera del MCT registran esta función del arte. Además, sostenemos la idea de que la implicación en la realización de las obras artísticas favorece el afianzamiento de cambios de actitud e incluso de comportamiento ante los desafíos ambientales. Ejemplo de ello serían los casos de Almócita y Carrícola en los que la población se implica cada vez más en proyectos como el compostaje de residuos o el ahorro energético Sin embargo, no es posible aislar la influencia de las obras artísticas de otros factores que incurren n la concienciación y transformación duradera to que sí hemos puesto de maifiesto con nuestros casos de estudio es que, de forma directa o indirecta, las práticas artísticas pueden en la la un atractor de vistiantes y nuevos pobladores. En Tooing, la acción de carnaval fomenta una diva la más ambión dival. La creación de una red colaborativa como El Cubo Verde, favorece la intervención creativa en la realidad del campo. De un modo más drecto, en el caso de DuO se faciltan la allimentación de proximidady la construcción de resilencia, $y$ en Aula- $R$ la reutilización de recursos de la que se benefician uno de cada cinco estudiantes, por citar los efectos más relevantes. Por tanto, concluimos que aunque no podemos saber su grado de influencia con exactitud, el arte sí facilita cambios en el comportamiento a largo plazo con efectos medibles en algunos casos.
Desde el primer capítulo, definimos los objetivos de la transición en el marco de los planteamientos de la UICN (Adams y Jeanrenaud, 2008) y el MCT (Brangwyn y Hopkins, 2008). En los capítulos tres y cuatro hemos comprobado que se cumplen los principios del arte transicional señalados por Neal en todos los casos de estudio (salvo puntuales y escasas excepciones). De hecho, pensamos que este postulado es demasiado laxo y abarcaría sas excepciones). De hecho, pensamos que este postulado es demasiado laxo y abarcaría
una gran variedad de propuestas artísticas en torno al arte y la ecología, pero también pouna gran variedad de propuestas artísticas en torno al arte y la ecología, pero tambien pola sostenibilidad. Por tanto, para aportar precisión sugerimos añadir tres principios más al la sostenibilidad. Por tanto,

conjunto de Neal como son:

- Arte con interés en tener una baja huella ecológica.

- Acuerdo con los principios de la transición de la UICN o el MCT.

- Ocuparse de cuestiones relacionadas con la ecología y/o la transición como el yturaleza, la ética ecologica y otras señaladas en capítulo uno apartado 2.2 .

De este modo, al igual que Marín (2015) profundiza en la delimitación del arte ecológico para distinguir proyectos con la misma terminología, pero distinta aproximació conceptual (Ruiz, 2014, p. 45), interesa profundizar en la demarcación de esta nueva categoría, como reflejo de un posicionamiento ético particularmente basado en el enfoqu colectivo y local frente a los retos del cambio climático y el pico del petróleo, entre otros desafíos del Antropoceno. Concluimos que, tal y como está definido y basándonos en sus similitudes con el arte público y las matizaciones de Marín al respecto del arte ecológico (2015), se podría nombrar simplemente como arte público con enfoque hacia la transición a la sostenibilidad sin necesidad de crear una nueva terminología.

Respecto a la identificación de los artistas entrevistados con el transitional art, en ningún caso, salvo la propia Neal, la propia autora y un miembro de El Cubo Verde, reconocen dicha etiqueta, aunque exista acuerdo con sus principios. Por otra parte, el arte transi- 
Aumentando el compromiso colectivo mediante la «informalidad» ${ }^{339}$ de la creació artística que permite una colaboración más distendida y abierta como en The Trashcatchers' Carnival (Sennet, 2012, p. 381).

- Aprovechando la flexibilidad en el ejercicio creativo, que permite una gran pluralidad de soluciones adaptables a cada contexto local (Aula-R).

\section{ARTISTAS, COOPERACIÓN Y COLECTIVIDAD PARA LA} TRANSICIÓN

A lo largo del capítulo tres hemos visto que para enfrentar de raíz los desafíos de la criindividualismo, et crecto placencia que nos reafirma en modelos conocidos aun a sabiendas de ser insostenibles. Para ello, el fomento de la cooperación, el fortalecimiento del tejido comunitario y lo colectivo es un punto crucial que tanto el MCT (Fernandes-Jesus et al., 2017) como otros autores (Parreño, 2018; González Reyes, 2018, pp. 233-235) reconocen. Así, hemos visto que las obras artísticas dentro de la Red de Transición suelen contar con voluntarios y ejecutores (en un $80 \%$ de los casos), colaboradores y desarrolladores $(50 \%)$, y responsables desde el origen (20\%). De hecho, en algunos casos la participación no es sólo una herramienta, sino también el objetivo principa de estas iniciativas de transición. También en el capítulo cuatro hemos aportado varios ejemplos artísticos participativos, fuera de la Red de Transición, que fomentan la comunidad y aue se pueden entender como modelos al pus crítica ha co un

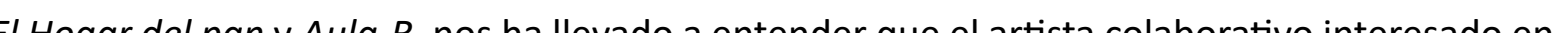

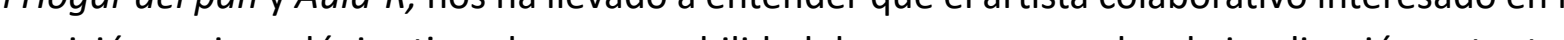
transición socioecologica tiene la responsabilidad de promover modos de implicación potentes, que creen un verdadero espacio de partipación ciurda el futuro de nuestras sociedades. En este sentido, fuera de la Red de Transición encontramos los
mejores ejemplos, en DUO y Biodivers.

Como adelantamos en el capítulo tres, los artistas pueden contribuir a un desarrollo comunitario más participativo y sostenible mediante las siguientes acciones:
Promoviendo una verdadera cooperación activa que incluya la diversidad social (DUO y The Trashcatchers' (arnival) y no una simple tolerancia.

- Utilizando la anticipación creativa para mediar en los primeros impulsos de estos proyectos (DUO). símbolos y fomento de la identidad de grupo para dotar de valor a los individuos en ta comunidad (The Nithraid).

- Favoreciendo un proceso creativo dialógico que acoja la diversidad de posturas y trabaje con la resistencia y no contra ella (The Stove y DUO). aprendizaje, apoyo mutuo y proyectos mejor adaptados al lugar (El Cubo Verde).

Quisiéramos realizar una última observación respecto a la acción comunitaria que hemos dvertido sobre todo en Reino Unido, donde la tendencia voluntarista es mayor $y$, como hemos visto, también la financiación privada. El MCT y el conservadurismo político se cruzan en el punto llamado la Gran Sociedad en Gran Bretaña. Nos referimos a los casos en los que la cooperación en la comunidad llega a sustituir las obligaciones asistenciales del Estado. En nuestra opinión, las iniciativas de transición, organizaciones de caridad y demás colectivos no deben sustituir a otras estructuras formales, sino complementarlas. De lo contrario, estaremos perdiendo diversidad de alternativas y el Estado, eludiendo su responsabilidad con la sociedad.
- Respondiendo a la parálisis causada por la magnitud de los desafíos ambientales con

- Aprendiendo de este diálogo con la comunidad y otros expertos para generar redes de
339 En el sentido que le da Sennet de im-
provisación, flexibilidad y ausencia de norprovisación, flex fijas (2012).
mas fije 


\section{LIMITACIONES, CRÍTICAS, OPORTUNIDADES}

Queremos cerrar esta investigación realizando un ejercicio (auto)crítico que señale nuestras limitaciones, objeciones y oportunidades.

Comenzamos por admitir cierto sesgo de subjetividad en el análisis de las funciones de los casos de estudio, sobre todo desde Trashcatchers' Carnival en adelante, por lo que los resulta dos han de tomarse con cierta cautela sin dejar de ser validos por ello. También mencionar e escaso número de iniciativas de transición en España, por lo que el impacto de las obras artísticas que desarrollan en la transición se considera pequeño. Probablemente en Reino Unido (con más de trescientas iniciativas) el efecto sea mayor, pero no tenemos noticias de que se haya hecho un estudio similar al nuestro. Los cinco ejemplos artísticos analizados fuera del MCT no pretenden ser representativos de toda la variedad de proyectos colaborativos de enfoque ecológico, pero hay que entender su importancia en términos de representación de funciones de arte poco comunes.

Por otra parte, en cuanto a nuestra obra propia, reconocemos la necesidad de establecer estrategias desde el arte para comunicar información sobre el problema de los residuos, y fomentar asi la implicación del alumnado y profesorado en Aula-R. El propósito es añadir la cuarta «R» de responsabilización, como dice la artista Ruth Peche, a la triada de las tres «R» (reducción reutilización, reciclaje). Respecto a El Hogar del pan, admitimos cierta pérdida de control de la estética de la pieza en favor de la opinión de los habitantes, lo cual no favorece su entendimiento como obra artística una vez el proceso colaborativo ha finalizado. Sin embargo, ya desde Beuys (o incluso antes) se aceptan estas prácticas sociales como parte de las artes plásticas (Marín Ruíz, 2015, p. 389), aunque aún no a nivel popular. Nos planteamos, pues, la realización de un cartel informativo del proceso de construcción colaborativo, que refleje la importancia del mismo y facilite su comprensión más allá de la visión utilitaria práctica.

Otra limitación que observamos a la expansión de este tipo de proyectos artísticos es que se unen aqui dos tipos de público minoritarios. los que demandan una transición a nuevos modos de vida más sostenibles y los que comprenden estos procesos colaborativos como prácticas artísticas. Ni uno ni otro ha llegado aún al punto de masa crítica necesario para cambiar la opi-

Respecto a las críticas a realizar, reparamos en la ausencia de mediciones de la huella enectos, pese al interés en mantener un impacto rerabajan en estos temas (2018, p. 122). Lo provechoso de estas mediciones no es la obtencion pone de manifiesto los puntos a mejorar.

Por otro lado, ya Marín (2015) y algunos miembros de El Cubo Verde advierten que, en ocasiones, las intervenciones artísticas en el entorno pueden desembocar en una turistificación del lugar que vaya precisamente en contra de las ideas que se defienden. Por ejemplo, la huella de carbono de la audiencia que se desplaza a visitar proyectos como Biodivers o La Noche con Alma en Almócita demuestra ula imposibilidad última de una práctica sostenible local dentro de un sistema global insostenible» (Demos, 2009, p. 28).

Nos preguntamos si estas obras suponen un verdadero replanteamiento de los sistemas de pensamiento y funcionamiento socioeconomicos que estan en la base de la crisis ambienta. En los casos de The Nithraid y The Trashcatchers' Carnival el arte impulsa procesos de transformación social en la línea de la transición a la sostenibilidad, pero sin planteamientos demasiado radicales que se dirijan a las fuentes de poder. The Trashcatchers' Carnival es muy general en su mensaje (celebrar la Tierra y nuestra relación con ella) y puede que muchos no lo distingan de un carnaval cualquiera. Lo mismo sucede con la Nithraid. Sin embargo, somos conscientes de que no siempre existe oportunidad desde el arte de rebatir las instituciones de poder y mucho menos de transformarlas ${ }^{30}$, no obstante, como Newton Harrison comenta, es preciso para introducir una vaz en la mesa de negciación (2017). Lo que estas obras proponen son paras for de con otras for as de concín hacia las estructuras de poder desde abajo hacia arriba: clos cambios

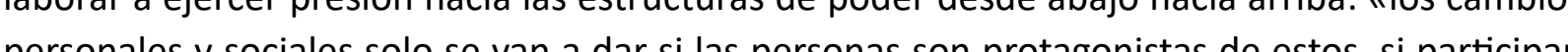
personales y sociales solo se van a dar si las personas son protagonistas de estos, si participan directamente en entornos que gratifich valores emancipadores. Por ello, más clave que los discursos que articulamos son las prácticas que promovemos" (González Reyes, 2018, p. 248). Es una estrategla más lenta, pero no deja de ser un nuevo engranaje que cumple una función en la transformación social. Ninguno de estos proyectos supone una crítica total al sistema ni va a propiciar un cambio drástico en sus contextos, pero han contribuido de alguna manera a 
discurso general de la transición, a crear la masa crítica necesaria o constituyen, al menos, una crítica parcial.

Por otro lado, se deja entrever cierta complacencia con el paradigma del crecimiento sostenible en muchos aspectos; uno de ellos es la ampliación de aparcamientos en Carrícola y A mócita para acoger más visitantes, el interés en impulsar el comercio en el centro de Dumfries - la ausencia de mensajes claros sobre disminución del consumo. En el fondo, en Almócita Carrícola las propuestas artísticas impulsan soluciones que fomentan un nuevo tipo decita

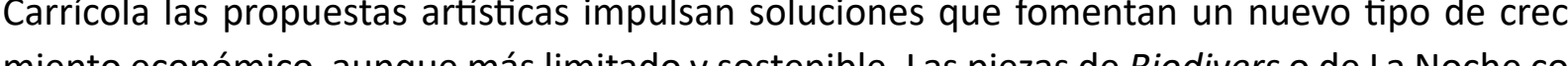
milma no

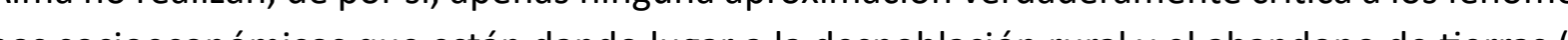

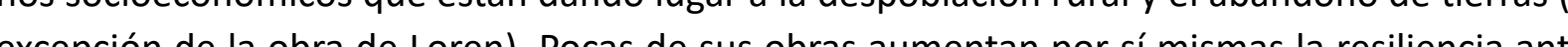
excepción de la obra de Loren). Pocas de sus obras aunentan por si mismas la resilencia ante un escenario futuro de escasez energetica (a excepción de El Hogar del pan y los talleres de cestería en todo caso). En Blodivers, teniendo en cuenta la voracidad con la que consumimos obras de arte yotros productos culurales, sugen mos la i la vicación de las obras con un discurso de la sostenibilidad mediante cartelas, códigos $Q$ r, o mapas interactivos, que faciliten al públco llevarse una idea más profunda del significado de las obras y porqué están allí. En cuanto DUO y Aula-R, la acción artística es constructora de nuevas realidades que se enfocan hacia los problemas del consumo, los límites del planeta y nuestra huella ecológica directamente, pero es sobre todo en DUO donde hay una crítica potente hacia el modelo socioeconómico vigente una contrafuerza.

En cuanto a las oportunidades, hemos detectado que la alianza con la Red de Transición no es tan determinante para el éxito de los proyectos como el apoyo de las instituciones. En los casos españoles de Almócita y Carrícola ha quedado patente que el apoyo municipal ha sido crucial. En el caso de Reino Unido además se detecta aún mayor apoyo a la sostenibilidad en el arte, desde el voluntarismo individual hasta la financiación de instituciones públicas y privadas, asi como un interés en exigir la inclusión de la sostenibilidad en las propuestas artísticas. Aunqu no podemos trasladar al completo ese sistema artístico y modelo cultural al contexto español, si que podemos extraer algunas ideas-reto como la introducción de requisitos de sostenibilidad hora de subvencionar obras y/o eventos artisticos, o el uso de calculadoras de huella de carbono. Por último, nos parece oportuno continuar la investigación dentro de la red El Cubo Verde para recopilar más datos y ejemplos de relación del arte y la transición. Con todo ello nos plan- temos elaborar una guía o manual procedimental y recopilatorio de ejemplos, accesible para

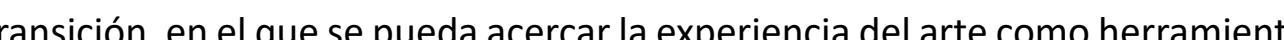
para la transformación ecosocial. 


\section{CHAPTER 6. CONCLUSIONS}

\section{HOW TO CONTRIBUTE TO THE TRANSITION THROUGH ART}

What follows is an attempt to provide an answer to the questions posed in Chapter One, Whathe explored). The main question asked is: How are ecological artistic prectices contributing to the tanstion sustainabilit? Within the limited scope of environmental humanities, the is areent as reards the capacty of cuture and art in their various manifestations - he is agreement as c, scenographic, etc- - to contribute to raising awareness about the environent and plasenvironmental challenes prectically. However, beyond this field of sudy and in a pophact sense, we stil comalenes practically. However, beyond this field of study and in a popular

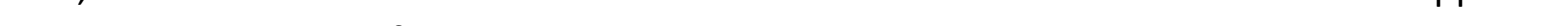
Nection, as has become clear in this study on the Spanish Transition crealion touches upon different fields within the transition network, carrying out functions that (Traste form a celebration (Trashcatchers Carnival) or by connecting with people (El Cubo Verde). So, in answer to the in in Spanish transition initiatives, it could be said that in only 22\% of cases (Almócita, Transicio $V N G$ and Butroi) are artistic practices given a very central or significant value, as in the case of stimulating the dynamics of transition in Almócita. Nevertheless, the TTM is a small movement in Spain compared to all of the art initiatives related to sustainability as a whole. It is mainly outside the Transition Networks where this research has discovered other works that are les common but which involve leadership and social transformation, such as: building up resilience (DUO), connecting people and their environs (The Stove) revitalising the land (Biodivers), applying ecological ethics to artistic creation (Aula-R) and more. Therefore, in answer to the third question in this rese and does it lea ${ }^{341}$ or accompany, show utopias or open up pathwas"), one coustainability these artists not only accompany the transitions but also guide them and foster new reorganiint the civilising paradigm. Without intending to cover all possible ways of doing this, the intention has been to focus on collaborative practices because of their ability to influence (more than discourses and ideology) the necessary change in values for the eco-social model (González Reyes, 2018, p. 234). The case studies attempt to produce some guidelines to enable practices to be more systematic an discover strong points, advantages, weaknesses and opportunities. However, it is worth notin that in the Scottish cases (DUO, The Stove, Trashcatchers' Carnival) it is an artist or group that leads the social transformation in collaboration with the inhabitants, whereas in the Spanis examples of Almócita and Carricola it is not one single artist or group that channels the action alone towards specific goals, but various creators are invited to take part in the place. It could be said that in these contexts, art is a tool that the inhabitants decide to use in their transformation process, whereas the artists, in collaboration with their fellow inhabitants, implement it. Thus, inhabitants and art-but not specific artists-are the engine that drives the transition in Almócita and Carrícola. In this vein, one could agree with García Cano (2014) that it is the place that contributes to the art and not only the art to the place. For this reason it is deduced that projects that manage to establish themselves over time are not always those led by a specific artist guiding the activity (in fact they usually aren't), but also those that mostly arise collectively from the place itself. There is no single model that is valid as a general example of how this work (Albelda, Sgaramella and Sánchez-León 2017). It can thus be concluded that this study confirms the value of art as a tool to generate eco-social transformation processes, whether initiated by artists and/or inhabitants in collaboration.

believe it is important to lend visibility to these artistic practices and their role in the transition for the following reasons:

- Art faces the challenge of asserting its role beyond the all too well-known functions some applications visible, such as those we saw in Chapter Four like reinforcing resilience or revitalising the land.

- Some works involving collaboration or processes can be especially difficult for the public at large to indentify as art, so the direct or indirect results of projects are no always acknowledged as the result of artistic practices. 
In many of these examples, the artist's activity and intention become obscured, dilu-

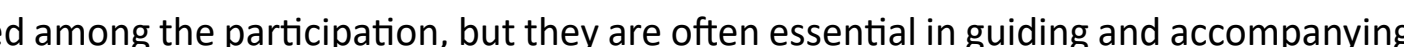
the work.

To what extent can artistic creation shift our consciences and lead to lasting transformations in behaviour? In Chapter One, the development of empathy and symhedonia was emphasised as one of the first steps in raising awareness. In fact, between $70-80 \%$ of the cases studied within and outside the TTM show this role of at. An example of this would be the cases of Almócita and Carricol in which the popultion is increasingly involved in projects such as waste compostind or encoling composting or energy savins. Moreover, I main in the idea that involvement in creating the ar-

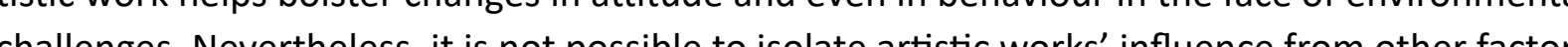
challenges. Neverheless, it is not possible to isolate artistic works' 1 nf wence from other factors that have an impact on raising awareness and lasting transformation. What it has been possible to clarify with these case studies is that, directly or indirectly, artistic practices can contribute to the success of transition activities. In the cases of Almocita and Cantcola, strengthening identity via art lends cohesion to the community and encourages participation, helping attract visitors and new residents. In Tooting, the carnival activity encourages a more ambitious attitude in carrying out other projects like the foodival ecological food festival. Creating a collaborative network such as EI Cubo Verde also fosters creative work in the real world in the field. More direct$y, D U O$ fosters proximity food and building up resilience, while Aula- $R$ encourages the re-use of resources for the benefit of one out of five students, to mention just the most relevant effects. It can therefore be concluded that although we cannot know the precise extent of its influence, art does bring about long-term changes in behaviour with some measurable effects in some cases.

\section{OUTLINING TRANSITIONAL ART}

Since the first chapter, the transition's aims have been defined in the context of the approaches by the IUCN (Adams and Jeanrenaud, 2008) and the TTM (Brangwyn and Hopkins, 2008). In Chapters Three and Four, it was confirmed that the principles of transitional art indicated by Neal are met in all of the cases studied (with very few, one-off exceptions). In fact, I believe that Neal's postulate is too lax and covers a great variety of artistic proposals around art and cology, but could also include public art projects or art in the environs that have nothing to $d 0$ with sustainability. Hence, to help clarify I suggest adding three more principles to Neal's group which are:

- Art with an interest in having a low carbon footprint.

- Agreement with the IUCN's or the TTM's principles of transition.

- Dealing with matters related to ecology and/or the transition such as re-balancing culture with nature, ecological ethics and others indicated in Chapter 1, Section 2.2.

Likewise, just as Marín (2015) studies the boundaries of ecological arts to distinguish projects with the same terminology but a different conceptual approach (Ruiz, 2014, p. 45), it is interesting to study the boundaries of this new category and define it as a reflection of an eth cal stance specifically based on a collective, local focus in the face of the challenges of climate change and peak oil, among other challenges of the Anthropocene. It is concluded that, with the way ecological art is defined, its similarities with the collaborative art and based on Marin's views on the matter (2015), one could simply call it public art with a transitional to sustainability focus without the need to create a new term.

As for the artists interviewed identifying themselves with transitional art, in no cases do they recognise the label except for Neal, our case and one member form El Cubo Verde, although they agree with its principles. Furthermore, transitional art seems to focus on change and getting results, which is contrary to the opinion of other artists who also contribute to social transformation without intending to convince the general public with their works.

\section{ARTISTS, COOPERATION AND COLLECTIVE WORK} FOR THE TRANSITION

Throughout Chapter Three we have seen that in order to address the root of the ch based on individualism, infinite growth, the markets and competition; and on the other, the 

the community and collective work, as the TTM (Fernandes-Jesus et al., 2017) and other authors (Parreño, 2018; González Reyes, 2018, pp. 233-235) acknowledge. Indeed, it has been seen that artistic works within the Transition Network usually rely on volunteers and implementers (in $80 \%$ of cases), collaborators and developers $(50 \%)$, and those who are responsible from the outset (20\%). In fact, in some cases participation is not only a tool, but also the main purpose of these transition initiatives. In Chapter Four, various participatory artistic examples outside the Transition Network were also shown that foster the community and that can be understood as alternative models that counter the cultural inertia and increase the critical mass toward a point of inflection. But the experience in carrying out El Hogar del Pan and Aula-R has led to the understanding that collaborative artists interested in the socio-ecological transition have a responsibility for promoting potent ways of implication that create a true space for citizens' participation in the process of taking decisions on the future of our societies. In this sense, the best examples can be found outside the Transition Network, such as DUO and Biodivers.

As mentioned in Chapter Three, artists can contribute to more participative, sustainable community development via the following activities:

- Increasing the collective commitment via the "informality" which allows for looser, more open collaboration as in The Trashcatchers' Carnival (Sennet, 2012, p. 381).

- Using flexibility in creative activity, which allows for a great plurality of solutions that are adaptable to each local context (Aula-R).

- Promoting truly active cooperation that includes social diversity (DUO and The Trashcatchers' Carnival); not just simple tolerance.

- Using creative anticipation to mediate in the early impulses about these projects (DUO).

- Responding to the inertia caused by the magnitude of the environmental challenges by using symbols and fostering a group identity to affirm the importance of individuals when they form part of a community (Nithraid).

- Learning from this dialogue with the community and other experts to generate networks for learning mutual support and projects better adapted to the place (El Cubo Verde)

We would like to make one last observation regarding community activity that we have noticed above all in the United Kingdom, where there is a greater tradition of volunteering and, as we have seen, also private funding. The TTM and political conservatism both agree with a concept known as Big Society in Great Britain. This refers to cases in which cooperation in the community ends up replacing the State's aid obligations. In my opinion, the initiatives for the transition, charity organisations and other social groups should not replace other formal strucwill evade its responsibility towards society.

\section{LIMITATIONS, CRITICISMS AND OPPORTUNITIES}

I would like to round off this research by carrying out an exercise in self-criticism, pointing out its limitations, objections and opportunities.

I shall begin by admitting a certain subjective bias in analysing the functions of the cases studied, above all from Trashcatchers' Carnival onwards, so the results should be taken with some caution while not losing their valdity because of this. The scarcity of transition initiatives in Spain should also be mentioned, for which reason the impact of the artistic works carried out within the transition is considered to be small. The effect in the United Kingdom (with over three hundred initiatives) is probably greater, but I am not aware of a similar study to this one having been carried out. The five artistic examples analysed outside the TTM are not intended to be representative of the entire range of collaborative projects with an ecological focus, but their importance must be understood in terms of their representativeness of uncommon function 
In terms of my own work, I recognise the need to lay down strategies that use art to communicate information about the problem of waste to thereby encourage students and teachers involvement in Aula- $R$. The intention is to add the fourth " $\mathrm{R}$ " of responsibility, as the artist Rut Peche says, to the triad of "Rs" (reduction, reuse and recycling) (2018). As for El Hogar del Pan, I must admit to a certain loss of control over the aesthetics of the piece in favour of the Pan,

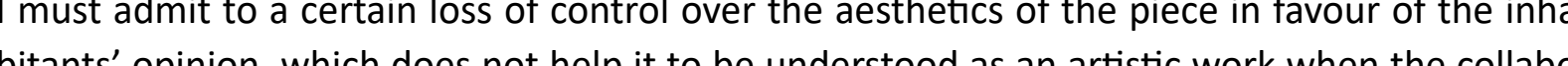
rative process is over Hows nor, since Beuys (and even befor) these social pabo-

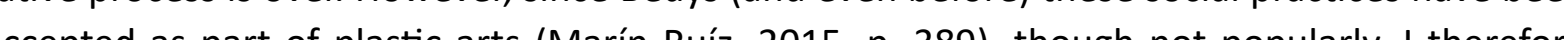
accepted as part of plastic arts (Marin Ruiz, 2015, p. 389), though not popularly. I therefore hows the importance of this a post of view.

Another limitation that can be seen in the spread of these kinds of artistic projects is that two types of minority public come together here: those that demand a transition to new, more sustain a opinion, so it is necessary to keep insisting.

As for the criticisms to be made, one could point to the lack of measurements of the ecological or carbon footprint in most of the projects, despite the interest in keeping the impact down. As Parreño points out this must be a self-imposed ren thiste for athists that matters (2018, p. 122). The usefulness of these measurements does not lie in obtaining these them, revealing the points to be improved.

Marín (2015) and some members of El Cubo Verde also warn that artistic interventions in the environment can sometimes lead to a touristification of the place, which runs completely against the ideas being championed. For example, the carbon footprint of the audience that travels to visit projects such as Biodivers or La Noche con Alma in Almócita reveals "the ultimate 2009, p. 28).

One must ask if these works represent a true reassessment of the systems of socio-ecoour relationship with it) and many may not distinguish it from any other carnival. The same occurs with Nithraid. Nevertheless, I am aware that it is not always possible to rebut powerf institutions through art, much less transform them ${ }^{343}$. Even so, as Newton Harrison comments, it put forward is other ways of raising awareness via participation to shift public opinion, thereby collaborating in putting pressure on the structures of power from below upwards: "Personal and social changes will only happen if the people have roles in them, if they participate directly in environments that reward emancipating values. For this reason, the practices we put forward are more important than the discourses we make" (González Reyes, 2018, p. 248). It is a slower strategy, but still a new approach that serves the purpose of social transformation. None of these projects represents a comprehensive criticism of the system, nor are they going to bring about a drastic change within their contexts, but in some way they have contributed to the general discourse about the transition and to creating the necessary critical mass or at least a partial criticism.

On the other hand, a certain complacence can be glimpsed with the paradigm of sustainable growth in many aspects. One of these is the extended car parks accommodate more visitors, the interest in boosting trade in Dumfries' town centre and the lack of clear messages about reducing consumption. In the end, in Almócita and Carrícola the artistic proposals generate solutions to foster a new kind of economic growth, albeit a more limited and sustainable one. The pieces from Biodivers and La Noche con Alma do not in themselves represent a truly critical approach to the socio-economic phenomena that are being seen with rural depopulation and abandonment of the land (with the exception of Loren's work). Few or their works in themselves bolster resilience in the face of a future scenario with energy scarcity into account the voracty with which we consume works of att and other cultural products, I sugest overaping the works with a discourse on sustainatity using posters, OR codes or interative thaps the her interactive maps that help give the public a deeper idea of the meaning of the works and why power. The Trashcatchers' Carnival has a very general message (a celebration of the Earth and is necessary to fight in order to bring a voice to the negotiating table (2017). What these works (except for El Hogar del Pan and the basket-weaving workshops at most). In Biodivers, taking

343 In the case of Platform, which was men-
tioned in Chapter Two, they are aimed at disassociating artistic institutions from the from extracting oil and damagins the envifrom extracting oil and damaging the env-
ronment in third world countries. 


\section{BIBLIOGRAFÍA}

As regards opportunities, the alliance with the Transition Network is not as determinant for the success of the projects as the support of the institutions. In the Spanish cases of AlmóCita and Carricola, it has become clear hat corncil support has been crict. In the case of the Unied King dom, exte has be to be ing to be included in the artistic proposals. Alhough we cannot completely transfer this artistic system and culnal model to the Spanish context, we can extract some ideas and challenges such as introducing sustainability requistes when subsidising artistic works and/or events, or using carbon footprint calculators. Lastly, it seems fitting to me to continue the research within El Cubo Verde in order to gather more data and examples related to art and the transition. All things considered, I propose to draw up an procedimental guide or compilation manual that would be useful for transition initiatives and which could include the experience of art as a too for eco-social transformation
Adams, W. M. (UICN) y Jeanrenaud, S. J. (UICN) (2008) Transición a la Sostenibilidad: hacia un Mundo Humanitario y Diverso. Gland, Suiza: UICN. Disponible en: https://portals.iucn.org/library/ sites/library/files/documents/2008-017-Es.pdf

Adamson, J., Riechmann, J., Albelda, J., Velayos, C., Marín Ruíz, C., Parreño, J. M., Sgaramella, C., Sánchez-León, N., Mattalía Rodríguez, L., Flys Junquera, C., Santiago Muiño, E., Carretero González, M. y González Reyes, L. (2018) Humanidades Ambientales. Pensamiento, arte y relatos para el siglo de la gran prueba. $\mathrm{Ma}-$ drid: Los libros de la Catarata.

Aiken, G. (2012) "Community Transitions to Low Carbon Futures in the Transition Towns Network (TTN)", Geography Compass, 6(2), pp. 89-99. doi: 10.1111/j.1749-8198.2011.00475.x.

Aiken, G. (2014) The production, practice and potential of "community» in Edinburgh's Transition Town Network. Durham University. doi: 10.1080/1331677X.2014.947132.

Albelda, J. (2007) «José albelda», Fabrikart:arte, tecnología, industria, sociedad, 7, 2(Naturaleza y paisaje), pp. 10-17.

Albelda, J. (2015) «Arte y ecología. Aspectos caracterizadores en el contexto del diálogo arte-naturaleza», en Raquejo, T. y Parreño, J. M. (eds.) Arte y Ecología. primera. Madrid: UNED, pp. 218-244.

Albelda, J. (2017) «Diálogos de la Transición Energética. Siempre fuimos $100 \%$ renovables y volveremos a serlo. La clave es en qué nivel», en Conam Local Valencia. Las ciudades conectan naturalmente. 1. ed. Valencia, pp. 1-11.
Albelda, J. (2017a) «El lugar de las artes visuales y las humanidades en procesos de transición ecosocially, en López del Rincón, D. y Manonelles Moner, L. (eds.) Arte, naturaleza y política en la creación contemporánea. Barcelona: Barcelona, edicions UB, pp. 87-107.

Albelda, J. (2017b) «La crisi ecològica i sistèmica», en La crisi ecològica i el llenguatge artístic. Pallars Jussà: Centre d'Art i Natura i Garsineu Edicions.

Albelda, J. y Saborit, J. (1997) La construcción de la naturaleza. Valencia: Generalitat Valenciana.

Albelda, J. y Sánchez-León, N. (2017) «Building the transition: inter and transdisciplinary strategies from the humanities», en Connecting with a low-carbon future conference. Celebrada en 19-20 abril 2017,Stirling: University of Stirling.

Albelda, J. y Sgaramella, C. (2015) «Arte, empatía y sostenibilidad . Capacidad empática y conciencia ambiental en las prácticas contemporáneas de arte ecológico», Ecozone, 2, pp. 10-25.

Albelda, J., Sgaramella, C. y Sánchez-León, N. (2017) «Mediterráneo(s) en transición a la sostenibilidad. Carrícola, un estudio de caso.», en Imaginar el Mediterráneo. Celebrada en 22-23 septiembre 2017, Valencia: Insituto Valenciano de Arte Moderno.

Allen, P., Hinshelwood, E., Smith, F., Thomas, R. y Woods, S. (2014) Culture Shift: how artists are responding to sustainability in Wales. Disponible en: http://www.emergence-uk.org/wp-content/ uploads/CULTURE-SHIFT.pdf.

Almenar-Asensio, R. (2016) El ingreso mínimo garantizado:una propuesta innovadora para un tiempo político nuevo. primera. Valencia: El Libro. 
Almenar, R., Bono, E. y García, E. (2000) La sostenibilidad desarrollo: El caso valenciano. Valencia: Universitat de València, Fundació Bancaixa.

Álvarez, V., Gallardo, J., Rocher, E., González, M. Oduber, R., Ferreiro, D. G, López, V. De Gredos, C. y Jonsssma, D. (2018) R., Cubo Verde.

Anderson, K. (2017) The MooCoo Collective: Nithraid 2017. Disponible en: https://www.thestove.org/moo-coo/ (Accedido: 16 de mayo de 2018).

Anderson, K., Foster, K., Pacheco, R., Jones, A., Slater, D. Bonaventura, M., Mc Queen, L., Baker, M., Zygadlo, M., Gott, , White, S., Smith, M., Soutar, L., Dewar, R., Powell, L. y Wheeler, K. (2015) We live with water. 2065: life today in Dumfries River Town. Dumfries. Disponible en: http://www.thestove.org/wp-content/ uploads/2015/12/wlww_booklet.pdf. (Accedido: 3 de agosto de 2016)

Archivo Documental de Artistas de Castilla y León (2012) ADACYL » A Ua Crag, Archivo Documental de Artistas de Castilla y León. Disponible en: http://www.adacyl.org/category/a_ua_ crag/ (Accedido: 8 de septiembre de 2017).

Arribas, F. (2015) «Arte, naturaleza y ecología», en Raquejo, T. y Parreño, J. M. (eds.) Arte y Ecología. primera. Madrid: UNED, pp. 191-216.

Arts Council England (2013) 10-year strategy alignment, Arts Council England. Disponible en: https://www.artscouncil. Arts Council England. Disponible en: https.//Www.artscouncil. junio de 2018). junio de 2018). art que dialogue amb la naturalesa, Biodivers 2010. Disponible en: https://biodivers2015.wordpress.com/biodivers-2010/ (Accedido: 1 de septiembre de 2017).

Ayuntamiento de Carrícola (2010b) "El fardatxo". Carrícola. Disponible en: http://www.carricola.es/ca/content/ fardatxo-itineraris-biodivers. (Accedido: 1 de septiembre de 2017).

Baker, M. (2015) The Stove Network, We Live With Water. Disponible en: http://www.thestove.org/we-live-with-water/ (Accedido: 21 de junio de 2016).

Balaguer-Nuñez, L. (2015) «Sinergias entre las intervenciones artisticas en el territorio y la restauración ecológica:ámbitos para el encuentro", en Raquejo, T. y Parreño, J. M. (eds.) Arte y Ecologia. $1^{\circ}$. Madrid: UNED, pp. 40-53.

Baxter, J. y Gittins, S. (2013) Dundee Urban Orchard. Disponible en: https://dundeeurbanorchard.net/ (Accedido: 12 de marzo de 2017).

Baxter, J. y Gittins, S. (2015) Sharing Not Hoarding, Shadow Work. Disponible en: http://dev.sharingnothoarding.org/ do: 5 index.php?/show-info/2017/06/shadow-work/ (Acceddo: 5 de junio de 2018).

Bayarri, M. y et. al. (2010) Biodivers Carrícola: Espai d’ArtMediam- biental. Picaña: Gráficas Vimar.

Beldad, I. (2017) El Cubo Verde, una red de arte apegado a la tierra, El salto diario. Disponible en: https://www.elsaltodiario.com/arte/el-cubo-verde-una-red-de-arte-apegado-a-latierra (Accedido: 21 de mayo de 2018).
Bellón, F. (2014) Carrícola, la prosperidad de la confianAgroicultura Perinquiets. Disponible en: http://agroicultura om/general/carricola-la-prosperidad-de-la-confianza/ (Acceddo: 17 de septiembre de 2017).

Ben-Tovim, R. (2012) The evolution and practice of the 'Transition Town Anywhere' activity, The evolution and practice 'T the 'Transition Town Anywhere' activity. Disponible en https/// www.transitionculture org/2012/11/19/the-evolution- $n$ hos// Wice-of-the-transition-town-anywhere-activity/ (Accedido: 2 de abril de 2018).

Blacksmith Institute y Green Cross Switzerland (2013) The worlds worst 2013: the top ten toxic threats. Disponible en: http:// www.worstpolluted org/docs/TopTenThreats 2013 pdf (Accedido: 21 de febrero de 2018)

Blanco, P. (2005) Prácticas artísticas colaborativas en la España de los años noventa, Desacuerdos. Sobre arte, politicas esfera pública en el Estado español. Granada: Edicions de l'Eixample.

Blanco, P., a.f.r.i.k.a., Gruppe, Bourriaud, N., Crimp, d., de Certeau, Michel Deutsche, R., Felshin, N., Obrera, F., Foster, $H$ Kluge, A., Negt, O., Lippard, L. R., Plier, N. P., Reclaim the Streets Rosler, M., @Tmark y Schneider, F. (2001) Modos de hacer. Arte crítico, esfera pública y acción directa. Editado por P. Blanco, J. Carrillo, J. Claramonte, y M. Expósito. Salamanca: Universidad de Salamanca. Disponible en: https://labencrisis.files.wordpress. com/2013/07/modos-de-hacer.doc. (Accedido: 2 de abril de 2015).

Boulding, K. E. (1964) The Meaning of the Twentieth Century: The Great Transition. HarperCollins.
Boulding, K. E. (1966) «The Economics of the Coming SpaceBet 3-14. doi: 10.4324/9781315064147.

Boyd, R. (2013) «Social Inertia in the face of Climate Change», Humanity' s Test. Disponible en: https://www.resilience.org/stories/2013-11-18/social-inertia-in-the-face-of-climate-change/. (ACcedido: 2 de junio de 2018).

Brangwyn, B. y Henfrey, T. (2013) Transition Research Primer. Disponible en: http://www.transitionresearchnetwork.org/ uploads/1/2/7/3/12737251/transition research primer.pdf. (Accedido: 22 de abril de 2015).

Brangwyn, B. y Hopkins, R. (2008) Transition Initiatives Primer. 26. Totnes. Disponible en: http://www.transitionpenwith.org.uk/files/TransitionInitiativesPrimer.pdf (Accedido: 12 de enero de 2018).

Brangwyn, B., Hopkins, R., Mooser, R. (trad) y Monzón, Á. (trad) (2010) Compendio de iniciativas de transicion. Olba: Ecohabitar. Disponible en: http://movimientotransicion.pbworks.com/w/ page/23759307/Compendio sobre la Transicion. (Accedido: 22 de abril de 2015).

Calle, R. de la y Forriols, R. (2012) «Diálogos entre el arte y la naturaleza, convertida en paisaje: En torno al proyecto "Biodivers-Caricola" Real Academia de Bellas Artes de San Carlos. Disponible en: https:// dialnet.unirioja.es/servlet/libro?codigo=582029 (Accedido: 7 de junio de 2018).

Campus habitat 5U (2010) Biodivers Carricola en contexto. Valencia. Disponible en: http://campushabitat5u.es/wp-content/ uploads/2011/07/Biodivers-Carricola.pdf (Accedido: 17 de septiembre de 2017). 
Candela, 1. (2007) Sombras de ciudad. Arte y transformación urbana en Nueva York, 1970-1990. Madrid: Alianza Forma.

Carson \& Trotter (2017) Financial Statements. Dumfries. Disponible en: http://www.thestove.org/wp-content/ uploads/2017/11/The-Stove-Network-Limited-2017-Accounts. pdf. (Accedido: 30 de abril de 2018).

Carson, S. H., Higgins, D. M. y Peterson, J. B. (2003) «Decreased Latent Inhibition is Associated with Increased Creative Achievement in High-functioning Individuals», Journal of Personality and Social Psychology, 85(3), pp. 499-506. doi: 10.1037/0022ality and Social 3514.85.3.499.
3514.

Centeno González, N. (2016) «Scarpia, una experiencia de creación artística en el medio rural», Anuario Fundación de Estudios Rurales , pp. 269-275. Disponible en: http://www.upa.es/ upa/_depot/_uploadlmagenes00/Scarpia.pdf (Accedido: 8 de septiembre de 2017).

Centola, D., Becker, J., Brackbill, D. y Baronchelli, A. (2018) "Experimental evidence for tipping points in social convention.», Science (New York, N.Y.). American Association for the Advancement of Science, 360(6393), pp. 1116-1119. doi: 10.1126/science.aas8827.

Chatterton, P. y Cutler, A. (2008) Tthe rocky road to a real transition: the transition towns movement and what it means for social change.Leeds. Disponible en: http://trapese.clearerchannel.org/resources/rocky-road-a5-web.pdf (Accedido: 2 de marzo de 2018).

Checa, R. (2016) Paisajes Vinculados. Hacia nuevas perspectivas de Ecologia y Restauración Ecológica en el Arte. Madrid:
Sección Departamental Historia del Arte III (Contemporánea) Fa- cultad de Bellas Artes, Universidad Complutense de Madrid. Dispo作 Checa.pdf. (Accedido: 12 de abril de 2018).

Chelleri, L. y del Río, J. (2017) «Transition in Spain: A First Assessment of Dimensions, Challenges and Opportunities for Transition Town Initiativesy, en Henfrey, T, Maschkowski, $G_{,}$y Penha-Lopes, . People, Place, Proctice, Pow G.

Chen, Y. (2015) El valor estético en el diseño del ecohabitat. Tesis doctoral no publicada. Universidad Complutense de Madrid.

Collins, T. (2003) «Lyrical Expression, Critical Engagement, Transformative Action: An Introduction to Art and the Environment». Disponible en: http://collinsandgoto.com/wp-content/uploads/2003/07/Lyrical-Expression.pdf (Accedido: 8 de junio de 2013).

Comité para la conservación del ICOM (2014) Declaration o Environmental Guidelines - ICOM-CC and IIC Declaration, M ICOMCC. Disponible en: http://www.icom-cc.org/332/-icom-cc-documents/declaration-on-environmental-guidelines/ (Accedido: 14 de junio de 2018).

Connors, P. y Peter, M. (2011) «Transitioning communities: community, participation and the Transition Town movement Community Development Journal, 46(4), pp. 558-572. doi: https:// doi.org/10.1093/cdj/bsq014.

Consorcio de Residuos V5 - COR (2017) Carricola, modelo de sostenibilidad, Consorci per a la gestió de residus. Disponible en: $\mathrm{ht}$ ad/\#quint (Accedido: 7 de junio de 2018).
Corbetta, P. (2007) «Los paradigmas de la investigación so. Madrid: Editorial McGraw-Hill.

El Cubo Verde (2015) El Cubo Verde - Red de proyectos espacios de arte en el campo. Disponible en: https://elcuboverde. org/ (Accedido: 18 de mayo de 2018).

El Cubo Verde (2017) Borrador de trabajo para la constitución del cubo verde. [e-mail] a El Cubo Verde. [28, diciembre, 2017]

EI Cubo Verde (2018) Acta VI Encuentro de EI Cubo verde. V. Madrid. [e-mail] a El Cubo Verde. [28, mayo, 2018]

Damasio, A. T. (1994) El error de Descartes: la emoción, la razón y el cerebro humano. 2003. ed. Barcelona: Crítica.

Demos, T. (2013) «Contemporary Art and the Poltics of Ecology", Third Text, 27(March 2015), pp. 1-9. doi 10.1080/09528822.2013.753187.

Demos, T. J. (2009) «The Politics of Sustainability: Art and Ecology», Radical Nature: Art and Architecture for a Changing Planet 1969-2009, Barbican A, pp. 16-30. Disponible en: http:// sustainabilityparadox.commons.gc.cuny.edu/files/2010/09/Demos-Politics-of-Sustainabilitypdf. Accedido: 9 de ma

DiClemente, C. C. (2003) Addiction and change: How addictions develop and addicted people recover. Nueva York: Guilford Press.

Domínguez, J. (2018) «Intersecciones entre arte y desarrollo sostenible. La contribución de la soci (impulsando una cultura sostenible. Celebrada en 23-24 enero 2018, Valencia: La Nau Unversitat de València.
Douglas, A. (2016a) «Context is half the work: developing doc政 Ellugar de las humanidades antes la crisis socio-ecológica global. [Conferencia] 25 de noviembre, 2016, Valencia, Universitat Politècnica de València pp. 1-14. doi: http://orcid.org/0000-0001-8145-7704.

Douglas, A. (2016b) «Leading cultures of transition through arts practice», en Tiempos de transición. El lugar de las humanidades antes la crisis socio-ecológica global. [Conferencia] 30 de noviembre, 2016, Valencia: Universitat Politècnica de València p. 15. doi: http:// orcid.org/0000-0001-8145-7704

Douglas, A., Cartiere, C., Zebracki, M. y De los Reyes, J. (2016) "“Context is half the work": developing doctoral research through arts practice of Public Art Art space and social inclusion. 1. a $\mathrm{cod}$ New York: Routledge, pp. 141-157. doi: http//orcid. org/0000-0001-8145-7704.

Ecohabitar (2013) Tiempos de Transición, 22 de febrero. Disponible en: http://www.ecohabitar.org/tiempos-de-transicion/ (Accedido: 20 de febrero de 2018).

Escribano Pizarro, J. (2004) «La población de la tercera edad en la Vall d Albaida. distribuciony equipamientosn, en IICongrés d'Estudis de la Vall dalbaida. Onteniente. Disponible en: https://www.academia.edu/3644726/La_población_de_la_tercera_edad_en_la_VaII___Albaida_distribución_y_equipamientos. (Accedido: 20 de abril de 2018).

guay: Katz.

vers, K. (2010) Cuando la materia se despierta. primera. Uru-

Fajardo, L. A. (2005) «Aproximación a los fundamentos neurológicos de la metáfora», 18(Forma y Funciłón), pp. 12-114. Disponible en: http://www.scielo.org.co/scielo.php?pi- 
Fernandes-Jesus, M., Carvalho, A., Fernandes, L. y Bento, S. (2017) "Community engagement in the Transition movement: views and practices in Portuguese initiatives", Routledge, 22:12 (Local Environment), pp. 1546-1562. doi 10.1080/13549839.2017.1379477. (Accedido: 3 de marzo de 2018).

Fernández-Pinto, I., López-Pérez, B. y Márquez, M. (2008) «Empatía : Medidas, teorías y aplicaciones en revisión», 24(1987), pp. 284-298.

Fernández Casadevante, J. L. (2015) «Un mundo nuevo en el corazón de las ciudades . Iniciativas comunitarias que anticipan nuevas formas de habitar lo urbano», Papeles, 130, pp. 143-152.

Filippetti, V. A., López, M. B. y Richaud, M. C. (2012) «Aproximación Neuropsicológica al Constructo de Empatía: Aspectos Cognitivos y Neuroanatomicos", Cuadernos de Neuropsicología 6(1), pp. 63-83. Disponible en: http://pepsic.bvsalud.org/pdf/ cnps/v6n1/a06.pdf. (Accedido: 13 de julio de 2017).

Fisher, S. (2016) Before the flood. EE.UU. Disponible en: http://channel.nationalgeographic.com/before-the-flood/.

Fremantle, C. y Douglas, A. (2009) The Artist as Leader Research Report, Performing arts. Aberdeen: On The Edge Research, Gray's School of Art, The Robert Gordon University. doi: http:// Gray's School of Art, The Robert
orcid.org/0000-0001-8145-7704.

Gablik, S. (1992) The Reenchantment of Art. New York: Thames and Hudson. Disponible en: journal.org/uploads/ file/2011 Volume 4/11 Squatting my Mind.pd f. ory. Disponible en: http://inland org/es/ (Accedido: 20 de septiembre de 2017).

García Cano, A. J. (2014) Prácticas Artísticas Ecológicas Relativas al Agua en un Contexto de Cambio Climático. Estrategias y Procesos de Aprendizaje., Tesis Doctoral dirigida por Santos Sánchez-Guzmán Eva y Rubio Marco, Salvador Facultad de Bellas A tes. Universidad de Murcia. Disponible en: https//digitum.umes/ (t)

García Cano, A. J. (2018) «Una experiencia enseñando Arte Ecológico en la Universidad de Washington-Tacoma (Washington, USA)», en Humanidades ambientales: pensamiento, arte y relatos para el siglo de la gran prueba. Celebrada en 3-6 julio 2018. Alcal á de Henares: Universidad de Alcalá de Henares.

García, E. (1999) El trampolin faustico ciencia, mito y poder en el desarrollo sostenible. Valencia: Tilde.

García, E. (2006) «El cambio social más allá de los límites el realismo en la socioloRevista de Ciencias Sociales, (27), pp. 1-24. Disponible en: http://www.apostadigital.com/revistav3/hemeroteca/egarcia.pdf.

Generalitat valenciana (2017) Datos Generales / Carrícola ARGOS, Portal de información Argos. Disponible en: http://www argos.gva.es/bdmun/pls/argos_mun/DMEDB_MUNDATOSGENERALES.DibujaPagina?aNMunld=46086\&aVLengua=c (Accedido:
20 de junio de 2018).

Gloria, A. y Vega, M. (2003) «Metodos morfométricos para 261.
González Reyes, L (2018) «Algunas ideas sobre cómo coso civilizatorio", en Humanidades ambientales:

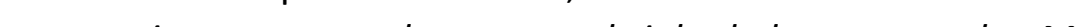
drid: Los libros de la catarata, pp. 233-250.

Goodland, R., Daly, H. El Serafy, S. y von Droste, B. (1997) De la en Medio an diente y desarrollo sostenbe,

Goodwin, K. (2017) High street take-over: Dumfries aim to be the first community to buy back its town centre, The Herald Scotland. Disponible en: http://www.heraldscotland.com/ news/16160120. High_street take-over_Dumfries_aims_to be the first_community to buy back its town _centre/\#tomments-anchor (Accedido: 22 de junio de 2018).

Goto Collins, R. (2012) Ecology and environmental art in public place talking tree: won "t you take a minute and listen to the plight of nature?, Doctoral thesis, OpenAIR@RGU The Open Access Institutional Repository at Robert Gordon University. Robert Gordon University. Disponible en: http://collinsandgoto. com/wp-content/uploads/2012/04/Reiko-PHD-Thesis-Reiko-Goto.pdf (Accedido: 28 de octubre de 2015).

Grossmann, M. y Creamer, E. (2016) «Assessing diversity and inclusivity within the Transition movement: an urban case study, Environmental Politics», Environmental Politics, 26(1), pp. 161-182. doi: 10.1080/09644016.2016.1232522.

Guattari, F. (1996) Las tres ecologías. Valencia: Pretextos.

Harrison, N. (2017) Lecture at the Barn centre. anchory, Celbrada en julio 2017. Reino Unido: Wooden Barn. Disponible en https://vimeo.com/243003841.
Heim, W. (2008) Evaluation Report DEFRA Climate ChalCCF9 Project code AE017 Greehnhose Britain . Losing Ground, Gaining Wistom. Disponible en http//greenhouseb列 house-britain-evaluation-report-heim-public-v.pdf.

Hogarth, J. y Thin-Smith, R. (2015) Environmental Art Fes(1) The tival Scotland / Off Grid Report. Galloway. Disponible en: http:// (Acedido: 22 de mano 2018$)$

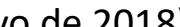

Hopkins, R. (2008a) El Manual de transición. De la dependencia del petróleo a la resiliencia local. Disponible en: http:// unionursula.org/wp-content/uploads/2016/11/manual-de-latransicion-rob-hopkins.pdf (Accedido: 2 de mayo de 2017)

Hopkins, R. (2008b) «Translated from the Transition Handbook by Rob Hopkins", en The Transition Handbook. Disponible en: http://www.ecohabitar.org/wp-content/uploads/2012/01/ ElConceptoDeTransicion.pdf. (Accedido: 22 de marzo de 2017)

Hopkins, R. (2015) What does a successful artist look like at a time of global change ? Disponible en. https.//transitionnetwork.org/news-and-blog/what-does-a-successful-artist-look-like-at-a-time-of-global-change/ (Accedido: 3 de marzo de 2018).

Hopkins, R. y Thomas, M. (2016) The Essential Guide to Doing Transition. 1. ${ }^{a}$ ed. Totnes: Transition Network. Disponible en: https://transitionnetwork.org/wp-content/uploads/2016/09/ The-Essential-Guide-to-Doing-Transition.pdf. (Accedido: 22 de enero de 2018)

Huertas, C. y Corraliza, J. A. (2016) «Resistencias psicológicas en la percepción del cambio climático», Papeles, 136(De 
relaciones ecosociales y cambio globall), pp. 107-119. Disponible en: http.//WwW.fuhem.es/meda/cdv//ie/biblioteca/revista_pa-

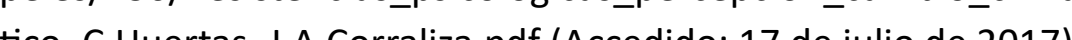

Inglechert, R. y Kingena, H. -Dieter (2000) uGenes, cul, democrac and ture, demart, R. y Kis S. (eds.) Culture and subjective Well Deing. MIT press, pp. 1655. 2siAl (1)

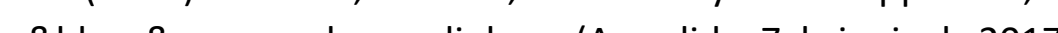

Instituto de Transición Rompe el Círculo (2015) Móstoles en sicion.rompeelcirculo.org/ (Accedido: 17 de abril de 2018).

International Council of Museums (2013) Código de Deontología del ICOM para los Museos. 21. Seul. Disponible en: http://icom.museum/fileadmin/user_upload/pdf/Codes/code ethics2013_es.pdf. (Accedido: 7 de mayo de 2018).

International Institute for Applied Systems Analysis (2017) The art of systems analysis. How can artist support transformations to sustainability? Laxenburg. Disponible en: http://www. iiasa.ac.at/web/home/about/scarts/ScienceArt_Brochure A4_28pages_singlepages_web.pdf. (Accedido: 14 de mayo de 2018)

Jiménez-Ambriz, M. G., Izal, M. y Montorio-Ruiz, I. (2012) «Psychological and Social Factors that Promote Positive Adaptation to Stress and Adversity in the Adult Life Cycle», Journal of Happiness Studies, 13(5), pp. 833-848. doi: 10.1007/s10902-0119294-2. ions, TippingPoint Commissions. Disponible en: https://www Jliesbicycle.com/tippingpoint-commissions (Accedido: 3 de abri de 2018). (Accedido: 14 de febrero de 2018)

Julie's Bicycle (2010) Long horizons. An Exploration of Art Climate Change. Londres. Disponible en: www.britishcouncil.org/ longhorizons. (Accedido: 4 de enero de 2018)

Julie's sicycle (2017) Sustaining Great Art. Manchester. Disponible en: https://www.artscouncil.org.uk/sites/default/files/ download-file/Sustaining Great Art report 2016-17.pdf. (Accedido: 14 de junio de 2018)

Kaprow, A. (2003) Essays on the blurring of art and life. Expanded e. Editado por J. Kelley. Berkeley: University Press Group Ltd. Disponible en: https://monoskop.org/images/3/36/Kaprow Allan_Essays_on_the_Blurring_of_Art_and_Life_with_Impurity Experimental_Art_The_Meaning_of_Life_missing.pdf.

Lacy, S. (1994) Mapping The Terrain: New Genre Public Art. Editado por S. Lacy. Seatle: Bay Press.

Lacy, S. (1995) «Debated Territory: Toward a Critical LanGenre Public Art. Seatle: Bay Press,U.S, pp. 172-184.

Lacy, S. (2013) Imperfect art: working in public. A Case Study of the Oakland Projects (1991-2001). Tesis doctoral sin publicar. Robert Gordon University.

Latouche, S. (2009) La apuesta por el decrecimiento: ¿cómo salir del imaginario dominante? Icaria.

Leff, E. (2004) Saber ambiental. Sustentabilidad, racionalidad, complejidad, poder. cuarta. Buenos Aires: Siglo XXI editores.
Liddle, T. (2010) Your Local Guardian, Tooting Trashcatchers' Carnival «surpasses expectations». Disponible en: http://www. Courlocalguardianco.uk/news/8254801_Eco_carnival_brings community_together/ (Accedido: 4 de abril de 2018).

Lintott, S. (2007) «Ethically Evaluating Land Art: Is It Worth It?), Ethics, Place \& Environment, 10(3), pp. 263-277. do 10.1080/13668790701567002.

Linz, M., Riechmann, J. y Sempere, J. (2007a) Sobre suficiencia y vida buena. segunda, Vivir (bien) con menos. Sobre suficiencia y sostenibilidad. segunda. Barcelona: Icaria. Disponible en http://www.istas.ccoo.es/descargas/SUFICIENCIA_Y_VIDA_BUENA_Manfred_Linz.pdf (Accedido: 20 de julio de 2013).

Linz, M., Riechmann, J. y Sempere, J. (2007b) Vivir (bien) con menos. Icaria.

Lippard, L. R. (2001) «Mirando alrededor dónde estamos Y dónde podríamos estar», en Blanco, P. (ed.) Modos de hacer : arte crítico, esfera pública y acción directa. Salamanca: Universidad de Salamanca, pp. 51-72. Disponible en: http://estrategiadepertenencia.interferencia-co.net/lippard_mirando al rededor.pdf.

Longhurst, N. (2016) Trashcatchers Carnival, Transformative Social Innovation Theory. Disponible en: http://www.transitsocialinnovation.eu/sii/ctp/trashcatchers-carnival (Accedido: 27 de junio de 2018).

López, J. (2013) «Francisco Mora"Aprender y memorizar moldea nuestro cerebro"», EIMundo Disponible en: http://www. elcultural.com/revista/ciencia/Francisco-Mora/32693.

Management, C. I. of W. and E. (2009) Policy Position Statement. Arts and the Environment. Reino Unido. Disponible http//www.ciwem.org/wp-content/uploads/2016/04/ Arts-and-the-Environment.pdf.

Marín, C. (2010) Arte, naturaleza y Sostenibilidad. Hacia un método de análisis de las actividades artísticas desde la Ecología.

Marín Ruíz, C. (2015) Arte Medioambiental y Ecología,. Paradigmas de comprensión, interpretación y valoración de las relaciones entre arte y ecologia. Tesis doctoral sin publicar. Universidad del País Vasco (UPV/EHU).

Martín Rodríguez, A. (2016) «El arte surca los pueblos», Culagosto. Disponible en. hitps://elpais.com/cultura/2016/08/23/actualidad/1471977038_880364.html. (Accedido: 2 de enero de 2018).

Martinell, A. (2018) «La dimensión cultural en los objetivos de desarrollo sostenible", en II Jornadas Sostenibilidad e Instituciones culturales. Impulsando una cultura sostenible. Celebrada en 23-24 de enero 2018. Valencia: La Nau Universitat de València. Disponible en: http://reds-sdsn.es/ii-jornadas-sostenibilidad-e-instituciones-culturales-impulsando-una-gestion-cultural-mas-sostenible.

Martínez Arroyo, E. (2016) «Cabanyal Portes Obertes : se acabó, ¿y ahora qué? Prácticas artísticas políticas y colaborativas en la ciudad》, Agora, 3(5), pp. 143-154. Disponible en: http://www.e-revistes.uj.es/Mndex.php/Kult-ur/aticle/New/6 doi: http://dx.doi. org/10.6035/Kult-ur.2016.3.5.6 -.(Accedido: 2 de junio de 2018).

Mauger, D. (2014) 2014 February» Transition Culture, Your step up moments: Dave Mauger of Transition Town Tooting. Disponible en: https://www.transitionculture.org/2014/02/ (Accedido: 4 de abril de 2018). 
Maulén, P. (2016) «Museo Mausoleo - Cementerio de Arte de Morille ¿ Una nueva tipología de museo ?», Sophia Austra 17, pp. 1-14. Disponible en: www.sop hustral. c//nd piaaustral/article/download/29/35/.

Mies, M. y Shiva, V. (1998) La praxis del ecofeminismo. Barcelona: Icaria.

Muñoz Gómez, F. (2018) «Medir, evaluar y mejorar nuestra huella ecologican, Conectando audiencias, Celebrada en 23-24 de enero 2018. Valencia: La Nau Universitat de València.

MUSAC (2017) MUSAC, HYBRIS. Una posible aproximación ecoestetica. Disponible en: http://musac.es/Hexposiciones/expo/?id=6301 (Accedido: 20 de enero de 2018).

Neal, L. (2010) Trashcatchers' Carnival, Transition Town Tooting. Disponible en: hetp.//ww Camival, Transition town chers-carnival/4565994824 (Accedido: 2 de abril de 2018).

Neal, L. (2012) Transition Town Tooting: Tooting Transition Shop, Tooting Transition Shop. Disponible en: http://transitiontowntooting.blogspot.com.es/p/tooting-transition-shop.html (Accedido: 2 de abril de 2018).

Neal, L. (2015) Playing for Time. Making art as if the world mattered. 1. ${ }^{\mathrm{a}}$ ed. Londres: Oberon books.

Novo, M. (2009) «Ciencia y arte : el abrazo necesario», Papeles, pp. 103-114. Disponible en: http://www.fuhem.es/media/cdv/ file/biblioteca/PDF Papeles/107/Ciencia_y_arte.pdf.

Ordoñez de Tena, B., González de Molina Soler, A., Tomé, I., Pérez Cossio, P., Muñoz, E. y Jenn, D. (2012) Stop rodando el cambio. [video en linea] España y Francia. Disponible en. https://www. youtube.com/watch?v=hGqpf3RX01k. (Accedido: 15 octubre 2014).
Parreño, J. M. (2018) «Las artes del cambio», en Humaniensamiento, arte y relatos para el siglo de la gran pruba. Madid: ta Catarta ediciones, pp. 109-124.

Parreño, J. M., Grego-Matos, J. M. y Arribas, F. (2006) NaSuralmente artifical. El arte español y la naturaleza 1968-2006. Segovia: Museo de Arte Contemporáneo Esteban Vicente, S govia.

Peche, R. (2018) «Mutaciones Plásticas», en Congreso Internacional de Humanidades Ambientales. Relatos, Mitos y Artes para el Cambio. Celebrada en 3-6 julio 2018, Alcalá de Henares: Universidad de Alcalá de Henares. Disponible en: http:// www.institutofranklin.net/eventos-franklin/congreso-interncional-humanidades-ambientales/.

Peck, S. M. (1998) The Different Drum: Community Making and Peace. segunda. Nueva York: Simon \& Schuster.

Prieto, P. A. y García Olivares, A. (2017) «Diálogo hacia una transición energética.», en Conama local Valencia Las ciudades conectan naturalmente. Celebrada en 28 noviembre 2017, Valencia: Las Naves.

Prochaska, J. O., Di Clemente, C. y Norcross, J. C. (1994) Prochaska, $J . O$, Di Clementer adictivos», Revista de Toxicomanias, (1), pp. 3-14.

Puig, F. (2016) Usted no se lo cree, 12/10/2016. Disponible en: https://ustednoselocree.com/2016/10/12/cambio-climatico-y-colapso-civilizatorio-hasta-que-punto-poria-ser-inminen te/ (Accedido: 13 de marzo de 2017).

Punset, E. (2007) El viaje al amor. Las nuevas claves cientificas. Barcelona: Destino.
Putnam, R. D. (2000) Bowling alone: the collapse and er. Nueva York: Touchstone.

Radio Ontinyent (2018) Carrícola renovarò l'enllumenat public amb ajuts d'un programa de I'TVACE per reduir la factura energètica, Radio Ontinyentcom. Disponible en: http //

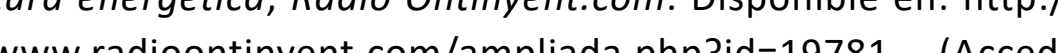
do: 20 de junio de 2018)

Raquejo, T. (2015) «La ficción en la construcción de la consciencia ecológica: correspondencia entre las dinámicas psíquicas y el planeta Tierran, en Raquejo, T. y Parreño, J-M (eds.) Arte y Ecologia . primera. Madrid: UNED, pp. $57-92$.

Raskin, P., Banuri, T., Gallopín, G., Gutman, P., Hammond A., Kates, R. Y swart, R. (2006) La gran transición: La promesa y la atracción del futuro. Santiago de Chile: Naciones Unidas. Disponible en: http://greattransition.org/documents/Great TransitionsSPANISH.pdf (Accedido: 20 de enero de 2018).

Red Española para el Desarrollo Sostenible (2017) «I Jornadas de sostenibilidad e instituciones culturales». Celebrad en 4-5 abril 2017, Madrid: La casa encendida.

Red Transibérica de espacios culturales independientes 2013) Red Transibérica de espacios culturales independienes. Disponible en: http://www.transiberica.org/red (Accedido: 21 de mayo de 2018)

Riechmann, J. (2004) Gente que no quiere viajar a MarEnsayos sobre ecología, ética y autolimitación. Los libros de la catarata.

Riechmann, J. (2005a) «¿Cómo cambiar hacia socieda- des sostenibles?», Isegoría, 32, pp. 95-117. doi: https://doi. org/10.3989/isegoria.2005.i32.459.

Riechmann, J. (2005b) Un mundo vulnerable. Ensayos sobre ecología, ética y tecnociencia. $2^{2}$. La Catarata ediciones. Riechmann, J. (2011) ¿Cómo vivir? Madrid: Los libros de la catarata.

Riechmann, J. (2013) Fracasar mejor (fragmentos, interrogantes, notas, protopoemas y reflexiones). $1^{\text {a. }}$. Zaragoza: Olifante ediciones de Poesia. Disponible en: https://ep00. epimg.net/descargables/2014/08/28/78ecf365dfa7c2d5f0aa000891df590c.pdf?rel=mas (Accedido: 31 de agosto de 2017).

Riechmann, J. (2014) Moderar Extremistán. Sobre el fuel capitalismo en la crisis civilizatoria. primera. Madrid: Díaz \& Pons.

Riechmann, J. (2015) Transición o colapso. Valencia: AMA Soluciones al cambio climático. Celebrada en 12 enero 2015. Valencia: La Nau, Universitat de València. Disponible en: https://www.youtube.com/watch?v=DwtVdPPnfrQ.

del Río, J. (2009) De la idea a la acción. Aprendiendo del movimiento de transición. Trabajo Final de Master. Universitat Politècnica de Catalunya. Disponible en: http://
www.reddetransicion.org/wp-content/uploads/2014/02/ De-la-idea-a-la-acci\%C3\%B3n--Aprendiendo-del-movimiento-Transition-Towns Juan-del-R\%C3\%ADo 2009 pdf Rojo cologí: El esMas, M. E. (2015) "Creaciones valencianas y ecología. El espacio de arte medioambiental "Blodivers Carricola "), 31(5), oa? ?d=31045570045. (Accedido: 20 de octubre de 2017). 
Romer, C. Y Richens, F. (2016) BP to end Tate sponsorship Atcofessional. Disponible en: https://www.artsprofesde mayo de 2018).

Royzman, E. B. y Rozin, P. (2006) «Limits of symhedonia: the differential role of prior emotional attachment in sympathy and sympathetic joy.), Emotion (Washington, D.C.), 6(1), pp. and sympathetic joy.), Emotion (Washington, D.C.), 6(1), pp
82-93. doi: 10.1037/1528-3542.6.1.82. Disponible en: https:// 82-93.us-w2.wpmucdn.com/web.sas.upenn.edu/dist/7/206/ cpb-us-w2.wpmucdn.com/web.sas.upenn.edu/dist/7/206/
files/2016/09/symhedoniaEmot06-1u2gha2.pdf (Accedido: 20 de agosto de 2017).

Ruiz, C. M. (2014) «Arte medioambiental y ecología. Elementos para una reflexión crítica», Arte y políticas de identidad, 10-11, pp. 35-54. Disponible en: http://revistas.um.es/api (Accedido: 7 de abril de 2018)

Ruth, P. (2016) Reprenem el cami, El forn de Carrícola. Disponible en: https://elforndecarricola.wordpress.com/2016/08/30/ reprenem-el-cami/ (Accedido: 10 de junio de 2018).

Samett, G. (2010) Trashcatchers' Carnival Tooting Second Workshop - YouTube. Disponible en: https://www.youtube.com/ watch?time_continue=17\&v=oCM3cTKo3Uw (Accedido: 5 de abril de 2018).

Sánchez-León, N. (2013) Arte Público de enfoque ecológico. Análisis de resultados según Suzanne Lazy. Producción propia como artista experimentador, informador, analista y activista. Trabajo final de master. UPV. Disponible en http://hdl.handle. net/10251/35686

Sánchez-León, N. (2018) «El papel del arte en la transición ecosocial: casos anglosajones y españoles», en Humanidades
Slovic, P. (2007) «"If I look at the mass I will never act"

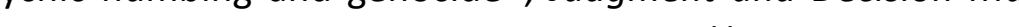
ing, 2(2), pp. 79-95. Disponible en: htps.//scholarsbank.uore$c e=1$ \&isAllowed=y (Accedido: 17 de julio de 2017).

Slovic, S. y Slovic, P. (2005) «Numbers and nerves: Toward an affective apprehension of environmental risk», Whole Terrain. Reflective Environmental Practice, 13(Risk), pp. 14-18. doi 10.4324/9781849776677.

Soler Vaya, F. y San Martín González, E. (2017) «La promoción del turismo rural a través del trail running: el caso de Carrícola en la comarca de La Vall d'Albaida (España)", Revisto de Turismo y Patrimonio Cultural, 15, pp. 49-69. Disponible en http://www.pasosonline.org/Publicados/15117/PASOS51.pdf\#page=49. (Accedido: 1 de junio de 2018).

Steffen, W., Grinevald, J., Crutzen, P. y McNeill, J. (2011) "The Anthropocene: conceptual and historical perspectives, Philosophical Transactions of the Royal Society A: Mathematical , 10.1098/rsta.2010.0327.

Svendsen, Z., Neal, L. y Town, T. (2009) Rehearsing for a climate-changed future: practising not preaching for environmental accountability.

Taibo, C. (2011) En defensa del decrecimiento. Sobre capitalismo, crisis y barbarie. cuarta. Madrid: Los libros de la catarata.

The Chartered Institution of Water and environmenta management, (CIWEM) (2012) WE ASSERT! WE ASSERT! The Manifesto of CIWEM's Arts and Environment Network (AEN). Nuria Sánchez León
Londres. Disponible en: http.//www.ciwem.org/wp-content/ uploads/2016/03/WE-ASSERT-FINAL.compressed.pdf.

The Stove (2015) The Stove Network. Disponible en: https://www.thestove.org/ (Accedido: 17 de abril de 2016).

The Stove network (2016) We live with water. Dumfries.

The Stove Network (2015) Artistic Policy, Bringing Proposals to The Stove Network. Disponible en: https://www.thestove. org/artistic-policy/ (Accedido: 21 de junio de 2018).

The Stove Network (2018) The Stove Network full press pack. Dumfries. Disponible en: http://www.thestove.org/ wp-content/uploads/2014/10/The-Stove-Network-Full-PressPack.pdf.

Thorne, M. (2010) Tooting's Trashcatchers Carnival a Huge Success " Transition Culture, Tooting's Trashcatchers Carnival a Huge Success. Disponible en: https://www.transitionculture. org/2010/07/05/tootings-trashcatchers-carnival-a-huge-success/ (Accedido: 2 de abril de 2018).

Transition Network (2010) Transition as a Pattern Language: Arts and Creativity" Transition Culture, Transition as a Pattern Language: Arts and Creativity. Disponible en: https:// www.transitionculture org/2010/09/24/transition-as-a pattern-language-arts-and-oreativity/ (Accedido: 3 de abrilde 2018).

Transition Network (2018) Purpose. Disponible en: http:// transitionnetwork.org/ about-the-movement/the-charity/purpose/ (Accedido: 3 de marzo de 2018).

Transition Research Network (sin fecha) Research Protocol - For Researchers Wanting towork With Transition Initiatives, Transition Research Network. Disponible en: http://www.transi- 
Transition Town Tooting (2010a) Trashcatchers' Carnival in Tooting, Project Phakama \& Emergency Exit Arts ably assisted by TTT. Disponible en: http://trashcatchers.blogspot.com.es/ (Accedido: 3 de abril de 2018)

Transition Town Tooting (2010b) TTT Method.mov. Disponible en: https://www.youtube.com/watch?v=pNrTiAsUceM (Accedido: 5 de abril de 2018).

Turiel, A. (2017) The crash oil, 1 marzo 2017. Disponible en: http://crashoil.blogspot.com.es/(Accedido: 13 de marzo de 2017).

Turiel, A., González, L., Riechmann, J., Serrano, A., Prieto, P., de Castro, C., Nieto, J. y García Casals, X. (2017) «FORO TRANSICIONES», en Debate Hills Group. Celebrada en 2017. Madrid: FUHEM.

Turner, V. (1988) El proceso ritual. Estructura y antiestructura. Editado por B. García, Rios. Madrid: Taurus.

UICN, Congreso Mundial de la Naturaleza, Naturaleza, C. M. de la y UICN (2012) Un anailisis del impacto de las resoluciones de la UICN en los esfuerzos internacionales de conservación. Gland, Suiza. Disponible en: https://portals.iucn.org/library/efiles/ edocs/2012-007-Es.pdf.

Ukeles, M. L. (1969) «FOR MAINTENANCE ART 1969 ! Proposal for an exhibition " CARE "». Disponible en: https://www. arnolfini.org.uk/blog/manifesto-for-maintenance-art-1969 (Accedido: 5 de febrero de 2016).

Velayos, C. (2008) Ética y cambio climático. 13. Bilbao: Desclçée de Brouwer.

\section{INDICE DE FIGURAS E IMÁGENES}

\section{CAPÍTULO 1}

Tabla 1. Fuente: The Transition Handbook by Rob Hopkins (Hopkins, 2008b). junio de 2018).

Your Local Guardian (2010) Envrionmental achievement in Wandsworth rewarded / Your Local Guardian, Envronmental achievement in Wandsworth rewarded. Disponible en: http://www.yourlocalguardian.co.uk/news/wandsworthnews/5006013.Envrionmental_achievement_rewarded/ (Accedido: 4 de abril de 2018).

Zarzuela-Aragón, J. (2009) «El Movimiento de Transición», El ecologista, 61. Disponible en: http://www.ecologistasenaccion.org/article20348.html. (Accedido: 5 de diciembre de 2017).
Imagen 1. Mapa de las iniciativas locales de transición en España de 2008 a 2014. Fuente. Red de transicion espaniolo. hetp.//whu Imagen 2. Esquema de la exposición Hybris. Una posible Troximación ecoestetica. Fuente: diseñado por Blanca de Torre y Jaume Marco para MUSAC.

Imagen 3. «Grados de compromiso imaginario como una (a) de interacción entre la realización y la espectación» Fuente elaboración propia desde (Lacy, 1995, p. 179).

Imagen 4. Continuo de roles no fijos para activistas artísticos fluando entre la expresión pública y la privada. Fuente: elaboración propia desde (Lacy, 1995, p. 175)

Imagen 5. Representación gráfica de los modos de hacer del artista en el arte ecológico-social. Fuente: Goto y Collins (2003)

Figura 1. Representación gráfica de los modos de hacer de artista enfocado hacia la transición. El área central más oscura es a que trata de explorar el presente estudio. Fuente: elaboración propia.

\section{CAPÍTULO 2}

2. Casos de estudio y adecuación a criterios de selección. Fuente: la autora
Tabla 3. Casos de estudio y características principales. Fuente: Ia

Imagen 6. Huerto vertical en el Centro de Educación Infantil y (Cantabria). Fuente: Torrelavega y comarca en transición.

Imágenes 7, 8 y 9. La buidor de l'abundància. Fuente: GenT.

Imágenes 10 a 12. Distintas obras ubicadas en el espacio urbano que expresan visiones del futuro de la ciudad. Fuente: ITRC

Imágenes 13-18. Fragmentos seleccionados del video Carril bici Pedala.

Imagen 19. Festival Arcu Atlánticu de Gijón con presencia de la López Fernández, 2016.

Imágenes 20, 21 y 22. Fragmentos del video promocional de

Imágenes 23 y 24. Pallets decorados colaborativamente para la acción reivindicativa. Fuente: Butroi en Transición.

\section{CAPÍTULO 3}

Figura 2. Gráficos de sectores con distribución de importancia otorgada al arte en iniciativas de transición españolas. Fuente: elaboración propia.

Tabla 4. Proyectos artísticos realizados por cada iniciativa de transición española. Fuente: recopilación de la autora. Figura 3. Distribución de la participación del público clasificada
en categorías de participación de Lacy en iniciativas de transición 
españolas. Fuente: elaboración propia.

Figura 4. Figura 4. Grático de barras con funciones detectadas dentro del MCT. Fuente: elaboración propia.

Imagen 25. Cartel del VII festival de La noche con alma. Fuente: Ayuntamiento de Almócita

Imagen 26. Mural Almócita: trabajo colaborativo realizado durante el campo de trabajo en 2009. Fuente: Fotografía de la autora 2017

Imágenes 27 y 28. Detalles del mural colaborativo realizado durante el campo de trabajo en 2009. Fuente: fotografías de la autora 2017.

Imagen 29. Mural con vista general del pueblo y poesía. Fuente:

Imagen 30. Mural homenaje a la mujer rural. Fuente: Sergio Pineda 2018.

Imagen 31. Una de las diez poesías que jalonan las paredes de Almócita. Fuente: fotografía de la autora, 2017.

Imágenes 32 y 33. Escultura Árbol de la música con instrumentos

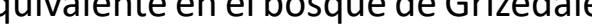
Fotografías de la autora, 2017 y 2016 respectivamente. Imagen 34. El candil más grande del mundo. Fuente: Fotografía de la autora 2017.

Imagen 35. Cartel del festival de la Noche de los Candiles. Fuente: Ayuntamiento de Almócita.

Imagen 36. Coe en Almouseum. Fuente: Fotografía de la autora

Imagen 37. Fragmento extraído del video de Almouseum
Imagen 38. Fragmento extraído del video de Almouseum en: https://www.youtube.com/watch?v=bdUOKLxj8is

Imágenes 39, 40 y 41 . El exterior e interior del domo. Fuente Fotografías de la autora, 2017

Tabla 5. Funciones del arte identificadas por Pineda y Coe en

Imagen 42. Billete de la libra de Totnes con David Bowie. Fuente: (Hopkins y Thomas, 2016, p. 39)

Imagen 43. Cartel anunciando algunos de los talleres de: música con instrumentos reciclados, creación de complementos y figuras para el carnaval, teatro y cuentacuentos. Fuente: (Transition Tow Tooting, 2010a) http://trashcatchers.blogspot.com.es/2009/

Imagen 44. Extracto del folleto realizado por Transition Town Tooting para atraer a carnivalistas, voluntarios, donantes colaboradores. Fuente: (Transition Town Tooting, 2010a)
http://trashcatchers.blogspot.com. es/2010/01/

Imagen 45. Noticia en el periódico del 20 de mayo de 2010 local Wandsworth Guardian Fuente: (Transition Town Tooting, 2010a) ens/2010/05/green-guardian-

Imagen 46. Extracto del segundo folleto lanzado en mayo desde Toloa) htt//trashcatchers.blogspo com.es/2010/06/

Imagen 47. Cartel preparatorio de Tooting Trashcatchers'Carnival. Fuente: (Transition Town Tooting, 2010a) http://trashcatchers. blogspot.com.es/2010/07/ Imagen 48. El pájaro Sankofa durante el desfile de carnaval en
Tooting. Fuente: Fotografías de Rachel Wheeley.

Imágenes 49 y 50. La Lady of Tooting y El gigante y durante e desfile de carnaval. Fuente: Fotografias de Rachel Wheeley. Imagen 51. El club de natación Lido de Tooting. Fuente: Fotografías de Rachel Wheeley.

Imagen 52. La tortuga del carnaval de Tooting. Foto: Rachel Wheeley

Tabla 6. Funciones del arte identificadas por la autora. Fuente: elaboración propia.

\section{CAPÍTULO 4}

erge. Fuente: The Stove, 2015 Imagen 54. Distribución de nuevos usos del suelo propuesta por We Live With Water para Dumfries. Fuente: The Stove 2016. Imagen 55. La carrera en el Nith a su paso por la meta de Mill
Green, en el corazón de Dumfries. Fuente: Kirstin McEwan, 2016. Imagen 56. La Salty Coo procesionada por las calles de Dum
hasta la meta en Mill Green. Fuente: Kirstin McEwan 2016. Imagen 57. Parte del desfile de la Salty Coo en 2016. Fuente: irstin McEwan 2016.

Imagen 58. La Salty Coo en el desfile vikingo por las calles de Dumfries hasta la meta en Mill Green. 2017. Fuente: Kirsti McEwan, 2017

Imagen 59. Colectivo de payasos MooCoo liderando la procesión de la vaca salada en Nithraid 2017. Fuente: Kirstin McEwan, 2017. Imagen 60. Performance en Mill Green a la llegada de la Salty

Imágenes 61 y 62. Inmersión de la Salty Coo en el Nith a cargo de la tripulación ganadora. Fuente: Colin Tennant, 2015
Tabla 7. Funciones del arte identificadas por la autora. Fuente: elaboración propia.

Imagen 63. Los dragones de la justicia socialy ambiental. Fuente: Fotografia de Jonathan Baxter, 2016.

Imagen 64. Los artistas Jonathan Baxter y Sarah Gittins junto a la huella de las conversaciones de las actividades de Dundee Artists in Resident's Reading Towards Action trazada por Gittins Live Festival y ubicada en el centro comercial Wellgate. Fuente: fotografía de la autora, 2016.

Imágenes 65 Ali Wilson trabajador en la biblioteca pública Arthurstone situada en una zona conflictiva de la ciudad que Baxter y Gittins tienen intención de activar para evitar que el centro cierre. Detrás de él, el cerezo plantado en el huerto de la misma.

Imagen 66 Gittins en el mismo espacio de Arthurstone con el hotel para insectos creado al fondo. Fuente: fotografías de la autora 2016

(nes fotografía de la autora, 2016.

Imagen 68. Serigrafías realizadas en sus talleres artísticos abiertos sobre la ciudad-huerto que homenajean a las personas
y los valores que sostienen el proyecto. Desde 2014 los carteles
han recorrido la ciudad (y otras ciudades) en una variedad de han recorrido la ciudad (y otras ciudades) en una variedad de eventos artisticos y comunitarios con la intención de ros centros su papel en la sociedad y la labor y generosidad de estos centros como hospedadores $y$ donantes de recursos. Fu

Imagen 69. El huerto realizado sobre tierra consagrada del centro Maxwell, con un grupo de escolares en prácticas al fondo. Al frente Jack Pocock, coordinador del huerto junto a los artistas Baxter y Gittins Fuente: fotografía de la autora 2016. 
Imagen 70. Shonagh Glen única cuidadora de este jardín trasero hoy atrae a multitud de insectos y avifauna. Fuente: fotografia de la autora 2016

Imágenes 71 y 72. A la izquierda exposición en el entorno de los jardines Slessor. A la derecha detalle de los dibujos. Fuente: elaboración propia.

Imagen 73. Listado de participantes en Biodivers I. Fuente: Pedro

Imagen 74. Pablo Guillén Marzal, coautor de la obra en el primer encendido del horno en mayo 2015. Fuente: fotografía de la autora, mayo 2015.

Imágenes $75,76,77$ y 78 . Detalles del horno en funcionamiento. Fuente: fotografías de la autora 2015-2016.

Imagen 79. Obra en cerámica Dones al carrer de Juán 2015. Fuente: Fotografía de Enric Pont. Imagen 80. Vicent Bohigues construyendo la base del horno y la
autora. Fuente: fotografía de la autora 2015 .

Imagen 81. Blog de Biodivers con comentarios sobre el avance de las obras durante su construccion: Traducción de la autora:
«Vicent Bohigues rematando la base de piedra seca del horno de Pabloy Nuria que ya tienen la primera fase con el suelo colocador Fuente: fotografías de Altabert, $2015 \mathrm{https}$ ://biodivers2015. wordpress.com/2015/02/16/cap-de-setmana-a-tope/

Imagen 82-85. El artista Pérez realizando la obra Diálogos de encuentro en colaboración con los lugareños. Fuente: fotografías

Imágenes 86-89. Blog de Biodivers. Traducción de la autora: «Fin
de semana a tope para hacer la segunda fase del horno, con la colaboración de amigos y la gente de Carrícola, que siempre
está a punto para echar una mano. Gracias a todos.» Fuente: fotografis de Altabert https://biodivers2015.wordpress.com/ page/5/

Imagen 90. Obra No som quatre gats? De Maro Aguilar: Fuente: I tografía de Arantxa Ferńndez Alcayde 2018.

Imagen 91. Ruth Palaci la panadera junto a uno de los carromatos del mercado agroecológico. Fuente: Fotografía de Pedro Altabert. Imagen 92. Cartel convocando a la participación en la obra de

Imágenes 93. Arriba obra de Loren para Biodivers 2015, aunque realizada con posterioridad. Las plantas de caléndula y lavanda forman esta interrogación que los carricolinos mantienen con riego por goteo $y$ usan en sus platos $y$ esencias artesanales. Fuente:

Imagen 94. Abajo vista de satélite de la obra de Loren en una de las muchas parcelas sin cultivar por falta de relevo generacional. Fuente: extraída de Google Maps.

Imágenes 95-97 Obra de Loren para Biodivers 2015. Fuente:

Imagen 98. La obra Polp de riu hecha con esparto y vidrio en 2015. Fuente: fotografía de Enric Pont.

Imagen 99. La obra Polp de riu durante su instalación. Fuente: fotografía de Altabert

Imagen 100. Polp de riu en primer plano sobre el tronco de un arboly derrás, la obra Xiprer (Ciprés) de 2010 de Emili Armengo en acero. Fuente: fotografía de Arantxa Fernández Alcayde 2018 Imagen 101. Marc Giner encendiendo el horno para cocer Crespins La Garrofera, en julio de 2016. Fuente: fotografía de
Altabert: https://biodivers2015.wordpress.com/visites/

Imagen 102. Logotipo de la empresa Forn de Carrícola con la elaci https://www. facebook.com/elforndecarricola/? ?ref=br_ $r$ s

Imagen 103. Estado actual del horno y construcción alrededor relacionadas con el pan. Fuente: Fotografías de Altabert 2018.

Imagen 104. Cena popular al aire libre en Carrícola. El pa ños y cocido en el horno, gracias al taller de pan organizado por Palaci. Fuente: fotografías de la autora 2015

Imagen 105. uno de los talleres de pan con niños durante verano. Fuente: Fotografía de Altabert.

Tabla 9. Funciones del arte identificadas por la autora. Fuente: elaboración propia.

Figura 5. Formas colaborativas de actuar de los artistas en transición, esquema 1. Fuente: La autora

Figura 6. Formas colaborativas de actuar de los artistas en la transición, esquema 2. Fuente: La autora

Figura 7. Formas colaborativas de actuar de los artistas en la transición, esquema 3. Fuente: La autora

Figura 8. Formas colaborativas de actuar de los artistas en la transición, esquema 4. Fuente: La autora

Imagen 106. Mapa de miembros de la red El Cubo Verde. Fuente El Cubo Verde, elaborado por Coco Moya, véase en: https:// elcuboverde.org/mission/

Imagen 107. Cubo realizado por Maite Centol para el proyecto Enverarte en Ábalos, La Rioja. Fuente: Maite Centol, 2018.

Tabla 10. Funciones del arte identificadas por la autora en la red
El Cubo verde. Fuente: la autora.

Imágenes 108 y 109. El espacio de Aula-R en la actualidad. Fuente: fotografías de la autora, 2016.

Imagen 110. Pegatina realizada para adherir a los materiales y seguir su registro. Fuente: la autora.

Imagen 111. Obra realizada con material recogido por la alumna del Master de Arteterapia Maninat Amirom en Aula R . . Fuente: fotografías de Mariana Amirom

Imágenes 112-113. Fotogramas extraídos del video realizado por Madame Cornucopia para Aula-R. Fuente: Madame Cornucopia.

Imagen 114. Material recogido por la alumna Lur C.G. y uso que le otorgó. Fuente: fotografías de Lur C.G.

Imágenes 115-116. Fotogramas extraídos del video realizado por Imagen 117. Tablón de anuncios de Aula-R. Fuente: fotografía de la autora.

Imagen 118. Pegatina del proyecto Aula-R con el código Qr realizado por Trascend. Fuente: La autora

Imágenes 119 y 120. Cartelería del proyecto. Fuente: izquierda

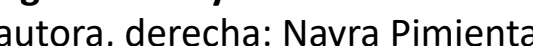

Figura 9. Motivos principales detectados para donar/apropiarse de materiales de Aula-R. Fuente: elaboración propia.

Figura 10. Gráfico de barras sobre tanto por ciento de alumnado que dona o se apropia de materiales en Aula-R. Fuente: ración propia.

Figura 11. Utilidad otorgada por el alumnado que conoce $y$ desconoce Aula-R. Fuene: elaboración propia.

Imagen 121. Cartel anunciador de la obra de Juan Carlos 
Rosa solicitando material a depositar en Aula-R. Fuente: info/887513normalc. html Véas/ens:

Imagen 122. La autora presentando Aula-R y otros proyectos

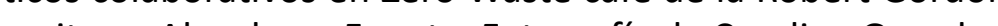
2016.

Imágenes 123 y 124. Aula-R antes y después de su remodelación en 2015. Fuente: fotografías de la autora.

Imágenes 125-126. Instalación con las encuestas realizadas del 7 -13 de mayo 2013. Fuente: fotografías de la autora.

Imágenes 127-129. Instalación con las encuestas realizadas del 7-13 de mayo 2013. Fuente: fotografías de la autora. Imagen 130. La instalación finalmente realiza
Mutante. Fuente: fotografía de la autora 2013

Imágenes 131-133. En el centro la proyección de la estantería real de Aula-R en la pared sobre la que se sitúan los jabones. A la izquierda las bolsas para llevar los jabones con los datos de A la derecha los jabones anclados a ja pared dispuestos para los espectadores se apropien de ellos. Fuente: fotografías de la autora 2013.

Tabla 11. Funciones del arte identificadas por la autora en Aula-R. Fuente: la autora.

\section{CAPÍTULO 5}

Figura 12. Tipos de participación de Lacy en tanto por ciento en proyectos dentro y fuera de la red de transición. Fuente:

Figura 13. En azul los puntos calve y de tensión en cada proyecto analizado. Fuente: elaboración propia.

Figura 14. Fuentes de financiación de los proyectos analizados segun sean españoles o anglosajones. Fuente: elaboración propia.

Figura 15. Análisis de las intenciones de cada proyecto, en azul las detectadas. Fuente: elaboración propia.

Figura 16. Aproximación y caracterización de los efecto causados por cada proyecto. Fuente: Elaboración propia.

Figura 17. Distribución de funciones del arte dentro y fuera del MCT. Fuente: elaboración propia

Figura 18. Gráfico de barras con frecuencia de detección de determinados papeles del arte en la red de transición. Fuente: laboración propia. 


\section{ANEXO 1}

\begin{tabular}{|c|c|c|c|c|}
\hline $\begin{array}{l}\text { INICIATIVAS DE TRANSICIÓN EN } \\
\text { ACTIVO }\end{array}$ & $\begin{array}{c}\text { NO } \\
\text { CONTESTAN }\end{array}$ & $<1$ AÑ̃O & $\begin{array}{l}\text { NO INTERÉS } \\
\text { EN ARTE }\end{array}$ & $\begin{array}{l}\text { SI INTERÉS EN } \\
\text { ARTE }\end{array}$ \\
\hline Activar la transición Almócita & & & & $x$ \\
\hline Arganzuela en Transición & & & $x$ & \\
\hline Arico en Transición & & & & $x$ \\
\hline Butroi en Transición & & & & $x$ \\
\hline Carcaboso en Transición & $x$ & & & \\
\hline Cardedeu en Transició & & & $x$ & \\
\hline Cigales en Transición & $x$ & & & \\
\hline Algarbia en Transición & & $\mathrm{x}$ & & \\
\hline Granada en Transición (GET) & & & & $x$ \\
\hline Granollers en Transició & & & & $x$ \\
\hline $\begin{array}{l}\text { Instituto de Transición Rompe el } \\
\text { Circulo (ITRC) }\end{array}$ & & & & $x$ \\
\hline $\begin{array}{l}\text { Jaén Instituto de Transición Rompe } \\
\text { el Circulo (JET) }\end{array}$ & & & & $x$ \\
\hline Jesús en transicion & & $x$ & & \\
\hline La Alquería Quentar & & $x$ & & \\
\hline Laboral Permacultural & & & $x$ & \\
\hline La Ecoaldea UCM & & & $x$ & \\
\hline Miengo en Transición & & & & $x$ \\
\hline Molins en Transició & & & $x$ & \\
\hline Osel Murcia & $x$ & & & \\
\hline Reus en Transició & & $x$ & & \\
\hline Segovia en Transición & & & $x$ & \\
\hline Torrelavega en Transición & & & & $x$ \\
\hline Transició VNG & & & & $x$ \\
\hline Valls en transició & & & $x$ & \\
\hline Zarzalejo en Transición & & & $x$ & \\
\hline Total: 25 & 3 & 4 & 8 & 10 \\
\hline
\end{tabular}

\section{ANEXO 2}

Nombre y apellidos de las personas que contestan (opcional, puede ser anónimo o contes列 el consentimiento informado que adjunto)

¿Cuánto tiempo hace desde que se formó el grupo de transición?

¿Por qué surgió?

¿Cuántos miembros aproximadamente sois?

¿Alguno de los miembros ha realizado algún curso de la red de transición?

¿Pertenecéis a la Red de Transición española, a la transition network o a algún otro como el proyecto de municipios en transición y desde cuándo?

Entrando ya en la materia que nos concierne en particular en esta investigación, nos gustaría saber vuestra relación con el arte:

¿Tenéis experiencia de haber realizado algún proyecto con artistas o bien habéis realizado agún proyecto relacionado con arte aunque no seáis artistas? En caso positivo, si tenéis links o info de estos proyectos indicadlos por favor.

¿En qué ha consistido esa colaboración?

¿Eran artistas invitados o formaban parte del grupo?¿Cómo podemos contactar con ellos? ¿Cuánto duró la colaboración?

¿Siguen colaborando?

\section{INTENCIÓN}

¿Qué intención teníais cuando iniciasteis el proyecto?

¿Qué intención (si lo expresaron) tenían los artistas? 


\section{EFECTIVIDAD}

¿Qué consecuencias o resultados ha tenido?

¿Ha cambiado algo en el entorno, normas, leyes, personas, actitudes, cantidad de residuos, espacios verdes, disminución del consumo...?

¿Ha satisfecho las expectativas del público?

¿Ha generado nuevos proyectos?

¿Ha incrementado el número de interesados en la cuestión?

Sus efectos son inmediatos, a medio o largo plazo?

¿Es un proyecto extrapolable?

¿Es un proyecto con capacidad de crecer?

PUNTOS DE TENSIÓN Y PUNTOS CLAVE

Qué limitaciones u obstáculos ha tenido el proyecto? Por ejemplo, limitación administrativa, de permisos, económica, obstáculos legales, de escasa participación climatológicas.

Qué tensiones o puntos clave ha tenido el proyecto? Por ejemplo si ha habido enfrentamientos, división, incoherencias, contradicciones, ambiente de aprendizaje, apoyo de la administración o instituciones, soporte de otras redes o grupos,...

¿Ha tenido financiación alguno de los proyectos? ¿privada o pública?¿qué tanto por ciento aproximado del coste ha supuesto

PARTICIPACIÓN Explicar la implicación con el público en aquellos proyectos relacionados con arte:

¿Cuantos asistentes o participantes hubo?

¿Podéis clasificar la participación del público en alguno de estos apartados para cada pro-

\begin{tabular}{|l|l|l|l|}
\hline \multicolumn{1}{|c|}{ TIPOS DE PARTICIPACIÓN } & PROYECTO 1 & PROYECTO 2 & PROYECTO 3 \\
\hline $\begin{array}{l}\text { Origen y responsabilidad (decisores/ } \\
\text { promotores desde el inicio) }\end{array}$ & & & \\
\hline $\begin{array}{l}\text { Colaboración y desarrollo (invitados a } \\
\text { participar en el diseño) }\end{array}$ & & & \\
\hline $\begin{array}{l}\text { Voluntarios y ejecutores (participantes } \\
\text { durante el desarrollo) }\end{array}$ & & & \\
\hline $\begin{array}{l}\text { Audiencia inmediata (espectadores que no } \\
\text { toman parte, solo miran) }\end{array}$ & & & \\
\hline $\begin{array}{l}\text { Público de los medios de masas } \\
\text { (espectadores posteriores que ven la obra a } \\
\text { posteriori) }\end{array}$ & & & \\
\hline $\begin{array}{l}\text { Público del mito y la memoria: cuando la } \\
\text { obra se convierte en un hito histórico en la } \\
\text { comunidad o bien pasa a la literatura del arte }\end{array}$ & & & \\
\hline
\end{tabular}

\section{ÉTICA, ESTÉTICA}

¿Os preocupa en general en vuestras actividades tener una reducida huella ecológica u otro principio ético?

¿Ha sido la huella ecológica del proyecto artístico/u otro principio ético señalado tenida en cuenta durante su diseño e implementación?

¿Tenéis herramientas de medición de la huella ecológica y las usáis?

¿Han contribuido los artistas/el arte a: crear una atmósfera, crear un espacio de creación o fomentar la intervención de diversas disciplinas y personas?

¿Qué os llevo a elegir el lugar de intervención del proyecto? 
¿La imagen final del proyecto se corresponde con vuestra intención inicial y con vuestros principios éticos?

¿El proyecto captura/representa la variedad de emociones y sentires sobre la cuestión?

FUNCIONES DEL ARTE. En general en cada proyecto, ćqué papel ha jugado el arte? por jemplo: (se puede señalar más de uno o añadir otros)

\begin{tabular}{|c|c|c|c|}
\hline FUNCIÓN & PROYECTO 1 & PROYECTO 2 & PROYECTO 3 \\
\hline \multicolumn{4}{|l|}{ Celebrar } \\
\hline \multicolumn{4}{|l|}{ Empoderar } \\
\hline \multicolumn{4}{|l|}{ Aumento de la resiliencia } \\
\hline \multicolumn{4}{|l|}{ Motor iniciador/generador de proyectos } \\
\hline \multicolumn{4}{|l|}{ Recaudar fondos } \\
\hline \multicolumn{4}{|l|}{ Desarrollar empatía } \\
\hline \multicolumn{4}{|l|}{$\begin{array}{l}\text { Conectar personas con espacios, entornos } \\
\text { o lugares }\end{array}$} \\
\hline \multicolumn{4}{|l|}{ |lustrar, representar, comunicar, difundir } \\
\hline \multicolumn{4}{|l|}{ Concienciar } \\
\hline \multicolumn{4}{|l|}{$\begin{array}{l}\text { Imaginar, desarrollar la visión del grupo, } \\
\text { su misión, futuros posibles, utopías o } \\
\text { ficciones }\end{array}$} \\
\hline \multicolumn{4}{|l|}{$\begin{array}{l}\text { Ofrecer soluciones, mostrar alternativas } \\
\text { reales o proyectos piloto, laboratorios de } \\
\text { pruebas }\end{array}$} \\
\hline \multicolumn{4}{|l|}{$\begin{array}{l}\text { Conectar personas, crear comunidad, } \\
\text { diálogo, reflexión, hacer redes, mediar o } \\
\text { facilitar }\end{array}$} \\
\hline \multicolumn{4}{|l|}{ Crear relatos positivos de cambio } \\
\hline \multicolumn{4}{|l|}{ Reforzar la identidad, crear símbolos } \\
\hline $\begin{array}{l}\text { Facilitar la comprensión del mensaje de la } \\
\text { ética ecológica aplicándola }\end{array}$ & & & \\
\hline \begin{tabular}{|l} 
Premiar, agradecer \\
\end{tabular} & & & \\
\hline
\end{tabular}

\begin{tabular}{|l|l|l|l|}
\hline $\begin{array}{l}\text { Fomentar la ciudadanía crítica, agitar, } \\
\text { denunciar, cuestionar }\end{array}$ & & & \\
\hline Restauración/recuperación del entorno & & & \\
\hline Construir consensos & & & \\
\hline Conectar áreas alejadas de conocimiento & & & \\
\hline $\begin{array}{l}\text { Revitalizar el territorio (Luchar contra } \\
\text { el éxodo rural, dinamizar el territorio, } \\
\text { activarlo) }\end{array}$ & & & \\
\hline
\end{tabular}
activarlo)

¿Qué valores, ventajas, o visiones particulares ha añadido la práctica o el enfoque artístico vuestros proyectos ?es decir, ¿qué ha aportado de diferente el arte?Valorar del 1 al 5 papel del arte en vuestras actividades siendo:

- 1 nula

- 2 puntual o poco importante;

- 3 media

- 4 muy importante

- 5 fundamental o desde el inicio del proyecto.

¿Qué opináis al respecto de que se institucionalicen vuestras actuaciones? ¿os gustaría o pensáis establecer lazos con alguna administración pública?

Observaciones: si consideráis importante mencionar cualquier otro dato/proyecto/ contacto os lo agradecemos. 

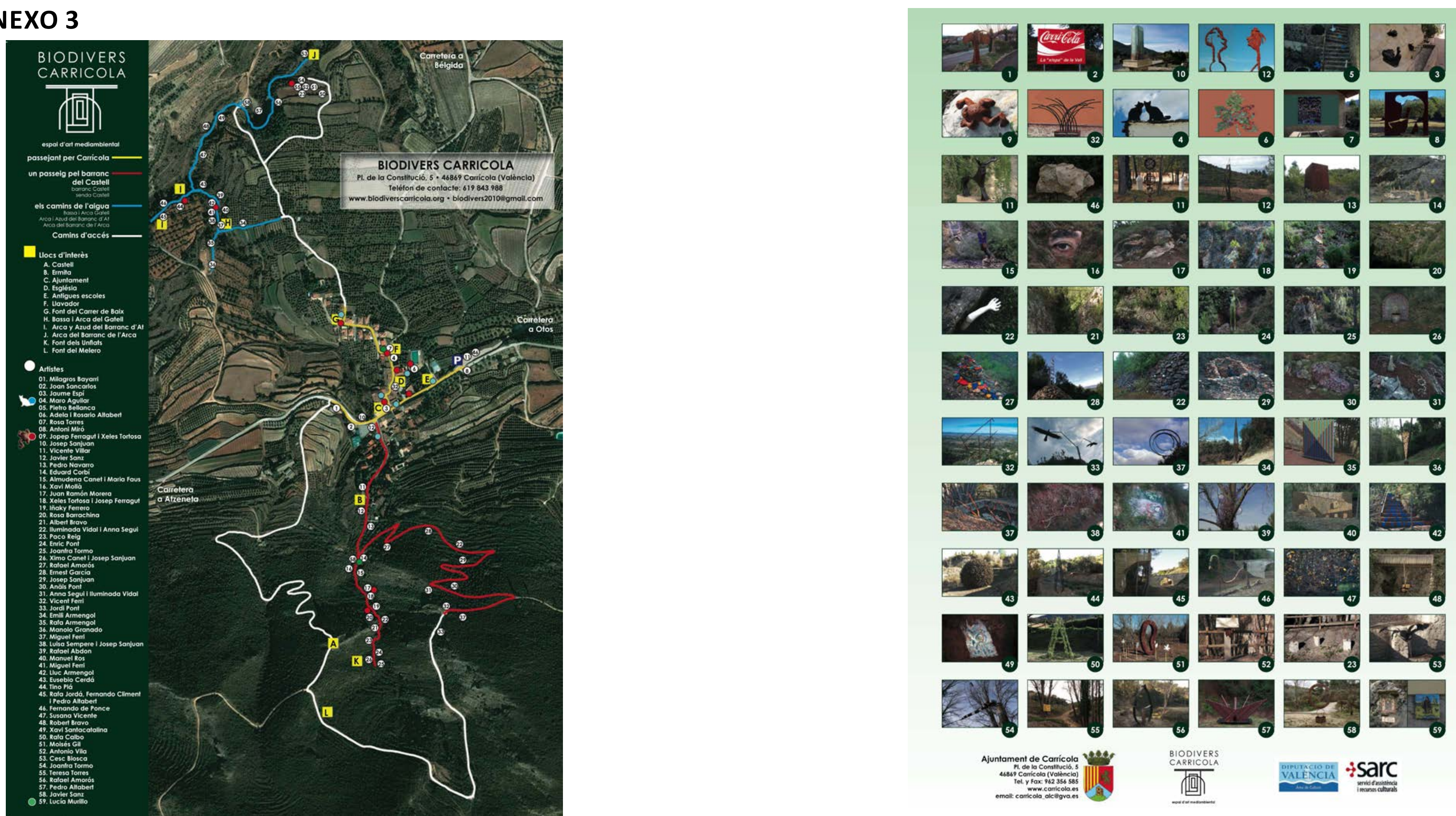


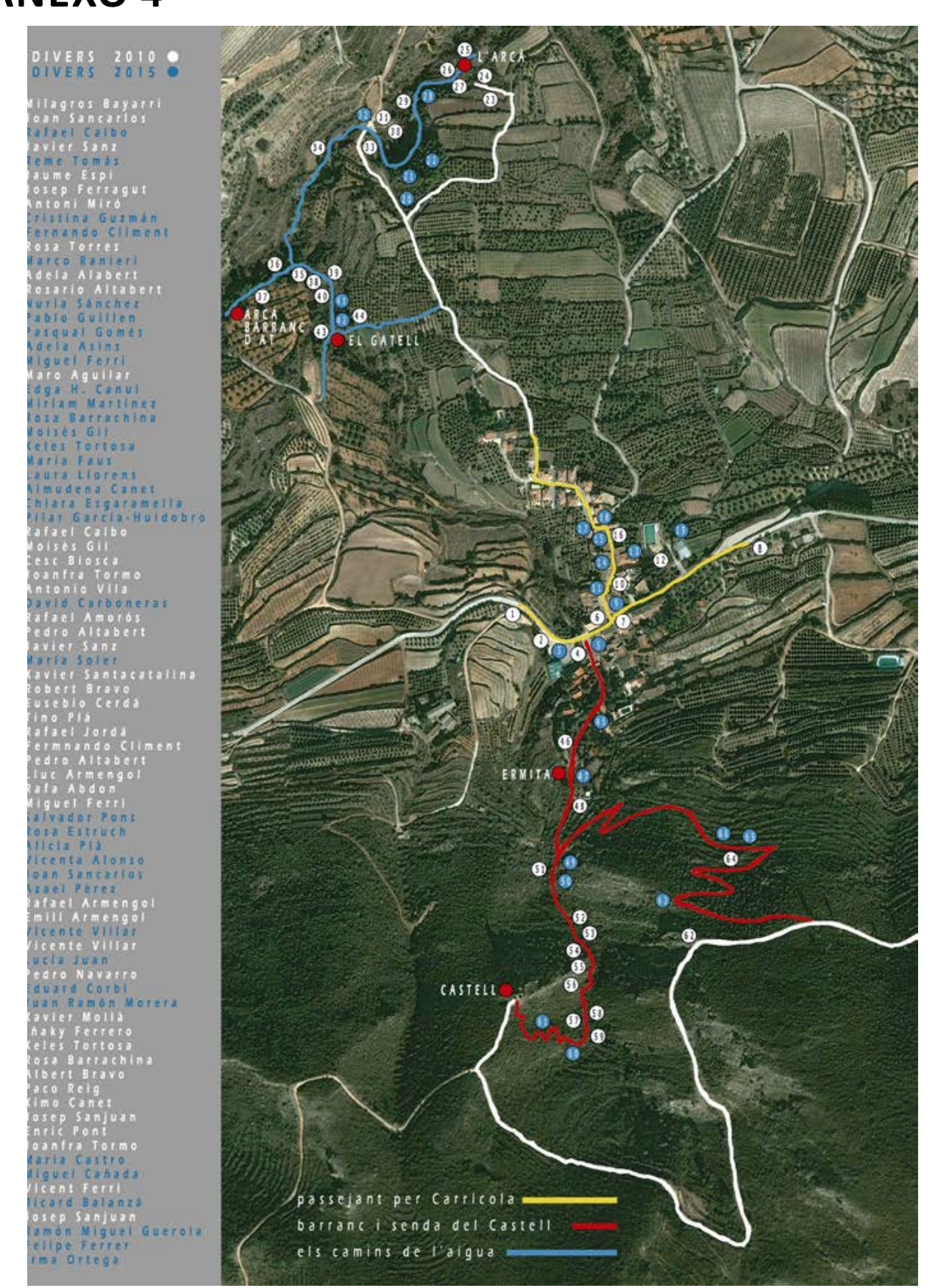

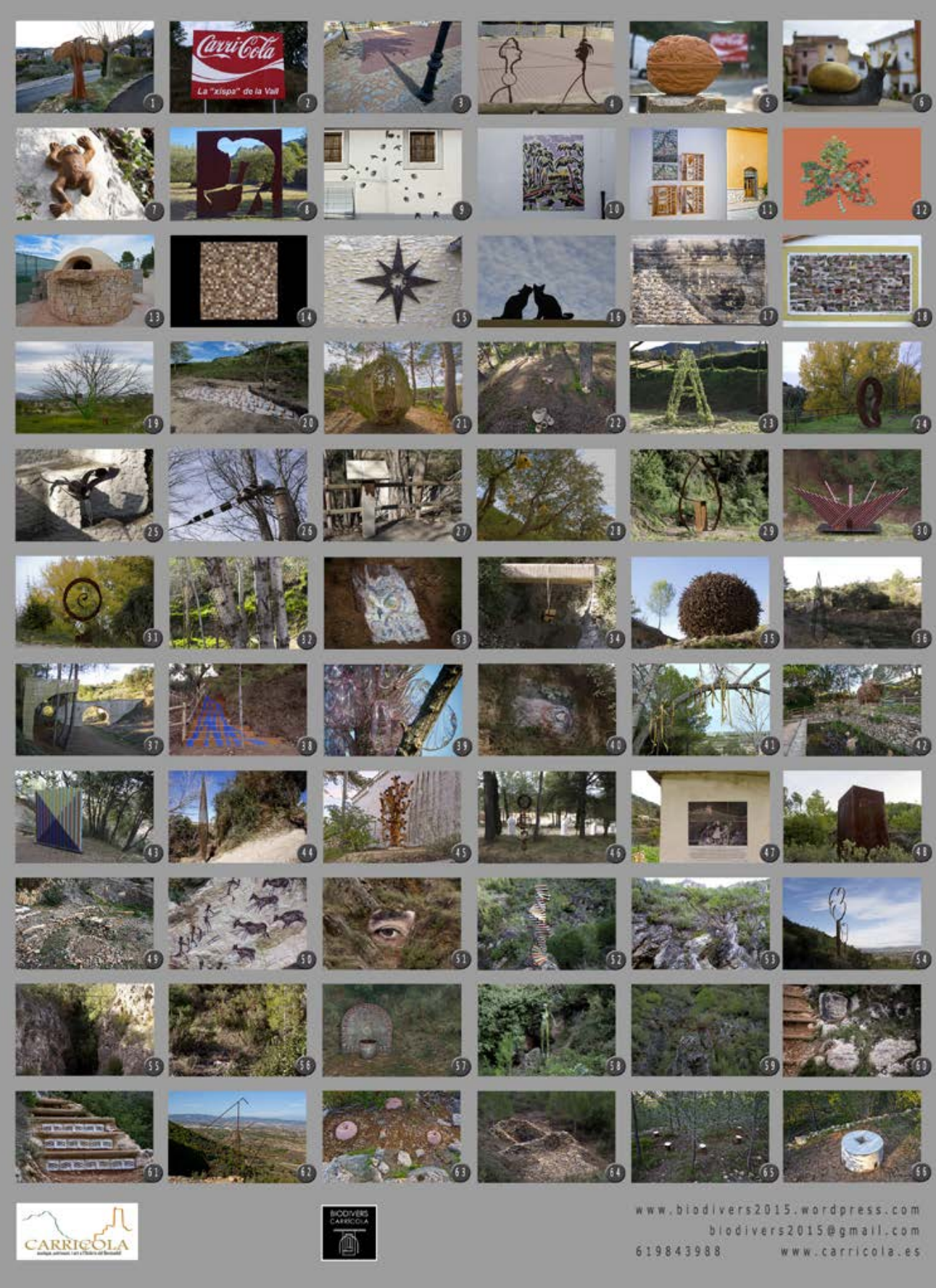




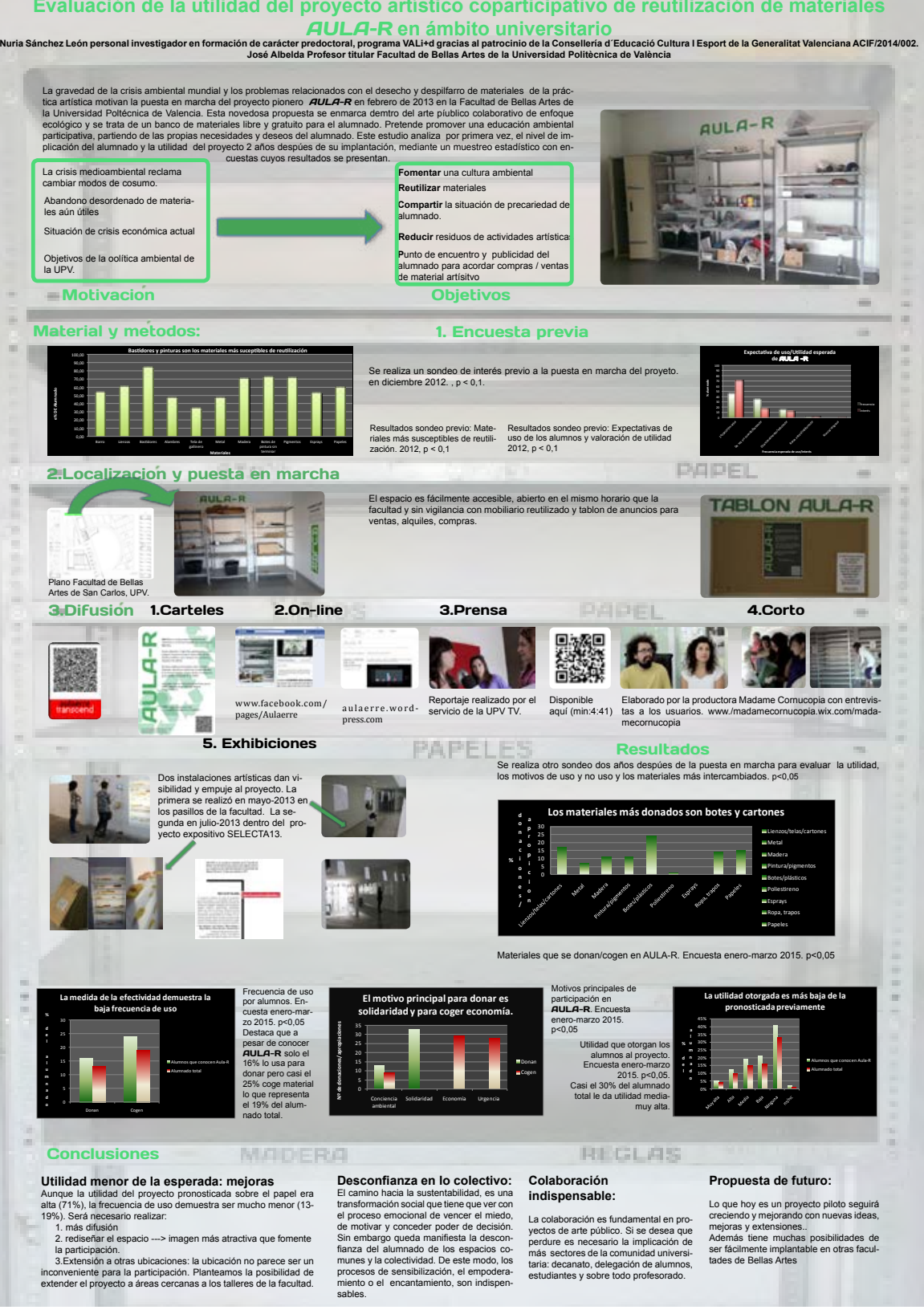




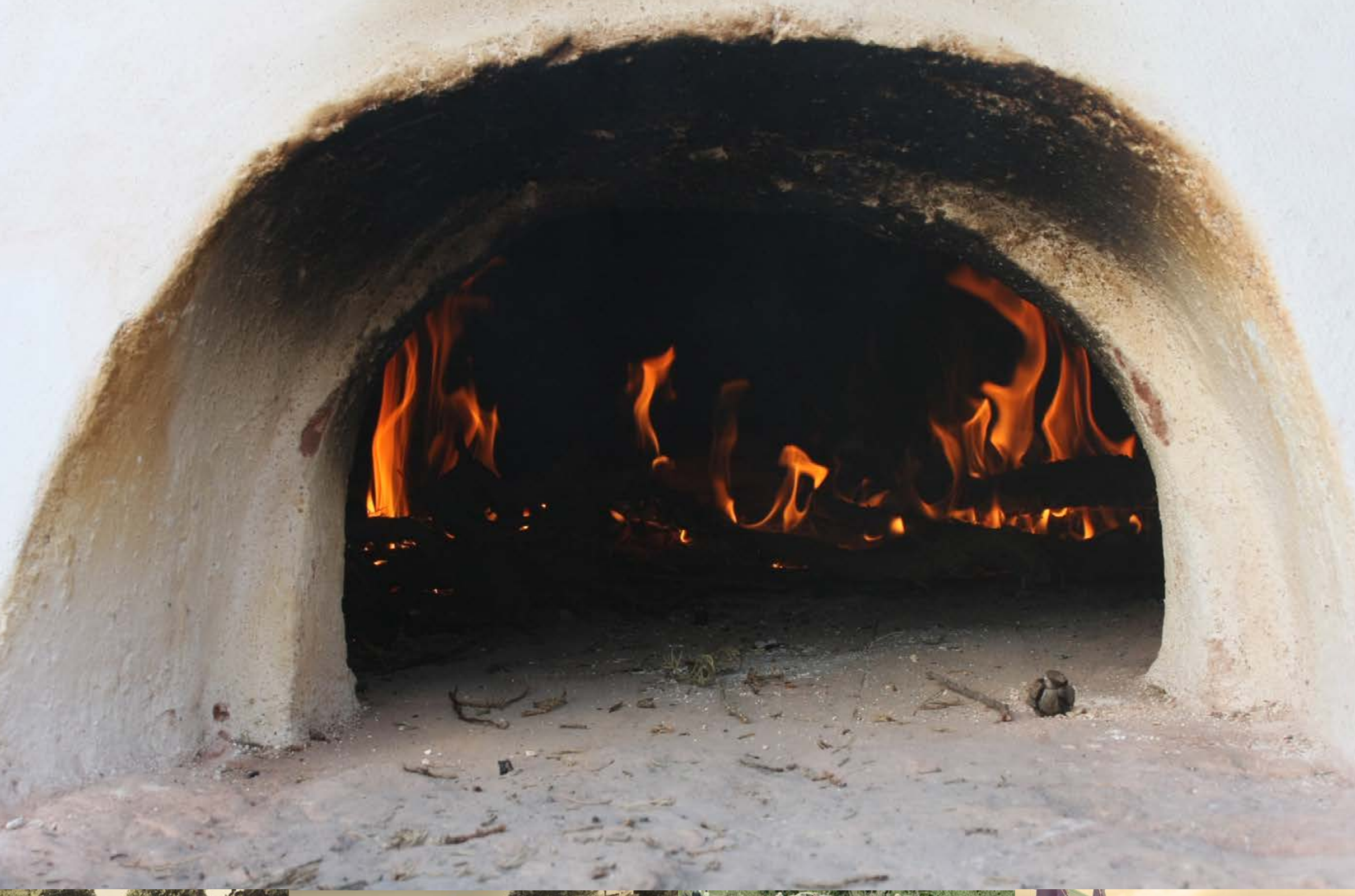

(1)

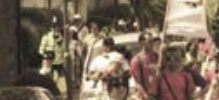
$-3 \times 1$ $-\frac{1}{2}+4=$ 